\title{
Integrating Statistical and System Dynamics Modelling to Analyse the Impacts of Climate Change on Rice Production in West Nusa Tenggara, Indonesia
}

by

Muhamad Khairul Bahri

\author{
A thesis \\ submitted to Victoria University of Wellington \\ in fulfillment of the requirements for the degree of \\ Doctor of Philosophy
}

Victoria University of Wellington 2017 


\section{ABSTRACT}

Climate change, manifested as temperature rise and rainfall change, will pose significant challenges to rice farmers, leading to a possible rice shortage under a changing climate. This research aims to understand the impacts of climate variability and change on rice production through the rest of this century using Representative Concentration Pathway (RCP) scenarios, and combination of statistical and system dynamic modelling. The area of study is West Nusa Tenggara, Indonesia. Wetland and dryland farming types are assessed separately because they have different rice varieties and different agricultural practices.

Overall, the research seeks to answer the question: How will climate change and climate variability affect rice production? Additional questions investigated are (1) What are the most significant supply uncertainties associated with a changing climate? and (2) What are possible solutions for reducing the impacts of climate change on rice production?. To answer these research questions, this study deals with three main research areas. First, based on observed data (1976-2011), this study developed regression-based statistical models in understanding the impacts of climate change on rice yield in West Nusa Tenggara. Statistical models find that the negative impacts of increased minimum temperature on rice yield are statistically significant.

By contrast, the effects of maximum temperature on rice yield are not statistically significant. A key reason for this is that the highest maximum temperature $\left(32^{\circ} \mathrm{C}\right)$ in the observed period (1976-2011) was lower than $35^{\circ} \mathrm{C}$, a rice threshold for maximum temperature. By 2090 (2077-2100), rice yield in wetland and dryland is projected to decrease by about 3\% (RCP2.6 scenario), 4\% (RCP4.5 scenario), 5\% (RCP6.0 scenario) and $14 \%$ (RCP8.5 scenario).

Second, a system dynamics model was developed to assess the impacts of climate change on three issues including rice yield, harvested areas and rice production by 2090 (20772100). After embedding statistical models and estimating the impacts of maximum temperature on rice yield based on existing studies, the impacts of climate change on rice yield are projected. The system dynamics model is also equipped by August SOI to estimate the impacts of climate change on the timing of monsoon onset i.e the beginning of planting seasons. For assessing harvested areas under a changing climate, the system dynamics model is equipped by a mathematical relationship between seasonal rainfall and harvested areas.

Because the system dynamics model includes the impacts of high maximum temperature, the projected loss of rice yield in wetland and dryland is relatively higher compared to that in statistical models. It is projected that rice yield loss will be about 3\% (RCP2.6 scenario), $6 \%$ (RCP4.5 scenario), 10\% (RCP6.0 scenario) and 23\% (RCP8.5 scenario) by 2090 (2077-2100). Likewise, rice production loss in wetland and dryland is projected to be about 1\% (RCP2.6 scenario), 2\% (RCP4.5 scenario), 7\% (RCP6.0 scenario) and 19\% (RCP8.5 scenario) by 2090 (2077-2100). The projected loss of rice production is relatively lower than rice yield loss as wetland harvested areas are projected to experience a slight increase about 3\% by 2090 (2077-2100) under a changing climate. This also means that the ranking of the impacts of climate change from the most 
significant to the least significant is its impact on rice yield, rice production and harvested areas.

Third, policy options in overcoming the impacts of climate change on rice production are assessed. This study suggests that research on finding rice varieties with three main traits: heat tolerance, short growth duration and high yield is key to balance rice demand and rice supply in West Nusa Tenggara by 2090 (2077-2100). A failure to improve rice yield in such ways is likely to lead to significant reductions in rice supply in the face of climate change.

This study makes theoretical contributions, including the development of statistical models for understanding the impacts of climate change on rice yield and a causal system for investigating the impacts of climate change on rice yield, rice production and harvested areas. Again, the combination of statistical and system dynamics modelling simultaneously investigates the impacts of climate change on rice yield, rice production and harvested areas. This means that this study provides a more holistic view of the impacts of climate change compared to existing studies.

This study also offers practical contributions, advising that declining rice research should be avoided under a changing climate, and suggesting that farming intensification (more climate-resilient rice varieties) is more effective than farming extension (area expansion) in sustaining rice production under a changing climate. Again, research on developing more resilient-climate rice varieties is possible as projected rice yield in sustaining rice production by 2090 (2077-2100) is similar to rice's yield potential. 


\section{Acknowledgements}

During this doctoral research and its compilation, I have had the help of many amazing people who have supported me in countless ways and to whom I owe my deepest thanks. Firstly, I would like to express my immeasurable gratitude to Bob Cavana who supervised me and gave me valuable advice, encouragement and support throughout this challenging journey. I am in debt to James Renwick, for his constant guidance and support, especially in supporting my understanding of the climate change studies and related issues. I am also deeply indebted to Lawrie Corbett who guided me throughout my research and writing process.

I am very thankful to the New Zealand Government for financing my study from my first arrival until my final year. I am also especially thankful to Linsell Richard and Helena Cook who supported me during my $\mathrm{PhD}$ journey in windy Wellington. I would like to express my gratitude to Kirsten Reid and Rebecca McKeown who commented on the the final version of my thesis. My sincere gratitude also goes to Jo Hodge and her colleagues (Amelia Guy Meakin, Emma Liu, Abby Sharock and Anya Maule) who provided me with valuable support during my study at this university.

Further thanks go to my friends, including Arthur Ahimbisibwe, Sarah Kimani and Geoff Harrison who shared their useful study experiences with me. From their shared experiences, I was able to draw great inspiration and moral support during my research. My thanks also go Thai An Vu and Ian Campbell for their enchanting chats.

I am deeply grateful to Megan Key, Misa Ito and Celine Ronze for their administrative support during my thesis writing. Without their help, I might not have enjoyed such wellarranged supervisory meetings. I would like to express my great gratitude to examiners including Dr. Vipul Jain, Dr. Daniel Kingston and Prof. Carl Smith. Their useful feedback helps me in improvement of this $\mathrm{PhD}$ thesis.

Finally, my last words of thanks go to my family. My great gratitude goes to my father and mother who always pray for me. I devote this research to my beloved wife, Rida, and to my daugthers, Ema and Aulia. They are my inspiration until the end. 
this page intentionally left blank 


\section{Contents}

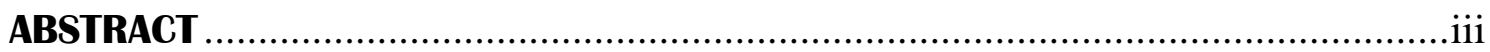

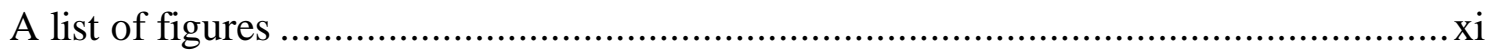

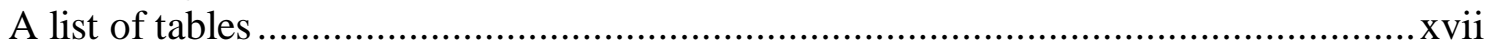

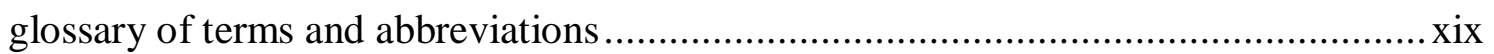

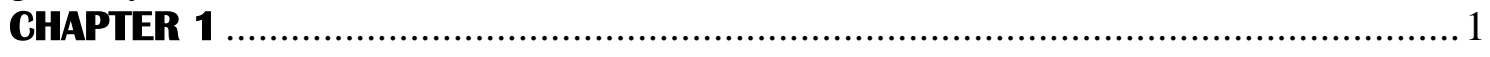

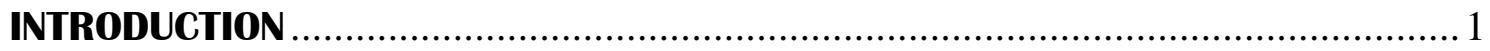

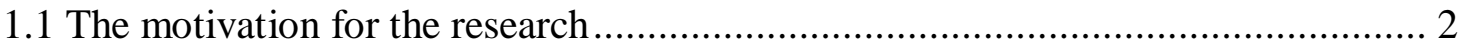

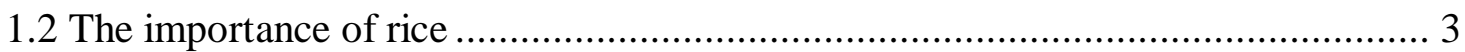

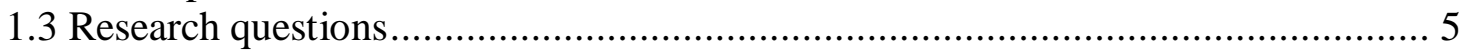

1.4 Scope of study and conceptual framework .................................................. 5

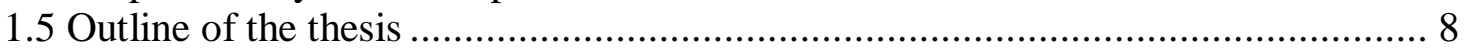

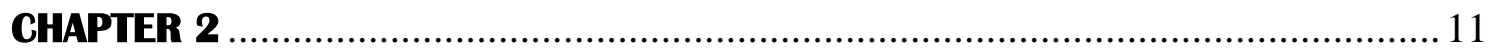

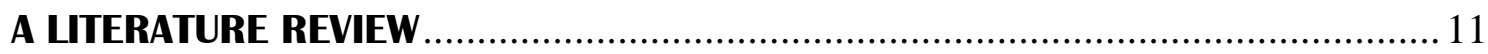

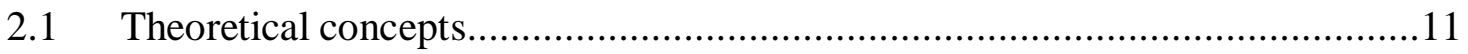

2.1.1 Definitions of climate change and climate variability ............................11

2.1.2 Indonesian climate: Past and projections ............................................12

2.1.3 The global climate models (global circulation models) .............................14

2.1.4 Carbondioxide concentration in Indonesia ...............................................16

2.1.5 Optimum conditions for rice production .............................................17

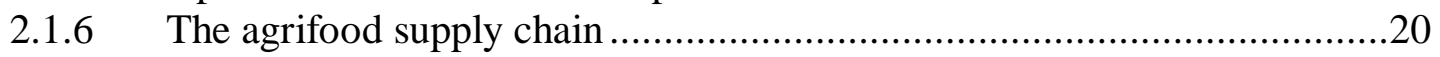

2.1.7 The rice supply chain in West Nusa Tenggara ......................................23

2.1.8 Definitions and types of supply chain uncertainty................................26

2.1.9 Climate as an inherent source of uncertainty in the rice supply chain........29

2.1.10 Some simulations in the supply chain management ................................30

2.1.11 Technological improvement on rice yields .............................................32

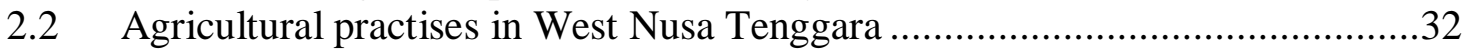

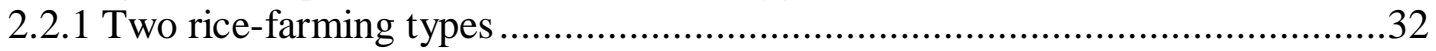

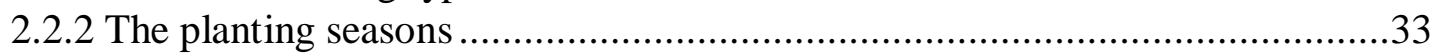

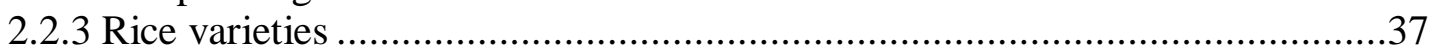

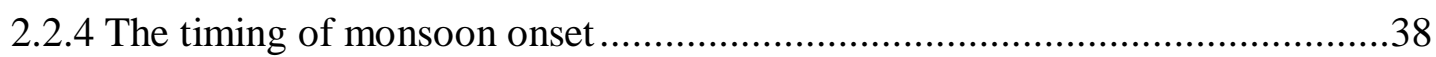

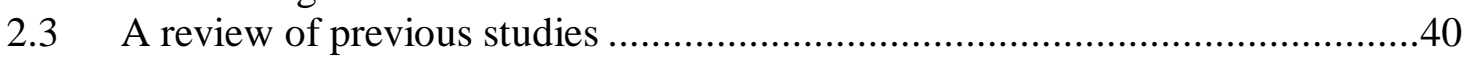

2.3.1 Supply uncertainties in the rice supply chain .........................................40

2.3.2 Climate change studies: statistical models and crop models......................41

2.3.3 System dynamics studies: climate change studies \& the agrifood supply

chain 43

2.3.4 System dynamics studies: measuring crop/agricultural production ...........44

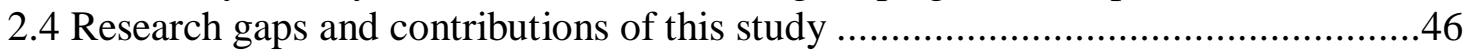

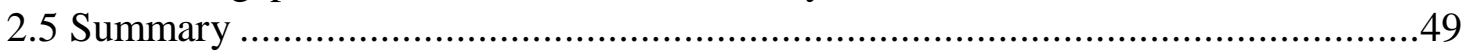

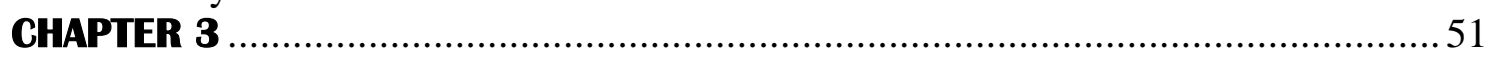

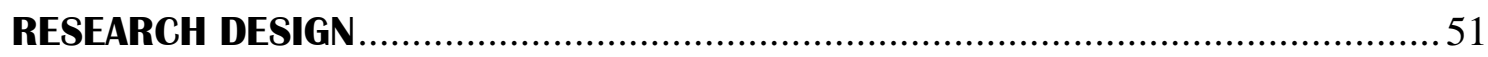

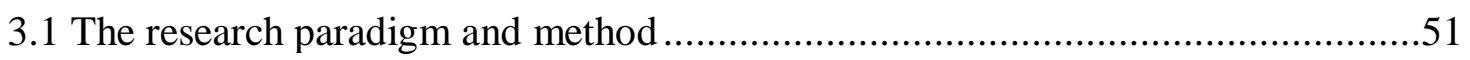

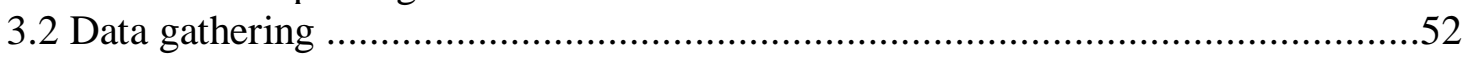

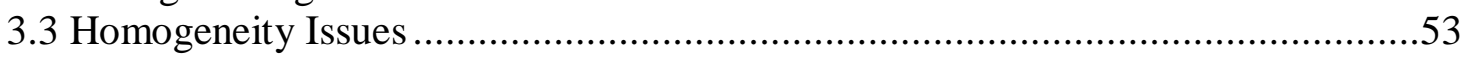

3.4 A methodological approach to obtain a statistical equation.................................54

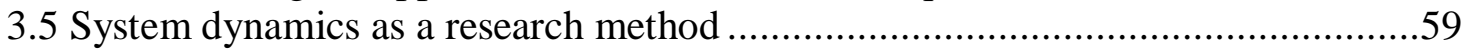

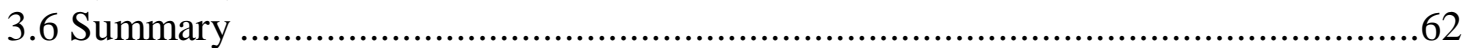




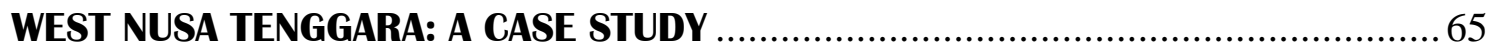

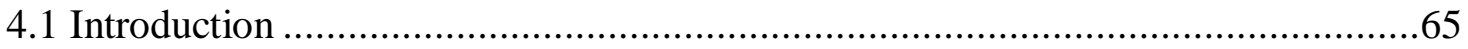

4.2 Research background: West Nusa Tenggara at glance ......................................65

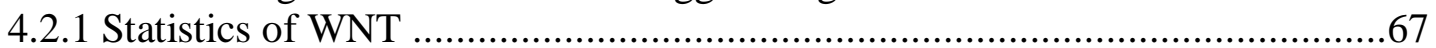

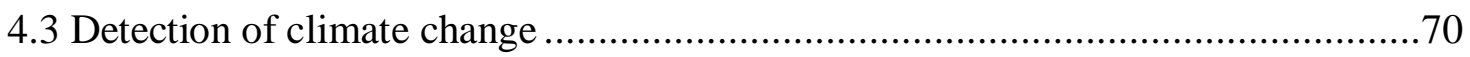

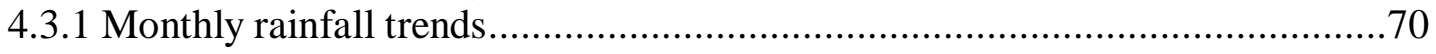

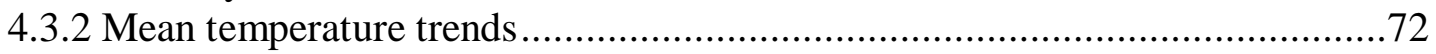

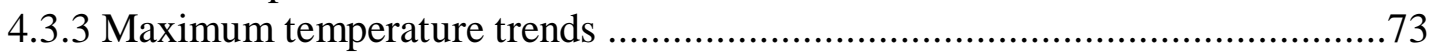

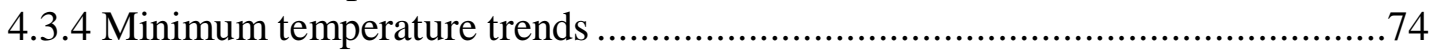

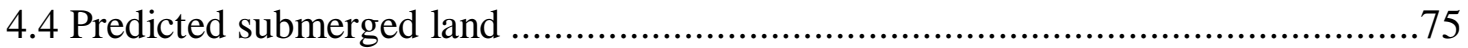

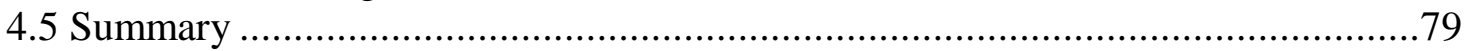

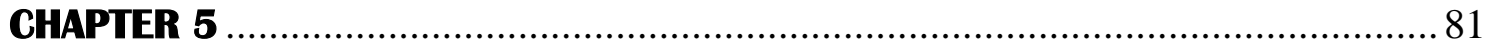

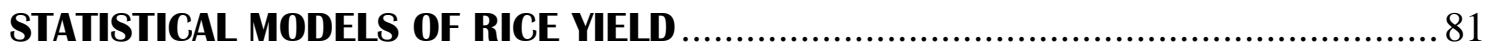

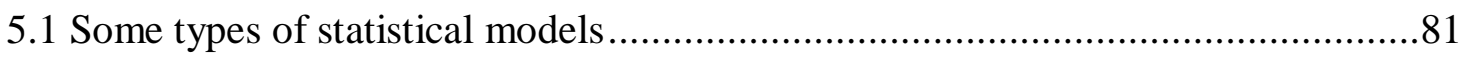

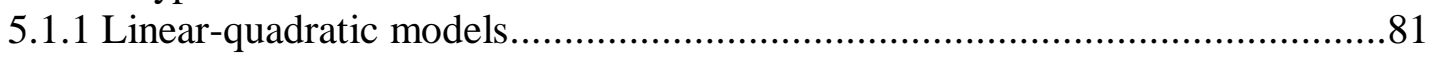

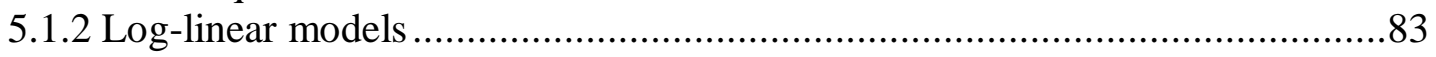

5.2 Statistical models of climate impacts on crop yield ....................................... 83

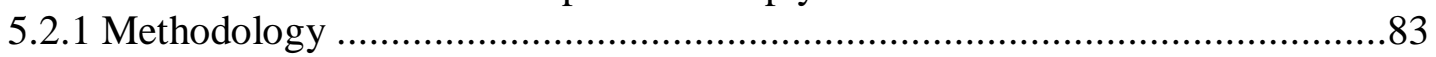

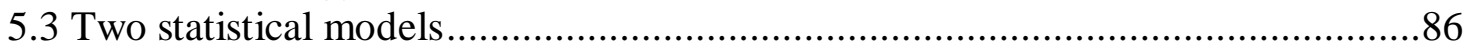

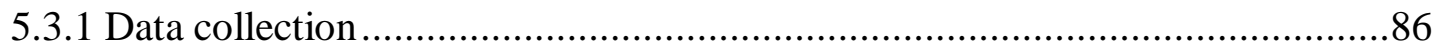

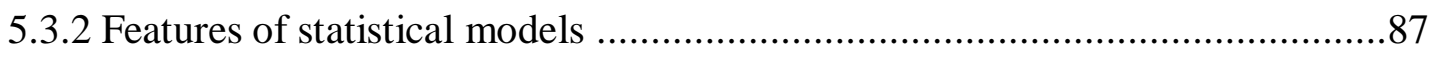

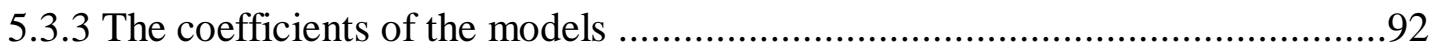

5.3.4 The effects of climate on rice yield: supporting studies ...............................100

5.4 The impacts of climate change on rice yield by $2090(2077-2100)$..................... 100

5.4.1 Forecasting parameters for predicting impacts of climate change .................100

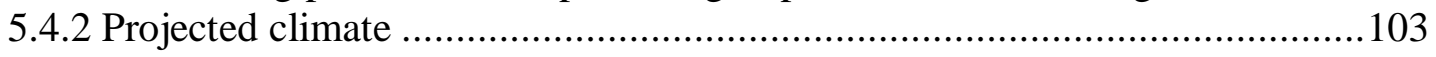

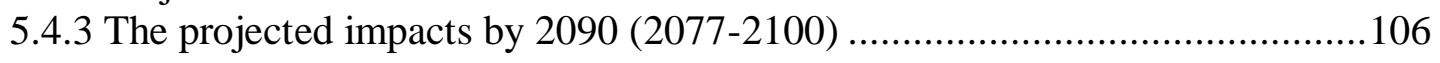

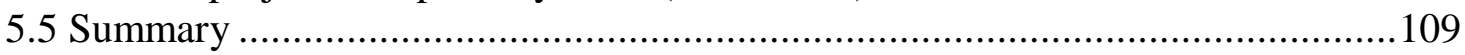

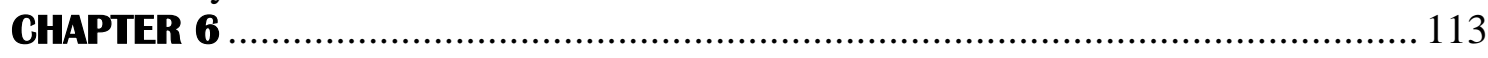

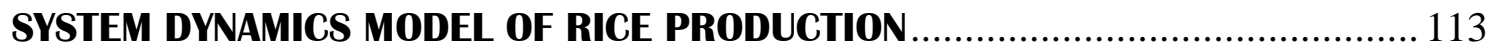

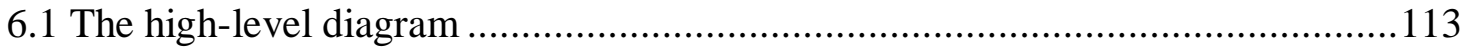

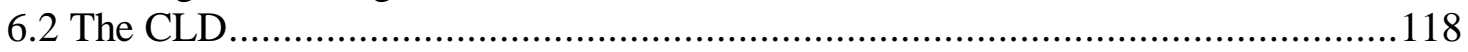

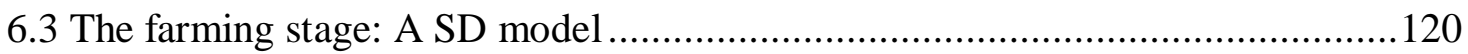

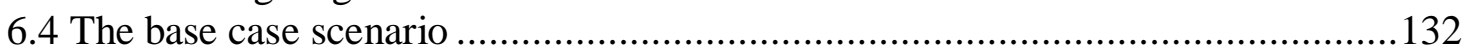

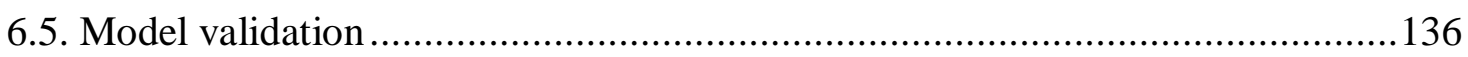

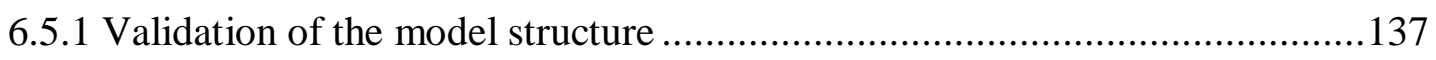

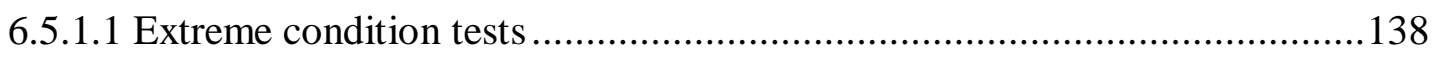

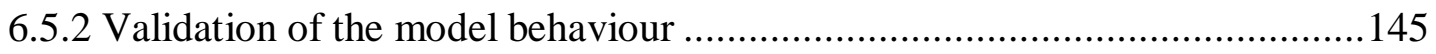

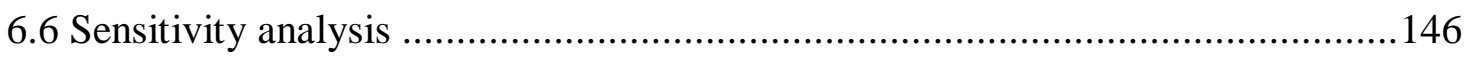

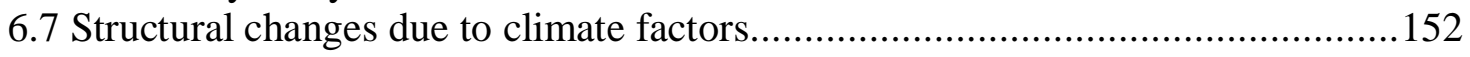

6.7.1 The basecase strategy or the first strategy............................................... 155

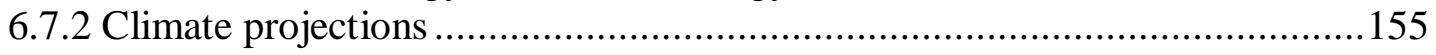

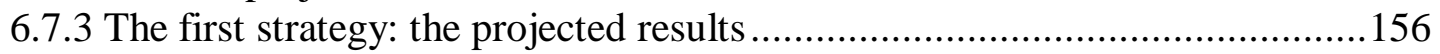

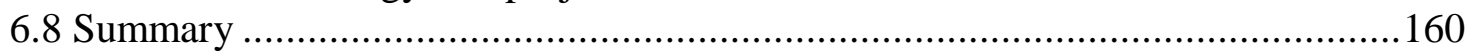

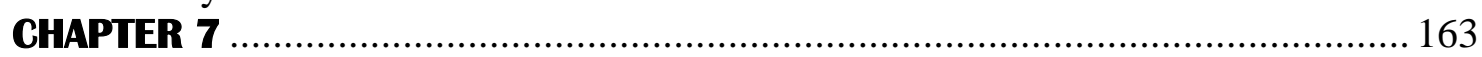

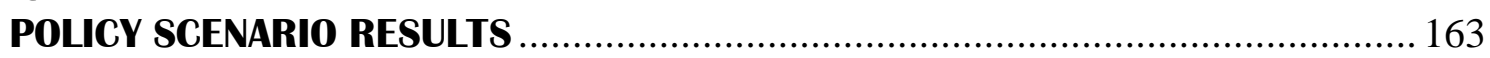

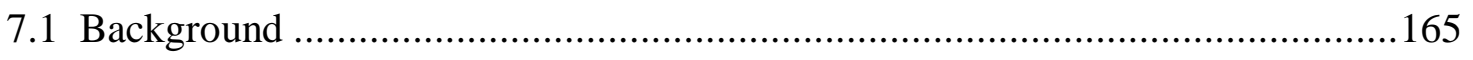




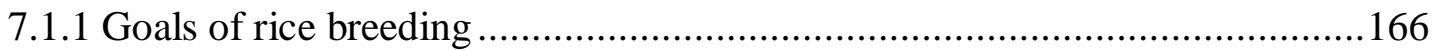

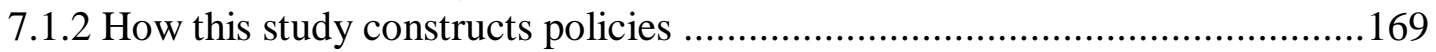

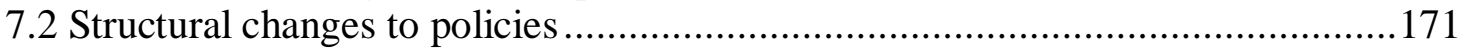

7.2.1 Policy 1: Research on finding rice varieties with shorter growth duration.....171

7.2.2 Policy 2: Research on finding rice varieties with higher yields .....................180

7.2.3 Policy 3: Research on finding rice varieties with heat tolerance (high

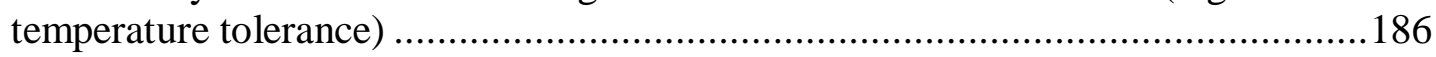

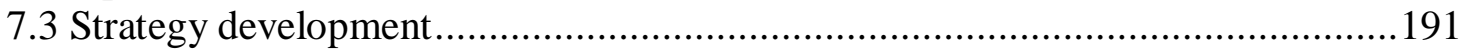

7.3.1 The second strategy: non-heat tolerant rice strategy ..................................195

7.3.2 The third strategy: heat tolerant rice varieties ...........................................198

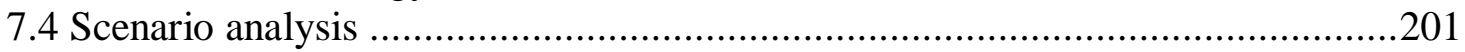

7.4.1 The second strategy: the projected results ................................................201

7.4.2 The third strategy: the projected results .......................................................203

7.5 A comparison between the three strategies and the observed period ....................205

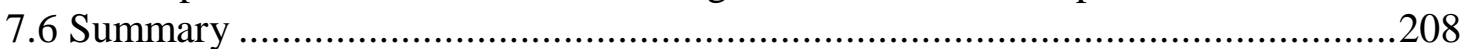

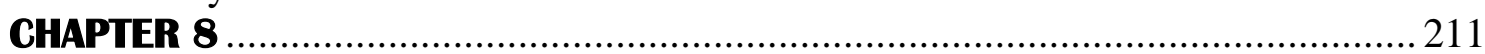

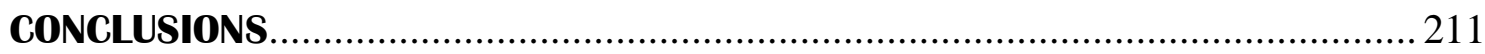

8.1 Combination of statistical analysis and the SD modelling ...............................213

8.2 The impacts of climate change on the rice production ......................................2. 216

8.3 The impacts of climate change on the rice supply uncertainties .........................218

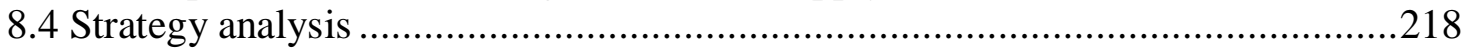

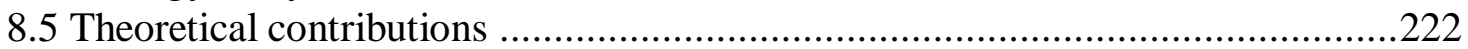

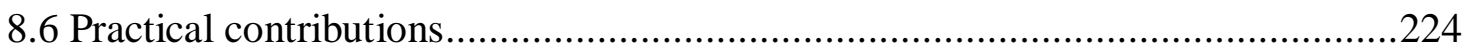

8.6.1 Creating system innovation to support rice breeding research......................225

8.6.2 Managerial implications in the global and the local contexts for the agrifood supply chain ...........................................................................................226

8.6.3 Some learning lessons for the global and the local contexts.......................228

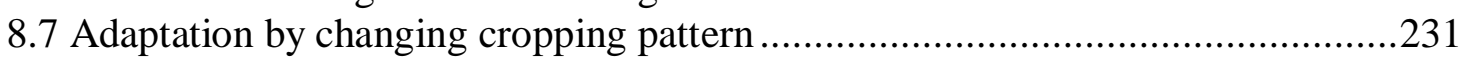

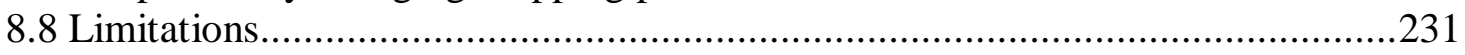

8.8.1 Comparing outputs of six chosen climate models and those of IPCC ensemble

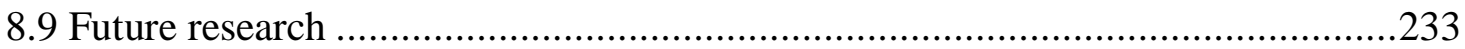

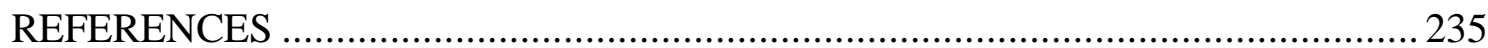

Appendix A. The kinds of structural break (Chapter 5) ........................................... 267

Appendix B. Correlation analysis after first differencing (Chapter 5) ....................... 269

Appendix C. The Historical System Dynamics Model (Chapter 6) ........................... 271

Appendix D. System Dynamics Model Documentation (SD Historical Model -

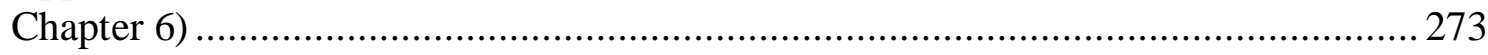

Appendix E. The Basecase Model (Chapter 6) ...................................................... 289

Appendix F. The Basecase Model Documentation..................................................... 291

Appendix G. The Basecase Strategy Model (Chapter 6) ............................................ 309

Appendix H. The Basecase Strategy Model Documentation (Chapter 6)................... 311

Appendix I. The SD Models With Policy Scenarios (Chapter 7) .............................. 351

Appendix J. Vensim Simulation Outputs (Chapter 7) ............................................. 357

Appendix K. Vensim Model Documentation (Chapter 7) ....................................... 365 
this page intentionally left blank 


\section{A list of figures}

Figure 1.1 Major rice growing areas across the world (GRIsP, 2013)...................... 1

Figure 1.2 An overview of the research methodology

Figure 2.1. This schematic illustrates possible changes in the frequency distribution of a typical climate variable, e.g. temperature (a. changing in a mean; b. changing in a variation and; c. changing both variation and mean). Shaded areas are climate extremes.

Figure 2.2 Median projected temperature change in December-February (top) and JuneAugust (bottom) relative to the period 1986-2005 for RCP (Representative Concentration Pathways) scenario 4.5 based on an ensemble of CMIP5 model projections. From left to right is the period 2016-2035, 2046-2065 and 2081-2100. The source is IPCC (2013) - Annex I: Atlas of Global and Regional Climate Projections (Figure AI.64-AI.65).

Figure 2.3 Median projected rainfall change in October-March (top) and AprilSeptember (bottom) relative to the period 1986-2005 for scenario RCP 4.5 based on an ensemble of CMIP5 model projections. From left to right is the period 2016-2035, 2046-2065 and 2081-2100. The hatched area denotes the area where the 20-year mean differences of the percentiles are less than the standard deviation of model-estimated present-day natural variability of 20-year mean differences. The source is (IPCC, 2013) - Annex I: Atlas of Global and Regional Climate Projections (Figure AI.66-AI.67). ..14 Figure 2.4 The comparison of the $\mathrm{CO}_{2}$ concentrations in Mauna Loa (blue), Global (pink) and Bukit Kototabang (green) for the period 2004-2009 (source: Nahas et al., 2009) .17

Figure 2.5 The stages of the rice growth (Haifa Group, n.d.)..................................18

Figure 2.6. Actors in agrifood supply chain (Dani, 2015) ...................... 22

Figure 2.7. The Indonesian rice supply chain (According to Hasan (2010), a blue circle is a vulnerable climate change and climate variability), while a blue dotted circle is the research focus in this study. .24

Figure 2.8 Some processes in rice production (the source: http://www.knowledgebank.irri.org)...... .25

Figure 2.9 A proportion of wetland and the dryland areas (BPS, 2014) ......................33

Figure 2.10 Wetland harvested areas in three harvesting seasons (BPS, 2000-2013) ..34

Figure 2.11 Dryland harvested areas in three harvesting seasons (BPS, 2000-2013)...34

Figure 2.12 Harvested area of wetland and dryland (BPS, 1986-2013)........................35

Figure 2.13 Cropping intensity in percentage (BPS, 2000-2013) ..............................

Figure 2.14 The mean of time to maturity for each rice variety and proportion of their applications ( $\mathrm{A}=$ amphibiotic, $\mathrm{W}=$ wetland and $\mathrm{M}=$ mixed) (Suprihatno et al., 2010) ....38 
Figure 2.15 Variations of monsoon onset (days) vs. August SOI (Southern Oscillation Index) in the period 1987-2013 (August SOI is taken from The Australian Bureau of Meteorology: http://www.bom.gov.au/climate/current/soihtm1.shtml) ......................39

Figure 2.16 The monsoon systems in the world (IPCC, 2013) ...............................40

Figure 3.1 Some steps for obtaining appropriate statistical models ...........................58

Figure 3.2 Some steps developing a system dynamics model .................................61

Figure 4.1 Indonesia and West Nusa Tenggara ....................................................66

Figure 4.2 The percentage of food consumption in WNT (BPS NTB, 2013) ............. 68

Figure 4.3 The importance of rice based on gross domestic product and employment 69 Figure 4.4 Monthly rainfall in the baseline (1971-2000) and the current period (20012013) with mean standard error as error bars (BMKG, 2014) ....................................71

Figure 4.5 Monthly mean temperature in the baseline (1971-2000) and the current period (2001-2013) with mean standard error as error bars (BMKG, 2014) .................72

Figure 4.6 Monthly maximum temperature in the baseline (1971-2000) and the current period (2001-2013) with mean standard error as error bars (BMKG, 2014)................73

Figure 4.7 Monthly minimum temperature in the baseline (1971-2000) and the current period (2001-2013) with mean standard error as error bars (BMKG, 2014) .................75

Figure 4.8. Land elevation ranges in the region (red is from $0 \mathrm{~m}$ to $1 \mathrm{~m}$, blue is from 1 $\mathrm{m}$ to 1,000 and green is upper $1,000 \mathrm{~m}$ ). (Butler et al., 2011, figure 8) .......................78

Figure 5.1 The relationship between temperature and crop yield (Lobell \& Burke,

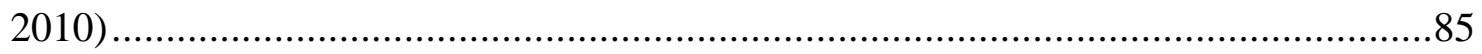

Figure 5.2. Rice yield of wetland farming in the period 1976-2011 .........................88

Figure 5.3. Rice yield of dryland farming in the period 1976-2011 ...........................89

Figure 5.4 Historical data of seed usage in wetland farming (BPS, 1976-2011)........91

Figure 5.5 Historical data of fertiliser usage in wetland farming (BPS, 1976-2011)...92

Figure 5.6 A comparison between rice yield of wetland farming (a statistical model

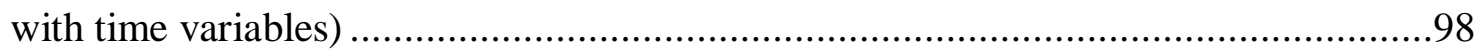

Figure 5.7 A comparison between rice yield of wetland farming (a statistical model with the first differenced variables)

Figure 5.8 A comparison between rice yield of dryland farming (a statistical model with time variables) .99

Figure 5.9 A comparison between rice yield of dryland farming (a statistical model with the first differenced variables).....

Figure 5.10 Rice yield pattern under the base case scenario by 2100 (brown and yellow lines represent rice yield based on $95 \%$ confidence interval of minimum temperature coefficients) 106 
Figure 5.11 Reduction percentages of rice yield in wetland farming (a) and dryland farming (b) (vertical lines inside bars are error bars based on $5^{\text {th }}$ and $95^{\text {th }}$ percentiles of climate projections 106

Figure 6.1 A simplified high level diagram of the SD model.................................114

Figure 6.2 Parts of CLDs from existing studies 118

Figure 6.3 Farming stage (A simplified CLD of the impacts of climate change on the

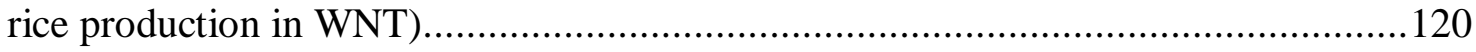

Figure 6.4 Interactions between farming areas and available land ..........................122

Figure 6.5 The interactions among production factors, climate and rice yield in the farming stage. 123

Figure 6.6 cropping intensity in wetland and dryland farming ............................... 124

Figure 6.7 Rice production in the farming area ................................................ 125

Figure 6.8 The August SOI and the timing of monsoon onset ...............................127

Figure 6.9 Harvested wetland areas based on observation and simulation .................129

Figure 6.10 Harvested dryland areas based on observation and simulation...............129

Figure 6.11 Wetland rice yield based on observation and simulation......................130

Figure 6.12 Dryland rice yield based on observation and simulation ......................130

Figure 6.13 Actual wetland rice production based on observation and simulation .....131

Figure 6.14 Actual dryland rice production based on observation and simulation......131

Figure 6.15 Rice yield (wetland-dryland) vs minimum temperature (basecase) .........134

Figure 6.16 Rice production (wetland-dryland) vs the timing of monsoon onset

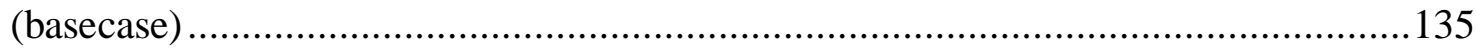

Figure 6.17 Cropping intensity in wetland and dryland (basecase) ..........................135

Figure 6.18 harvested areas vs rice farming areas (basecase)................................. 136

Figure 6.19 Projections under the basecase, RCP2.6 and RCP8.5 scenarios .......139-140

Figure 6.20 Extreme climate projections 141-142

Figure 6.21 Extreme conditions of technological progress

Figure 6.22 Extreme conditions of the increase of farming areas......................144-145

Figure 6.23 Changes in the basecase SD model .............................................. 148

Figure 6.24 A lookup function of the effects of maximum temperature ....................153

Figure 6.25. A structural change of the effects of maximum temperature ..................153

Figure 6.26. A structural change in according to the negative impacts of minimum temperature after $24.7{ }^{0} \mathrm{C}$. All variables in this figure are new variables except for rice yield (wetland) and rice yield (dryland)

Figure 6.27 Simulation results based on the first strategy (the base case strategy).157158 
Figure 6.28 Results of the first strategy (base case strategy). Compared to those in the basecase scenario. Vertical lines are error bars $\left(5^{\text {th }}\right.$ and $95^{\text {th }}$ percentiles - climate projections). It should be noted that dryland harvested areas are not influenced by climate, hence no available error bars for dryland harvested areas. . 159

Figure 7.1 Structural changes of shorter growth duration varieties days 174-175

Figure 7.2 Simulation results after policy change of shorter rice growing days (Vensim outputs)

Figure 7.3 Results after a structural change of shorter rice growing days (multi-year average).

Figure 7.4 A comparison before and after a structural change of increasing technological progress (higher yield varieties) 181

Figure 7.5 Simulation runs after a structural change of increasing technological progress i.e. higher yield varieties (Vensim outputs). 183-184

Figure 7.6 Results after a structural change of increasing technological progress i.e. higher yield varieties (multi year average). The changes compared to those in the basecase scenarios 185

Figure 7.7 A structural change due to finding heat tolerant varieties (wetland and dryland)

Figure 7.8 Benefits relating to heat tolerant rice varieties (target years are the years when the heat tolerant varieties are found)-Vensim outputs 189-190

Figure 7.9 Some benefits relating to heat tolerant rice varieties (the heat tolerant varieties found by 2030) - multi year outputs

Figure 7.10 Results of the second strategy 196-197

Figure 7.11 Results of the third technology strategy: if heat tolerant rice varieties will be found by 2030 ..... $199-200$

Figure 7.12 Simulation results based on the second strategy. Compared to those in the basecase scenario. Vertical lines are error bars $\left(5^{\text {th }}\right.$ and $95^{\text {th }}$ percentiles - climate projections). It should be noted that dryland harvested areas are not influenced by climate, hence no available error bars for dryland harvested areas. 202

Figure 7.13 Simulation results based on the third technology strategy (heat tolerant varieties found in 2030). Compared to those in the basecase scenario. Vertical lines are error bars $\left(5^{\text {th }}\right.$ and $95^{\text {th }}$ percentiles - climate projections). It should be noted that dryland harvested areas are not influenced by climate, hence no available error bars for dryland harvested areas.

Figure 7.14 A comparison of strategies results and the observed period for wetland rice under RCP2.6 and RCP8.5 scenarios. 206

Figure 7.15 A comparison of strategies' results and the observed period for dryland rice under RCP2.6 and RCP8.5 scenarios 207 
Figure 8.1 The impacts of climate change on total rice yield, total rice production \& total harvested areas (the first strategy/the basecase strategy) ................................217 Figure 8.2 A comparison of total rice yield, total rice production and total harvested areas (RCP2.6 vs RCP8.5) 
this page intentionally left blank 


\section{A list of tables}

Table 2.1 A summary of the four RCP scenarios ............................... 16

Table 2.2. Stages of rice growth.

Table 2.3 Two types of the agrifood supply chain (Dani, 2015; Mardiyanto, Supriyatna \& Agustin, 2005; van der Vorst, 2007; Xiao et al., 2012; William, 2012)

Table 2.4 Possible SCUs in the agrifood supply chain (adapted from Van der Vorst \& Beulens, 2002).

Table 2.5 System Dynamics, Discrete Event Simulation and Agent Based Modeling: A Comparison (Borshchev \& Filippov, 2004; Schieritz \& Milling, 2003)....

Table 2.6 The wetland (irrigated land) and the dryland (unirrigated land) by area (BPS, 2014)

Table 3.1 A list of required data.

Table 4.1. Data rice production, area harvested and productivity (BPS, 2006-2014)...67

Table 4.2. Rice surplus in WNT, Bali and ENT (Lantarsih et al., 2011) 68

Table 4.3 A summary statistics tests for monthly rainfall . .71

Table 4.4 A summary statistics tests for monthly mean temperature .72

Table 4.5 A summary statistics tests for monthly maximum temperature .74

Table 4.6 A summary statistics tests for monthly minimum temperature .75

Table 4. 7 Altitudes of each municipality's capital in West Nusa Tenggara (BPS, 2014) .76

Table 4. 8 Names and altitudes of mountains (BPS, 2014)

Table 5.1 Correlation analysis of production factors, climate and rice yield based on detrended method (dryland farming)

Table 5.2 Correlation analysis of production factors, climate and rice yield based on detrended method (wetland farming)

Table 5.3 Unstandardised coefficients of each statistical model for wetland farming...94 Table 5.4 Unstandardised coefficients of each statistical models for dryland farming..95 Table 5.5 Data distribution of climate (BMKG, 2014)

Table 5.6. A complete setting of minimum temperature and production factors with no climate change.

Table 5.7 Ensemble projections of seasonal rainfall, minimum and maximum temperature

Table 5.8 Reduction percentages of rice yield based on the average of six climate models $\left(5^{\text {th }}-95^{\text {th }}\right.$ percentiles based on climate projections).

Table 5.9 the main differences between statistical models, crop models and system dynamics 
Table 6.1. Added variables in chapter 6, compared to chapter 5. A definition of all variables can be seen in appendix H............................................................... 116

Table 6.2 Definitions and dimensions of major variables in the farming stage ..........128

Table 6.3 Mean absolute percentage errors (MAPEs).......................................... 132

Table 6.4 The values of parameter on the base case simulation ..............................133

Table 6.5 The values of major variables on the base case simulation.......................136

Table 6.6 Parameters for the extreme condition tests (RCP2.6 and RCP8.5 climate

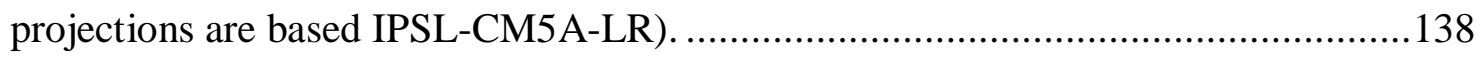

Table 6.7 Sensitivity experiments for testing parameters ...................................... 149

Table 6.8 Results of sensitivity analysis ( $+10 \%$ change; $-10 \%$ change) $\ldots \ldots \ldots \ldots \ldots \ldots \ldots . . . . . . .150$

Table 6.9 Sensitive parameters and their parameter categories ................................ 152

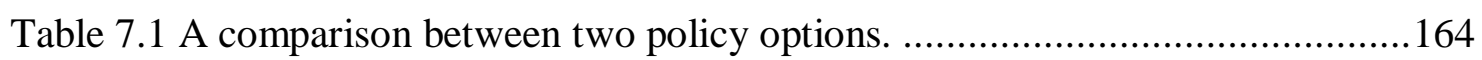

Table 7.2 Rice planting in wetland and dryland. Secondary crops are peanut, maize \&

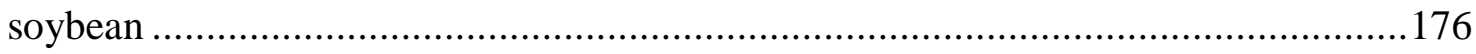

Table 7.3 Problems and technical opportunities in rice farming ..............................193

Table 7.4 A summary of three strategies ........................................................ 195

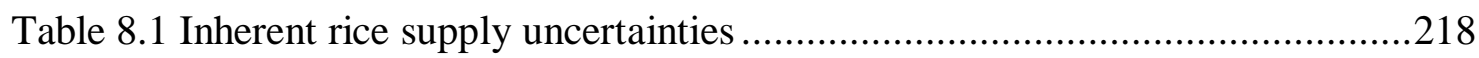

Table 8.2 The highest rice yield for each strategy in each period (wetland/dryland) ..221 


\section{glossary of terms and abbreviations}

\begin{tabular}{|c|c|}
\hline $\mathrm{ABM}$ & Agent Based Modelling \\
\hline AOGCMs & The Atmospheric Ocean General Circulation Models \\
\hline BATAN & $\begin{array}{l}\text { Badan Tenaga Atom Nasional: The Indonesian Agency for } \\
\text { Nuclear Power Facilities }\end{array}$ \\
\hline BMKG & $\begin{array}{l}\text { Badan Meteorologi Klimatologi dan Geofisika: The Indonesian } \\
\text { Agency for Meteorology Climate and Geophysics }\end{array}$ \\
\hline BPS & Biro Pusat Statistik : The Indonesian's Statistics Bureau \\
\hline BULOG & Badan Umum Logistik: The Indonesian Agency for Logistics \\
\hline $\mathrm{CFCs}$ & Chlorofluorocarbon \\
\hline $\mathrm{CH} 4$ & Methane (gas) \\
\hline CLD & A causal loop diagram \\
\hline CMIP3 & $\begin{array}{l}\text { Coupled Model Intercomparison Project } 3 \text { is the third } \\
\text { coupled model intercomparison project as described in IPCC's } \\
2007 \text { report. }\end{array}$ \\
\hline CMIP5 & $\begin{array}{l}\text { Coupled Model Intercomparison Project } 5 \text { is the fifth coupled } \\
\text { model intercomparison project as described in IPCC's } 2013 \text { report. }\end{array}$ \\
\hline $\mathrm{CO}$ & Carbon monoxide \\
\hline CROAD & $\begin{array}{l}\text { Climate Rapid Overview and Decision Support } \\
\text { (www.climateinteractive.org) }\end{array}$ \\
\hline DES & Discrete Event Simulation \\
\hline Dryland & Land without standing water in which plants rely on rainfall \\
\hline Growth duration & $\begin{array}{l}\text { The length of rice growth from planting until harvesting. This } \\
\text { includes vegetative, reproductive and ripening stages. }\end{array}$ \\
\hline ENT & East Nusa Tenggara, an Indonesian province in the east of WNT \\
\hline Photosynthesis & $\begin{array}{l}\text { The process of capturing light energy and converting it to sugar } \\
\text { energy, in the presence of chlorophyll using carbon dioxide }\left(\mathrm{CO}_{2}\right) \\
\text { and water }\left(\mathrm{H}_{2} \mathrm{O}\right) \text { (source: } \\
\text { http://www.ext.colostate.edu/mg/Gardennotes/141.pdf) }\end{array}$ \\
\hline GDP & Gross Domestic Product \\
\hline Genes & $\begin{array}{l}\text { A unit of heredity which is transferred from a parent to offspring } \\
\text { and is held to determine some characteristic of the offspring }\end{array}$ \\
\hline IPCC & Intergovernmental Panel on Climate Change \\
\hline Irrigated & $\begin{array}{l}\text { The land with standing water which supported by irrigation } \\
\text { facilities }\end{array}$ \\
\hline NIWA & $\begin{array}{l}\text { National Institute of Water and Atmospheric Research } \\
\text { (www.niwa.co.nz) }\end{array}$ \\
\hline Non-Irrigated & Land without standing water in which plants highly rely on rainfall \\
\hline Nusa Tenggara Barat & The Indonesian name for West Nusa Tenggara \\
\hline Paddy or Rice & $\begin{array}{l}\text { Husked rice which should be milled to be milled rice (unhusked } \\
\text { paddy) }\end{array}$ \\
\hline $\mathrm{RCP}$ & Representative Concentration Pathway \\
\hline Rice farming areas & $\begin{array}{l}\text { Rice farming fields where climate, technology and labour interact } \\
\text { with each another (Hasan, 2010) }\end{array}$ \\
\hline Milled rice & Unhusked rice as a result of rice milling \\
\hline Respiration & $\begin{array}{l}\text { The process of metabolizing (burning) sugars to yield energy for } \\
\text { growth, reproduction, and other life processes (source: } \\
\text { http://www.ext.colostate.edu/mg/Gardennotes/141.pdf) }\end{array}$ \\
\hline
\end{tabular}


SRES

Special Report on Emissions Scenarios (IPCC, 2007)

The historical model The SD model to reproduce the observed system (1976-2011)

The basecase model The SD model with the absence of climate change. This is also called the basecase scenario

The basecase strategy The SD model with business as usual strategy. This is also

Traits called the first strategy

Transpiration A genetically determined characteristic The loss of water vapour through the stomata of the leaves. This serves about $80 \%$ of the cooling effect of a shade tree (source: http://www.ext.colostate.edu/mg/Gardennotes/141.pdf)

Variety A taxonomic category that ranks below subspecies (where present) or species, its members differing from others of the same subspecies or species in minor but permanent or heritable characteristics.

Wetland The land with standing water which supported by irrigation facilities

WNT West Nusa Tenggara 


\section{CHAPTER 1 \\ INTRODUCTION}

Agriculture is one of a number of sectors that are vulnerable to climate change (IPCC, 2007; IPCC, 2012; IPCC, 2013). Agriculture is also an important sector for economic development, particularly in developing countries (FAO, 2003; GRIsP, 2013; IFRRI, 2009). This means that understanding climate change impacts on agriculture is important, especially for middle and low income countries (Chijioke, Haile \& Waschkeit, 2011; FAO, 2003; GRIsP, 2013, IFRRI, 2009) as they have limited capabilities to tackle the negative impacts of climate change.

Figure 1.1 shows that rice is planted in a number of regions across the world, such as Africa, Australia and the USA. However, rice is primarily planted in developing countries, i.e. low and middle income countries (GRIsP, 2013). In particular, rice is mostly planted in Asian regions which make up approximately $90 \%$ of total rice farming areas. In Asia, rice is a staple food and a main source of employment (GRIsP, 2013). Around 3 billion people depend on rice and a significant proportion of the world population will depend on rice by 2035 (IRRI, 2015).

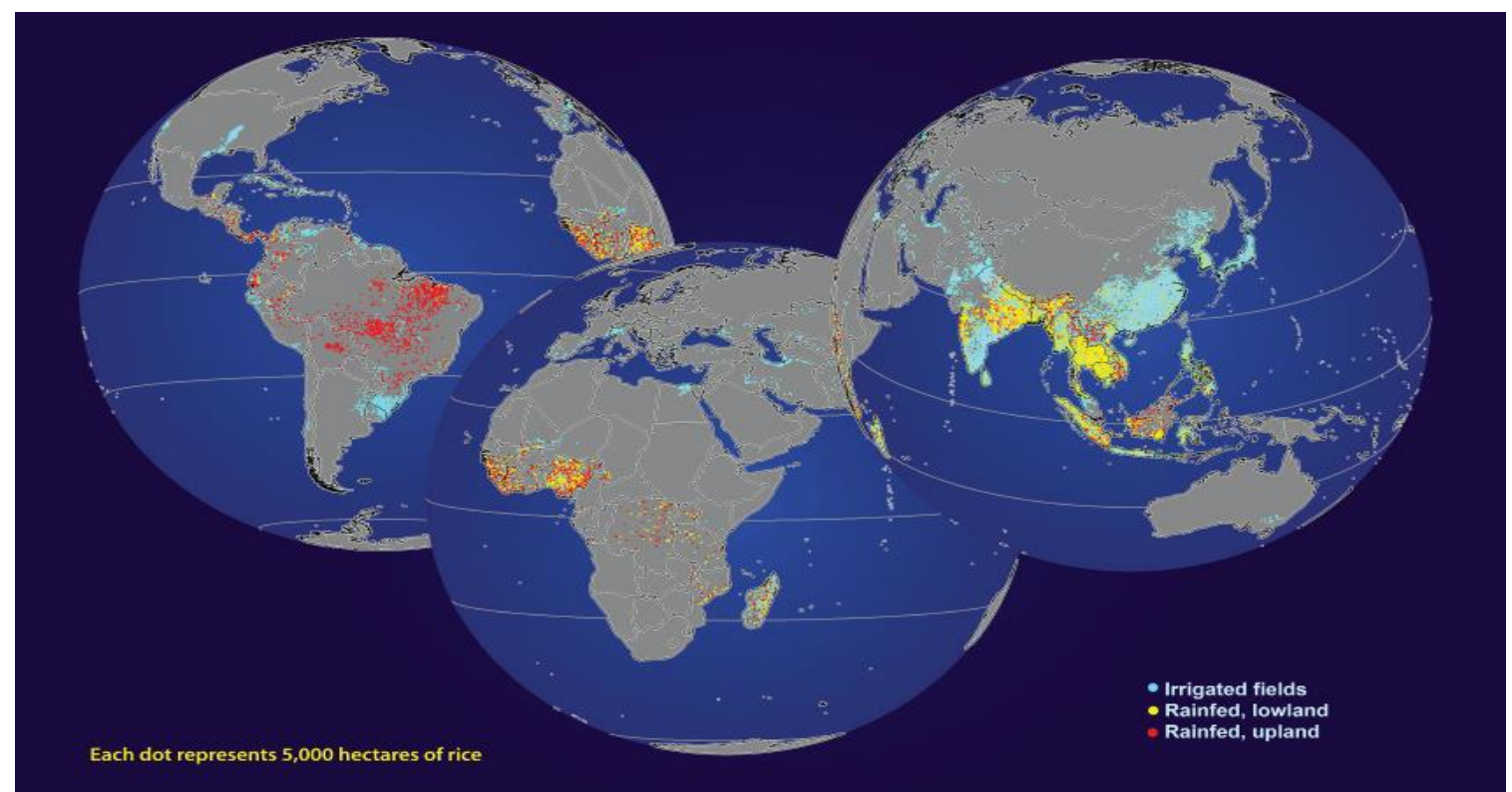

Figure 1.1 Major rice growing areas across the world (GRIsP, 2013)

Rice grows well within its optimum temperature (Yoshida, 1981). In general, rice yield is higher in the rice's optimum temperature than that beyond the rice's optimum 
temperature. In other words, rice yields gradually increase up to their temperature thresholds, but rice yield tends to decrease above those thresholds (Ackerman \& Stanton, 2012; Yoshida, 1981).

Since the recent maximum temperature in Asian regions is close to the maximum temperature threshold of rice (Devkota, 2011) and the recent minimum temperature is higher than the minimum temperature threshold of rice (Peng et al., 2004; Welch et al., 2010), the rice is highly vulnerable to climate change. Futhermore, the concept of a higher crop yield due to higher $\mathrm{CO}_{2}$ concentration is clearly limited (Ackerman \& Stanton, 2012), since crops require other inputs such as nitrogen and water to support photosynthesis. It seems that positive impacts of climate change on rice (crop) yield such as a greater yield due to a higher $\mathrm{CO}_{2}$ concentration can be negated by the negative impacts of climate change such as a lower rice yield due to high maximum temperature and high minimum temperature.

\subsection{The motivation for the research}

Existing studies show that an increase in temperature due to climate change can decrease rice yield in all parts of the world such as South East Asia, South Asia and Southern Africa (Lobell et al., 2008; Lobell et al., 2011; Lobell \& Gourdji, 2012). Those studies also affirm that many crops, such as maize, rice and sorghum are susceptible to the negative impact of high temperature (Moron et al, 2015), and the impacts of temperature on crop yield are highly important (Klink et al., 2014; Lobell et al., 2008; Lobell et al., 2011; Lobell \& Gourdji, 2012; Mottaleb et al., 2015; Ramirez-Rodrigues et al., 2014; Sarker et al., 2012).

Other existing studies exploring the impacts of climate variability on Indonesian rice production (Falcon et al., 2004; Naylor et al., 2002; Naylor \& Mastrandea, 2009). Those studies find that climate variability, i.e. El-Niño Southern Oscillation (ENSO), can delay the planting seasons and decrease precipitation, leading to smaller harvested areas and a lower Indonesian rice production (Naylor et al., 2002). However, those studies did not consider the impacts of temperature and precipitation change on Indonesian rice production. 
Although existing studies analyse the impacts of climate variability on Indonesian rice production (Falcon et al., 2004; Naylor et al., 2002; Naylor \& Mastrandea, 2009) and the impacts of climate change on Asian rice production (Lobell et al., 2011), those studies did not analyse possible adaptation policies in tackling the negative impacts of climate change on rice supply.

This study develops a new assessment methodology which has not been explored in previous studies. In particular, the aim of this study is to assess the impacts of climate change, such as temperature and precipitation change, on rice production. This study also incorporate production factors and climate in understanding the impacts of climate change impacts on rice production. Again, some adaptation policies in tackling the negative impacts of climate change on rice production will be assessed.

Furthermore, this research investigates the impacts of climate change on rice production in West Nusa Tenggara, one rice-growing area in Indonesia. Indonesia is well-known as one of the largest rice producers and consumers in the world (GRIsP, 2013). As Indonesia is a tropical country, the recent minimum temperature and the recent maximum temperature is relatively close to, if not over, rice temperature thresholds. In attempting to understand the impacts of climate change, this study assesses the impacts of climate change with reference to rice production in West Nusa Tenggara, one of the hosts of rice production in Indonesia.

\subsection{The importance of rice}

In Indonesia, rice is a major staple food (Hermawan, 2011; Syaukat, 2011; Lantarsih, Widodo, Darwanto, Lestari, \& Paramita, 2011). Rice farming makes significant contributions to employment and Gross Domestic Product (GDP) for the country (Malian, Mardianto, \& Ariani, 2004). Because rice is important for food security and economic development, the Indonesian government has supported some programs to increase rice production. For example, the government has continuously subsidised inputs for farmers such as fertilisers, pesticides and high quality seeds (Hadi, \& Susilowati, 2010). As a result, Indonesian rice production has increased gradually by about $3 \%$ per year since 2007 (Maulana \& Rachman, 2010; Iswari, 2013). 
Rice yield and rice production may be affected by two different factors. The first are production factors such as fertiliser, pesticide and seed. The second are climatic factors such as rainfall and temperature. Although rice yield may increase substantially due to the introduction of new high yield varieties, climate can decrease rice yield. Since climate cannot be controlled, rice production may be vulnerable in the near future regardless of the positive effect of production factors.

In addition to the impacts of climate on rice yield, climate change may bring about some critical impacts given that it leads to rainfall and temperature change. The impacts of climate (change) on rice yield have been assessed by some scholars. For example, researchers claim that minimum temperature can decrease rice yield, particularly if minimum temperature is higher than $22^{\circ} \mathrm{C}$ (Peng et al., 2004). Some studies also point out that rainfall can influence rice production (Naylor, Battisti, Vimont, Falcon, \& Burke, 2007). A lower rainfall owing to El-Niño tends to decrease rice production, while a higher rainfall owing to La-Niña may increase rice production (Naylor et. al, 2007).

All of these possible impacts of climate change can affect rice production. Lower precipitation rates and higher temperatures can reduce rice yield to the point that the rice supply chain may not provide sufficient rice supply. Greater precipitation leads to a larger harvested area, leading to a higher rice production. It appears that climate change can cause uncertainties in the rice production. 


\subsection{Research questions}

As explained earlier, temperature and rainfall change may induce some negative impacts such as a lower rice yield and a lower rice production. These impacts can provoke some uncertainties in the rice supply. Because of this, a central aim of this research is to understand the impacts of climate change as a key source of uncertainty in rice production, and to investigate the impacts using the system dynamics approach.

Since the aim of this study is to explore climate change impacts on rice production, its central research question is: How will climate change and climate variability affect rice production? Additional questions investigated are:

1. What are the most significant supply uncertainties associated with a changing climate?

2. What are possible solutions to reduce impacts of climate change on the rice production?

The area of study is West Nusa Tenggara, one of the national rice producers in Indonesia since rice farming contributes significantly to economic growth and employment in West Nusa Tenggara.

\subsection{Scope of study and conceptual framework}

Figure 1.2 shows an overview of the methodological approach of this study. This study combines statistical modelling, climate projections and the system dynamics modelling to answer the research questions. The effects of climatic and non-climatic factors on rice yield is measured using a statistical model. After embedding statistical models into a system dynamics model, it will be used to explore the impacts of climate change on rice yield, harvested areas, and rice production. 


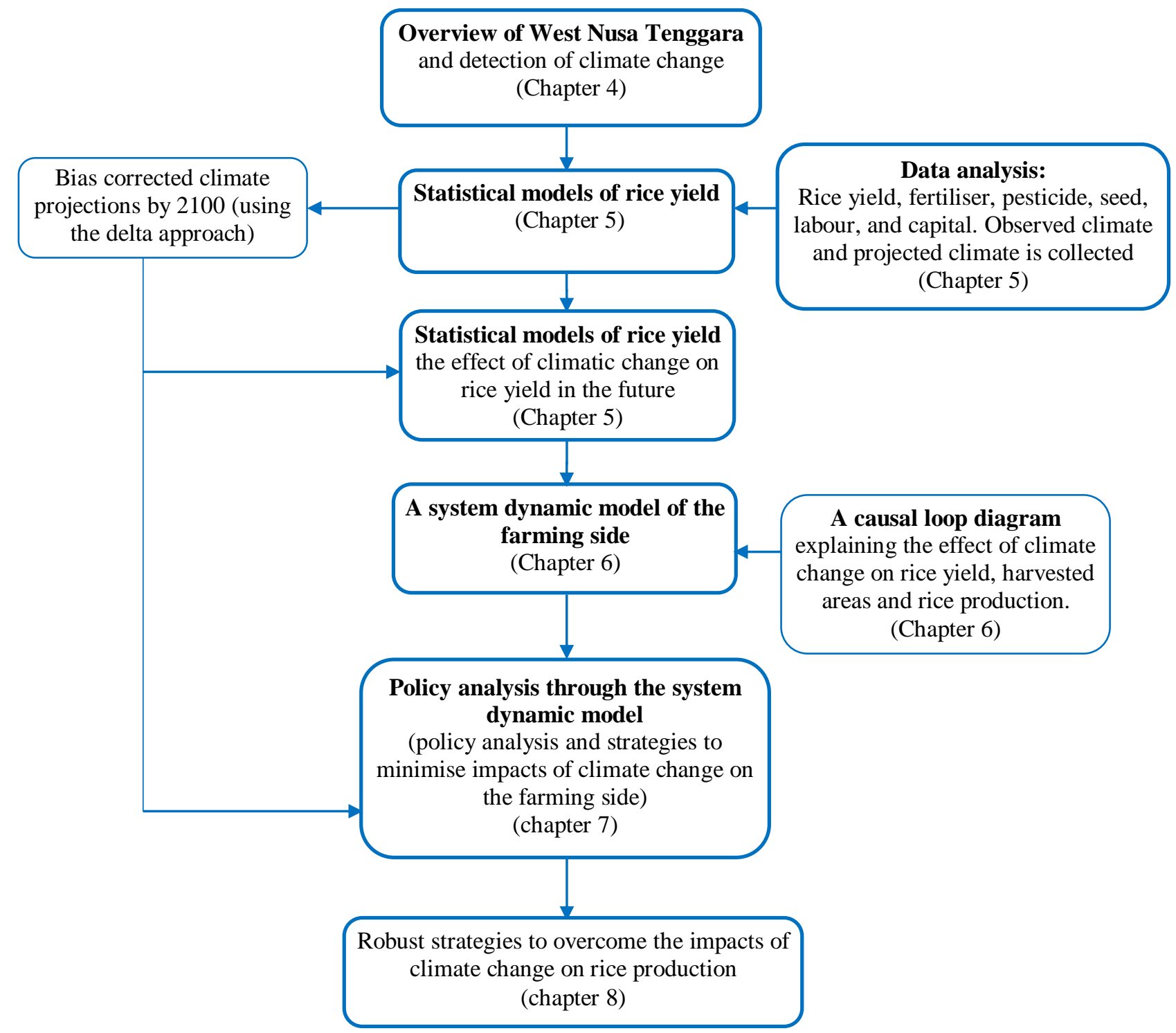

Figure 1.2 An overview of the research methodology 
Geographically, this research centres on West Nusa Tenggara (WNT), an eastern Indonesian province. This also study explains important aspects of rice farming systems in WNT as well as the roles of agriculture in the province. Climate change detection in WNT is also discussed in order to detect rainfall and temperature change.

This study explores the impacts of climate change on rice yield by assessing the relationships between rice yield and two types of variables. The first type variable is production factors such as labour and seed and the second type is observed climate. Using observed data, a statistical model explaining the impacts of climate change on rice yield is developed. Projected impacts of climate change on rice yield are offered using bias-corrected climate outputs. Later, a statistical model of rice yield is embedded into a system dynamics model to measure the impacts of climate change on the rice production.

Assessment of the impacts of climate change requires plausible climate projections. Climate projections from the CMIP5 suite of model run will be collected. As Indonesia is influenced by monsoon and El-Niño Southern Oscillation (ENSO), projections of rainfall and temperature will be extracted from the climate models which simulate the interaction between ENSO and the monsoon. Before applying climate projections, climate outputs are bias-corrected using the delta approach (Hay, Wilby, \& Leavesley 2000; Lenderink, Buishand, \& Deursen, 2007; van Roosmalen, Sonnenborg, Jensen, \& Christensen, 2011) which is also called a perturbation of observed data (POD) (van Roosmalen et al. 2011; Wibig, Maraun, Benestad, Kjellström, Lorenz, \& Christensen, 2015).

Based on the literature review and data analysis, a causal loop diagram (CLD) is constructed. This CLD explains the impacts of climate change on the rice production and then the system dynamics model is constructed according to this CLD. After the system dynamics model is validated, some policies and strategies are constructed based on sensitivity analysis. These strategies are assessed based on some factors in the rice farming, such as rice yield and rice production. In order to obtain robust strategies within a changing climate situation, some strategies will be assessed for different scenarios involving varied climate projections. 


\subsection{Outline of the thesis}

The structure of the thesis as follows:

\section{ABSTRACT}

\section{CHAPTER 1 INTRODUCTION}

This chapter offers some brief information about rice, such as its importance globally and in Indonesia, how climate can affect rice yield, and some possible effects of climate on rice production. In addition, this chapter also outlines the research questions, the scope of the study, and its conceptual framework in answering the research questions.

\section{CHAPTER 2 LITERATURE REVIEW}

This chapter aims to present several studies in three fields, namely: the sources of the agrifood supply chain uncertainty, system dynamics, and climate change studies. This chapter also explains the concepts and examples of uncertainties in the agrifood supply chain, the application of system dynamics in assessing climate change impacts, and climate change issues such as the impacts of temperature on crop yields.

\section{CHAPTER 3 RESEARCH DESIGN}

This chapter explains the methodology applied in this study and the steps followed in answering the research questions posed by this study. This chapter also explains the formulation of the statistical models which assess the impacts of climate change on rice yield, as well as the development of a robust system dynamics model.

\section{CHAPTER 4 WEST NUSA TENGGARA: A CASE STUDY}

This chapter offers some information about West Nusa Tenggara in terms of climate and its agricultural contribution. Detection of climate change is explained in this chapter.

\section{CHAPTER 5 STATISTICAL MODEL OF RICE YIELD}

This chapter discusses analysis of climate and production factors to obtain appropriate statistical equations for both farming types: wetland and dryland farming. This chapter also explains some statistical tests in validating statistical equations assessing the impacts of climate change on rice yield in wetland and dryland separately.

\section{CHAPTER 6 SYSTEM DYNAMICS MODEL OF RICE PRODUCTION}

This chapter discusses a system dynamics model that depicts three possible impacts of climate change on rice production as described in chapter 2 . Based on literature review in 
chapter 2, a causal loop diagram is constructed. A causal loop diagram incorporated with statistical models in chapter 5 is used to a system dynamics model. This chapter also explains the base case run and validation of the model in ascertaining that the system dynamics model is a valid representation of the real world. This chapter also analyses some sensitive parameters which will be used in chapter 7 to develop scenarios and strategies. Afterwards, the impacts of climate change on rice yield, rice production and harvested areas are explained for different RCP scenarios by 2090 (2077-2100). These impacts are called outputs of the first strategy or the business as usual strategy.

\section{CHAPTER 7 POLICY SCENARIO RESULTS}

Some policies and strategies to minimise the impacts of climate change will be constructed and tested under different RCP scenarios. Two strategies based on sensitivity analysis from chapter 6 are developed and tested under different RCP scenarios by 2090 (2077-2100). Outputs of three strategies i.e. the first strategy from chapter 6 and two strategies tested in this chapter are compared.

\section{CHAPTER 8 CONCLUSIONS}

This chapter explains conclusions relating to the impacts of climate change and climate variability on rice production derived from chapter 6 . This chapter also assesses the benefits of strategies derived in chapter 7 in tackling the impacts of climate change on rice production. Some academic contributions and implications for theory and practice are described prior to limitations and possible future research.

\section{REFERENCES} APPENDIXES 
this page intentionally left blank 


\section{CHAPTER 2 A UTERATURE REVIEW}

In this section, some theoretical concepts are explained and a critical review of existing studies is offered. Concepts of climate change, climate variability and sources of supply chain uncertainty make up the theoretical basis of this research. The critical literature review explains some findings and limitations of previous studies as well as the research focus.

\subsection{Theoretical concepts}

\subsubsection{Definitions of climate change and climate variability}

Climate variability is natural variability that occurs because of non-human factors such as solar radiation and ocean circulation. One notable pattern of climate variations is ENSO (El-Niño Southern Oscillation), the largest seasonal-interannual climate signal after the annual cycle. During El-Niño, the Walker circulation weakens and leads to widespread droughts in Asia and Australia. During La Niña, by contrast, the circulation strengthens, causing earlier rainy seasons in Indonesia, India and Australia (IPCC, 2007).

Human-induced climate change is distinct from climate variability and is associated with a changing global radiative balance. IPCC (2013) demonstrates that climate change is mainly caused by increasing greenhouse gas concentrations such as ${ }^{1} \mathrm{CO}_{2}, \mathrm{~N}_{2} \mathrm{O}$ and $\mathrm{CH}_{4}$ (IPCC, 2007; 2012; 2013). The increase by approximately $40 \%$ in atmospheric carbon dioxide concentrations since the pre-industrial period is currently the main cause of climate change, due to emissions from fossil fuels and changes in land usage (IPCC, 2013).

Figure 2.1 shows that climate change can be a change in mean (figure 2.1a) or in variation (figure 2.1b) or both (figure 2.1c) for any climate variable. Figure 2.1 also shows the probability of climate extremes changing markedly (high extremes are on the

${ }^{1} \mathrm{CO}_{2}=$ carbon dioxide, $\mathrm{N}_{2} \mathrm{O}=$ nitrous oxide and $\mathrm{CH}_{4}=$ methane 
right side, while low extremes on the left side) under the current climate (dark shading) and a changed climate (the light shading).
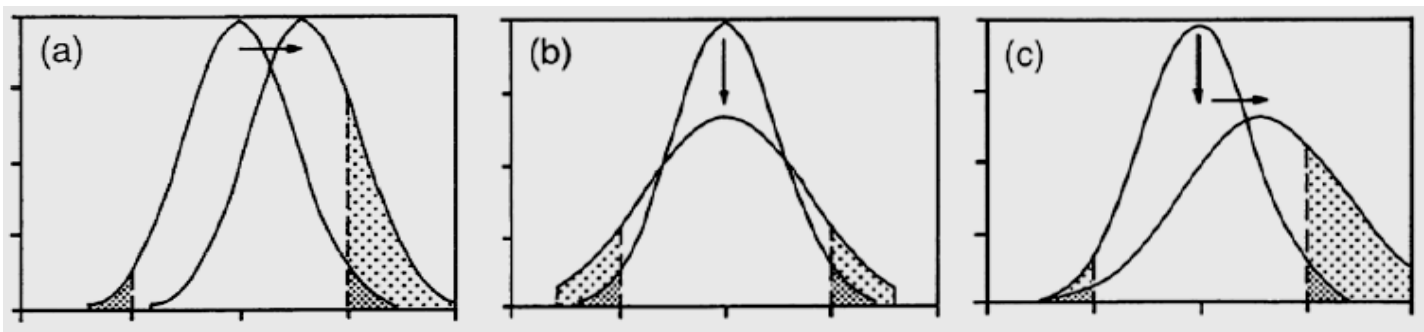

Figure 2.1. This schematic illustrates possible changes in the frequency distribution of a typical climate variable, e.g. temperature (a. changing in a mean; b. changing in a variation and; c. changing both variation and mean). Shaded areas are climate extremes. (source: The Indonesian Ministry of Environment, 2010).

\subsubsection{Indonesian climate: Past and projections}

Statistics show that Indonesia has experienced an increasing temperature but an insignificant rainfall change since the mid- $20^{\text {th }}$ century. The annual mean of Indonesian rainfall $^{2}$ in the period $1950-1979$ was $2832 \pm 296 \mathrm{~mm} /$ year about and in the current period 1980-2009 was about $2786 \pm 272 \mathrm{~mm} /$ year. The difference of the annual mean rainfall between the periods is statistically insignificant $(\mathrm{t}(58)=.63, \mathrm{p}>0.1)$. The Indonesian mean temperature from $1950-1979$ was about $25.6 \pm 0.17^{\circ} \mathrm{C}$, while the mean temperature in the period $1980-2009$ was about $26 \pm 0.16^{\circ} \mathrm{C}$. This temperature difference is statistically significant $(\mathrm{t}(58)=10.24, \mathrm{p}<0.01)$. After statistical analysis on different periods such as the period of 1960-1989 and the period of 1990-2009, these results are not sensitive on chosen periods ${ }^{3}$.

Figure 2.2 shows that Indonesia is projected to experience higher temperatures in the future. According to IPCC (2013) and RCP4.5 scenario (Van Vuuren et al., 2011), Indonesia is projected to experience an increase in mean temperature in the range of 0.3$1.2^{\circ} \mathrm{C}$ by 2035 and in the range of $0.8-2.7^{\circ} \mathrm{C}$ by 2100 . Temperature in wet seasons (December-February) and dry seasons (June-August) is projected to experience a relatively similar increase.

\footnotetext{
${ }^{2}$ Data for Indonesian rainfall and temperature is from KNMI climate centre (http://climexp.knmi.nl).

3 Respectively, the annual rainfall of Indonesia is not statistically significant $(\mathrm{t}(48)=0.05, \mathrm{p}>0.1)$, and is not statistically significant $(\mathrm{t}(38)=1.4, \mathrm{p}>0.1)$ between the period 1960-1989 $(2789 \pm 302)$ and the period 1990-2009 (2785 \pm 273$)$ and between the period 1980-1999 (2784 \pm 314$)$ and the period 2000-2009 $(2901 \pm 189)$. The difference in mean for temperature is statistically significant $(\mathrm{t}(48)=6.6, \mathrm{p}<0.01)$ and is statistically significant $(\mathrm{t}(38)=2.24, \mathrm{p}<0.05)$ between the period $1960-1989\left(25.7 \pm 0.27^{\circ} \mathrm{C}\right)$ and the period $1990-2009\left(26 \pm 0.15^{\circ} \mathrm{C}\right)$ and between the period 1980 $1999\left(25.9 \pm 0.24^{\circ} \mathrm{C}\right)$ and the period $2000-2009\left(26 \pm 0.14^{\circ} \mathrm{C}\right)$ respectively. This means that results are not sensitive on chosen periods.
} 


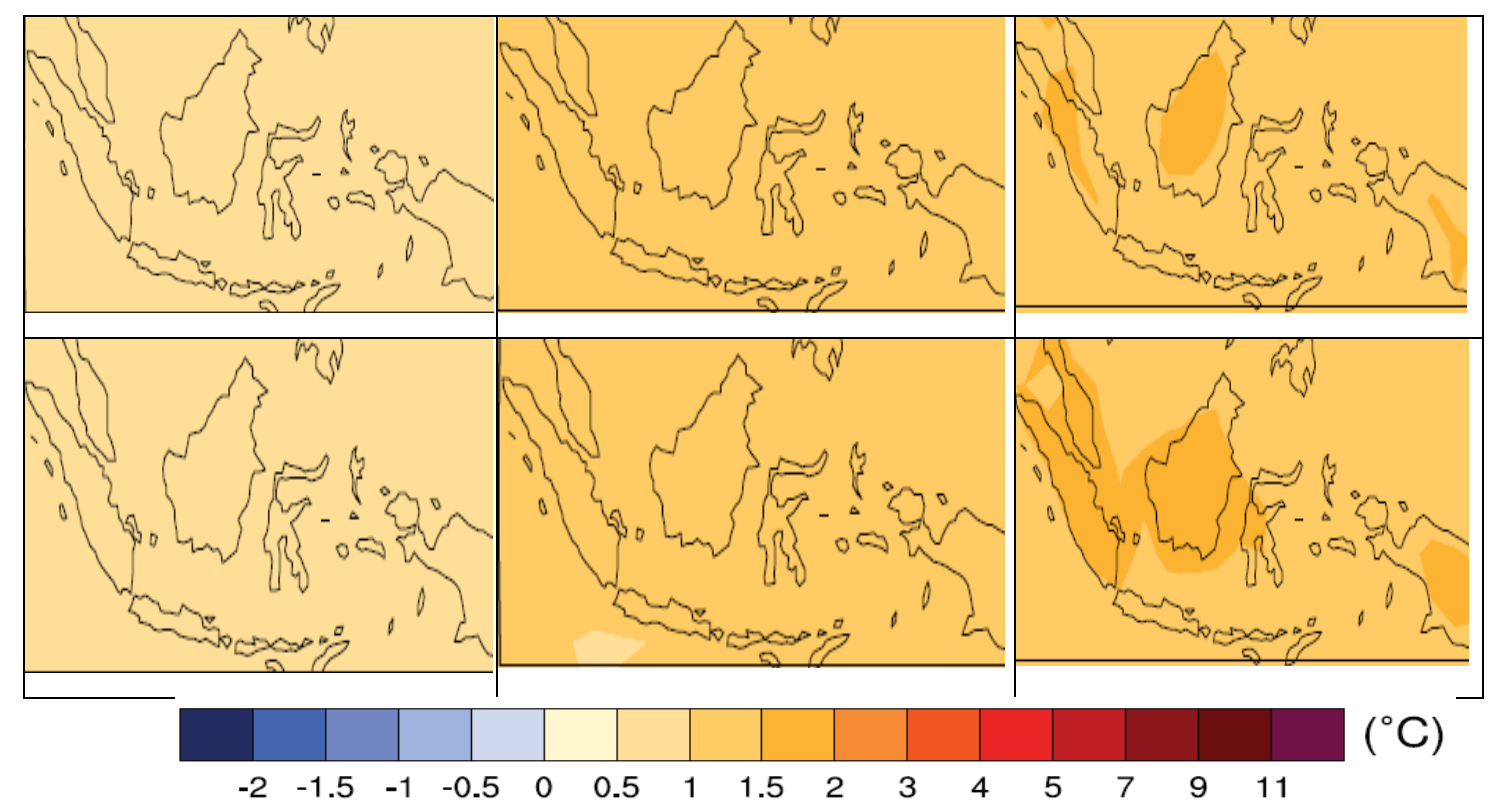

Figure 2.2 Median projected temperature change in December-February (top) and June-August (bottom) relative to the period 1986-2005 for ${ }^{4} \mathrm{RCP}$ (Representative Concentration Pathways) scenario 4.5 based on an ensemble of CMIP5 model projections. From left to right is the period 2016-2035, 2046-2065 and 2081-2100. The source is IPCC (2013) - Annex I: Atlas of Global and Regional Climate Projections (Figure AI.64-AI.65).

As shown in figures 2-3, Indonesia is projected to experience mixed and relatively insignificant rainfall change (IPCC, 2013). Total Indonesian rainfall is projected to change between $-1 \%$ and $13 \%$ by 2046 and between $-2 \%$ and $18 \%$ by 2100 . The average projected decrease of rainfall in the southern Indonesia areas such as West Nusa Tenggara, is about $-5 \%$ by $2100^{5}$. However, the magnitude of projected changes is not expected to exceed that of natural decadal variability ${ }^{6}$ over much of Indonesia.

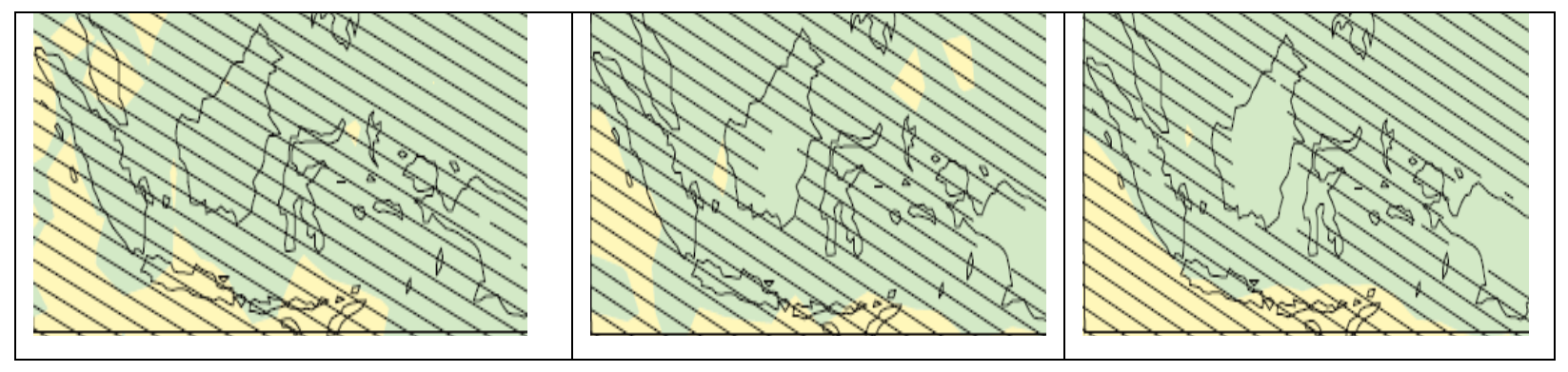

${ }^{4} \mathrm{RCP} 4.5$ is a climate scenario with a stable radiative forcing at $4.5 \mathrm{Watts} / \mathrm{m}^{2}$ in the year $2100 . \mathrm{RCP}=\mathrm{Representative}$ Concentration Pathways.

${ }^{5}$ Southern Indonesia is influenced by Australian Maritime Monsoon that leads to a lower rainfall while northern Indonesia is influenced by East Asian and Indian Monsoon that lead to a higher precipitation (IPCC, 2013).

${ }^{6}$ Decadal variability is climate variability for the period for decades. 


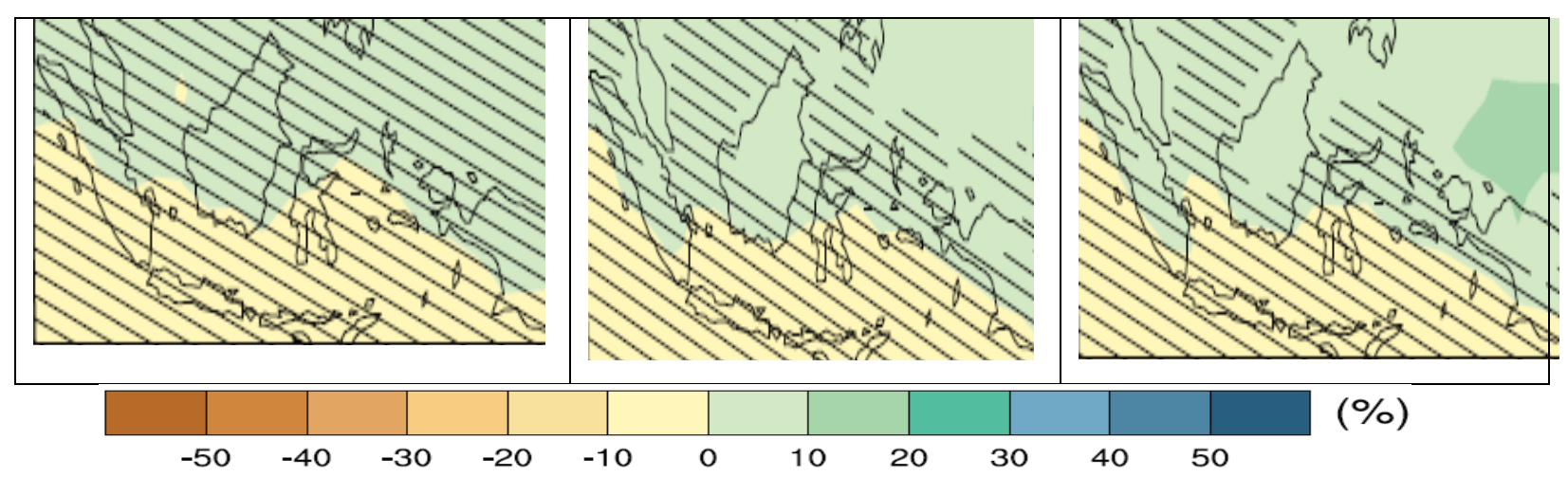

Figure 2.3 Median projected rainfall change in October-March (top) and AprilSeptember (bottom) relative to the period 1986-2005 for scenario RCP 4.5 based on an ensemble of CMIP5 model projections. From left to right is the period 2016-2035, 2046-2065 and 2081-2100. The hatched area denotes the area where the 20-year mean differences of the percentiles are less than the standard deviation of model-estimated present-day natural variability of 20 -year mean differences. The source is (IPCC, 2013) - Annex I: Atlas of Global and Regional Climate Projections (Figure AI.66AI.67).

\subsubsection{The global climate models (global circulation models)}

The notable tools used to study and simulate the behaviour of the climate system are called climate models. Climate models are primarily used to study natural variability, climate processes, and to project climate responses to human-induced activity. In climate models, interaction of the components of the climate system such as atmosphere, ocean, and cryosphere are included. Moreover, each component of a climate system, or coupled combinations of components, may by represented with varied complexity.

The interaction of components of the climate system in climate models are described based on physical laws through some mathematical equations. Most mathematical equations are non-linear. The latter requires the equations of climate models to be constructed by well-established mathematical techniques. As climate models include some sophisticated mathematical equations, they should be run in powerful computers (Randall et. Al, 2007).

The two important climate models are the General Circulation Models - also known as Atmospheric General Circulation Models (AGCMs) - and the Ocean General Circulation Models (OGCMs). Separately, these models represent dynamic interaction in atmosphere and ocean systems. The coupled combination of these models is called Atmosphere 
Ocean General Circulation Models (AOGCMs). The latter model may be combined with other components of the climate system such as cryosphere and land surface.

In term of quality, climate models can be examined in two ways. The first way is to compare results of climate models with the present climate. By comparing present climate observation with simulation results, the model can be evaluated and improved substantially. The second way is to compare model simulations with palaeoclimate situations.

The IPCC (2007) has published one set scenario called the Special Report on Emission Scenario (SRES, Nakicenovic \& Swart, 2000). The climate projection using SRES families is usually associated with Coupled Model Intercomparison Project Phase 3 (CMIP3). In the Fifth Assessment Report, IPCC (2013) uses different climate scenarios. These scenario types are usually called the Representative Concentration Pathways (RCPs, Van Vuuren et al., 2011). Climate projections using RCP families are usually associated with Coupled Model Intercomparison Project Phase 5 (CMIP5). The descriptions of RCP scenarios can be seen as follows (Moss et al., 2010):

RCP 2.6: This scenario is usually known as the peak and decline scenario. Under this scheme, radiative forcing ${ }^{7}$ reaches levels $3.1 \mathrm{~W} / \mathrm{m}^{2}$ mid-century, returning to $2.6 \mathrm{~W} / \mathrm{m}^{2}$ by 2100 . In order to reach such values, greenhouse gas emissions (and indirectly emissions of air pollutants) are reduced substantially over time.

RCP 4.5: This is usually called medium-low RCP. Total radiative forcing reaches 4.5 $\mathrm{W} / \mathrm{m}^{2}$ and is stabilised before 2100 by employment of a range of technologies and strategies for reducing greenhouse gas emissions.

RCP 6.0: Usually known as medium-high RCP. The radiative forcing reaches $6 \mathrm{~W} / \mathrm{m}^{2}$ and is stabilised after 2100 without overshoot by employment of a range of technologies and strategies for reducing greenhouse gas emissions.

\footnotetext{
${ }^{7}$ Radiative forcing is used to assess and compare the anthropogenic and natural drivers of climate change. It is defined as the difference between radiant energy that is absorbed by the earth and releases back to the space.
} 
RCP 8.5: Also known as the highest RCP. The radiative forcing is $8.5 \mathrm{~W} / \mathrm{m}^{2}$ in 2100 . This RCP scenario is based on occurrences of increasing greenhouse gas emissions over time representative for scenarios in the literature leading to high greenhouse gas concentration levels. Table 2.1 summarises all RCP scenarios described above.

\begin{tabular}{|c|c|c|c|}
\hline Name & $\begin{array}{l}\text { Radioactive } \\
\text { forcing }\end{array}$ & Concentration (ppm) & Pathway \\
\hline RCP 2.6 & $\begin{array}{l}\text { Peak at } \sim 3 \mathrm{Wm}^{-2} \\
\text { before } 2100 \text { and } \\
\text { then declines }\end{array}$ & $\begin{array}{l}\text { Peak at } \sim 490 \quad \mathrm{ppm} \quad \mathrm{CO}_{2} \\
\text { equivalent before } 2100 \text { and then } \\
\text { declines }\end{array}$ & $\begin{array}{l}\text { Peak and } \\
\text { decline }\end{array}$ \\
\hline RCP 4.5 & 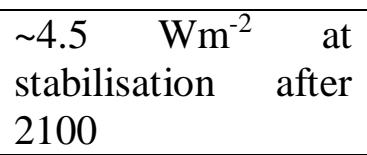 & $\begin{array}{l}\sim 650 \text { ppm } \mathrm{CO}_{2} \text { equivalent (at } \\
\text { stabilisation after 2100) }\end{array}$ & $\begin{array}{l}\text { Stabilisation } \\
\text { without } \\
\text { overshoot }\end{array}$ \\
\hline RCP 6.0 & $\begin{array}{l}\sim 6 \quad \mathrm{Wm}^{-2} \text { at } \\
\text { stabilisation after } \\
2100\end{array}$ & $\begin{array}{l}\sim 850 \text { ppm } \mathrm{CO}_{2} \text { equivalent (at } \\
\text { stabilisation after } 2100 \text { ) }\end{array}$ & $\begin{array}{l}\text { Stabilisation } \\
\text { without } \\
\text { overshoot }\end{array}$ \\
\hline RCP 8.5 & $>8.5 \mathrm{Wm}^{-2}$ in 2100 & $\begin{array}{l}>1,370 \mathrm{ppm} \mathrm{CO}_{2} \text { equivalent in } \\
2100\end{array}$ & Rising \\
\hline
\end{tabular}

Table 2.1 A summary of the four RCP scenarios

\subsubsection{Carbondioxide concentration in Indonesia}

Figure 2.4 shows that Indonesia has experienced an increase in $\mathrm{CO}_{2}$ concentration (Nahas, Masalakah \& Setiawan, 2009). As shown in figure 2.4, carbon dioxide concentration in Indonesia has a similar pattern to the global concentration. The projection of carbon dioxide concentration is between about $530 \mathrm{ppm}$ and $770 \mathrm{ppm}$ by 2100, depending on SRES scenarios (Nahas et al., 2009). Because the concentration of $\mathrm{CO}_{2}$ tends to increase, understanding the impacts of climate change on the Indonesian rice supply should be encouraged. It should be noted that the carbon dioxide concentration for Indonesia is measured in Kototabang, the Indonesian greenhouse station. 


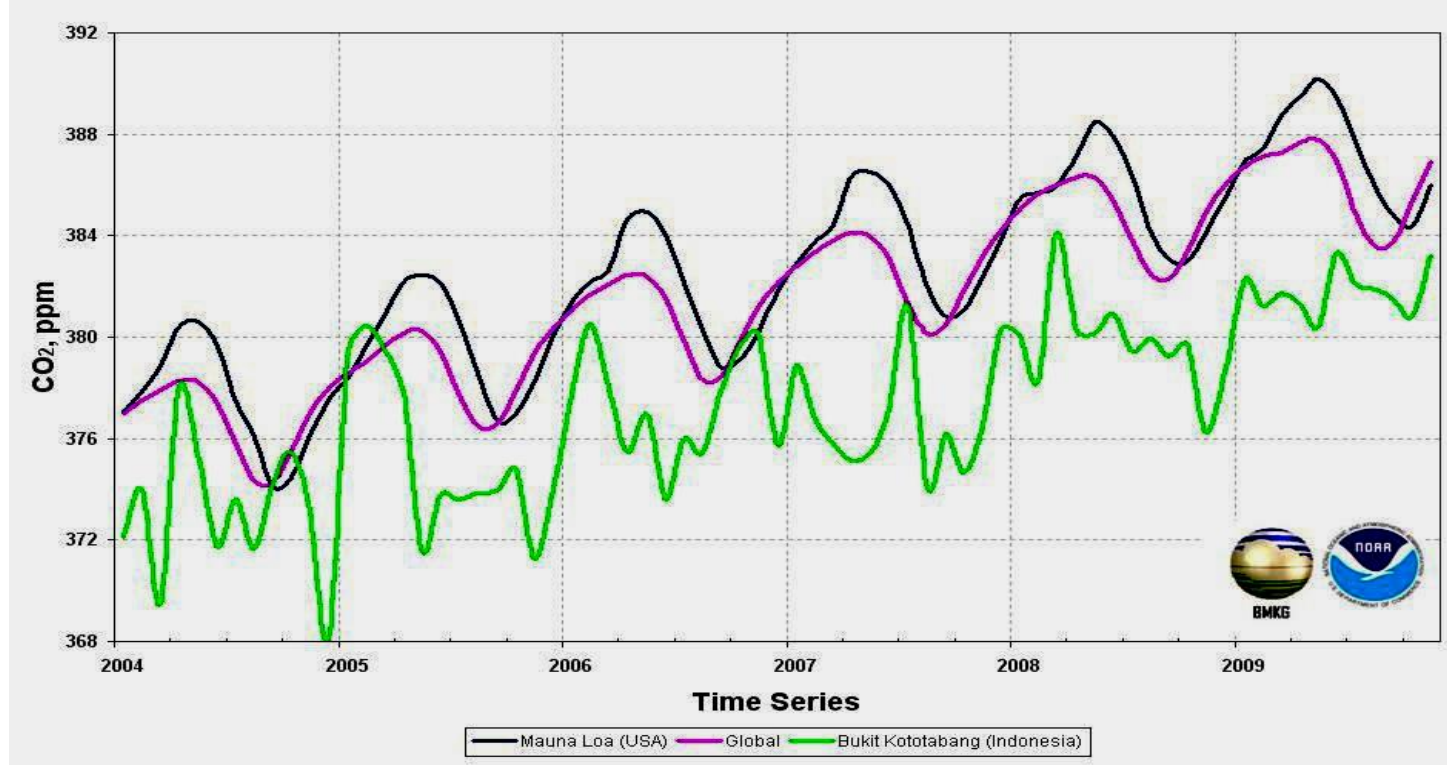

Figure 2.4 The comparison of the $\mathrm{CO}_{2}$ concentrations in Mauna Loa (blue), Global (pink) and Bukit Kototabang (green) for the period 2004-2009 (source: Nahas et al., 2009)

\subsubsection{Optimum conditions for rice production}

Rice (oryza sativa) requires seasonal rainfall about 300-500 millimeters (Suprihatno \& Poniman 2007; Supriyanto, 2012), an altitude of 0-1500 meters, and an optimum temperature of between 23 and $35^{\circ} \mathrm{C}$ (Suprihatno, Samaullah \& Sri, 2008, Jagadish et al., 2010). For dryland rice, it is required about $1,000 \mathrm{~mm}$ of seasonal year for dryland rice.

In addition, rice needs a number of other production factors in order to grow well. Those production factors are, for example, seed, labor, fertiliser, pesticide and chemical substances (Mulyantara \& Hendriadi, 2004; Yoshida, 1981). Before rice planting, farmers hoe the land to increase the soil moisture (Mulyantara \& Hendriadi, 2004). Afterwards, seed is spread across the farming area. Following this, fertilisers and pesticides are distributed during the growing period.

Throughout the photosynthesis process, chemical substances are converted into the assimilation pool to compose rice biomass (Yoshida, 1981). During the stages of rice growth, the rice biomass is converted to root, stem, leaf and panicle through a respiration growth mechanism (Yoshida, 1981; The Indian Ministry of Science Technology \& Ministry of Environment \& Forest, 2011; Li, Angeles, Marcaida, \& Manalo, 2012).

Rice does the respiration maintenance that could reduce the amount of the assimilation pool, leading to a lower rice biomass (Mohammed \& Tarpley, 2009). The minimum 
temperature or the night-time temperature could induce the respiration growth mechanism, particularly if the night-time temperature exceeds its critical point of $22^{\circ} \mathrm{C}$ (Peng et al., 2004; Mohammed \& Tarpley, 2009).

Figure 2.5 and table 2.2 show the three stages of rice growth, including the vegetative, the reproductive, and the ripening stages. In the vegetative stage, rice may experience chloroplast damage, if the maximum temperature exceeds its temperature threshold (Wassmann et al., 2009). However, in this stage, rice is relatively tolerant to higher temperatures, compared to other stages (Yoshida, 1981). A possible vulnerability in the reproductive stage is spikelet sterility when rice is continuously exposed to high temperatures. In the ripening stage, rice may experience a lower grain weight and a short grain filling period, causing a lower yield.

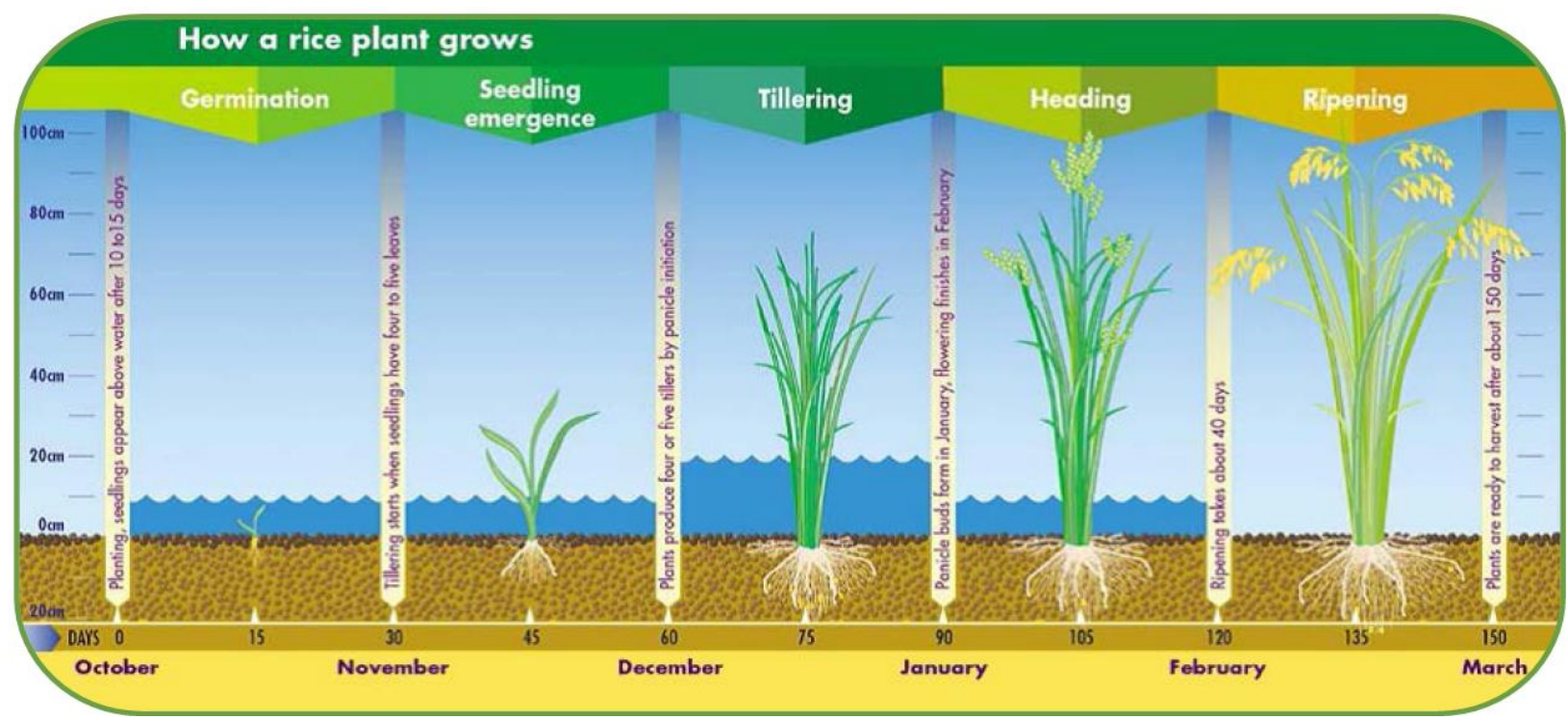

Figure 2.5 The stages of the rice growth (Haifa Group, n.d.) 


\begin{tabular}{|c|c|c|}
\hline \multicolumn{2}{|r|}{ Rice growth phase } & Vulnerabilities \\
\hline I. & $\begin{array}{l}\text { Vegetative (germination to panicle initiation, } 45- \\
65 \text { days) } \\
\text { Rice biomass is converted into roots, and stems } \\
\text { through respiration growth mechanism (Yoshida, } \\
\text { 1981; Li et al., 2012). }\end{array}$ & $\begin{array}{l}\text { This phase is relatively tolerant to higher } \\
\text { temperature. Wassmann et al. (2009) } \\
\text { suggests that midday temperature exceeding } \\
\text { temperature threshold }\left(35^{\circ} \mathrm{C}\right) \text { could damage } \\
\text { chloroplast so that photosynthesis would not } \\
\text { work properly. Yoshida }(1978) \text { and Jagadish } \\
\text { et al., (2010) claim that this phase has higher } \\
\text { temperature tolerance }\left(>40^{\circ} \mathrm{C}\right) \text {. }\end{array}$ \\
\hline II. & $\begin{array}{l}\text { Reproductive (panicle initiation to flowering, } \\
\qquad 35 \text { days); } \\
\text { Panicle emergence in reproductive stage is a } \\
\text { critical stage because it will affect the amount of } \\
\text { panicle per farming area and grains per panicle } \\
\text { (The Indian Ministry of Science Technology \& } \\
\text { The Indian Ministry of Environment \& Forest, } \\
\text { 2011). In the reproductive stage, photosynthesis is } \\
\text { increased by number of rice leaves (Yoshida, } \\
\text { 1981) }\end{array}$ & $\begin{array}{l}\text { If rice is exposed in high maximum } \\
\text { temperature, it would experience spikelet } \\
\text { sterility that induces lower rice output } \\
\text { (Wassmann et al., 2009). In some cases, } \\
\text { spikelet sterility occurs if temperature } \\
\text { exceeds } 40^{\circ} \mathrm{C} \text { (Yoshida, 1981) }\end{array}$ \\
\hline III. & $\begin{array}{l}\text { Ripening (flowering to mature grain, } 30 \text { days) } \\
\text { Rice grains are filled with milky materials into } \\
\text { soft dough. Afterwards, panicles and leaves turn } \\
\text { yellow with mature and hard grain. }\end{array}$ & $\begin{array}{l}\text { High temperature could reduce grain weight } \\
\text { and shorten grain filling period (Wassmann } \\
\text { et al., 2009) }\end{array}$ \\
\hline
\end{tabular}

Table 2.2. Stages of rice growth 


\subsubsection{The agrifood supply chain}

The agrifood supply chain consists of sequential activities that include processes and flows (material, money and information). These activities aim to meet customer demand between and within differents stages, from production to final consumption (Vorst, Da Silva, \& Trienekens, 2007). In general, the agrifood supply chain may involve producers, processors (manufacturers), retailers and final consumers (Dani, 2015; Haverkort \& Verhagen, 2008; Thorpe \& Fennel, 2012; Van der Vorst, 2007). The agrifood supply chain may include activities such as processing, milling, and marketing.

If supply chain activities include raw materials such as seeds, vegetables, fruits and animals, the supply chain is usually called the agrifood supply chain. The agrifood supply chain is relatively vulnerable to climate since climate cannot be controlled (Aramyan, Lansink, Van der Vorst \& Kooten, 2007; Van der Vorst, Da Silva \& Trienekens, 2007; Widyaningrum \& Masruroh, 2012). For example, crop production or quantity of vegetables (or fruits) may be lower than usual because of a lower precipitation or higher temperature (Haverkort \& Verhagen, 2008; Thorpe \& Fennel, 2012).

Van der Vorst et al. (2007) suggest that the agrifood supply chain can be categorised into two groups. The first group is the fresh agrifood supply chain such as fresh flowers, and fresh vegetables. The main processes for this chain are handling, conditioned storing, and packing (Vorst et al., 2007). The second group is the processed agrifood supply chain such as includes snacks, rice, canned food products and juice chains. The latter group aims to manufacture raw materials such as vegetable, fruit to provide consumers with higher value-added products (Dani, 2015; Van der Vorst et al., 2007). Moreover, food processing in the second type of the agrifood supply chain can extend the shelf-life of products (Dani, 2015; Van der Vorst et al., 2007).

A comparison between the first type and the second type of the agrifood supply chain is summarized in table 2.3. The fresh agrifood supply chain usually offers shorter-shelf life products and low-variety product compared to the second one. The processed agrifood 
supply chain usually offers specialised products or higher value-added products such as healthy food and other canned products and this chain might have less predictable demand compared to the first one (Van der Vorst \& Beulens, 2002; Van der Vorst et al., 2007).

\begin{tabular}{|l|l|}
\hline \multicolumn{2}{|c|}{ Examples and Characteristics of each agrifood supply chain } \\
\hline \multicolumn{1}{|c|}{ The fresh agrifood supply chain } & \multicolumn{1}{c|}{ The processed agrifood supply chain } \\
\hline Fresh vegetable, fruit & $\begin{array}{l}\text { canned food and drink; bread and healthy } \\
\text { food; grain (rice, corn, maize) }\end{array}$ \\
\hline Shorter-shelf life & Extended-shelf life \\
\hline Low-variety product & $\begin{array}{l}\text { High-variety product or branded products } \\
\text { such as healthy food }\end{array}$ \\
\hline More predictable demand & $\begin{array}{l}\text { Less predictable demand owing to highly } \\
\text { specialised products }\end{array}$ \\
\hline Low profit margin & High profit margin \\
\hline
\end{tabular}

Table 2.3 Two types of the agrifood supply chain (Dani, 2015; Mardiyanto, Supriyatna \& Agustin, 2005; van der Vorst, 2007; Xiao et al., 2012; William, 2012).

It should be noted that the agrifood supply chain may face supply uncertainty and demand uncertainty simultaneously, especially for the agrifood supply chain with highvariety products (Verdouw, 2010; van der Vorst et al., 2007). The agrifood supply chain with high variety product such as Dutch-flower chain and Dutch-vegetable chain is relatively sensitive to supply and demand uncertainty (Verdouw, 2010; van der Vorst et al., 2007). However, the rice supply chain discussed in this study has low-variety product (Astuti, 2008; BPS, 2015) and relatively predictable demand as rice is a staple food (Astuti, 2008; BPS, 2015). Hence, the rice supply chain analysed in this study is categorised as the supply-driven chain (please see section 2.1.8 about the supply-driven chain).

Figure 2.6 displays some actors in the agrifood supply chain such as food producer, processor and consumer. The chain starts with producers who are also farmers. After getting input such as seed and fertiliser from suppliers, farmers sow their seed under uncertain climatic patterns and scarcity of waters. After harvesting seasons, harvested food will be sent to (through trader or directly to) food processor that will transform food products through some processes into products that meet consumer requirement or consumer demand. This process is usually called food processing. 
Food processing is much important as this caters food customer demand and requirement Food processing also can increase shelf-life food products (Dani, 2015; van der Vorst et al., 2007). In some cases, producer and food processor may directly sell their product to caterer such as restaurant and hotel who will convert food product (from producer or food processor) into food product for final consumer. Although food processor faces a challenge on forecasting customer demand, food processor much challenge is on availability of supply from producers (Dani, 2015; Xiao, Cai \& Zhang, 2012; Williams, 2012).

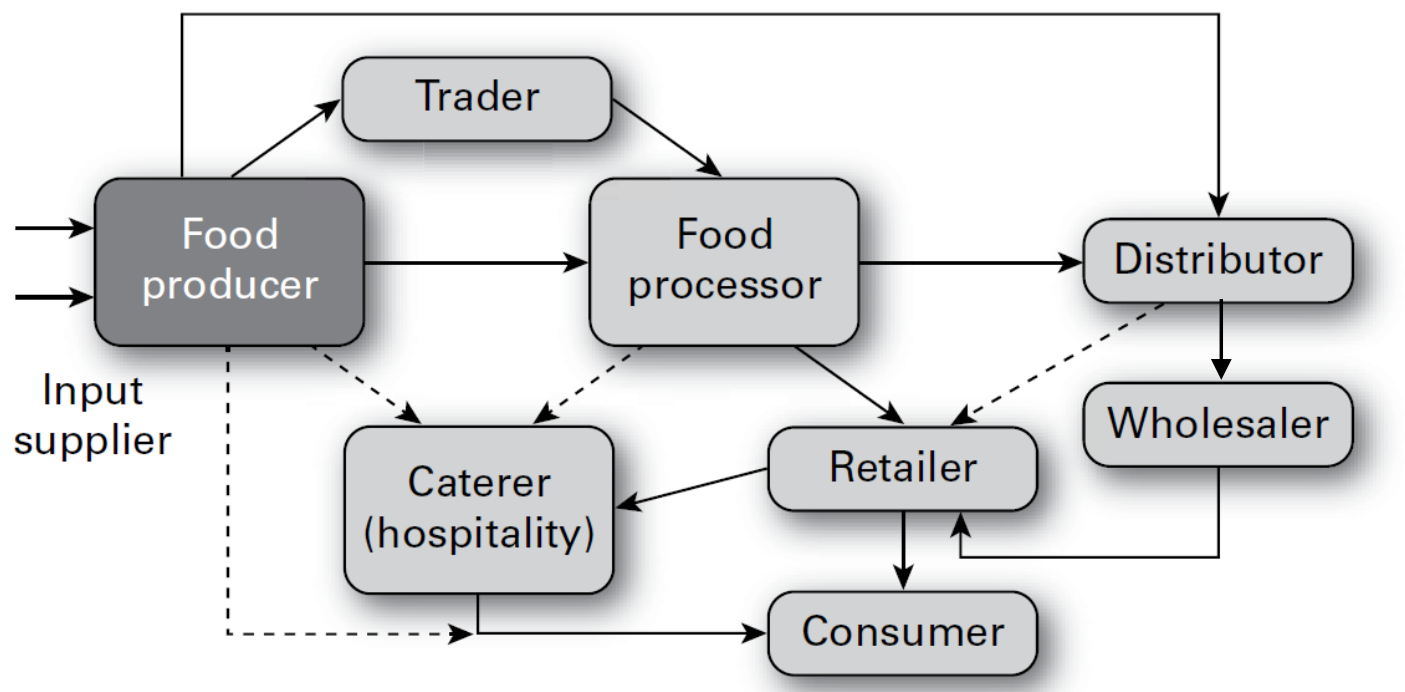

Figure 2.6. Actors in agrifood supply chain (Dani, 2015)

Distributor is another entity in agrifood supply chain that buys in bulk either raw material from producer or from food processor. Distributor may sell the food product through its channels such as retailer and wholesaler (Dani, 2015).

Furthermore, based on its activities, Hasan (2010) divides the rice supply chain into three phases. The first phase includes distribution production inputs such as fertiliser, seed and pesticide. The second stage consists of rice production in farming areas where climate, technology and labour interact with each another. The third phase is delivering the milled rice to households and industrial customers.

Because climate cannot be controlled, the second phase is more vulnerable to climate change and climate variability (Hasan, 2010). Owing to this, this study focuses on the impacts of climate change on the second phase of the rice supply chain as seen as a blue 
dotted circle in figure 2.7. Two following sections explain the rice supply chain in West Nusa Tenggara and the types of supply chain uncertainty. Section 2.1.8, in particular, explains the importance of supply uncertainty in the second phase of the rice supply chain.

\subsubsection{The rice supply chain in West Nusa Tenggara}

The rice supply chain described in this study is relatively similar to the agrifood supply chain described in figure 2.6. As seen in figure 2.7 some parties are involved in the rice supply chain in West Nusa Tenggara. They include farmers, wholesalers, BULOG (Badan Urusan Logistik - The National Agency for Logistics), rice millers, retailers and rice brokers ${ }^{8}$ (Mardiyanto et al., 2005; BPS, 2012). They can be categorised into three roles: the producers, the distributors and the retailers (Dani, 2015; van der Vorst et al., 2007). In this case, farmers are the producers, while BULOG, and rice brokers are the distributors. The rice retailers play the role of the retailers who distribute rice to the end consumer, such as private households and industry.

After spreading fertiliser and pesticide, farmers will harvest their rice during harvesting periods. In the rice-harvesting period, farmers usually sell their rice to either rice brokers or BULOG. After drying their rice (Sutrisno, 2004), wholesalers and BULOG mill the rice in the rice millers. Milled rice will be polished to increase its whiteness (Iswari, 2013). Afterwards, BULOG and wholesalers distribute their rice to households and industrial customers through regular market channels.

The rice distributors, wholesalers, rice brokers (similar to hoarders in the context of the general agrifood supply chain - see Williams, 2012) and BULOG all have different aims. Rice brokers and wholesalers aim to gain the highest possible profits in the rice trade, whereas BULOG aims to balance between the rice supply and the rice demand, particularly in harvesting seasons (when rice supply exceeds rice demand during February-March each year).

\footnotetext{
${ }^{8}$ The rice supply chain in all Indonesia regions is relatively similar. One difference is the fraction of rice bought by BULOG and wholesalers
} 
In rice harvesting seasons, BULOG buys rice (balancing the supply and demand so that the rice price would not fall substantially) and puts their rice in BULOG's storage. In dry seasons (between July and October, when limited rice is planted), BULOG will distribute its rice to the rice market. Rice supply can be increased by importing rice if the BULOG's buffer stock is less than the rice demand. Otherwise, rice is exported to other Indonesian regions (Mardiyanto et al., 2005). BULOG exports and imports rice to help Indonesian regions with insufficient rice production. This activity, importing and exporting rice, does not aim to get profit (Hadi \& Susilowati, 2011, Lantarsih et al., 2011).

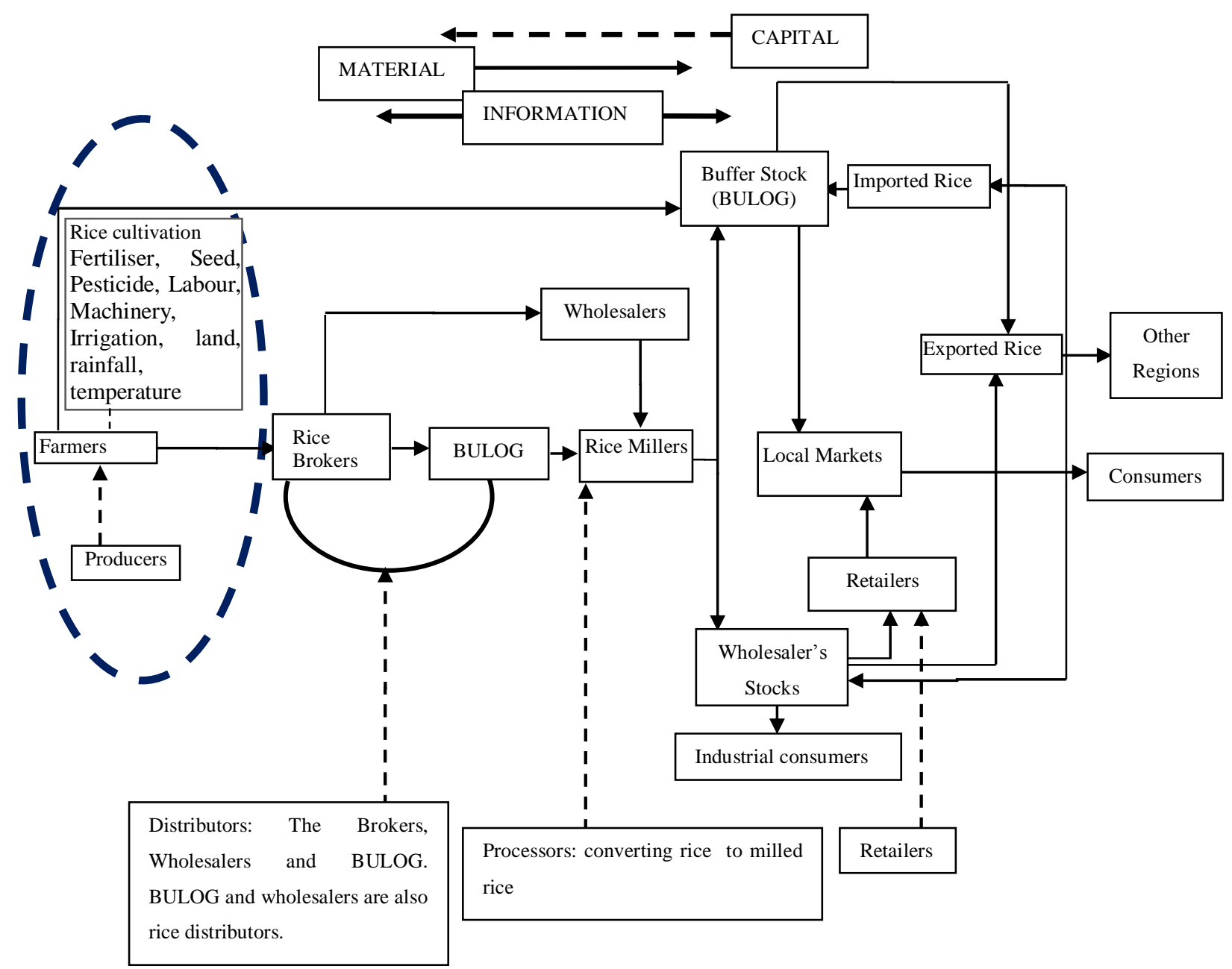

Figure 2.7. The Indonesian rice supply chain, a blue dotted circle is a vulnerable climate change and climate variability Hasan (2010), so this circle is the research focus in this study. 
Rice producers including rice millers and farmers, are usually sell their rice directly to rice wholesalers (40\%), rice retailers (26\%), end consumer (17\%) and industrial consumer (17\%) (BPS, 2015). There are two types industrial consumer: bakery and rice flour industries (1\%) and hotels \& restaurants (16\%) (BPS, 2015). Moreover, rice wholesalers usually distribute their rice to household $(25 \%)$ and rice retailers $(75 \%)$ (BPS, 2015).

Figure 2.8 shows some processes in the production of rice, particularly in the harvesting and post-harvesting periods. In the rice-harvesting season, rice is cut and threshed. The rice cutting is a process to separate rice from its root and threshing is a process to take the rice grain from the rice panicle. Following this, paddy (in some cases, rice with husk is called paddy) is dried under sunlight (Sutrisno, 2004).

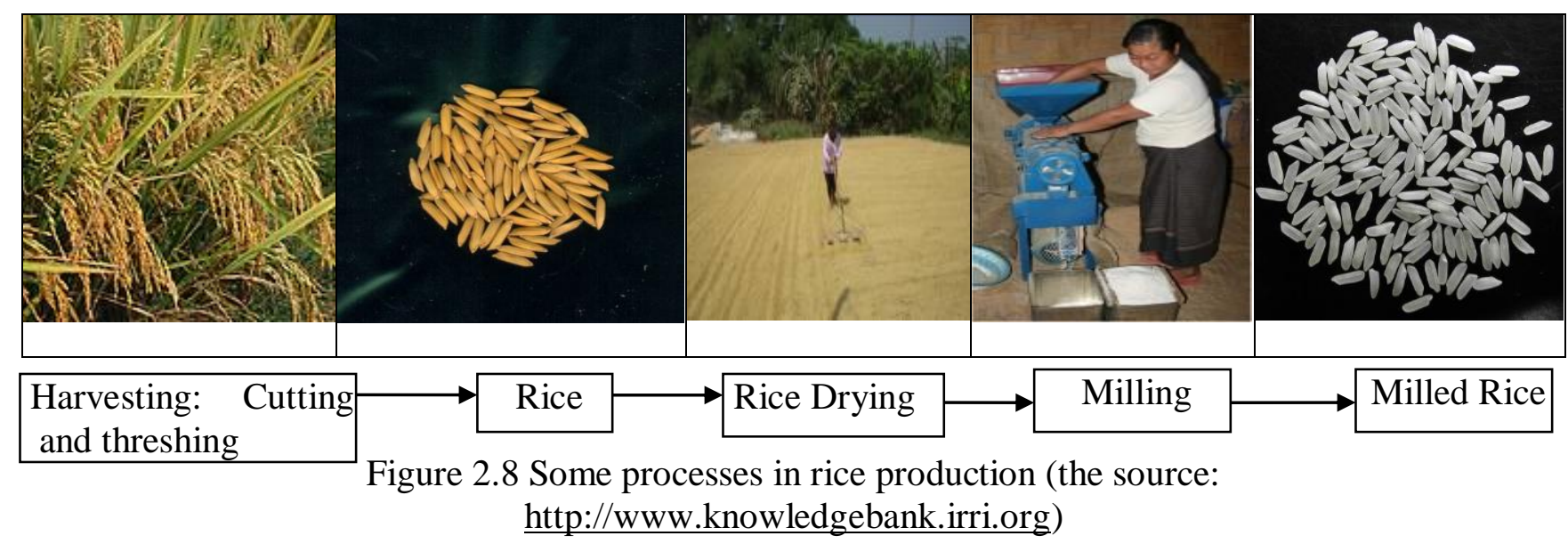

After rice is dried, it is milled using rice-milling machines. Rice milling aims to separate rice from its husk. The ratio between rice and milled rice is called the milling factor. The rice milling factor is about $63 \%$ for small rice millers and $66 \%$ for medium rice millers (Swastika, 2012). The rice milling factor is highly influenced by rice moisture levels its ideal moisture is $14 \%$, leading to a higher milling factor (Listyawati, 2007) and a longer storage life (Swastika, 2012). 


\subsubsection{Definitions and types of supply chain uncertainty}

This section explains a definition of supply chain uncertainty and its types. A table explaining types of uncertainty and its aspects is described. Following that, some studies highlighting the importance of supply uncertainty in the rice supply chain are described.

Van der Vorst and Beulens (2002) offer the following definition:

Supply chain uncertainty refers to decision making situations in the supply chain in which the decision maker does not know definitely what to decide as he is indistinct about the objectives; lacks information about (or understanding of) the supply chain or its environment; lacks information processing capacities; is unable to accurately predict the impact of possible control actions on supply chain behaviour; or, lacks effective control actions (non-controllability). (Van der Vorst \& Beulens, 2002, p.413).

Supply chain uncertainty can negatively threaten supply chain performances. For instance, because farmers do not know the amount of fertiliser needed, they might order insufficient fertiliser, causing a lower rice yield. Therefore, some uncertainties may affect performance in the supply chain.

There are three sources of supply chain uncertainty. The first source is the inherent or natural characteristics of the supply chain (Hasan, 2010; Verdouw, 2010; Van der Vorst \& Beulens, 2002). The second source of uncertainty is supply chain design and the third source is external sources such as pandemics and terrorist attacks. External sources are relatively infrequent, compared to the first two groups (Verdouw, 2010).

Table 2.4 shows four types of supply chain uncertainty, namely, supply uncertainty, demand uncertainty, process uncertainty and planning \& control uncertainty (Van der Vorst \& Beulens, 2002). Supply uncertainty is the situation in which firms cannot get appropriate materials. As climate fluctuates, the crop production or the planting season can vary according to climatic condition. Because of this, climate can be an inherent source of supply uncertainty in an agrifood supply chain such as the rice supply chain. For instance, insufficent rainfall can decrease crop production and delay the planting seasons (Falcon et al., 2004; Naylor et al., 2007). Please note that the impacts of climate 
change on rice quality such as rice nutrient are beyond the scope of this study as stated in section 8.8 limitations.

Demand uncertainty relates to product characteristics and this may cause barriers in predicting and planning the product demand. Process uncertainty relates to some factors that disturb or hinder production processes. Planning and control uncertainty happens when actors within supply chain lack of information about planning and control within supply chain such as inventory level (Van der Vorst \& Beulens, 2002).

Each type of supply chain uncertainty can be categorized into three aspects including quantity, time and quality. For instance, supply quantity is categorized as supply chain uncertainty in the aspect of quantity, while supply quality is supply uncertainty in the aspect of quality.

\begin{tabular}{|l|l|l|l|l|}
\hline $\begin{array}{l}\text { Types supply chain } \\
\text { uncertainty } \\
\text { (colum)-Aspect of } \\
\text { uncertainty (row) }\end{array}$ & Supply Side & Demand Side & Process Side & \multicolumn{1}{|c|}{$\begin{array}{l}\text { Planning } \\
\text { and Control }\end{array}$} \\
\hline Quantity & $\begin{array}{l}\text { The supply } \\
\text { quantities }\end{array}$ & $\begin{array}{l}\text { The customer } \\
\text { demand for } \\
\text { product } \\
\text { quantities }\end{array}$ & $\begin{array}{l}\text { The production } \\
\text { yield and scrap }\end{array}$ & $\begin{array}{l}\text { Information } \\
\text { availability }\end{array}$ \\
\hline Time & $\begin{array}{l}\text { The supplier } \\
\text { lead time }\end{array}$ & $\begin{array}{l}\text { The customer } \\
\text { order time }\end{array}$ & $\begin{array}{l}\text { The production } \\
\text { throughput time }\end{array}$ & $\begin{array}{l}\text { Information } \\
\text { throughput } \\
\text { time }\end{array}$ \\
\hline Quality & Supply quality & $\begin{array}{l}\text { Customer } \\
\text { demand for } \\
\text { product } \\
\text { specifications }\end{array}$ & $\begin{array}{l}\text { Processed product } \\
\text { quality }\end{array}$ & $\begin{array}{l}\text { Information } \\
\text { accuracy }\end{array}$ \\
\hline
\end{tabular}

Table 2.4 Possible SCUs in the agrifood supply chain (from Van der Vorst \& Beulens, 2002)

Some specific uncertainties such as demand uncertainty can be manageable (Eastham, Sharples, \& Ball, 2007; Hasan, 2010; Hull; 2005; Nguyen et al., 2005; Van der Vorst \& Beulens, 2002; Verdouw, 2010; Williams, 2012) but supply uncertainty in the second phase of the rice supply chain or the agrifood supply chain cannot easily managed owing 
to unpredictable weather fluctuation (Hasan, 2010; Hull, 2005; Nguyen et al., 2005; Williams, 2012) $)^{9}$.

Owing to this, the agrifood supply chain can be categorized as supply-driven chains (Dreyer \& Grønhaug, 2012; Hull, 2005; Lam, Zhang Lai, 2015; Ottesen, \& Grønhaug, 2002; Reardon \& Zilberman, 2017; Sehgal, 2010; Xiao et al., 2012). The supply-driven chain is the supply chain that is induced by supply availability (Hull, 2005; Xiao et al., 2012). This is different from demand-driven chain which is induced by product demand (Hull, 2005; Xiao et al., 2012).

The agrifood supply chain such as the rice supply chain of this study tends to be supplydriven chain because of following reasons. Main reasons are the agrifood supply chain has some features including product perishability, low-variety product (Hull, 2005; O'Keeffe, 1988) and a predictable demand ${ }^{10}$ (Xiao et al., 2012). As the agrifood supply chain also has a long throughput time and its output highly depend on climate variability, it is difficult to obtain timely and reliable supply (Hull, 2005; Stock, 2004; Xiao et al., 2012).

Supply uncertainty in the agrifood supply chain is diminished only once harvesting seasons occur (Hamprecht, Corsten, Noll, \& Meier, 2015; Williams, 2012). This means that beyond the harvesting seasons, insufficient supply will be difficult to handle. Furthermore, focusing on supply uncertainty in the agrifood supply chain means handling approximately a half of full costs and value added of the agrifood supply chain, especially in developing countries (Reardon, 2015; Reardon \& Zilberman, 2017). Hence, supply uncertainty is probably the most important uncertainty for the agrifood supply chain such as rice supply chain considered in this study.

This study focuses on supply uncertainty as other uncertainty such as demand and process uncertainty can manageable through proper management of the rice suppy chain

\footnotetext{
${ }^{9}$ Supply uncertainty may occur in the third phase of the rice supply chain (Hasan, 2010; Van der Vorst et al., 2007). But, supply uncertainty in the third phase is management issues (Hasan, 2010) and can be managed through storing and packing (Van der Vorst et al., 2007). However, supply uncertainty in "the open field" i.e. rice farming field cannot be controlled as climate caanot be controlled. Hasan (2010) categorises the open farming field as the second phase of the rice supply chain.

${ }^{10}$ Especially the grain supply chain such as the rice supply chain
} 
(Hasan, 2010; Williams, 2012). As explained above, supply uncertainty is highly important for the rice supply chain in West Nusa Tenggara or other rice supply chain in developing countries. In particular, this study investigates the impacts of climate change on rice yield, rice production and harvested areas since climate change and climate variability may influence rice yield (Peng et al., 2004; Welch et al., 2010), rice production (Falcon et al., 2004; Naylor \& Mastrandea, 2009; Naylor et al., 2007) and harvested areas (Falcon et al., 2004; Naylor \& Mastrandea, 2009).

\subsubsection{Climate as an inherent source of uncertainty in the rice supply chain}

Several studies explain the effects of climate variability on the Indonesian rice production, and particularly the effects of rainfall variability. La-Niña tends to start earlier planting seasons, leading to a higher rice production, while El-Niño can delay the timing of monsoon onset by about 10-30 days (Sumarno et al., 2008; Irianto \& Suciantini, 2006) leading to a lower rice production.

The high maximum and minimum temperature can affect rice yields at each stage of rice growth: the vegetative, the reproductive and the ripening stages (Wassmann et al, 2009). The reproductive stage is relatively vulnerable to the high maximum temperature (Wassmann et al., 2009; Yoshida, 1981). For instance, the high maximum temperature (close to temperature threshold) can induce spikelet sterility, causing lower rice yields. Furthermore, the high minimum temperature can reduce rice yield. In particular, minimum temperature can severely decrease rice yield, particularly if rice is exposed to $22^{0} \mathrm{C}$ or above (Peng et al., 2004).

Another important factor that may negatively affect rice yields is sea level rise. IPCC (2013) indicates that Indonesia is projected to experience sea level rise in the range of 0.3-1 $\mathrm{m}$ by 2100 (RCP2.6-RCP8.5 scenario, relative to the period 1986-2005). As sea levels rise, rice-farming areas can be inundated, particularly low-lying areas (IPCC, 2012; Toriman et al., 2013). Sea level rise also leads to the salination of fresh water supplies. Sea level rise also is likely to damage coastal infrastructure and public facilities close to the coast (Franck, 2009; IPCC, 2013). Please see section 4.4 for estimated submerged land in West Nusa Tenggara due to sea-level rise. 
Several rice supply chain uncertainties may influence the performance of the rice supply chain (Hasan, 2010; Lam, Zhang Lai, 2015; Thongrattana \& Jie, 2010). Some of the uncertainties, such as rice supply, lead time (due to delayed rainy seasons) and inundated farming areas may disrupt the rice supply chain in Indonesia. In other words, as climate change is associated with rainfall, and temperature changes, climate change is an inherent source of the rice supply chain uncertainty.

\subsubsection{Some simulations in the supply chain management}

In modelling or simulation, modelers usually face the trade-off between detailed aggregations (heterogeneous or homogeneous agents) and breadth of the system boundary (Rahmandad, 2004; Rahmandad \& Sterman, 2008). For example, focusing on individual behaviour could sacrifice the system boundary of the rice supply chain, while smoothing a group of individual behaviours could increase the system boundary of the rice supply chain. If, for instance, a study focuses on individual behaviour (a farmer, for example), the government may not understand how climate change could affect other parties such as wholesalers, rice / paddy brokers and rice millers. Since rice is a staple food for over $90 \%$ of Indonesians, looking at how some farmers (as a group) behave under changing climate conditions could help the government to understand how climate change influences society as a whole.

Table 2.5 shows three modelling types that are frequently used in operational research and social science research such as Discrete Event Simulation (DES), System Dynamics (SD) and Agent Based Modelling (ABM) (Behdani, 2012; Borshchev \& Filippov, 2004; Maidstone, 2012). Although ABM is relatively new, it gets many positive responses within the academic environment as it can effectively capture agent behaviour. SD is a relatively mature model compared to $\mathrm{ABM}$, although it has been criticised because of its continuous characteristic (Behdani, 2012; Borshchev \& Filippov, 2004).

Because DES is only suitable for microscopic modelling, it is not suitable to model systems with a high abstraction level such as the supply chain. ABM and DES are stochastic and discrete modelling while SD is continuous and deterministic modelling. Furthermore, SD is based on the top down approach while the others are based on the bottom up approach. 


\begin{tabular}{|c|c|c|c|}
\hline Description & SD & DES & ABM \\
\hline Unit Analysis & Structure & Entity Rules & Agent Rules \\
\hline Level of Modelling & Macroscopic View & Microscopic View & $\begin{array}{l}\text { Tends towards to } \\
\text { Macroscopic View }\end{array}$ \\
\hline Handling Time & Continuous & Discrete & Discrete \\
\hline Perspective & Top Down & Bottom Up & Bottom Up \\
\hline Variables & Handle large variables & $\begin{array}{c}\text { Require high } \\
\text { computational costs } \\
\text { and time to handle } \\
\text { large entities }\end{array}$ & $\begin{array}{c}\text { Require high } \\
\text { computational costs } \\
\text { and time to handle } \\
\text { large entities }\end{array}$ \\
\hline Type of Parties & Homogenous parties & $\begin{array}{l}\text { Heterogeneous } \\
\text { Entities }\end{array}$ & Heterogeneous Agents \\
\hline Action & Passive Agents & Active Entities & Active Agents \\
\hline
\end{tabular}

Table 2.5 System Dynamics, Discrete Event Simulation and Agent Based Modelling: A Comparison (Borshchev \& Filippov, 2004; Schieritz \& Milling, 2003)

Rahmandad and Sterman (2008) assert that an SD's weakness on a homogenous issue can be replaced by widening the system boundary. For instance, while a demographic ABM model could draw each individual separately, it will presume fertility and mortality exogenously, whereas the demographic model in SD is likely to describe fertility and mortality endogenously (Rahmandad \& Sterman, 2008). Other literature describes strong points of system dynamics such as model comprehensibility (Ortiz, Sarriegi \& Santos, 2006), fewer programming skills than ABM (Lorenz \& Bassi, 2005) and a simple structure (Ossimitz \& Mrotzek, 2008).

Studies apply the system dynamics (SD) approach to investigate impacts of climate change and supply chain uncertainty. The SD approach can simulate varied inputs, particularly different uncertain inputs such as climate projections, in order to explore impacts of climate change. Compared to other climate models, the SD approach offers transparency in model structures and equations (Fiddaman, 1997; Sterman et al., 2013). These SD studies also show that the SD approach can combine different types of inputs and methods to assess impacts of climate on the rice supply chain. For instance, an SD study combines climatic and non-climatic data to estimate impacts of climate change on economic systems and social systems (Kopainsky, Züllich, \& Blanco, 2013). 


\subsubsection{Technological improvement on rice yields}

Some possible technological improvements in rice farming are cultivar (farm-based) management and germplasm research (Haefele, Ismail, Johnson, Vera Cruz, \& Samson, 2010; Gujja, \& Thiyagarajan, 2010; Li, \& Wassmann, 2010). Improved farm management such as optimum fertiliser and pesticide can increase crop yield, however, their positive effects are limited (Gujja, \& Thiyagarajan, 2010).

$\mathrm{Li}$ and Wassmann (2010) claim that germplasm research will play a pivotal role in reducing the negative effects of climate change, as the research can result in a higher quality of seed. For example, germplasm research leads to high temperature-tolerant rice or drought-tolerant rice.

\subsection{Agricultural practises in West Nusa Tenggara}

This section describes agricultural practices in West Nusa Tenggara (WNT), Indonesia. The main locus of this research is WNT, one of the main national rice producers in Indonesia. As described earlier, two types of rice farming - wetland and dryland - have different agricultural practices and different types of varieties and because of this, this research assesses the impacts of climate change on wetland and dryland separately.

\subsubsection{Two rice-farming types}

There are two types of rice farming conducted in West Nusa Tenggara. The first type is wetland ("padi sawah") and the second type is dryland farming ("padi ladang"). Wetland farming is usually called irrigated farming as this has permanent water-logging from dams. Conversely, dryland farming utilises land without permanent water-logging. Dryland farming might be called non-irrigated land or rainfed farming.

Table 2.6 and figure 2.9 show a proportion of wetland and dryland farming in WNT (BPS, 2014). The irrigated land (wetland) covers about $84 \%$ of the total rice area in WNT. Productivity of irrigated land is between 4.9 and 5.6 tonnes per hectare, while rainfed land has productivity ranges between 3.5 and 4.7 tonnes per hectare (BPS, 2014). 


\begin{tabular}{|r|l|r|r|r|r|}
\hline \multirow{2}{*}{ No } & \multirow{2}{*}{ Municipality } & \multicolumn{2}{|c|}{ Wetland/Irrigated land } & \multicolumn{2}{c|}{ Rainfed/Dryland } \\
\cline { 3 - 6 } & & $\begin{array}{c}\text { Harvested } \\
\text { Area (Ha) }\end{array}$ & $\begin{array}{c}\text { Productivity } \\
\text { (Tonnes/Ha) }\end{array}$ & $\begin{array}{c}\text { Harvested } \\
\text { Area (Ha) }\end{array}$ & $\begin{array}{c}\text { Productivity } \\
\text { (Tonnes /Ha) }\end{array}$ \\
\hline 1 & Lombok Barat & 32,934 & 5.46 & 1,858 & 3.46 \\
\hline 2 & Lombok Tengah & 84,968 & 4.96 & 2,096 & 4.32 \\
\hline 3 & Lombok Timur & 69,191 & 4.92 & 3,714 & 4.34 \\
\hline 4 & Sumbawa & 75,567 & 5.59 & 15,178 & 4.64 \\
\hline 5 & Dompu & 27,087 & 5.09 & 7,416 & 4.32 \\
\hline 6 & Bima & 53,406 & 4.93 & 21,040 & 4.07 \\
\hline 7 & Sumbawa Barat & 18,027 & 4.77 & 166 & 4.75 \\
\hline 8 & Lombok Utara & 5,129 & 5.31 & 2,031 & 3.59 \\
\hline 9 & Kota Mataram & 11,042 & 5.43 & 1,718 & 0 \\
\hline 10 & Kota Bima & 5,489 & 5.63 & 0 & 4.07 \\
\hline 11 & Total/Average & 382,840 & 5.14 & 5,522 & \\
\hline
\end{tabular}

Table 2.6 The wetland (irrigated land) and the dryland (unirrigated land) by area (BPS, 2014)

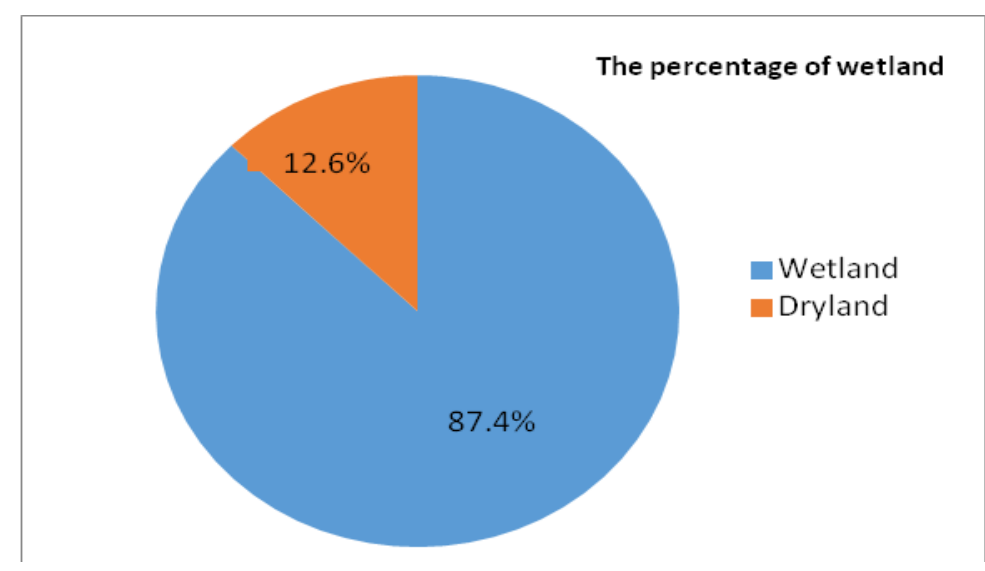

Figure 2.9 A proportion of wetland and the dryland areas (BPS, 2014)

\subsubsection{The planting seasons}

There are three growing seasons in WNT for rice cultivation. About $65 \%$ of the total rice production is planted in the first planting season between September and December. As such, most rice is harvested between January and April. In the second planting season between February and April, about $30 \%$ of total rice is planted which will go on to be harvested between May and August. The rest of the rice sown is harvested between September and December.

Figure 2.10 and 2.11 illustrate harvested areas for both farming types; wetland and dryland. Since wetland rice is sown in three planting seasons, wetland rice is usually 
harvested in three harvesting seasons (January-April, May-August and SeptemberDecember). By contrast, most dryland rice is usually harvested in the first harvesting season: January-April. Approximately $97 \%$ of total dryland rice is harvested in the first harvesting season, while the second harvesting season only covers about $3 \%$.

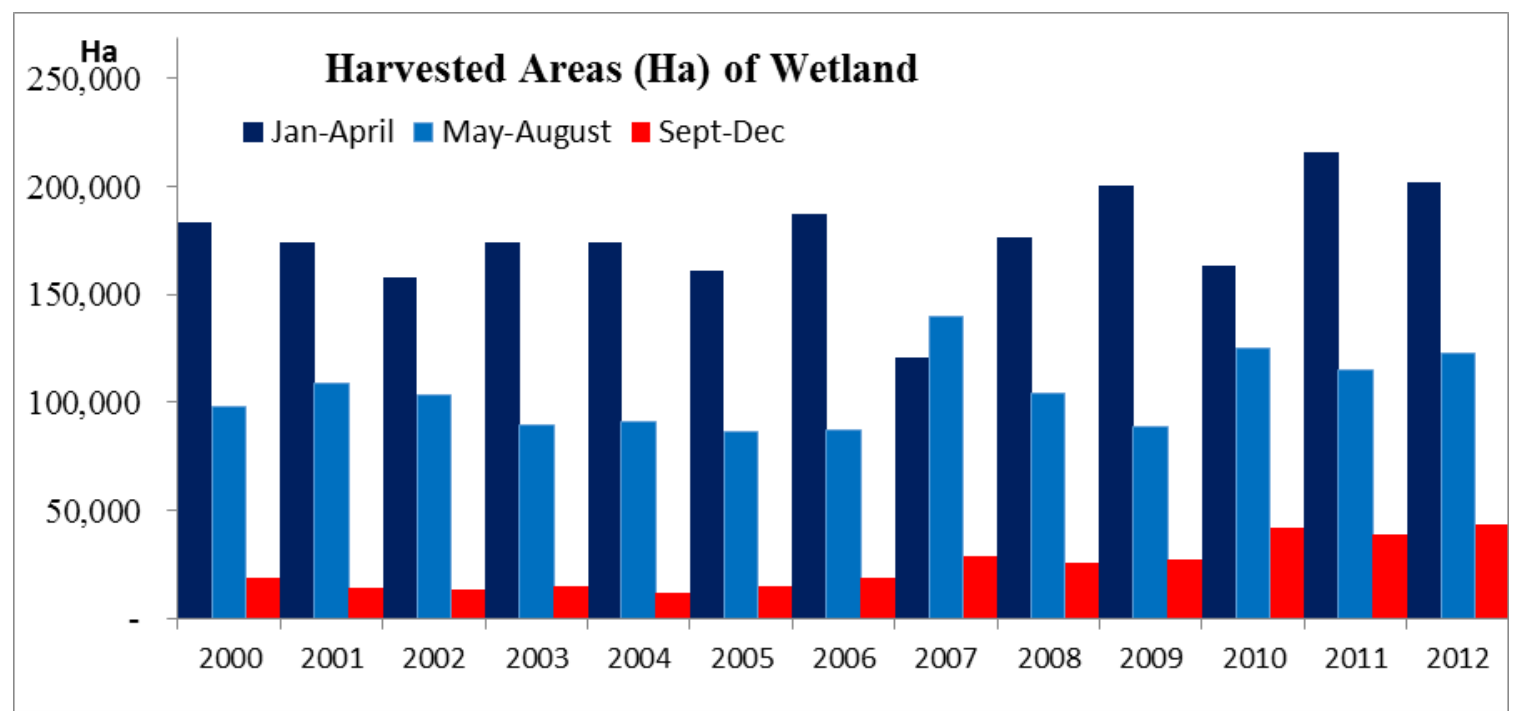

Figure 2.10 Wetland harvested areas in three harvesting seasons (BPS, 2000-2013)

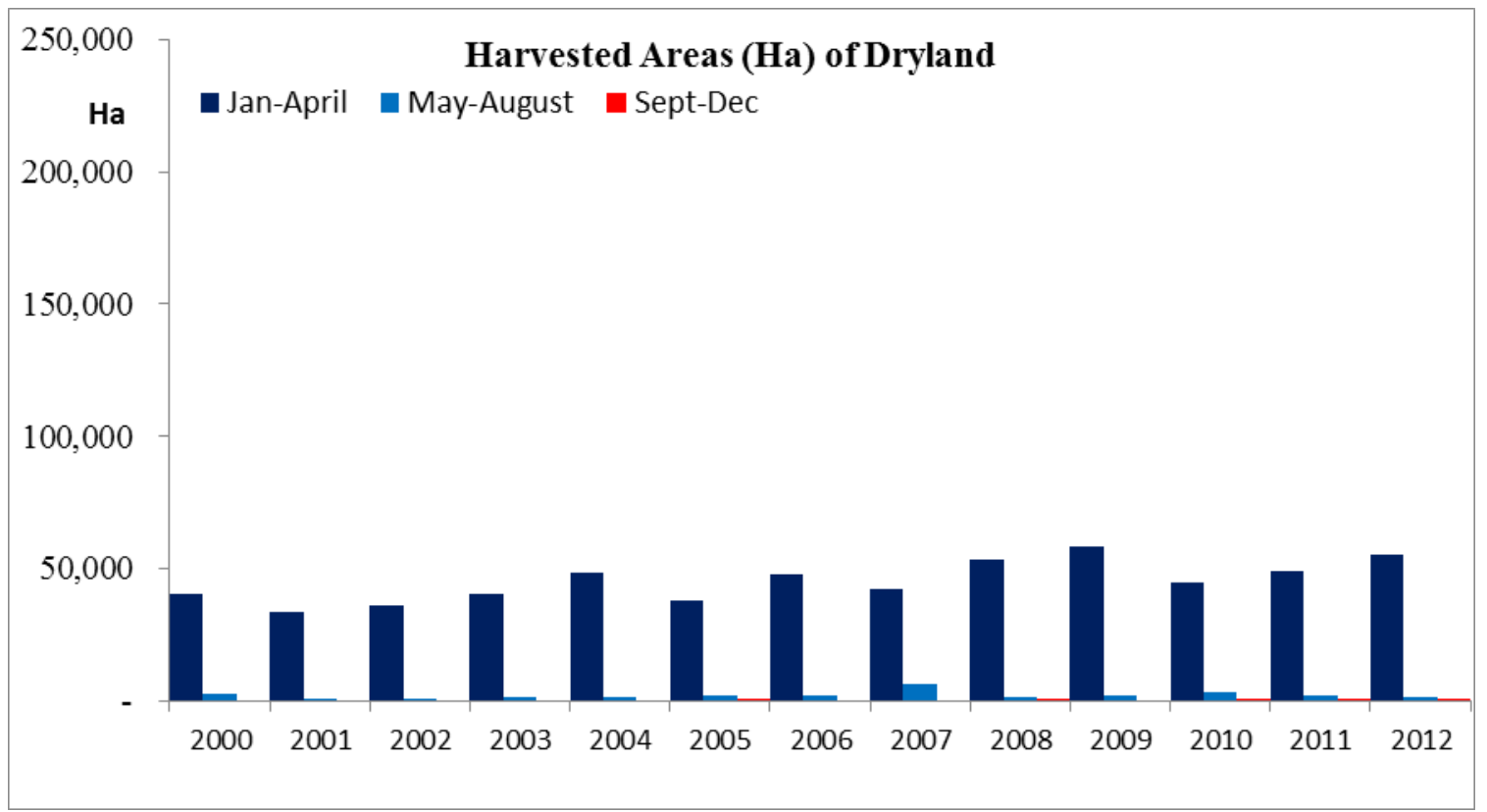

Figure 2.11 Dryland harvested areas in three harvesting seasons (BPS, 2000-2013)

Wetland and dryland harvested areas tend to increase over time. However, harvested areas may experience a decrease due to land conversion. As shown in figure 2.12, between 2004 and 2005 the harvested area of wetland dwindled from 280,069 ha to 
259,484 ha, owing to a massive land conversion (BPS, 2010; Nazam, 2009). For dryland farming, figure 2.12 shows a huge increase in harvested areas of about 16,000 ha, owing to deforestation in the period of $2004-2009^{11}$ (BPS, 2009). This led to a dramatic increase in dryland farming during the same period. However, as farmers open new farms, the harvested area of both farming types is likely to rise over time. Since 2013, the government has secured potential ${ }^{12}$ land to increase farming areas for wetland and dryland farming (The government of West Nusa Tenggara, 2013).

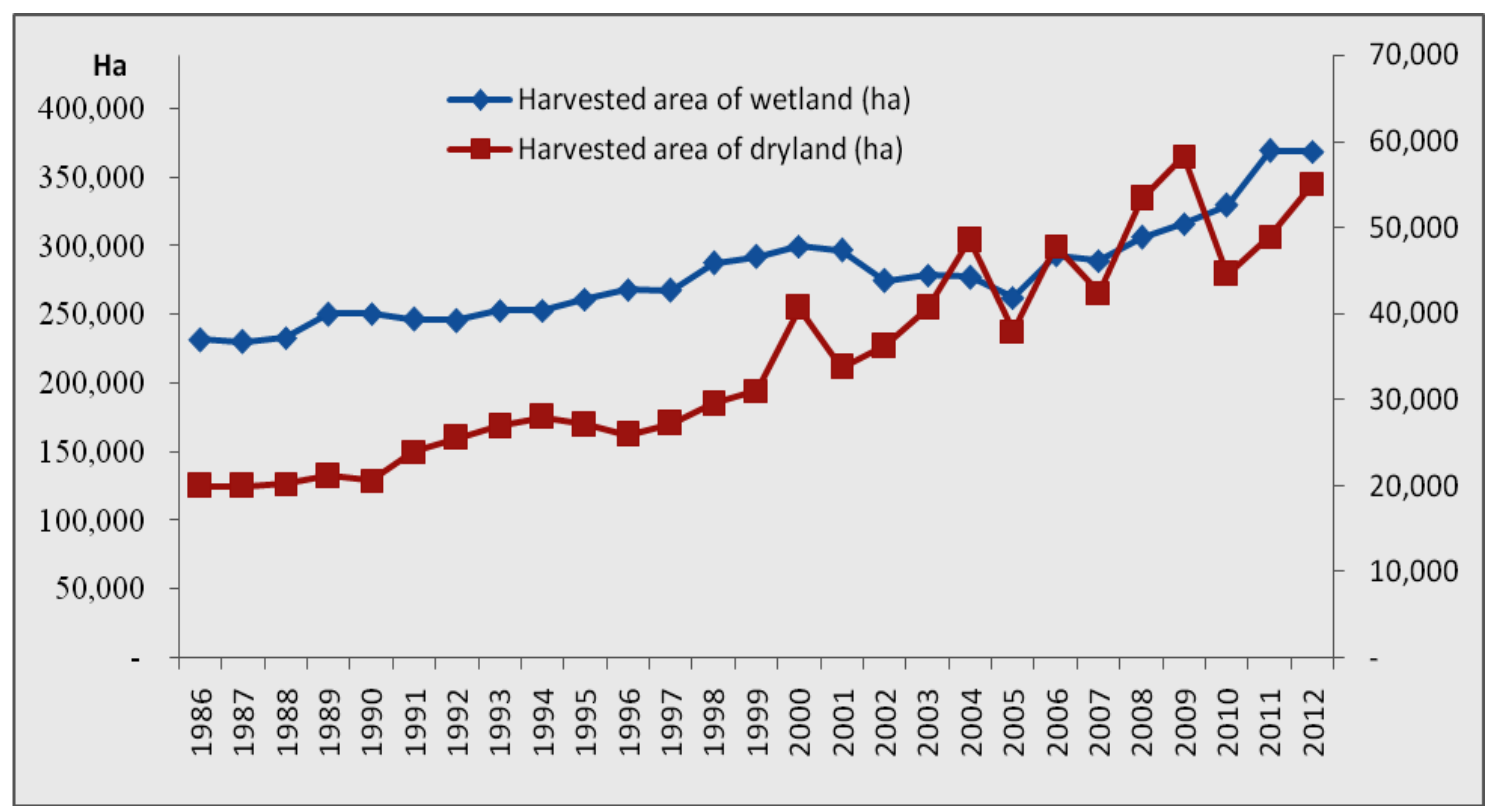

Figure 2.12 Harvested area of wetland and dryland (BPS, 1986-2013)

It is not difficult for dryland farmers to increase their farming areas since dryland farming does not require irrigation facilities. By contrast, as wetland farming requires irrigation facilities, increases in wetland farming are relatively low. On average, the increase in wetland areas was about $1.15 \%$ a year ( 909 ha/year), while dryland farming experienced a higher increase of 3.55\% per year (2,400 ha/year) in the period 1976-2012.

Since farmers can sow rice in consecutive growing seasons, the harvested area may be higher than the farming area. A comparison between harvested area and farming area is usually termed 'cropping intensity' (Nazam, 2009). A higher cropping intensity leads to a higher harvested area.

${ }^{11}$ Between 2000 and 2001, there was deforestation about 40,000 ha owing to new dryland farming (BPS, 2005)

12 Potential land here is defined as available land for new farming areas. 
One main factor affecting the cropping intensity is rainfall (Nazam, 2009; Naylor et al., 2001; Naylor et al., 2002). A higher rainfall tends to boost the cropping intensity, while a lower precipitation seems to reduce the cropping intensity (Irianto \& Suciantini, 2006; Naylor et al., 2001; Naylor et al., 2002; Naylor et al, 2007; Sumarno et al., 2008). For dryland farming, cropping intensity is about $100 \%$ since $97 \%$ of its total harvested area is sown in the first growing season. In the case of wetland farming, cropping intensity may vary according to the proportions of harvested area across the three harvesting seasons.

Figure 2.13 shows a relationship between the cropping intensity of wetland farming and rainfall pattern for the period 2000-2012 ${ }^{13}$. It seems that cropping intensity in this period correlates with rainfall. This may be caused by the improvement and enhancement of irrigation facilities. Since the reformation era, the local government of WNT has improved existing irrigation facilities and constructed new ones (Dinas Pertanian, 2006; 2012). It aims to boost rice production through a higher cropping intensity and new farming land. A single linear regression analysis shows that cropping intensity can be significantly regressed by seasonal rainfall $\left(\mathrm{R}^{2}=.45, F(1,2)=9.811, p<.01\right)$.

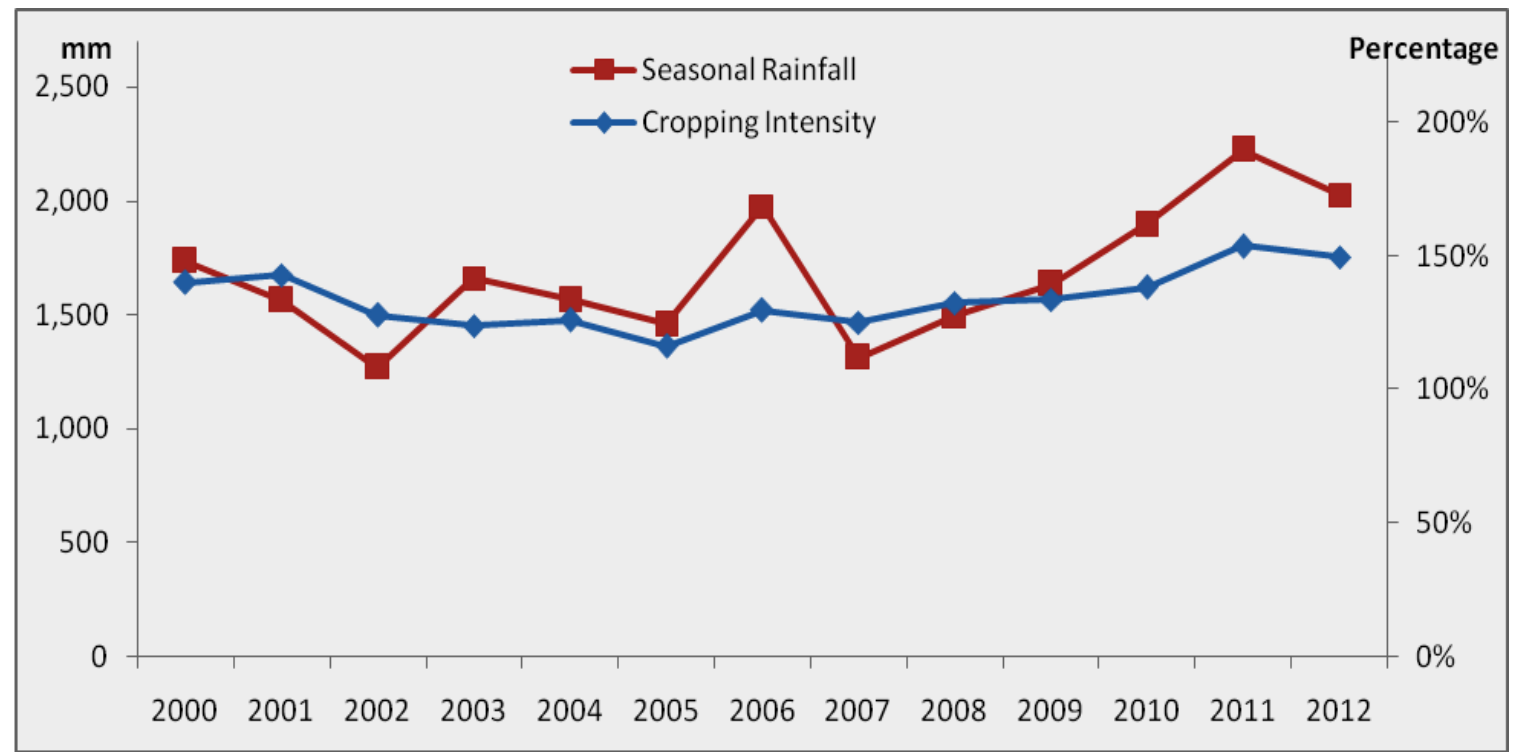

Figure 2.13 Cropping intensity in percentage (BPS, 2000-2013) and seasonal rainfall (mm) between September and August (BMKG, 2014)

\footnotetext{
${ }^{13}$ Seasonal rainfall is measured in milimetres from September to August, and cropping intensity is measured in percentage (118\% of cropping intensity means 1.18 times of total available land is planted in related seasons).
} 


\subsubsection{Rice varieties}

There are many rice varieties sown in the WNT region, including Ciherang, Situbagendit, Cigeulis, Ciliwung, Mekongga and Inpari Sidenuk. Again, these rice varieties can be categorised into three groups: wetland, dryland and amphibiotic varieties (figure 2.13). Wetland varieties can only be sown in wetland areas, while dryland varieties can only be sown in dryland areas. Rice varieties which can be sown both in dryland and wetland areas are called amphibiotic varieties.

Rice varieties in wetland and dryland areas have different features. Dryland varieties have a shorter growth duration (shorter time to maturity) and are relatively more tolerant of droughts. Wetland varieties have a higher productivity and a longer growth duration (or a longer time to maturity).

The role of new rice varieties in boosting rice yield is substantial. Gmamanickam (2009) and Sitorus (2006) point out that an increase in rice productivity is highly dominated by new rice varieties. For instance, new rice varieties of higher potential productivity (5-6 tonnes/ha) and more resistance to pests and diseases have been introduced, such as Cigeulis and Ciherang, compared with previous varieties such as IR 26 and IR 36 (Departemen Pertanian Republik Indonesia, 2012).

Moreover, as the climate continues to change, more intensive research is carried out to find better rice varieties. Some research institutions such as BATAN (The Bureau of Nuclear Research) and Puslitbang Tanaman Pangan (The Bureau of Research on Crops) have produced improved varieties for both farming types (wetland and dryland). Wetland varieties that are relatively tolerant to submergence have been introduced, such as Inpari33. An improved dryland variety that is more tolerant to droughts and with a shorter growth duration has also been found in Inpari Sidenuk. 


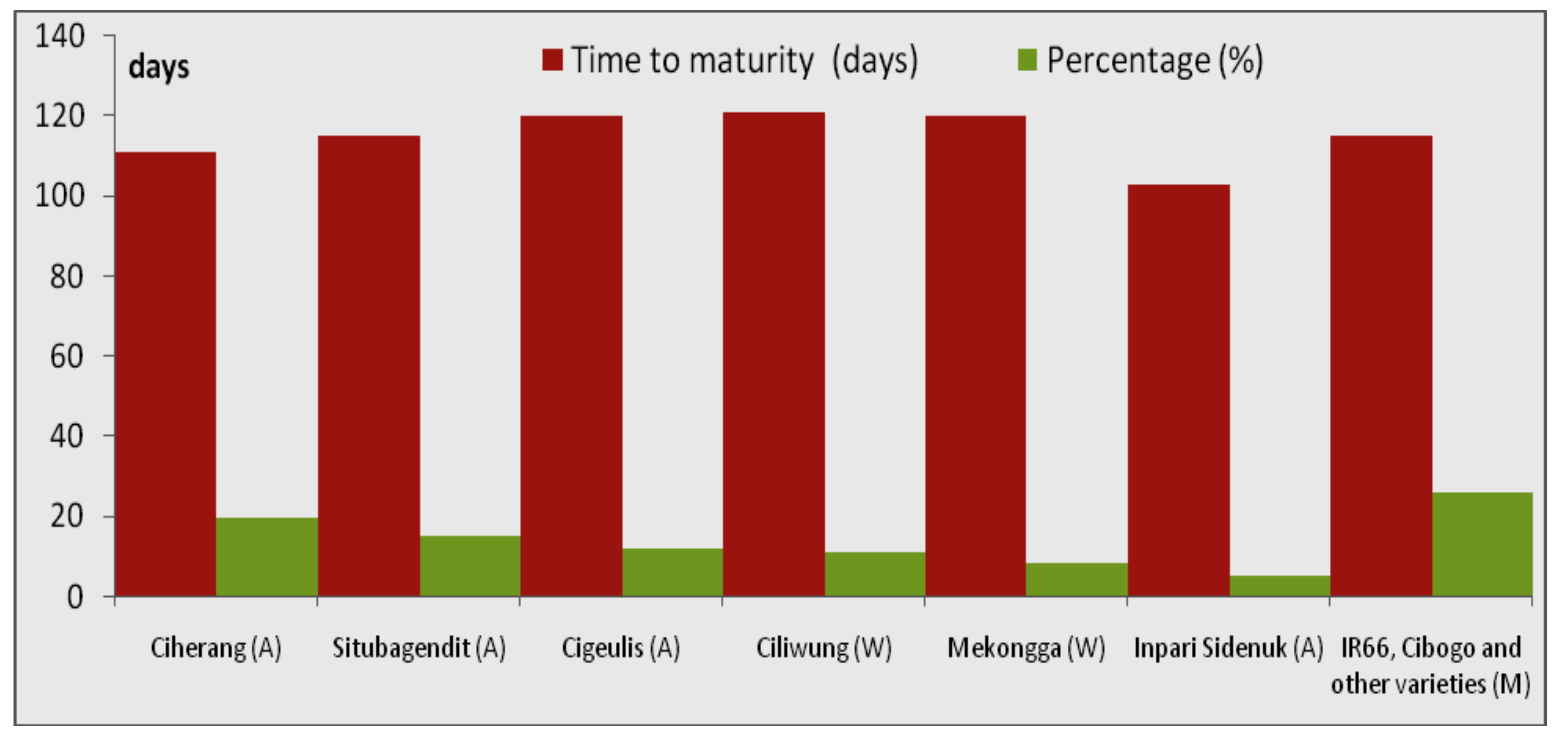

Figure 2.14 The mean of time to maturity (growth duration) for each rice variety and proportion of their applications ( $\mathrm{A}=$ amphibiotic, $\mathrm{W}=$ wetland and $\mathrm{M}=\mathrm{mixed}$ ) (Suprihatno et al., 2010)

\subsubsection{The timing of monsoon onset}

In the rainy seasons, monthly rainfall can reach about $200 \mathrm{~mm}$, an ideal rainfall to support rice growth. Because of this, rice cultivation usually begins in the rainy season when sufficient rainfall occurs. Naylor et al. (2007) indicate that in Indonesia the monsoon onset starts when the cumulative rainfall from August 1 is about $200 \mathrm{~mm}$.

The timing of monsoon onset in WNT is generally in the second week or around November 15 (Indriani, 2010). Therefore, if cumulative rainfall between August and the second week of November reaches $200 \mathrm{~mm}$, then there is no delay in the timing of monsoon onset. If the cumulative rainfall reaches $200 \mathrm{~mm}$ before November 15, this means that the monsoon onset comes earlier. Conversely, delayed timing of the monsoon onset occurs when the cumulative rainfall between August and the second week of November is less than $200 \mathrm{~mm}$.

The precipitation pattern in West Nusa Tenggara is highly affected by monsoon (IPCC, 2013). In general, the difference in thermal inertia between land and ocean as well as the seasonal cycle of solar heating is responsible for the variability of precipitation within the tropics (IPCC, 2013). However, the abnormal warming of the tropical eastern to central Pacific may influence the monsoon onset in Indonesia. This abnormal warming leads to a delayed monsoon onset (El Niño) or an earlier monsoon onset (La Niña). 
Figure 2.15 depicts the varied timing of monsoon onset according to the August SOI ${ }^{14}$ (Southern Oscillation Index in August) based on available data of daily rainfall from 1987 to 2014 (BMKG NTB, 2014). In 1997, the timing of monsoon onset delayed about 35 days due to El Niño (in 2010, a delay of the timing of monsoon onset was about 30 days) while in 1998, the timing of monsoon onset began earlier about 10 days (in 2010, the timing of monsoon onset started earlier about 20 days) due to La Niña.

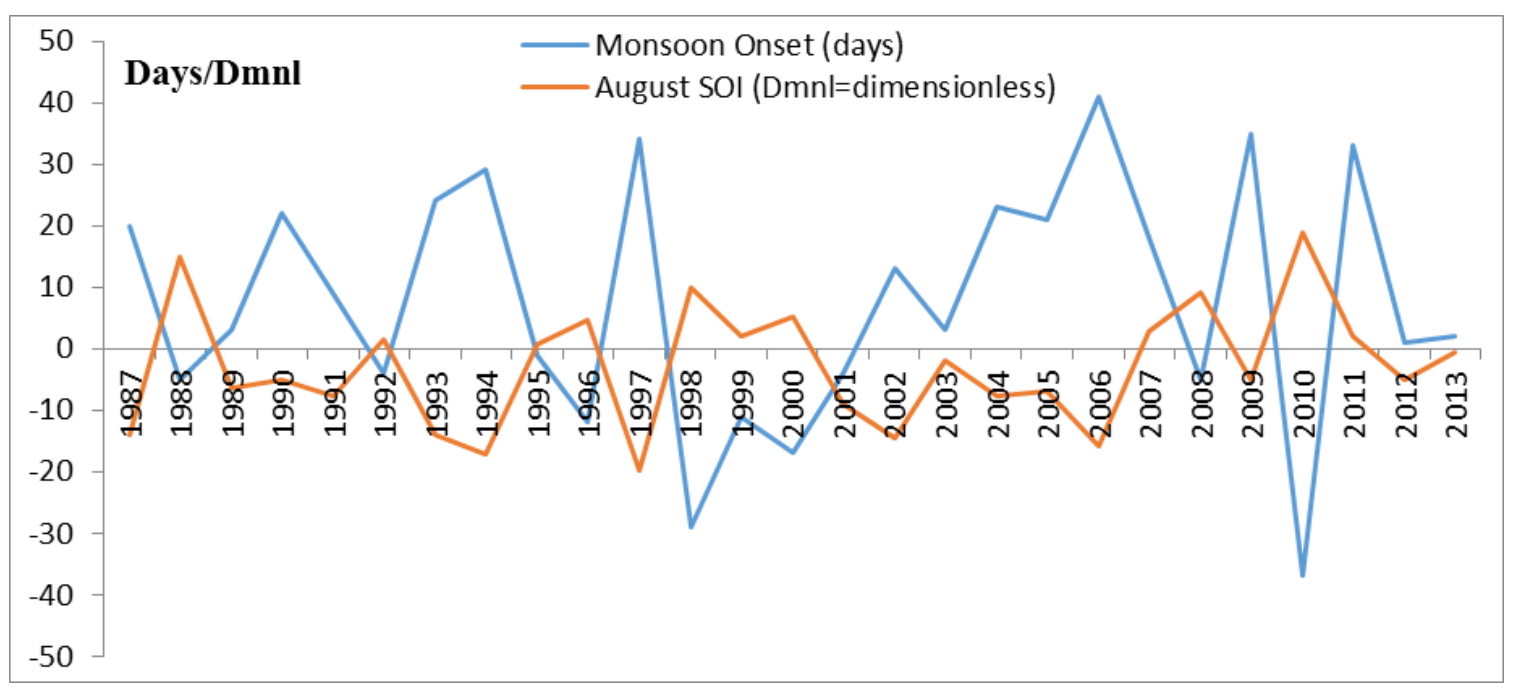

Figure 2.15 Variations of monsoon onset (days) vs. August SOI (Southern Oscillation Index) in the period 1987-2013 (August SOI is taken from The Australian Bureau of Meteorology: http://www.bom.gov.au/climate/current/soihtml.shtml)

IPCC (2013) describes several of the monsoon systems in the world as seen in figure 2.16. The East Asian Monsoon (EAS) covers Japan and Korea (SAS is the South Asia monsoon covering India and Bangladesh) while the Australian Maritime Continent (AUSMC) captures the whole of Indonesia and some parts of Australia. Because there is no agreement among CMIP 5 models about future precipitation in Indonesian regions such as West Nusa Tenggara. Owing to this, Indonesian annual rainfall, based on RCP 4.5 scenario, is projected to change between $-2 \%$ and $18 \%$ by 2100 (IPCC, 2013).

\footnotetext{
${ }^{14}$ ENSO can be indicated sea pressure level between Darwin and Tahiti (Yasin et al., 2003; IPCC, 2013 p.233). SOI is standardised differences between sea level pressure in Darwin and Tahiti (Yasin et al., 2003; IPCC, 2013 p.233).
} 


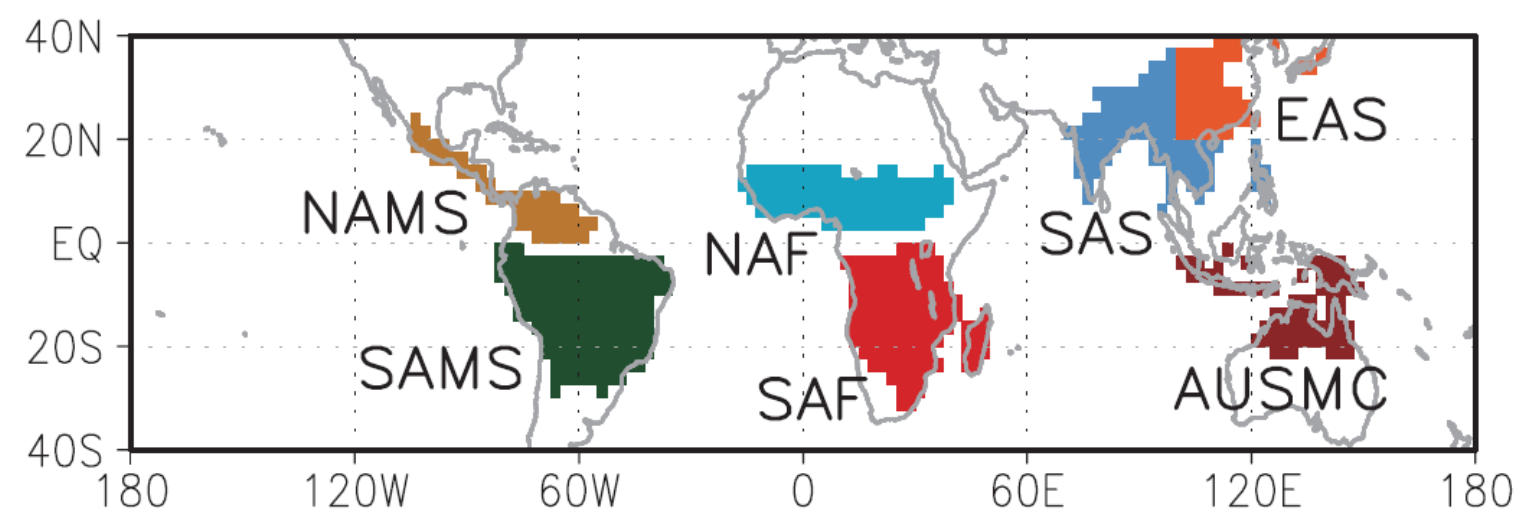

Figure 2.16 The monsoon systems in the world (IPCC, 2013)

\subsection{A review of previous studies}

\subsubsection{Supply uncertainties in the rice supply chain}

Studies outlined in this section affirm that supply uncertainty is highly important for the rice supply chain. They also explain that climate can affect the supply chain. Some limitations of those studies are explained in the following paragraphs. Although a lot of studies focused on the agrifood supply chain (as seen in section 2.1.6 and 2.1.8), supporting studies on analysing the rice supply chain is very limited, leading to limited studies explained in this section.

As explained earlier in section 2.1.6, Hasan (2010) divides the rice supply chain into three phases. The first phase includes distribution production inputs such as fertiliser, seed and pesticide. The second stage (in figure 2.7, the second phase is circled by a blue line) consists of rice production in farming areas in which climate, technology and labour interact with each another. The third phase is delivering the milled rice to household and industrial customers. Because climate cannot be controlled, the second phase is vulnerable to climate change and climate variability (Hasan, 2010). Hasan (2010) also claims that due to droughts and floods, the rice supply chain cannot provide appropriate rice supply, leading to a rice shortage in Bangladesh.

In his study, Hasan (2010) applies probability functions to estimate the effect of droughts and floods on the Bangladesh rice supply chain. However, Hasan's study (2010) should include the impacts of increased temperature and the impacts of the timing of monsoon onset on rice supply. 
Other studies explore the effects of uncertainties on Thailand's rice supply chain (Thongrattana, 2012; Thongrattana \& Jie, 2010). Those studies also claims that demand uncertainty (Thongrattana, 2012) and climate uncertainty (Thongrattana \& Jie, 2010) may highly affect performance of the rice supply chain. Since those studies (Thongrattana, 2012; Thongrattana \& Jie, 2010) limit their focus on exporting rice companies and rice millers, those studies disregards empirical evidence of climate effects on the rice supply chain i.e. the second phase of the rice supply chain.

\subsubsection{Climate change studies: statistical models and crop models}

In this section, several studies are reviewed which highlight either the impacts of climate variability and climate change on crop yield. Moreover, each of those studies employs one of two well-known methods in approximating impacts of climate change on the rice yields: statistical and crop models.

Several studies claim that Indonesian rice is vulnerable to El-Niño, because El-Niño could significantly decrease rainfall and delay the timing of monsoon onset (Naylor, Falcon, Wada, \& Rochberg, 2001, 2002; Falcon et al., 2004; Naylor \& Mastrandrea, 2009), leading a smaller harvested area and a lower rice production. Another study (Naylor, Battisti, Vimont, Falcon, \& Burke, 2007) explains impacts of climate change on Indonesian rice production, suggesting that a lower precipitation leads to a lower rice production.

Despite their useful findings, those studies (Naylor et al., 2001; 2002; Falcon et al., 2004; Naylor et al., 2007) should explain the impacts of increased temperature on rice production. Again, those studies (Naylor et al., 2001; 2002; Falcon et al., 2004; Naylor et al., 2007) should investigate possible options in tackling the negative impacts of climate change on rice production.

A number of studies successfully apply statistical models in estimating impacts of climate change on crop yields (Lobell et al., 2008, Lobell, Schlenker \& Costa-Roberts, 2011). In general, those studies employ two types of variables (linear and quadratic terms), climatic (temperature and rainfall) and non-climatic variables.

Those studies, based on statistical models, were successful of incorporating climate and technological progress (represented by time variables) in understanding the impacts of 
climate change on major crops in Asia, Africa and Erope (Lobell et al., 2008; Lobell et al., 2011). As those studies using statistical models, those studies analysed the impacts of climate either in the past (Lobell et al., 2011; Naylor et al., 2001; 2002; Falcon et al., 2004; Naylor et al., 2007) or in near future by 2030 (Lobell et al., 2008). Furthermore, those studies would be more beneficial if those studies discuss the impacts of climate change on harvested areas and possible options in tackling the impacts of climate change on crop supply.

All of those studies applying statistical methods to estimate impacts of climate change or climate variability on Indonesian rice production. Statistical methods require less data than crop models (Lobell \& Burke, 2010). Lobell \& Burke (2010) suggest that statistical models, compared to crop models, do not require more intensive data, namely: daily weather (solar radiation, temperature and rainfall), cultivar management (fertiliser), soil properties and rice/crop genetics. However, statistical models have limitations such as collinearity and stationarity (Lobell \& Burke, 2010). Another limitation of statistical models is that they are based on historical data. As projected temperature may far higher than observed temperature, mathematical relationships in the statistical models may not be appropriate (Lobell, 2010).

Using crop models, several studies have investigated the effects of climate change on global crop production (Deryng, Sacks, Barford \& Ramankutty, 2011; Deryng, 2014; Müller et al., 2015; Rosenzweig \& Parry, 1994), suggesting that assuming constant harvested areas, climate change will probably threaten the world crop supply, especially crop supply in developing countries i.e. low altitude countries.

Existing studies using crop models investigated options in tackling the impacts of climate change on crop production. Possible options are mitigating of climate change (Müller et al., 2015) and developing more climate-resilient crop varieties (Rosenzweig \& Parry, 1994) will probably sustain world crop production.

Although those crop-model studies were successfully in analysing the impacts of climate change on major world crops either by 2050 or by 2100 (longer than statistical-model 
studies) and investigate possible options in tackling the negative impacts of climate change on crop production, those studies assume constant harvested areas which may be misguided as crop production is also influenced by harvested areas.

\subsubsection{System dynamics studies: climate change studies \& the agrifood supply chain}

Fiddaman (1997) successfully constructs a climate-economy model to find an appropriate carbon tax policy in order to mitigate impacts of climate change. Fiddaman (1997) constructs the climate-economy model with some relaxed assumptions such as endogenous technical change and endogenous population. Inspired by Fiddaman's study (1997), Sterman et al. (2013) construct the C-ROAD model to predict some variables such as global mean temperature and sea level rise for different greenhouse emissions. The C-ROAD model can run faster than global climate models, as this is a onedimensional climate model.

The C-ROAD model can be used to measure the effects of mitigation proposed by policy makers in any country to the total greenhouse emission. As the C-ROAD model runs faster in a laptop, we can see the effects of mitigation of climate change initated in any country to the total greenhouse emission in any minutes. Hence, the C-ROAD model cannot be used measure the impacts of climate change.

A study (Bassi, Herren, Tan, \& Saslow, 2010) uses the SD approach to elucidate the impacts of ecological agriculture on agricultural production, economy and social sectors. That study (Bassi e al., 2010) believes that investments in ecological agriculture such as water efficiency practices and biofuel can sustain agricultural production, leading to sustainable growth of economic and social sectors.

Other SD studies explain that climate change is projected to reduce water supply in Turkey (Koca \& Sverdrup, 2012) and in Mexico (Huerta, Esquivel-Longoria, ArellanoLara, Dominguez-Ruiz, \& Rosales-Flores, 2011). Those studies conclude that a lower water supply could negatively affect agricultural production, employment and industry. However, those studies (Huerta et al., 2011; Koca \& Sverdrup, 2012) offer a preliminary 
concept ${ }^{15}$ in understanding the impacts limited water supply owing to climate change on some issues such as agricultural production and social sectors.

In addition, some SD studies explore impacts of climate on the agrifood supply chain uncertainty. One study (Kumar \& Nigmatullin, 2011) claims that coordination among supply chain parties is needed to decrease demand uncertainty on the food supply chain. That study (Kumar \& Nigmatullin, 2011) shows that lead time and demand uncertainty in the third phase of the agrifood supply chain (similar to the third phase of the rice supply chain based on Hasan's study, 2010) are management issues.

Another study claims that due to droughts, the sheep slaughter rate tends to increase, providing a higher meat supply and a lower meat price (Adl \& Parvizian, 2009). In turn, a higher meat price will occur in subsequent seasons because of a lower stock of sheep. In this case, providing meat stock can be a suitable way of sustaining affordable meat price (Adl \& Parvizian, 2009).

This section shows that the SD approach has been applied in multiple cases such as climate change, ecological agriculture and the agrifood supply chain. Although previously cited SD studies successfully explain a range of subjects such as climate change and supply chain uncertainty in the agrifood supply chain, none of those studies discuss the effects of climate change on the rice supply chain, a staple food for more than a half world population (Gnanamanickam, 2009; GRisP, 2013).

In the next section, some studies using the SD approach are explained. In particular, those studies in the next section use a relatively simply limited mathematical expressions in measuring agricultural production.

\subsubsection{System dynamics studies: measuring crop/agricultural production}

The SD approach may involve labour and capital (Haghighi, 2009) or involve labour, capital and climate (Kopainsky et al., 2013) in estimating agricultural production. Other studies such as Dudley (2012), Li, Dong and Li (2012) use linear models ${ }^{16}$ in estimating

\footnotetext{
${ }^{15}$ Huerta et al., (2011) only forecasts reduced rainfall and Koca \& Sverdrup (2012) only provides a causal loop diagram

${ }^{16}$ Linear models in this context is models with linear time variable (representation of the technological progress)
} 
crop production. Although those studies might successfully estimate crop production, they have limitations which are outlined by the following paragraphs.

A study (Kopainsky et al., 2013) assessed the impacts of climate change on multiple sectors such as agricultural production and social sectors. That study argues that the impacts of climate change on agricultural production will plague the improvement in social sectors. That study also combines statistics and the SD approach in assessing the impacts of climate change on multiple sectors. A possible improvement to enhance the output of that study is to include the impacts of minimum temperature on agricultural production as IPCC (2013) projects that increase in minimum temperature is far higher than increase in maximum temperature.

Dudley (2012) explores the effects of African droughts on sorghum and maize. In normal years (without droughts), farmers prefer to sow maize as it has a higher yield and a higher price than sorghum. But when droughts occur, farmers tend to sow sorghum as it more drought tolerant than maize. Dudley (2012) suggests that the government should encourage farmers to sow sorghum instead of maize to sustain food security. That study (Dudley, 2012) assumes that outputs of that study are robust under differently future climate. That assumption leads to further suggestions in enhancing outputs of that study. The first suggestion is that study should include temperature as a climate output to get better insights or outputs. The second suggestion is that study should use different RCP scenarios to represent more various future climate.

Two studies (Haghighi, 2009; Shahbazbegian \& Bagheri, 2010) assess the interaction between agricultural sectors and other sectors. Haghighi (2009) recommends that the Iranian government should combine some policies such as improving agricultural technologies and increasing non-agricultural industries to stabilise employment between rural and urban areas. Although that study (Haghighi, 2009) suggests that the impacts of climate are important that study did not explicitly include climate inputs such as temperature. This is important as that study (Haghighi, 2009) investigated the interaction in a relatively long period i.e. by 2027 , suggesting that the role of climate should be considered.

Another study by Shahbazbegian \& Bagheri (2010), claims that highly agriculturallydependent regions in Iran should diversify their targeted yield, leading sustainable 
agricultural production. This is important given that agricultural production can affect social issues such as income and migration. Although that study (Shahbazbegian \& Bagheri, 2010) suggests that agricultural production is highly important as agricultural production can affect social issues such as income and migration that study did not consider the effects of other factors that may increase or affect agricultural production such as production factors and climate.

The system dynamics approach can also be used to evaluate ecological agriculture, the concept that balances economic and ecological benefits (Li et al., 2012; Ibáñez, Martínez-Valderrama, Taguas, \& Gómez, 2014). For instance, another study (Li, Dong \& $\mathrm{Li}, 2012$ ) applies the SD approach to study ecological agriculture in China. That study explains how agricultural production induces interaction between economy, industry and $\mathrm{CO}_{2}$ emission. That study ( $\mathrm{Li}$ et al., 2012) should consider the effects of climate on crop production as that study seek the interaction (agriculture, industry and $\mathrm{CO}_{2}$ emission) in a relatively long period (by 2050). It should be noted that by 2050, there will possibility of increased temperature under a changing climate.

System dynamics is also used to explain the impacts of soil erosion on olive growth in Spain (Ibáñez et al., 2014). That study (Ibáñez et al., 2014) explains that olive yield might be positively affected by rainfall through soil moisture. The positive effects of soil moisture might be hampered by soil erosion. Although that study seeks the long term effects, that study did not consider the effects of temperature on dryland olive yield.

Studies explained in this section have a feature to measure agricultural production. However, compared to statistical models or crop models, studies in this section did not consider the roles technological progress, the effects of climate (combining temperature and rainfall) and the effects of production factors on crop or agricultural production simultaneously.

\subsection{Research gaps and contributions of this study}

Section 2.3 explains limitation of existing studies mostly in terms of individual studies. This section aims to explain general understanding of existing studies and how this study fulfil research gaps explained in existing studies. 
Existing studies (Hasan, 2010; Thongrattana \& Jie, 2010) agree that supply uncertainty in the rice supply chain is highly important. But, those studies did not consider the impacts of temperature (Hasan, 2010) or did not empirically measure the impacts of climate change on the rice supply chain (Thongrattana, 2012; Thongrattana \& Jie, 2010).

Most studies applying crop models can estimate the impacts of climate change in longer periods (for example by 2050 or by 2100 ). Crop models also can modify crop genetics variables to assess possible options such as heat tolerant varieties in tackling the negative impacts of climate change on crop yield. However, crop models did not consider the effects of climate change on harvested areas.

Furthermore, existing studies using statistical models successfully investigate the impacts of climate change on crop production across the world. With limited data compared to crop models, statistical models can investigate the impact of climate change on crop yield. However, the application of statistics in understanding the impacts of climate change on crop yield can be challenged when known impacts of climate change in literature are not observable.

The system dynamics approach as an alternative method offers some features to compromise limitations and strength of crop models and statistical models. As explained earlier, some studies can assess possible solutions in tackling the impacts of climate change on agriculture or the water system. System dynamics studies (Haghighi, 2009; Shahbazbegian \& Bagheri, 2010; Ibáñez et al., 2014, Li et al., 2012) also can be combined with statistics to assess relationships given by the observed data. Where data is limited or statistics cannot capture important relationship, the SD models use knowledge or literature to estimate the relationships (Ibáñez et al., 2014). The system dynamics approach also can be used to assess the multiple outputs. For instance, the impacts of climate change on multiple outputs such as agriculture and income are explained in studies (Bassi et al., 2010; Kopainsky et al., 2012; Li et al., 2012).

A main insight from all of SD studies is those studies remind us that understanding the climate change impacts crop production is highly important. However, existing studies 
using the SD approach such as Ibáñez et al. (2014) and Li et al. (2012) did not explore the effects of climate and production factors on crop production.

Again, regardless their approaches, those studies have a main limitation. That is, there is not an integrated study that explores the varied impacts of climate change on rice production including the impacts of climate change on rice yields, the impacts of climate change on the timing of monsoon onset, and the impacts of climate change on harvested areas.

This study is similar to Hasan's study (2010) in that it explores the impacts of climate change on rice production. This study, however, offers three further contributions. Because none of the system dynamics studies investigate the impacts of climate change on rice production, this study makes the first such contribution. That is, to combine the system dynamics and statistical modelling in assessing the impacts of climate change on the rice production.

While another system dynamics study explore the impacts of droughts and floods (Hasan, 2010) on the rice supply chain, this study investigates climate change impacts on rice production (the upstream of the rice supply chain) owing to rainfall and temperature change based on plausible RCP scenarios. Because some studies using crop models assess the impacts of climate change on crop production with constant harvested areas eg. (Deryng et al., 2011; Deryng, 2014; Müller, 2015), the third contribution of this study is to investigate the impacts of climate change on rice production without assuming constant harvested areas.

This study also will be useful in understanding the impacts of climate change in other geographical locations. As rice is a staple food for more than half of the world's population, this study will give some insights into the impacts of climate change outside West Nusa Tenggara. Across the world, rice farming is separated into two categorises namely dryland and wetland rice. Hence, since this study separates the impacts of climate change on dryland and wetland rice, this study features such as research design and statistical models can be applied into other regions across the world. 
In addition, the three contributions of this study will provide more information on minimising impacts of climate change on rice production in other regions. For instance, proposed options for overcoming the impacts of climate change on rice production in West Nusa Tenggara may be applied in other regions.

\subsection{Summary}

This chapter dealt with theoretical concepts of climate change, climate variability and optimum conditions for rice growing. Other theoretical concepts such as supply uncertainties and Indonesian climate were also described.

This chapter also outlined important points relating to this research, such as wetland and dryland rice-growing practices in WNT. The planting seasons in WNT usually start in the third quarter (September-December) whilst the first quarter (January-April) is typically the harvesting season. Statistics regarding the two farming types, wetland and dryland, were also detailed in this chapter, as well as details of the planting seasons. Data regarding rice varieties was also highlighted.

This chapter also overviewed existing studies in three fields: system dynamics, statistical models and crop models. It also compared the application of statistical models and crop models in assessing the impacts of climate change on crop production. Furthermore, the application of system dynamics in assessing the impacts of climate change were explained. This chapter also described limitations of existing studies.

This study aims to address limitations of existing studies, leading to filled research gaps explained in the end of chapter. Because the second phase of the rice supply chain (i.e the rice farming area) is the most vulnerable to climate change (Hasan, 2010), this study focuses on the impacts of climate change on rice yield, rice production and harvested areas. Likewise, since wetland and dryland farmers have different practices such as different varieties and different water requirement. Hence, this study investigates the impacts of climate change on the second phase of the rice supply chain, assessing the impacts of climate change on wetland and dryland rice separately. 
this page intentionally left blank 


\section{CHAPTER 3 RESEARCH DESIGN}

The main aim of this chapter is to explain the modelling approach used in this research. This chapter begins by describing the research paradigm and following this, data collection and data analysis are explained. Later, the contributions of this study are described, as well as a step-by-step methodological approach to obtaining an appropriate statistical model combining climate and production factors. Finally, a detailed description of the research method - the system dynamics approach - is offered.

\subsection{The research paradigm and method}

The research paradigm applied in this study is based on the system dynamics philosophy. That philosophy holds that, to gain in-depth understanding of the real world, the world must be studied as a feedback structure, leading to correct results or appropriate understanding of real world behaviour (Sterman, 2000). This is important as real world behaviour arises from interactions among components of the real world (Sterman, 2000).

The feedback structure is an important foundation of system dynamics (Forrester, 1961; Richardson, 2011) as it allows users to analyse and modify the internal structure of the system dynamics model as well as to explore the model's behaviour. In the context of this study, system dynamics can determine interactions among components of rice farming, such as production factors and climate. As interactions among components are visible, system dynamics can explain how climate change affects the rice production and how the negative impacts of climate change can be minimised.

The system dynamics model is constructed based on scientific process to obtain statistically significant findings and to generalise the findings without bias. This means that the feedback structure is based on a scientific method so that it can be categorised as a positivistic approach. 
In order to construct the feedback structure, the case study of West Nusa Tenggara will be used. The aim of the case study is to gain an in-depth understanding of real world behaviour through documentation such as historical data, observations and artefacts (Merriam, 1998). Again, according to Sterman (2000) and Saeed (1992), empirical evidence such as historical data and observations can provide guidelines for reproducing the feedback structure as a reliable representation of the real world.

\subsection{Data gathering}

Table 3.1 shows climatic and non-climatic data collected from relevant institutions. Climatic and non-climatic data are needed to obtain statistical equations determining the impact of climate change on rice production. For example, temperature, rainfall and production factors will be aggregated to obtain the impact of climate change on rice yield.

Historical climate data such as rainfall and temperature was collected from BMKG, the Indonesian Bureau for Climatology and Geophysics. Observed rainfall and temperature was collected as monthly climate data for the period 1971-2011. Data regarding production factors such as fertiliser and seed was collected for the period 1976-2011. The latter was collected from BPS, the Indonesian Bureau for Statistics.

Data regarding rice yield, rice production and harvested areas was also collected from BPS. This data was collected as annual data (January-December) and seasonal data (September-August). The seasonal data means data between September in year $t$ and August in year $t+1$. Other important agricultural data is available land and new farming land which was collected from the agricultural institution in West Nusa Tenggara. Moreover, to measure the impacts of sea level rise on West Nusa Tenggara, data regarding the impacts of sea level rise was collected from the Indonesian Ministry of Environment.

Although data availability was good, there were difficulties in data gathering. The first difficulty was the complex Indonesian bureaucracy. This means that that some specific procedures to collect data such as registering the research, collecting the supporting letters and presenting of the research proposal are required. The second difficulty is most 
data is kept as hard copies, as the Indonesian government offices do not maintain database files and do not publish data online, especially for data up to 2010. As data gathering passed some procedures such as quality control and data checking, data accuracy and data reliability is good. BMKG and BPS conducts some procedures to ascertain data reliability such as repeated data sampling.

In this study, climate projections from some climate models were collected from New Zealand's National Institute of Water and Atmospheric Research (NIWA), from their archive of output from the CMIP5 suite of GCM simulations. Climate projections to the year 2100 were collected to estimate the impacts of climate change on the rice production.

\section{DATA AND INSTITUTIONS}

1. BMKG (Meteorology Climatological and Geophysics Agency)

a. historical data of monthly rainfall and historical data of temperature (for the period 1971-2011)

2. The Indonesian Ministry of Environment

a. The impacts of sea level rise on WNT

3. BPS (Indonesia's Statistics Agency)

a. Rice yield, rice harvested areas and rice production

b. Production factors (labour, seed, pesticide, fertiliser, capital) in the rice farming (for the period 1976-2011)

4. Agricultural Institutions

a. Division of General of Agricultural Infrastructure Fertiliser use, pesticide use, seed, machinery in farmers Available farming land, new farming land (All data for the period 1976-2011)

5. Future climate projections from NIWA (http://cmippcmdi.llnl.gov/cmip5/data portal.html) Projections of temperature, rainfall and southern oscillation index until 2100 (Global Climate Model outputs from GFDL-ESM2G, GFDL-ESM2M, IPSL-CM5A-LR, IPSLCM5A-MR and NorESM1-M.

Table 3.1 A list of required data

\subsection{Homogeneity Issues}

This section explains some homogeneities and heterogeneities in this study. Some homogeneities explained in this section are farming practices and climate. The section 
also discusses farming type as a possible heterogeneity in this study. Furthermore, it describes the way in which system dynamics can be used to combine possible homogeneities and heterogeneities to resemble rice farming behaviour under climate change.

In this study, there are several homogeneities relating to the agricultural system. Firstly, farmers tend to apply similar farming practices. The local government of West Nusa Tenggara provides the training of agricultural management, such as farming and rice milling practices. As this region has a low human development index ranking (BPS, 2014), farmers tend to have limited information and limited funding to acquire better farming practices, leading to the application of farming practices offered by the government. This means that farmers tend to have similar agricultural practices. In this study, farming practice similarities may include the use of similar rice varieties or similar tractor characteristics.

Secondly, all parts of West Nusa Tenggara have similar climate characteristics. For example, all parts have about 3-4 wet months and 6-9 dry months. To capture any possible heterogeneity, Lobell \& Burke (2010) suggest that statistical models can be used to assess the impacts of climate change on rice yield where different types of agricultural management may be practised by farmers.

\subsection{A methodological approach to obtain a statistical equation}

A number of studies have employed parametric and non-parametric models to examine the impacts of climate change on crop yield. Many studies have used non-parametric models such as regression trees and the neural network to estimate the impact of climate on crop yield. For example, Lobell, Ortiz-Monasterio, Asner, Naylor, and Falcon (2005) applied regression trees to estimate the impact of climate on wheat yield variability. That study was able to capture a non-linear relationship between management practices and wheat yield variability. Another study (Khairunniza-Bejo, Mustaffha, \& Ismail, 2014) explains that the artificial neural network (ANN) can capture any non-linear association between production input and crop yield. 
Although non-parametric models might capture the impact of climate on crop yield, those models have some shortcomings. The first shortcoming is that non-parametric models do not allow scientists to extrapolate away from the samples (Horowitz, 2009; Kvam \& Vidakovic, 2007). The second shortcoming is that non-parametric models are relatively difficult to be displayed or to be communicated to readers (Horowitz, 2009; Matzkin, 1994). Likewise, parametric models should be used instead of non-parametric models if observed data is sufficient, data behaviour can be easily predicted, and statistical assumptions are fulfilled (Horowitz, 2009).

For the reasons outlined above, this study applies a parametric model to estimate the impacts of climate change on crop yield. A parametric model (i.e. a statistical model) is easy to interpret and is more appropriate if the models pass statistical assumptions. Again, other forms such as regression trees and neural networks should not be used as long as all mathematical relationships between input (climate and production factors) and output (rice yield) can be measured appropriately (Horowitz, 2009; Kvam \& Vidakovic, 2007).

There are three frequent forms of parametrically statistical equations or parametrically statistical models to estimate impacts of climate change on rice yield (Lobell \& Burke, 2010a). The first functional form is a log-linear model (Gomez \& Iglesias, 2005; Lee, Nadolnyak \& Hartarska, 2012; Lobell, Schlenker \& Roberts, 2011). The second is a model with time variables (Lobell, Bonfils \& Duffy, 2007; Lobell \& Burke, 2008; Lobell \& Burke, 2010a; Wang, Chang, Lu, Chang \& Tan, 2012). The third is a first differencing model. These models may contain two variable types, namely: climate and production factors or production inputs (Lobell \& Burke, 2010).

Time series are not usually stationary (Greene, 2003; Gujarati, 2004; Baltagi, 2008). The main objective of using either the first differenced models or models with time variables is to ascertain that the models are stationary (Lobell \& Burke, 2010). Non-stationary data tends to result in spurious regression (Greene, 2003; Gujarati, 2004; Baltagi, 2008).

Sometimes, after differencing or adding time variables, models might have a heteroscedasticity issue (Lobell \& Burke, 2010). To overcome this heteroscedasticity issue, transforming crop yield i.e log-linear models into log might heal a heteroscedasticity issue (Lobell \& Burke, 2010). 
A model of the first-difference method is a model that employs the first differenced variables: the first differenced independent and the first differenced dependent variables. Differing from a model with time variables, a first-differenced model explains crop yield without significant technological progress. A model with time variables is a model employing at least one time variable as an independent variable. The application of a model with time variables stems from the fact that crop yield may be increased by technological progress. Hence, time variables as independent variables represent technological progress in crop yield.

Some studies apply time variables as a representation of technological progress (Lobell $\&$ Burke, 2010). Time variables are representations of the impact of technological progress on crop yield. In general, scientists include time variables to capture the impact of technological progress based on historical data, and then the impact of technological progress is applied in assessing the future impact of climate change.

By implementing both equations (a model with time variables and a model of the first difference method) this study can assess whether the impacts of technological progress on rice yield is significant or not. The application of both models also helps to find models that pass some statistical assumptions such as auto correlation and heteroscedasticity.

Both statistical models may include production factors such as fertiliser (Ambarinanti, 2007), seed, capital and labour (Mariyono, 2009), and climate factors such as rainfall and temperature (Lobell et al., 2007; Lobell \& Burke, 2008; Lobell \& Burke, 2010; Wang et al., 2012). Moreover, this study assumes that the variability of rice yield, rice production and harvested areas is caused by climate but not vice versa (Lobell and Field, 2007). This study also applies multiple regressions subject to the ordinary least squares method (Gujarati, 2004; Lobell \& Burke, 2010; Greene, 2003).

Figure 3.1 outlines some statistical tests that will be applied to validate both models. Assessing the models or equations aims to clearly prove that equations capture the essence of the subject under study (Gujarati, 2004). These models are the best equations or the best models if, and only if, they pass statistical tests such as significant predictors, high adjusted $\mathrm{R}^{2}$, autocorrelation, and heteroscedasticity (Gujarati, 2004; Stark, 1997). Statistical models can also be labelled as the best models if they conform to the 
appropriate theoretical backgrounds (Gujarati, 2004; Stark, 1997). Some steps in finding appropriate statistical models are summarised as follows:

1. Embedding all possible predictors and including squared climate variables if necessary. For a model with time trends, including squared climate variables if observed climate includes any climate threshold. Eliminating the least significant predictors (predictors with the highest p-values) and stop eliminating the predictors when the information criterion values (AIC=Akaike Information Criterion or SIC=Schwarz Information Criterion) tend to increase (Baltagi, 2008; Greene, 2003);

2. Conducting Step 1 for both models, i.e. a model of the first differenced variables and a model with time variables (a model with a time trend);

It should be noted that this study applies the general to simple model approach (Greene, 2003) as it leads to the correct of specification model at the end of procedure (Greene, 2003; Quiroga \& Iglesias, 2009). This is a common approach in modern analysis and the most commonly used approach according to Greene (2003, p. 583).

3. Obtaining residuals from tentative models to apply some statistical tests such as normality test, autocorrelation and heteroscedasticity. If models pass normality test (Jarque-Bera), heteroscedasticity (White test); autocorrelation (BreuschGodfrey serial correlation), multicollinearity and a goodness of fit (F-test) then the models adequately represent relationships among rice yields and independent variables (Gujarati, 2004).

Statistical models used in this should fulfill normality assumptions so that F-tests can be used to assess the model performance (Greene, 2003; Gujarati, 2004). Statistical models should fulfill a homoscedasticity assumption (homoscedasticity relates to constant variance while heteroscedasticity relates to changing variance) and should have no correlated predictors - no multicollinearity (Greene, 2003; Gujarati, 2004; Lobell \& Burke, 2010). Autocorrelation test is needed as data used in this study is time-order (Greene, 2003; Gujarati, 2004). No serial correlations means that residual are not correlated (Greene, 2003; Gujarati, 2004). 
If models violate serial correlation tests, then lagged predictand should be a predictor (Gujarati, 2004) and when models violate heteroscedasticity, Lobell and Burke (2010) suggest to change linear predictand (crop yield) to log crop yield. Please note that models assessed in this study are Generalised Linear Model (GLM) and statistical models follow normality assumption can be categorised as a special case of GLM (Guisan, Edwards, \& Hastie, 2002).

4. The best models should also conform to appropriate theoretical backgrounds (Stark, 2007; Studenmund, 2005).

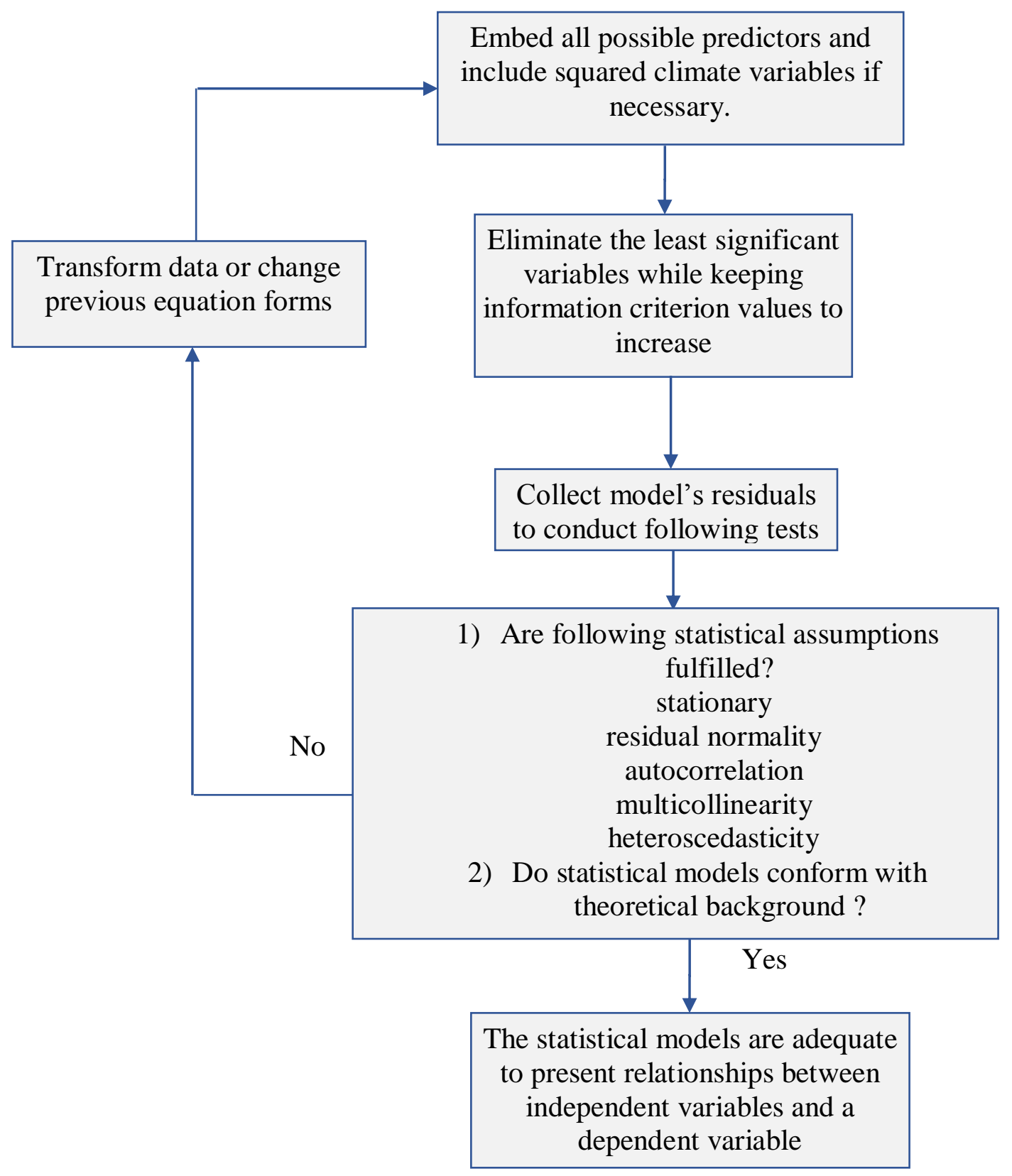

Figure 3.1 Some steps for obtaining appropriate statistical models 


\subsection{System dynamics as a research method}

System dynamics relates to the interaction of the elements of a system in time and captures the dynamic aspects of its main concepts such as stock and flow as well as feedback and delay (Sterman, 2000; Maani \& Cavana, 2007). Hence, system dynamics can be seen as a set of conceptual tools that help us to understand the structure and dynamic of complex systems. Because of this, system dynamics has been successfully applied in different disciplines to build a deep understanding of the behaviour of elements in some systems such as supply chain, climate change research and organisational issues with a variety of policy interventions (Sterman, 2000).

The system dynamics model will be simulated using Vensim@ $\bigodot$. Computer simulation is a useful tool to study the behaviour of complex systems (Sterman, 2000; Maani \& Cavana, 2007). Furthermore, the computer simulation is a compromised way in which to understand real world patterns, as real world experiments may be difficult to conduct (Sterman, 2000) ${ }^{17}$. Other benefits of applying the system dynamics approach include catching effects of delay such as the effect of delayed monsoon onset, as well as capturing non-linear relationships such as the effect of rainfall on the timing of monsoon onset.

Moreover, system dynamics also focuses on understanding the causes and effects that are expressed by the relationship between stocks (levels) and flows (rates). In system dynamics models, dynamics are a function of initial conditions and structures of the models (Myrtveit, 2005).

Figure 3.2 depicts some steps involved in constructing a system dynamics model (Saeed \& Meadows, 1994; Maani \& Cavana, 2007). The first step is to employ problem structuring methods such as identifying problems, time horizon and key variables. This stage starts by reviewing literature in the fields of system dynamics, climate change and supply uncertainties. Several existing studies are deeply reviewed to develop problem structuring methods. Following that, data such as climate variables, production factors

\footnotetext{
${ }^{17}$ A possibly main weakness of simulation models is transferring our understanding of the real world into a computer simulation. It is caused our understanding on real world usually on "events" not in systemic perspective or mental model (Maani \& Cavana, 2007). Another weak point is difficulty in examining decision rules/soft variables/model boundary (Sterman, 1991).
} 
and rice yield is collected to gain an understanding of the impact of climate on the rice supply chain. The results of this stage will later be used to estimate the future behaviour within the rice farming areas.

Some key themes on the impacts of climate change on the rice production are explored in chapter 2. Furthermore, in chapters 4 and 5, analysis of observed climate and analysis of the impacts of climate change on rice yield is offered.

The next step is to construct a dynamic hypothesis based on a summary of historical information or decision rules used by actors in the system (reference modes). This is called dynamic hypothesis as it may change along the modelling process (Sterman, 2000). In this step, a boundary system (a boundary model) should be constructed to capture all important feedbacks. This step also builds endogenous and exogenous variables within the observed system, leading to a causal loop diagram (CLD) and a stock flow model. In case there is important feedback relating to exogenous variables, a system boundary should be expanded. In short, a boundary model can in fact reproduce the observed system and answer research questions appropriately.

Chapter 6 contains a boundary model, and a list of endogenous and exogenous variables would not explain relationships among these variables. Hence, a CLD should be constructed to explain relationships among these variables. This diagram does not only display causal links among variables but also the effect, including negative or positive effects among variables.

Based on this CLD, a stock flow model is developed. In a stock flow model, a stock may accumulate materials such as a population and product inventory. To distribute a stock, a flow should be constructed to either decrease or increase any stock. As a stock flow model also explains mathematical relationships among the variables in the observed system, it is called a virtual model of the observed system.

Since the virtual model is constructed, the model is validated based on reference modes. If the model does not imitate real world behaviour, then the model structure is restructured and modified, if necessary. The virtual model is labelled a valid representation of the real world if there is a close correspondence between the real world 
and the virtual model (Bell and Senge, 1980; Forrester and Senge, 1980; Richardson and Pugh, 1984; Sterman, 2000).

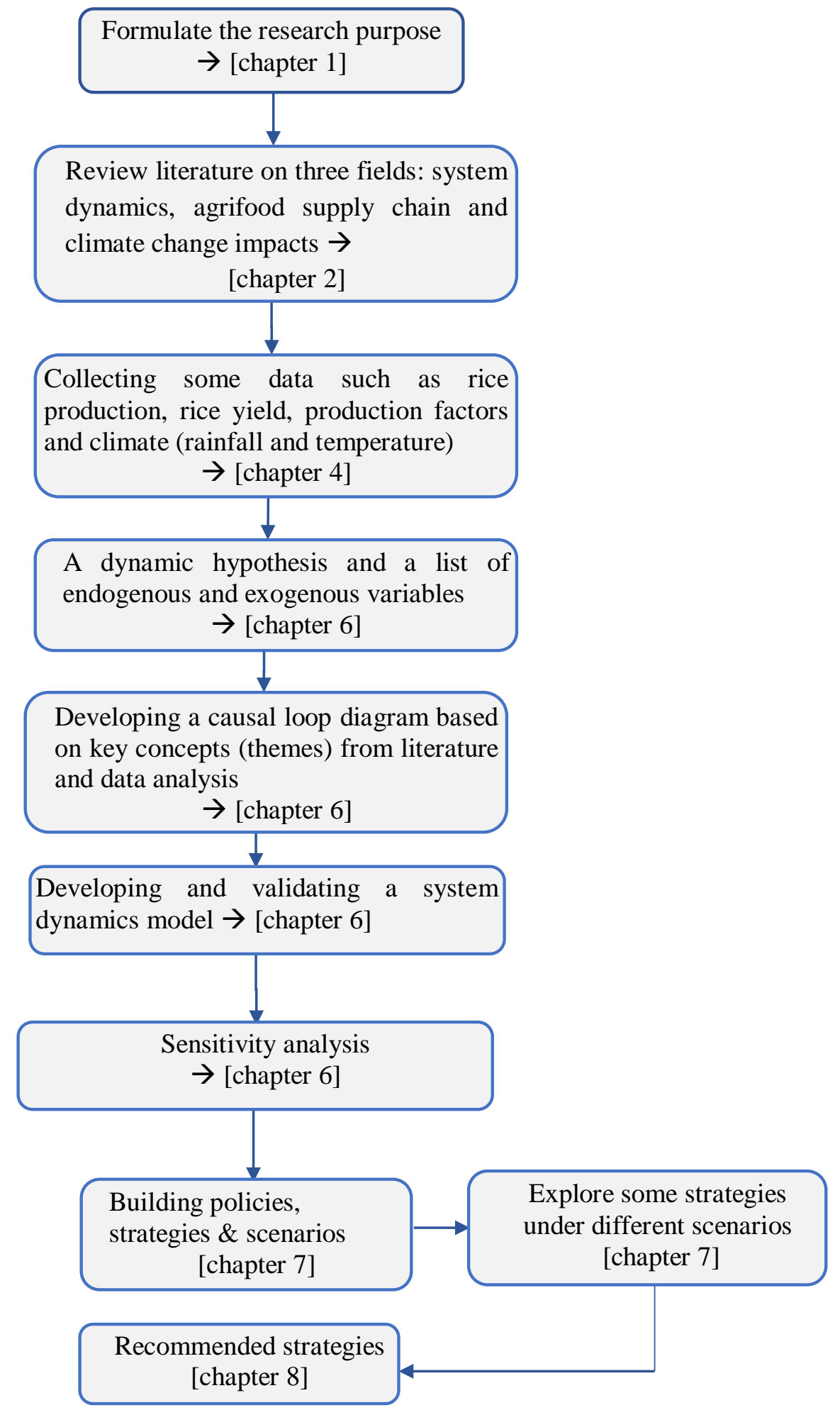

Figure 3.2 Some steps in developing a system dynamics model 
Forrester and Senge (1980) offer some validity tests for increasing confidence in the system dynamics models. The tests categorise some key areas for assessing the system dynamic models, namely model structure, model behaviour and policy implications. Validation of model structure examines whether model structure matches the structure of the real world i.e. models should correspond with relevant existing studies, and validation of model behaviour examines similarities between model behaviour and behaviour in the real world. In this study, MAPE (Mean Absolute Percentage Error) is used to compare system dynamics model outputs and observed system outputs.

After a validated system dynamics model is built, strategies based on policy and sensitivity analysis will be constructed in chapter 7. This aims to verify that models are beneficial for the policy makers. Following that, some strategies are constructed to find options for minimising the impact of climate change.

Maani and Cavana (2007) suggest developing scenario planning and modelling after a virtual model or dynamic model is constructed. In this phase, various policies and strategies are tested. Changing an internal variable is called a policy and some policies can be united as strategies. Furthermore, scenario modelling means assessing some strategies under some external conditions. Following this, some conclusions after simulating given strategies are summarised in chapter 8 .

\subsection{Summary}

This chapter has explained some issues regarding research designs, such as research paradigm, data gathering and research methodology. The research paradigm explains that system dynamics, a research method used in this study, is similar to the positivistic approach.

Existing studies in system dynamics and climate change impacts have also been summarised. The latter highlighted the contributions made by this study. Finally, a methodological approach to obtaining statistical equations and to constructing a system dynamics model was described. Some steps to obtaining appropriate statistical models were explained accompanied by statistical tests to assess statistical model performance. 
Steps in constructing a system dynamics model were given, and the role of policy and strategy simulation in finding appropriate solutions for minimising the negative impacts of climate change was also explained. 
this page intentionally left blank 


\section{CHAPTER 4 WEST NUSA TENGGARA: A CASE STUDY}

\subsection{Introduction}

Because rice is the most important food in Indonesia, the Indonesian government has implemented several programs to boost rice production since the 1970s. In early 1980, the government implemented Bimas (Bimbingan Masyarakat $=$ Society Guidance) and Insus (Intensifikasi Khusus = Special Intensification) which both aim to increase farmers' agricultural skills. Since most farmers are from the lower socio-economic classes, the government has also provided some subsidies such as seed, fertiliser and pesticide. In the 1990s, the government introduced IPM (Integrated Pest Management) which aimed to reduce pesticide consumption, leading to environmentally friendly agricultural practices. Since 2008, the government has implemented the Program of National Rice Production (P2BN). This program aims to assist farmers with subsidies such as fertiliser and seed.

As one of the national rice buffers, West Nusa Tenggara (WNT) is expected to contribute a rice surplus of more than 70,000 tonnes of dried rice, equal to 40,000 tonnes of rice per year (the WNT Agricultural Office, 2008). However, WNT might not fulfil this target if some aspects associated with climate change such as higher temperatures and sea level rise negatively affect the rice production. Therefore, understanding the impacts of climate change on rice production is highly valuable.

This chapter highlights some points relating to climate change issues, such as the importance of agriculture in WNT and detection of climate change. The Mann-Whitney test and the Levene test will be used, respectively, to detect changes in climate mean and climate variability.

\subsection{Research background: West Nusa Tenggara at glance}

Figure 4.1 below shows two maps: Indonesia and West Nusa Tenggara. As shown in figure 4.1a, Indonesia consists of 33 provinces: from Aceh in western Indonesia to Papua 
in eastern Indonesia. West Nusa Tenggara is located in southern Indonesia, close to Bali and East Nusa Tenggara.

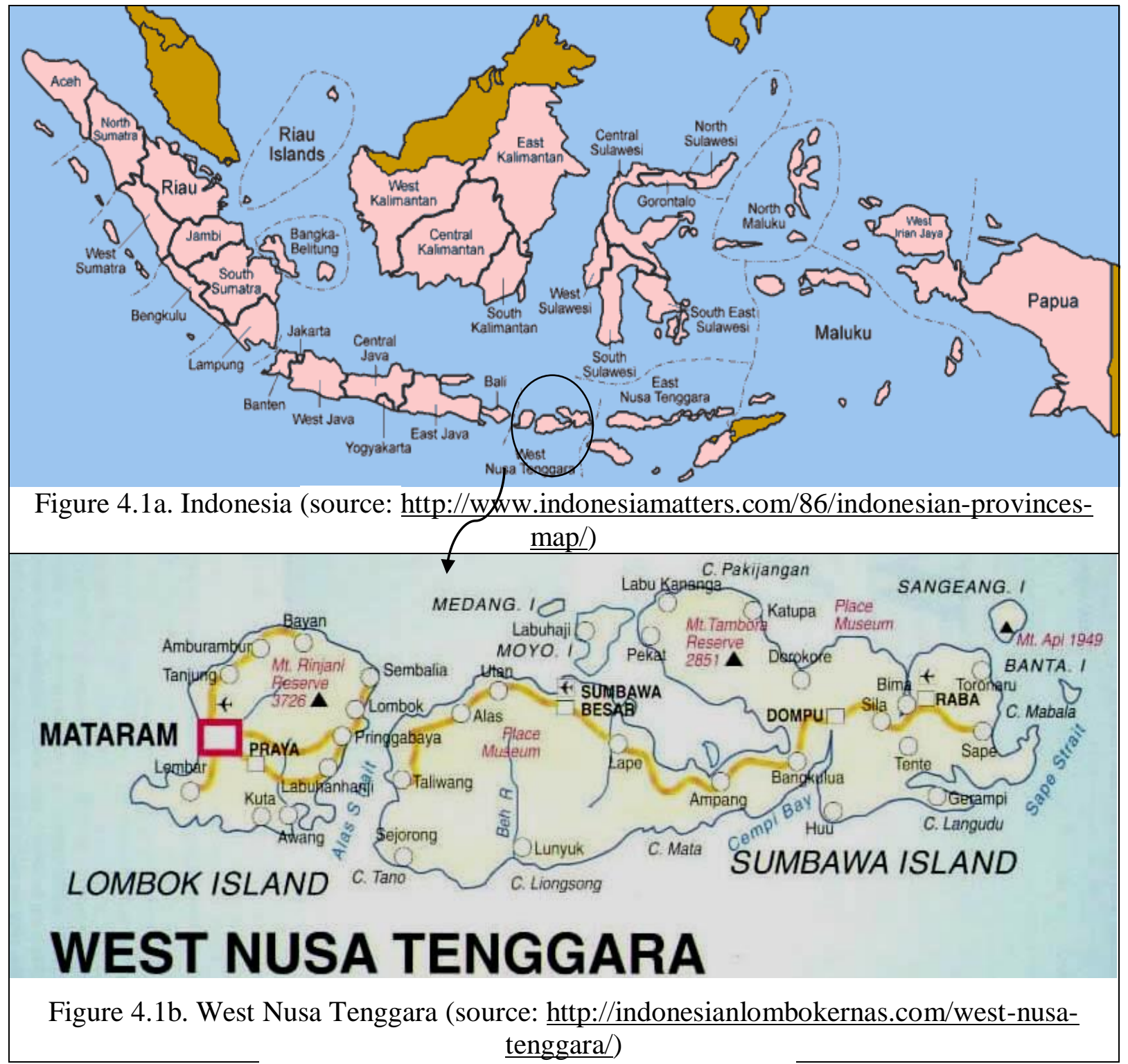

Figure 4.1 Indonesia and West Nusa Tenggara

Figure $4.1 \mathrm{~b}$ shows that WNT consists of two main islands, Lombok and Sumbawa. This region is located in eastern Indonesia at $115^{0} 46^{\prime}-119^{0} 5^{\prime}$ East Longitude and $8^{0} 10^{\prime}-9^{0}$ 5' South Latitude (BPS NTB, 2010). The average maximum temperature ranges from $30^{\circ} \mathrm{C}$ to $32^{\circ} \mathrm{C}$ (the highest temperature is in November), while the minimum temperature varies on average between $21^{\circ} \mathrm{C}$ and $25^{\circ} \mathrm{C}$ (the lowest temperature is in June or July). The maximum temperature in the rainy seasons is about $31^{\circ} \mathrm{C}$, whereas the minimum temperature in the rainy seasons is about $22^{\circ} \mathrm{C}$. The relative humidity is between $74 \%$ 
and $81 \%$ with the annual rainfall approximately $1,600 \mathrm{~mm}$. Some years, annual rainfal can reach about $2,100 \mathrm{~mm}$.

The wet season usually occurs between October and March, while the dry season usually occurs between April and September. Most rice, about $65 \%$ of the total rice areas, is usually planted between November and December, so that the greatest harvesting period is between February and March.

\subsubsection{Statistics of WNT}

Table 4.1 shows rice production and productivity in WNT and Indonesia as an aggregate of wetland and dryland. Generally speaking, rice production, area harvested, and productivity have increased over time. It also appears that an increase in rice production is caused by higher productivity and new farming land. Although WNT has a small fraction $(3 \%)$ of rice production, compared to the total Indonesian rice production, WNT is a main rice supplier for its closest regions as explained in the following paragraph. Furthermore, a t-test shows that average productivity in WNT and Indonesia is statistically different $(t(10)=3.43, p<.01)$.

\begin{tabular}{|c|c|c|c|c|c|c|}
\hline Year & $\begin{array}{c}\text { WNT } \\
\text { (Rice } \\
\text { Production in } \\
\text { Million } \\
\text { Tonnes) }\end{array}$ & $\begin{array}{c}\text { Indonesia } \\
\text { (Rice } \\
\text { Production in } \\
\text { Million } \\
\text { Tonnes) }\end{array}$ & $\begin{array}{c}\text { WNT } \\
\text { Area } \\
\text { Harveste } \\
\text { d (1000 } \\
\text { Ha) }\end{array}$ & $\begin{array}{c}\text { Indonesia } \\
\text { Area } \\
\text { Harvested } \\
(1000 \mathrm{Ha})\end{array}$ & $\begin{array}{c}\text { WNT } \\
\text { Productivi } \\
\text { ty } \\
\text { (Tonnes/H } \\
\text { a) }\end{array}$ & $\begin{array}{c}\text { Indonesia } \\
\text { Productivit } \\
\text { y } \\
\text { (Tonnes/H } \\
\text { a) }\end{array}$ \\
\hline 2014 & 2.08 & 70.61 & 430 & 13,768 & 4.84 & 5.13 \\
\hline 2013 & 2.19 & 71.28 & 438 & 13,835 & 5.0 & 5.15 \\
\hline 2012 & 2.11 & 69.06 & 425 & 13,445 & 4.97 & 5.14 \\
\hline 2011 & 2.06 & 65.76 & 418 & 13,204 & 4.95 & 4.98 \\
\hline 2010 & 1.77 & 66.47 & 374 & 13,253 & 4.74 & 5.02 \\
\hline 2009 & 1.87 & 64.40 & 374 & 12,884 & 5.00 & 5.00 \\
\hline 2008 & 1.75 & 60.32 & 360 & 12,327 & 4.87 & 4.89 \\
\hline 2007 & 1.52 & 57.16 & 332 & 12,148 & 4.60 & 4.71 \\
\hline 2006 & 1.55 & 54.45 & 341 & 11,786 & 4.55 & 4.62 \\
\hline 2005 & 1.37 & 54.15 & 300 & 11,839 & 4.55 & 4.57 \\
\hline 2004 & 1.47 & 54.10 & 326 & 11,923 & 4.50 & 4.54 \\
\hline
\end{tabular}

Table 4.1. Data rice production, area harvested and productivity (BPS, 2006-2014)

Table 4.2 shows rice surplus in WNT and WNT's closest regions: Bali and East Nusa Tenggara (ENT). WNT has a large rice surplus about 411,060 tonnes, while Bali has limited rice-surplus of around 7,170 tonnes. Bali may experience a rice deficit, if rice demand for Bali's industry is also calculated. The rice surplus provinces such as WNT 
should distribute their rice surplus to their closest regions in order to reduce the rice distribution cost (Lantarsih et al., 2011). Because of this, WNT plays an important role supplying rice for ENT, since ENT has a large rice deficit of about $-292,450$ tonnes. WNT can also supply rice to Bali, as Bali tends to experience a rice deficit.

\begin{tabular}{|l|l|c|}
\hline No & Provinces & $\begin{array}{c}\text { Rice Surplus (+)/Deficit (-) } \\
(\mathbf{1 0 0 0} \text { tonnes) }\end{array}$ \\
\hline 1 & Bali & +7.17 \\
\hline 2 & West Nusa Tenggara & +411.060 \\
\hline 3 & East Nusa Tenggara & -292.45 \\
\hline
\end{tabular}

Table 4.2. Rice surplus in WNT, Bali and ENT (Lantarsih et al., 2011)

Figure 4.2 shows the percentage of food consumption in WNT. Rice is the most consumed food in WNT (about 25\% of total food consumption), following by prepared food and beverages (about $20 \%$ of total food consumption). In other words, rice is a main source of energy and protein for people in WNT (Pemerintah Nusa Tenggara Barat, 2011).

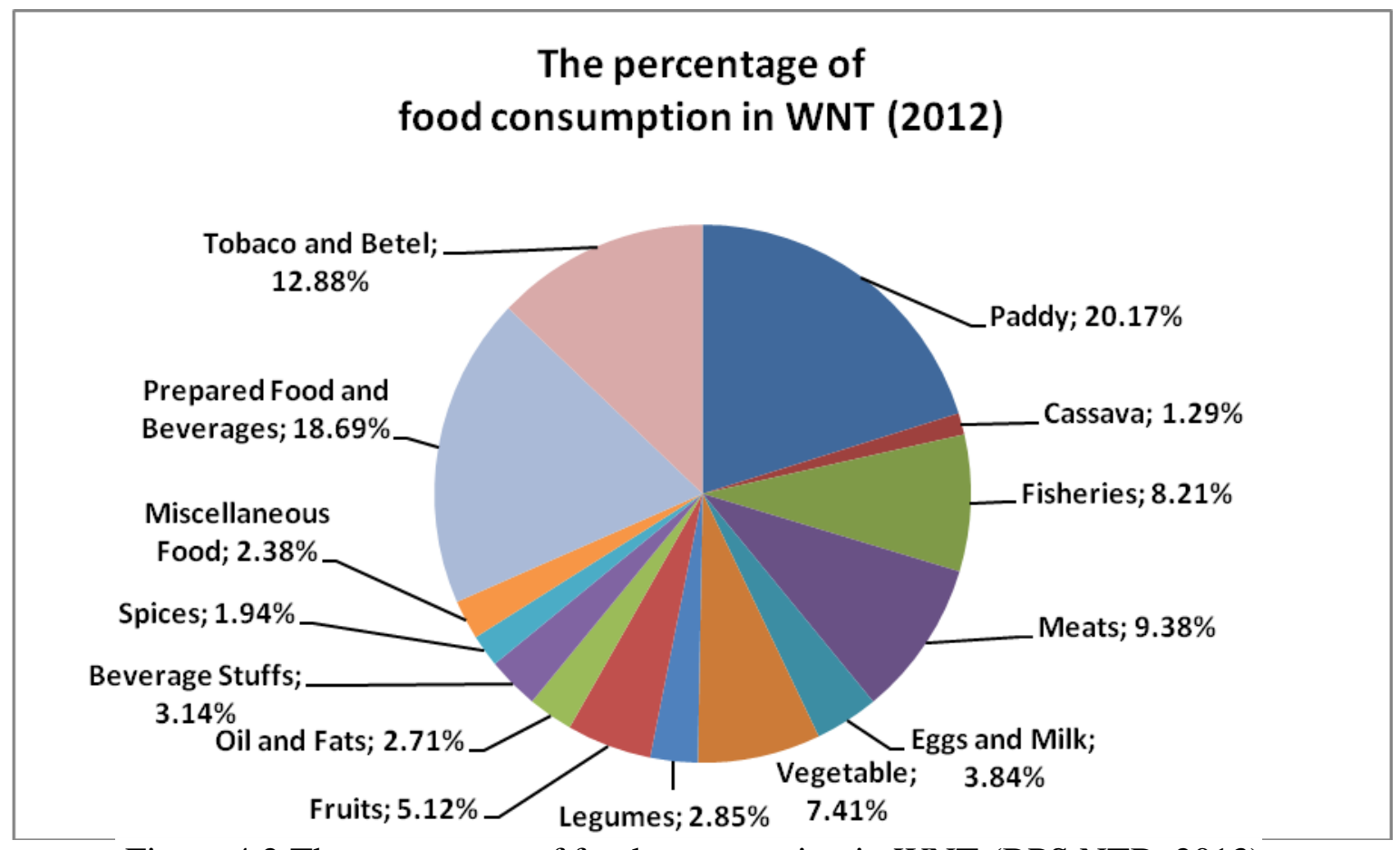

Figure 4.2 The percentage of food consumption in WNT (BPS NTB, 2013) 
Figure 4.3 shows the percentage of gross domestic product (GDP) and percentage of employment by industry in WNT. Agriculture has the highest GDP contribution (29\% of GDP) and the highest total employment contribution in WNT (about 45\%).

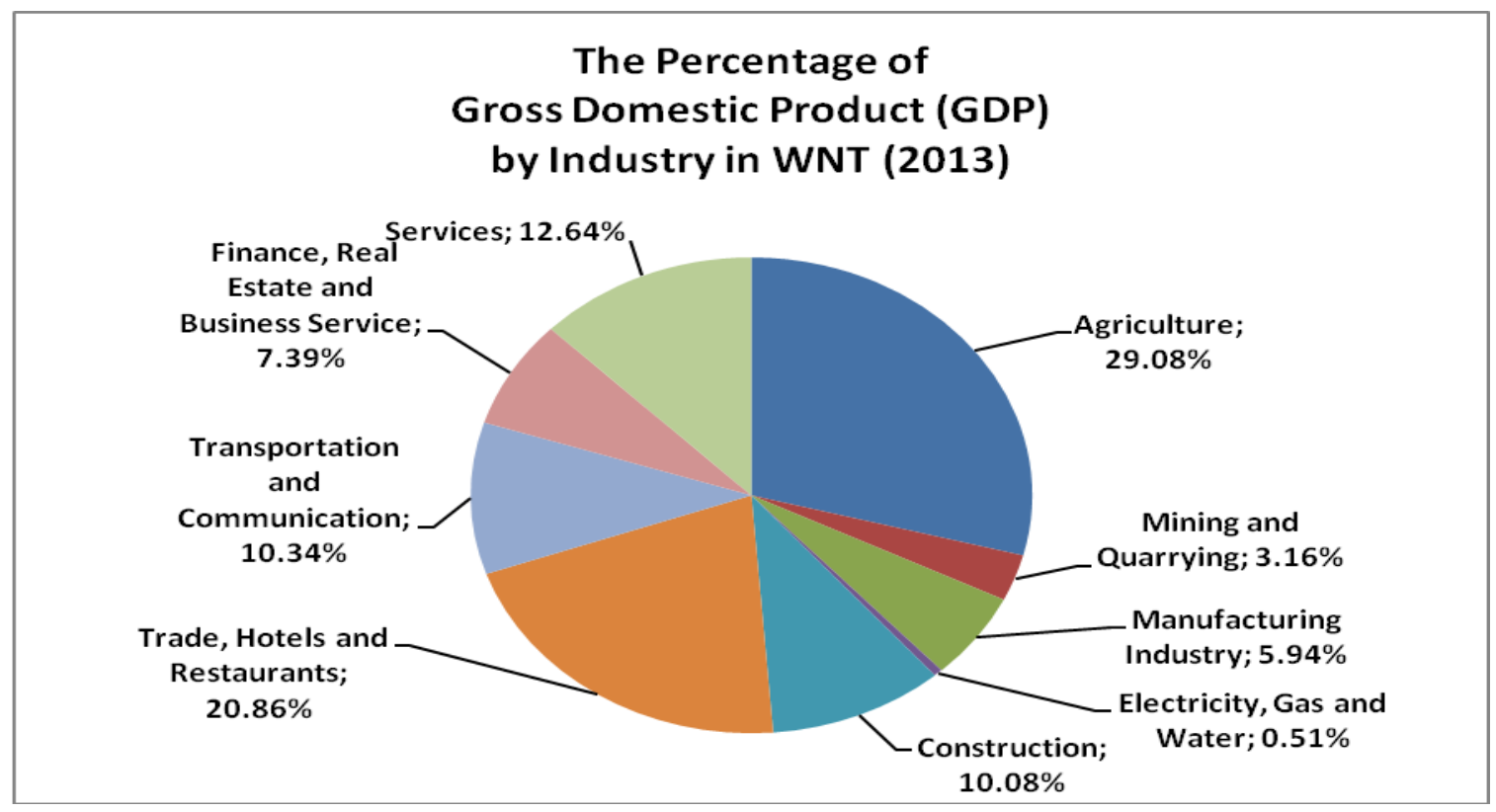

a. The percentage of gross domestic product (GDP) by industrial origins in WNT (BPS NTB, 2014)

\section{Percentage of Employment by Industry in WNT (2013)}

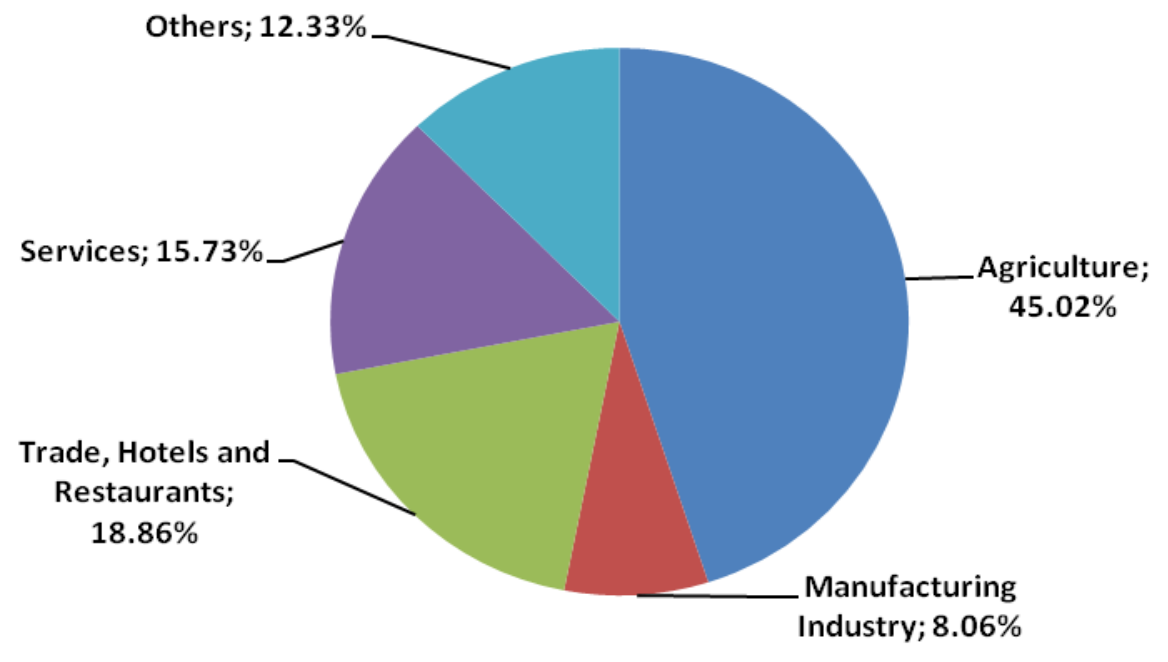

b. Percentage of Employment by Industry in WNT (BPS NTB, 2014)

Figure 4.3 The importance of rice based on gross domestic product and employment 
Based on data recorded between 2004 and 2013, the contribution of agriculture to GDP was relatively similar during that period. In that period, agriculture contributed between $20 \%$ and $26 \%$ to GDP (BPS NTB, 2014). Likewise, agriculture contributed between $44 \%$ and $47 \%$ to employment in the period 2007-2013 (BPS NTB, 2014). These figures show that agriculture is a highly important sector for West Nusa Tenggara.

\subsection{Detection of climate change}

Some local climate data was collected from BMKG (Indonesian Agency for Meteorological, Climatological and Geophysics) in Mataram, the capital city of West Nusa Tenggara. BMKG of Mataram, West Nusa Tenggara is located at about Latitude $8.33^{\circ}$, about Longitude $116.06^{\circ}$ and at an elevation of approximately 16 metres (BWS NTB, 2011). Again, climatic data such as rainfall, and maximum temperature between 1971 and 2013 is separated into two periods, namely, the baseline periods (1971-2000) and the recent period (2001-2013). This is in order to assess any possible changes in climate mean and climate variability in both periods.

Statistics shows that WNT has not experienced significant rainfall change since the late$20^{\text {th }}$ century. Annual rainfall in the baseline (1971-2000) is $1,718 \pm 462 \mathrm{~mm} / \mathrm{year}$ and in the current period (2001-2013) it is $1,684 \pm 315 \mathrm{~mm} /$ year. However annual rainfall in both periods is not statistically different $(t(41)=.28, p=n s)$. In contrast, as shown later, a few monthly rainfalls such as February rainfall are statistically different.

By contrast, a lot of monthly temperatures in both periods are statistically different. In particular, monthly temperatures in the rainy seasons (October-March) are statistically different, while many months in the dry seasons (June-August) are not statistically different. In other words, there is a significant increase in temperature variability across mean temperature, minimum temperature and maximum temperature in WNT.

\subsubsection{Monthly rainfall trends}

Figure 4.4 shows monthly rainfall in the baseline period (1971-2000) and the recent period (2000-2013). Except for May and December, all monthly rainfall in the recent period is relatively higher than that in the baseline period. However, monthly rainfall of the recent period is still higher than $150 \mathrm{~mm}$, leading to sufficient rainfall in supporting 
rice farming. This figure also shows that error bars of monthly rainfall in May and August are overlapped, while the others are not overlapped. As explained later, overlapped error bars indicate statistical difference, while non-overlapped error bars might not indicate statistical difference.

The Mann-Whitney tests indicate that monthly rainfall in May $(U=123, z=-1.904, p<.1)$ and August $(\mathrm{U}=127, \mathrm{z}=-1.808, \mathrm{p}<.1)$ is statistically different. In addition, only variability of monthly rainfall in February $(\mathrm{F}(1,41)=3.38, \mathrm{p}<.1)$ is statistically different. It seems that there are no significant differences of monthly rainfall throughout the rainy seasons. A summary of statistical results for all monthly rainfall can be seen in table 4.3.

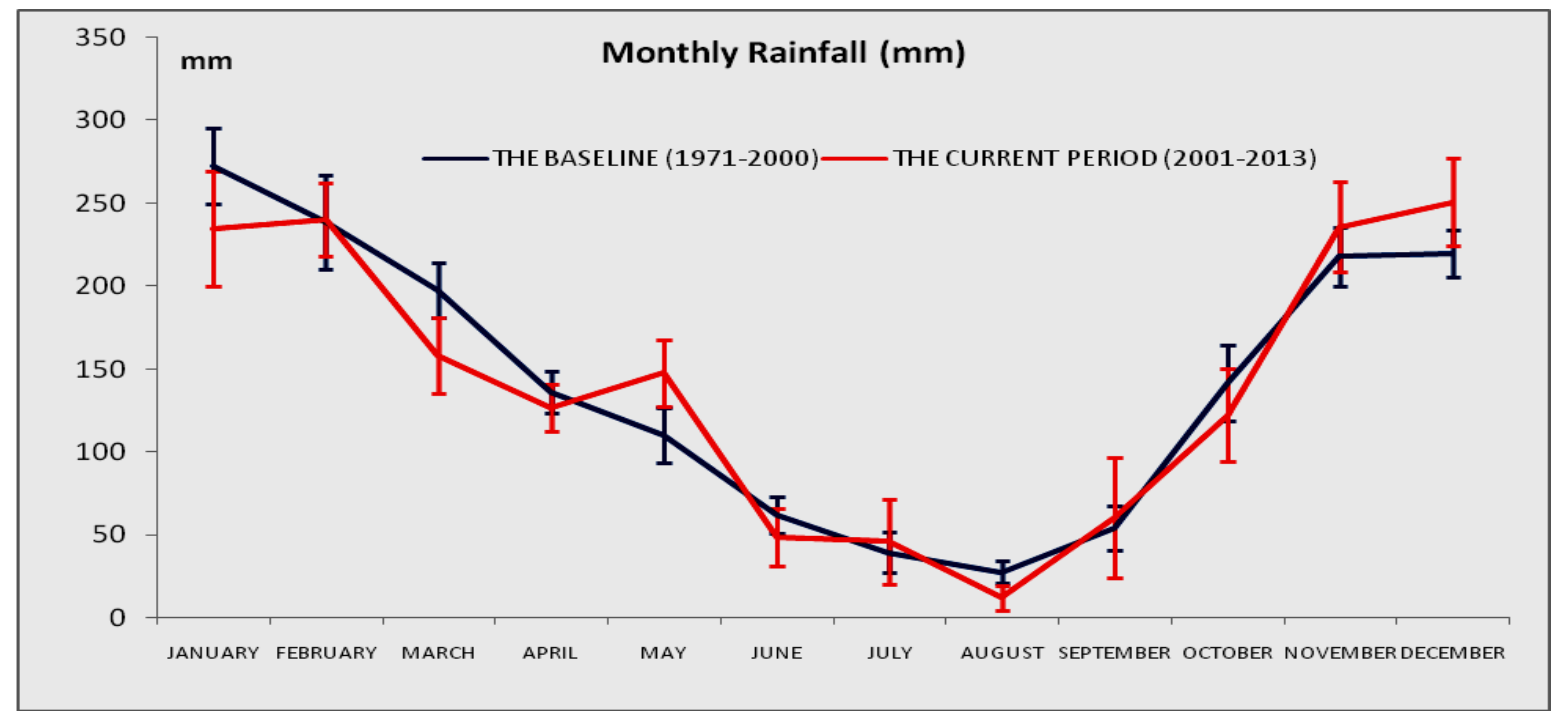

Figure 4.4 Monthly rainfall in the baseline (1971-2000) and the current period (20012013) with mean standard error as error bars (BMKG, 2014)

\begin{tabular}{|l|c|c|}
\hline \multicolumn{1}{|c|}{ Monthly Rainfall } & $\begin{array}{c}\text { Statistical Results of Mean } \\
\text { (two tailed) }\end{array}$ & $\begin{array}{c}\text { Statistical Results of Variance } \\
\text { (two tailed) }\end{array}$ \\
\hline January & $U=170, z=-.661, p>.1$ & $F(1,41)=.29, p>.1$ \\
\hline February & $U=167.5, z=-.727, p>.1$ & $F(1,41)=3.38, p<.1$ \\
\hline March & $U=140, z=-1.455, p>.1$ & $F(1,41)=.55, p>.1$ \\
\hline April & $U=180.5, z=-.384, p>.1$ & $F(1,41)=1.58, p>.1$ \\
\hline May & $U=123, z=-1.904, p<.1$ & $F(1,41)=1.24, p>.1$ \\
\hline June & $U=158.5, z=-.966, p>.1$ & $F(1,41)=.02, p>.1$ \\
\hline July & $U=173, z=-.582, p>.1$ & $F(1,41)=0.2, p>.1$ \\
\hline August & $U=127, z=-1.808, p<.1$ & $F(1,41)=2.66, p>.1$ \\
\hline September & $U=187.5, z=-.199, p>.1$ & $F(1,41)=.9, p>.1$ \\
\hline October & $U=190.5, z=-.119, p>.1$ & $F(1,41)=2.3, p>.1$ \\
\hline November & $U=181.5, z=-.357, p>.1$ & $F(1,41)=.01, p>.1$ \\
\hline December & $U=147.5, z=-1.256, p>.1$ & $F(1,41)=.87, p>.1$ \\
\hline
\end{tabular}

Table 4.3 A summary of statistics tests for monthly rainfall 


\subsubsection{Mean temperature trends}

Figure 4.5 demonstrates that mean temperature in the recent period is relatively higher than that of the baseline period. By average, mean temperature of the recent period is about $0.3^{0} \mathrm{C}$ higher than that in the baseline period. For rainy seasons, error bars of mean temperature in both periods are not overlapped. Non-overlapped error bars might show that mean temperature in rainy seasons is statistically different. The Mann-Whitney tests indicate that mean temperature in rainy seasons such as January $(U=79, z=-3.069$, $p<.01)$, November $(\mathrm{U}=107, \mathrm{z}=-2.328, \mathrm{p}<.05)$ and December $(\mathrm{U}=103, \mathrm{z}=-2.434, \mathrm{p}<.05)$ is statistically different. Likewise, temperature variability in June $(F(1,41)=4.57, p<.05)$, August $(\mathrm{F}(1,41)=4.24, \mathrm{p}<.05)$ and October $(\mathrm{F}(1,41)=8.48, \mathrm{p}<.01)$ is statistically different.

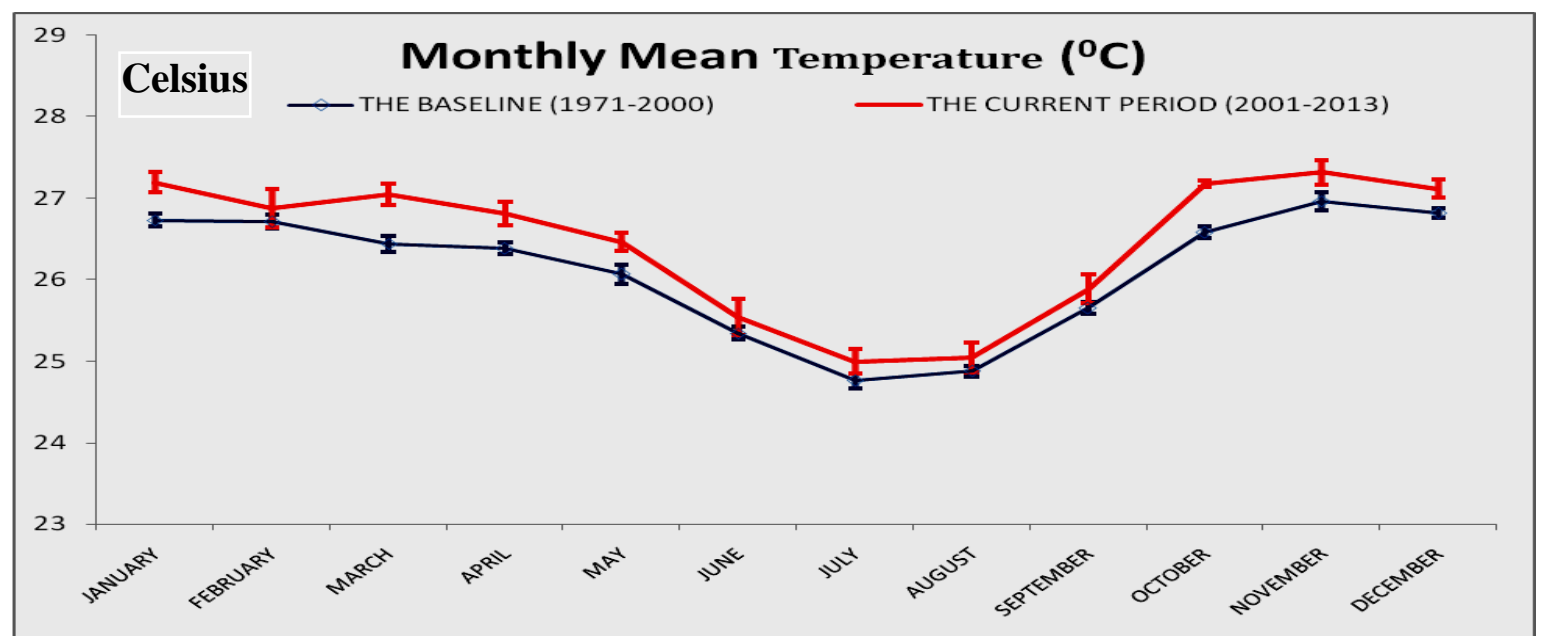

Figure 4.5 Monthly mean temperature in the baseline (1971-2000) and the current period (2001-2013) with mean standard error as error bars (BMKG, 2014)

\begin{tabular}{|l|c|c|}
\hline $\begin{array}{l}\text { Monthly } \\
\text { temperature }\end{array}$ & $\begin{array}{c}\text { mean } \\
\text { Statistical Results of Mean } \\
\text { (two tailed) }\end{array}$ & $\begin{array}{c}\text { Statistical Results of Variance } \\
\text { (two tailed) }\end{array}$ \\
\hline January & $U=79, z=-3.069, p<.01$ & $F(1,41)=.13, p>.1$ \\
\hline February & $U=139.5, z=-1.468, p>.1$ & $F(1,41)=4.23, p<.05$ \\
\hline March & $U=62, z=-3.518, p<.01$ & $F(1,41)=.01, p>.1$ \\
\hline April & $U=102, z=-2.460, p<.05$ & $F(1,41)=.7, p>.1$ \\
\hline May & $U=97.5, z=-2.579, p<.05$ & $F(1,41)=1.57, p>.1$ \\
\hline June & $U=160, z=-0.926, p>.1$ & $F(1,41)=4.57, p<.05$ \\
\hline July & $U=142, z=-1.402, p>.1$ & $F(1,41)=.001, p>.1$ \\
\hline August & $U=163, z=-0.846, p>.1$ & $F(1,41)=4.24, p<.05$ \\
\hline September & $U=128.5, z=-1.759, p<.1$ & $F(1,41)=2.16, p>.1$ \\
\hline October & $U=39.5 z=-4.113, p<.01$ & $F(1,41)=8.48, p<.01$ \\
\hline November & $U=107, z=-2.328, p<.05$ & $F(1,41)=.02, p>.1$ \\
\hline December & $U=103, z=-2.434, p<.05$ & $F(1,41)=.38, p>.1$ \\
\hline
\end{tabular}

Table 4.4 A summary of statistics tests for monthly mean temperature 


\subsubsection{Maximum temperature trends}

Figure 4.6 explains that WNT has experienced a significant increase of about $0.5^{\circ} \mathrm{C}$ in maximum temperature in the recent period, compared to the baseline period. In rainy seasons, maximum temperature in the recent period might be about $0.7^{\circ} \mathrm{C}$ higher than that in the baseline period. However, all monthly maximum temperature in the recent period is relatively lower than the rice threshold of $35^{\circ} \mathrm{C}$ (Welch et al., 2010; Yoshida, 1981).

The Mann-Whitney tests indicate that maximum temperature in rainy seasons such as October $(\mathrm{U}=117, \mathrm{z}=-2.068, \mathrm{p}<.05)$ and April $(\mathrm{U}=120, \mathrm{z}=-1.989, \mathrm{p}<.05)$, is statistically different. The Levene tests affirm a significant change of temperature variability in April $(\mathrm{F}(1,41)=16, \mathrm{p}<.01)$ and October November $(\mathrm{F}(1,41)=3.5, \mathrm{p}<.1)$. A simplified statistical result of maximum temperature is drawn in table 4.5.

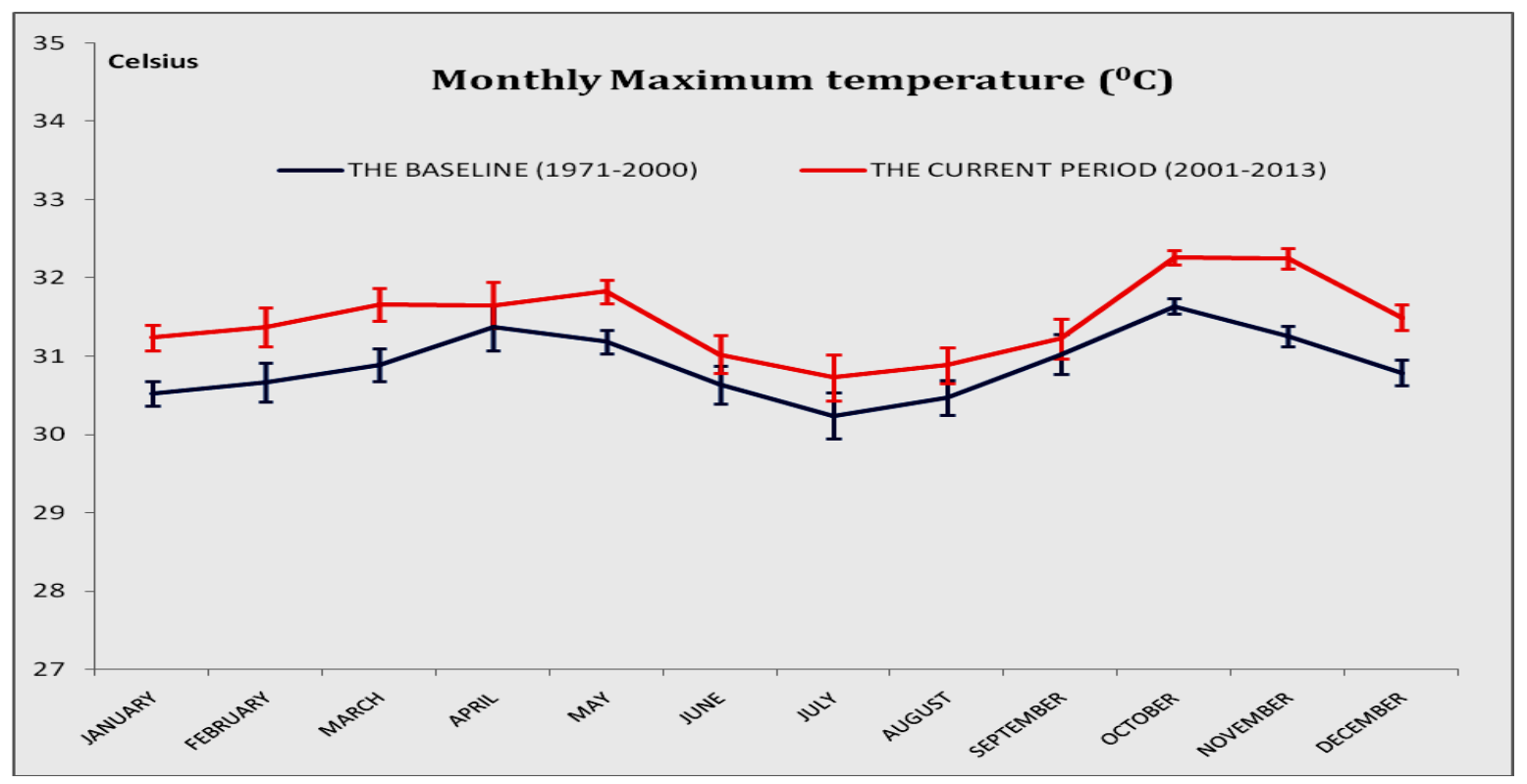

Figure 4.6 Monthly maximum temperature in the baseline (1971-2000) and the current period (2001-2013) with mean standard error as error bars (BMKG, 2014). 


\begin{tabular}{|l|r|c|}
\hline $\begin{array}{l}\text { Monthly maximum } \\
\text { temperature }\end{array}$ & $\begin{array}{c}\text { Statistical Results of Mean } \\
\text { (two tailed) }\end{array}$ & $\begin{array}{c}\text { Statistical Results of Variance } \\
\text { (two tailed) }\end{array}$ \\
\hline January & $U=72, z=-3.255, p<.01$ & $F(1,41)=.046, p>.1$ \\
\hline February & $U=91, z=-2.755, p<.01$ & $F(1,41)=.000, p>.1$ \\
\hline March & $U=63, z=-3.502, p<.01$ & $F(1,41)=.16, p<.01$ \\
\hline April & $U=120, z=-1.989, p<.05$ & $F(1,41)=16, p<.01$ \\
\hline May & $U=56, z=-3.684, p<.01$ & $F(1,41)=.000, p>.1$ \\
\hline June & $U=103.5, z=-2.426, p<.05$ & $F(1,41)=.63, p>.1$ \\
\hline July & $U=96.5, z=-2.614, p<.01$ & $F(1,41)=8.4, p<.01$ \\
\hline August & $U=88.5, z=-2.829, p<.01$ & $F(1,41)=1.77, p>.1$ \\
\hline September & $U=148, z=-1.245, p>.1$ & $F(1,41)=.1, p>.1$ \\
\hline October & $U=117, z=-2.068, p<.05$ & $F(1,41)=3.5, p<.1$ \\
\hline November & $U=53, z=-3.763, p<.01$ & $F(1,41)=.25, p>.1$ \\
\hline December & $U=57.5, z=-3.644, p<.01$ & $F(1,41)=2, p>.1$ \\
\hline
\end{tabular}

Table 4.5 A summary of statistics tests for monthly maximum temperature

\subsubsection{Minimum temperature trends}

Figure 4.7 depicts that the minimum temperature is likely to have increased in the recent period compared to the baseline period. It can be concluded that minimum temperature in the rainy seasons such as January, February and March are statistically different. In addition, temperature variability is significantly different in July $(F(1,41)=2.95, p<.01)$ and December $(F(1,41)=7, p<.05)$.

As minimum temperature in the rainy seasons is higher than $22^{\circ} \mathrm{C}$ (the threshold of minimum temperature for rice (Peng et. al, 2004; Welch et al., 2010)), rice will probably experience the negative effects of minimum temperature. For complete statistical results, refer to table 4.6. 


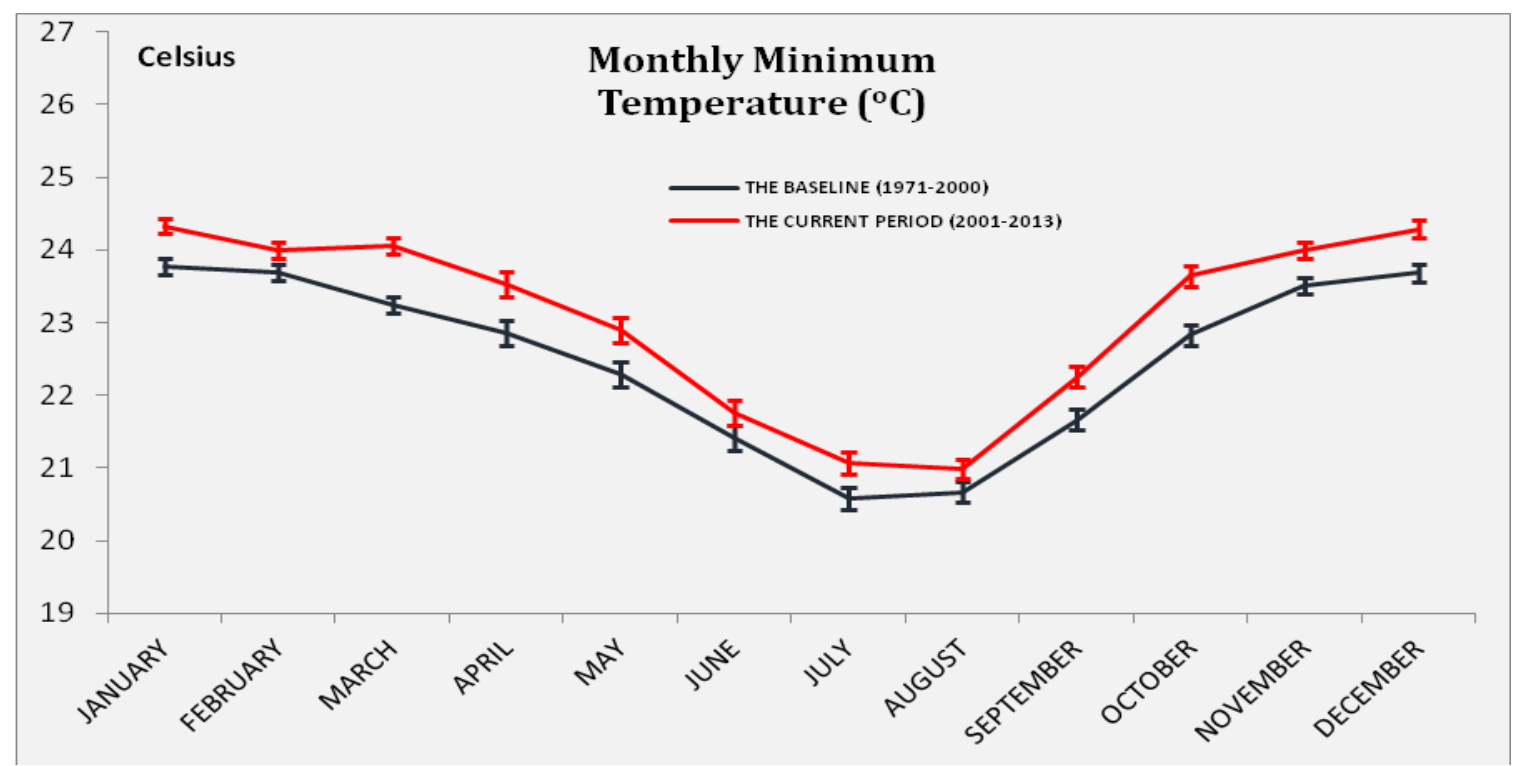

Figure 4.7 Monthly minimum temperature in the baseline (1971-2000) and the current period (2001-2013) with mean standard error as error bars (BMKG, 2014)

\begin{tabular}{|l|c|c|}
\hline $\begin{array}{l}\text { Monthly minimum } \\
\text { temperature }\end{array}$ & $\begin{array}{c}\text { Statistical Results of Mean } \\
\text { (two tailed) }\end{array}$ & $\begin{array}{c}\text { Statistical Results of Variance } \\
\text { (two tailed) }\end{array}$ \\
\hline January & $U=79.5, z=-3.06, p<.01$ & $F(1,41)=.19, p>.1$ \\
\hline February & $U=124.5, z=-1.87, p<.1$ & $F(1,41)=.08, p>.1$ \\
\hline March & $U=58.5, z=-3.6, p<.01$ & $F(1,41)=.000, p>.1$ \\
\hline April & $U=107 z=-2.33, p<.05$ & $F(1,41)=1.98, p>.1$ \\
\hline May & $U=120.5 z=-1.97 p<.05$ & $F(1,41)=1.39, p>.1$ \\
\hline June & $U=159 z=-.95 p>.1$ & $F(1,41)=1.78, p>.1$ \\
\hline July & $U=131.5, z=-1.68, p<.1$ & $F(1,41)=2.95, p<.1$ \\
\hline August & $U=166.5, z=-.75, p>.1$ & $F(1,41)=2.2, p>.1$ \\
\hline September & $U=110 z=-2.25, p<.05$ & $F(1,41)=.09, p>.1$ \\
\hline October & $U=80.5, z=-3.03, p<.01$ & $F(1,41)=10, p<.01$ \\
\hline November & $U=102.5 z=-2.45, p<.05$ & $F(1,41)=.54, p>.1$ \\
\hline December & $U=82 z=-2.99, p<.01$ & $F(1,41)=7, p<.05$ \\
\hline
\end{tabular}

Table 4.6 A summary of statistics tests for monthly minimum temperature

\subsection{Predicted submerged land}

West Nusa Tenggara is a mountainous area with 16 mountains: 9 mountains on Sumbawa and 7 mountains on Lombok. At 3,775 m, Mount Rinjani is the second highest one in Indonesia. Ten municipal capitals in West Nusa Tenggara have a height of between 11 and $148 \mathrm{~m}$. As explained later, the estimated inundated area due to sea level rise is relatively small compared with the total land of this region. 


\begin{tabular}{|l|c|c|}
\hline \multicolumn{1}{|c|}{ Regency / Municipality } & Capital & Altitude (Meter) \\
\hline 1. Lombok Barat & Mataram & 16 \\
\hline 2. Lombok Tengah & Praya & 101 \\
\hline 3. Lombok Timur & Selong & 148 \\
\hline 4. Sumbawa & Sumbawa Besar & 20 \\
\hline 5. Dompu & Dompu & 50 \\
\hline 6. Bima & Raba & 13 \\
\hline 7. Kota Mataram & Mataram & 16 \\
\hline 8. Kota Bima & Raba & 13 \\
\hline 9.Sumbawa Barat & Taliwang & 11 \\
\hline 10.Lombok Utara & Tanjung & 12 \\
\hline
\end{tabular}

Table 4. 7 Altitudes of each municipality's capital in West Nusa Tenggara (BPS, 2014)

IPCC (2013) projects that southern Indonesian regions such as WNT will experience sea level rise in a range of $0.4-0.8$ metre by 2100 (RCP 4.5 scenario, relative to the period 1986-2005). Based on RCP 8.5 scenario, the highest possible sea level rise is about 0.5$1.2 \mathrm{~m}$ (IPCC, 2013).

Figure 4.8 shows three elevation ranges of WNT (Butler et al., 2011). All areas depicted in red show an elevation range of between 0 and $1 \mathrm{~m}$ and those coloured blue are from 1 to $1,000 \mathrm{~m}$. Areas of $1,000 \mathrm{~m}$ and higher are highlighted with green. It is likely that some land in northern Sumbawa, as well as in southern and northern Lombok, may be submerged due to sea level rise. It is projected that the total inundated area by 2100 ( if sea level rise is about $1 \mathrm{~m}$, similar to RCP 8.5 scenario) will be about $200 \mathrm{Ha}$ (Butler et al., 2011). This also means that the total submerged land by 2100 will be about $0.024 \%$ compared to the total possible farming land in WNT (according to the governor decree 1 of 2013, the total possible farming land in WNT is about $830,000 \mathrm{Ha}$ ). Furthermore, as rice farming can exist in a saline area (BPS, 2012; IRRI, 2007), the effect of sea level rise on rice farming may be relatively insignificant. 


\begin{tabular}{|l|c|c|}
\hline Island & Name of Mountains & Altitude (Meters) \\
\hline 1. Lombok & Rinjani & 3,775 \\
\hline \multirow{5}{*}{} & Mareje & 716 \\
\cline { 2 - 3 } & Timanuk & 2,362 \\
\cline { 2 - 3 } & Nangi & 2,330 \\
\cline { 2 - 3 } & Parigi & 1,532 \\
\cline { 2 - 3 } & Pelawangan & 2,638 \\
\cline { 2 - 3 } & Baru & 2,376 \\
\hline 2. Sumbawa & Batu Lanteh & 1,730 \\
\hline \multirow{5}{*}{} & Tukan & 1,400 \\
\cline { 2 - 3 } & Jaran Pusang & 1,283 \\
\cline { 2 - 3 } & Soromandi/Donggo & 1,467 \\
\cline { 2 - 3 } & Tambora & 2,851 \\
\cline { 2 - 3 } & Sangiang & 1,449 \\
\cline { 2 - 3 } & Dodu & 1,447 \\
\cline { 2 - 3 } & Pajo & 728 \\
\cline { 2 - 3 } & Sambi & 697 \\
\hline
\end{tabular}

Table 4. 8 Names and altitudes of mountains (BPS, 2014) 


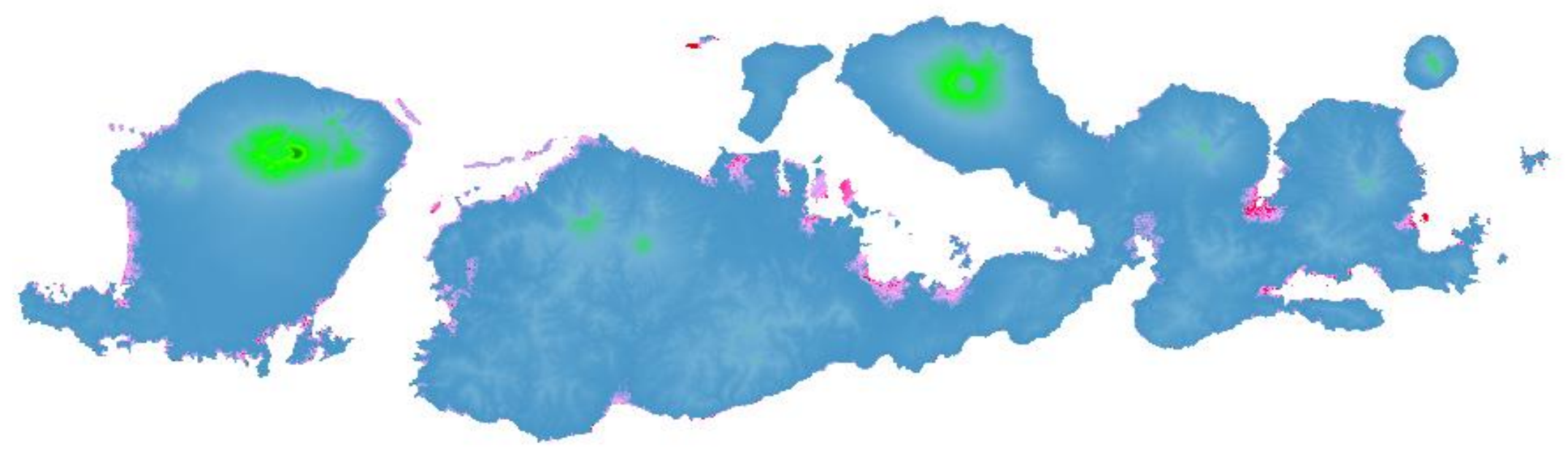

Figure 4.8. Land elevation ranges in West Nusa Tenggara, Indonesia (Butler et al., 2011, figure 8)

$$
\begin{aligned}
& : 0-1 \mathrm{~m} \\
& : 1-1,000 \mathrm{~m} \\
& :>1,000 \mathrm{~m}
\end{aligned}
$$




\subsection{Summary}

This chapter explained some background information about the Indonesian province of West Nusa Tenggara. The region plays an important role in terms of the country's rice production. This area is the main source of rice for its neighbours such as East Nusa Tenggara and Bali. West Nusa Tenggara is significantly dependent on agriculture as a main provider of employment and economic activity. In terms of climate, West Nusa Tenggara has experienced significant change in its monthly mean, minimum and maximum temperature. In particular, an increase in temperature has occurred in the rainy seasons during which rice is predominantly sown.

Because changes in all types of monthly temperature were detected, it is obligated to assess the impacts of climate change on rice yield. The next chapters will assess the impacts of climate change and climate variability on rice yield, rice production and harvested areas in West Nusa Tenggara. 
this page intentionally left blank 


\section{CHAPTER 5 STATISTICAL MODELS OF RICE YIELD}

As explained in chapter 2 (section 2.3), statistical models can be used to estimate the impact of climate and production factors on rice yield (tonnes/year*hectare). In doing so, this chapter highlights existing studies that apply different statistical models. The chapter also gives a theoretical background and an analysis of data in an effort to obtain the most appropriate statistical model. Finally, the impact of climate change on rice yield by 2090 (2077-2100) are explained for different RCP scenarios.

\subsection{Some types of statistical models}

There are two types of statistical models that have been widely used to estimate the impact of climate change on crop yield (Lobell \& Burke, 2010). The first model is a linearquadratic model and the second is a log-linear model. Linear-quadratic models combine linear and squared independent variables. The main idea for using a squared climate is to capture non-linear impacts of climate on crop yield with a low-order polynomial (Lobell \& Burke, 2010). Log-linear models are usually used to estimate crop yield if it follows a logarithmic curve, and log-linear models can be used to tackle heteroscedasticity ${ }^{18}$ (Lobell \& Burke 2010).

\subsubsection{Linear-quadratic models}

In case of Indonesian rice, Falcon et al. (2004) and Naylor et al. (2009) employ linearquadratic models in capturing the impact of ENSO (El Niño Southern Oscillation) on Indonesian rice production. Those studies employ models that embed time variables and August SSTAs (Sea Surface Temperature Anomalies in August) and show a strong negative impact of ENSO on rice production.

Existing studies also have employed linear-quadratic models to assess the impacts of climate change beyond Indonesian rice. Although climate models might not agree on the direction of rainfall change, climate models generally agree that changes in the magnitude of precipitation are relatively small compared with year-to-year rainfall variability (Lobell $\&$ Burke, 2008). Furthermore, Lobell and Burke (2008) suggest that uncertain impacts of

\footnotetext{
${ }^{18}$ heteroscedasticity occurs when data has not the same variance over time
} 
rainfall on crops are relatively lower than negative impacts of high temperature. Thus, assessment of the impacts of temperature on crops and the assessment of temperature change is key to evaluating the impacts of climate change on crops (Lobell \& Burke, 2008).

In assessing the impacts of temperatures on crop yield, Lobell, Bonfils and Duffy (2007) suggest that employing minimum and maximum temperature might be better than employing average temperature. This finding is similar to other studies (Lobell \& Gourdji, 2012; Sarker, Alam, \& Gow, 2012) which show the different responses of crops to maximum temperature and to minimum temperature. Those studies (Lobell et al., 2007; Lobell \& Gourdji, 2012; Sarker, et al., 2012) also show that the role of temperature is relatively more important than that of precipitation. High maximum temperatures may increase crop production as observed maximum temperatures are lower than the threshold for rice growth. By comparison, high minimum temperatures tend to decrease crop production as observed minimum temperatures are already higher than the threshold for rice growth.

There has been an increasing interest in combining production and climate factors to assess the impact of climate change on crops. For instance, Wang et al. (2012) investigated the impact of climate change on Taiwanese rice and showed that a statistical model embedding climate and production factors tends to have a higher correlation (R-squared of 49\%) than a statistical model without climate (R-squared of 30\%). This also means that excluding production factors on the production function tends to overestimate the effect of climate on rice yield (Wang, et al., 2012).

Many of the above studies are, in some respects, limited. For instance, some studies tend to overestimate the impact of climate change on crops by not taking into account production factors (Lobell et al., 2007; Sarker et al, 2012). Others (Lobell \& Burke, 2008; Wang, et al., 2012) did not consider the different impacts of minimum and maximum temperature on crops. Wang et al. (2012) did not consider the spatial variability of climate and production factors from a regional perspective in Taiwan as that study explores Taiwanese rice at a national scale. 


\subsubsection{Log-linear models}

Two existing studies (Gomez \& Iglesias, 2005; Quiroga \& Iglesias, 2009) employ a loglinear model to estimate impacts of climate variability on crops in Spain. They claim that the impacts of temperature are more pronounced than those of precipitation and production factors. Lee et al. (2012) show that climate change can negatively affect crop production in Asian countries. That study reveals that high temperature has a detrimental effect on crops, whereas a higher rainfall might increase crop production (Lee et al., 2012).

Lobell, Schlenker, and Costa-Roberts (2011) show that technological progress plays an important role in increasing crop yield. For this reason, embedding time variables may be useful in noting the effect of technological progress. After combining temperature, precipitation and time variables, Lobell et al. (2011) show that the negative impacts of climate change may negate the positive impact of technology. Again, the negative impact of temperature rise on crop production is more predominant than that of increased precipitation (Lobell et al., 2011).

\subsection{Statistical models of climate impacts on crop yield}

\subsubsection{Methodology}

Data are called stationary if their variance and mean do not change over time (Gujarati, 2004). If non-stationary data are used in a regression test, any regression result tends to be biased (Gujarati, 2004; Greene, 2003; Sarker et al, 2012). Time series such as crop yield, and climate and production factors are usually non-stationary which means they must be either detrended (if time series is trend-stationary) or differenced (if the time series is stochastic-stationary) (Gujarati, 2004; Greene, 2003; Lobell \& Burke et al., 2010).

Since observed rice yield follows linear-quadratic patterns (see figure 5.2 and figure 5.3), this study evaluates two statistical models in analysing the impact of climate change on rice yield. The first is a model with time variables and the second is a model of the first differenced variables. As the effect of technological progress is eliminated, a model with the first differenced variables will estimate rice yield without considering the effect of technological progress on rice yield (this is only true if the effects of technology are linear in time). If statistical models involve some significant variables such as minimum 
temperature and labour, equation 5.1 is an appropriate statistical model with time variables and equation 5.2 is an appropriate statistical model with the first differenced variables.

$\mathrm{Yi}=\mathrm{c}_{1}+\alpha_{1} \mathrm{Ai} * \mathrm{Dw}+\alpha_{2} \mathrm{Ai}^{2} * \mathrm{Dw}+\alpha_{3} \mathrm{Li}+\alpha_{4} \mathrm{Ci}+\alpha_{5} \mathrm{Si}+\alpha_{6} \mathrm{Fi}+\alpha_{7} \mathrm{Pi}+\alpha_{8} \mathrm{Ti}+\alpha_{9} \mathrm{Ta}+$ $\alpha_{10} \mathrm{Ri}+\alpha_{11} \mathrm{Ti}^{2}+\alpha_{12} \mathrm{Ta}^{2}+\alpha_{13} \mathrm{Ri}^{2}+\mathrm{Dd}+\varepsilon$

$\mathrm{Yi}=$ rice yield (tonnes/ha) in year $\mathrm{t}$;

$\mathrm{Ai}=$ time variable as a representation of technological change of rice (dimensionless);

$\mathrm{Ai}^{2}=$ time variable square as a representation of technological change of rice (dimensionless);

$\mathrm{Li}=$ labour (IDR/year) in year $\mathrm{t}$ (IDR=Indonesian rupiahs in constant prices for all production factors);

$\mathrm{Ci}=$ capital (IDR/year) in year $\mathrm{t}$;

$\mathrm{Si}=$ seed (IDR/year) in year $\mathrm{t}$;

$\mathrm{Fi}=$ fertiliser $(\mathrm{IDR} / \mathrm{year})$ in year $\mathrm{t}$;

$\mathrm{Pi}=$ pesticide $(\mathrm{IDR} /$ year $)$ in year $\mathrm{t}$;

$\mathrm{Ti}=$ minimum temperature in Celsius in year $\mathrm{t}$;

$\mathrm{Ta}=$ maximum temperature in Celsius in year $\mathrm{t}$;

$\mathrm{Ri}=$ seasonal rainfall in $\mathrm{mm} /$ year in year $\mathrm{t}$;

Dw =dummy variables for wetland rice (the value is 1 since 1996);

$\mathrm{Dd}=$ dummy variables for dryland rice (the value is 1 since 2008);

$\mathrm{Ti}^{2}=$ squared minimum temperature in Celsius in year $\mathrm{t}$;

$\mathrm{Ta}^{2}=$ squared maximum temperature in Celsius in year $\mathrm{t}$;

$\mathrm{Ri}^{2}=$ squared seasonal rainfall in $\mathrm{mm} /$ year in year $\mathrm{t}$;

$\mathrm{c}_{1}=$ constant;

$\varepsilon_{1}=$ error.

$\Delta \mathrm{Yi}=\mathrm{c}_{2}+\beta_{1} \Delta \mathrm{Li}+\beta 2 \Delta \mathrm{Ci}+\beta 3 \Delta \mathrm{Si}+\beta 4 \Delta \mathrm{Fi}+\beta_{5} \Delta \mathrm{Pi}+\beta_{6} \Delta \mathrm{Ti}+\beta_{7} \Delta \mathrm{Ta}+\beta_{9} \Delta \mathrm{Ri}$

$+\mathrm{Dw}+\mathrm{Dd}+\varepsilon_{2}$

$\Delta \mathrm{Yi}=$ the first difference rice yield (tonnes/ha) in year $\mathrm{t}$;

$\Delta \mathrm{Li}=$ the first difference labour (IDR/year) in year $\mathrm{t}$;

$\Delta \mathrm{Ci}=$ the first difference capital (IDR/year) in year $\mathrm{t}$;

$\Delta \mathrm{Si}=$ the first difference seed (IDR/year) in year $\mathrm{t}$;

$\Delta \mathrm{Fi}=$ the first difference fertiliser (IDR/year) in year $\mathrm{t}$;

$\Delta \mathrm{Pi}=$ the first difference pesticide (IDR/year) in year $\mathrm{t}$; 
$\Delta \mathrm{Ti}=$ the first difference minimum temperature in celsius in year $\mathrm{t}$;

$\Delta \mathrm{Ta}=$ the first difference maximum temperature in Celsius in year $\mathrm{t}$;

$\Delta \mathrm{Ri}=$ the first difference seasonal rainfall in $\mathrm{mm} /$ year in year $\mathrm{t}$;

Dw =dummy variables for wetland rice (the value is 1 since 1996);

$\mathrm{Dd}=$ dummy variables for dryland rice (the value is 1 since 2008);

$\mathrm{c}_{2}=$ constant;

$\varepsilon_{2}=$ error.

Observed climate in climate change studies may occur in the following three regions. As shown in figure 5.1, if observed temperature is in region 1 (below temperature threshold) or region 3 (upper temperature threshold), a linear climate variable could be used to approximate the impact of temperature or climate on crop yield (Lobell \& Burke, 2010). If observed temperature includes its threshold as in region 2 (observed temperature includes temperature threshold), a squared term of temperature could be applied to capture the nonlinear impacts of temperature (Lobell \& Burke, 2010). This means a squared climate variable will switch (from the negative to the positive impacts) the impacts of temperature when temperature crosses the temperature thresholds.

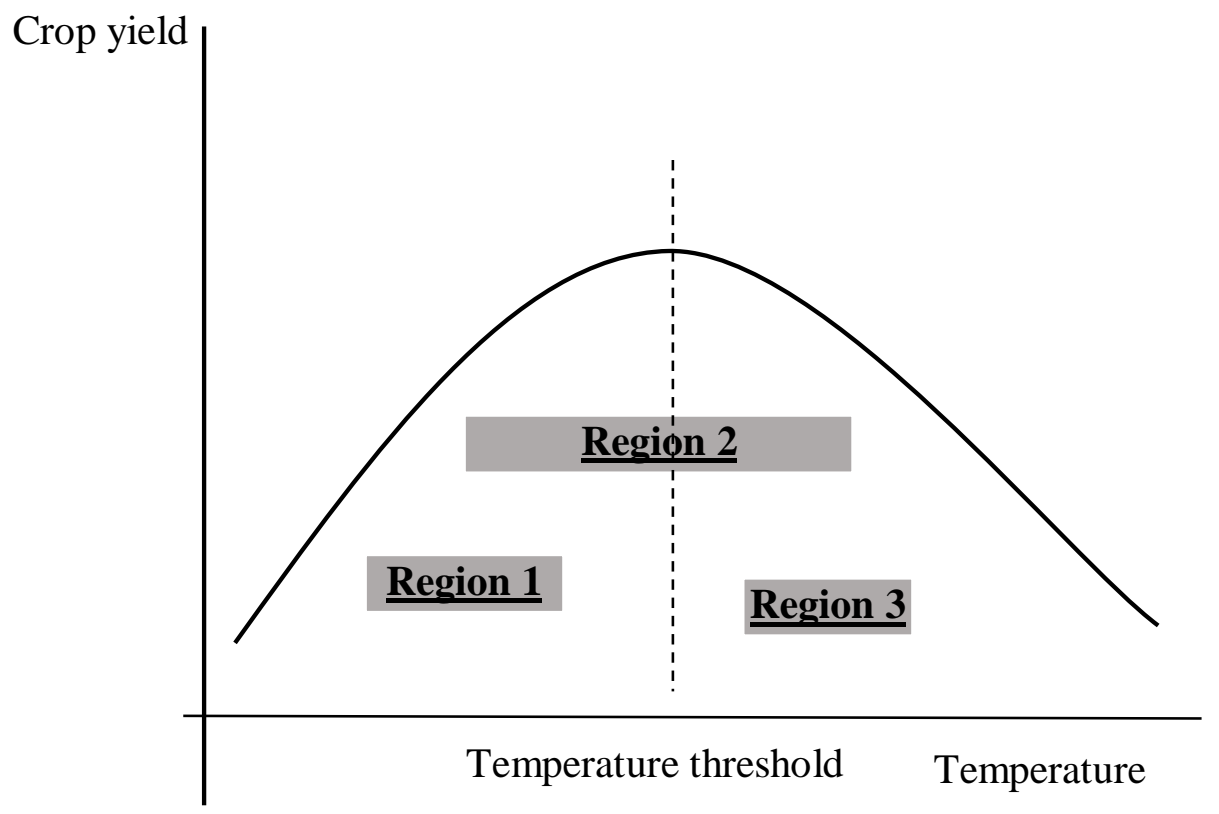

Figure 5.1 The relationship between temperature and crop yield (Lobell \& Burke, 2010)

For the maximum temperature and minimum temperature, rice thresholds are $35^{\circ} \mathrm{C}$ (Welch et al., 2010; Yoshida, 1981) and $22^{\circ} \mathrm{C}$ (Peng et al., 2004) respectively. Although observed 
minimum temperature is typically higher than the rice threshold and observed maximum temperature is lower than the rice threshold (table 5.5), variables of quadratic temperature will be embedded in equation (5.1). This study also includes a variable of squared rainfall in equation (5.1).

To complete the statistical analysis, statistical models should be tested. Good statistical models should include significant predictors and satisfy statistical assumptions such as a normality test, homoscedasticity and non-serial correlation, as this means that models can be used to forecast (Agunbiade, \& Adeboye, 2012; Ayyangar, 2007; Greene, 2003; Gujarati, 2004; Stark 2007; Yan \& Su, 2009). This study applies key tests, namely, Jarque-Bera, Breusch-Godfrey serial correlation, White test, and Vector Inflation Factor (VIF), for the normality test, the serial correlation and the heteroscedasticity test respectively (Brooks, 2009; Gujarati, 2004; Vogelvang, 2005).

Other important criteria for good models are those which have high adjusted R-square, the lowest information criterion (Baltagi, 2008; Greene, 2003), and good models should also conform to relevant evidence (Gujarati, 2004). For instance, if statistical tests conclude that fertiliser is a significant predictor, the significance of fertiliser should be supported by relevant evidence such as fertiliser is important as this crop is planted in less fertile areas.

\subsection{Two statistical models}

\subsubsection{Data collection}

Climatic data from BMKG NTB $^{19}$ (1976-2011) and production factors from BPS NTB ${ }^{20}$ (1976-2011, from the statistics of the cost structure of rice farming) were collected for this study. Because the statistics of cost structure have been published in monetary terms, these data are deflated ${ }^{21}$ (using Gross Domestic Product (GDP) deflators) to take out inflation ${ }^{22}$. For missing data, this study applies linear interpolation over the relatively short periods of

\footnotetext{
${ }^{19}$ BMKG NTB refers to the BMKG office in West Nusa Tenggara (NTB is an Indonesian name of West Nusa Tenggara).

${ }^{20}$ BPS NTB refers to the BPS office in West Nusa Tenggara (NTB is an Indonesian name of West Nusa Tenggara).

${ }^{21}$ This means that data of production factors is adjusted to take out inflation.

${ }^{22}$ For instance, $50 \mathrm{~kg}$ of seed in 2000 was about $\$ 100$ and after a $10 \%$ inflation from 2000 and $2001,50 \mathrm{~kg}$ of seed was worth about $\$ 110$ in 2001. For the same amount, seed in 2000 is more expensive (due to inflation) than in 2001. To make comparable seed, cost of seed in 2001 is deflated by $10 \%$ inflation, so deflated cost of seed in 2001 is about $\$ 100$.
} 
missing data. For example, missing data for labour, fertiliser and pesticide (for wetland farming) in the period 2003-2007 is estimated using a linear interpolation.

Farmers typically sow their rice (unhusked rice) three times a year. The first growing season usually starts during September and October and the first harvesting season is during December and January. Farmers sow rice again in the second growing season during January and February, and the farmers harvest their rice during April and May. Again, farmers start planting in May and harvest their rice during August. So, this study uses seasonal data supported by other existing studies as described in the following paragraph.

Following existing studies (Falcon et al., 2004; Lobell \& Burke, 2010; Naylor \& Mastrandea, 2009), a 12-month average climate from September to August is used in this study's statistical models. Again, statistics used in this study, like other Indonesian rice studies (Falcon et al., 2004; Naylor \& Mastrandea, 2009), show that annual climate does not correlate to annual rice yield.

\subsubsection{Features of statistical models}

This subsection describes some features of statistical models, namely a possible pattern of rice yield and correlation analysis. The possible pattern relates to a suitable mathematical form that can estimate rice yield. Correlation analysis aims to explain possible significant variables and supporting studies or theories that explain the variable significances.

Figure 5.2 and 5.3 demonstrate that rice yield might have a combination of convex and linear patterns. For this reason, rice yield in wetland and dryland farming may follow a linear and quadratic trend (Gujarati, 2004).

Figure 5.2 and figure 5.3 also show that wetland and dryland farming experienced structural breaks in 1996 and 2008 respectively. For wetland farming, a number of studies (Zeigler, \& Mohanty, 2010) suggest that due to decreased research funding in the middle of the 1990s, Asian rice yields levelled off. This probably led to a structural break in wetland farming after 1996 (Susanto et al., 2003; Wahyuni, \& Indraningsih, 2016). 
Rice yield in wetland farming in the period 1976-1995 increased from 2.9 tonnes/ha in 1976 to 4.5 tonnes/ha in 1995 , though rice yield experienced a levelling-off from 4.5 tonnes/ha in 1995 to 5 tonnes/ha in 2011. This is shown in figure 5.2 by two red lines showing different trends before and after 1996.

Figure 5.3 also shows an intercept change in 2008 that occurred due to P2BN (P2BN=Program Peningkatan Beras Nasional: the national program for increasing rice production), which provides more suitable rice varieties for dryland farming. Differing from that of wetland areas, dryland farming experienced a structural break of intercept. This is shown by a vertical line in figure 5.3. Appendix A explains different types of structural breaks.

As dryland farming covers less than $10 \%$ of total rice production, the Indonesian government has paid little attention to this farming (Toha, 2012). Before 2008, dryland farmers used to plant rice varieties that were not suitable for dryland farming, ie. dryland farmers planted wetland rice varieties (Toha, 2012). However, after the national program for increasing rice production (P2BN) started in 2008, dryland rice yield increased significantly as dryland farmers began to plant suitable rice varieties ${ }^{23}$.

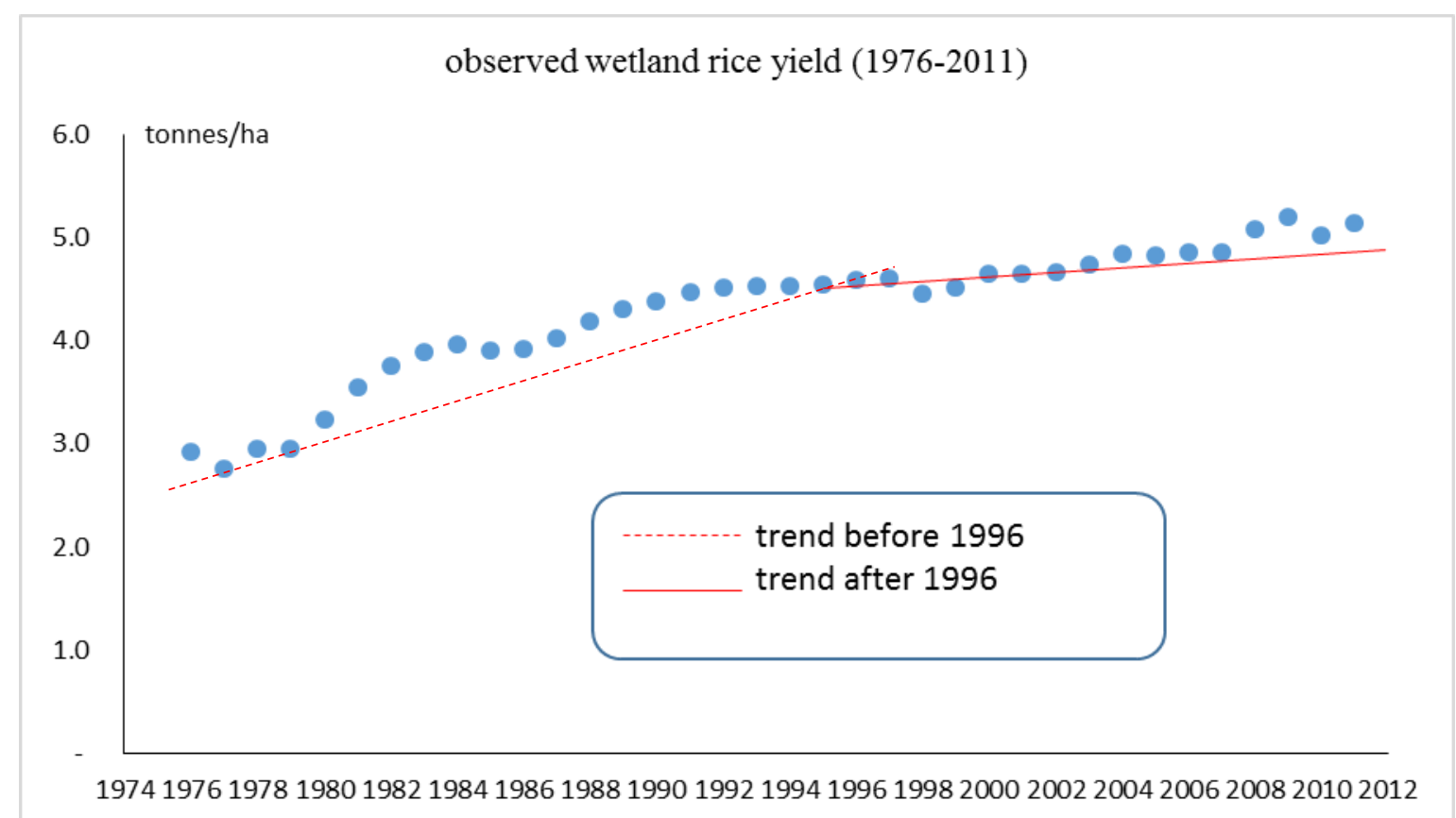

Figure 5.2. Rice yield of wetland farming in the period 1976-2011

${ }^{23}$ One feature of dryland rice is it is drought tolerant varieties. 


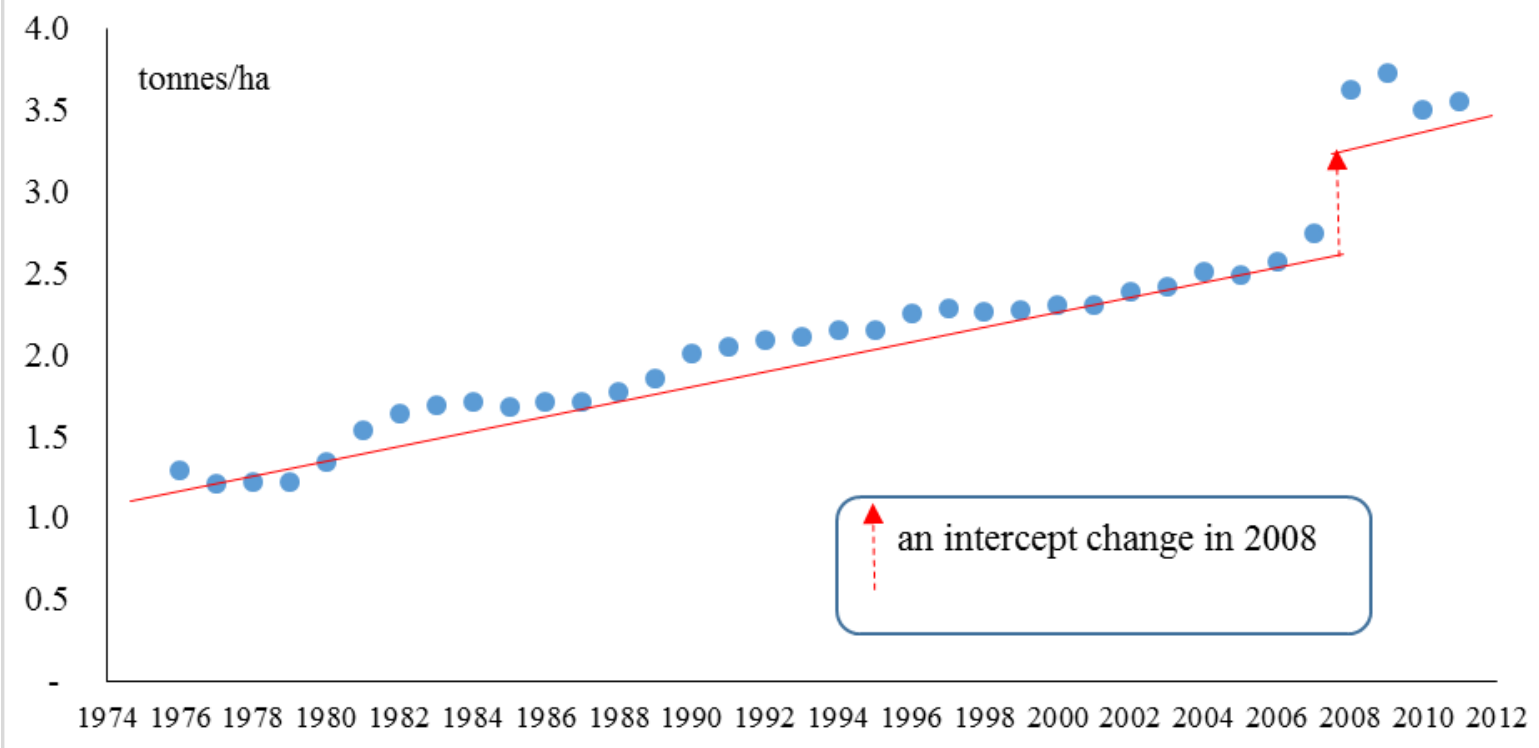

Figure 5.3. Rice yield of dryland farming in the period 1976-2011

All observed data - such as rice yield, rainfall and minimum temperature - is not stationary in its level, but this data is stationary after detrending (taking residuals after detrending with time variable) and first differencing (value in year $t+1$ is subtracted by value in year $\mathrm{t}$ ). Table 5.1 and table 5.2 summarise a full list of correlations of rice yield either with climate or production factors after data detrending in dryland and wetland farming respectively (appendix B describes correlations after first differencing). Based on the detrended method, correlation analysis reveals that seasonal minimum temperature tends to negatively affect wetland rice yield $(r=-.36, \mathrm{p}<.05)$ and dryland rice $(r=-.33$, $\mathrm{p}<.05)$. By contrast, seasonal rainfall ( $r=.0, \mathrm{p}>.1$ for wetland farming and $r=-.19, \mathrm{p}>.1$ for dryland farming) and seasonal maximum temperature $(r=-.18, \mathrm{p}>.1$ for wetland farming and $r=-.12, \mathrm{p}>.1$ for dryland farming) have an insignificant impact on rice yield.

\begin{tabular}{|l|c|c|}
\hline Variables & $\mathbf{r}$ (correlation) & p-values \\
\hline Seasonal Minimum Temperature & $\mathbf{r}=-.36$ & $\mathbf{p}<.05$ \\
\hline Seasonal Maximum Temperature & $\mathrm{r}=-.18$ & $\mathrm{p}>.1$ \\
\hline Seasonal Rainfall & $\mathrm{r}=-.00$ & $\mathrm{p}>.1$ \\
\hline Capital & $\mathrm{r}=.13$ & $\mathrm{p}>.1$ \\
\hline Labour & $\mathbf{r}=.39$ & $\mathbf{p}<. \mathbf{0 5}$ \\
\hline Seed & $\mathrm{r}=.11$ & $\mathrm{p}>.1$ \\
\hline Fertiliser & $\mathrm{r}=-.05$ & $\mathrm{p}>.1$ \\
\hline Pesticide & $\mathrm{r}=.11$ & $\mathrm{p}>.1$ \\
\hline
\end{tabular}

Table 5.1 Correlation analysis of production factors, climate and rice yield based on detrended method (wetland farming) 


\begin{tabular}{|l|l|l|}
\hline Variables & $\mathbf{r}$ (correlation) & p-values \\
\hline Seasonal Minimum Temperature & $\mathbf{r}=-.33$ & $\mathbf{p}<. \mathbf{0 5}$ \\
\hline Seasonal Maximum Temperature & $\mathrm{r}=-.12$ & $\mathrm{p}>.1$ \\
\hline Seasonal Rainfall & $\mathrm{r}=-.19$ & $\mathrm{p}>.1$ \\
\hline Capital & $\mathrm{r}=.09$ & $\mathrm{p}>.1$ \\
\hline Labour & $\mathrm{r}=-.11$ & $\mathrm{p}>.1$ \\
\hline Seed & $\mathbf{r}=.33$ & $\mathbf{p}<. \mathbf{0 5}$ \\
\hline Fertiliser & $\mathrm{r}=.13$ & $\mathrm{p}>.1$ \\
\hline Pesticide & $\mathrm{r}=-.24$ & $\mathrm{p}>.1$ \\
\hline
\end{tabular}

Table 5.2 Correlation analysis of production factors, climate and rice yield based on detrended method (dryland farming)

Wang et al. (2013) claim that rainfall might not have significant impacts on rice yield as wetland farming is surrounded by irrigation facilities. Likewise, the insignificance of maximum temperature could be caused by transpirational cooling as irrigation facilities may reduce ambient temperature. The insignificance of maximum temperature may also occur as observed maximum temperature is lower than $35^{\circ} \mathrm{C}$, the rice threshold for maximum temperature (Welch et al., 2010; Yoshida, 1981). However, the negative impacts of maximum temperature might be significant in the future as projected maximum temperature by 2100 is relatively close to $35^{\circ} \mathrm{C}$.

Labour $(r=.39, \mathrm{p}<.05)$ has a significant correlation with the rice yield of wetland farming. As most farmers are farming less than 0.5 ha (BPS NTB, 2014), the role of labour is important for wetland farming (Kasryno, Pasandaran, \& Fagi, 2004). With such small farming land, the use of tractors is not beneficial. As such, some farming practices such as land preparation and sowing are much more economical if handled manually by farmers.

In dryland farming, seed $(r=.33, \mathrm{p}<.01)$ has a highly significant correlation with rice yield. Hence, a statistical model of dryland farming will include minimum temperature and seed as independent variables and the model of wetland farming will include labour and minimum temperature as independent variables. Seed is highly important as dryland farmers do not prepare land prior to rice planting seasons. Without land preparation and without irrigation, possibility of seed growing is relatively small. Hence, more seed is needed to increase the possibility of seed cultivation. 
Pesticide $(r=.11, p>.1)$ is insignificant in supporting rice yield in wetland farming and in dryland farming ( $r=-.24, p>.1)$. This finding is supported by low harvest failure due to pests and diseases (Dinas Pertanian, 2012; Hutapea, 2012; Piao, 2010; Sari, 2012). Pesticide has little impact as new rice varieties have been introduced regularly to overcome new pests and diseases (Departemen Pertanian Republik Indonesia, 2012).

The impacts of pesticide in dryland farming are relatively minimal, as weed, a main biotic barrier in dryland farming, is manually eradicated during growing season (Wirajaswadi, 2004). This may also lead to overused pesticide, leading in turn to a negative correlation of pesticide. The biggest barrier to dryland rice growing (Wirajaswadi, 2004), weed, is usually minimised by increased labour usage (Wirajaswadi, 2004). Through Integrated Pest Management (IPM), pests and diseases can also be minimised significantly (BPTP, 2004). These factors may, respectively, explain the overuse of labour and the insignificance of pesticide in dryland farming.

Figures 5.4 and 5.5 display the use of seed $(r=.1, p>.1)$ and fertiliser $(r=-.05, p>.1)$, respectively, from 1976 to 2011 in wetland farming. Wetland farmers are likely to overuse seed as they sow it at about $60 \mathrm{~kg} / \mathrm{ha}$, which is higher than the optimum use of about $35 \mathrm{~kg} / \mathrm{ha}$. Another study (Wirajaswadi, 2004) suggests that the use of nitrogen fertiliser at a rate of $200 \mathrm{~kg} / \mathrm{ha}$ does not have a significant impact compared with the use of nitrogen fertiliser at $125 \mathrm{~kg} / \mathrm{ha}$. All of these are reasons for insignificant correlations between fertiliser, seed and rice yield in wetland farming.

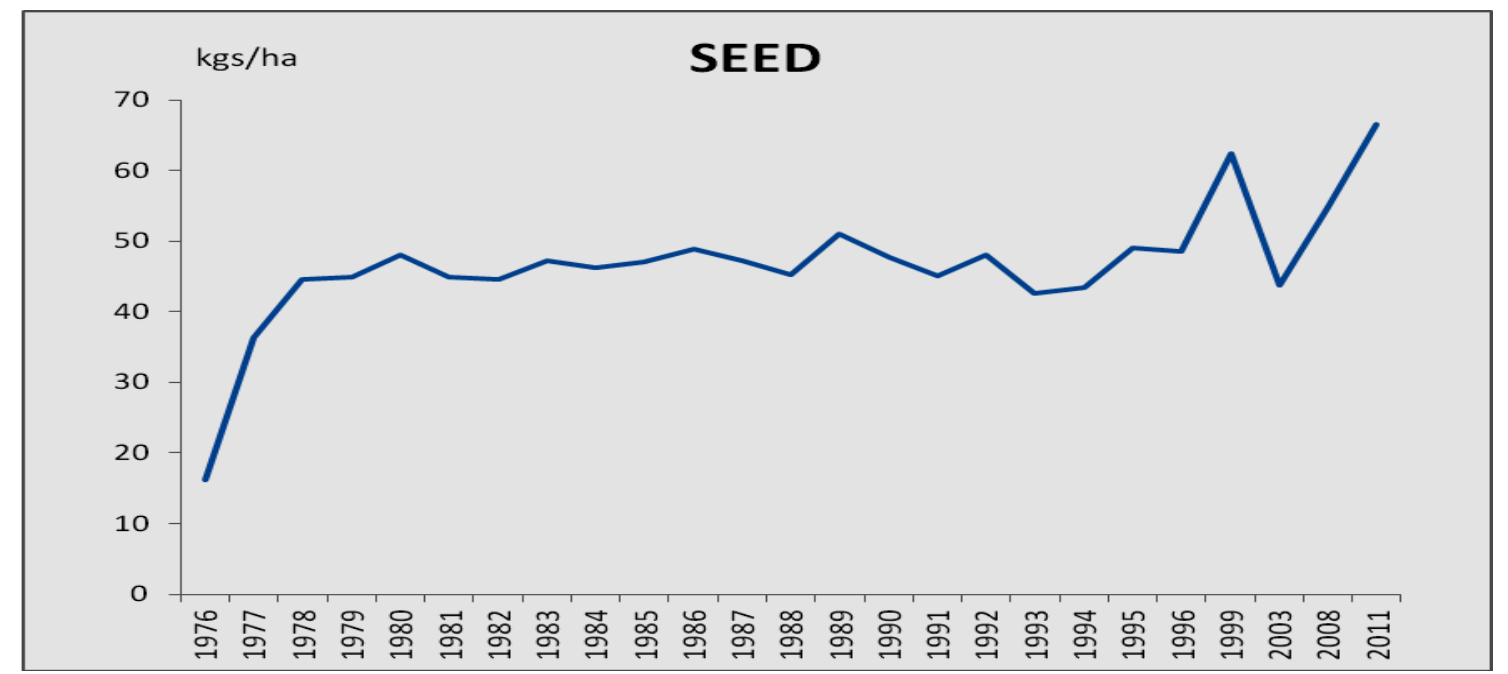

Figure 5.4 Historical data of seed usage in wetland farming (BPS, 1976-2011) 


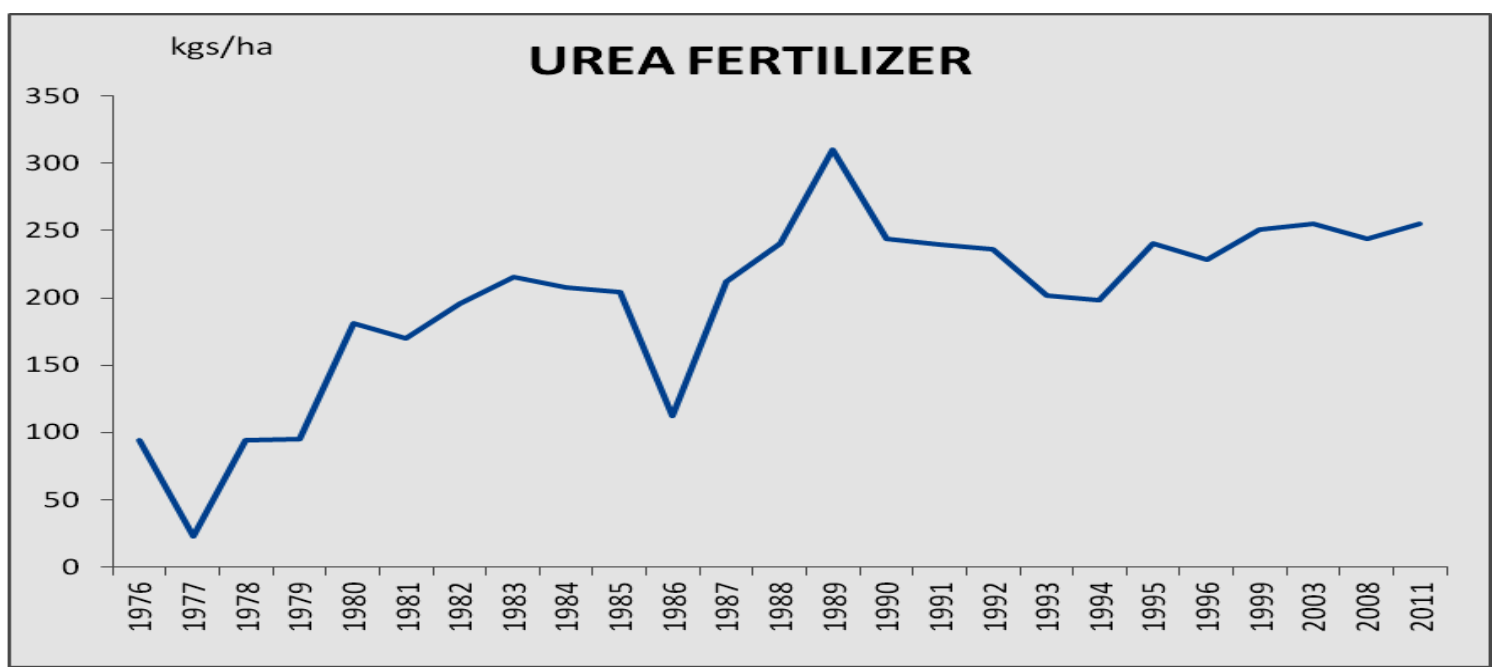

Figure 5.5 Historical data of fertiliser usage in wetland farming (BPS, 1976-2011)

Capital $^{24}(r=-.01, p>.1)$ is not significantly correlated with the rice yield of dryland farming. Land preparation of dryland farms is difficult as the soil is hard (Kartaatmadja et al., 2004). As dryland farming usually consists of hard soil, use of machines such as tractors is not beneficial (Wirajaswadi, 2004). For wetland farming, capital ( $r=.13, p>.1)$ is not useful, given that West Nusa Tenggara has some mountains, resulting in highly sloped land or plateaus (Dinas Pertanian Nusa Tenggara Barat, 2006).

Labour is not significant in dryland farming $(r=-.04, p>.1)$ owing to overused labour in rice dryland farming. As a comparison, in wetland farming labour is employed to sow seeds and to cut harvested rice. In dryland farming, by contrast, labour is not only sowing seeds and cutting harvested rice, but also manually arranging seeds and handling weeds (between planting seasons and harvesting seasons), leading to the overuse of labour in dryland farming (The Indonesian Ministry of Agriculture, 2005; Kartaatmadja, 2004, Wirajaswadi, 2004).

\subsubsection{The coefficients of the models}

Estimated statistical models by ordinary least square for wetland farming involve many dependent variables such as labour and minimum temperature. Statistical models for dryland farming, by comparison, involve many variables such as seed and minimum temperature. As shown in table 5.3, dummy variables in both models of wetland farming are

${ }^{24}$ Capital is defined as total payment for the use agricultural tools such as tractors and hand sprayers. BPS (2011) claims that tractors are the most used wetland agricultural tool in West Nusa Tenggara. 
significant ( $\mathrm{p}<.01$ for models with time variables), supporting a structural break of wetland farming in 1996. Note that a dummy variable, dummy1996, is used as a representation of structural break in wetland farming.

A structural break of dryland farming in 2008 is supported given that the dummy variable dummy2008 (a representation of a structural break in 2008) is significant (table 5.4). As mentioned earlier, since 2008, the government has distributed suitable rice varieties for dryland farming, leading to a significant increase of dryland rice yield in 2008.

Table 5.3 and table 5.4 show that linear variables and squared time variables have significant impacts on rice yield in wetland and dryland farming. In particular, linear time variables emphasise the roles of increased technological progress, while negative squared time variables emphasise the roles of decreased technological progress in wetland farming (Falcon et al., 2004). Some existing studies claim that research and development in rice varieties plays an important role in supporting rice yield in Indonesia (Sembiring 2008; Susanto, Daradjat, \& Suprihatno, 2003) and in Asia (Hossain, 1988; Pingali \& Hossain, 1998; Suresh, 2013). 


\begin{tabular}{|c|c|c|}
\hline Variables & $\begin{array}{l}\text { An equation with time } \\
\text { variables }\end{array}$ & $\begin{array}{l}\text { An equation with the first } \\
\text { differenced variables }\end{array}$ \\
\hline Seasonal minimum temperature & $-0.197(p<.01)$ & $-0.12(p<0.05)$ \\
\hline Total labour & $3.3 \mathrm{e}-3(p<0.01)$ & $3 \mathrm{e}-3(p=.1)$ \\
\hline Time variable & $0.18(p<.001)$ & - \\
\hline Time variable square & $-4 \mathrm{e}-3(p<.01)$ & - \\
\hline Dummy1996*time variable & $-5.4 \mathrm{e}-2(\mathrm{p}<.01)$ & - \\
\hline $\begin{array}{l}\text { Dummy } 1996 * \text { time variable } \\
\text { square }\end{array}$ & $2.4 \mathrm{e}-3(\mathrm{p}<.01)$ & - \\
\hline Dummy1996 & - & $-7 \mathrm{e}-2(\mathrm{p}<.1)$ \\
\hline Constant & $6.73(p<.01)$ & $8.8 \mathrm{e}-2(p<.01)$ \\
\hline $\mathrm{R}$-adjusted square & $98 \%$ & $21 \%$ \\
\hline MAPE & $1.75 \%$ & $3.2 \%{ }^{25}$ \\
\hline $\begin{array}{l}\text { Normality Test (Jarque-Bera) } \\
\text { Ho: data is normally distributed }\end{array}$ & $\begin{array}{c}\mathrm{p}=.77 \\
\text { (Accept Ho: normally } \\
\text { distributed data) }\end{array}$ & $\begin{array}{c}\mathrm{p}=.9 \\
\text { (Accept Ho: normally } \\
\text { distributed data) }\end{array}$ \\
\hline $\begin{array}{l}\text { Autocorrelation (Breusch-Godfrey } \\
\text { Serial Correlation LM Test or Run } \\
\text { Test) } \\
\text { Ho: data is random (no serial } \\
\text { correlation) }\end{array}$ & $\begin{array}{c}\mathrm{p}=.134 \\
\text { (Accept Ho: no serial } \\
\text { correlation or no } \\
\text { correlated data) }\end{array}$ & $\begin{array}{c}\mathrm{p}=.9 \\
\text { (Accept Ho: no serial } \\
\text { correlation or no } \\
\text { correlated data) }\end{array}$ \\
\hline $\begin{array}{l}\text { Heteroscedasticity (White test) } \\
\text { Ho: data is homoscedastic (i.e. has } \\
\text { unchanging variance) }\end{array}$ & $\begin{array}{c}\mathrm{p}=.62 \\
\text { (Accept data is } \\
\text { homoscedastic (i.e. has } \\
\text { unchanging variance) }\end{array}$ & $\begin{array}{c}\mathrm{p}=.54 \\
\text { (Accept data is } \\
\text { homoscedastic (i.e. has } \\
\text { unchanging variance) }\end{array}$ \\
\hline $\begin{array}{l}\text { Multicollinearity } \\
\text { Ho: there is no multicollinearity } \\
\text { among independent variables }\end{array}$ & $\begin{array}{l}\text { All Vector Inflation } \\
\text { Factors are lower than } \\
10 \\
\text { (Accept Ho: there is no } \\
\text { multicollinearity among } \\
\text { independent variables) }\end{array}$ & $\begin{array}{l}\text { All Vector Inflation } \\
\text { Factors are lower than } 10 \\
\text { (Accept Ho: there is no } \\
\text { multicollinearity among } \\
\text { independent variables) }\end{array}$ \\
\hline $\begin{array}{l}\text { Goodness of fit (F-test) } \\
\text { Ho: The model has no explanatory } \\
\text { power at all }\end{array}$ & $\begin{array}{l}\mathrm{p}<.001 \\
\text { (Reject Ho so the model } \\
\text { has explanatory power) }\end{array}$ & $\begin{array}{l}\mathrm{p}<.05 \\
\text { (Reject Ho so the model } \\
\text { has explanatory power) }\end{array}$ \\
\hline
\end{tabular}

Table 5.3 Unstandardised coefficients of each statistical model for wetland farming

${ }^{25}$ For models with the first differenced variables, MAPE and R-square are measured after comparing rice yield, not by comparing the first differenced rice yield 


\begin{tabular}{|c|c|c|}
\hline Variables & $\begin{array}{l}\text { An equation with time } \\
\text { variables }\end{array}$ & $\begin{array}{l}\text { An equation with the first } \\
\text { differenced variables }\end{array}$ \\
\hline Seasonal minimum temperature & $-0.12(\mathrm{p}<.05)$ & $-6.5 e-2(p<0.1)$ \\
\hline Seed $^{26}$ & $1.8 \mathrm{e}-2(\mathrm{p}<.01)$ & - \\
\hline Time variable & $6.2 \mathrm{e}-2(\mathrm{p}<.01)$ & - \\
\hline Time variable square & $-5.6 e-4(p<.01)$ & - \\
\hline Dummy2008 & $0.85(\mathrm{p}<.01)$ & $0.8(\mathrm{p}<.01)$ \\
\hline Constant & $3.7(\mathrm{p}<.01)$ & $4.4 \mathrm{e}-2(\mathrm{p}<.01)$ \\
\hline R-adjusted square & $99 \%$ & $81 \%$ \\
\hline MAPE & $2.3 \%$ & $4.7 \%^{27}$ \\
\hline $\begin{array}{l}\text { Normality Test (Jarque-Bera) } \\
\text { Ho: data is normally distributed }\end{array}$ & $\begin{array}{c}\mathrm{p}=.8 \\
\text { (Accept Ho: normally } \\
\text { distributed data) }\end{array}$ & $\begin{array}{c}\mathrm{p}=.12 \\
\text { (Accept Ho: normally } \\
\text { distributed data) }\end{array}$ \\
\hline $\begin{array}{l}\text { Autocorrelation (Breusch-Godfrey } \\
\text { Serial Correlation LM Test or Run } \\
\text { Test) } \\
\text { Ho: data is random (no serial } \\
\text { correlation/ no autocorrelated data) }\end{array}$ & $\begin{array}{c}\mathrm{p}=.197 \\
\text { (Accept Ho: no serial } \\
\text { correlation or no } \\
\text { correlated data) }\end{array}$ & $\begin{array}{c}\mathrm{p}=.699 \\
\text { (Accept Ho: serial } \\
\text { correlation or no } \\
\text { correlated data) }\end{array}$ \\
\hline $\begin{array}{l}\text { Heteroscedasticity (White Test) } \\
\text { Ho: data is homoscedastic (i.e. has } \\
\text { unchanging variance) }\end{array}$ & $\begin{array}{c}\mathrm{p}=.1 \\
\text { (Accept data is } \\
\text { homoscedastic (i.e. has } \\
\text { unchanging variance) }\end{array}$ & $\begin{array}{c}\mathrm{p}=.44 \\
\text { (Accept data is } \\
\text { homoscedastic (i.e. has } \\
\text { unchanging variance) }\end{array}$ \\
\hline Multicollinearity & $\begin{array}{l}\text { All Vector Inflation } \\
\text { Factors are lower than } \\
10 \\
\text { (Accept Ho: there is no } \\
\text { multicollinearity } \\
\text { among independent } \\
\text { variables) }\end{array}$ & $\begin{array}{l}\text { All Vector Inflation } \\
\text { Factors are lower than } 10 \\
\text { (Accept Ho: there is no } \\
\text { multicollinearity among } \\
\text { independent variables) }\end{array}$ \\
\hline $\begin{array}{l}\text { Goodness of fit (F-test) } \\
\text { Ho: The model has no explanatory } \\
\text { power at all }\end{array}$ & $\begin{array}{c}\mathrm{p}<.001 \\
\text { (Reject Ho, so the } \\
\text { model has explanatory } \\
\text { power at all) }\end{array}$ & $\begin{array}{c}\mathrm{p}<.001 \\
\text { (Reject Ho, so the model } \\
\text { has explanatory power at } \\
\text { all) }\end{array}$ \\
\hline
\end{tabular}

Table 5.4 Unstandardised coefficients of each statistical models for dryland farming

\footnotetext{
${ }^{26}$ A model with the first differenced variable does not include seed, as the model of the first differenced variable that includes seed has a higher information criterion than the model of the first differenced variables without seed. Note, a lower information criterion leads to better statistical models.

27 For models with the first differenced variables, MAPE and R-square are measured after comparing rice yield not comparing delta rice yield
} 
As shown in table 5.3 and table 5.4, every increase of seasonal minimum temperature by $1^{0} \mathrm{C}$ tends to decrease rice yield by -0.197 tonnes/ha and -0.12 tonnes/ha in wetland and dryland farming respectively. A statistical model of wetland rice shows that an increase in one unit labour leads to a higher rice yield by 0.003 tonnes/ha. Moreover, a statistical model of dryland rice reveals that each increase of seed by $1 \mathrm{IDR} /$ year results in 0.018 tonnes/ha.

Table 5.3 and table 5.4 also summarise that all statistical models satisfy statistical assumptions such as non-autocorrelation and homoscedasticity. However, as shown in table 5.3 and table 5.4, percentage errors (MAPE) of statistical models with time variables is lower than that of statistical models with the first differenced variables. Moreover, for wetland farming the model with the first differenced variables has a lower explanatory power, as this model passes the goodness of fit test at $\alpha=5 \%$, whereas the model with time variables passes the goodness of fit test at $\alpha=1 \%$. Again, given that some existing studies claim that the role of technology is highly important for rice yield (Hossain, 1988; Pingali \& Hossain, 1998; Sembiring 2008; Susanto et al., 2003; Suresh, 2013), the model with time variables of wetland farming is better than the model with the first differenced variables of wetland farming as the models with time variables embed time variables as the representation of technological progress.

Although minimum temperature is a significant predictor in a statistical model with time variables, minimum temperature is not a significant predictor in models with the first differenced variables (table 5.4). The main reason for this is that a model with the first differenced variables does not capture the effects of technological progress on dryland rice yield. So, the effects of technological progress on rice yield might negate the effects of minimum temperature on rice yield, leading to the insignificant effects of minimum temperature on rice yield.

Moreover, since some existing studies claim that high minimum temperature tends to negatively affect rice yield (Peng et al., 2004; Welch et al., 2010; Zhang et al., 2013a), the model with time variables of dryland farming is better than the model with the first differenced variables of dryland farming, as the model with time variables has a significant variable of minimum temperature. 
This study does not include squared variables of climate as predictors since the squared variables do not improve models (i.e. squared climate variables are insignificant predictors). Models embedding squared variables have higher information criterion such as Akaike information criterion and Schwarz information criterion. Excluding squared variables of climate is also supported by observed data. As shown later in table 5.5, observed minimum temperature, in general, falls in region 3 (please refer to figure 5.1) which means observed minimum temperature is higher than the rice threshold for minimum temperature $\left(22^{\circ} \mathrm{C}\right)$. For maximum temperature, observed maximum temperature falls in region 1 (please refer to figure 5.1) which means this data is lower than the rice threshold of maximum temperature $\left(35^{0} \mathrm{C}\right)$.

An important consideration is whether statistical models with time variables accurately explain the relationship between independent variables and rice yield. An R-adjusted square of $98 \%$ means that statistical models with time variables can explain about $98 \%$ of the variation in rice yield. Furthermore, Lobell and Burke (2008) suggest using statistical models in assessing the impacts of climate change if statistical models have an R-squared higher than $67 \%$. Thus, this study applies statistical models with time variables in estimating the impacts of climate change on rice yield.

Figure 5.6 and figure 5.7 summarise a comparison between historical rice yield and simulated rice yield for wetland farming based on a statistical model of time variable and a statistical model with the first differenced variables respectively (statistical errors between historical and simulated yield are measured in MAPEs as shown in table 5.3 and table 5.4). Likewise, figure 5.8 and figure 5.9 display a comparison between historical rice yield and simulated rice yield for dryland farming based on a statistical model of time variables and a statistical model with the first differenced variables respectively. As explained earlier, models with time variables are more representative than models with the first differenced variables. 


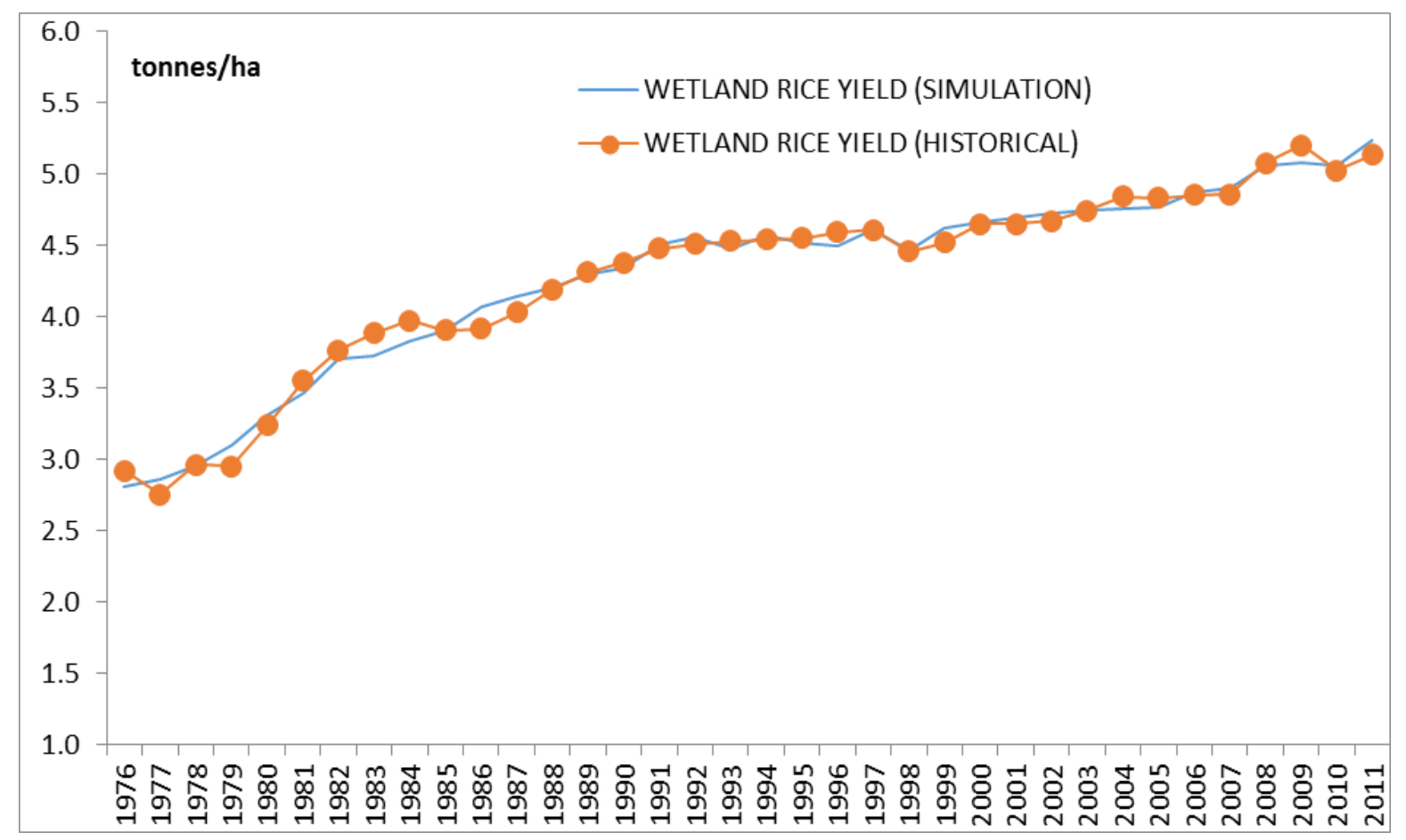

Figure 5.6 A comparison between rice yield of wetland farming (a statistical model with time variables)

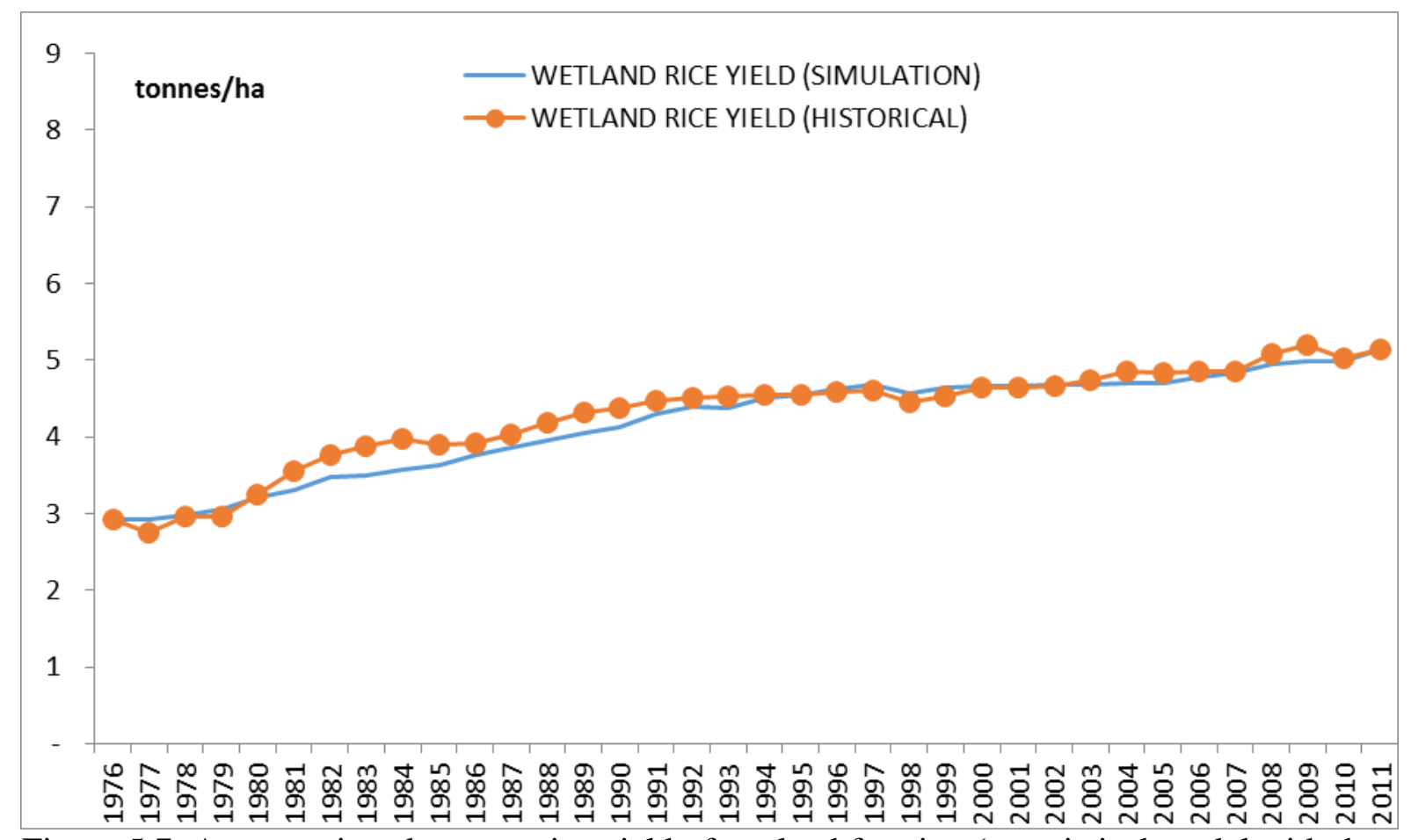

Figure 5.7 A comparison between rice yield of wetland farming (a statistical model with the first differenced variables) 


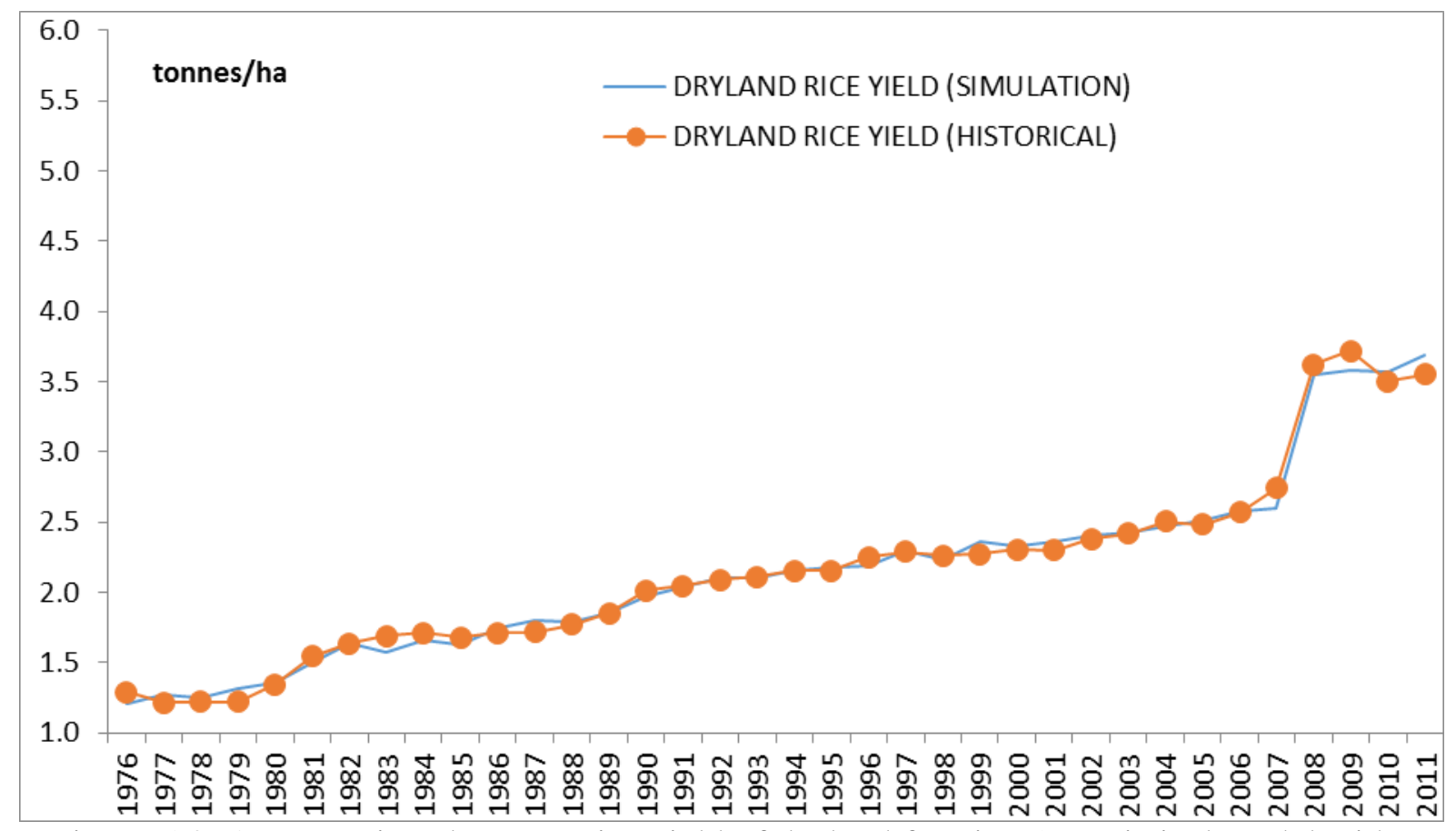

Figure 5.8 A comparison between rice yield of dryland farming (a statistical model with time variables)

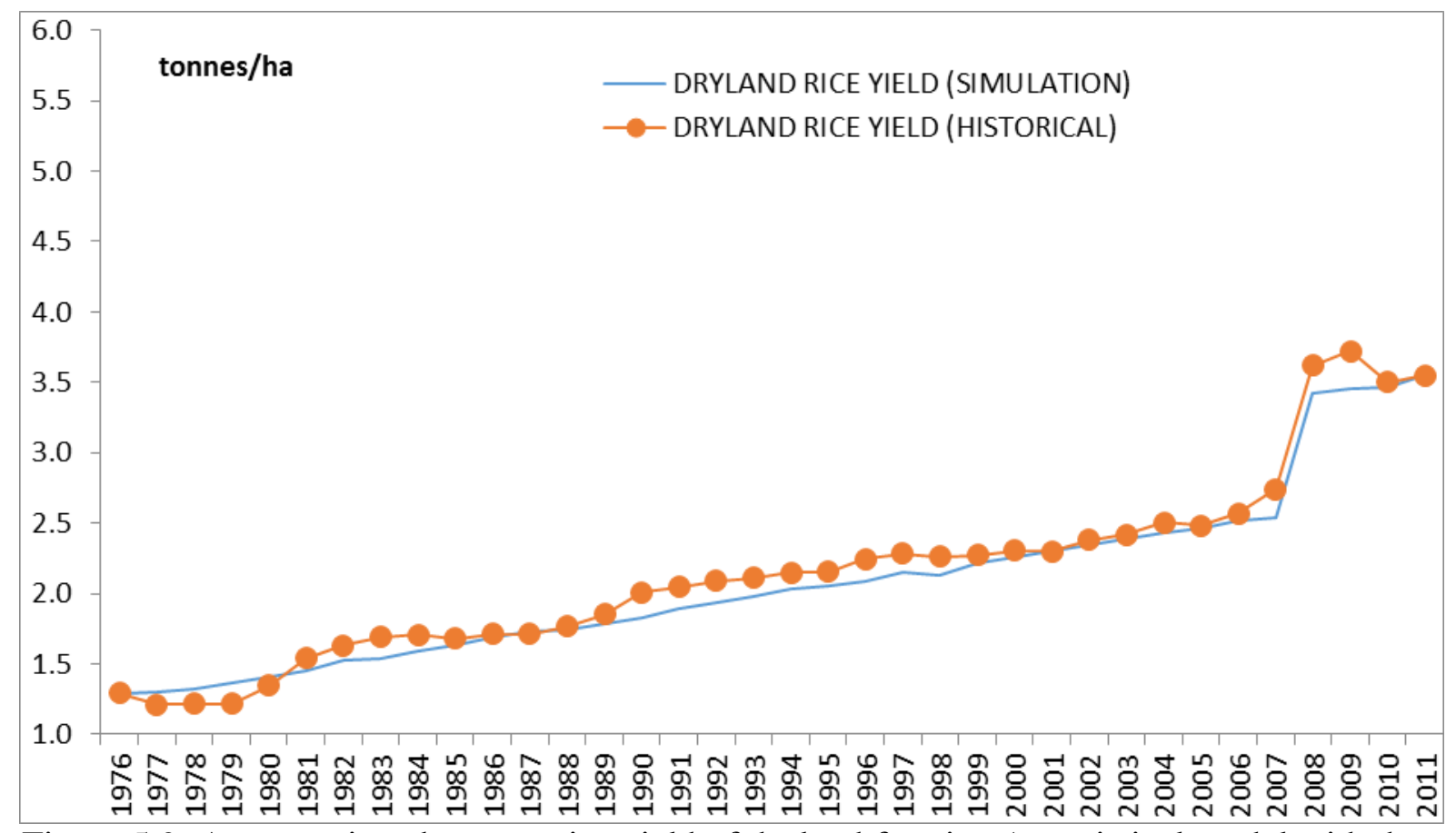

Figure 5.9 A comparison between rice yield of dryland farming (a statistical model with the first differenced variables) 


\subsubsection{The effects of climate on rice yield: supporting studies}

Table 5.5 shows that minimum temperature in WNT has exceeded its threshold of $22^{\circ} \mathrm{C}$ since 1977 (Peng et al., 2004), whereas the upper quantile of maximum temperature was about $31.4^{\circ} \mathrm{C}$, meaning that it has not ever exceeded its threshold of $35^{\circ} \mathrm{C}$ (Welch et al., 2010; Yoshida, 1981).

\begin{tabular}{|l|c|c|c|}
\hline Data Distribution & Seasonal Rainfall & $\begin{array}{c}\text { Seasonal Minimum } \\
\text { Temperature }\end{array}$ & $\begin{array}{c}\text { Seasonal Maximum } \\
\text { Temperature }\end{array}$ \\
\hline Mean & 1,658 & 22.9 & 31.1 \\
\hline Standard Deviation & 318 & 0.4 & 0.5 \\
\hline Percentile 25\% & 1,412 & 22.6 & 30.8 \\
\hline Percentile 50\% & 1,571 & 22.9 & 31.0 \\
\hline Percentile 75\% & 1,839 & 23.1 & 31.4 \\
\hline
\end{tabular}

Table 5.5 Data distribution of climate (BMKG, 2014)

As wetland farming is surrounded by irrigation facilities, rainfall is not a significant factor in supporting rice growth (Wang et al., 2013). For dryland farming, rainfall tends not to affect yield of dryland rice as monthly rainfall during growing seasons was largely above $100 \mathrm{~mm} /$ month (BMKG NTB, 1976-2012). This finding corroborates another existing study (Yunizar, 2004) explaining that dryland rice can grow well when monthly rainfall is about $100 \mathrm{~mm} /$ month and this also is underscored by another study (Wirajaswadi, 2004) suggesting that a rainfall higher than $100 \mathrm{~mm} / \mathrm{month}$ has insignificant impacts on dryland rice.

As observed maximum temperature is below its rice threshold $\left(35^{\circ} \mathrm{C}\right)$, the negative effects of maximum temperature are not statistically significant in both farming types. This study corroborates existing analyses concluding that rice yield is strongly affected by minimum temperature rather than maximum temperature (Peng et al., 2004; Jagadish et al., 2010; Mohammed \& Tarpley, 2009). It appears that the effects of minimum temperature might be more important in the future as minimum temperature is projected to increase more rapidly than maximum temperature (IPCC, 2013).

\subsection{The impacts of climate change on rice yield by 2090 (2077-2100)}

\subsubsection{Forecasting parameters for predicting impacts of climate change}

As mentioned earlier, labour and seed is a significant production factor for wetland and dryland farming respectively. In 2011, the use of seed was about IDR 20.8/ha which is 
similar to its optimum use: $60 \mathrm{~kg} / \mathrm{ha}$ (Wirajaswadi, 2004). For labour, the marginal product of labour is about $3.46 \times 10^{-3}$ (tonnes/IDR) which is measured by taking the first derivative of a statistical model with time variables. It should be noted that the first derivative of the statistical model is a slope of marginal product of labour or the amount of output (rice yield) after one additional input of labour. Because the marginal product of labour was close to zero $^{28}$, this study assumes that the used labour in 2011 i.e IDR 203.3/ha is optimal. Again, the marginal product of labour is evaluated instead of the marginal revenue of labour, owing to limited data measuring the marginal revenue of labour.

This study assumes that in the future, the effects of technological progress on rice yield is similar to the effects of technological progress in the observed period (1976-2011) (W. Falcon, personal communication, November $4^{\text {th }}$, 2015; P. Rowhani, personal communication November $\left.13^{\text {th }}, 2015\right)$. Thus, to estimate future rice yield, models with variables as shown in table 5.3 can be reformulated as follows:

$\mathrm{Yw}=6.73+\left[\left(0.18-5.4 \mathrm{e}-2^{29}\right) * \mathrm{Ai}+(2.4 \mathrm{e}-3-4 \mathrm{e}-3) * \mathrm{Ai}^{2}\right]+(3.3 \mathrm{e}-3 * \mathrm{Li})-\{0.197 * \mathrm{Ti}\} \ldots$

$\mathrm{Yw}=6.73+\left[0.126 * \mathrm{Ai}-1.6 \mathrm{e}-3^{*} \mathrm{Ai}^{2}\right]+(3.3 \mathrm{e}-3 * \mathrm{Li})-\{0.197 * \mathrm{Ti}\}$

in 2011, $\mathrm{Ai}=36$ so equation (5.3.1) can be rewritten as follows:

$\mathrm{Yw}=6.73+[4.536-2.1]+(3.3 \mathrm{e}-3 * \mathrm{Li})-\{0.197 * \mathrm{Ti}\}$

$\mathrm{Yw}=6.73+[2.46]+(3.3 \mathrm{e}-3 * \mathrm{Li})-\{0.197 * \mathrm{Ti}\}$

$\mathrm{Yw}=$ rice yield in wetland farming (tonnes/ha)

Statistical models with time variables for dryland farming, as shown in table 5.4, can also be rewritten as follows:

$\mathrm{Yd}=3.7+\left[\left(6.2 \mathrm{e}-2 * \mathrm{Ai}-5.6 \mathrm{e}-4 * \mathrm{Ai}^{2}\right)\right]+1.86 \mathrm{e}-2 * \mathrm{Si}+0.85-0.12 * \mathrm{Ti}$

in 2011, $\mathrm{Ai}=36$ so equation (5.4.1) can be reformulated as follows:

$\mathrm{Yd}=4.56+[2.25-0.73]+(1.86 \mathrm{e}-2 * \mathrm{Si})-\{0.12 * \mathrm{Ti}\}$

$\mathrm{Yd}=4.56+[1.52]+(1.86 \mathrm{e}-2 * \mathrm{Si})-\{0.12 * \mathrm{Ti}\}$

\footnotetext{
${ }^{28}$ Huang (1985) suggests to increase labour until the marginal product labour approaches to zero.

29 The coefficient of linear (squared) variable is reduced by its dummy variable. This is also applied to statistical models of dryland farming for both linear and squared time variables.
} 
$\mathrm{Yd}=$ rice yield in dryland farming (tonnes/ha)

Equation (5.3.2) and equation (5.4.2) can be seen as the combination of some impacts, such as those of minimum temperature and those of technological progress as follows:

$\mathrm{Yw}=$ constant + [the effects of technological progress $]+$ (the effects of labour $)+\{$ the effects of minimum temperature $\}$.

$Y d=$ constant $+[$ the effects of technological progress $]+($ the effects of seed $)+\{$ the effects of minimum temperature\}

Table 5.6 summarises parameter values to estimate rice yield in wetland and dryland farming under "no climate change" or the base case scenario. A projection of minimum temperature, under "no climate change", is similar to observed minimum temperature. Rice yield under "no climate change" in the following sections will be used to estimate reductions of rice yield owing to climate change.

\begin{tabular}{|l|c|l|}
\hline \multicolumn{1}{|c|}{ Parameters } & $\begin{array}{c}\text { Values in IDR/ha (Wetland; } \\
\text { Dryland) }\end{array}$ & \multicolumn{1}{c|}{ Description } \\
\hline Labour (IDR/ year) & $(203.3) ;($ none) & $\begin{array}{l}\text { Projected labour and seed are } \\
\text { similar to their values of 2011 } \\
\text { as the use of seed in 2011 is } \\
\text { optimum and the marginal } \\
\text { products of labour is relatively } \\
\text { close to zero. }\end{array}$ \\
\hline $\begin{array}{l}\text { Seasonal minimum } \\
\text { temperature (celsius) }\end{array}$ & $\begin{array}{c}\text { Duplicating observed minimum } \\
\text { temperature }\end{array}$ & $\begin{array}{l}\text { This is assumed as a climate } \\
\text { projection with climate change } \\
\text { absence. }\end{array}$ \\
\hline
\end{tabular}

Table 5.6. A complete setting of minimum temperature and production factors with no climate change

Based on the values of labour of wetland farming and seed of dryland farming, rice yield in the base case scenario can be calculated as follows:

$\mathrm{Li}=203.3($ IDR/year),

$\mathrm{Ti}=22.9^{\circ} \mathrm{C}$ (average minimum temperature in the period 1976-2011),

$\mathrm{Yw}=6.73+[2.46]+(3.3 \mathrm{e}-3 * 203.308)-\{0.197 * 22.9\}$ 
$\mathrm{Yw}=5.35$ tonnes/ha in the base case scenario.

For dryland, rice yield at the base case scenario is computed as follows:

$\mathrm{Si}=20.8$ (IDR/year),

$\mathrm{Ti}=22.9^{\circ} \mathrm{C}$ (average minimum temperature in the period 1976-2011),

$\mathrm{Yd}=4.56+[1.52]+(1.86 \mathrm{e}-2 * 20.8)-\{0.12 * 22.9\}$

$\mathrm{Yd}=3.7$ tonnes/ha in the base case scenario.

This study measures the impacts of climate change on rice yield in three steps. The first is to generate ensemble climate projections from some climate models such as GFDL-CM3 and IPSL-CM5A-LR, as these climate models can appropriately simulate the interaction between ENSO and monsoon in South East Asia (Sperber et al., 2013). The second is to measure projected rice yield under ensemble climate projections based on the aforementioned climate models. The last is to compare rice yield in the second step with rice yield based on the base case scenario (Karim, Ishikawa, Ikeda, Islam, 2012).

\subsubsection{Projected climate}

IPCC (2013) describes 4 different climate projections from the RCP2.6 to RCP8.5 scenarios. Concisely, the climate projections relate to their radiative forcing at the year 2100 $\left(2.6,4.5,6.0\right.$ and $8.5 \mathrm{~W} / \mathrm{m}^{2}$, respectively $\left.{ }^{30}\right)$. Moreover, RCP8.5 scenario represents a climate projection without mitigation policy and RCP2.6 represents a climate projection with the most significant mitigation policy. A simplified explanation of RCP scenarios is summarised in table 2.1.

\footnotetext{
${ }^{30} \mathrm{~W} / \mathrm{m}^{2}=$ Watts per square metre
} 
Though climate data is now available from nearly 40 CMIP5 models, this study extracted climate projections from six models (GFDL-CM3; GFDL-ESM2G; GFDL-ESM2M; IPSLCM5A-LR; IPSL-CM5A-MR and NorESM1-M) as these climate models can appropriately simulate the interaction between ENSO and monsoon in South East Asia (Sperber et al., 2013). It should be noted that due to limited funding, this study only extracted six climate models.

For each climate model, this study considered the climate time series for the grid point nearest to West Nusa Tenggara. The study presents three time slices - short term or near future i.e., 2030 (2015-2045), midterm i.e., 2060 (2046-2076) and long term i.e., 2090 (2077-2100). Since climate models usually provide only mean temperature, this study estimated minimum and maximum temperature by calculating the average difference between monthly maximum and monthly minimum from observed data and then adding (subtracting) a half of this difference to the mean temperature from each model to estimate projected maximum and minimum temperatures.

Model output for future projections was bias-corrected based on a comparison between observed and simulated climate from 1976-2011. Temperature offsets were calculated month-by-month and subtracted from modelled temperatures (van Roosmalen et al., 2011; Wibig et al., 2015). Precipitation scalings were calculated month-by-month as the ratio of average observed to modelled precipitation, with future projected precipitation multiplied by the appropriate monthly ratio (van Roosmalen et al., 2011; Wibig et al., 2015). Compared with observed climate during 1976-2011, climate models tended to simulate higher temperature (too warm) and higher rainfall (too wet). No further downscaling was attempted as this study seeks only to assess broad changes in climate and their likely effects on rice yield.

For each climate variable, this study calculates a 12-month average data from September (year $\mathrm{t}$ ) to August (year $\mathrm{t}+1$ ) as projections of seasonal climate. Ensemble projections of seasonal climate based on six different climate projections are given in tables 5.7. 


\begin{tabular}{|c|c|c|c|c|c|c|}
\hline \multirow{2}{*}{$\begin{array}{l}\text { RCP } \\
\text { scenarios }\end{array}$} & \multicolumn{2}{|c|}{$2030(2015-2045)$} & \multicolumn{2}{|c|}{$2060(2046-2076)$} & \multicolumn{2}{|c|}{$2090(2077-2100)$} \\
\hline & $\mathrm{Ti}\left({ }^{\circ} \mathrm{C}\right)$ & $\mathrm{Ta}\left({ }^{\circ} \mathrm{C}\right)$ & $\operatorname{Ti}\left({ }^{\circ} \mathrm{C}\right)$ & $\mathrm{Ta}\left({ }^{\circ} \mathrm{C}\right)$ & $\mathrm{Ti}\left({ }^{\circ} \mathrm{C}\right)$ & $\mathrm{Ta}\left({ }^{\circ} \mathrm{C}\right)$ \\
\hline $\begin{array}{l}\mathrm{RCP} 2.6 \\
\left(5^{\text {th }}-95^{\text {th }}\right)\end{array}$ & $\begin{array}{c}23.54 \\
(23.06-23.69)\end{array}$ & $\begin{array}{c}31.34 \\
(30.66-31.29)\end{array}$ & $\begin{array}{c}23.63 \\
(23.26-23.88)\end{array}$ & $\begin{array}{c}31.23 \\
(30.86-31.48)\end{array}$ & $\begin{array}{c}23.52 \\
(23.20-24.03)\end{array}$ & $\begin{array}{c}31.12 \\
(30.8-31.63)\end{array}$ \\
\hline $\begin{array}{l}\text { RCP4.5 } \\
\left(5^{\text {th }}-95^{\text {th }}\right)\end{array}$ & $\begin{array}{c}23.55 \\
(23.06-23.73)\end{array}$ & $\begin{array}{c}31.15 \\
(30.66-31.33)\end{array}$ & $\begin{array}{c}24.18 \\
(23.55-24.50)\end{array}$ & $\begin{array}{c}31.78 \\
(31.15-32.10)\end{array}$ & $\begin{array}{c}24.44 \\
(23.73-24.88)\end{array}$ & $\begin{array}{c}32.04 \\
(31.33-32.48)\end{array}$ \\
\hline $\begin{array}{l}\text { RCP6.0 } \\
\left(5^{\text {th }}-95^{\text {th }}\right)\end{array}$ & $\begin{array}{c}23.47 \\
(23.01-23.80)\end{array}$ & $\begin{array}{c}31.07 \\
(30.61-31.40)\end{array}$ & $\begin{array}{c}24.27 \\
(23.54-24.76)\end{array}$ & $\begin{array}{c}31.87 \\
(31.15-32.36)\end{array}$ & $\begin{array}{c}25.02 \\
(23.97-25.50)\end{array}$ & $\begin{array}{c}32.62 \\
(31.57-33.16)\end{array}$ \\
\hline $\begin{array}{l}\text { RCP8.5 } \\
\left(5^{\text {th }}-95^{\text {th }}\right)\end{array}$ & $\begin{array}{c}23.60 \\
(23.19-23.87)\end{array}$ & $\begin{array}{c}31.20 \\
(30.79-31.47)\end{array}$ & $\begin{array}{c}24.99 \\
(24.07-25.32)\end{array}$ & $\begin{array}{c}32.59 \\
(31.67-32.92)\end{array}$ & $\begin{array}{c}26.12 \\
(25-27.02)\end{array}$ & $\begin{array}{c}33.72 \\
(32.60-34.62)\end{array}$ \\
\hline
\end{tabular}

a. Projected seasonal maximum and minimum temperature $(\mathrm{Ti}=$ minimum temperature, $\mathrm{Ta}=$ maximum temperature).

\begin{tabular}{|l|c|c|c|}
\hline \multirow{2}{*}{ RCP scenarios } & $\mathbf{2 0 3 0}(\mathbf{2 0 1 5 - 2 0 4 5})$ & $\mathbf{2 0 6 0}(\mathbf{2 0 4 6 - 2 0 7 6})$ & $\mathbf{2 0 9 0}(\mathbf{2 0 7 7 - 2 1 0 0})$ \\
\cline { 2 - 4 } & $\mathrm{R}(\mathrm{mm})$ & $\mathrm{R}(\mathrm{mm})$ & $\mathrm{R}(\mathrm{mm})$ \\
\hline $\mathrm{RCP} 2.6$ & 1,631 & 1,704 & 1,685 \\
$\left(5^{\text {th }}-95^{\text {th }}\right)$ & $(1,512-1,853)$ & $(1,595-1,783)$ & $(1,524-1,753)$ \\
\hline $\mathrm{RCP} 4.5$ & 1,696 & 1,747 & 1,732 \\
$\left(5^{\text {th }}-95^{\text {th }}\right)$ & $(1,543-1,918)$ & $(1,605-1,803)$ & $(1,659-1,845)$ \\
\hline $\mathrm{RCP6.0}$ & 1,765 & 1,766 & 1,882 \\
$\left(5^{\text {th }}-95^{\text {th }}\right)$ & $(1,597-1,834)$ & $(1,584-1,858)$ & $(1,578-1,934)$ \\
\hline $\mathrm{RCP} 8.5$ & 1,744 & 1,839 & 1,754 \\
$\left(5^{\text {th }}-95^{\text {th }}\right)$ & $(1,621-1,895)$ & $(1,649-1,984)$ & $(1,591-2,034)$ \\
\hline
\end{tabular}

b. Projected seasonal rainfall $(\mathrm{R}=$ rainfall)

Table 5.7 Ensemble projections of seasonal rainfall, minimum and maximum temperature

Before calculating the impacts of climate change on rice yield in wetland and dryland farming, this study displays estimated rice yield under the base case scenario or the without climate change scenario for wetland and dryland rice respectively (figure 5.10). Rice yield in wetland for the base case scenario is measured using equation (5.3.2) and for dryland rice, its yield is calculated based on equation (5.4.2). 


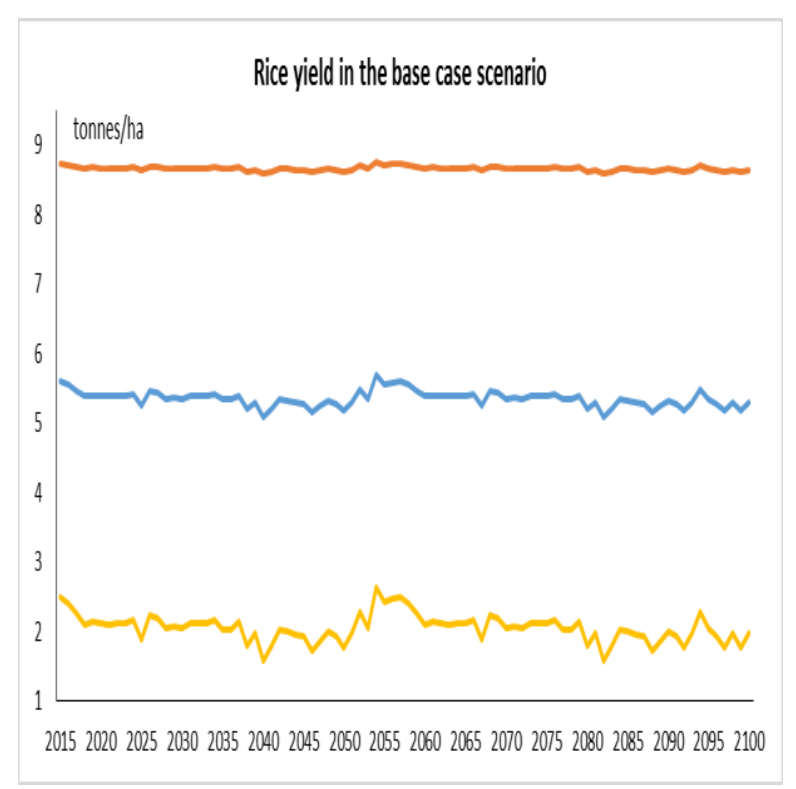

a. Wetland farming

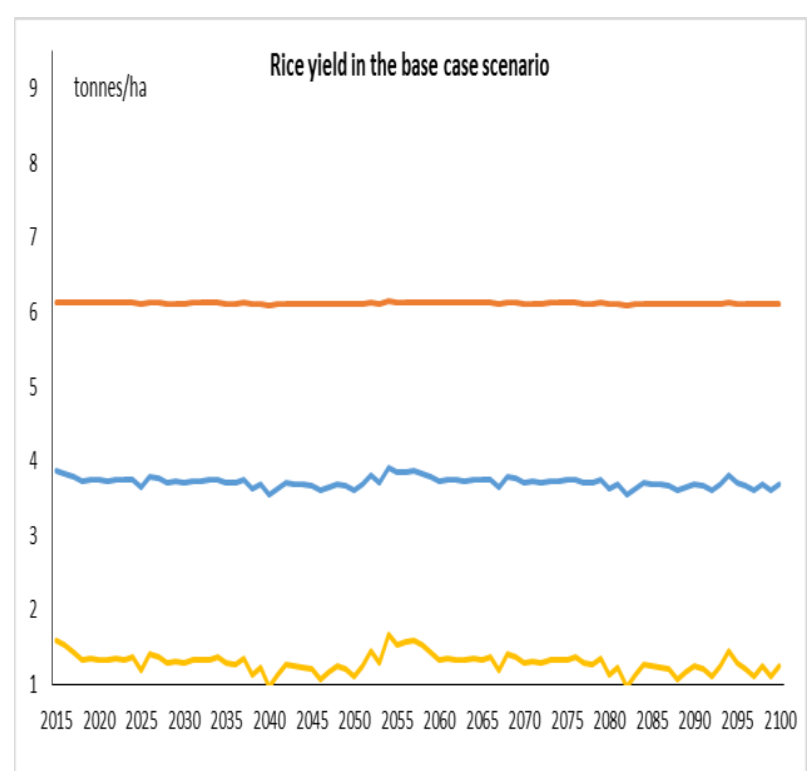

b. Dryland farming

Figure 5.10 Rice yield pattern under the base case scenario by 2100 (brown and yellow lines represent rice yield based on $95 \%$ confidence interval of minimum temperature coefficients)

\subsubsection{The projected impacts by $2090(2077-2100)$}

After generating projections from 6 climate models, it is concluded that rice yield in both farming types is projected to decrease by 2090 (2077-2100). The higher the RCP scenarios, the greater the decrease in rice yield. For instance, the RCP4.5 scenario projects that wetland rice yield loss and dryland rice yield loss will be about 4\% by 2090 (2077-2100). On the other hand, RCP8.5 projects that wetland rice yield loss and dryland rice yield loss will be about $14 \%$ by 2090 (2077-2100).

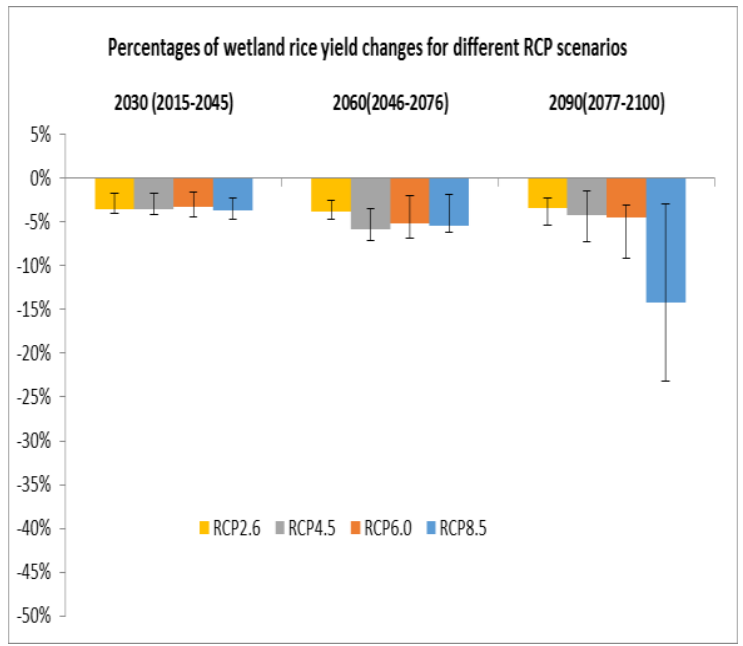

a) wetland farming

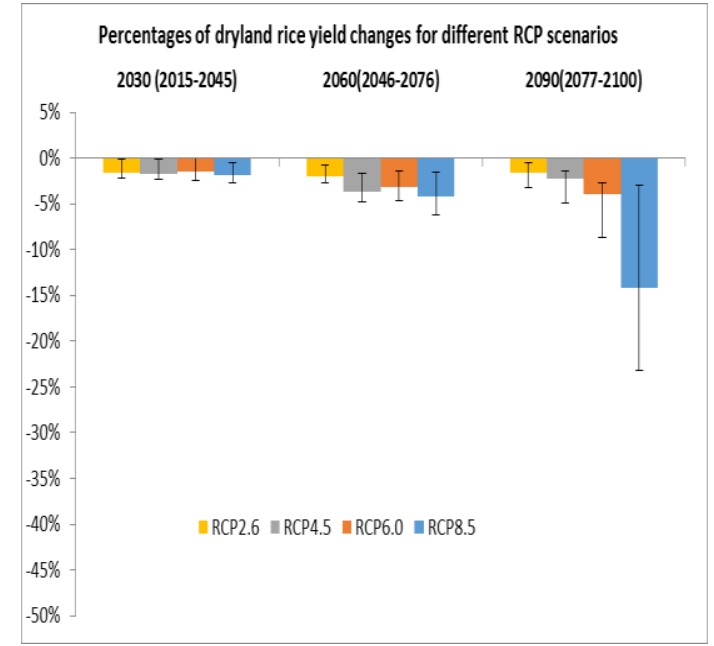

b) dryland farming

Figure 5.11 Reduction percentages of rice yield in wetland farming (a) and dryland farming (b) (vertical lines inside bars are error bars based on $5^{\text {th }}$ and $95^{\text {th }}$ percentiles of climate projections. 
Table 5.8 shows reduction percentages of rice yield in dryland and wetland farming from the $5^{\text {th }}$ percentiles and $95^{\text {th }}$ percentiles of climate projections. As the table demonstrates, the higher RCP scenarios lead to a higher loss of rice yield. In order to help readers compare this study with previous ones, this study suggests that a decrease of rice yield is projected between $0 \%$ and 5\% for the average loss in both farming types in 2030 (both farming types show similar rice yield loss). This finding conforms to Lobell et al. (2008) who claim that the loss of rice yield in South East Asia by 2030 will probably be from $0 \%$ to $5 \%$.

\begin{tabular}{|c|c|c|c|c|}
\hline Period & $\begin{array}{c}\text { Ensemble } \\
(\mathrm{RCP} 2.6 \text { scenario) }\end{array}$ & $\begin{array}{c}\text { Ensemble } \\
(\mathrm{RCP} 4.5 \text { scenario })\end{array}$ & $\begin{array}{c}\text { Ensemble } \\
\text { (RCP6.0 scenario) }\end{array}$ & $\begin{array}{c}\text { Ensemble } \\
(\mathrm{RCP} 8.5 \text { scenario })\end{array}$ \\
\hline $\begin{array}{c}2030 \\
(2015-2045)\end{array}$ & $3 \%(2 \%-4 \%)$ & $4 \%(2 \%-4 \%)$ & $3 \%(2 \%-4 \%)$ & $4 \%(2 \%-5 \%)$ \\
\hline $\begin{array}{c}2060 \\
(2046-2076)\end{array}$ & $4 \%(2 \%-5 \%)$ & $6 \%(4 \%-7 \%)$ & $5 \%(2 \%-7 \%)$ & $5 \%(2 \%-6 \%)$ \\
\hline $\begin{array}{c}2090 \\
(2077-2100)\end{array}$ & $3 \%(2 \%-5 \%)$ & $4 \%(1 \%-7 \%)$ & $5 \%(3 \%-9 \%)$ & $14 \%(3 \%-23 \%)$ \\
\hline
\end{tabular}

a) wetland farming

\begin{tabular}{|c|c|c|c|c|}
\hline Period & $\begin{array}{c}\text { Ensemble } \\
(\text { RCP2.6 scenario) }\end{array}$ & $\begin{array}{c}\text { Ensemble } \\
\text { (RCP4.5 scenario) }\end{array}$ & $\begin{array}{c}\text { Ensemble } \\
\text { (RCP6.0 scenario) }\end{array}$ & $\begin{array}{c}\text { Ensemble } \\
\text { (RCP8.5 scenario) }\end{array}$ \\
\hline $\begin{array}{c}2030 \\
(2015-2045)\end{array}$ & $2 \%(0 \%-2 \%)$ & $2 \%(0 \%-2 \%)$ & $1 \%(0 \%-3 \%)$ & $2 \%(1 \%-3 \%)$ \\
\hline $\begin{array}{c}2060 \\
(2046-2076)\end{array}$ & $2 \%(1 \%-3 \%)$ & $4 \%(2 \%-5 \%)$ & $3 \%(1 \%-5 \%)$ & $4 \%(2 \%-6 \%)$ \\
\hline $\begin{array}{c}2090 \\
(2077-2100)\end{array}$ & $2 \%(1 \%-3 \%)$ & $2 \%(1 \%-5 \%)$ & $4 \%(3 \%-9 \%)$ & $14 \%(3 \%-23 \%)$ \\
\hline
\end{tabular}

b) dryland farming

Table 5.8 Median reduction percentages of rice yield based on the average of six climate models. $\left(5^{\text {th }}-95^{\text {th }}\right.$ percentiles based on climate projections $)$

Perhaps the most important message from these projected impacts is the impact of climate change in near future (2030) and in 2060. RCP 4.5 projects the highest possible impact of climate change on loss of rice yield might be about $4 \%$ and $7 \%$ by $2030(2015-2045)$ and by 2060 (2046-2076) respectively. Although these negative impacts appear relatively small, they should be managed properly, as minimum temperatures have already exceeded the $22^{\circ} \mathrm{C}$ threshold for optimal rice growth (BPS, 2015b).

Rice scientists (Ye et al., 2015) have already claimed to have found genes or traits responsible for heat tolerance, however, finding heat tolerant rice varieties may require greater time as the rice breeding process is very complex and involves several steps 
including genetic donor identification, hybridisation and recombination, preliminary evaluation, multi-environment testing, on-farm trials, varietal release procedures and promotion of approved cultivars (Kondamudi et al., 2012). Therefore, rice scientists have to work hard to find heat tolerant varieties to tackle the impacts of climate change in the near future or by 2030 (2015-2045).

It could be argued that the future impacts of rainfall might not be similar to the impacts of rainfall explained in this study. Since IPCC (2013) projects that rainfall change in southern Indonesian regions such as West Nusa Tenggara might be less than a standard deviation of the observed rainfall variability. Hence, the future impacts of rainfall change on rice yields to 2100 is also unlikely to be significant. Moreover, as projected rainfall tends to exhibit more spatial variability than projected temperature, the impacts of rainfall in the future is less important than temperature (Lobell \& Burke, 2008; IPCC, 2013).

Since climate change is associated with a higher temperature, one possible option for minimising the impact of climate change is to breed new rice varieties (i.e. heat tolerant rice varieties), tackling the negative impact of high temperature on rice yield (Li \& Wassmann, 2011; Manigbas et al., 2014; Tao et al., 2008). Related studies contend that finding heat tolerant rice varieties is key to minimising the impacts of climate change on crop yield. Although this option might be promising, finding heat tolerant varieties could require a lot of time (Manigbas et al., 2014). Again, the yield of current heat tolerant varieties is significantly lower than the current rice varieties in WNT. For example, N22 (the most heat tolerant variety) has yield about 2 tonnes/ha (Manigbas et al., 2014; Zhang et al., 2013a), while yields of recent rice varieties in Indonesia are about 5 tonnes/ha or higher (Suprihatno et al., 2010). Because of this, it is hard to persuade farmers to replace their current rice varieties with the lower yield of heat tolerant rice varieties.

Statistical models based on the observed data might be relevant in estimating the impacts of climate change in the future without considering any possible future adaptation such as heat tolerant rice varieties (Karim et al., 2012; Lobell \& Burke, 2008; Lobell et al., 2008; Lobell $\&$ Burke, 2010). It should be noted that heat tolerant rice varieties might alleviate the negative impacts of climate change. 


\subsection{Summary}

This chapter detailed existing studies which apply statistical models in investigating the impact of climate change on crop production. Existing studies also show how production functions or statistical models combining climate factors and non-climate factors as independent variables can be applied in assessing the impact of climate change on crop production.

Next, the theoretical background behind the chosen statistical models was explained. For instance, seed is highly important for dryland rice as a greater amount of seed can increase rice yield. Again, labour is important for wetland farming as most farmers have farming land of less than 0.5 ha which means that the use of labour is more beneficial than tractors.

This chapter has shown that a structural break occurred in 1996 and in 2008, respectively, in wetland farming and dryland farming. For wetland farming, a main cause of the structural break might be decreased research funding in the middle of the 1990s, leading to a structural break in 1996 (Zeigler, \& Mohanty, 2010; Susanto et al., 2003; Wahyuni, \& Indraningsih, 2016). For dryland farming, a main cause of the structural break is the national program for increasing the national rice production (P2BN) which was initiated in 2008.

This study also shows that models with time variables are more suitable than those with the first differenced variables. This is owing to the importance of technological progress in wetland and dryland farming. Models with time variables also have higher explanatory power and lower percentage errors than those with the first differenced variables.

Minimum temperature appears to be more important than maximum temperature as this has passed its rice threshold, confirming the negative impacts of minimum temperature on rice yield. The negative impacts of high minimum temperature might be more pronounced in the future as minimum temperature tends to increase more significantly higher than maximum temperature. By contrast, since wetland rice is surrounded by irrigation facilities and dryland rice requires less rainfall than observed rainfall, the impacts of rainfall is not statistically obvious. 
Moreover, since the impacts of minimum temperature on rice yield is higher than the impacts of labour (wetland farming) or seed (dryland farming), progress with breeding heat tolerant rice varieties might be key to minimising the impacts of climate change on rice yield.

RCP 4.5 and RCP8.5 project that by 2090 (2077-2100) respectively, the impacts of climate change on rice yield loss is about $4 \%$ and $14 \%$. Ensemble climate models project that maximum temperature by 2090 (2077-2100) will probably be close to the threshold of maximum temperature for rice $\left(35^{\circ} \mathrm{C}\right)$. Owing to this, the projections of rice yield loss in this chapter may be underestimated. The extent of the effects of maximum temperature on rice yield will be discussed in next chapters.

Although this chapter can estimate the impacts of climate change on rice yield, it tends to fail in capturing the impacts of climate change on the farming stage such as the impacts of rainfall on harvested areas. This is important since some existing studies claim that seasonal rainfall might influence rice production in Indonesia. In addition, the timing of monsoon onset might affect rice production in Indonesia regions.

In conclusion, this chapter recommends three points to be investigated in subsequent chapters. The first is an investigation of the different projections of technological progress in understanding the effects of climate change on rice yield. The second point relates to a need to evaluate the effects of maximum temperature on rice yield, as projected maximum temperature by 2090 (2077-2100) is relatively close to its rice threshold. Lastly, the following chapters will assess the impacts of seasonal rainfall on rice harvested areas and on rice production. In higlighting issues that will be discussed in next chapter, table 5.9 depicts a simplified comparison among crop models, statistical models and system dynamics. 


\begin{tabular}{|c|c|c|}
\hline $\begin{array}{l}\text { Three impacts of climate change } \\
\text { investigated in this study }\end{array}$ & $\begin{array}{l}\text { Statistical Models and } \\
\text { Crop Models }\end{array}$ & System Dynamics \\
\hline $\begin{array}{l}\text { 1. The impacts of climate change } \\
\text { on rice yield }\end{array}$ & $\begin{array}{l}\text { The impacts of climate } \\
\text { change on rice yield can be } \\
\text { assessed by statistical } \\
\text { models or crop models (see } \\
\text { section 2.2.2) }\end{array}$ & $\begin{array}{l}\text { Statistical models are } \\
\text { embedded to system } \\
\text { dynamics models in } \\
\text { unveiling the impacts of } \\
\text { climate change on rice } \\
\text { yield (chapter } 6 \text { and } 7 \text { ) }\end{array}$ \\
\hline $\begin{array}{l}\text { 2. The impacts of climate change } \\
\text { on harvested areas and rice } \\
\text { production }\end{array}$ & $\begin{array}{l}\text { Although seasonal rainfall } \\
\text { might not influence rice } \\
\text { yield as shown in this } \\
\text { study, seasonal rainfall } \\
\text { might influence rice } \\
\text { production through affected } \\
\text { harvested areas. } \\
\text { Since crop models focus on } \\
\text { phenological developments } \\
\text { (Lobell Cassman, Field, } \\
\text { 2009; Rosenzweig, Elliot \& } \\
\text { Deryng, et al., 2013) such } \\
\text { as interactions } \\
\text { temperature, water and } \\
\text { nutrients affected by } \\
\text { climate change, crop } \\
\text { models tend to assume } \\
\text { constant harvested areas } \\
\text { (Deryng et al., 2016; } \\
\text { Wang, 2014). }\end{array}$ & $\begin{array}{l}\text { A } \\
\text { relationship mathematical } \\
\text { seasonal rainfall and } \\
\text { harvested areas is } \\
\text { embedded into a system } \\
\text { dynamics model (chapter } 6 \\
\text { and 7). } \\
\text { As shown in chapter } 6 \text { and } \\
7, \text { harvested areas tend to } \\
\text { increase subject to } \\
\text { available rice farming } \\
\text { areas. } \\
\text { As there is limited farming } \\
\text { areas, system dynamics } \\
\text { complements statistical } \\
\text { models by capturing an } \\
\text { increase of harvested areas } \\
\text { and rice farming areas } \\
\text { (chapter } 6 \text { and } 7 \text { ). }\end{array}$ \\
\hline $\begin{array}{l}\text { 3. The negative impacts of high } \\
\text { maximum temperature on rice } \\
\text { yield in the future }\end{array}$ & $\begin{array}{l}\text { Crop models can assess the } \\
\text { impacts of high maximum } \\
\text { temperature on rice yield } \\
\text { but crop models require a } \\
\text { lot of data than statistical } \\
\text { models/ system dynamics } \\
\text { (Lobell \& Burke, 2010). } \\
\text { Statistical models cannot } \\
\text { capture the negative } \\
\text { impacts of maximum } \\
\text { temperature on rice yield } \\
\text { since observed maximum } \\
\text { temperature is lower than } \\
\text { the rice threshold }\left(35^{\circ} \mathrm{C}\right) \text {. }\end{array}$ & $\begin{array}{l}\text { System dynamics can } \\
\text { quantify uncertain effects } \\
\text { of high maximum } \\
\text { temperature on rice yield } \\
\text { (chapter 7). } \\
\text { System dynamics can } \\
\text { quantify the negative } \\
\text { impacts of maximum } \\
\text { temperature based on } \\
\text { expert opinions (chapter 7) }\end{array}$ \\
\hline
\end{tabular}

Table 5.9 The main differences between statistical models, crop models and system dynamics 
this page intentionally left blank 


\section{CHAPTER 6 SYSTEM DYNAMICS MODEL OF RICE PRODUCTION}

This chapter deals with a system dynamics (SD) model that represents the impacts of climate change on rice production. The high-level diagram presented in section 6.1 represents the endogenous, exogenous and excluded variables of this study. Following this, a causal loop diagram (CLD) representing causal relationships between climate and nonclimate factors is also offered. Although a CLD can describe causal relationships, this diagram cannot depict mathematical relationships in the farming stage. Owing to this, the SD model containing mathematical relationships will be explained in the first instance.

The base case scenario derived from observed data is also explained. Next, validation of the SD is explained to assess whether the model can represent the real world appropriately. Afterwards, sensitivity analysis to obtain sensitive parameters will be discussed prior to an explanation of structural changes due to climate factors. At the end of this chapter, the impacts of climate change on rice production are discussed.

\subsection{The high-level diagram}

Figure 6.1 shows a simplified high-level diagram that explains the relationships between climate and production factors in the farming stage. In this figure, there are four types of boxes: oval, diamond, rectangle and rounded rectangle. The oval box represents excluded variables including climate change causes. In this model, related causes of climate change such as agricultural activity and fossil fuel burning are not included. Excluding main causes of climate change does not makes this study incomplete (Franck, 2009). Rather, this study tends to focus on assessing the impacts of climate change on rice production. At one hand, the diamond box shows a boundary system that is discussed in this chapter and more generally in this study.

The italics and regular texts, respectively, are major exogenous and major endogenous variables that may affect the model behaviour. The values of exogenous variables will not be altered during the simulation while the values of endogenous variables might be altered during the simulation. For instance, during simulation, rice yield, an endogenous variable, 
may be affected by exogenous variables such as temperature. However, the values of temperature, an exogenous variable, will not be altered during the simulation.

Italics texts, i.e. exogenous variables, include climate factors such as seasonal minimum temperature and seasonal rainfall. Although recent studies (Franck, 2009; Kopainsky et al., 2013) explore the impact of climate change on economic systems, those studies set climate as an exogenous variable. In line with existing studies (Franck, 2009; Kopainsky et al., 2013), this analysis categorises climate as an exogenous variable in order to analyse the impacts of climate change on rice production.

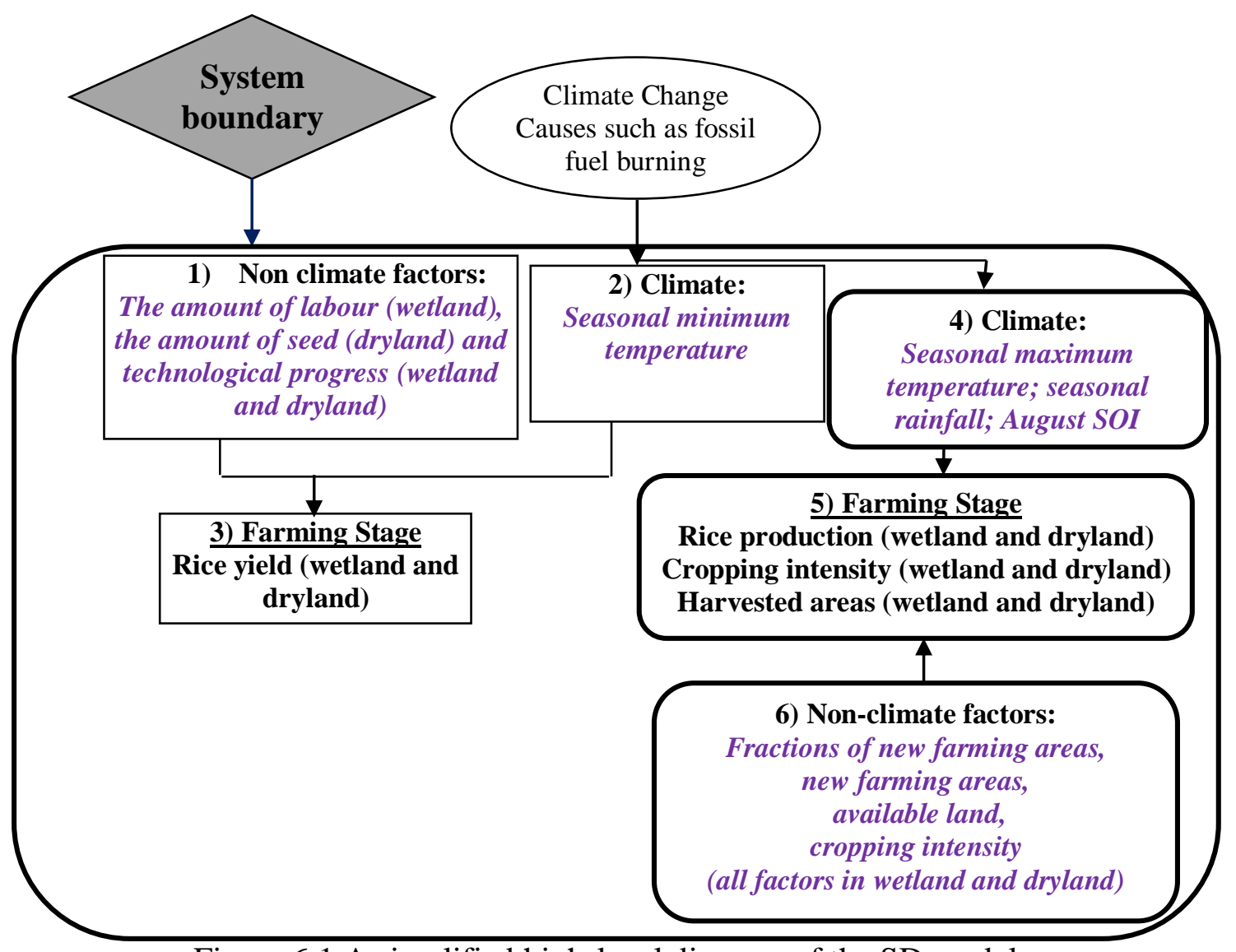

Figure 6.1 A simplified high-level diagram of the SD model

As described earlier in chapter 5, wetland rice yield is affected by seasonal minimum temperature, technological progress, and labour. Again, dryland rice yield is affected by the amount of seed, technological progress and seasonal minimum temperature. In this study, the amount of labour, the amount of seed (non-climate factors) and minimum temperature are exogenous variables. It should be noted that variables explained in chapter 5 are shown 
in the rectangle boxes of figure 6.1, while rounded rectangle boxes describe variables added in chapter 6.

Possible impacts of climate change on rice production can be categorised as follows: the impacts of climate change on rice yield (Lobell et al., 2008; Welch et al., 2008), the impacts of climate change on rice production (Falcon et al., 2004; Naylor and Mastrandea, 2009) and the impacts of climate change on harvested areas (Falcon et al., 2004; Sumarno et al., 2008). Since statistical models in chapter 5 only focused on the impacts of climate change on rice yield, this chapter expands the statistical models to capture other effects of climate change on rice production.

During a seasonal year (from September year $n$ to August year $n+1$ ), there are three cycles of planting seasons. That is, the first cycle is between September and December, the second cycle is between January and April and the last cycle is from May and August. To measure total harvested areas in all cycles, a concept of cropping intensity ${ }^{31}$ is introduced in this chapter. The cropping intensity represents the number of hectares of harvested areas compared to rice farming areas in three cycles during a seasonal year.

As shown in figure 6.1 (rounded rectangle box no.5), the SD model captures other effects of climate change. For instance, seasonal rainfall may affect rice production through cropping intensity (Apriyana \& Kailaku, 2015; Naylor et al., 2002). In general, a higher rainfall leads to a higher cropping intensity while a lower rainfall leads to a lower cropping intensity (Apriyana \& Kailaku, 2015; Naylor et al., 2002).

This chapter also expands the statistical models as they do not capture the effects of maximum temperature. Statistical models in chapter 5 do not include the negative impacts of maximum temperature since the observed maximum temperature was lower than $35^{\circ} \mathrm{C}$ i.e the rice threshold for maximum temperature (Yoshida, 1981). The negative effects of high

\footnotetext{
31 Take, for example, the scenario of cropping intensity in a seasonal year where the total rice farming areas during a seasonal year are about $1,000 \mathrm{ha}$. In the first cycle, farmers plant rice in all of these farming areas so that farmers get total harvested areas of about 1,000 ha. In the next cycle, farmers get, due to limited rainfall, rice in about 500 ha of harvested areas and in the last cycle, again due to limited rainfall, farmers only harvest rice in about 100 ha of rice farming areas. Total harvested areas during a seasonal year therefore $=1,000 \mathrm{ha}+500 \mathrm{ha}+100 \mathrm{ha}=1,600$ ha. This means that cropping intensity in given a seasonal year is $1.6(1,600 / 1000)$.
} 
maximum temperature are included, as projected maximum temperature by 2090 (20772100 ) is relatively close to $35^{\circ} \mathrm{C}$. Section 6.7 shows the estimation of the negative effects of maximum temperature on rice yields.

Table 6.1 explains variables added in the SD model, compared to variables in the statistical models in chapter 5. Added variables can be grouped into two categories: climate variables and non-climate variables. Climate variables such as maximum temperature and seasonal rainfall are added to explain other effects of climate change on rice production. Non-climate variables such as harvested areas and rice production are added to describe the effects of non-climate factors and affected variables in rice production.

Non-climate variables added in this chapter are available land and fractions of new farming areas. It should be noted that 'available land' is defined as the land that is available to be converted to new rice farming areas. The rate expansion of new farming areas each year is defined by the fractions of new farming areas.

\begin{tabular}{|l|l|l|}
\hline No & \multicolumn{1}{|c|}{ Variable Names } & \multicolumn{1}{c|}{ Dimension } \\
\hline 1 & Harvested areas & ha \\
\hline 2 & Cropping intensity & dimensionless \\
\hline 3 & Rice production & tonnes/year \\
\hline 4 & Available land & ha \\
\hline 5 & Fractions of new farming areas & $\% /$ year \\
\hline 6 & New farming areas & ha/year \\
\hline 7 & Rice farming areas & ha \\
\hline 8 & Seasonal rainfall & mm/year \\
\hline 9 & August SOI index & dimensionless \\
\hline 10 & Maximum temperature & celsius \\
\hline
\end{tabular}

Table 6.1. Added variables in chapter 6, compared to chapter 5. A definition of all variables can be seen in appendix F.

Before the SD model of the rice production is described, this study introduces some guidelines for readers (Martinez-Moyano, 2012; Oliva \& Sterman, 2010; Sterman, 2000) which are as follows: 
1) Diagrams (causal loop diagrams and system dynamics model ${ }^{32}$ ) may depict variables or factors with surrounding boxes which are called stocks. They accumulate any differences between their inflows and outflows;

2) Flows are any arrows pointing out of stocks or pointing into stocks. Inflows are arrows pointing into stocks, while outflows are arrows pointing out of stocks. In other words, inflows increase the values of the stocks while outflows decrease the values of the stocks;

3) Causal loop diagrams contain "+" and "-"signs. The positive signs represent positive relationships between two connected factors or variables. The negative signs represent negative relationships between connected factors. For example, as shown later, seasonal minimum temperature is connected with rice yield with a "_" sign. This means that an increase in minimum temperature might decrease rice yield. A "+" sign between labour and rice yield means that labour might increase rice yield;

4) A CLD also contains loops either reinforcing loops (R) or balancing loops (B). Balancing loops mean that the interactions between any factors or variables leads to a stable condition or a desired condition, while reinforcing loops mean that interaction between any factors leads to any growing or declining actions;

5) Diagrams might depict some variables beginning with the letter of "a". These letters are coefficients of variables that are used to estimate the effects of respective variables (Sterman, 2000, p.264). For instance, "aw seasonal mintemp" is the coefficient of minimum temperature for wetland rice and "ad seasonal mintemp" is the coefficient of minimum temperature for dryland rice.

6) Diagrams might also depict some variables beginning with the first letter of "table". These letters are a lookup function (Martinez-Moyano, 2012; Oliva \& Sterman, 2010). The lookup function is a predefined function to provide respective variable values. For instance, "table labour (wetland)" defines the values of labour in wetland farming throughout model simulation.

7) Diagrams might also contain some variables with the words "unit" or "converter". These variables aim to equate variable dimensions and these variables do not intend to show any causal relationships, so none of them have either any "++" or "_" signs.

${ }^{32}$ The system dynamics model is also called the stock flow diagram. 


\subsection{The CLD}

Many studies use a CLD to describe crop yield and crop production (see section 2.2.4 for more studies). Rasmussen et al. (2012) use a CLD, as shown in figure 6.2a, that explains relationships among climate (rainfall), crop yield, areas and crop production. Similar to that study (Rasmussen et al., 2012), Dudley (2012) describes a relationship between areas, crop yield and crop production. Another study (Li, Dong, Li, 2012) also uses a CLD to show a relationship between technological progres and rice yield as shown in figure $6.2 \mathrm{~b}$.

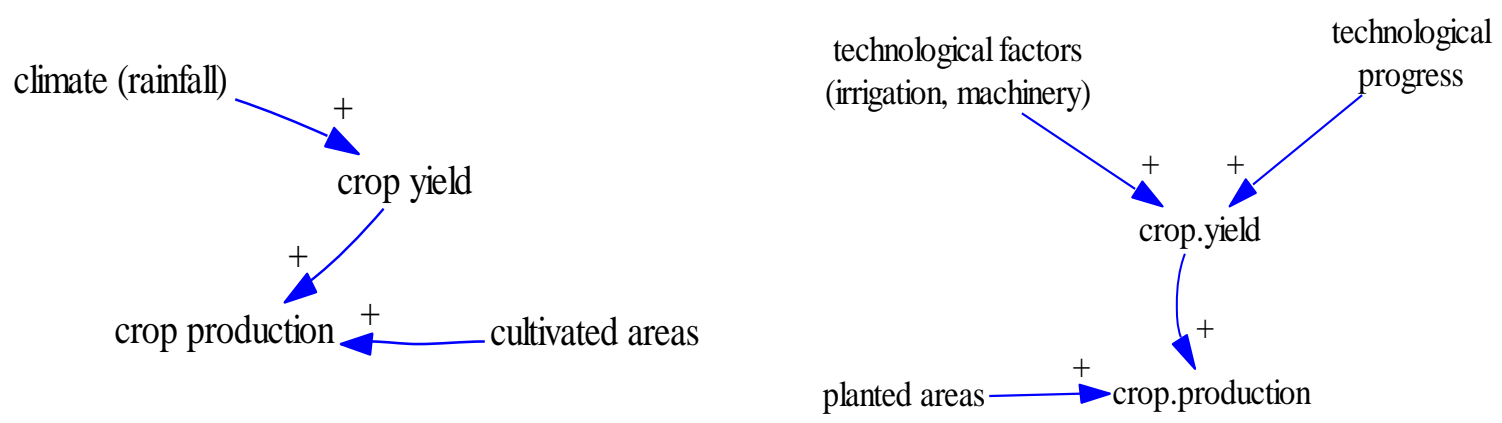

Figure 6.2a. A part of CLD (Rasmussen et Figure 6.2b. A part of CLD (Li et al., 2012) al., 2012; Dudley, 2012)

Figure 6.2 Parts of CLDs from existing studies

As with those cited studies, this study uses a CLD in describing the impacts of climate change on the rice production, as shown in figure 6.3. For instance, those cited studies and this study affirm that crop yield might be affected by technological progress and climate.

Statistical models, as described in chapter 5, explain that rice or rice yield might be affected by minimum temperature (wetland and dryland rice) and seed (dryland rice) or labour (wetland rice). As an increase of minimum temperature might negatively influence rice yield, connecting lines between minimum temperature and the yield have "_" signs. Conversely, connecting lines between seed (dryland rice) and labour (wetland rice) have "+” signs.

Those cited studies also show that crop production is affected by planted areas or cultivated areas and crop yield. In this study, rice production is a multiplication of harvested areas and rice yield. As farmers might plant rice multiple times in a growing season, harvested areas are influenced by cropping intensity and farming areas. Delayed rainfall leads to lower cropping intensities (Sumarno et al., 2008). 
A fraction of new farming areas can increase new farming areas while delay in opening farming areas may hinder new farming areas. Since fractions of new rice farming increase new farming areas, a line arrow connecting fractions of new farming areas and new farming areas have a "+" sign. Fractions of new farming areas represent the seasonal growth of new farming areas. By contrast, longer delays of new farming areas (wetland and dryland farming) lead to smaller farming areas, represented by “-” signs between the delays and farming areas in wetland and dryland farming.

In line with other studies (Falcon et al., 2004; Naylor et al., 2001; 2002), the CLD also suggests that rainfall might not affect Indonesian rice yield but rather Indonesian rice production. Sufficient rainfall is needed to start planting seasons, so less rainfall leads to delayed planting seasons and less rice production (Falcon et al., 2004; Naylor et al., 2001; 2002), represented by a “-” sign between the timing of monsoon onset and rice production. In this study, the beginning of rice planting seasons is called the timing of the monsoon onset. A “-” sign is also assigned between growth duration of rice variety (wetland and dryland) and rice production (wetland and dryland). The latter is supported by IRRI (1985) and Khush (1987), explaining that shorter growth duration of rice varieties tends to increase rice production.

The August Southern Oscillation (SOI) Index is used as a proxy to estimate the timing of monsoon onset. This diagram also shows that the harvested area of wetland is influenced by the rainfall pattern as a higher rainfall leads to a higher cropping intensity (Sumarno et al., 2008; Falcon et al., 2004).

The CLD also shows two balancing loops that explain the interactions between available land and rice farming (wetland and dryland). The first loop (B1) and second loop (B2) explain the interaction between available land and wetland farming and dryland farming respectively. If dryland or wetland area increases, available land decreases. In principle, the desired condition is to increase wetland and dryland areas until available land is nil. 


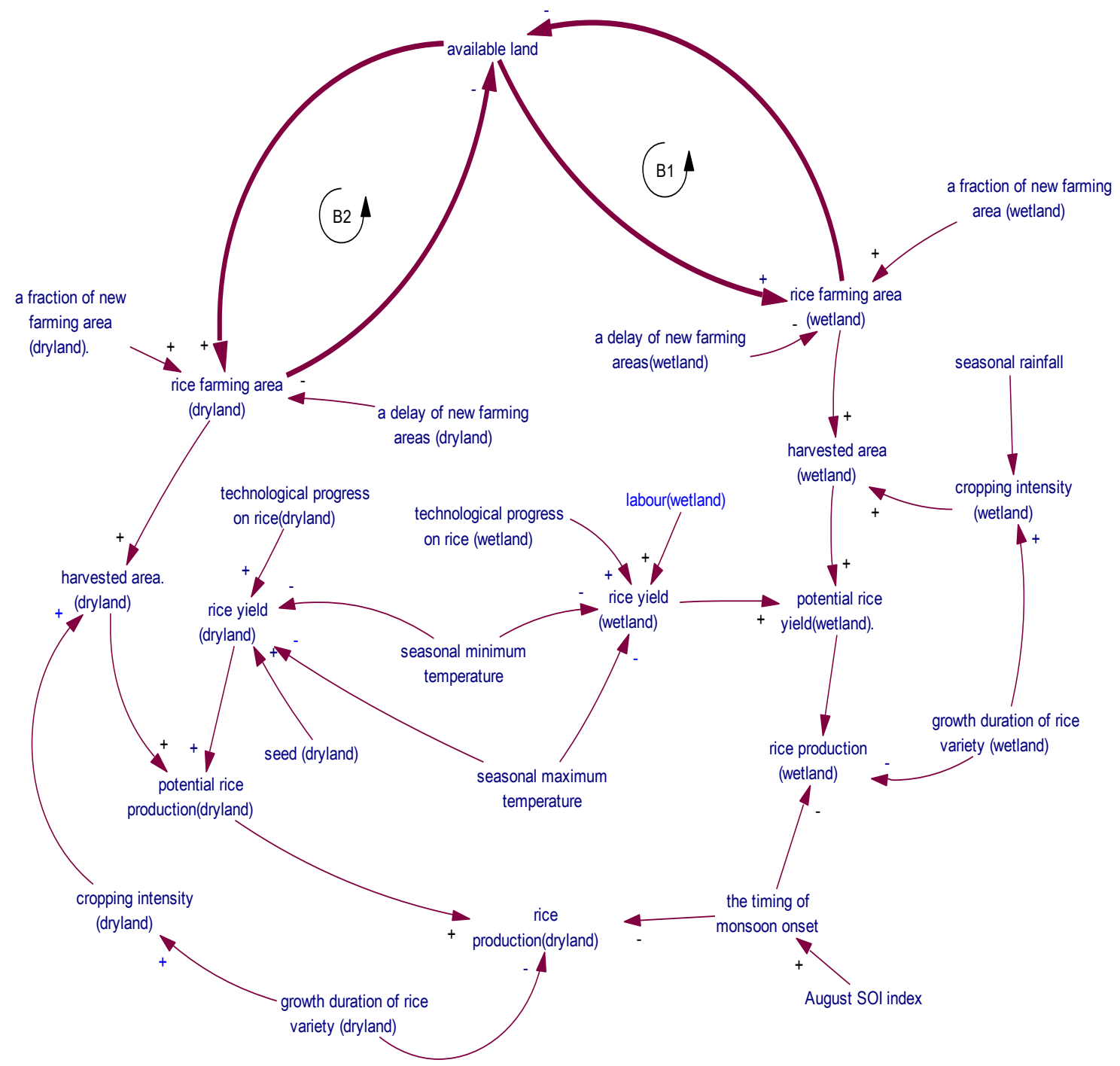

Figure 6.3 Farming stage (A simplified CLD of the impacts of climate change on the rice production in WNT)

\subsection{The farming stage: A SD model}

This section describes interactions in the farming stage. The interactions between available land and rice farming areas are described and then mathematical relationships between production factors (seed, labour), minimum temperature, and rice yield are explained. The effects of rainfall on the timing of monsoon onset and cropping intensity are described later.

Figure 6.4 describes farming areas in wetland and dryland farming. Based on observed data in the period 1976-2011, wetland and dryland farming areas increased by about $1.15 \%$ and $3.55 \%$ a year respectively. Again, increasing farming areas is supported by available land as the government provided about 700,000 ha of available land in 2015 (Pemerintah Nusa Tenggara Barat, 2013). The government of West Nusa Tenggara has initiated sustainable 
farming areas since 2012, meaning that the conversion of rice farming to other purposes is not allowed (Pemerintah Nusa Tenggara Barat, 2013).

It should be noted that available land is potential land or reserved land that aims to increase the farming areas. In the future, the available land of 700,000 ha will be converted into wetland and dryland farming. The WNT government has not explicitly stated the fraction of available land for either wetland or dryland farming. So, in this study, it is assumed that the future conversion of available land to be wetland and dryland farming is based on the conversion during the period 1976-2011 i.e 1.15\% per year for wetland and $3.55 \%$ per year for dryland farming.

In this study, it is assumed that the projected farming areas in wetland and dryland farming are based on the maximum capability of the government to open new farming areas. This means that new irrigation facilities are fully maximised to open new wetland farming and not to convert dryland areas to be wetland areas. Dryland is usually located in plateaus, so it is difficult to convert dryland to wetland areas.

Moreover, rice farming areas will be fully planted to sustain and/or increase rice supply in West Nusa Tenggara. The latter is important because West Nusa Tenggara is one of the main Indonesian rice producers, supplying rice for local people and people in the neighbouring regions. The rice farming areas will also be fully sown as rice farming is a main source of employment and economic growth in West Nusa Tenggara.

Each year, the government prepares a development planning program which includes the new farming area programs. Usually there is a period of delay between the approval of new farming area programs and the implementation of the programs of approximately one year. Note that within a year's delay, the government and rice farmers will prepare available land to be converted into either wetland or dryland rice farming. Possible preparations are, for example, irrigation facilities for wetland rice farming and subsidised seed so that available land will not covered by floods and is ready to be planted. To represent a delay in preparing either wetland or dryland farming, a variable named "delay of new farming areas (wetland/dryland)" is involved in figure 6.4. 


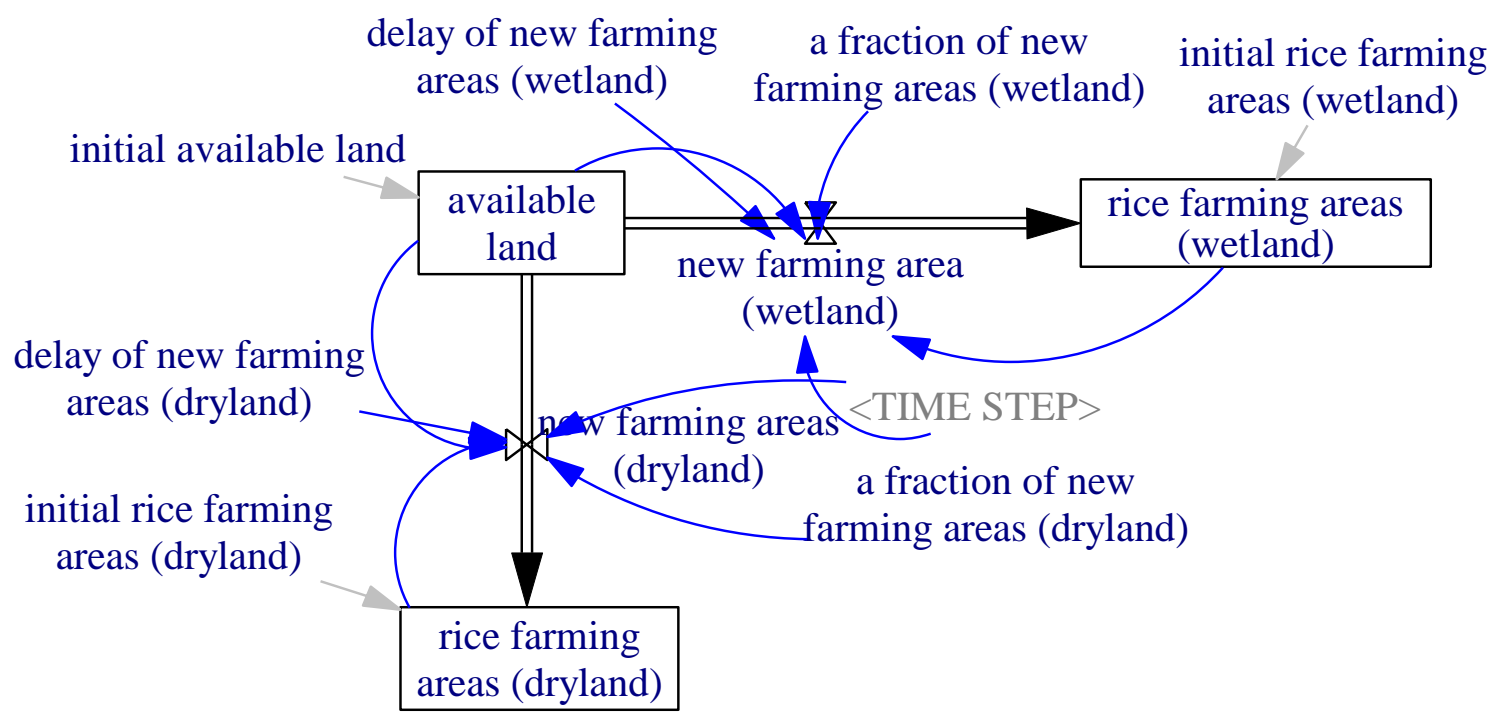

Figure 6.4 Interactions between farming areas and available land

As new farming areas are influenced by the delay of new farming areas and fractions of new farming areas, the amount of new farming areas is measured using the delay function as follows:

new farming areas $=$ DELAY1 (a fraction of new farming areas (wetland) $*$ rice farming areas (wetland), delay of new farming areas (wetland))

This means that new farming areas are an expected value of multiplication between fractions of new farming areas and rice farming areas with a delay time as much as "delay of new farming areas (wetland)".

Furthermore, "new farming areas" is an outflow which decreases the amount of "available land". During simulation, the amount of "available land" might decrease throughout

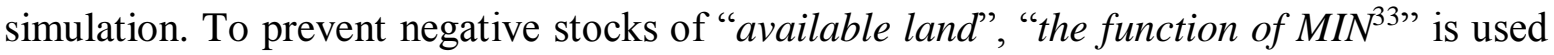
to ascertain that "available land" will never lower than nil as follows:

MIN((DELAY1 (a fraction of new farming areas (wetland)*rice farming areas (wetland), delay of new farming areas (wetland))), available land/ TIME STEP)

This mathematical relationship states that the amount of new farming areas will not be higher than the change of "available land" over time (available land /TIME STEP). Rice

\footnotetext{
${ }^{33}$ The function of "MIN" in Vensim(C) has syntax MIN (val1, val2). This means that new farming areas never be higher than the change of available over time (available land/TIME STEP). This guarantees that a stock of available land will never be less than nil.
} 
yield in wetland is affected by minimum temperature, labour and technological progress (mathematical relationships are similar to those in table 5.5 in chapter 5). By contrast, dryland rice yield is affected by seed, minimum temperature and technological progress (represented by a linear and a squared time variable as described in table 5.6 in chapter 5). The relationships between minimum temperature, seed (labour) and rice yield are sumarised in figure 6.5. Note that, as explained in chapter 5, dummy1996 and dummy2008 represent a structural break in wetland and dryland farming respectively.

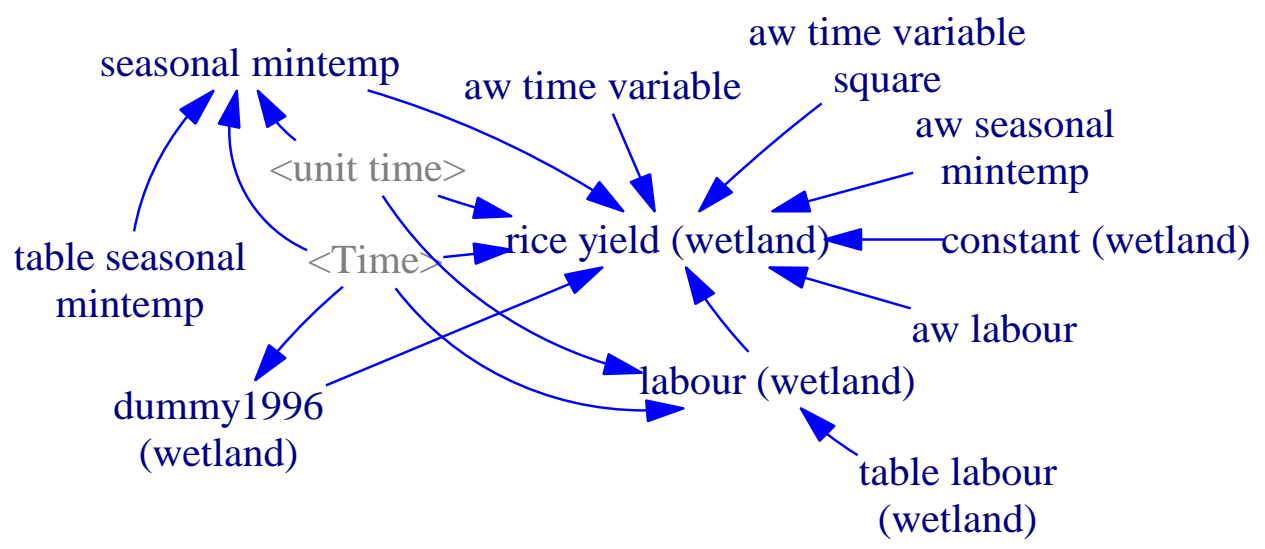

a) wetland farming

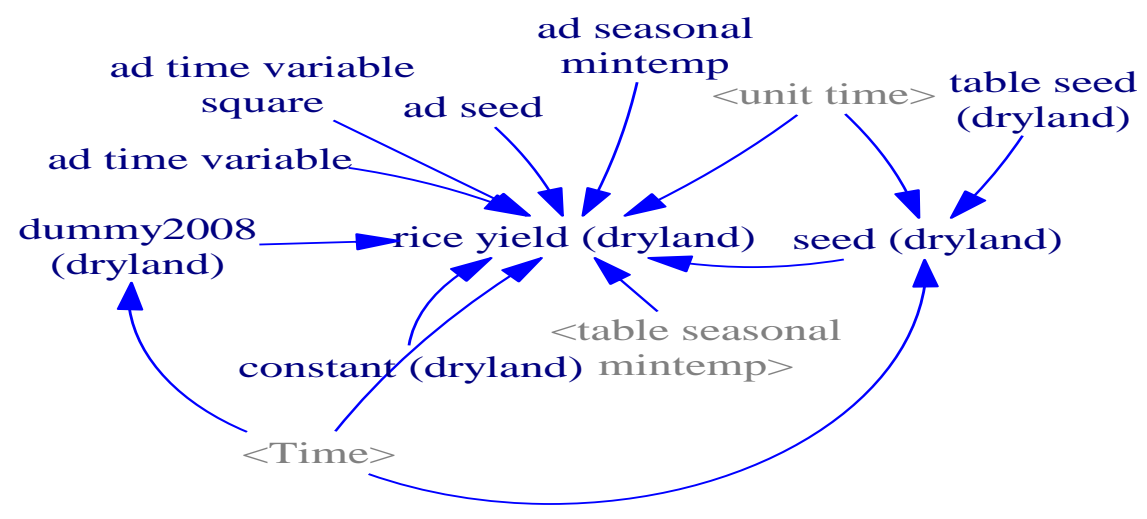

b) dryland farming

Figure 6.5 The interactions among production factors, climate and rice yield in the farming stage

Figure 6.6a shows that a higher seasonal rainfall leads to a higher cropping intensity (Apriyana \& Kailaku, 2015), leading in turn to more sizeable harvested areas in wetland farming (Nazam, 2009). Historical data (BPS NTB, 1999-2012) shows that cropping intensity and seasonal rainfall have a significant linear relationship $\left(\mathrm{R}^{2}=.45, F(1,2)=9.81\right.$, 
$p<.01$ ). In contrast, cropping intensity of dryland farming is relatively constant (figure 6.6b) as most dryland rice is only sown during the first cycle ${ }^{34}$ (Nazam, 2009).

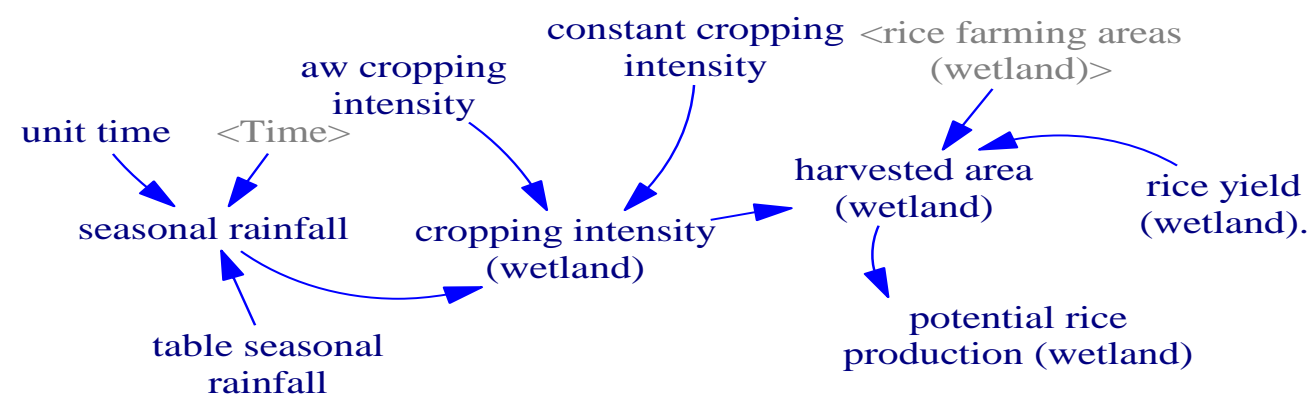

a) wetland farming

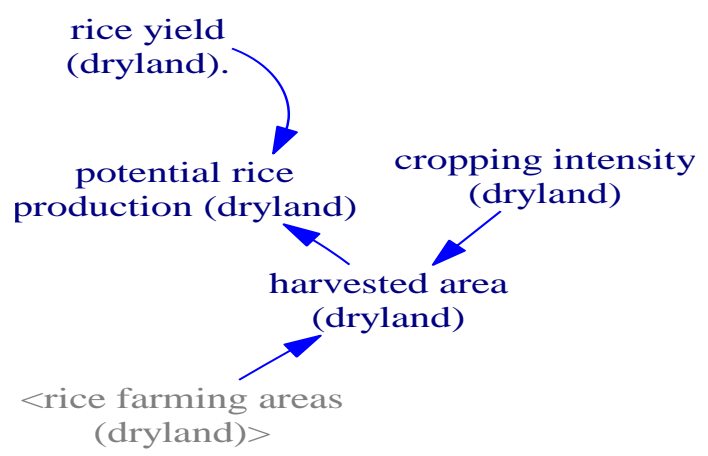

b) dryland farming

Figure 6.6 cropping intensity in wetland and dryland farming

As shown in figure 6.6, potential rice production in the farming stage is a multiplication between rice yield and harvested areas. In addition, harvested areas is a multiplication between cropping intensity and farming areas. Thus, an increase of cropping intensity and rice yield leads to a larger rice production.

Actual rice production in the farming stage depends on, as shown in figure 6.7, two factors. The first factor is potential rice production and the second factor is the timing of monsoon onset. In principle, earlier monsoon timing leads to greater rice production whereas delayed monsoon timing leads to lower rice production.

Potential rice production, in either wetland or dryland farming, is the expected actual rice production if the timing of monsoon onset is not delayed or not earlier. If the timing of monsoon onset is delayed or earlier than the normal monsoon onset, actual rice production

${ }^{34}$ Dryland farmers tend to sow their rice only during the first cycle (September - December) in order to counter limited/insufficient rainfall in the next cycles. So, during a seasonal year (September year $t$ and August year $\mathrm{t}+1)$, dryland cropping intensity is about $1(100 \%)$. 
is subjected to the timing of monsoon onset and a rice growing day. This means that earlier monsoon onset tends to increase actual rice production, while a longer rice growing day tends to decrease actual rice production. So, actual rice production in wetland can be formulated as follows:

DELAY3 (STEP (potential rice production (wetland), timing of monsoon-onset (years), growth duration of rice variety (wetland))

Note that the sum of wetland rice production and dryland rice production is called total rice production.

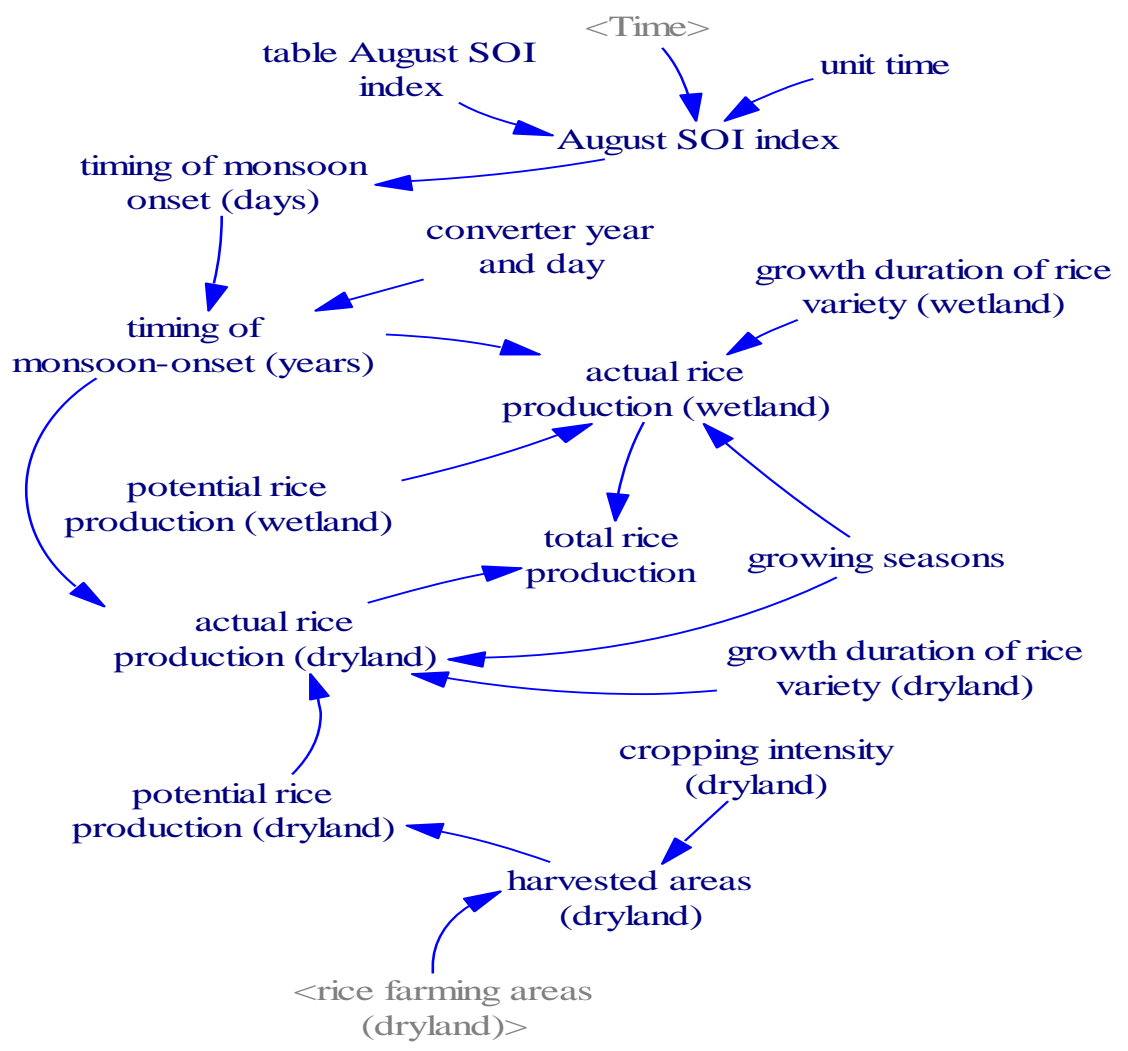

Figure 6.7 Rice production in the farming area

Another study (Yasin, Ma'shum, Abawi \& Hadiahwaty, 2004) claims that the August Southern Oscillation (SOI) Index ${ }^{35}$ is a good proxy to estimate the timing of monsoon onset in West Nusa Tenggara. The Australian Bureau of Meteorology (http://www.bom.gov.au/climate/current/soi2.shtml) states that SOI values between -7 and 7 relate to the normal monsoon. Higher SOI values than 7 relate to La Niña and SOI values lower than -7 relate to El Niño.

${ }^{35}$ In general, negative values of August SOI relate to delayed monsoon onset. 
Figure 6.8a summarises the SOI values and its timing of monsoon onset based on observed data in the period 1986-2012. This figure shows that the relationship between SOI values and the timing of monsoon onset tends to be a non-linear relationship. For instance, when August SOI is between -7 and +7 , there is no a delayed monsoon onset, but when August SOI is about -30 , the timing of monsoon onset delay is about 30 days.

Like other studies (Falcon et al., 2004; Naylor \& Mastrandea, 2009), this study uses seasonal year (as seen on the first horizontal line in figure $6.8 \mathrm{~b}$ ) in observing the impacts of climate change on the timing of monsoon onset. As seen in figure $6.8 \mathrm{~b}$, the seasonal year is the period between September (year $\mathrm{t}$ ) and August (year $\mathrm{t}+1$ ). In normal years (no La-Niña and no El-Niño), a previous study (Indriani, 2010) suggests that the timing of monsoon onset normally starts on November 15 each year (as seen on the second horizontal line in figure $6.8 \mathrm{~b})$.

If the timing of monsoon onset starts on November 20, this means that the monsoon onset is delayed by about 5 days (as seen as the third horizontal line in figure $6.8 \mathrm{~b}$ ) and if the timing of monsoon onset starts on November 10, this means that the monsoon onset starts about 5 days earlier (as seen on the fourth horizontal line in figure 6.8b). This means El-Niño (LaNiña) tends to shorten (lengthen) rice growing seasons ${ }^{36}$.

\footnotetext{
${ }^{36}$ It should be noted that the effects of timing of monsoon onset is "a forwarded effect". For example, if the August SOI index in 2017 is about -17 (a delayed monsoon onset), harvested areas and rice production during September 2017-August 2018 tend to decrease.
} 


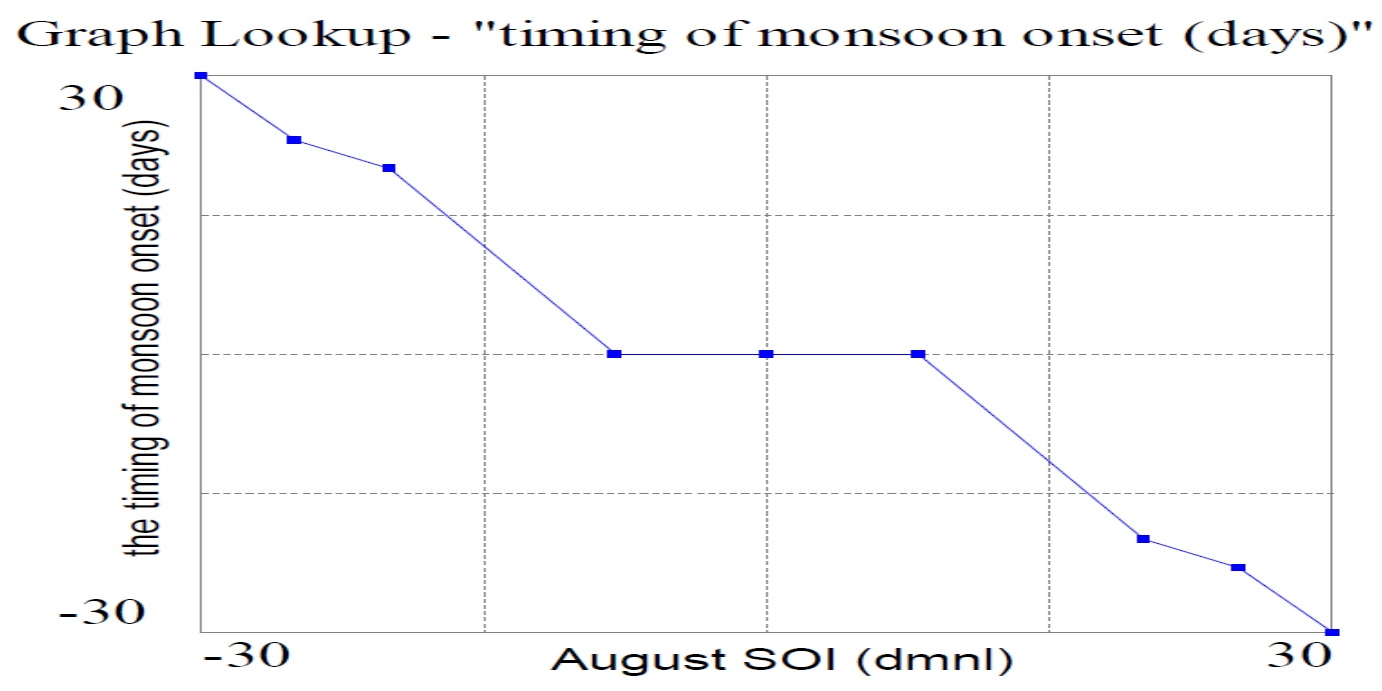

a) A lookup function the August SOI and the monsoon onset in days (source: http://www.bom.gov.au/climate/current/soi2.shtml)

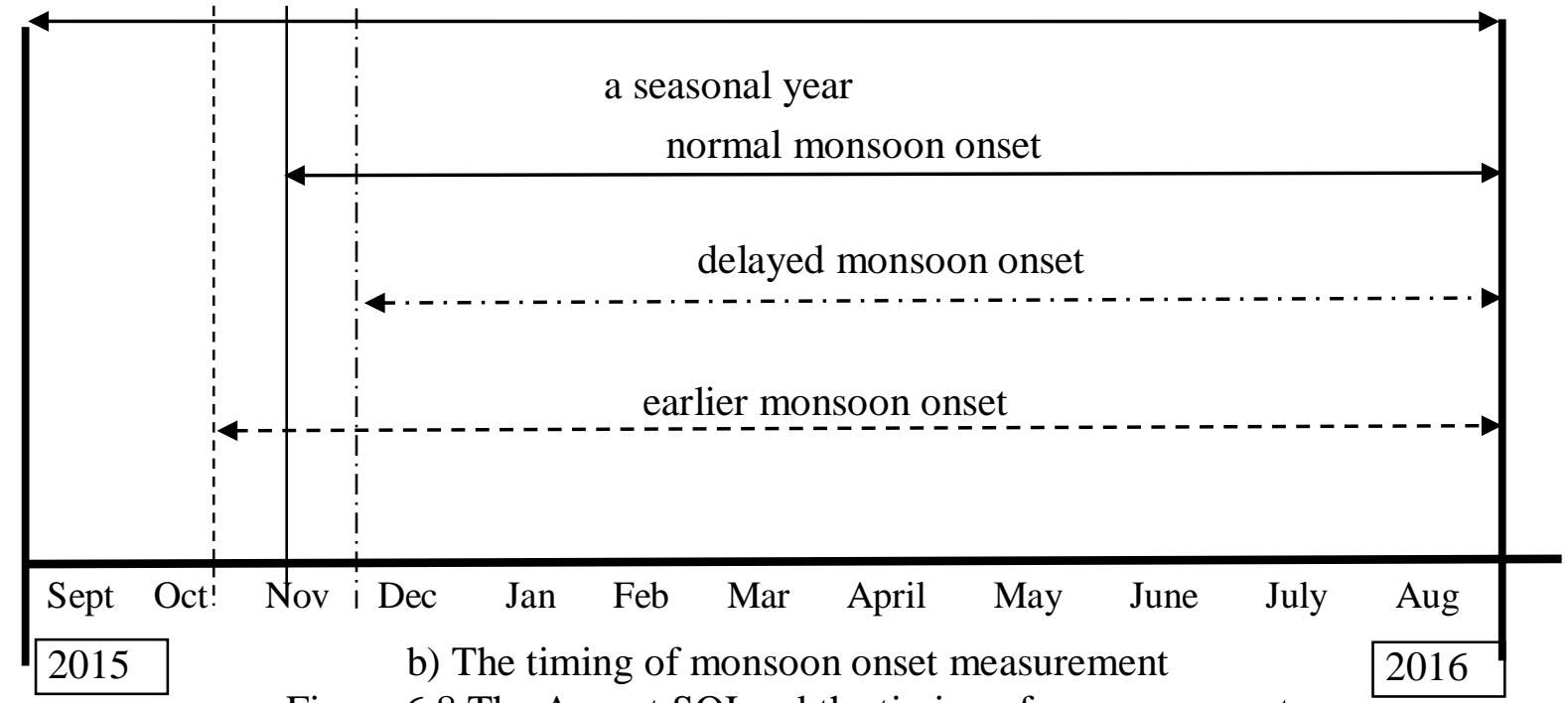

Figure 6.8 The August SOI and the timing of monsoon onset

Table 6.2 shows major equations for both wetland and dryland farming (for a complete list of the model equation, please see appendix D). Rice yield in wetland farming is affected by labour, minimum temperature, and technological progress of wetland rice. By contrast, rice yield in dryland farming is affected by seed, minimum temperature and technological progress of dryland rice. For wetland and dryland farming, they have relatively similar equations of potential and actual rice production as shown in table 6.2. 


\begin{tabular}{|c|c|c|}
\hline Variables & Dimensions & $\begin{array}{ll}\text { Formulas } \\
\end{array}$ \\
\hline Rice yield (wetland) & Tonnes/ha*year & $\begin{array}{l}\text { aw mintemp*seasonal mintemp+aw labour*labour (wetland)+aw time } \\
\text { variable*((Time-1975)/unit time })+ \text { aw time variable square*((Time- } \\
\left.1975)^{\wedge} 2 / \text { unit time }{ }^{\wedge} 2\right)+ \text { dummy } 1996 *(\text { Time-1975)*(-0.054)*(1/unit } \\
\text { time)+dummy1996*(Time-1975)^2*(0.0024)*(1/unit time^2)+constant } \\
\text { (wetland) }\end{array}$ \\
\hline Rice yield (dryland) & Tonnes/ha*year & $\begin{array}{l}\text { ad mintemp*seasonal min temp+ad seed*seed (dryland)+ad time } \\
\text { variable square*((Time-1975)^2/unit time^2)+ad time variable*((Time- } \\
\text { 1975)/unit time)+constant (dryland)+dummy2008) }\end{array}$ \\
\hline $\begin{array}{lr}\text { Potential } & \text { rice } \\
\text { production } & \text { in } \\
\text { wetland or dryland } \\
\text { farming }\end{array}$ & Tonnes/year & Rice yield (tonnes/ha*year)*harvested areas (ha) \\
\hline $\begin{array}{lr}\text { Actual } & \text { rice } \\
\text { production } & \text { in } \\
\text { wetland or dryland } \\
\text { farming }\end{array}$ & Tonnes/year & $\begin{array}{l}\text { (DELAY3(STEP(potential rice production (wetland), } \\
\text { timing of monsoon-onset (years), growth duration of } \\
\text { rice variety (wetland)) } \\
\text { (DELAY3(STEP(potential rice production (dryland), } \\
\text { timing of monsoon-onset (years), growth duration of } \\
\text { rice variety (dryland)) }\end{array}$ \\
\hline
\end{tabular}

Table 6.2 Definitions and dimensions of major variables in the farming stage

Simulation outputs of the SD model for the farming stage are depicted by figures 6.9 - 6.14, over the historical period from 1976-2011. It seems that the model can reproduce similar outputs compared with observed data. For dryland farming, there were errratically harvested areas between 2007 and 2009 as farmers engaged in deforestation in order to open new dryland farming areas. Statistics (BPS, 2009) show that there was about 51,000 ha of deforestation in the period of 2007-2009, leading to erratically harvested areas in dryland farming. As massive deforestation leads to run-off and tends to ruin spatial planning, the local government has banned deforestation since 2013 and has restricted the conversion of rice farming, leading to sustainable rice farming areas (Pemerintah Nusa Tenggara Barat, 2013). 


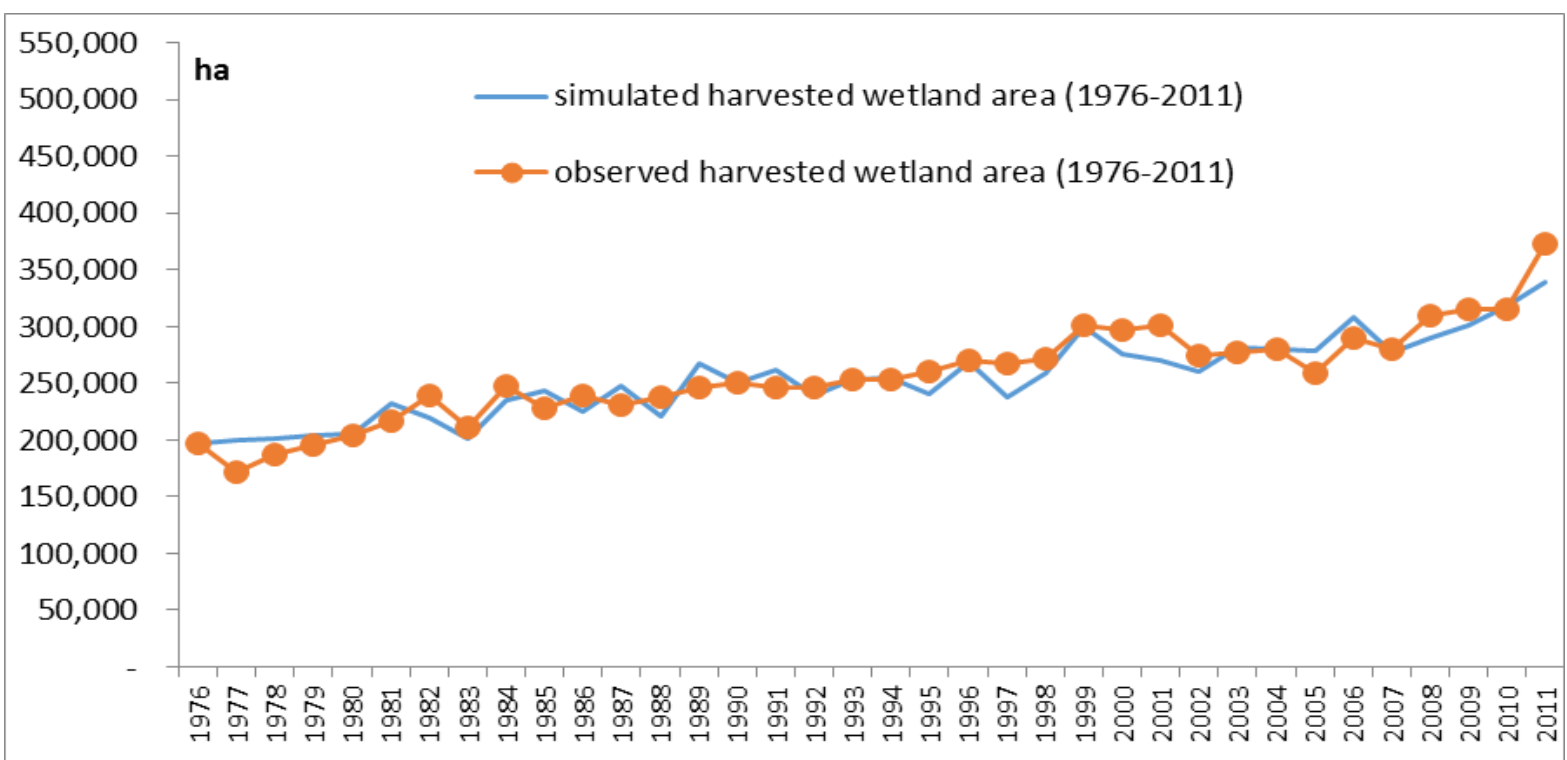

Figure 6.9 Harvested wetland areas based on observation and simulation

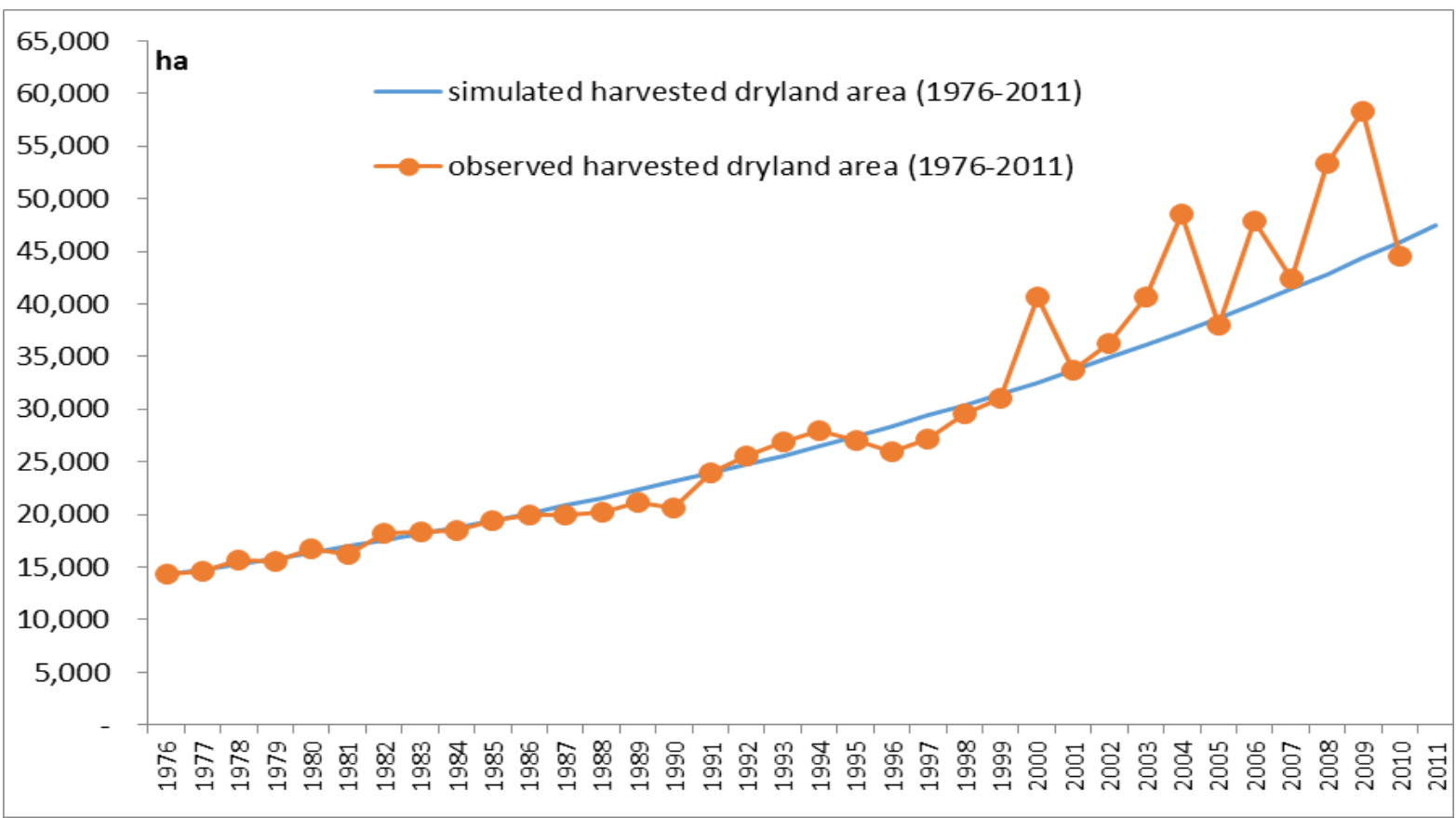

Figure 6.10 Harvested dryland areas based on observation and simulation 


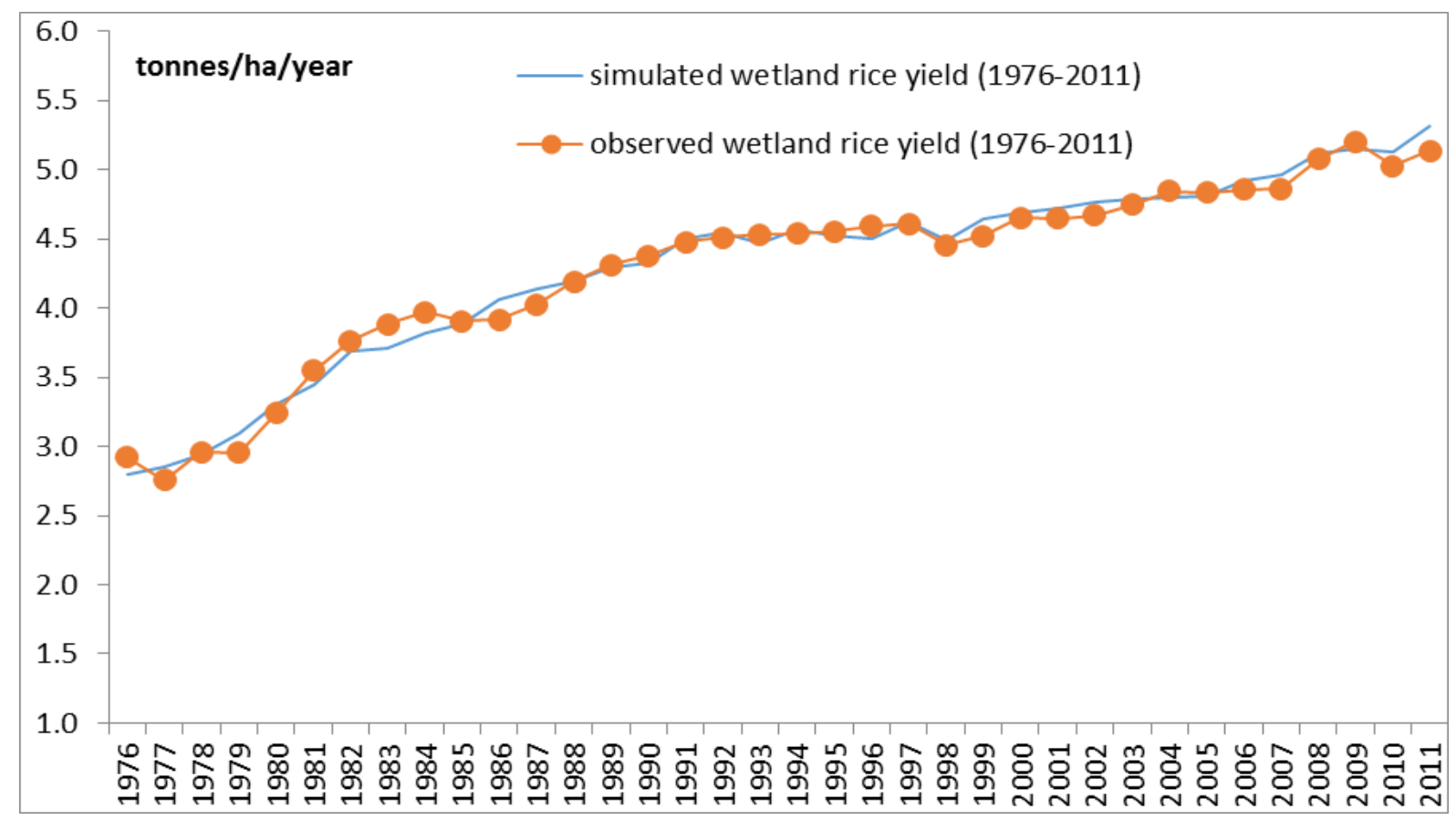

Figure 6.11 Wetland rice yield based on observation and simulation

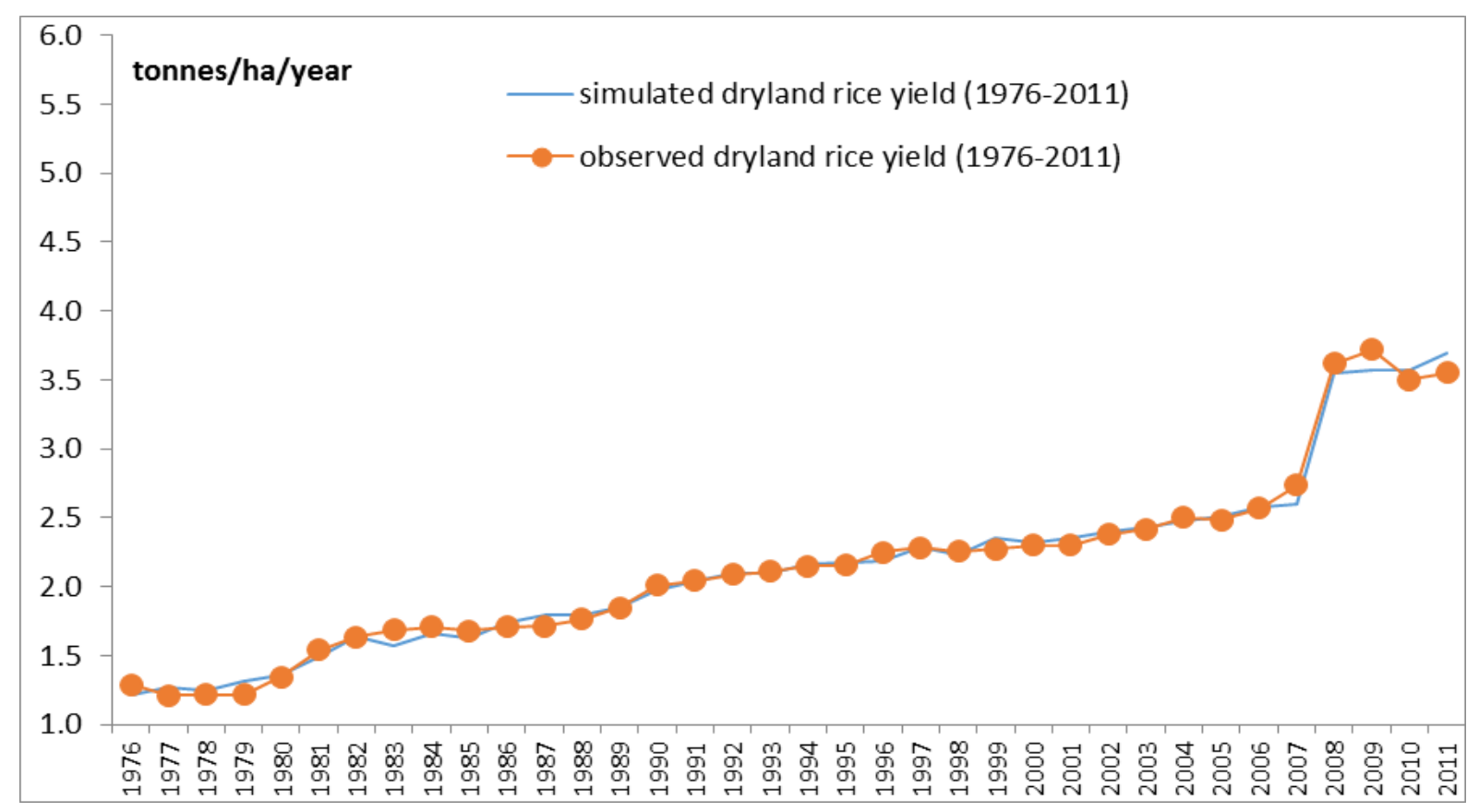

Figure 6.12 Dryland rice yield based on observation and simulation 


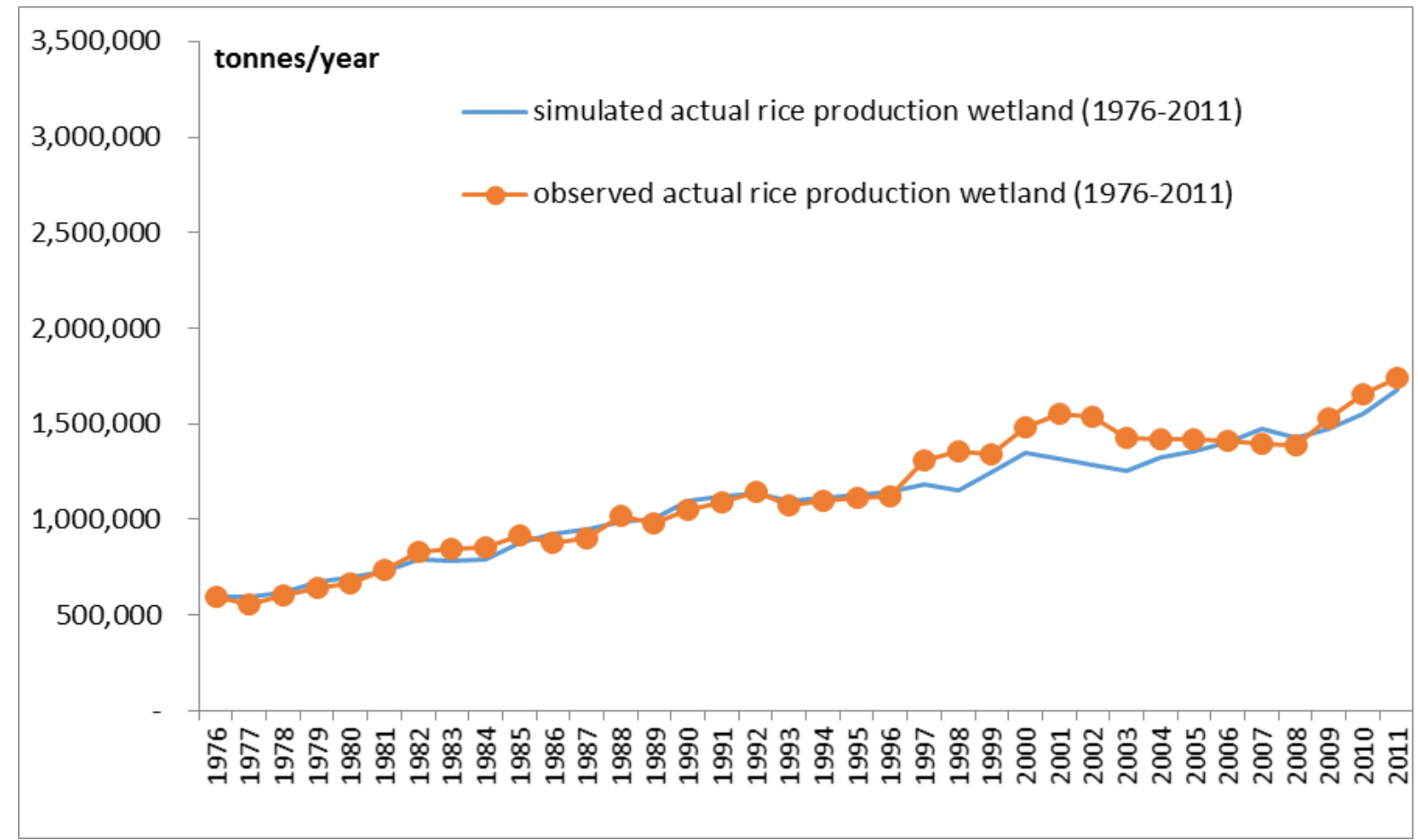

Figure 6.13 Actual wetland rice production based on observation and simulation

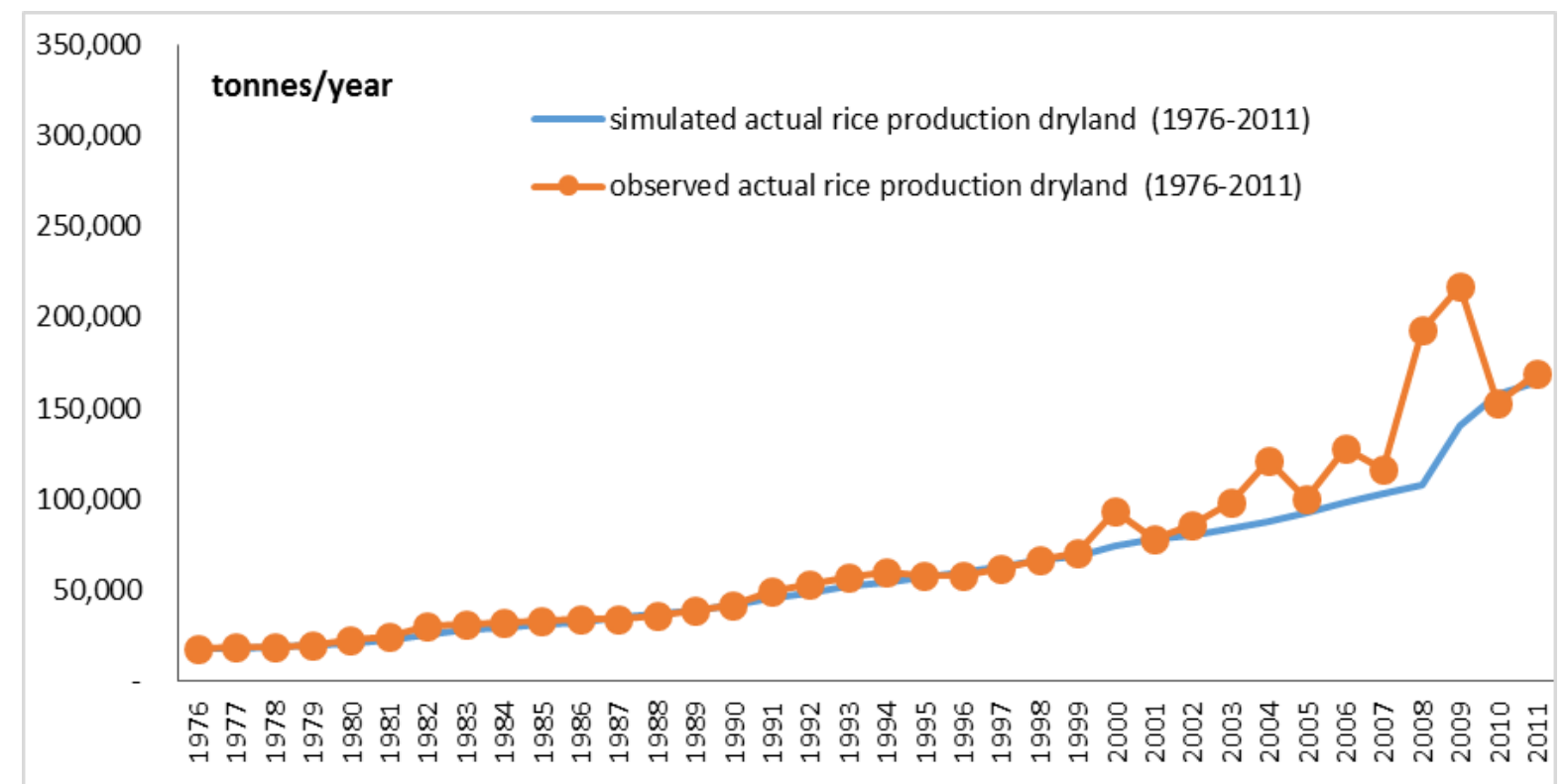

Figure 6.14 Actual dryland rice production based on observation and simulation

To measure the performance of model behaviour, MAPEs (Mean Absolute Percentage Errors), as shown in table 6.3, are used to measure errors between simulated output and observed data (Hanke et al., 2001; Sterman, 2000). Except for three variables such as actual rice production and harvested areas, all variables have MAPEs lower than 5\% which means the models are highly accurate to reproduce respective observed data (Hanke et al., 2001). 
The remaining variables, which have MAPEs higher than $5 \%$ but below $10 \%$, show that the models are accurate to reproduce respective observed data ${ }^{37}$ (Hanke et al., 2001).

\begin{tabular}{|l|c|}
\hline Parameters & MAPE \\
\hline Rice yield (wetland) & $1.8 \%$ \\
\hline Actual rice production (wetland) & $5 \%$ \\
\hline Harvested area (wetland) & $5 \%$ \\
\hline Rice yield (dryland) & $1.8 \%$ \\
\hline Actual rice production (dryland) & $8 \%$ \\
\hline Harvested area (dryland) & $5.9 \%$ \\
\hline
\end{tabular}

Table 6.3 Mean absolute percentage errors (MAPEs)

\subsection{The base case scenario}

The base case behaviour is based on the existing structure and parameters derived from observed data. The base case scenario is usually used as a basis to do sensitivity analysis and conduct policy scenarios (Franck, 2009; Maani \& Cavana, 2007; Sterman, 2000). This scenario will be simulated for 85 years, starting from 2015 to 2100 . It should be noted that subsequent figures (figures 6.15 - 6.19) are derived from Vensim@, a SD software used in this dissertation (Sterman, 2000).

For the base case simulation, some variables are set based on table 6.4. As explained in section 5.4.1, projection of minimum temperature, under "no climate change", is similar to observed minimum temperature. This is also applied to seasonal rainfall and August SOI index. In doing so, observed climate in the period 1976-2011 is replicated to be projected climate in the period 2015-2100. As described in section 5.4.1, the amount of seed and the amount of labour in 2011 is optimal, so those amounts are used in the base case simulation. Other variables and parameters are same as those in the historical SD model.

\footnotetext{
37 Actual rice production (dryland) and harvested areas (dryland) have MAPEs higher than 5\% as their historical data show deforestation in the period 2003-2009. This deforestation has been banned since 2013 due to the first act of the governor of WNT of 2013.
} 


\begin{tabular}{|c|c|c|}
\hline Parameters & Values in IDR/ha (Wetland; Dryland) & Description \\
\hline Labour (IDR/ year) & $(203.3) ;($ none $)$ & \multirow[b]{2}{*}{$\begin{array}{l}\text { Projected labour and seed } \\
\text { are similar to their values } \\
\text { of } 2011 \text { as the use of seed } \\
\text { in } 2011 \text { is optimum and } \\
\text { the marginal products of } \\
\text { labour in } 2011 \text { tend to be } \\
\text { zero. }\end{array}$} \\
\hline Seed (IDR/ year) & (none); (20.8) & \\
\hline Technological progress & $\begin{array}{l}\text { These are taken from equation (5.3.2) } \\
\text { and equation (5.4.2) in chapter } 5 .\end{array}$ & - \\
\hline $\begin{array}{l}\text { Seasonal minimum } \\
\text { temperature (celsius) }\end{array}$ & $\begin{array}{l}\text { Duplicating observed minimum } \\
\text { temperature }\end{array}$ & $\begin{array}{l}\text { This is assumed as a } \\
\text { climate projection with } \\
\text { climate change absence. }\end{array}$ \\
\hline Rainfall (mm/year) & Duplicating observed seasonal rainfall & $\begin{array}{l}\text { This is assumed as a } \\
\text { climate projection with } \\
\text { climate change absence. }\end{array}$ \\
\hline August SOI Index & Duplicating observed August SOI index & $\begin{array}{l}\text { This is assumed as a } \\
\text { climate projection with } \\
\text { climate change absence. }\end{array}$ \\
\hline
\end{tabular}

Table 6.4 The values of parameter on the base case simulation

Because the effects of seasonal climate on rice yields might be significant, the SD model is built based on seasonal climate and seasonal rice yields between September in year $\mathrm{t}$ and August in year $\mathrm{t}+1$ which is also called seasonal years or crop years (Falcon et al., 2004; Naylor \& Mastrandea, 2009). For instance, a seasonal year 2015 represents outputs between September 2014 and August 2015.

Figure $6.15^{38}$ shows that rice yield might be influenced by seasonal minimum temperature. For example, in 2025 and 2055, when seasonal minimum temperature increases and decreases respectively, seasonal rice yield (wetland and dryland farming) increases and decreases too.

Another climate effect is that the timing of monsoon onset might affect rice production. As shown in figure 6.16, when the monsoon onset is delayed in 2030, harvested areas in

\footnotetext{
${ }^{38}$ This is a guideline to read figures derived from Vensim $\odot$. In figure 6.15 , there are three legends namely, rice yield (wetland), rice yield (dryland) and seasonal mintemp. To scale these legends, there are two titles of vertical axis namely, "(3-6) tonnes/ha*year" and "(20-25) Celsius" The first two labels in the bottom of vertical axis tell us the lowest axis values and other two labels in the top of y-axis tell us the highest axis values of each label. For instance, for rice yield (dryland), the lowest value scale is about 3 tonnes/ha*year and the highest scale is about 6 tonnes/ha*year.
} 
wetland farming tends to decrease ${ }^{39}$. This finding is similar to other studies (Falcon et al., 2004; Naylor \& Mastrandea, 2009) claiming that the effects of the timing of monsoon onset on Indonesian rice production might be significant in terms of seasonal years.

Figure 6.17 shows that cropping intensity of wetland areas and seasonal rainfall are connected. When seasonal rainfall rises, cropping intensity in wetland areas tends to increase, leading to larger harvested areas. For dryland farming, cropping intensity is steady despite seasonal rainfall patterns, so harvested areas in dryland farming tend to increase (as long as available land is not nil as shown in figure 6.18), ignoring seasonal rainfall patterns. Note that dryland farmers tend to sow most their rice in the first cycle (during SeptemberDecember) to counter the possibility of insufficient rainfall from May-August.

Figure 6.18 demonstrates that rice farming areas and harvested areas tend to increase when available land is not nil. It should be noted that available land has all been planted in rice crops by about 2077 .

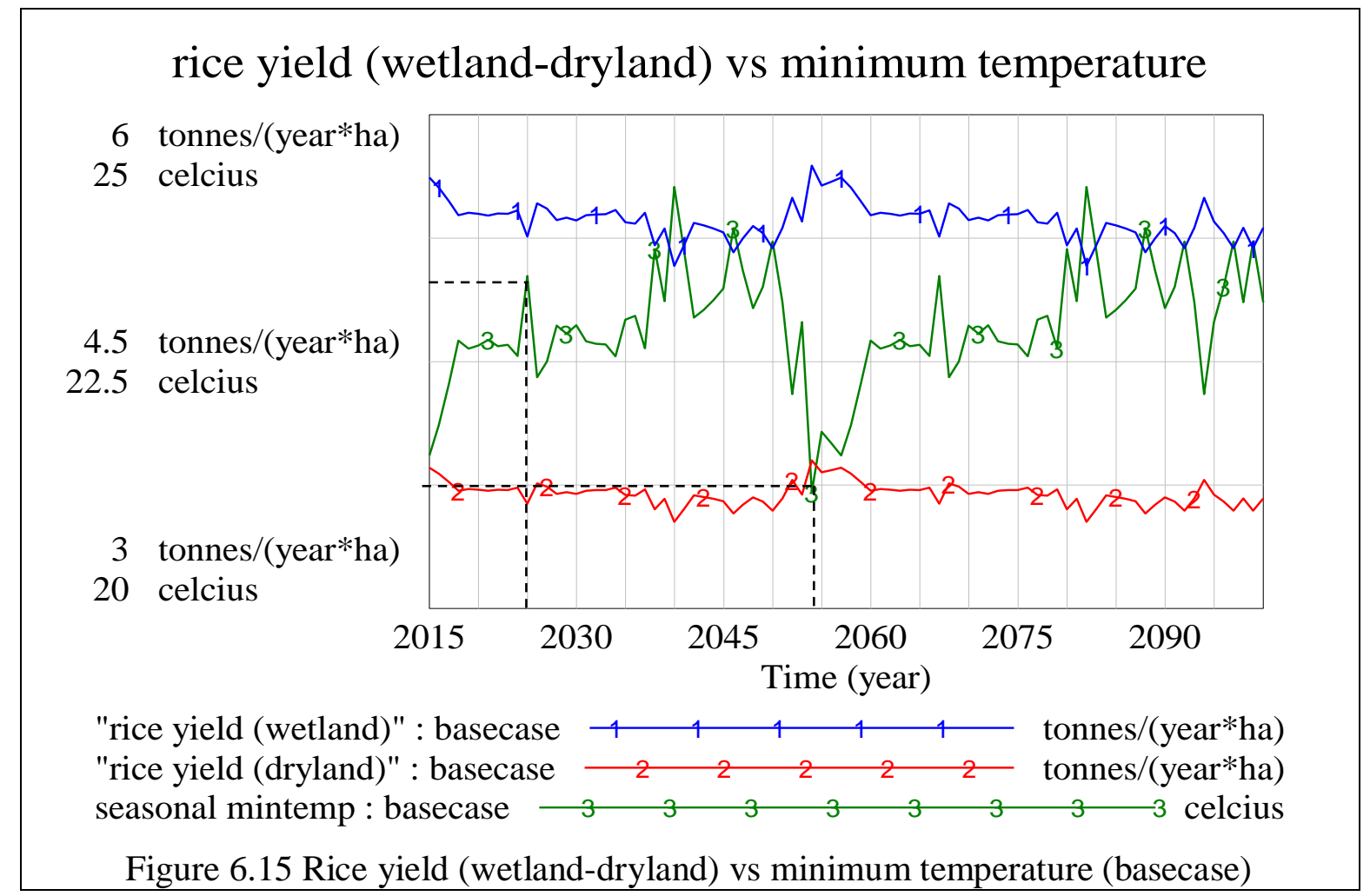

\footnotetext{
${ }^{39}$ In 2030, the monsoon onset is delayed, so harvested areas between September 2030 and August 2031 tend to decrease.
} 
the timing of monsoon onset vs rice production $\&$ harvested areas

$\begin{aligned} 850,000 & \text { ha } \\ 30 & \text { days } \\ 4 \mathrm{M} & \text { tonnes/year } \\ 450,000 & \text { ha } \\ 0 & \text { days } \\ 2.05 \mathrm{M} & \text { tonnes/year } \\ 50,000 & \text { ha } \\ -30 & \text { days } \\ 100,000 & \text { tonnes/year }\end{aligned}$

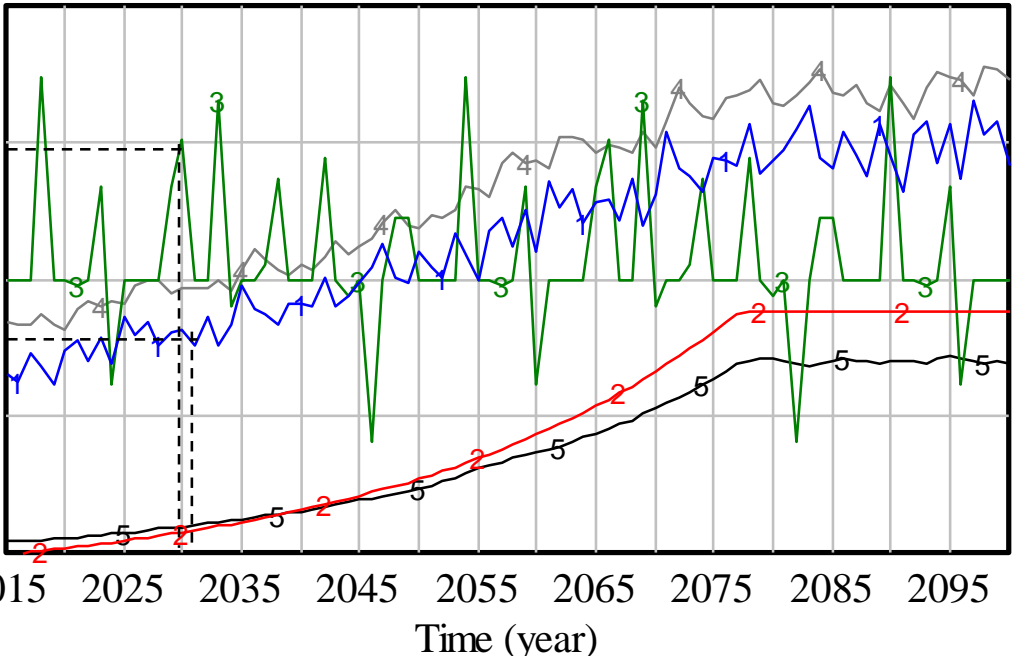

"harvested areas (wetland)" : basecase

"harvested areas (dryland)" : basecase

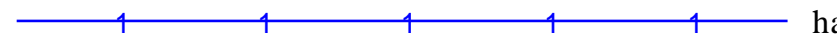

"timing of monsoon onset (days)" : basecase $\begin{array}{lllll}3 & 3 & 3 & 3 & 3\end{array}$

"projected rice production (wetland)" : basecase $\begin{array}{lllll}4 & 4 & 4 & 4 & \text { tonnes/year }\end{array}$

"projected rice production (dryland)" : basecase

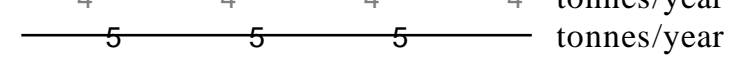

Figure 6.16 Rice production (wetland-dryland) vs the timing of monsoon onset (basecase)

\section{cropping intensity vs seasonal rainfall \& harvested areas}

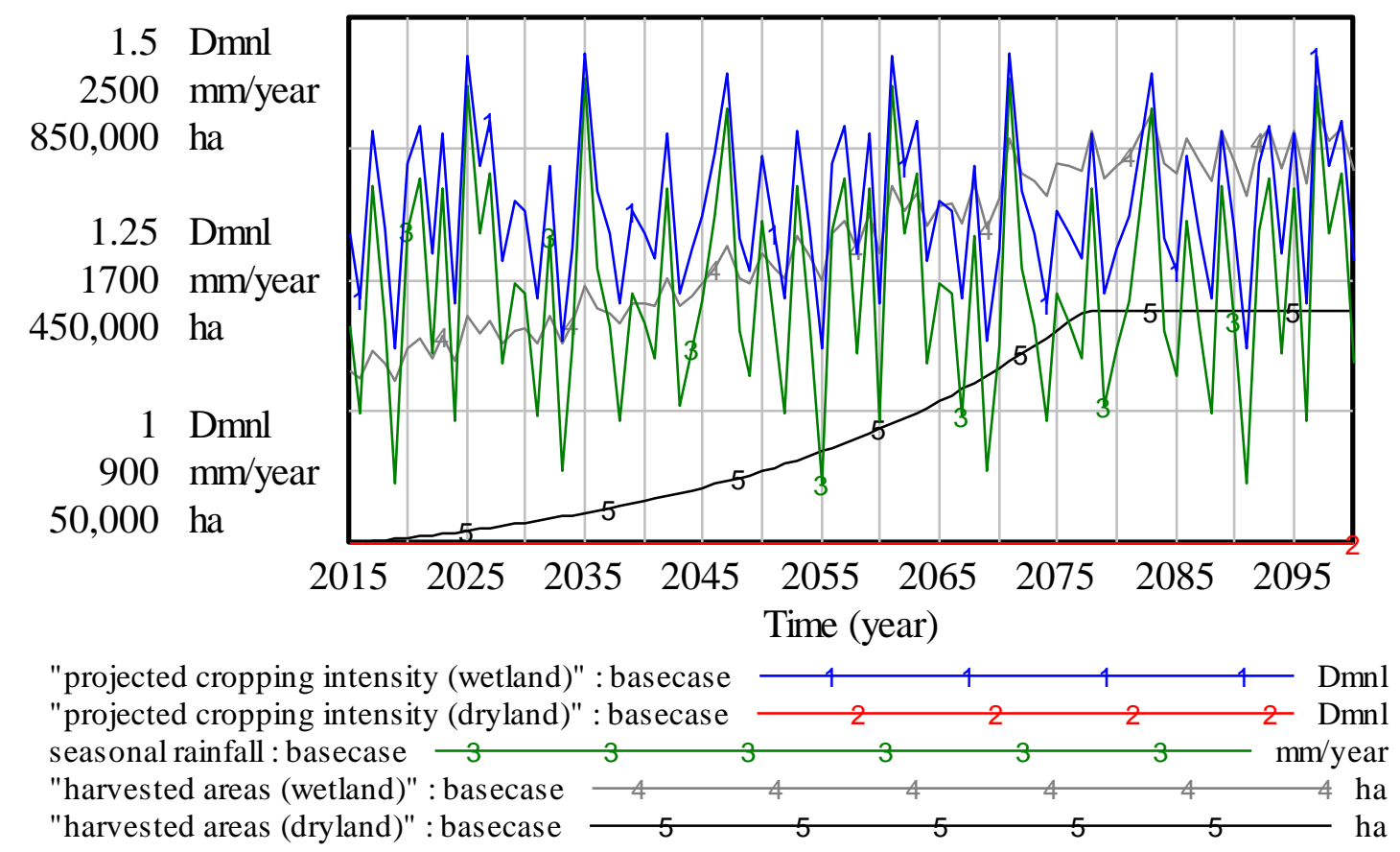

Figure 6.17 Cropping intensity in wetland and dryland (basecase) 


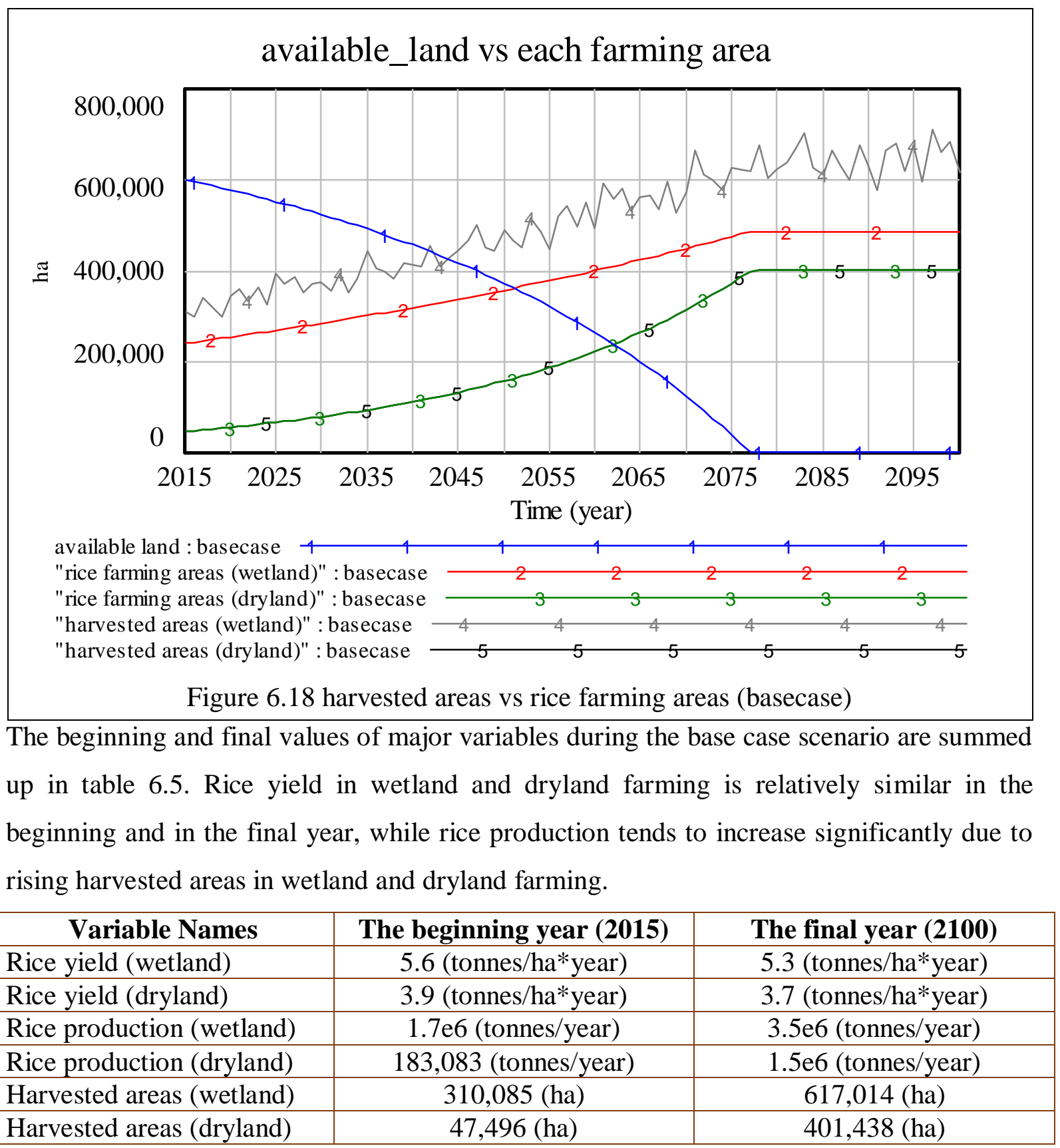

Table 6.5 The values of major variables on the base case simulation

\subsection{Model validation}

Forrester and Senge (1980) and Barlas (1996) discuss some assessments in validations of SD models. These assesments are, for example, boundary adequacy, structure verification, dimensional consistency and behaviour reproduction. In short, these assessments aim to validate the model structure and model behaviour. Section 6.5.1 explains the validation of model structure and section 6.5.2 explains the validation of model behaviour. 


\subsubsection{Validation of the model structure}

This study's objective is to assess three different impacts of climate change on the rice production. The first objective is to assess the impacts of climate change on rice yield. Minimum temperature tends to decrease rice yield (Peng et al., 2004; Welch et al., 2010; Zhang et al., 2013a). Labour might significantly affect wetland rice yield as farmers usually have limited farming areas less than 0.5 Ha (Kasryno et al., 2004). In dryland farming, seed might significantly affect dryland rice yield as a higher use of seed tends to increase rice yield in dryland farming (BPTP, 2011; Kasryno et al., 2004; Wirajaswadi, 2004).

The second objective is to assess the impacts of seasonal rainfall on harvested area. Seasonal rainfall tends to affect harvested area in wetland farming (Irianto \& Suciantini, 2006; Naylor et al., 2001; Naylor et al., 2002; Naylor et al, 2007; Sumarno et al., 2008). Those studies also show that the seasonal rainfall might influence harvested areas through cropping intensity as a higher seasonal rainfall leads to a higher cropping intensity.

The third objective is to assess the impacts of the timing of monsoon onset on rice production. In general, farmers start to sow their rice when the rainy seasons begin (Falcon et al., 2004; Naylor \& Mastrandea, 2009; Sumarno et al., 2008). In turn, delayed (reduced seasonal rainfall) or earlier monsoon onset (a higher seasonal rainfall) might affect rice production as the timing of monsoon onset is a signal of rice growing seasons (Naylor et al., 2001; Naylor et al., 2002; Naylor \& Mastrandea, 2009; Sumarno et al., 2008).

The previous sections explain that the SD model is supported by some scientific studies. Vensim@ also shows that the SD model has dimensional consistency (i.e no "unit errors" identified). Below it is demonstrated that the model structure of the SD model is structurally verified.

Good SD models should not have negative stocks (Sterman, 2000). The SD model is also equipped with relevant mathematical equations so that the model will not ever have negative stocks or negative quantities. To prevent negative stocks the SD model has appropriate mathematical forms. For example,

MIN ((DELAY1 (a fraction of new farming area (wetland)*rice farming area (wetland), delay of new farming land (wetland))), available land/TIME STEP) 
This equation ascertains that the stock of "available land" will never be less than zero as the equation sets new farming areas of wetland farming subject to "available land".

\subsubsection{Extreme condition tests}

Another important structural test is "extreme conditions" (Forrester \& Senge, 1980; Maani \& Cavana, 2007; Sterman, 2000). The assessment of extreme conditions means to set key variables with extreme values in evaluating whether the model behaves appropriately under extreme conditions or beyond historical data (Sterman, 2000). The following table 6.6 shows the extreme values of some variables accompanied by the baseline values. As shown later, the behaviour of the SD model is plausible, which means that the SD model shows expected outputs.

To conduct extreme condition tests, this chapter defines 6 possible extreme variables as shown in table 6.6. The first three variables, such as minimum temperature and seasonal rainfall, are used to draw extreme climate scenarios i.e RCP 2.6 and RCP8.5 scenarios. Figures 6.19-6.20 show the SD model outputs for climate extreme tests. The next extreme condition test is technological growth which is depicted in figure 6.21. Likewise, figure 6.22 depicts extreme tests for a fraction of new farming areas in wetland and dryland.

\begin{tabular}{|c|c|c|c|c|c|}
\hline No & Variables & $\begin{array}{l}\text { Baseline } \\
\text { Values }\end{array}$ & $\begin{array}{c}\text { Low } \\
\text { Extreme } \\
\text { Test }\end{array}$ & $\begin{array}{c}\text { High } \\
\text { Extreme } \\
\text { Test }\end{array}$ & $\begin{array}{l}\text { Related } \\
\text { figures }\end{array}$ \\
\hline 1 & Minimum temperature & $\begin{array}{c}\text { Observed } \\
\text { data }\end{array}$ & $\begin{array}{l}\mathrm{RCP} 2.6 \\
\text { scenario }\end{array}$ & $\begin{array}{l}\mathrm{RCP} 8.5 \\
\text { scenario }\end{array}$ & \multirow[t]{3}{*}{$\begin{array}{c}\text { Figures } \\
6.19-6.20\end{array}$} \\
\hline 2 & Seasonal Rainfall & $\begin{array}{c}\text { Observed } \\
\text { data }\end{array}$ & $\begin{array}{l}\mathrm{RCP} 2.6 \\
\text { scenario }\end{array}$ & $\begin{array}{l}\mathrm{RCP} 8.5 \\
\text { scenario }\end{array}$ & \\
\hline 3 & $\begin{array}{l}\text { The timing of monsoon } \\
\text { onset (August SOI) }\end{array}$ & $\begin{array}{c}\text { Observed } \\
\text { data }\end{array}$ & $\begin{array}{l}\mathrm{RCP} 2.6 \\
\text { scenario }\end{array}$ & $\begin{array}{l}\mathrm{RCP} 8.5 \\
\text { scenario }\end{array}$ & \\
\hline 4 & Technological progress & $\begin{array}{c}\text { Observed } \\
\text { data }\end{array}$ & $\begin{array}{c}\text { No } \\
\text { technology } \\
\text { available }\end{array}$ & $10 \% /$ year & $\begin{array}{l}\text { Figures } \\
6.21\end{array}$ \\
\hline 5 & $\begin{array}{l}\text { A fraction of new } \\
\text { wetland farming }\end{array}$ & $1.15 \%$ & 0 & $10 \% /$ year & \multirow[t]{2}{*}{$\begin{array}{l}\text { Figures } \\
6.22\end{array}$} \\
\hline 6 & $\begin{array}{l}\text { A fraction of new } \\
\text { dryland farming }\end{array}$ & $3.55 \%$ & 0 & $10 \% /$ year & \\
\hline
\end{tabular}

Table 6.6 Parameters for the extreme condition tests (RCP2.6 and RCP8.5 climate projections are based IPSL-CM5A-LR ${ }^{40}$ ).

${ }^{40}$ Among available data of Global Climate Models, IPSL-CM5A-LR projects the most extreme temperature and rainfall. 
RCP8.5 and RCP2.6 scenario represent, respectively, the highest and the lowest climate projections (IPCC, 2013). RCP8.5 scenario projects that seasonal minimum temperature and seasonal rainfall will probably be about $27^{\circ} \mathrm{C}$ and about $1,800 \mathrm{~mm} / \mathrm{year}$, respectively, by 2090 (IPSL-CM5A-LR). On the other hand, RCP2.6 scenario projects that seasonal minimum temperature and seasonal rainfall will probably be about $24^{\circ} \mathrm{C}$ and about 1,700mm/year, respectively, by 2090 (IPSL-CM5A-LR).

It should be noted that RCP2.6 scenario is the highest mitigated scenario, leading to the lowest projection of temperature while RCP8.5 scenario is the least mitigated scenario, leading to the highest projection of temperature (IPCC, 2013). These projections are summarised in figures 6.19 .

\section{minimum temperature, seasonal rainfall \& timing monsoon onset}

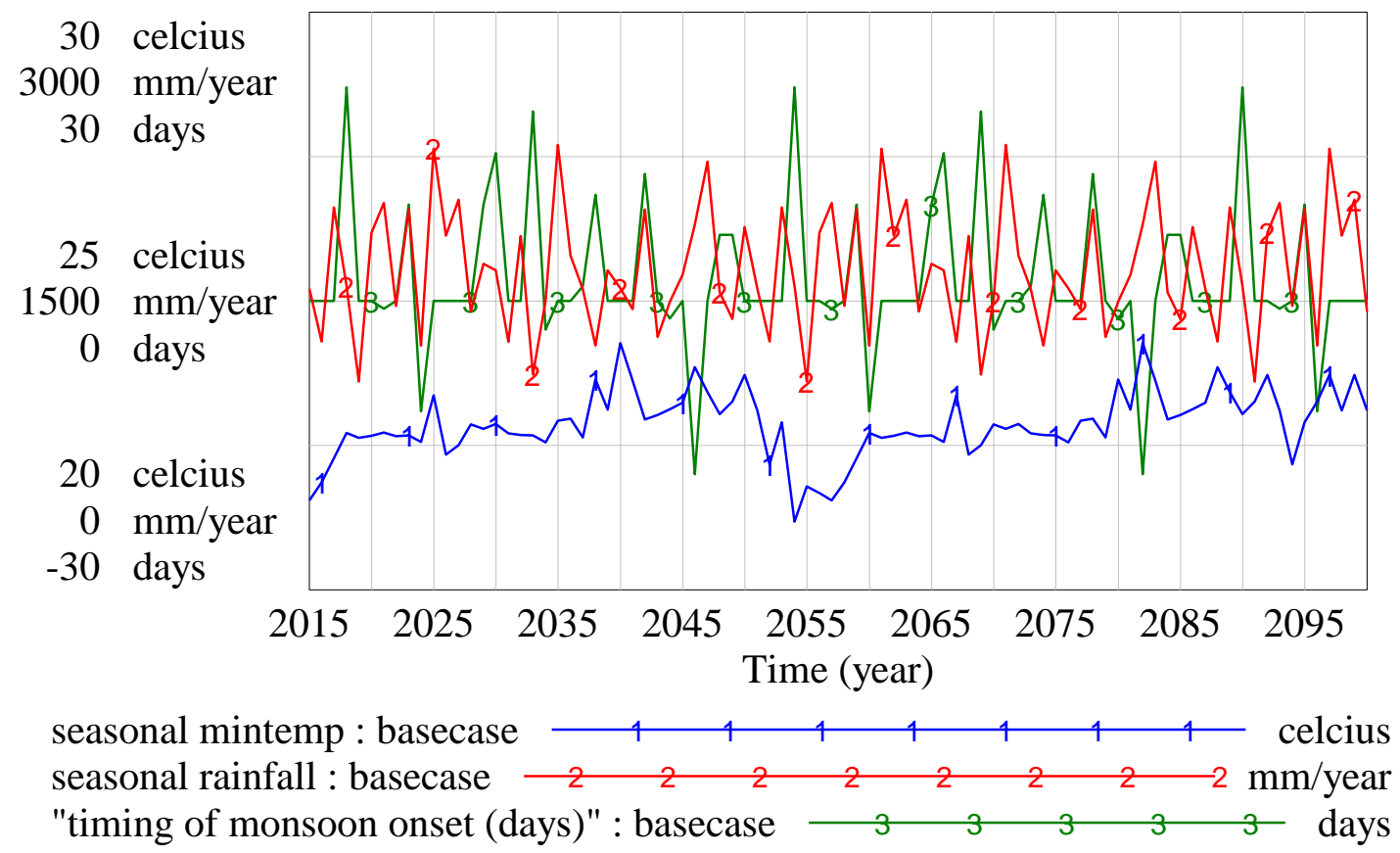

a) basecase scenario 
minimum temperature, seasonal rainfall \& timing monsoon onset

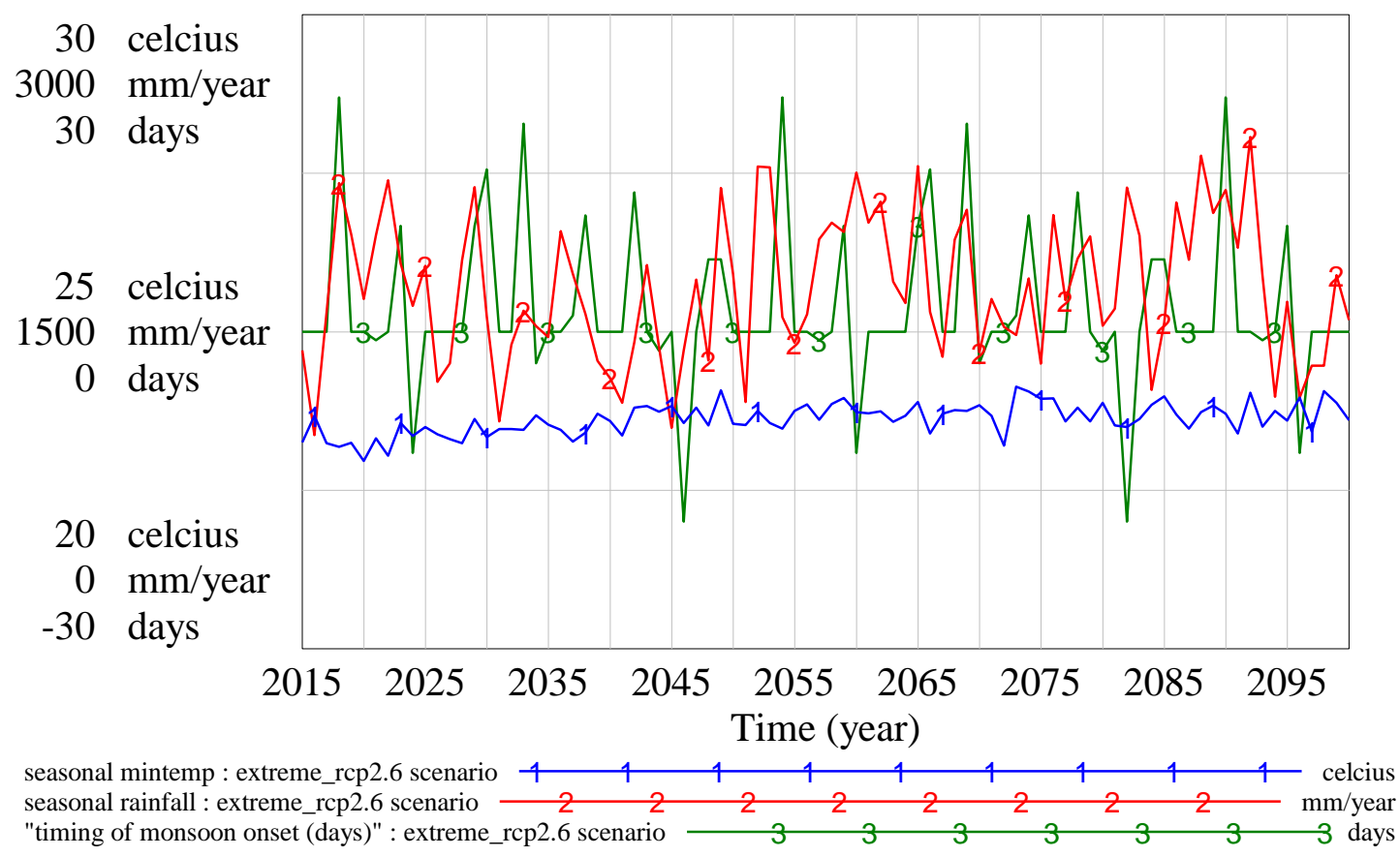

b) RCP2.6 scenario

minimum temperature, seasonal rainfall \& timing monsoon onset

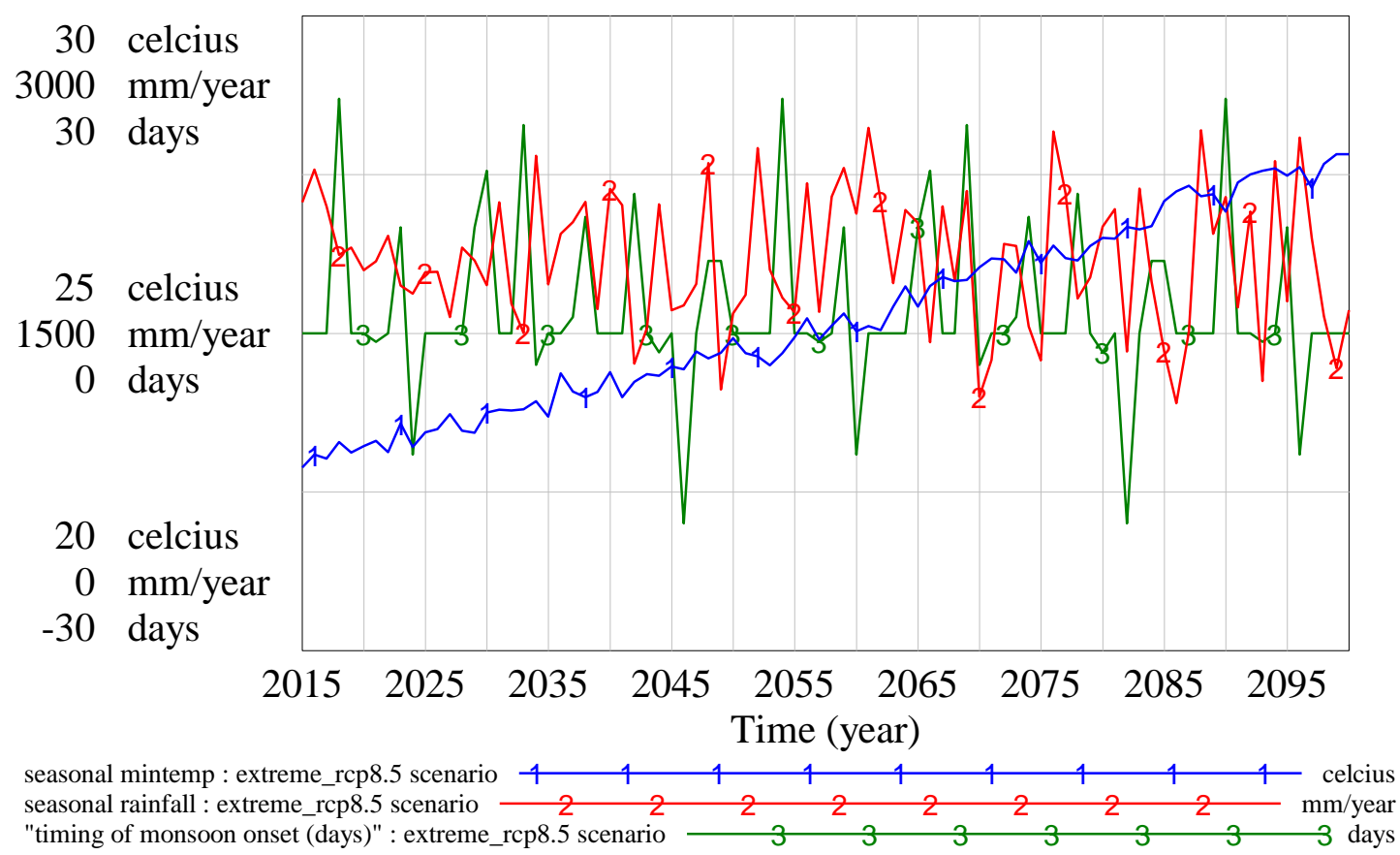

c) RCP8.5 scenario

Figure 6.19 Projections under the basecase, RCP2.6 and RCP8.5 scenarios 
Figures 6.20 depict rice yield and rice production by 2100 under RCP2.6 and RCP8.5 scenarios. As seen in figure 6.20, rice yield, rice production and harvested areas (wetlanddryland) behave appropriately, subject to minimum temperature and the timing of monsoon onset. RCP2.6 scenario projects similar outputs to those in the basecase scenario. For example, wetland rice yield under RCP2.6 scenario is about 5.5 tonnes/ha*year which is relatively similar to that in the basecase scenario.

By constrast, rice yield in dryland and wetland farming tends to decrease over time as RCP8.5 scenario projects a rise in minimum temperature. Dryland and wetland rice yield is projected to plummet significantly to about 1.5 tonnes/ha*year and about 1.5 tonnes/ha*year in 2100 . RCP 8.5 scenario also projects that rice production in wetland and dryland areas will probably decrease by more than half of those in the basecase scenario in 2100.

\section{RCP2.6 scenario - outputs}

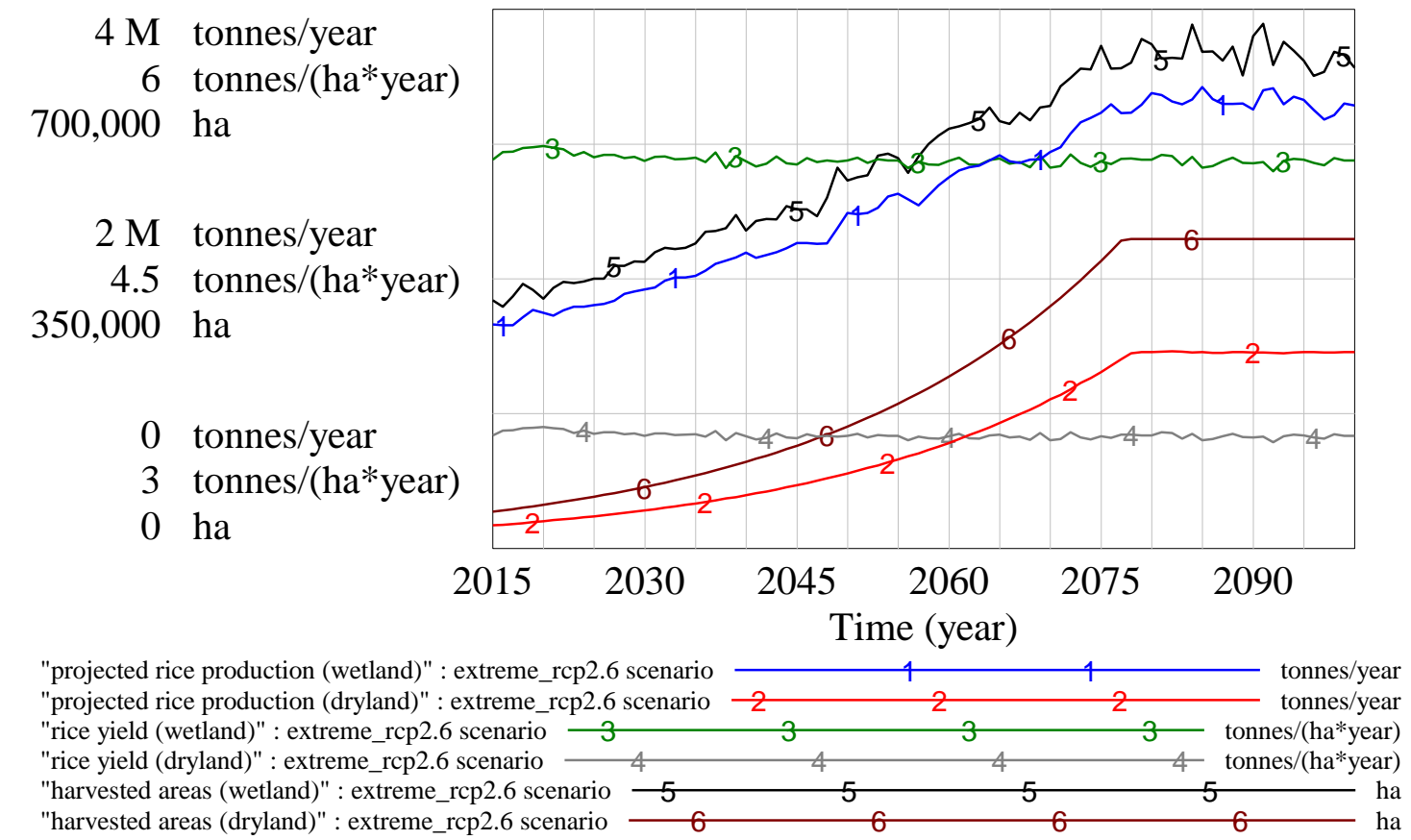

a) Extreme conditions - RCP2.6 scenario 


\section{RCP8.5 scenario - outputs}

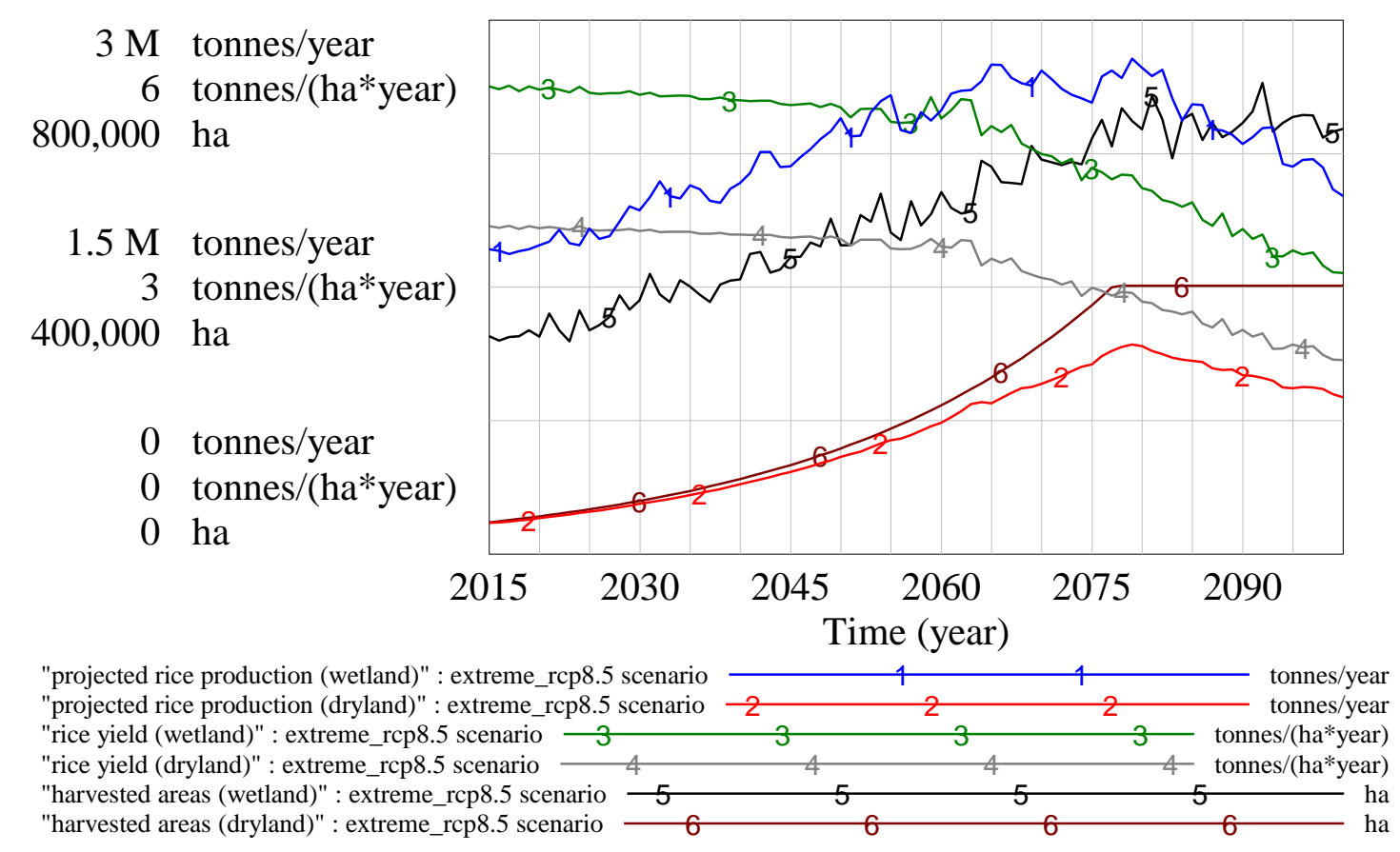

b) Extreme conditions - RCP8.5 scenario

Figure 6.20 Extreme climate projections

Under extremes of technological progress, the SD model behaves appropriately (figure 6.21a and figure 6.21b). For instance, if technological progress is nil, the yield and the production in wetland and dryland farming follows the pattern of minimum temperature. Without technological progress, rice yield in wetland and dryland will probably be stagnant at about 3.7 tonnes/ha*year and 5.5 tonnes/ha*year respectively which are relatively similar to those in basecase scenario. This pattern also occurs for rice production in the base case and in this extreme condition (zero technological growth).

When technological progress grows by about $10 \%$ annually $^{41}$, rice yield and rice production in wetland and dryland tends to increase from about 5.5 tonnes/ha*year to 7 tonnes/ha*year and from about 3.7 tonnes/ha*year to 4.5 tonnes/ha*year respectively. This leads to $50 \%$ higher rice production in wetland and dryland, compared to those in the basecase scenario.

\footnotetext{
${ }^{41}$ For setting extreme technological progress i.e $0 \%$ a year and $10 \%$ a year, this study applies a structure as described in figure 7.5
} 


\section{extreme conditions - technological progress at $0 \% /$ year}

$4 \mathrm{M}$ tonnes/year

6 tonnes/(ha*year)

3 Dmnl

$2 \mathrm{M}$ tonnes/year

4.5 tonnes/(ha*year)

2 Dmnl

0 tonnes/year

3 tonnes/(ha*year)

1 Dmnl

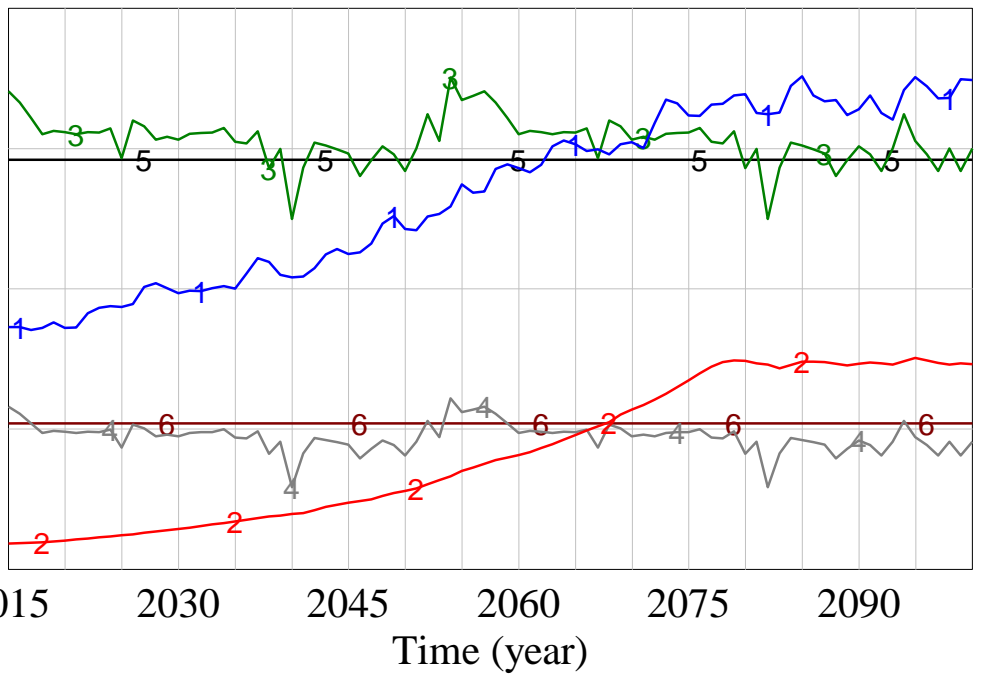

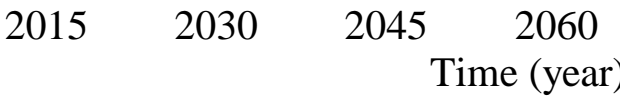

"projected rice production (wetland)" : low_extreme_tech_progress "projected rice production (dryland)" : low_extreme_tech_progress "rice yield (wetland)" : low_extreme_tech_progress

"rice yield (dryland)" : low_extreme_tech_progress

"projected technological progress on rice (wetland)" : low_extreme_tech_progress "projected technological progress on rice (dryland)" : low_extreme_tech_progress

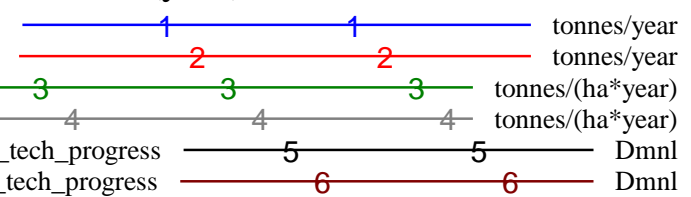

a) Extreme conditions - technological progress (0\%)

\section{extreme conditions - technological progress at 10\%/year}

\section{$7 \mathrm{M}$ tonnes/year \\ 20 tonnes/(ha*year) \\ 8 Dmnl}

\section{5 $\mathrm{M}$ tonnes/year \\ 10 tonnes/(ha*year) \\ 4 Dmnl \\ 0 tonnes/year \\ 0 tonnes/(ha*year) \\ 0 Dmnl}

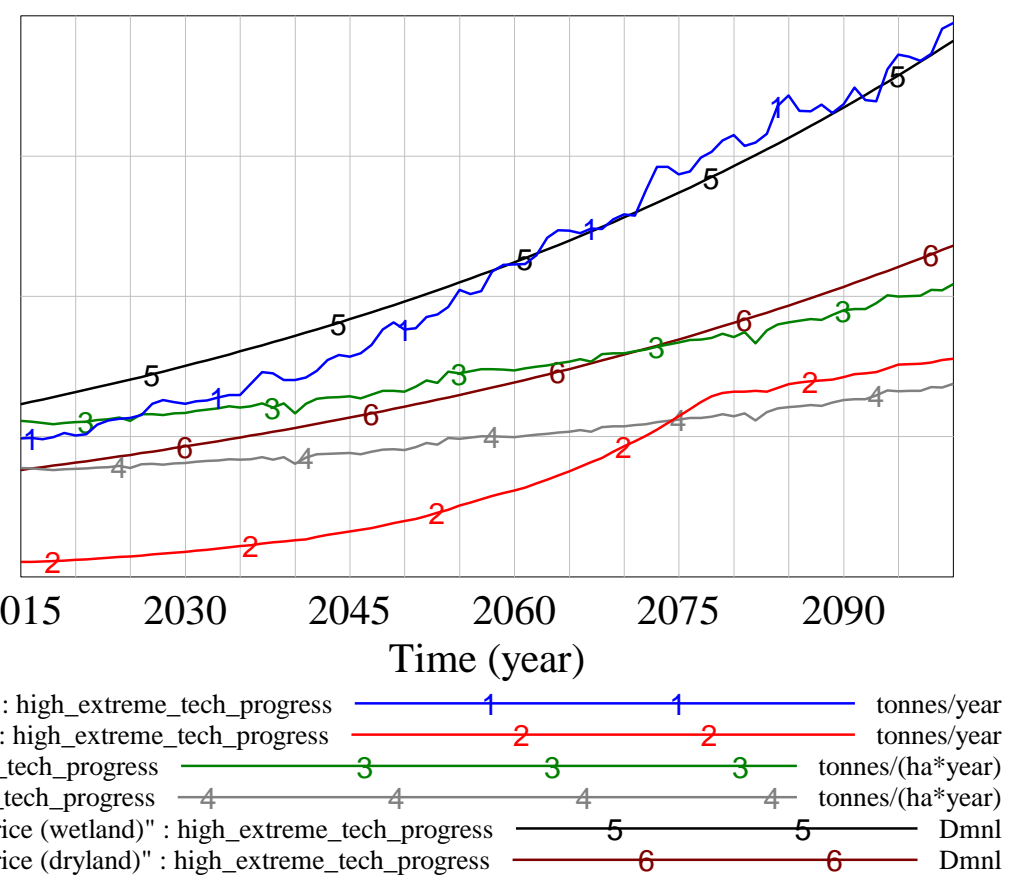

b) Extreme conditions - technological progress (10\%) 
The behaviour of the SD model is appropriate ${ }^{42}$ under extreme fractions of new farming areas. For instance, farming areas and rice production are relatively stagnant when fractions of new farming areas is $0 \%$ a year. Without new farming areas, rice production in wetland and dryland will not increase at all (i.e similar to those values in 2015).

By contrast, when fractions of new farming areas are set to $10 \%$, farming areas in wetland and dryland farming increase rapidly and then tend to be constant afterwards (as available land is nil). If new farming areas in wetland farming are opening at about $10 \%$ a year, it appears that by 2030 , rice production in wetland will increase about $150 \%$ compared to those in 2015. All of these patterns are shown in figures 6.22.

\section{extreme condition - a low fraction farming area at $0 \% /$ year}

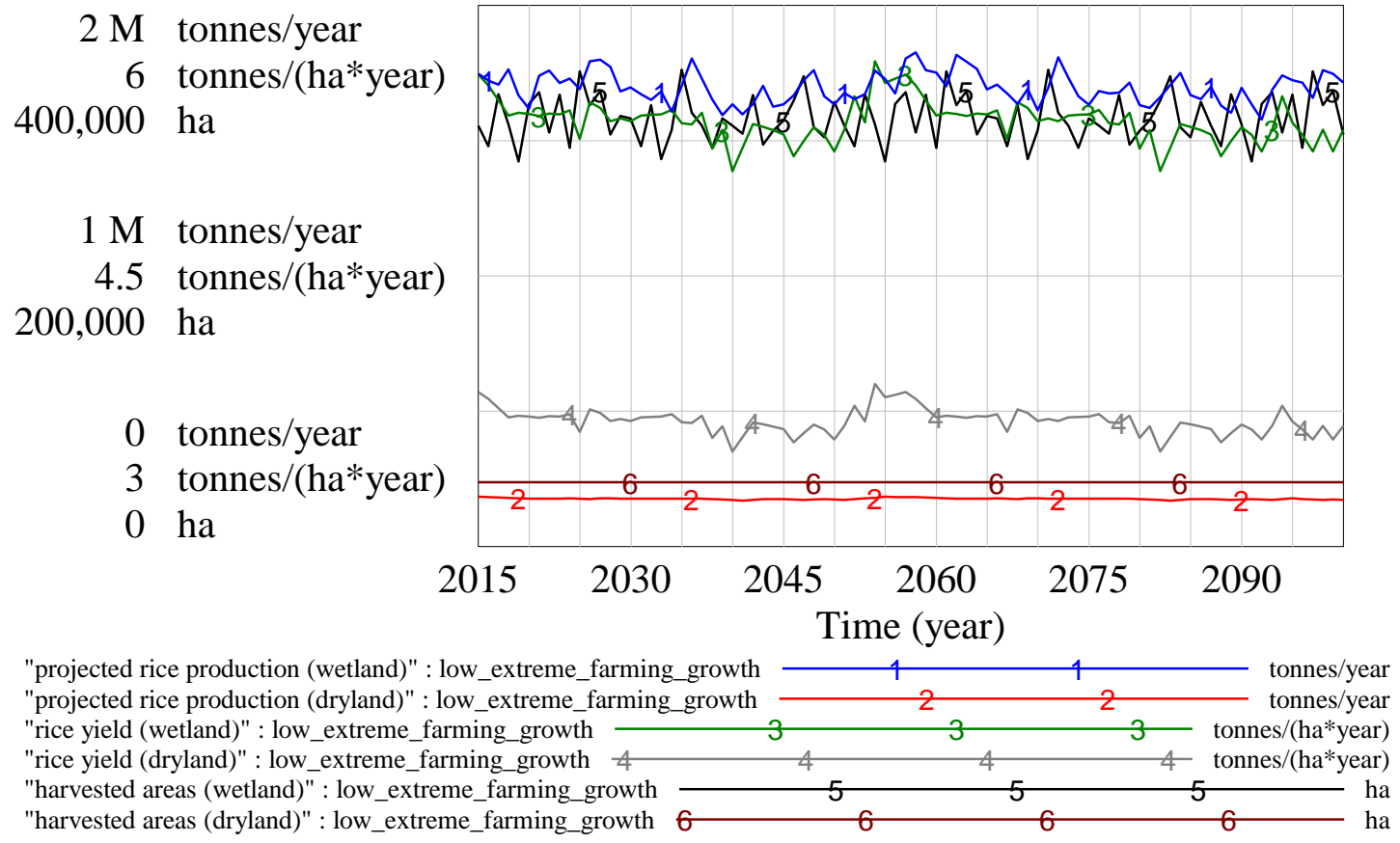

a) Extreme conditions - fractions of new farming areas $(0 \%$ of new fractions of wetland and dryland)

\footnotetext{
42 "Appropriate" in this context means the model behaviour similar to expected behaviour. Farming areas increase rapidly when a fraction growth is about $10 \%$ and farming areas tend to be stagnant when a fraction growth is about $0 \%$
} 


\section{extreme condition - a high fraction farming area at 10\%/year}

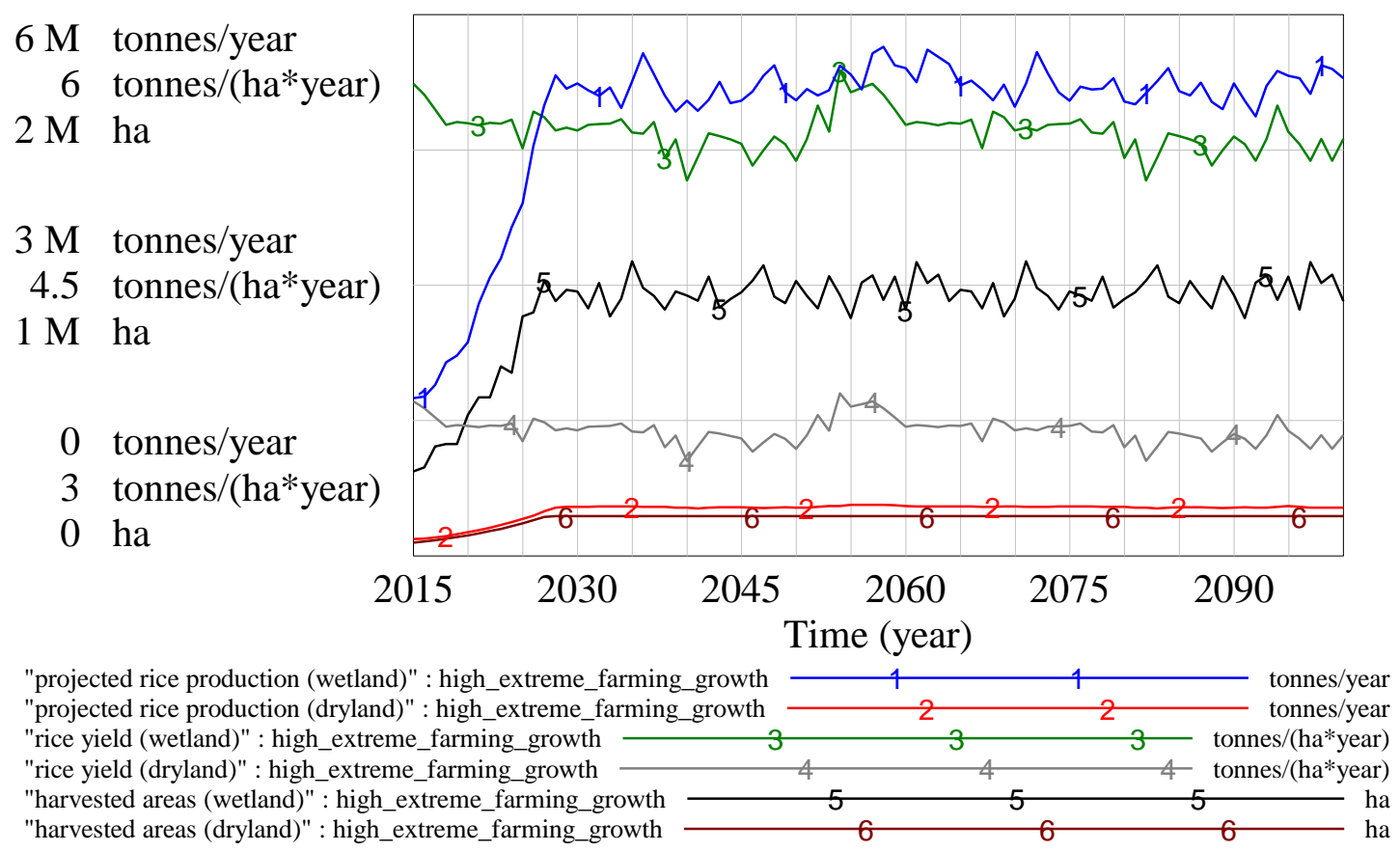

b) Extreme conditions - fractions of new farming areas $(+10 \%$ of new fractions of wetland and dryland $)$

Figure 6.22 Extreme conditions of the increase of farming areas

\subsubsection{Validation of the model behaviour}

The SD models are behaviourally validated if the models can reproduce similar behaviour compared to the observed world (Forrester and Senge, 1980; Sterman, 2000). The good SD models can also generate a wide range of different patterns of behaviour with different policies (Sterman, 2000).

Previous figures (figures 6.9 - 6.14) demonstrate that the SD has similar patterns to the real world (observed data of 1976-2011). Table 6.3 shows that the SD model results in relatively low MAPEs, less than 10\%, showing high SD model performances in replicating patterns of observed system (Hanke et al., 2001). Below it is demonstrated that the SD model is also behaviourally validated.

The SD model also generates, as seen in figures 6.20, a wide range of different behaviour under two projections of future climate i.e RCP2.6 and RCP 8.5 scenarios. For example, rice yield in wetland and dryland farming tends to decrease when minimum temperature rises whereas rice yield tends to increase when minimum temperature decrease (figure 
6.20). The latter is supported by existing studies (Peng et al., 2004; Welch et al., 2010; Zhang et al., 2013a), which explain that the rise of minimum temperature tends to significantly decrease rice yield. Another point of note is that rice farming areas tend to increase when available land is still available and conversely, rice farming areas tend to be stagnant when available land is limited or nil (figure 6.18). Forrester and Senge (1980, p.423) call this feature a behaviour prediction test.

It should be noted that dryland farmers tend to sow their rice during the first cycle (September-December) to counter possible insufficient rainfall in subsequent cycles while wetland farmers sow their rice subject to the patterns of seasonal rainfall. This means that cropping intensity in dryland farming is about 1, while cropping intensity in wetland farming can be higher than 1 and subject to patterns of seasonal rainfall.

It is demonstrated in figure 6.17 that dryland harvested areas tend to increase regardless of the patterns of seasonal rainfall, while wetland harvested areas tend to behave subject to the patterns of seasonal rainfall. This simple example shows the SD model's family member behaviour (Sterman, 2000 p.881) which means that harvested areas in wetland and dryland have different behaviour.

\subsection{Sensitivity analysis}

In conducting sensitivity analysis, this study identifies the parameter assumptions that influence the SD model the most. In doing so, model parameters will be varied \pm 10 percent from their initial values (Maani \& Cavana, 2007). The results of sensitivity analysis will be assessed based on three indicators, namely, rice yield, rice production, and harvested areas. These indicators are used as some variables might influence them differently.

The magnitude of change will be assessed by comparing outputs of important indicators from modified parameters and the base case scenario. Parameters should be categorised as sensitive, very sensitive, and highly sensitive parameters if corresponding output changes are from $5 \%$ to $14 \%, 15 \%-35 \%$ and over $35 \%$ consecutively (Maani \& Cavana, 2007 p.249). 
The magnitude of the change is compared between the simulation outputs of modified parameters $( \pm 10$ percent from their initial values) and their base case values. As simulation might result in temporary or transient changes over time, a gap between the simulation outputs was squared over time (Franck, 2009). The squared rooted gaps are then compared to the average basecase runs in assessing the output sensitivity.

Before doing sensitivity analysis, the SD historical model is altered to represent the basecase scenario. Compared to figure 6.5, the effects of technological progress on rice yield, i.e. the coefficients of time variables (linear and squared time variables), are changed to be a constant for wetland rice yield (equation 5.3.2) and for dryland rice yield (equation 5.4.2) (W. Falcon, personal communication, November $4^{\text {th }}$, 2015; P. Rowhani, personal communication November $\left.13^{\text {th }}, 2015\right)$.

The changes in technological progress are shown in figures $6.23 \mathrm{a}-6.23 \mathrm{~b}$. After changing the effects of technological progress on rice yield, the basecase SD model can be depicted as shown in figure $6.23 \mathrm{c}$. It should be noted that the main difference between the historical SD model and the basecase SD model is the setting of technological progress. In the historical SD model, technological progress is based on observed data i.e the period 1976-2011, while in the basecase SD model, technological progress is set to be a constant. 


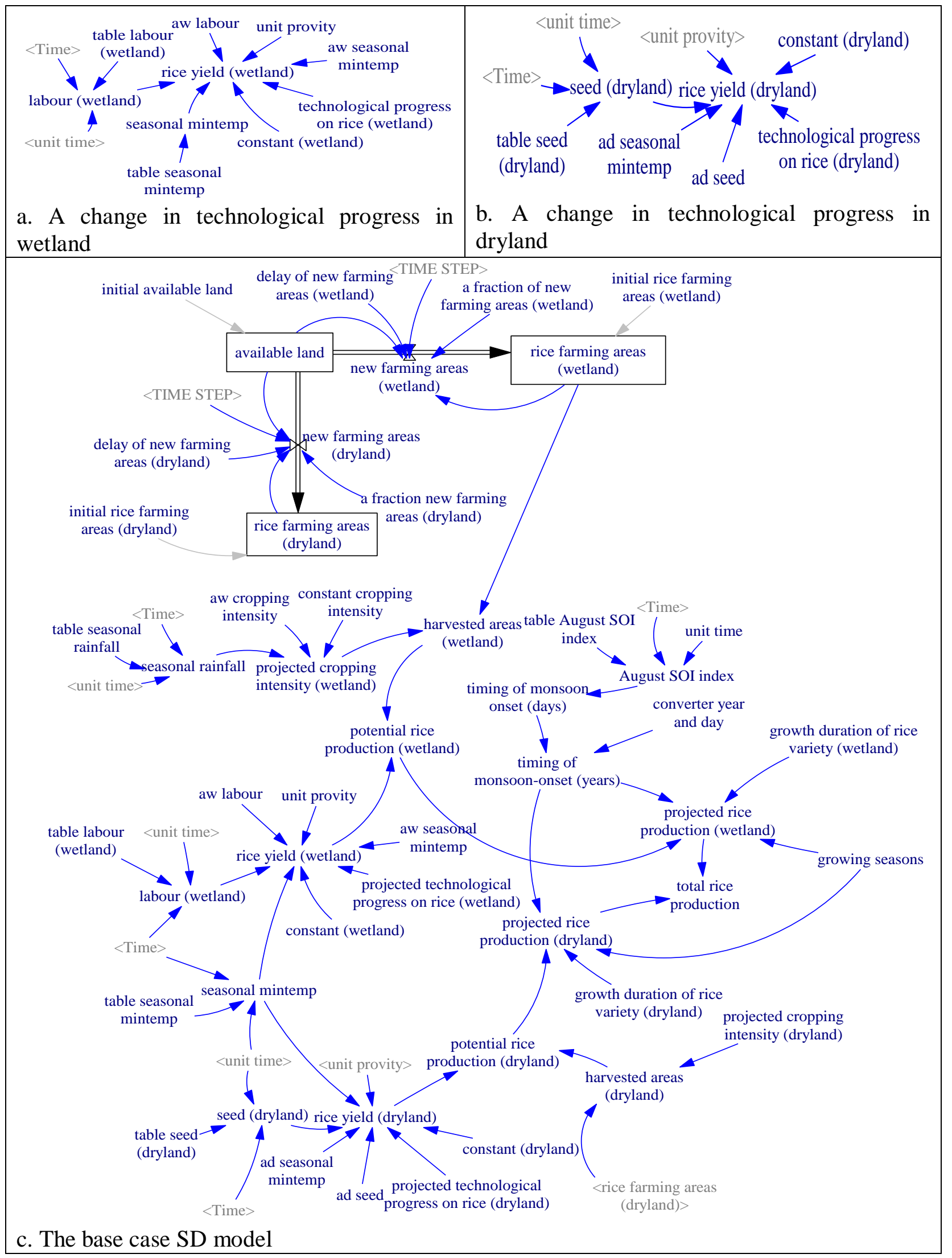

Figure 6.23 Changes in the basecase SD model 
Table 6.7 describes parameter changes in conducting the sensitivity analysis. For example, parameters of technological progress in wetland farming is changed about $\pm 10 \%$ of its basecased parameters i.e 2.71 and 2.21 dimensionless as seen in point 2 table 6.7. For long range data such as seasonal rainfall, table 6.7 only displays the first and the last value i.e the value in 2015 and the value in 2100.

\begin{tabular}{|c|c|c|c|c|}
\hline No & Descriptions & The basecase & $10 \%$ increase & $10 \%$ decrease \\
\hline 1 & $\begin{array}{l}\text { Minimum temperature } \\
\text { (wetland/dryland) }\end{array}$ & $\begin{array}{c}(21.55, \ldots, 23.1) \\
\text { tonnes/(ha*year*Celsius) }\end{array}$ & $\begin{array}{c}(23.7, \ldots, 25.4) \\
\text { tonnes/(ha*year*Celsius) }\end{array}$ & $\begin{array}{c}(19.4, \ldots, 20.8) \\
\text { tonnes/(ha*year*Celsius) }\end{array}$ \\
\hline 2 & $\begin{array}{l}\text { Technological progress on } \\
\text { rice (wetland) }\end{array}$ & $\begin{array}{c}2.46 \\
\text { dimensionless }\end{array}$ & 2.71 dimensionless & 2.21 dimensionless \\
\hline 3 & $\begin{array}{l}\text { Technological progress on } \\
\text { rice (dryland) }\end{array}$ & 1.52 dimensionless & 1.67 dimensionless & 1.37 dimensionless \\
\hline 4 & $\begin{array}{ll}\text { Seasonal } & \text { rainfall } \\
\text { (wetland/dryland) }\end{array}$ & $\begin{array}{c}(1562, \ldots, 1443) \\
\text { mm/year }\end{array}$ & $\begin{array}{c}(1718, \ldots, 1588) \\
\text { mm/year }\end{array}$ & $\begin{array}{c}(1406, \ldots, 1299) \\
\text { mm/year }\end{array}$ \\
\hline 5 & $\begin{array}{l}\text { August SOI (wetland and } \\
\text { dryland) }\end{array}$ & $\begin{array}{c}(-5, \ldots, 14) \\
\text { dimensionless }\end{array}$ & $\begin{array}{c}(-5.5, \ldots, 15.4) \\
\text { dimensionless }\end{array}$ & $\begin{array}{c}(-4.5, \ldots, 12.6) \\
\text { dimensionless }\end{array}$ \\
\hline 6 & $\begin{array}{l}\text { Cropping } \\
\text { (wetland) }\end{array}$ & $\begin{array}{c}\left(2.3 \mathrm{e}-3^{*} \text { seasonal }\right. \\
\text { rainfall }+0.935) \\
\text { dimensionless }\end{array}$ & $\begin{array}{l}(2.53 \mathrm{e}-3 * \text { seasonal } \\
\text { rainfall }+1.3)\end{array}$ & $\begin{array}{l}(2.1 \mathrm{e}-3 * \text { seasonal } \\
\text { rainfall }+0.84)\end{array}$ \\
\hline 7 & Cropping intensity (dryland) & 1 dimensionless & 1.1 dimensionless & 0.9 dimensionless \\
\hline 8 & $\begin{array}{l}\text { Growth duration of rice } \\
\text { variety (wetland) }\end{array}$ & 115 days & 127 days & 104 days \\
\hline 9 & $\begin{array}{l}\text { Growth duration of rice } \\
\text { variety (dryland) }\end{array}$ & 110 days & 121 days & 99 days \\
\hline 10 & Labour (wetland) & 203.3 IDR/year & 223.63 IDR/year & 182.97 IDR/year \\
\hline 11 & Seed (dryland) & 20.8 IDR/year & $22.88 \mathrm{IDR} /$ year & 18.72 IDR/year \\
\hline 12 & $\begin{array}{l}\text { A fraction of new wetland } \\
\text { areas }\end{array}$ & $1.15 \%$ & $1.27 \%$ & $1.04 \%$ \\
\hline 13 & $\begin{array}{l}\text { A fraction of new dryland } \\
\text { areas }\end{array}$ & $3.55 \%$ & $3.9 \%$ & $3.2 \%$ \\
\hline 14 & $\begin{array}{l}\text { Delay of new farming areas } \\
\text { (wetland and dryland) }\end{array}$ & 1 year & 1.1 year & 0.9 year \\
\hline 15 & $\begin{array}{l}\text { The timing of monsoon } \\
\text { onset (days) }\end{array}$ & $\begin{array}{c}(-30, \ldots, 30) \\
\text { days }\end{array}$ & $\begin{array}{c}(-33, \ldots, 33) \\
\text { days }\end{array}$ & $\begin{array}{c}(-27, \ldots, 27) \\
\text { days }\end{array}$ \\
\hline
\end{tabular}

Table 6.7 Sensitivity experiments for testing parameters

Table 6.8 summarises the sensitivity analysis of the model. For instance, minimum temperature is a sensitive parameter as $\pm 10 \%$ changes of minimum temperature lead to an output change about $\pm 8 \%$ and $\pm 9.5 \%$ for rice yield and rice production respectively. 


\begin{tabular}{|c|c|c|c|c|}
\hline No & Descriptions & $\begin{array}{c}\text { Rice yield }(+10 \% \\
\text { change; }-10 \% \\
\text { change })\end{array}$ & $\begin{array}{c}\text { Rice production } \\
\text { ( }+10 \% \text { change; }- \\
10 \% \text { change })\end{array}$ & $\begin{array}{l}\text { Harvested area } \\
(+10 \% \text { change; - } \\
10 \% \text { change })\end{array}$ \\
\hline 1 & Minimum temperature (wetland) & $\begin{array}{c}(8 \% ; 8 \%) \\
(4.9 ; 5.8)\end{array}$ & $\begin{array}{c}(9.5 \% ; 9.5 \%) \\
(3.4 \mathrm{e} 6 ; 4 \mathrm{e} 6)\end{array}$ & - \\
\hline 2 & Minimum temperature (dryland) & $\begin{array}{c}(8 \% ; 8 \%) \\
(3.4 ; 3.9)\end{array}$ & $\begin{array}{l}(9.8 \% ; 9.8 \%) \\
(1.6 \mathrm{e} 6 ; 1.9 \mathrm{e} 6)\end{array}$ & - \\
\hline 3 & Technological progress on rice (wetland) & $\begin{array}{c}(4.4 \% ; 4.4 \%) \\
(5.06 ; 5.56)\end{array}$ & $\begin{array}{c}(5 \% ; 5 \%) \\
(3.54 \mathrm{e} 6 ; 3.89 \mathrm{e} 6)\end{array}$ & - \\
\hline 4 & Technological progress on rice (dryland) & $\begin{array}{c}(4 \% ; 4 \%) \\
(3.8 ; 3.5)\end{array}$ & $\begin{array}{c}(5 \% ; 5 \%) \\
(1.69 \mathrm{e} 6 ; 1.89 \mathrm{e} 6)\end{array}$ & \\
\hline 5 & Seasonal rainfall (wetland) & - & $\begin{array}{c}(3 \% ; 3 \%) \\
(3.6 \mathrm{e} 6 ; 3.8 \mathrm{e} 6)\end{array}$ & $\begin{array}{c}(3 \% ; 3 \%) \\
(6.4 \mathrm{e} 5 ; 6.8 \mathrm{e} 5)\end{array}$ \\
\hline 6 & Seasonal rainfall (dryland) & - & $\begin{array}{c}(0 \% ; 0 \%) \\
(1.8 \mathrm{e} 6 ; 1.8 \mathrm{e} 6)\end{array}$ & $\begin{array}{c}(0 \% ; 0 \%) \\
(4.9 \mathrm{e} 5 ; 4.9 \mathrm{e} 5)\end{array}$ \\
\hline & $\begin{array}{l}\text { Growth duration and August SOI } \\
\text { (*wetland and dryland farming have a } \\
\text { relatively similar output) }\end{array}$ & - & $\begin{array}{c}(<1 \% \% ;<1 \%) \\
(6.6 \mathrm{e} 5 ; 6.6 \mathrm{e} 5) \\
(4.9 \mathrm{e} 5 ; 4.9 \mathrm{e} 5)\end{array}$ & $\begin{array}{l}(<1 \% \% ;<1 \%) \\
(3.7 \mathrm{e} 6 ; 3.7 \mathrm{e} 6) \\
(1.77 \mathrm{e} 6 ; 1.77 \mathrm{e} 6)\end{array}$ \\
\hline 8 & Cropping intensity (wetland) & - & $\begin{array}{l}(10 \% ; 10 \%) \\
(1.5 \mathrm{e} 6 ; 1.9 \mathrm{e} 6)\end{array}$ & $\begin{array}{l}(10 \% ; 10 \%) \\
(2.7 \mathrm{e} 5 ; 3.3 \mathrm{e} 5)\end{array}$ \\
\hline 9 & Cropping intensity (dryland) & & $\begin{array}{l}(12 \% ; 12 \%) \\
(1.6 \mathrm{e} 6 ; 1.9 \mathrm{e} 6)\end{array}$ & $\begin{array}{l}(12 \% ; 12 \%) \\
(4.4 \mathrm{e} 5 ; 5.4 \mathrm{e} 5)\end{array}$ \\
\hline 10 & Labour & $\begin{array}{l}(1 \% ; 1 \%) \\
(5.2 ; 5.4)\end{array}$ & $\begin{array}{c}(1 \% ; 1 \%) \\
(3.6 \mathrm{e} 6 ; 3.8 \mathrm{e} 6)\end{array}$ & - \\
\hline 11 & Seed & $\begin{array}{l}(1 \% ; 1 \%) \\
(3.6 ; 3.7)\end{array}$ & $\begin{array}{c}(1 \% ; 1 \%) \\
(1.75 \mathrm{e} 6 ; 1.79 \mathrm{e} 6)\end{array}$ & - \\
\hline 12 & A fraction of new wetland farming & - & $\begin{array}{c}(5 \% ; 5 \%) \\
(3.7 \mathrm{e} 6 ; 3.72 \mathrm{e} 6)\end{array}$ & $\begin{array}{c}(5 \% ; 5 \%) \\
(6.57 \mathrm{e} 5 ; 6.59 \mathrm{e} 5)\end{array}$ \\
\hline 13 & A fraction of new dryland farming & - & $\begin{array}{c}(15 \% ; 15 \%) \\
(1.764 \mathrm{e} 6 ; 1.769 \mathrm{e} 6)\end{array}$ & $\begin{array}{c}(15 \% ; 15 \%) \\
(4.87 \mathrm{e} 5 ; 4.88 \mathrm{e} 5)\end{array}$ \\
\hline & $\begin{array}{l}\text { delay of new farming areas (wetland and } \\
\text { dryland) }\end{array}$ & - & $\begin{array}{c}(<1 \% \% ;<1 \%) \\
(6.6 \mathrm{e} 5 ; 6.6 \mathrm{e} 5)\end{array}$ & $\begin{array}{l}(<1 \% \% ;<1 \%) \\
(3.7 \mathrm{e} 6 ; 3.7 \mathrm{e} 6)\end{array}$ \\
\hline & $\begin{array}{l}\text { The timing of monsoon onset (days) } \\
\text { (*wetland and dryland farming express a } \\
\text { relatively similar output) }\end{array}$ & - & $\begin{array}{l}(<1 \% \% ;<1 \%) \\
(4.9 \mathrm{e} 5 ; 4.9 \mathrm{e} 5)\end{array}$ & $\begin{array}{l}(<1 \% \% ;<1 \%) \\
(1.77 \mathrm{e} 6 ; 1.77 \mathrm{e} 6)\end{array}$ \\
\hline
\end{tabular}

Table 6.8 Results of sensitivity analysis ( $+10 \%$ change; $-10 \%$ change)

Likewise, some non-climatic parameters such as fractions of new farming areas (wetland and dryland farming) are also sensitive parameters. Technological progress tends to be a sensitive parameter as technological progress results in $\pm 5 \%$ change of rice production in wetland and dryland farming.

Fractions of new farming areas also are sensitive parameters as they lead to a change in rice production greater than $\pm 5 \%$. It appears that a fraction of dryland farming area is more sensitive than a fraction of wetland farming areas. For seasonal rainfall, a $\pm 10 \%$ change of 
seasonal rainfall leads to $\pm 3 \%$ of change of rice production and harvested areas in wetland farming. Consequently, this study categorises seasonal rainfall as an insensitive parameter.

August SOI and the timing of monsoon onset are not sensitive parameters. August SOI and the timing of monsoon onset tend not to significantly influence rice production, as $\pm 10 \%$ change of August SOI and the timing of monsoon onset leads to a less than 1 day change in the timing of monsoon onset which corresponds to less than $1 \%$ change in rice production.

Previous studies (Sumarno et al., 2008) claim that a delay in the timing of monsoon onset of about 20 days or longer leads to an insignificant change in rice production. As rice's growth duration (rice growing days) in wetland and dryland are, respectively, about 115 and 110 days, 1 day change in the timing of monsoon onset might not impact rice production significantly. This claim is supported by existing studies (Falcon et al., 2004; Falcon, W.P., personal communication, March 13, 2013). During El Niño in 1997 (one of the most significant El Niños), the timing of monsoon onset was delayed by about 20 days (IPCC, 2013; Irianto \& Suciantini, 2006), and there were about 2,000 hectare rice areas (1\% of total rice areas) which led to insignificant change in rice production in WNT.

Sensitivity analysis concludes that climate might affect the rice farming in terms of rice yield and rice production. Again, some non-climatic factors such as technological progress and fractions of new farming areas are sensitive parameters. Sensitive parameters can also be categorised into two categories, namely external and internal parameters. Minimum temperature is an external parameter as climate cannot be controlled, while other sensitive parameters such as fractions of new farming areas are internal parameters as they might be controlled by the government or stakeholders of the rice supply chain. For cropping intensity, this parameter is classified as "both parameters" since cropping intensity can be influenced by seasonal rainfall (an external factor) and farmer initiatives or the government subsidy (an internal factor). A complete list of parameter categories can be seen in table 6.9. 


\begin{tabular}{|c|l|c|c|}
\hline No & \multicolumn{1}{|c|}{ Descriptions } & \multicolumn{1}{|c|}{$\begin{array}{c}\text { Internal } \\
\text { Parameters }\end{array}$} & $\begin{array}{c}\text { External } \\
\text { Parameters }\end{array}$ \\
\hline 1 & Minimum temperature (wetland and dryland) & - & x \\
\hline 2 & Technological progress (wetland and dryland) & $\mathrm{x}$ & - \\
\hline 3 & $\begin{array}{l}\text { Fractions of new farming areas (wetland and } \\
\text { dryland) }\end{array}$ & $\mathrm{x}$ & - \\
\hline 4 & $\begin{array}{l}\text { Rice growing days i.e growth duration of rice variety } \\
\text { (wetland and dryland) }\end{array}$ & $\mathrm{x}$ & $\mathrm{x}$ (both) \\
\hline 5 & Cropping intensity (wetland and dryland) & \multicolumn{1}{|c|}{} \\
\hline
\end{tabular}

Table 6.9 Sensitive parameters and their parameter categories

\subsection{Structural changes due to climate factors ${ }^{43}$}

Two structural changes relating to climate factors are explained in this section. The first is the effects of maximum temperature on rice yield and the second is the impacts of high minimum temperature when it exceeds $24.7^{0} \mathrm{C}$.

Since projected maximum temperature by 2090 (2077-2100) will probably be higher than $33^{\circ} \mathrm{C}$, the negative effects of maximum temperature on rice yield should be considered. Since existing studies (Hatfield \& Krueger, 2015; Kim, 1996; Luo, 2011) explain that rice yields tends to decrease linearly from $33^{\circ} \mathrm{C}$ to to $40^{\circ} \mathrm{C}$, rice yield will probably decrease about $12.5 \%$ for every $1{ }^{\circ} \mathrm{C}$ increase of the maximum temperature from $33^{\circ} \mathrm{C}$ to $40^{\circ} \mathrm{C}$ (Hatfield \& Krueger, 2015; Kim, 1996; Luo, 2011). The lookup function to express this decrease is shown in figure 6.24 and a related structural change is depicted in figure 6.25 . It should be noted that the detriemental effects of the maximum temperature are not seen because maximum temperature in the base case scenario is lower than $33^{\circ} \mathrm{C}$.

\footnotetext{
${ }^{43}$ After adding structural changes due to climate factors, sensitivity analysis of minimum temperature based on wetland and dryland rice yields is about $12 \%$ and $14 \%$ respectively. This is relatively higher than sensitivity of minimum temperature before adding these structural changes, shown at aroun $8 \%$ in table 6.8 . Please note that sensitivity analysis results of minimum temperature based on rice production is a little higher relative to those in table 6.8 .

For maximum temperature, sensitivity analysis reveals that +10 change leads to about $25 \%$ change of rice yield and to about $30 \%$ change of rice production, while $-10 \%$ leads to less than $5 \%$ of change on yield and production. All of these elucidate that minimum and maximum temperature are a sensitive parameter and a very sensitive parameter respectively.
} 


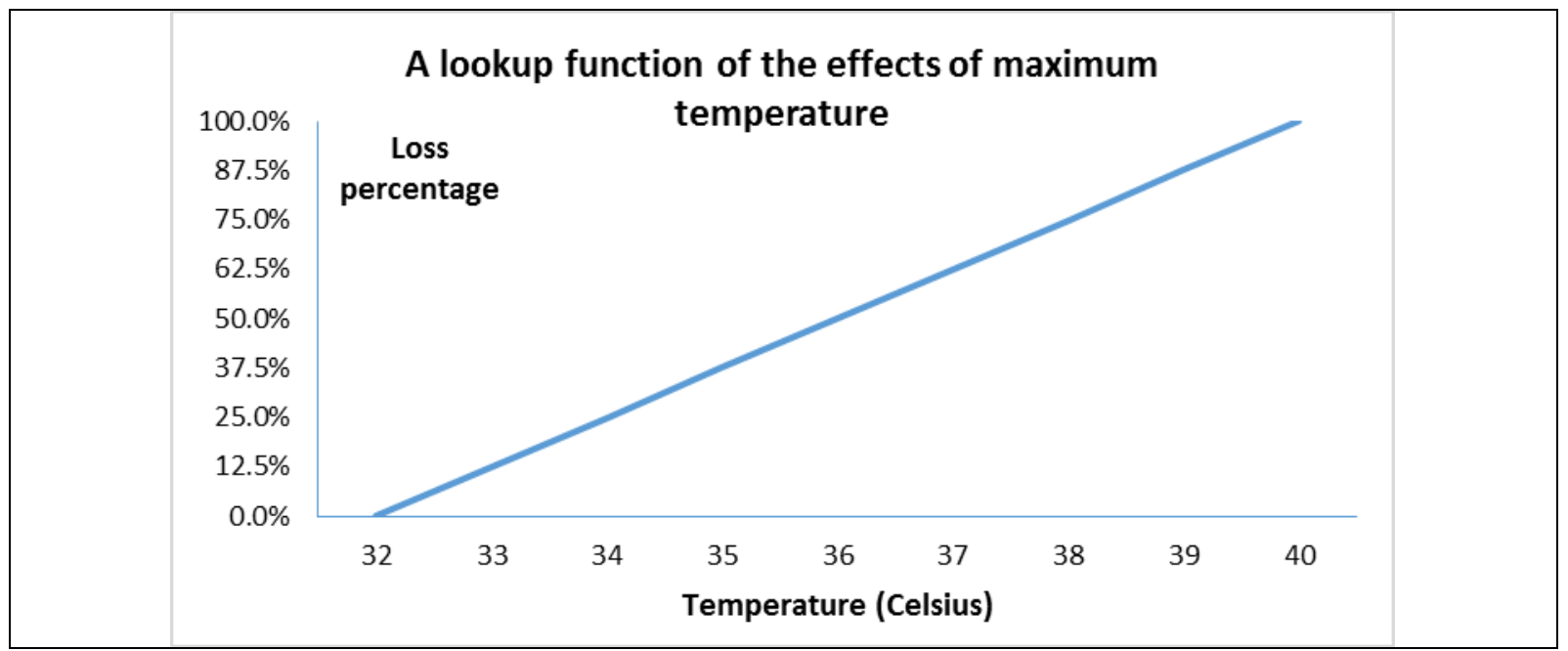

Figure 6.24 A lookup function of the effects of maximum temperature

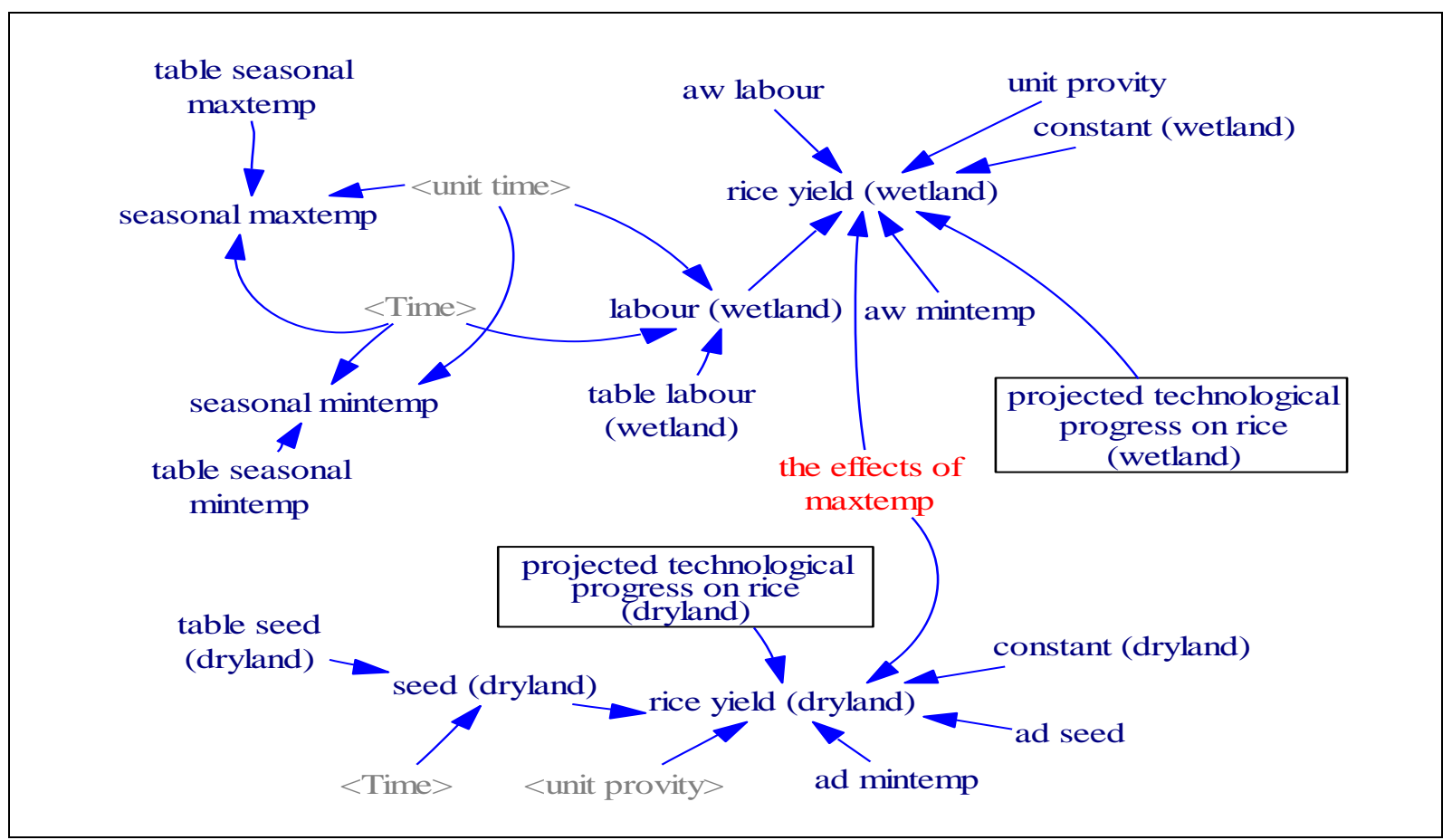

Figure 6.25. A structural change of the effects of maximum temperature

Lobell \& Burke (2010) suggest that statistical models assessing the impacts of climate on rice yield are not reasonable when projected temperature (i.e. future temperature) is higher by $1^{0} \mathrm{C}$ than the highest observed minimum temperature. Since the highest observed minimum temperature is about $23.7^{\circ} \mathrm{C}$ and projected minimum temperature by 2090 (20772100) under RCP8.5 scenario is about $27^{\circ} \mathrm{C}$ (see section 6.7.2), the impacts of minimum temperature on rice yield should be reformulated as explained in subsequent paragraphs. 
In capturing the effects of minimum temperature if projected minimum temperature exceeds $24.7^{0} \mathrm{C}$ ("critical minimum temperature"), a structural change is embedded in the SD model as shown in figure 6.26. A critical minimum temperature in this study is defined as the highest observed minimum temperature in the period 1976-2011. This structural change introduces some new variables such as "the fraction loss after critical minimum temperature", "the basecase rice yield (wetland)" and "rice yield after critical minimum temperature (wetland)". "The fraction loss after critical minimum temperature" is set to be -0.1 which means that a decrease of rice yield will be about $10 \%$ for every $1^{\circ} \mathrm{C}$ increase of minimum temperature if minimum temperature exceeds $24.7^{\circ} \mathrm{C}$ (Zhang et al., 2013).

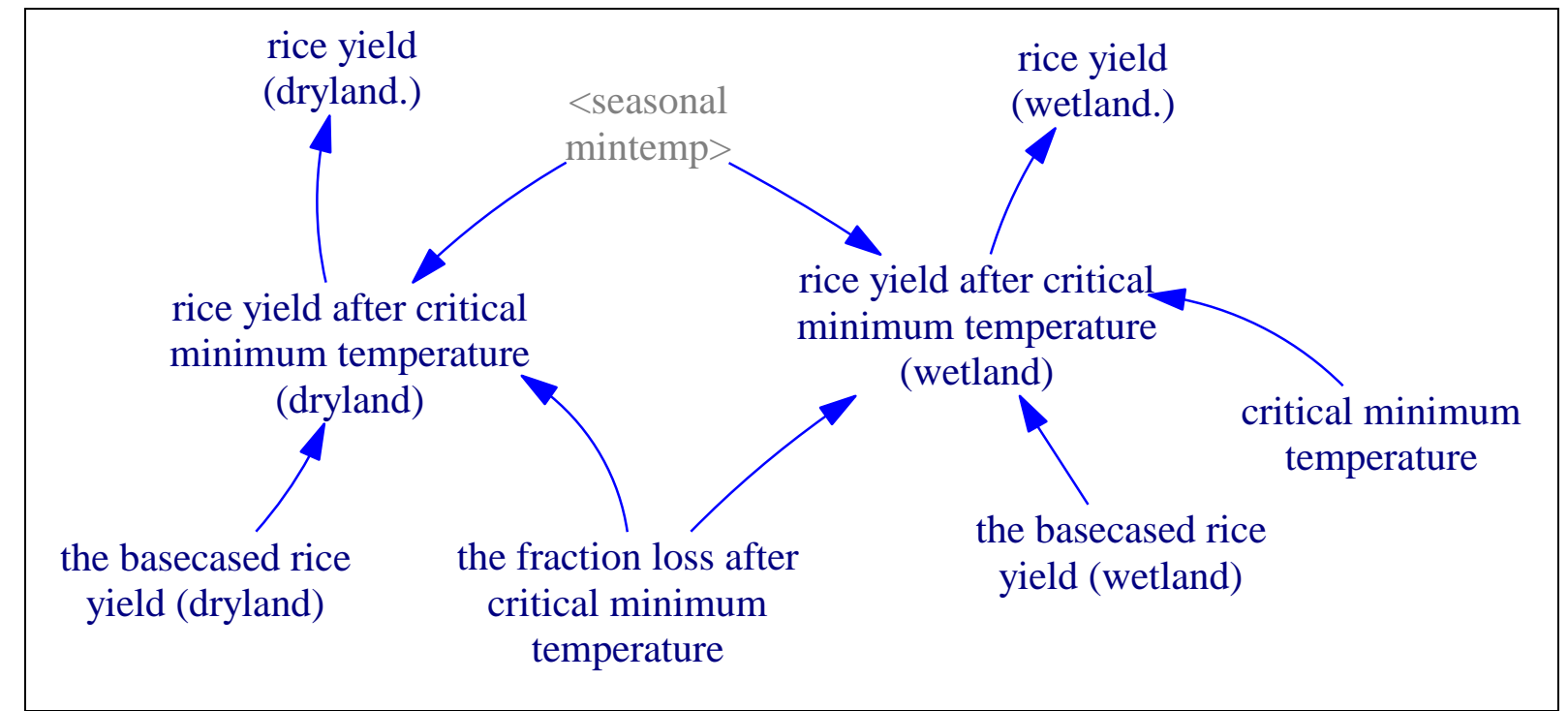

Figure 6.26. A structural change of the negative impacts of minimum temperature after 24.7 ${ }^{0} \mathrm{C}$. All variables in this figure are new variables except for rice yield (wetland) and rice yield (dryland)

On average, rice yield in the basecase scenario is about 3.7 tonnes/ha*year and about 5.4 tonnes/ha*year in dryland and wetland farming respectively. In the SD model, they are called "the basecase rice yield (dryland)" and "the basecase rice yield (wetland)" respectively. "Rice yield after critical minimum temperature (wetland)" is rice yield measured after minimum temperature exceeds $24.7^{\circ} \mathrm{C}$. So if projected minimum temperature is higher than $24.7^{\circ} \mathrm{C}$, rice yield will be measured as follows:

Rice yield after critical minimum temperature (wetland)" = "the basecase rice yield (wetland)"+ ("seasonal mintemp"- "critical minimum temperature")*"the fraction loss after critical minimum temperature"*"the basecased rice yield (wetland)" 


\subsubsection{The basecase strategy or the first strategy}

This strategy resembles the base case model with two added structural changes owing to climate factors: the effects of maximum temperature and the negative impacts of minimum temperature as explained in section 6.7.

It appears that rice yield will probably decrease due to high minimum and high maximum temperature. For example, when maximum temperature is about $33^{\circ} \mathrm{C}$ in 2040 and in around 2077, wetland rice yield is projected to decrease (the blue line or the line 1 in figure 6.27a). However, due to higher harvested areas, rice production tends to increase at the same time (the red line or the line 2 in figure 6.27a). If, for instance, harvested areas will not increase, rice production is projected to decrease, similar to a decrease of rice yield (i.e negative growth of rice yields). Similar patterns also occur in dryland farming, as shown in figure $6.27 \mathrm{a}$ (dryland rice yield) and figure $6.27 \mathrm{~b}$ (dryland rice production).

As seen in figures $6.27 \mathrm{c}-6.27 \mathrm{~d}$, harvested areas (wetland and dryland farming) increase as rice farming areas and cropping intensity increase. Wetland harvested areas are influenced by cropping intensity, so when cropping intensity increases, wetland harvested areas also increase. However, when rice farming areas are levelling-off in around 2080, harvested areas in wetland and dryland farming area are also stagnant.

\subsubsection{Climate projections}

Different climate projections are the representation of an uncertain future and understanding of the impacts of climate change (IPCC, 2013, Franck, 2009; Hoekema, 2011). Ensemble climate projections from 6 different climate models such as GFDL-CM3 and IPSL-CM5ALR are used to assess the impacts. Every strategy is tested under different RCP scenarios eg. RCP2.6 scenario (the highest mitigated scenario) and RCP8.5 scenario (the least mitigated scenario). Tables 6.10 displays ensemble projection of climate for seasonal rainfall, seasonal minimum temperature and seasonal maximum temperature.

For a simplification, this section depicts Vensim simulations based on the ensemble projection (IPCC, 2013). Again, results of the simulation are summarised as a 30-year average i.e. 2030 (2015-2045), 2060 (2046-2076) and 2100 (2077-2100). Ensemble projections of seasonal climate are given in tables 5.7. 


\subsubsection{The first strategy: the projected results}

The first strategy or the base case strategy reveals that under a changing climate, rice yield tends to decrease significantly, especially under RCP8.5 scenario. Under RCP4.5 scenario, it is projected that wetland rice yield will probably decrease by about $3 \%(1 \%-4 \%)^{44}$ by $2030(2015-2045)$ and by $6 \%(3 \%-8 \%)$ by 2090 (2077-2100) (figure 6.28a), compared to rice yield without climate change (i.e the basecase scenario). For the same periods, RCP4.5 projects that dryland rice loss will be about $2 \%(1 \%-4 \%)$ and $4 \%(2 \%-8 \%)$ as seen in figure $6.28 b$.

Similarly, climate change will probably negatively threaten rice production over time for all RCP scenarios. Compared to the rice production in the basecase scenario, wetland rice production by 2030 (2015-2045) and by 2090 (2077-2100) is projected to decrease by about $2 \%(-3 \%$ to $+3 \%)$ and $2 \%(0 \%-6 \%)$ respectively under RCP4.5 (figure 6.28c). Dryland farmers are projected to experience a higher production loss 3\% (1\%-3\%) and 3\% (2\%-8\%) (figure 6.28d) for the same periods and the same RCP scenario. Depending on RCP scenarios, it is projected that rice yield and rice production loss will be between $3 \%-19 \%$ and $2 \%-21 \%$ by 2090 (2077-2100) respectively.

By contrast, harvested areas are projected to increase under different RCP scenarios (except for RCP2.6 scenario by 2090). RCP6.0 scenario and RCP8.5 scenario project that wetland harvested areas will probably increase by about 3\% by 2090 (2077-2100) (figure 6.28e). While harvested areas in dryland farming will probably not experience a change under different RCP scenarios (figure 6.28f). Since dryland cropping intensity is not affected by seasonal rainfall patterns, harvested areas in dryland farming are unlikely to change under the basecase strategy.

\footnotetext{
${ }^{44}$ The bracket includes $5^{\text {th }}$ and $95^{\text {th }}$ percentile climate predictions. This is applied for all brackets in this chapter
} 


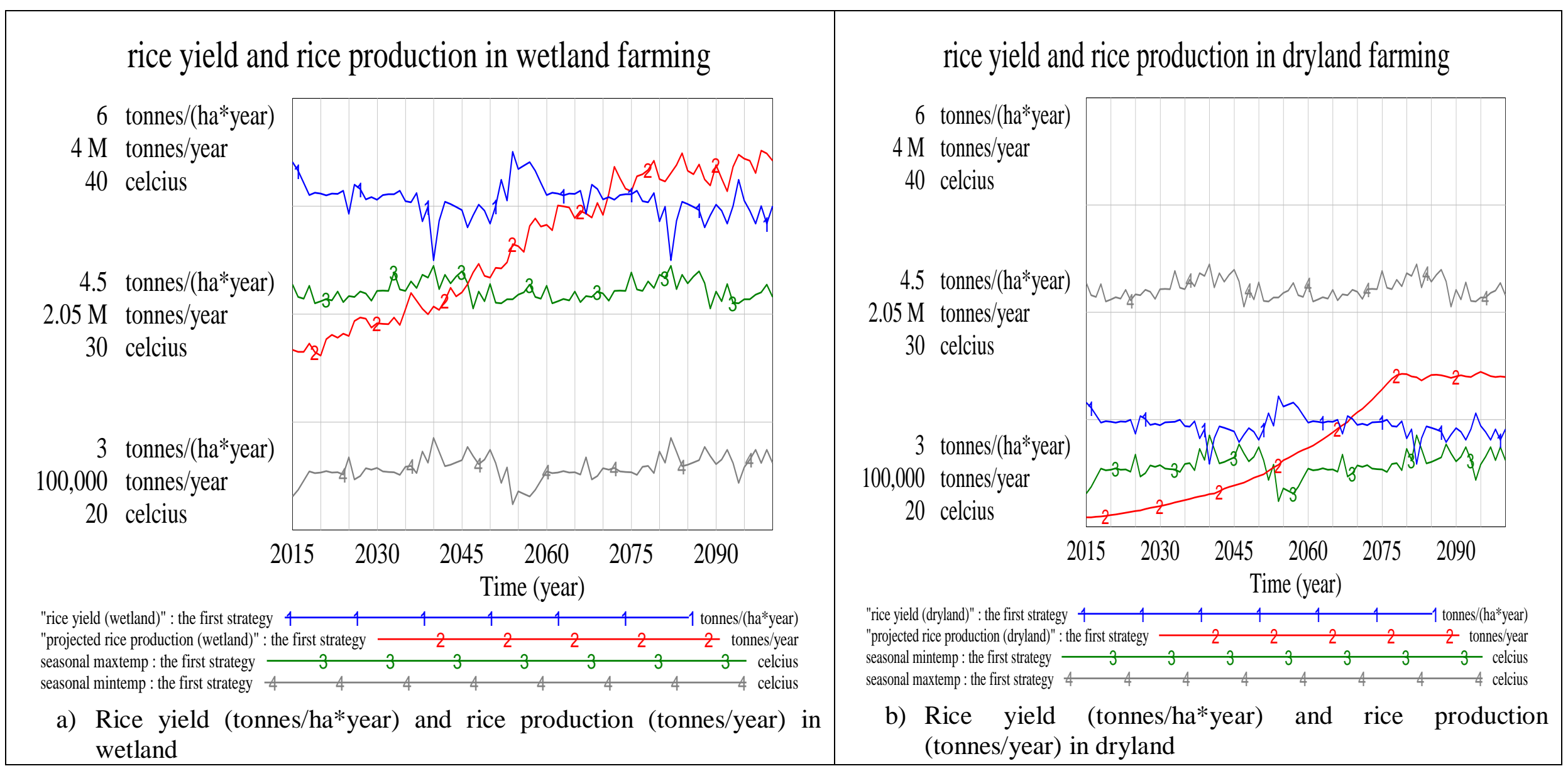




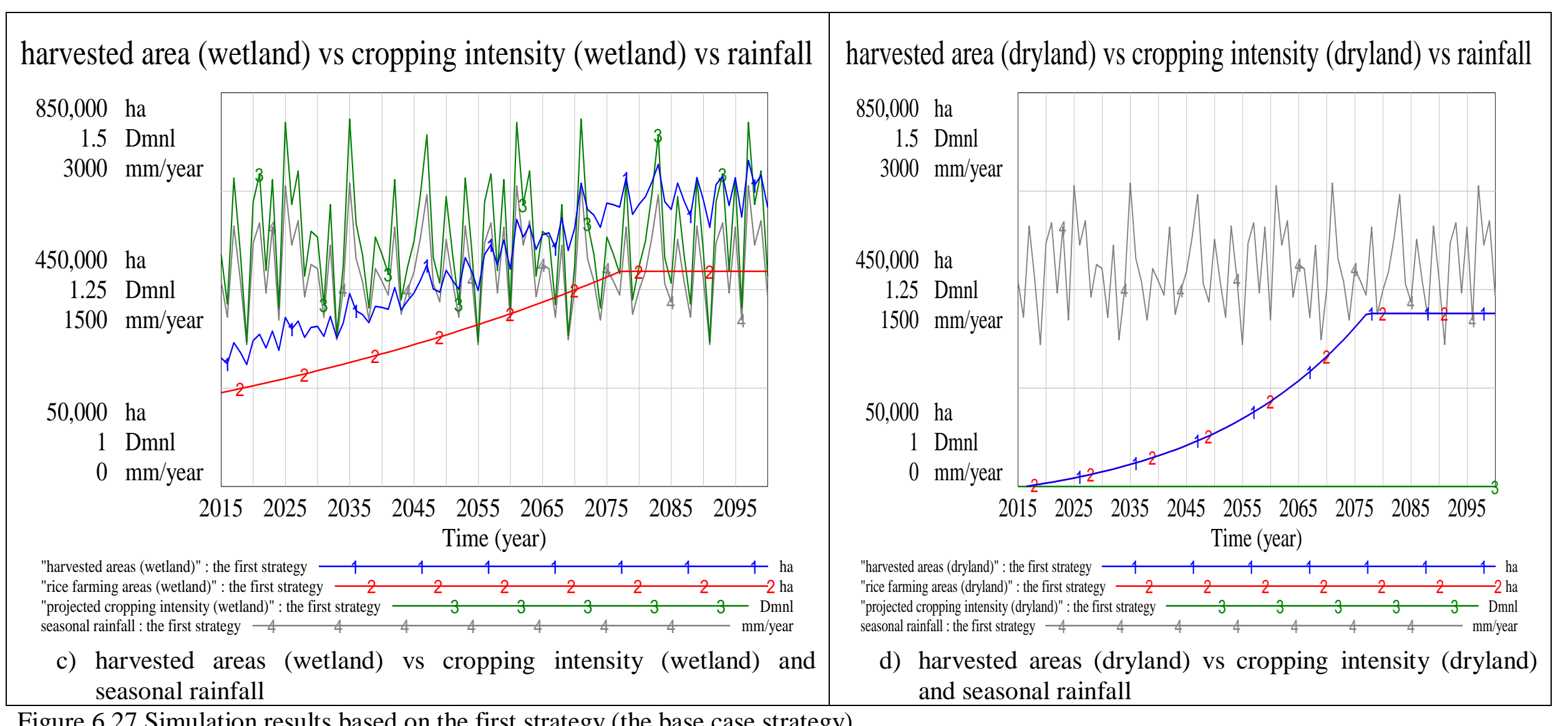

Figure 6.27 Simulation results based on the first strategy (the base case strategy). 


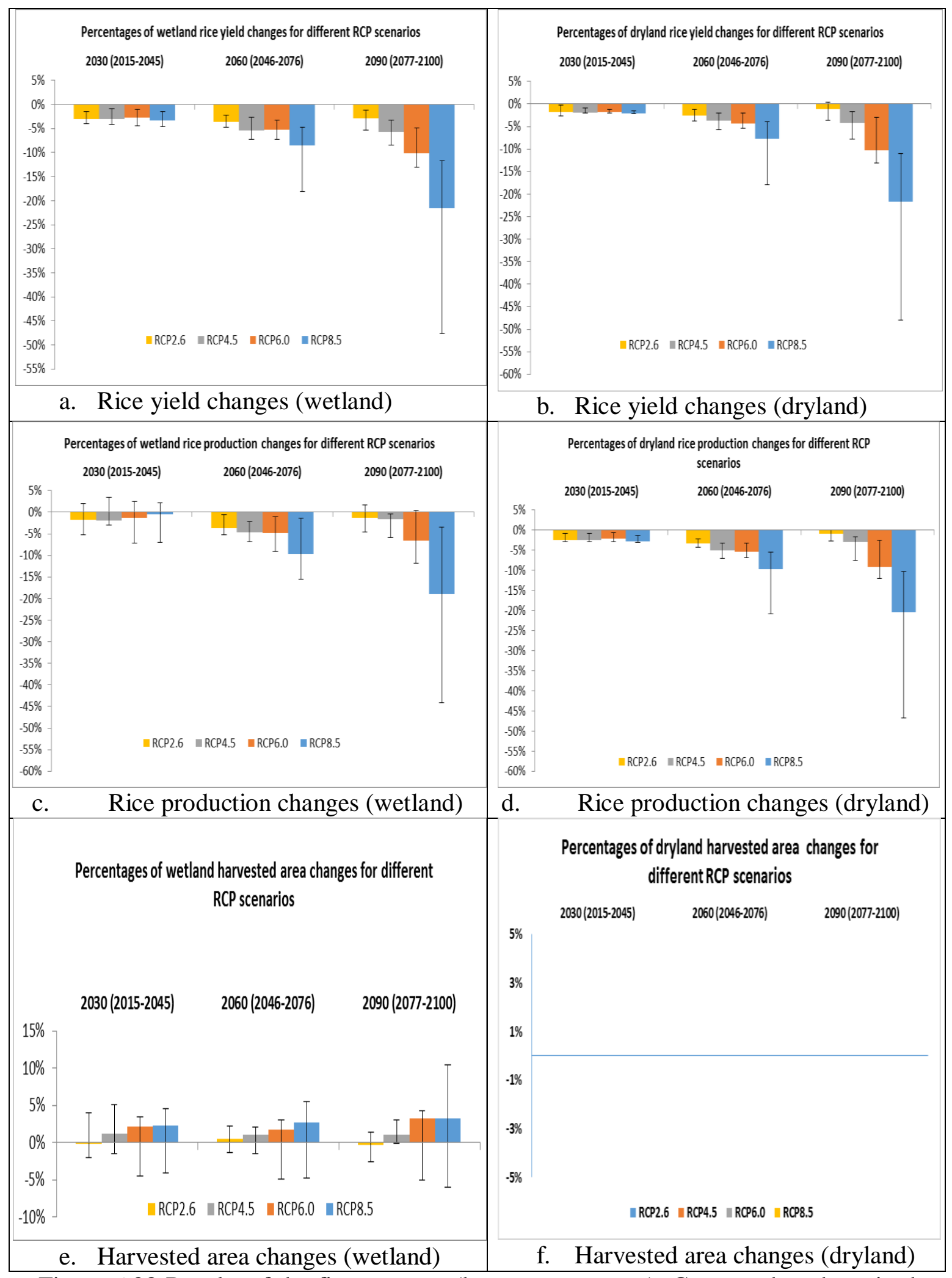

Figure 6.28 Results of the first strategy (base case strategy). Compared to those in the basecase scenario. Vertical lines are error bars $\left(5^{\text {th }}\right.$ and $95^{\text {th }}$ percentiles - climate projections). It should be noted that dryland harvested areas are not influenced by climate, hence no available error bars for dryland harvested areas. 
From the explanation offered in the three preceeding paragraphs, this study elucidates that rice yield and rice production will probably experience the worst effects of climate change and the second worst effects of climate change. By contrast, climate change tends to increase harvested areas throughout time. This means that developing more resilientclimate rice varieties is the best solution rather than farming extension in tackling the negative impacts of climate change on rice supply.

\subsection{Summary}

The SD model assesses three different impacts of climate change on rice production. The first is the impact of climate change on rice yield through minimum temperature. The second is the impact of seasonal rainfall on harvested areas and rice production. The third is the impact of the timing of monsoon onset on rice production.

The SD model is built based on existing studies and it has been demonstrated in this chapter that the outputs of the SD model are relatively similar to observed data. In addition, the SD model shows appropriate behaviour under "extreme conditions".

Sensitivity analysis shows that seasonal minimum temperature is a sensitive parameter. A main implication of this is that rice production will probably be in danger, given that climate change is well associated with an increase in temperature. Non-climatic factors such as technological progress and rice growing days are sensitive parameters too. On the other hand, production factors, namely seed and labour and seasonal rainfall are not sensitive parameters. Again, August SOI tends to be an insensitive parameter.

Findings of sensitivity analysis are supported by existing studies. Some agree that the effects of minimum temperature on rice yield are more pronounced than those of precipitation (Lobell et al., 2008 \& 2011; Sarker et al., 2012). Some studies also claim that the effects of technological progress on rice yield are highly important (Gnanamanickam, 2009; Kondamudi et al., 2012; Mangrauthia et al., 2014) while the impacts of production factors might be relatively limited (Wang et al., 2012; Wirajaswadi, 2004). 
By comparison, the basecase scenario projects that under the RCP4.5 scenario, wetland rice yield will probably decrease by about 3\% (1\%-4\%) ${ }^{45}$ by $2030(2015-2045)$ and $6 \%$ (3\%-8\%) by 2090 (2077-2100). Although RCP4.5 scenario projects an increase in harvested areas about $1 \%$ by 2090 (2077-2100), RCP4.5 scenario projects that wetland rice production will probably decrease by about $2 \%(-3 \%$ to $+3 \%)$ and $2 \%(0 \%-6 \%)$ by 2030 (2015-2045) and by 2090 (2077-2100) respectively. This means that rice yield will probably experience the worst impacts of climate change, followed by rice production.

Because rice yield will probably be more affected by climate change than harvested areas and rice production, more resilient-climate rice varieties should be developed to minimise the negative impacts of climate change on rice production. Again, although climate change tends to increase harvested areas, farming extension will probably offer minimal help in tackling the negative impacts of climate change on the rice supply.

To enhance users' confidence in the SD model, the SD model will be analysed further by designing some policies and some strategies in the next chapters. Policies will be composed from internally sensitive parameters and then some policies will be combined to be strategies. Running policies in the SD model can increase the user's confidence as a good SD model should show correct patterns of future behaviour i.e behaviour prediction tests (Forrester \& Senge, 1980, p. 424) and should demonstrate different patterns of behaviour under different policies i.e (Forrester \& Senge, 1980, p. 424). Some strategies will be tested under different scenarios i.e combinations of externally sensitive parameters. Possible policies to be discussed in the next chapter are outlined in the following paragraph.

More resilient-climate rice varieties such as heat tolerant rice varieties and rice varieties with a shorter growth duration might be important in overcoming the impacts of climate change on the rice farming stage of the rice supply chain. The different patterns of more resilient-climate rice varieties such as varieties with shorter growth duration should be

\footnotetext{
${ }^{45}$ The bracket includes $5^{\text {th }}$ and $95^{\text {th }}$ percentile climate predictions. This is applied for all brackets in this chapter
} 
simulated to see their roles in tackling the negative impacts of climate change on rice production. Moreover, as climate projections such as projections of minimum temperature and seasonal rainfall are uncertain, testing policies such as heat tolerant rice varieties and shorter growth duration (shorter-growing day) varieties under different climate projections will be conducted in the next chapter. 


\section{CHAPTER 7 \\ POLICY SCENARIO RESULTS}

The Government of Indonesia has expressed its hope to see an increase in rice production (Abdullah, Tjokrowidjojo \& Sularjo, 2008; Susanto et al., 2003; Sembiring, 2008), in the face of concerns about possible rice shortages due to a changing climate (Asnawi, 2016). Enhancing rice production means supporting Indonesia's GDP, given that agriculture makes up $15 \%$ of the country's GDP and $45 \%$ of its employment (BPS, 2010). Similar to the Indonesian situation as a whole, agriculture and specifically rice farming plays a major role in WNT and rice farming is a major contributor to the agricultural sector in the region (BPS NTB, 2010). Agriculture makes up around 25\% of WNT's GDP and $55 \%$ of WNT's employment (BPS NTB, 2010). In turn, increasing rice production in Indonesia and WNT is very important.

A number of studies discuss two policy options for increasing rice production. The first option is farming extension i.e. opening new farming areas (Maulana, 2004; Zulmi \& Arianti, 2011). The second option is farming intensification i.e developing improved rice varieties such as high yield varieties (Ahmad, Wani, Azooz \& Tran, 2014; Abdullah et al., 2008; Kondamudi et al., 2014; Khush, 1987; Khush, 2005; Susanto et al., 2003; Sembiring, 2008; Zulmi \& Arianti, 2011). This chapter will focus on the development of improved rice varieties such as higher yield and heat tolerant varieties in the context of a changing climate.

Table 7.1 shows the time periods and descriptions of relevant policies in raising rice supply in the period 1970s-2000s. Farming extension is a common practice and typical business option for increasing rice production (Khush, 1987; 2000; 2005) ${ }^{46}$. However, farming extension is not feasible over time as it leads to higher subsidies, including subsidised seed and larger irrigation facilities (Maulana, 2004; Zulmi \& Arianti, 2011). It

\footnotetext{
46 In general, farming extension will probably increase farmer income. As most farmers are poor (BPS, 2015), farming extension is a government initiative (Wahyuni \& Indraningsih, 2016). Farmers are usually asked to support farming extension, not to initiate it. As explained in corresponding paragraphs, farming extension is not easy as it requires subsidised inputs such as seed, fertiliser and pesticide, leading to a central role for government in rice farming extension.
} 
is also hard to extend farming areas if rice yield is relatively low (Orr, Riches, Mortimer, Harris, \& Mazid, 2008).

Historically, farming extension was applied in Asia prior to the 1970s (Estudillo \& Otsuka, 2013). However, that policy may have led to a widespread hunger as the population grew more rapidly than rice production (Estudillo \& Otsuka, 2013). With the introduction of improved rice varieties, a higher rice demand prompted by a growing population could, between the 1970s and 2000s, be solved with the rapid increase of rice production (Estudillo \& Otsuka, 2013; Khush, 1987; 2000; 2005).

\begin{tabular}{|c|c|c|}
\hline Policy Options & Applied Period & Descriptions \\
\hline $\begin{array}{l}\text { Opening } \\
\text { farming areas }\end{array}$ & $\begin{array}{l}\text { This was practised prior to } \\
\text { the 1970s (Estudillo \& } \\
\text { Otsuka, 2013). After } \\
\text { decreasing funding of rice } \\
\text { research in 1990s, an } \\
\text { increase of rice production } \\
\text { depended on area expansion } \\
\text { (Estudillo \& Otsuka, 2013). }\end{array}$ & $\begin{array}{l}\text { This policy might be costly as new } \\
\text { farming areas lead to a higher subsidy } \\
\text { and a higher cost of irrigation } \\
\text { facilities. } \\
\text { Section } 7.1 .2 \text { explains further this } \\
\text { option. }\end{array}$ \\
\hline $\begin{array}{l}\text { Increasing rice } \\
\text { production } \\
\text { developing improved } \\
\text { rice varieties such as } \\
\text { short- growth } \\
\text { duration of high } \\
\text { yield varieties. }\end{array}$ & $\begin{array}{l}\text { During the Green revolution } \\
\text { of the 1970s-1990s, } \\
\text { improved rice varieties } \\
\text { (known as modern rice } \\
\text { varieties, MRV) } \text { were } \\
\text { released to boost rice } \\
\text { production. }\end{array}$ & $\begin{array}{l}\text { In Asia, the Green revolution (1970s- } \\
\text { 1990s) increased rice production by } \\
\text { about } 130 \% \text {, which was higher than } \\
\text { the increase of population (about } 90 \% \text { ) } \\
\text { for the same period (Khush 1987; } \\
\text { 2000; 2005). } \\
\text { Section } 7.1 .2 \text { explains policy options } \\
\text { related to improved rice varieties and } \\
\text { sections } 7.2 \text { describe related structural } \\
\text { changes. } \\
\text { Composition of strategy is described } \\
\text { in early paragraphs in section } 7.3 \\
\text { (table } 7.3 \text { ). } \\
\text { Sections 7.4-7.5 compare each } \\
\text { strategy output in dealing with a } \\
\text { changing climate }\end{array}$ \\
\hline
\end{tabular}

Table 7.1 A comparison between two policy options.

Farming intensification tends to increase rice yield (tonnes/year*ha), leading to a higher profit and a larger farming area. Improved rice varieties also can motivate farmers to open new farming areas (Estudillo \& Otsuka, 2013; Khush, 1987; 2000; 2005). After a 
rapid increase in rice production prior to the 1990s, funding for rice breeding research decreased significantly (Zeigler, \& Mohanty, 2010), leading to a levelling-off of rice yield in the middle of 1990s (Axelsson, 2010; Susanto et al., 2003; Wahyuni, \& Indraningsih, 2016; Zeigler \& Mohanty, 2010). After the middle of 1990s, an increase in rice production has depended significantly on farming extension (Susanto et al., 2003; Zeigler, \& Mohanty, 2010).

Although previously cited studies describe the impacts of each rice growing policy, none of those studies compare the benefits of each policy option in relation to a changing climate. Thus, this chapter will investigate the output of each policy and combined policies (eg. policies regarding improved rice varieties under different climate projections) in finding the best strategy for sustaining rice production in West Nusa Tenggara. In doing so, this chapter will explain the policy options in three consecutive steps.

The first step is to change model structures which are conducted by adding variables and/or adding linkages between variables. The second step is strategy development which is conducted by combining some policies. In the last step, this chapter assesses the robustness of given strategies under different climate projections based on RCP scenarios (van Vuuren et al., 2011).

This chapter is separated into sections. Background information regarding rice breeding goals as well as descriptions of each policy are offered in section 7.1. Following this, policy-induced structural changes are described in section 7.2. Comparisons between policies under the basecase scenario are revealed in section 7.3, prior to analysis of strategies under a changing climate in sections 7.4 and 7.5. This chapter summarises its key points in section 7.6.

\subsection{Background}

This section explains important background information such as rice breeding goals prior to structural changes and running policies in the SD model. Specifically, this section explains some goals of rice breeding in the past (section 7.1.1), and some rice research policies (section 7.1.2). The objectives of policies relating to rice breeding research are also explained in section 7.1.2. 


\subsubsection{Goals of rice breeding}

Finding rice varieties with higher yields is the main concern of research in rice breeding technology (IRRI, 1985; Khush, 1987). Research of varieties tolerant to biotic factors (pests and diseases) and abiotic factors (droughts, low temperature and toxic soils) was initiated in IRRI in the 1970s after pests and diseases attacked rice in key Asian rice growing regions. (IRRI, 1985; Khush, 1987). Some objectives of rice breeding are as follows (IRRI, 1985; Khush, 1987):

1. Finding rice varieties with higher yields;

This is the main objective of rice breeding as this trait ${ }^{47}$ relates to a higher rice demand stemming from a growing population (IRRI, 1985; Khush, 1987). Due to population growth, scientists had been concentrating on finding higher yield varieties. For example, after crossing two traditional rice varieties, Peta and DGWG48, a higher yield variety named IR8 was distributed to Asian farmers (IRRI, 1985; Khush, 1987), leading to a significant increase in production during the 1970s. Rice breeding in pursuit of higher yield varieties has continued since that period.

2. Finding rice varieties with shorter growth duration;

Rice varieties with short-growth duration tend to increase cropping intensities, leading to higher rice production. This rice variety also is suitable when El-Niño occurs (Abdullah et al., 2008). In some instances, rice varieties with short-growth duration might have a comparable yield to rice varieties with long-growth duration. IR36, with its 110 days of growth duration, was found in 1976 and is a rice variety with comparable yields to IR8 which has a growth duration of 130 days and which was found in 1966 (IRRI, 1985; Khush, 1987). These shortgrowth duration (SGD) varieties help farmers to harvest their rice up to three times per year with favourable conditions.

3. Finding rice varieties which are resistant to biotic and abiotic stresses;

Since the early 1970s, rice scientists of the IRRI have collected a large gene pool that are resistant to pests and diseases. This gene pool may help rice scientists in the future anticipate new pests and diseases. For this reason, there is little impact

\footnotetext{
${ }^{47} \mathrm{~A}$ trait is a genetically determined characteristic such as high yield and heat tolerance

${ }^{48}$ DGWG = Dee-geo-woo-gen, a short-statured rice varieties from China
} 
by pests and diseases on rice yield (Dinas Pertanian Nusa Tenggara Barat, 20052014) as new rice varieties usually have better resistance than their predecessors (IRRI; 1987; Suprohatno et al., 2010).

Moreover, rice scientists have already anticipated some abiotic stresses such as low temperature, droughts, and soil problems. As such, since the 1970s, rice scientists have developed rice varieties that are resistant to low temperature, droughts and toxic soils (IRRI, 1985, Khush, 1987). For instance the rice variety Situbagendit can grow well in droughts and toxic soil with high iron content (Sembiring, 2008; Susanto et al., 2003).

By contrast, abiotic stress to heat tolerance or high temperature has not yet been addressed. This results in a very limited gene pool that is tolerant to high temperatures (Kondamudi et al., 2014; Zhu et al. 2007). Another impact of the limited gene pool of heat tolerance is that it takes approximately 10 years for scientists to isolate the genes responsible for heat tolerance (Ye et al, 2015). This is relatively long when compared to research of rice varieties that are tolerant to other stresses.

4. Finding improved rice varieties under high temperature;

Although seasonal minimum temperature has exceeded the rice threshold since 1979, scientists have found a lot of rice varieties with special characteristics such as SGD varieties and higher yield varieties (IRRI, 1985; Khush, 1987; Sembiring, 2008; Susanto et al., 2003). There were about 194 new rice varieties ${ }^{49}$ released during the period 1979-2011 (Brennan \& Malabayabas, 2011). This means that developing improved higher yield rice varieties under high minimum temperature is possible (Sembiring, 2008; Susanto et al., 2003).

A study (Ye et al., 2015) claims that quantitative trait loci $\left(\mathrm{QTL}^{50}\right)$ related to heat tolerance were found in 2015. As QTL related to heat tolerance were found about 1 year ago and the use of rice genomics breeding in finding improved rice variety

\footnotetext{
${ }^{49}$ Most rice varieties were released prior to the 1990s.

${ }^{50} \mathrm{QTL}=$ quantitative trait loci is a region of DNA associated with a particular trait (Ye et al., 2015).
} 
is relatively new, many uncertainties might occur in the research process. These uncertainties relate, for instance, to how much heat tolerant rice varieties can cope with climate change, and to the time required to develop real heat tolerant varieties. However as explained in the following paragraphs of this section, developing heat tolerant varieties is possible.

Rice does not experience membrane injury (damaged leaves) until maximum temperature reaches about $40^{\circ} \mathrm{C}$ (Luo, 2011; Hatfield \& Krueger, 2015; Kim, 1996; Prasad, Boote, Allen, Sheehy, \& Thomas, 2006). Regarding high minimum temperature, rice will experience membrane injury (damaged leaf) when minimum temperature (night temperature) is similar to or higher than $33^{\circ} \mathrm{C}$ (Mohammed \& Tarpley, 2010; Ziska \& Manalo, 1996). This means that rice will probably not experience membrane injury (damaged leaf) as projected maximum temperature and projected minimum temperature is about $35^{\circ} \mathrm{C}$ and $27^{\circ} \mathrm{C}$ by 2090 respectively.

Rice, like other crops, might minimise or recover the negative effects of temperature (such as yield loss) as long as temperature does not exceed rice's lethal limits: $40^{\circ} \mathrm{C}$ for maximum temperature (Luo, 2011; Hatfield \& Krueger, 2015; Kim, 1996; Prasad et al., 2006; Yoshida, 1981) and $33^{\circ} \mathrm{C}$ for minimum temperature (Mohammed \& Tarpley, 2010; Ziska \& Manalo, 1996). Owing to this, the development of heat tolerant rice varieties by 2090 is technically possible.

As explained above, there are many uncertainties regarding the extent to which heat tolerant varieties can cope with the negative effects of climate change, as well as the amount of time needed to develop more resilient-climate varieties. This leads to discussing how to plan or how to assess a highly uncertain future. A possible solution is to build a framework of management decision-making using the SD approach. The principle of the SD approach is to reproduce a robust system which simulates accurately when given varying uncertain inputs. In other words, when there are large numbers of uncertain inputs, it is unwise to predict uncertain inputs such as required development time of heat tolerant rice varieties. Rather, it 
is better to build robust models that run well for uncertain inputs (Radzicki \& Taylor, 1997).

\subsubsection{How this study constructs policies}

Table 6.9 shows that technological progress on higher yield rice, SGD varieties, and fractions of new farming areas are internally sensitive parameters. Consequently, these parameters can be used as policy options. However, this study does not consider the increase of the fraction of new farming areas as a possible policy, as it assumes that observed farming growth during 1976-2011 is the highest possible growth of new farming areas in wetland and dryland farming.

This assumption is also supported by three key points. The first is that WNT has some mountainous areas, leading to many difficulties inlcuding expensive irrigation costs and delays in constructing irrigation facilities supporting rice farming in mountainous areas. The second point is that WNT has a low Human Development Index (HDI). Owing to this, the long term development plan revolves around boosting education levels, the economy (agriculture contributes to the most economic growth) and health facilities. Furthermore, WNT has been self-sufficient in rice since 1983 (BPTP NTB, 2013), so any remaining funding should be used to support development in education and health, otherwise, there will be an imbalance of funding between the economy, health and education sectors.

The third point is that WNT has limited funding for boosting farming areas and most agricultural funding comes from the central government. With about 11 buffer provinces for the national rice supply (Lantarsih et al., 2011), increasing the growth of new farming areas is very difficult due to limited funding. Increasing farming areas not only leads to more irrigation facilities, but also to increasing farmer subsidies such as subsidised seed, subsidised fertiliser and subsidised pesticide.

In turn, this study assumes the observed farming growth is the highest possible growth considering WNT's landscape, its long-term development planning, and its limited funding availability. This study does not consider a lower fraction of new farming areas as an option, given that a changing climate leads to lower rice production. 
With regard to possible policies for increasing or sustaining rice production under a changing climate, this study considers three options. Those three policy options are: a) finding shorter growth duration varieties, b) finding higher yield varieties and c) finding heat tolerant rice varieties. The following paragraphs explain these policies respectively.

The main objective in shortening short-growth duration is to increase rice production through a higher cropping intensity, especially during El-Niño (Abdullah et al., 2008). This was seen with the replacement of IR36 by IR8 in the 1970s, which increased cropping intensity as farmers could sow their rice from one time a year to three times a year (IRRI, 1985; Khush, 1987). The Indonesian government has also had a long term policy of finding rice varieties with shorter growth duration (Susanto et al., 2003). Another policy experiment is finding higher yield rice varieties, which has played a significant role in increasing Indonesian rice production (Sembiring, 2008; Susanto et al., 2003). The Indonesian government has also conducted research to develop higher yield rice varieties (Abdullah et al., 2008; Susanto et al., 2003).

This policy (developing higher yield varieties) is also important to appeal to farmers when sowing their rice, as higher yield varieties tend to increase farmer profit per hectare. This is especially important for small-scale farmers (e.g., Indonesian farmers) as their farming areas are usually less than 0.5 ha (BPS NTB, 2014). Also, if farmers can get a higher profit, their government subsidy can be minimised as they have more funding to buy agricultural inputs such as seed and fertiliser.

Because the negative impacts of high minimum temperature on rice yields are known (Peng et al., 2004; Welch et al., 2010) and considering the negative impacts of high maximum temperature by 2090 , finding heat tolerant rice varieties is in high demand. A number of studies (Ahmad et al., 2014; Kondamudi et al., 2014) urge us to find heat tolerant rice varieties in order to minimise the negative impacts of climate change owing to high temperature. Also, in recent years, existing studies (Magnibas et al., 2014; Ye et al., 2015) have focused on developing heat tolerant rice varieties. 


\subsection{Structural changes to policies}

\subsubsection{Policy 1: Research on finding rice varieties with shorter growth duration}

The use of improved rice varieties such as shorter growth duration and higher yielding varieties is a key factor behind the continuous improvement of rice production in recent decades (Las, Abdullah, \& Darajat, 2002; Gmamanickam, 2009; Nurhasanah \& Sunaryo, 2015; Suprihatno \& Daradjat, 2008; Susanto, et al., 2003). Normally, about 5 to 10 years is required to find improved rice varieties (Subantoro, Wahyuningsih \& Prabowo, 2008) i.e. rice varieties with shorter growth duration (shorter time to maturity or shorter growing days) and higher yields.

In the past, rice scientists have focused on finding higher yield rice varieties rather than other improved type varieties (Hossain, 1988; IRRI, 1985; Khush, 1987). Some studies (Hossain, 1988; IRRI, 1985; Khush, 1987; Pingali \& Hossain, 1998; Sembiring 2008; Suresh, 2013; Susanto, et al., 2003) also suggest that higher yield varieties are the main cause of higher rice production. In this study, progress finding higher yield varieties is termed 'technological progress on rice yield', while the progress on rice varieties with shorter growth duration is termed 'research in finding shorter growth duration rice varieties'.

It is possible to decrease the growth duration of rice by about 5 days within 10 years (Sembiring, 2008; Susanto et al., 2003). In this study, a ten-year delay is assumed for finding rice varieties with shorter growing days. There is no available data of growth duration for each rice variety introduced in Indonesia. Owing to this, this study estimates the delay in finding shorter growth duration varieties using existing studies (Sembiring, 2008; Susanto et al., 2003).

Figure 7.1a depicts a part of the basecase model relating to the growth duration of rice varieties. As shown in figure 7.1b, new variables are introduced into the SD model, such as intended growth duration (wetland/dryland) and projected growth duration (wetland/dryland). Intended growth duration is projected growth duration lessened by 5 days, so there is a recursive process to decrease projected growth duration by 5 days within a decade. It is assumed that the shortest growth duration is about 90 days (figure $7.2 a-7.2 b)$. 
The assumption of the shortest growth duration being about 90 days conforms to rice development stages. The minimum period for the three rice development stages (i.e the vegetative, reproductive and ripening stages) is about 90 days (Yoshida, 1978). It is possible to develop a shorter growth duration, however, a growth duration of less than 90 days will probably sacrifice rice yield potential (Yoshida, 1978).

A structural change and impacts of better varieties of shorter growth duration are depicted in figure $7.1 \mathrm{~b}$. Figure $7.1 \mathrm{~b}$ explains that projected rice growth duration (stock variables) are decreased subject to intended growth duration and a delay in growth duration invention.

In this study, it is assumed that expected cropping intensity is subject to cropping intensity and a ratio between initial and projected growth duration of rice varieties, as shown in figure 7.1d and figure 7.1f. Again, it is assumed that farmers will start more crop rotation within 1 year i.e delay to apply expected cropping intensity (BPTP NTB, 2013). For wetland rice, new variables are defined as follows:

ratio between initial and projected growth duration (wetland)" = "initial growth duration of rice variety (wetland)"/"projected growth duration of rice variety (wetland)"

"expected cropping intensity" = "ratio between initial and projected growth duration (wetland)" * "cropping intensity (wetland)"

consequently, wetland cropping intensity can be formulated as follows:

"actual cropping intensity (wetland)" ="DELAY3) ("expected cropping intensity (wetland)", delay to apply expected cropping intensity)"

For dryland rice, expected cropping intensity and cropping intensity can be formulated as follows:

ratio between initial and projected growth duration (dryland)"="initial growth duration of rice variety (dryland)"I" projected growth duration of rice variety (dryland)"

"expected cropping intensity" = "ratio between initial and projected growth duration dryland)" * "cropping intensity (dryland)"

"actual cropping intensity (dryland)"= "DELAY3("expected cropping intensity (dryland)", delay to apply expected cropping intensity)" 
It should be noted that rice yield under this policy is the same as rice yield in the base case scenario, as these SGD varieties tend to increase rice production through a cropping intensity rise (Sembiring, 2008).

Likewise, this study assumes that the timing of monsoon onset and/or harvested areas are only influenced by seasonal rainfall. This is true as Indonesia is a tropical Asian country in which temperature is not a limiting factor for beginning rice planting (Deryng, Sacks, Barford \& Ramankutty, 2011; Sacks, Deryng, Foley \& Ramankutty, 2010; Yoshida, 1981). According to some studies (Deryng et al., 2011; Sacks et al., 2010; Yoshida, 1981), regions should be called temperature-limited ones if they have temperatures lower than the base temperature (i.e. the lowest temperature in which a crop can grow), and for rice, the base temperature is about $10^{\circ} \mathrm{C}$ (Rani, \& Maragatham, 2013; Tang et al., 2009; Yoshida, 1981). Because the recent maximum temperature in WNT is higher than the base temperature and the projected maximum temperature by 2090 is about $35^{\circ} \mathrm{C}$, this study assumes that temperature will not influence the timing of monsoon onset and harvested areas by 2090 .

If research to find shorter growth duration varieties is introduced, dryland and wetland rice farming will probably experience a significant increase in cropping intensity (figures $7.2 \mathrm{c}-7.2 \mathrm{~d}$ ) and in rice production (figures $7.2 \mathrm{e}-7.2 \mathrm{f}$ ) by 2090 . This is owing to a decrease in projected growth duration of dryland rice and wetland rice (figures 7.2a7.2b). This means that a decrease in projected growth duration would lead to higher crop rotations for the same farming areas, leading to a higher rice production.

The growth duration of wetland rice was about 115 days in 2015, while that of dryland rice is about 110 days. That is why wetland rice is projected to have a growth duration of about 90 days by around 2065, while dryland rice is projected to have a growth duration of about 90 days by around 2055 . 


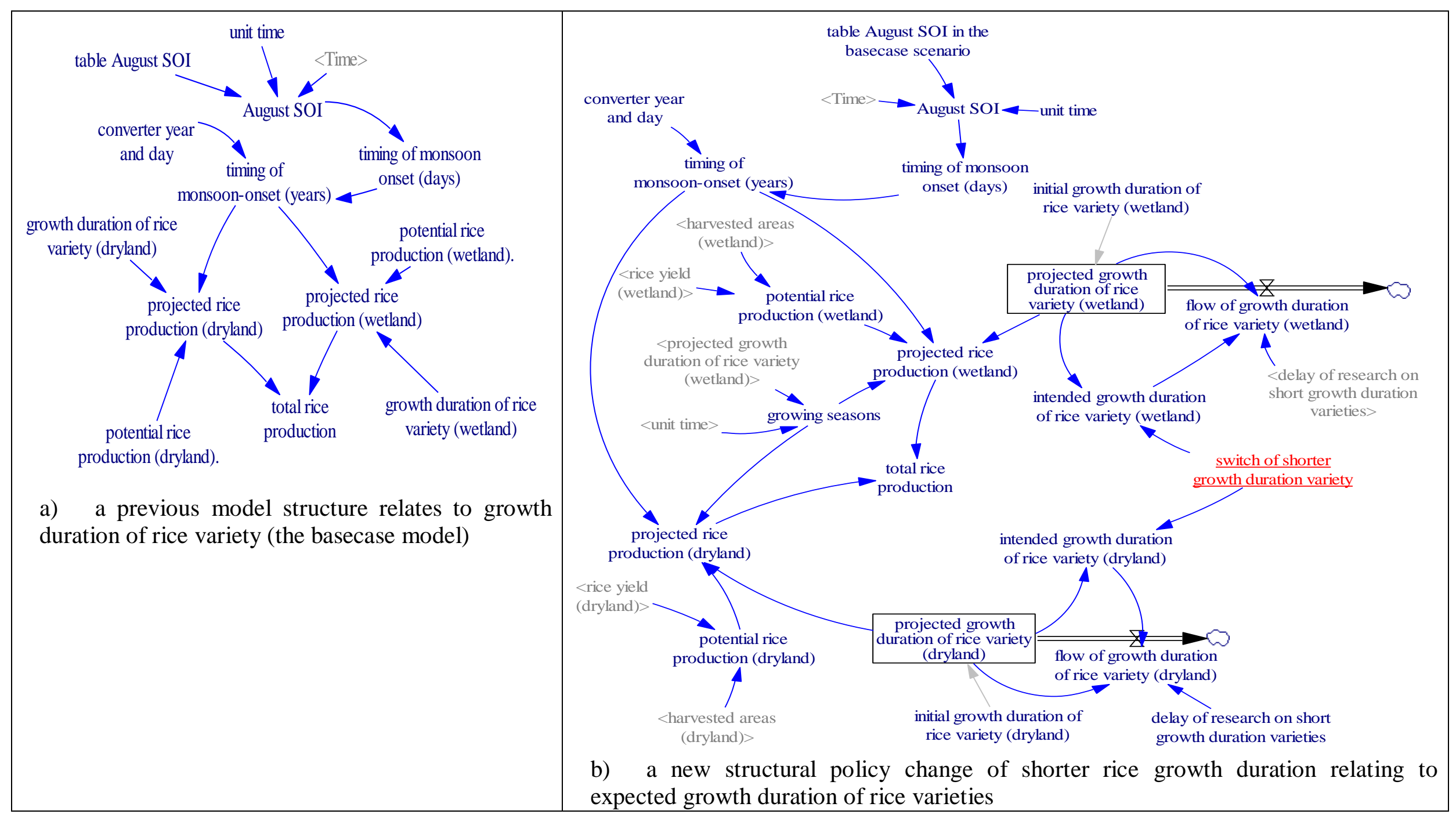




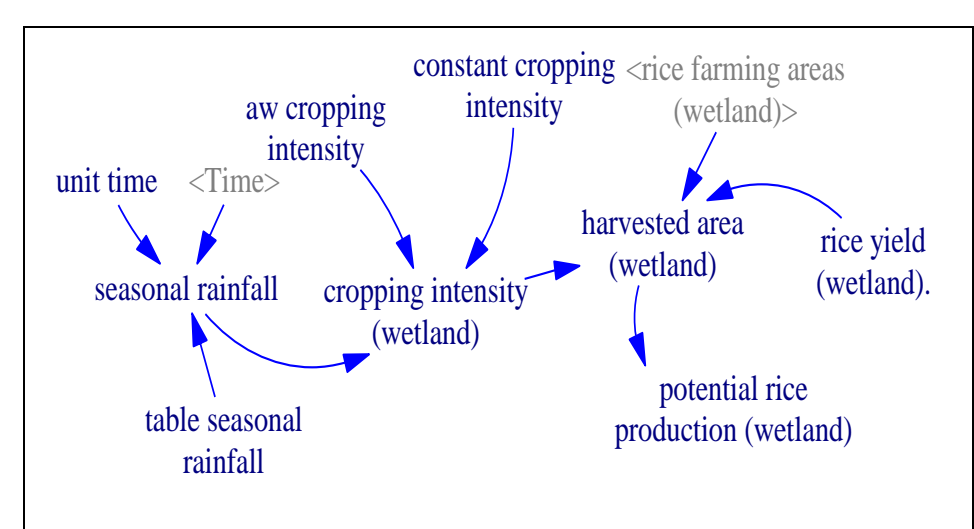

c) a previous model structure to cropping intensity in wetland farming (the basecase model)

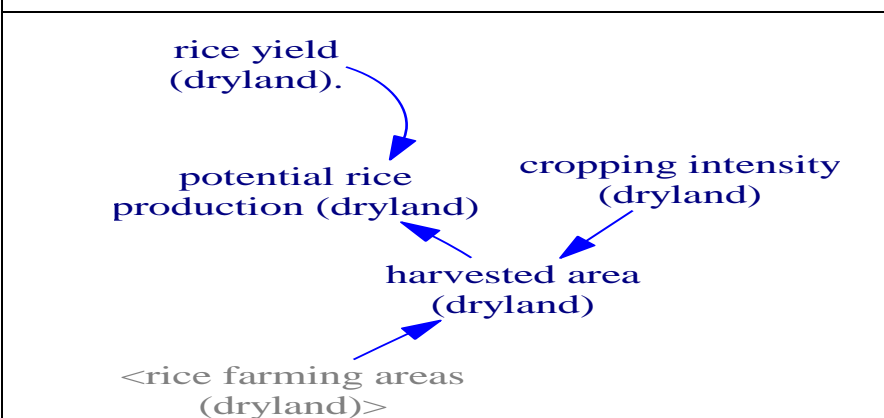

e) a previous model structure relates to cropping intensity in dryland farming (the basecase model)

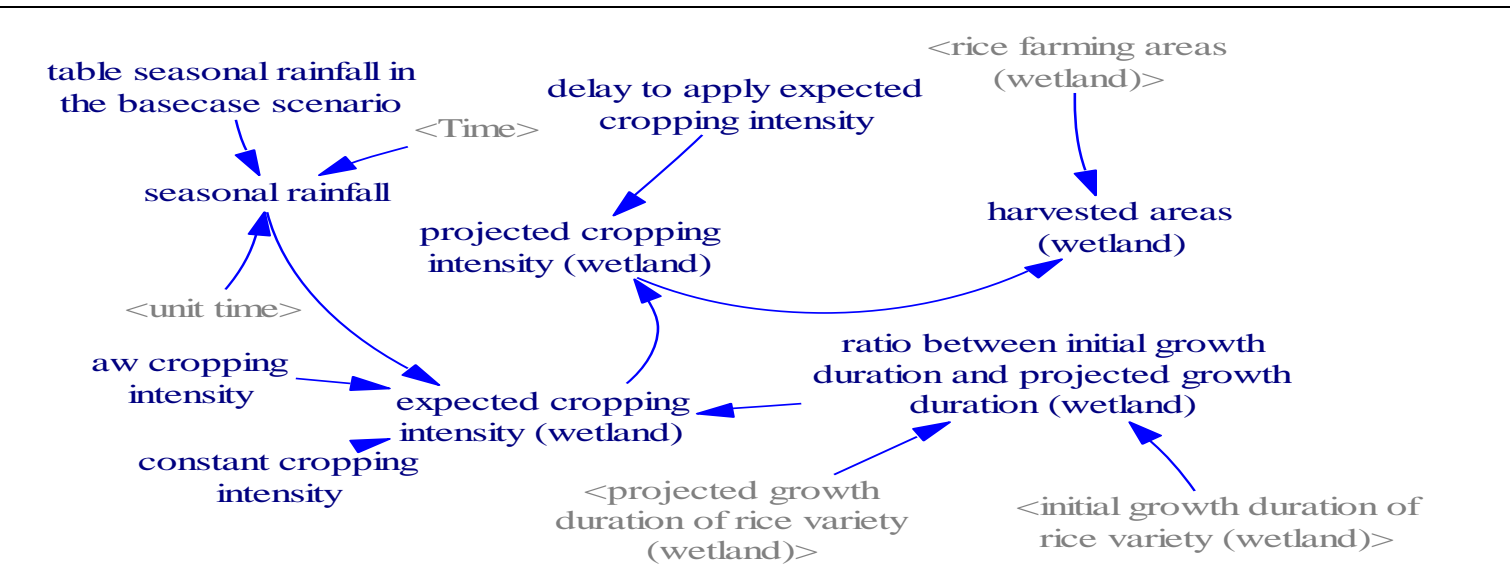

d) a new structural policy change of shorter rice growing days relating to expected cropping intensity (wetland)

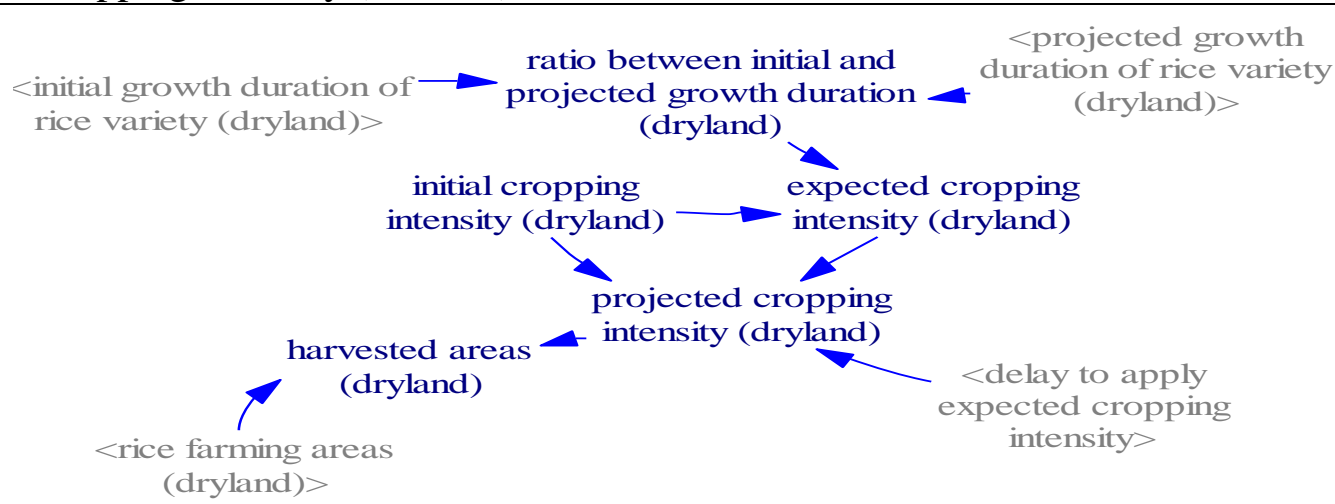

f) a new structural policy change of shorter rice growing days relating to expected cropping intensity (dryland)

Figure 7.1 Structural changes of shorter growth duration varieties days 
It should be noted that dryland farmers tend to sow their rice during the first cycle (September-December) to pre-empt possible insufficient rainfall in the following cycles, while wetland farmers sow their rice subject to the patterns of seasonal rainfall. This means that cropping intensity in dryland farming is about 1, while cropping intensity in wetland farming is subject to patterns of seasonal rainfall. This explains why cropping intensity in dryland areas is relatively constant (as seen in figure 7.2d), while cropping intensity in wetland areas is relatively fluctuating, as seen in figure $7.2 \mathrm{c}$ (subject to seasonal rainfall patterns).

Table 7.2 explains further the patterns of cropping intensity in wetland and dryland farming. In the first cycle, rice farmers in wetland and dryland areas tend to sow their rice and then harvest their rice in the second cycle. In the second cycle, dryland will be sown with secondary crops while wetland will be sown with rice again. A different crop pattern in the latter case owes to insufficient rainfall during the third cycle (dry seasons). Likewise, wetland farmers can sow their rice during the second cycle as wetland is surrounded by irrigation facilities.

\begin{tabular}{|l|l|l|l|}
\hline Farming types & \multicolumn{1}{|c|}{$\begin{array}{c}\text { The first cycle } \\
\text { (Sept-Dec) }\end{array}$} & \multicolumn{1}{c|}{$\begin{array}{c}\text { The second cycle } \\
\text { (Jan-April) }\end{array}$} & \multicolumn{2}{c|}{$\begin{array}{c}\text { The third cycle } \\
\text { (May-August) }\end{array}$} \\
\hline Dryland & $\begin{array}{l}\text { Rice planting and } \\
\text { secondary crop } \\
\text { harvesting }\end{array}$ & $\begin{array}{l}\text { Rice harvesting and } \\
2^{\text {nd }} \text { crop planting }\end{array}$ & $\begin{array}{l}\text { Secondary crop } \\
\text { harvesting and 2nd } \\
\text { crop planting }\end{array}$ \\
\hline Wetland & $\begin{array}{l}\text { Rice planting and } \\
\text { secondary } \\
\text { harvesting }\end{array}$ & $\begin{array}{l}\text { Rice harvesting and } \\
\text { Rice planting }\end{array}$ & $\begin{array}{l}\text { Rice harvesting and } \\
\text { secondary crop } \\
\text { planting }\end{array}$ \\
\hline
\end{tabular}

Table 7.2 Rice planting in wetland and dryland. Secondary crops are peanut, maize \& soybean

As seen in these figures (7.3a-7.3b), it is projected that rice production in wetland and dryland areas will probably increase by $30 \%$ (about 3\%) per year and 20\% (about $1.2 \%$ per year) respectively, compared to that in the basecase scenario by 2090 (2077-2100). It should be noted that research on finding SGD does not intend to increase rice yields but to increase cropping intensity, so this research will not lead to higher rice yields. (IRRI, 1985, Khush, 1987; Sembiring, 2008). 


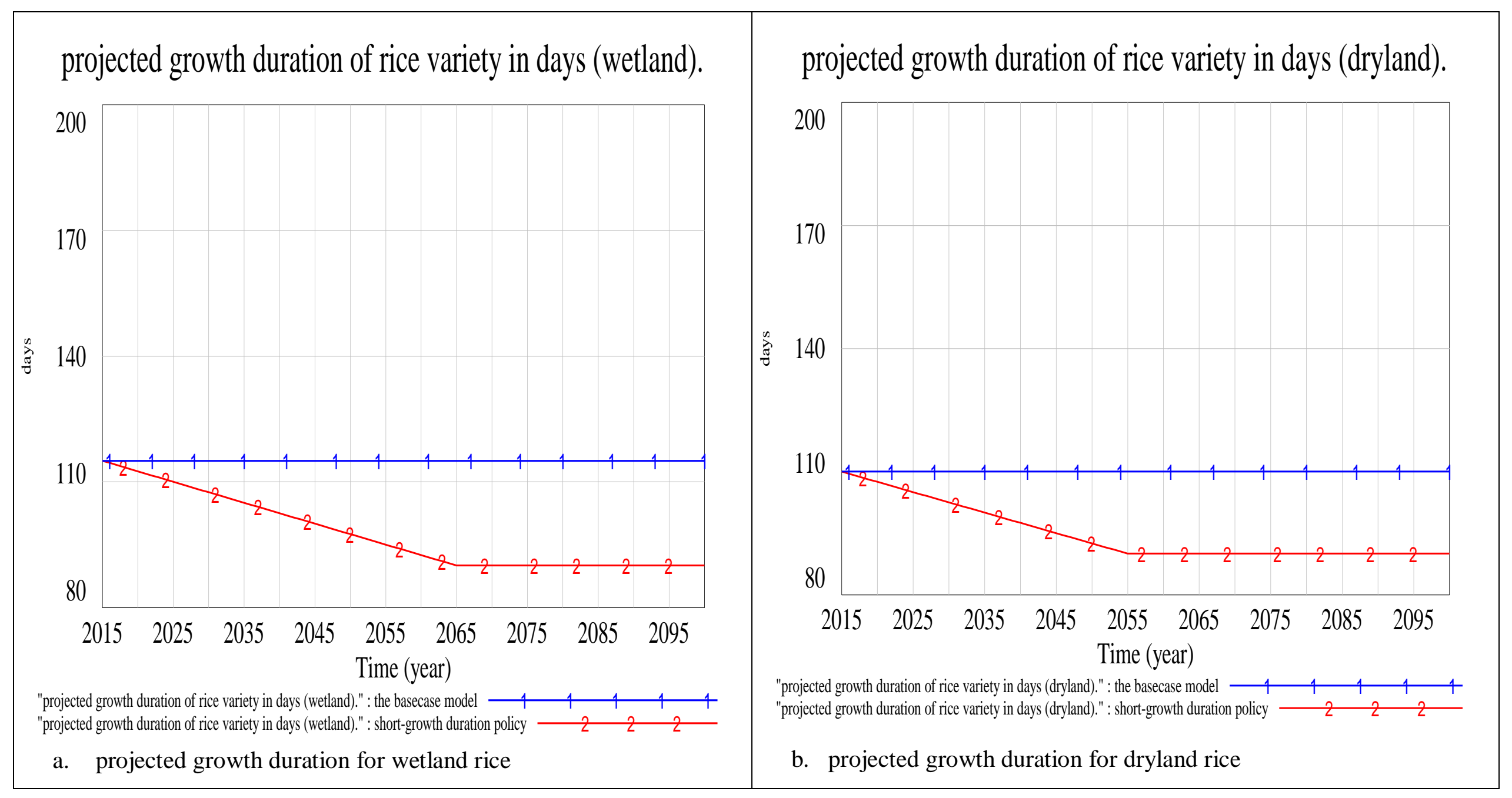




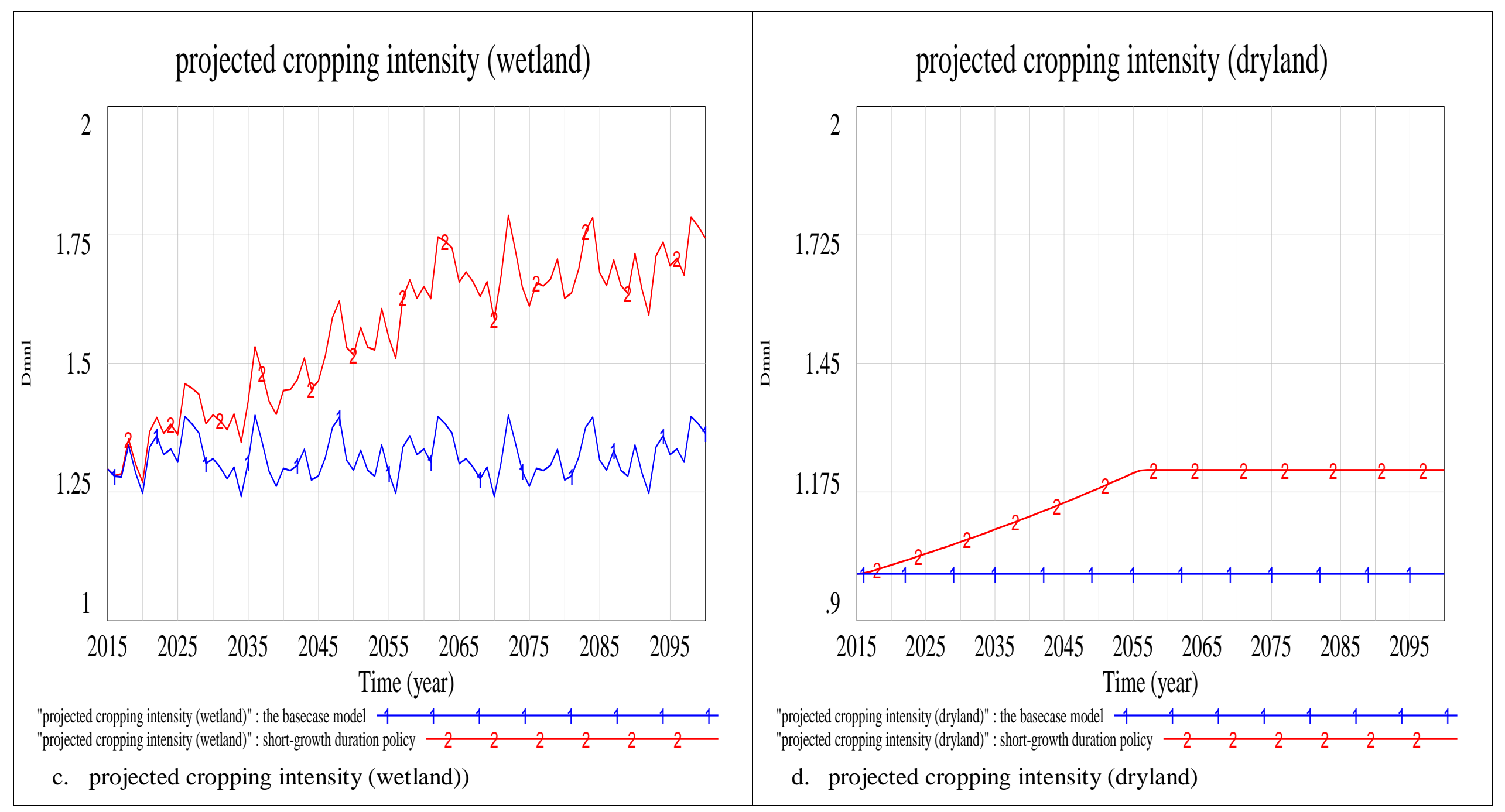




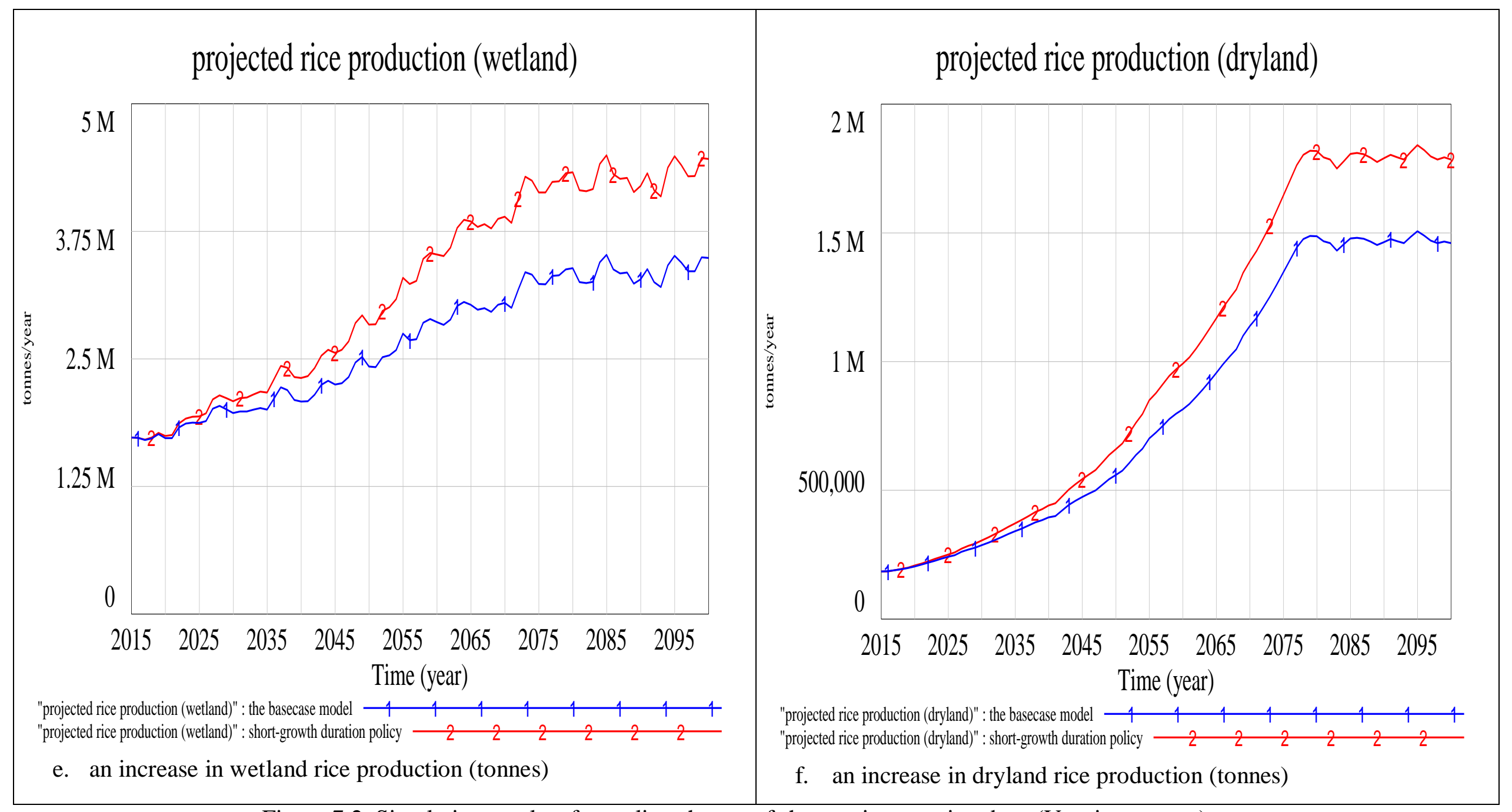

Figure 7.2 Simulation results after policy change of shorter rice growing days (Vensim outputs) 


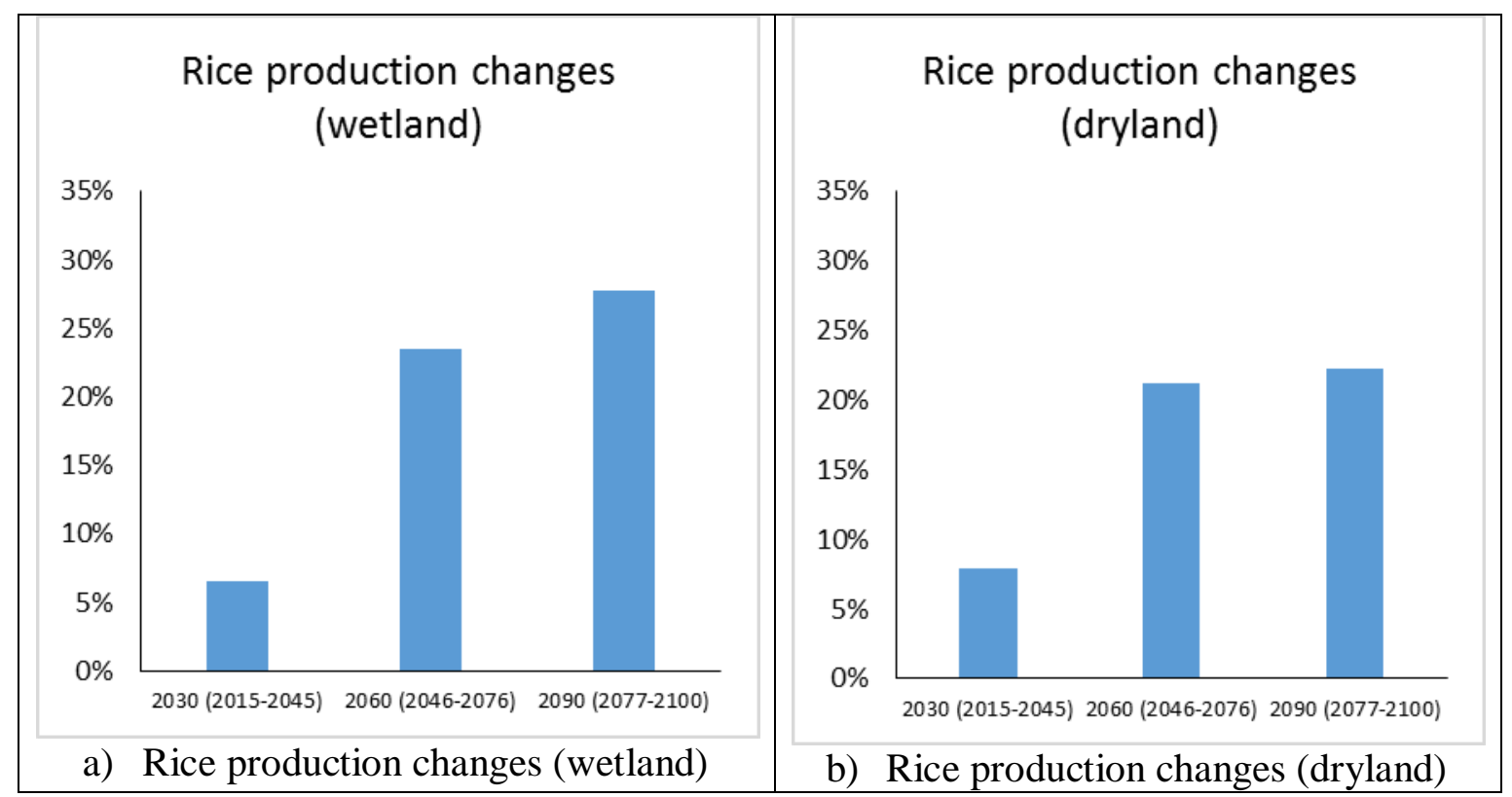

Figure 7.3 Results after a structural change of shorter rice growing days (multi-year average)

\subsubsection{Policy 2: Research on finding rice varieties with higher yields}

Figure 7.5 depicts another structural change i.e. the technological progress of higher yield varieties. As seen in figure 7.4, an increase in technological progress is subject to a fraction technological progress.

There were a lot of higher yield rice varieties introduced between 1976 and 1995 (Sembiring, 2008; Susanto et al., 2003), leading to higher rice production in this period of about $4 \%$ per year. A higher rice production might be due to either a larger farming area or better management or improved varieties. However, during that period (1976-1995), an increase in rice production was mainly caused by higher yield varieties (Sembiring, 2008; Susanto et al., 2003). Owing to this, this study assumes that a fraction of technological progress on rice varieties (i.e. the intended growth of rice yield (Khush, 2005) is about 4\% per year and a related delay is about seven years (Sembiring, 2008; Susanto et al., 2003). The importance of higher yield rice in Asian rice production is supported by previous studies (Khush, 1987; IRRI, 1985).

In principle, a structural change relating to technological progress on higher yields leads to new variables. A structural change leads to changing technological progress from an auxiliary (figure 7.4a-7.4b) to be a stock (figure 7.4c). Other new variables are, for instance, intended technological progress on rice and a fraction of technological progress on rice as shown in figure $7.4 \mathrm{c}$. 


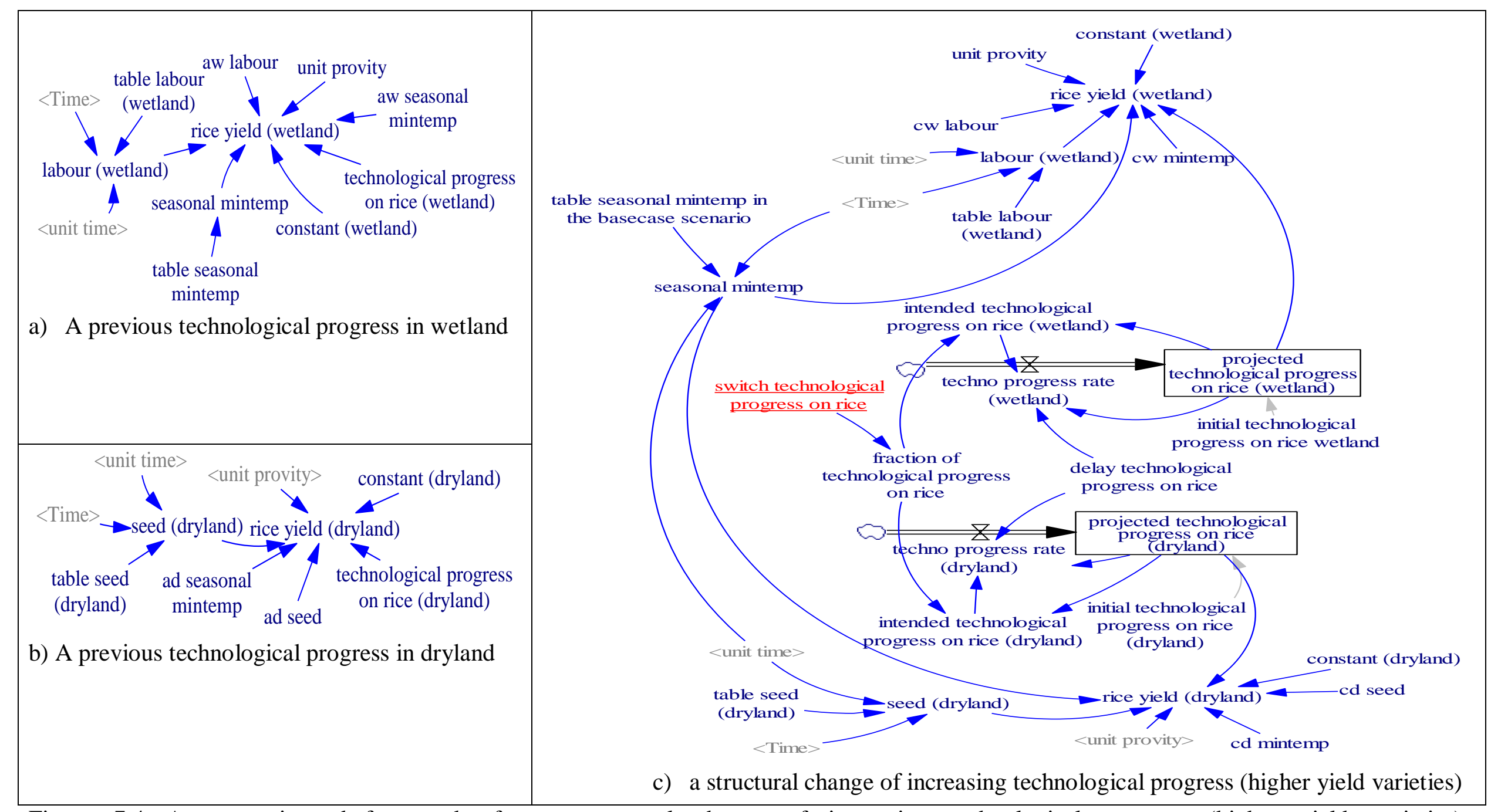

Figure 7.4 A comparison before and after a structural change of increasing technological progress (higher yield varieties) 
If research on finding higher yield varieties is initiated, wetland rice will probably increase from about 5.6 tonnes/year*ha to 6.7 tonnes/year*ha i.e $0.2 \%$ per year by 2100 (figure 7.5a). Dryland rice yield will probably increase from about 3.8 tonnes/year*ha to about 4.6 tonnes/year*ha by 2100 , i.e $0.2 \%$ per year (figure $7.5 \mathrm{~b}$ ). These increases in rice yield lead to higher rice production in wetland (1.2\% per year) and dryland (3\% per year) by 2100 (figures $7.5 \mathrm{c}-7.5 \mathrm{~d}$ ).

Figures 7.6a-7.6d, depict a multi-year average of rice yield and rice production. It seems that research on high yield varieties leads to higher yields compared to that in the basecase scenario (figures 7.6a-figure 7.6b). However, rice production in wetland and dryland is relatively lower (figures 7.6c-7.6d) than those due to a policy of shorter growth duration varieties (figures $7.3 \mathrm{a}-7.3 \mathrm{~b}$ ). 


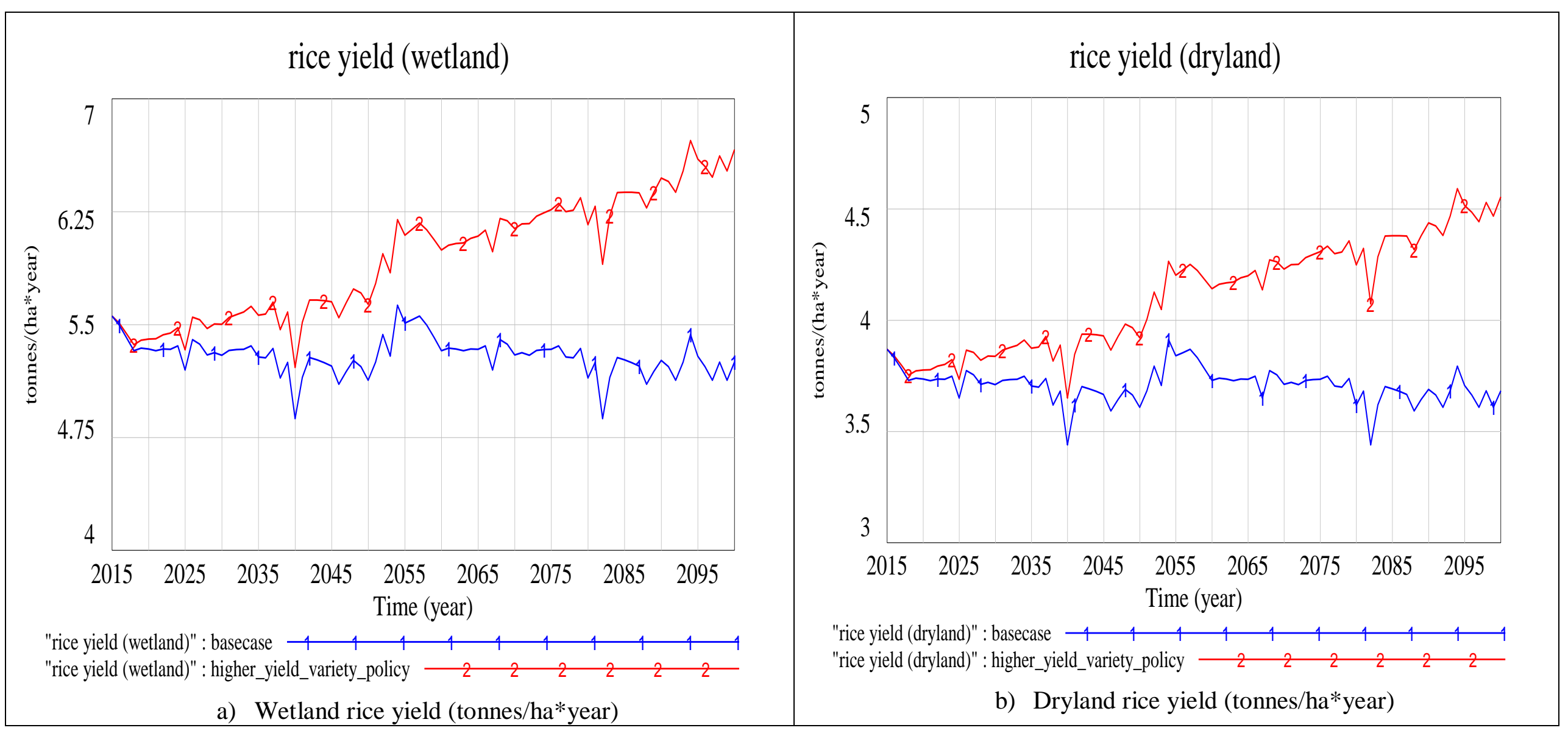




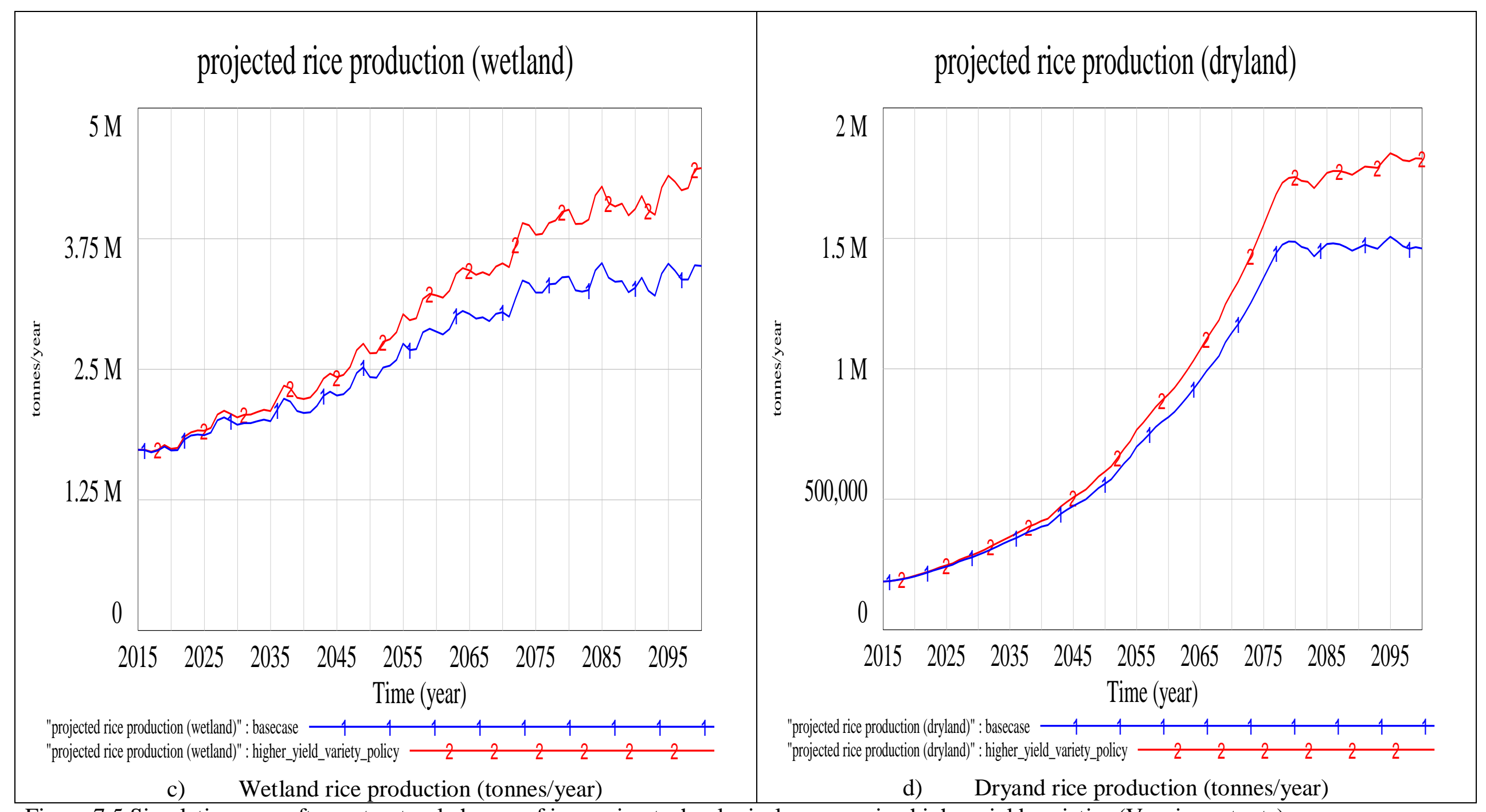

Figure 7.5 Simulation runs after a structural change of increasing technological progress i.e. higher yield varieties (Vensim outputs) 


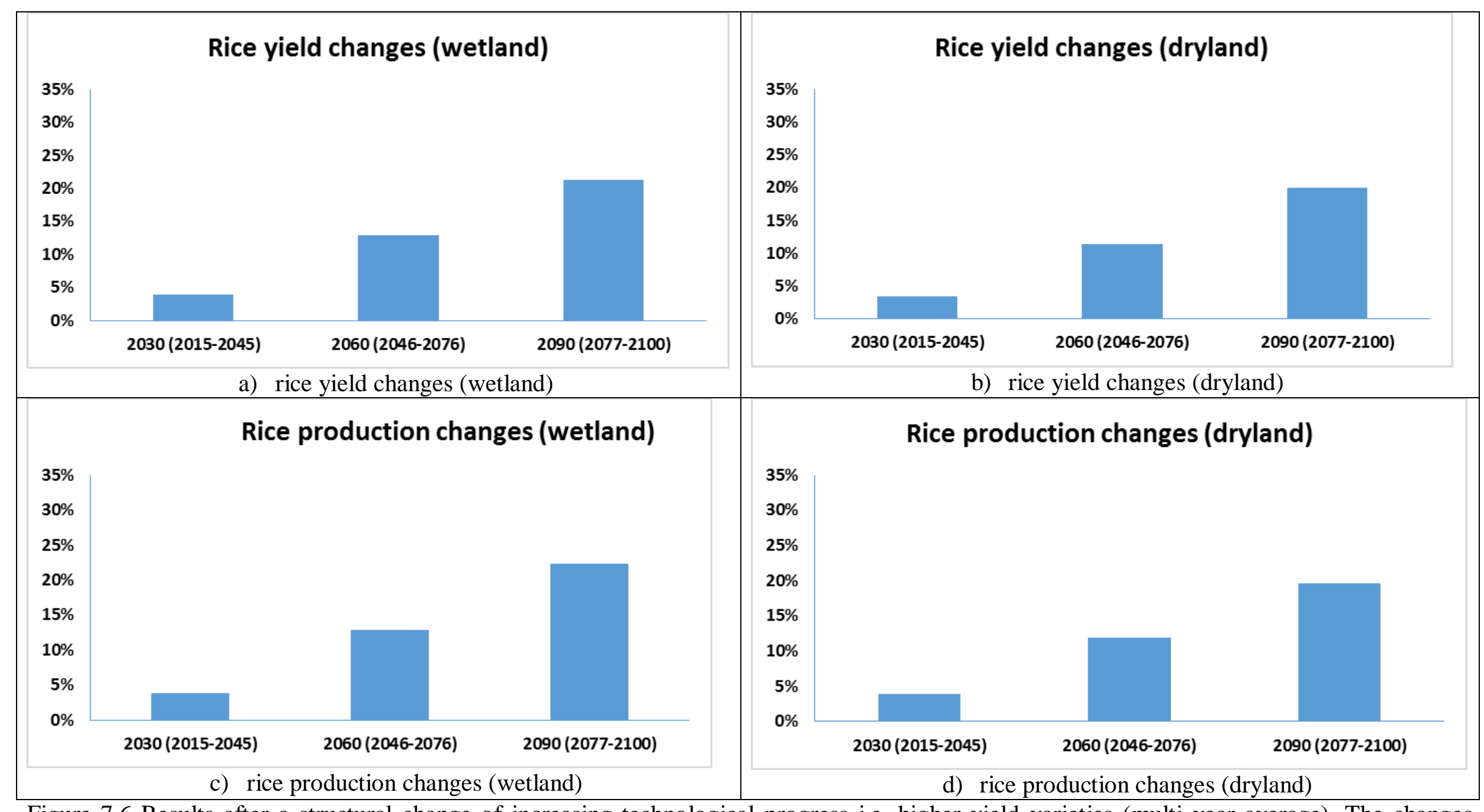

Figure 7.6 Results after a structural change of increasing technological progress i.e. higher yield varieties (multi year average). The changes compared to those in the basecase scenarios 


\subsubsection{Policy 3: Research on finding rice varieties with heat tolerance (high temperature}

tolerance)

The other possible policy in tackling the impacts of climate change on rice yield is to find heat tolerant rice varieties ${ }^{51}$. This aims to minimise the negative impacts of high temperature on rice yield. In addition, heat tolerant varieties should have comparable yields so that farmers are interested in replacing their current rice varieties.

Like Ye et al. (2015), this study assumes that scientists have started research for developing heat tolerant rice varieties in 2015. Another study (Zeigler \& Mohanty, 2010) suggests a 15year delay between agricultural research spending and its impact on yield. With that in mind, this study assumes a 15-year delay (2030-2015) in developing heat tolerant rice varieties that are comparable to recent yields.

The current yield of heat tolerant varieties in 2015 is assumed to be similar to N22's rice yield. N22 is the most tolerant rice variety which has a yield of about 2 tonnes/ha (Zhang et al., 2015). N22 is not only heat tolerant but also drought tolerant (Poli et al., 2013; Shivani et al., 2015). Some studies claim that N22 has QTL that is tolerant to high minimum temperature (Ye et al., 2015) and high maximum temperature (Shivani et al., 2015; Ye et al., 2015).

Figures 7.7 depicts structural changes relating to heat tolerant rice varieties in wetland and dryland farming respectively. This figure has a delay variable ("delay in finding heat tolerant rice variety") which represents 15 years (2030-2015) if the desired varieties are found by 2030 in wetland and dryland farming respectively.

Expected rice yield is similar to equation 5.3.2 (chapter 5) and equation 5.4.2 (chapter 5), eliminating the impacts of minimum temperature on wetland rice and dryland rice respectively (the coefficient of minimum temperature is deleted). Changing the negative coefficient of minimum temperature i.e genetic coefficients follows existing studies (Hillel \& Rosenzweig, 2011; Raymundo, Kleinwechter, \& Asseng, 2014). In this study, deleting the negative coefficient of minimum temperature is conducted, suggesting that heat tolerant genes in $\mathrm{N} 22$ can sustain rice yield up to a minimum temperature of about $27^{\circ} \mathrm{C}$ and up to a maximum temperature of $38^{\circ} \mathrm{C}$. It should be noted that the highest projected minimum

${ }^{51}$ This study assumes that heat tolerant varieties are varieties that grow well under high minimum temperature and high maximum temperature 
temperature and the highest projected maximum temperature by 2090 is about $27^{\circ} \mathrm{C}$ and $35^{\circ} \mathrm{C}$ respectively.

Equation 7.7 and 7.8 represent equations of expected rice yield in wetland and dryland farming respectively for the basecase scenario. These equations are derived from equation 5.3.2 and 5.4.2 (chapter 5), eliminating the negative coefficient of minimum temperature. By eliminating the negative coefficient of temperature, this study assumes that heat tolerant rice varieties will not be negatively affected by high temperature by 2090 (2077-2100). It should be noted that the highest projection (RCP8.5 scenario) of maximum and minimum temperature is about $35^{\circ} \mathrm{C}$ and $27^{\circ} \mathrm{C}$ by 2090 .

Expected rice yield $($ wetland $)=6.73+[2.46]+(3.3 \mathrm{e}-3 * 203.308)$

Expected rice yield $($ wetland $)=9.86$ tonnes/year* ha

Expected rice yield $($ dryland $)=4.56+[1.52]+(1.8 \mathrm{e}-2 * 20.8)$

Expected rice yield $($ dryland $)=6.4$ tonnes/year*ha

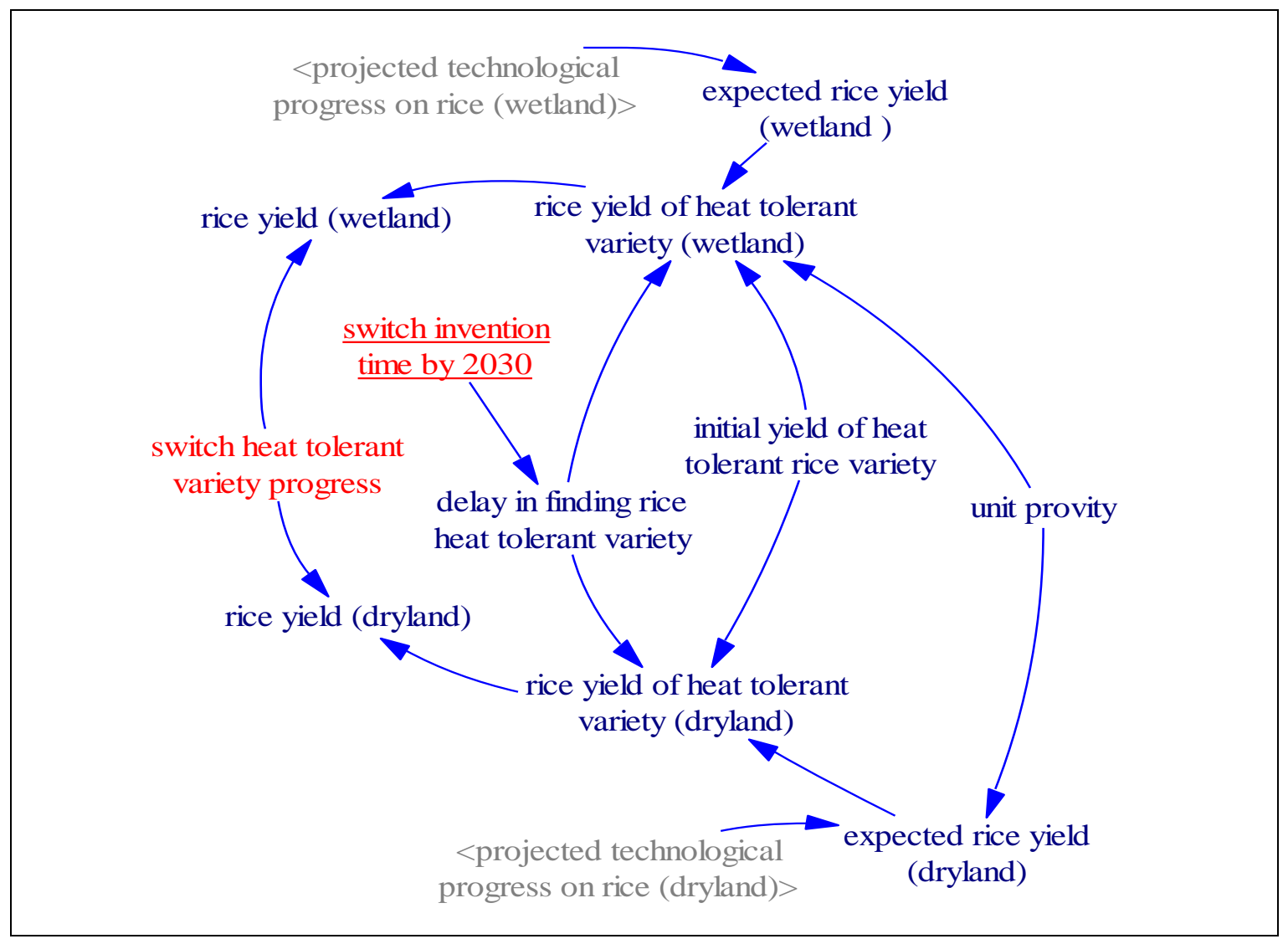

Figure 7.7 A structural change due to finding heat tolerant varieties (wetland and dryland)

The following figures (figures 7.8a-7.8d) depict the patterns of rice yield and rice production based on Vensim simulations if scientists can find desirable heat varieties by 2030. As expected, rice yield and rice production will probably increase significantly, 
compared to the basecase scenario. It appears that rice yield will probably increase by about 10 tonnes/year*ha and about 6 tonnes/year*ha in wetland and dryland farming, leading to an increase of rice production in wetland and dryland farming.

Figures $7.9 \mathrm{a}-7.9 \mathrm{~d}$ show the benefits of heat tolerant rice varieties in three different periods 2030 (2015-2045), 2060 (2046-2076) and 2090 (2046-2076). If rice scientists can find heat tolerant rice varieties in 2030, rice yield in wetland and dryland areas will probably be higher by about $20 \%$ as shown in figures 7.9 a-7.9b by 2030 (2015-2045), respectively, compared to rice yield in the basecase scenario. In addition, assuming heat tolerant rice varieties are found in 2030, rice production in wetland and dryland farming will probably increase by about $20 \%$ by 2030 (2015-2045), compared to rice production in the basecase scenario.

Figures $7.9 \mathrm{c}-7.9 \mathrm{~d}$ show that compared to rice production in the basecase scenario, rice production is projected to increase by about $75 \%$ (i.e $1.6 \%$ per year) and $89 \%$ (i.e $3 \%$ per year) by 2090 (2077-2100), compared to those in the basecase scenario in wetland and dryland respectively, if heat tolerant varieties are found by 2030 .

The policy of heat tolerant rice varieties will lead to higher yield (figures 7.9a-7.9b) than previous policies or previous structural changes such as a policy in finding higher yield rice varieties (figures $7.6 \mathrm{a}-7.6 \mathrm{~b}$ ). This policy will also lead to higher rice production (figures 7.9c-7.9d) than previous policies including, a policy in finding shorter growth duration varieties (figures 7.3a-7.3b) and policy in finding higher yield rice varieties (figures 7.6c $7.6 \mathrm{~d})$. 


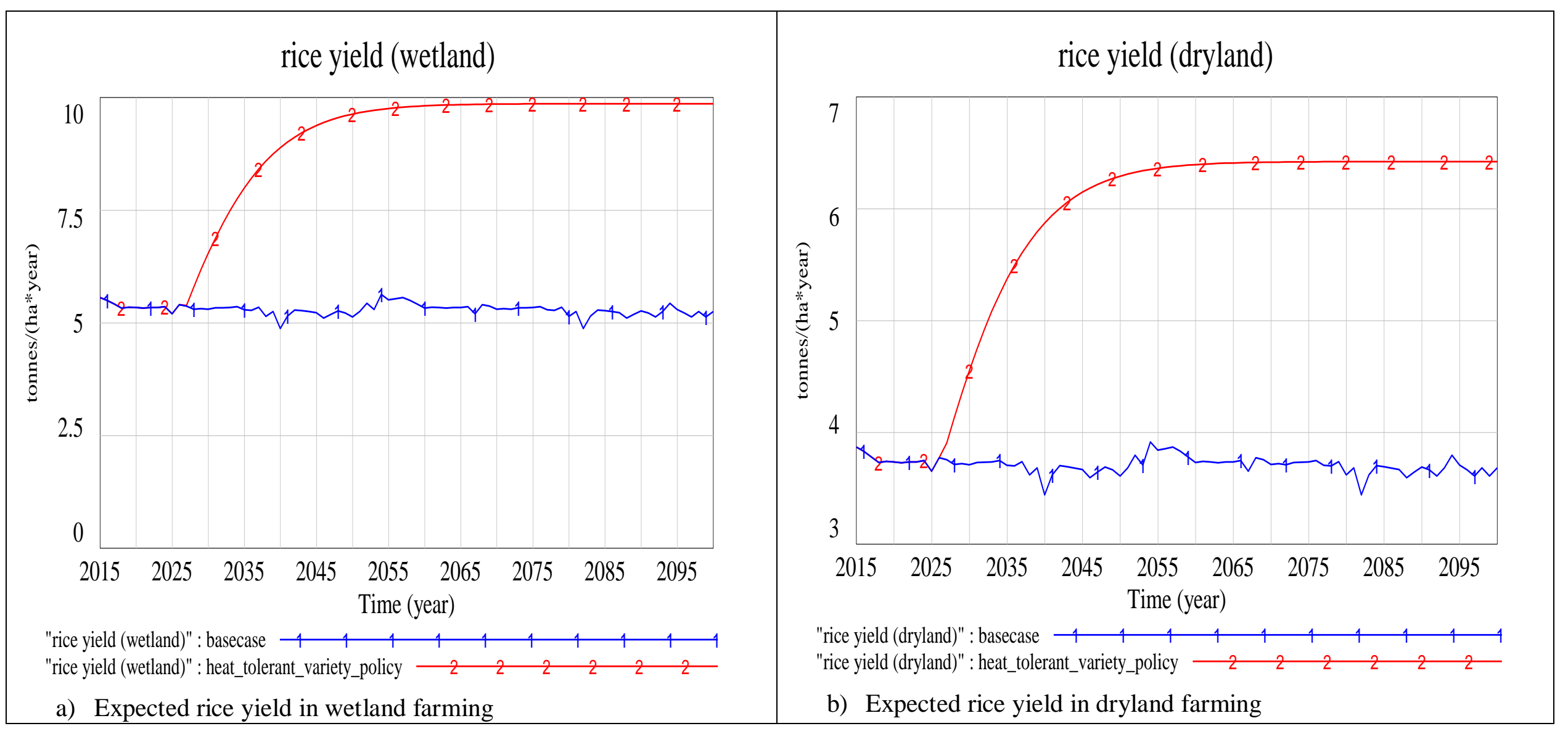




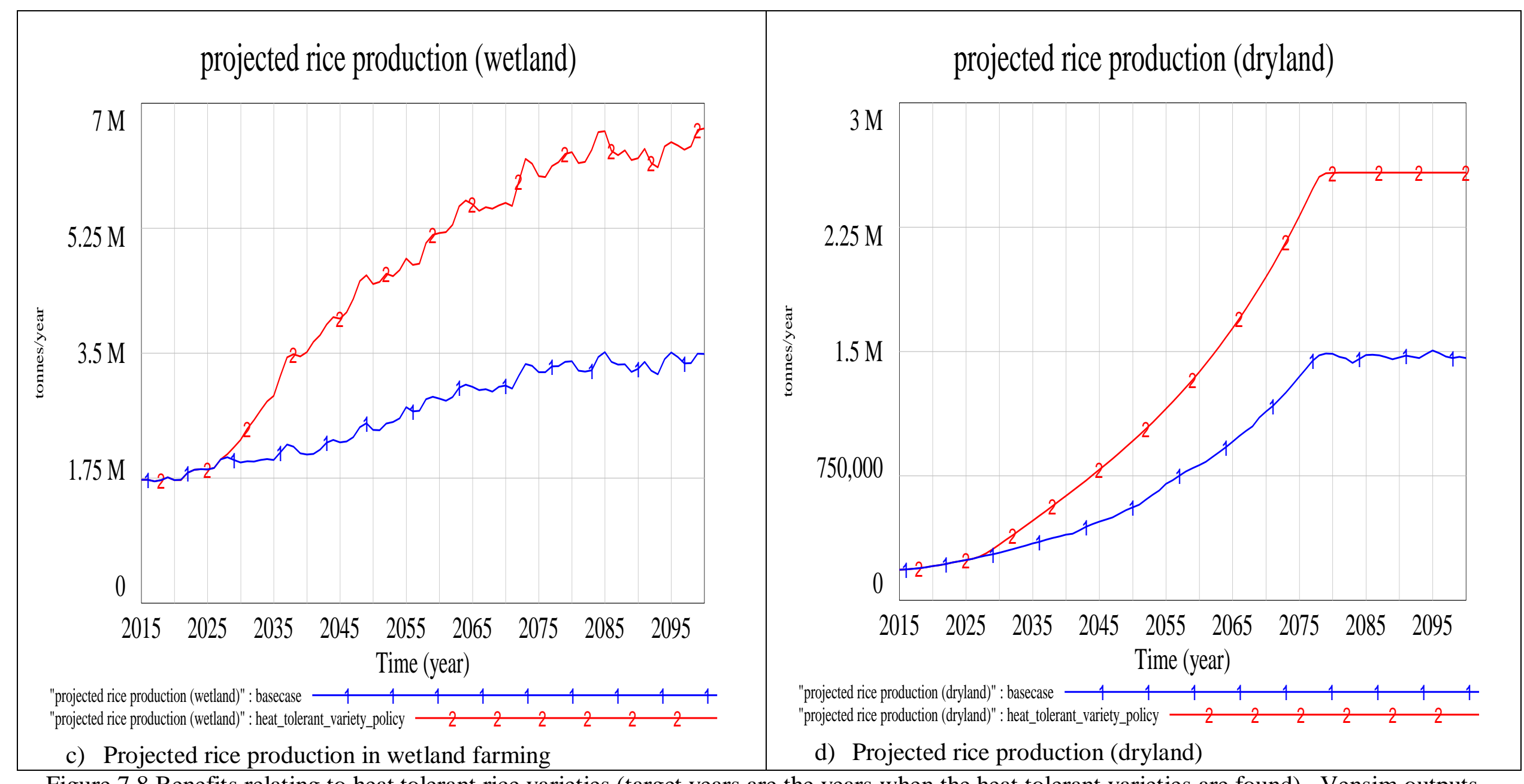

Figure 7.8 Benefits relating to heat tolerant rice varieties (target years are the years when the heat tolerant varieties are found)- Vensim outputs 


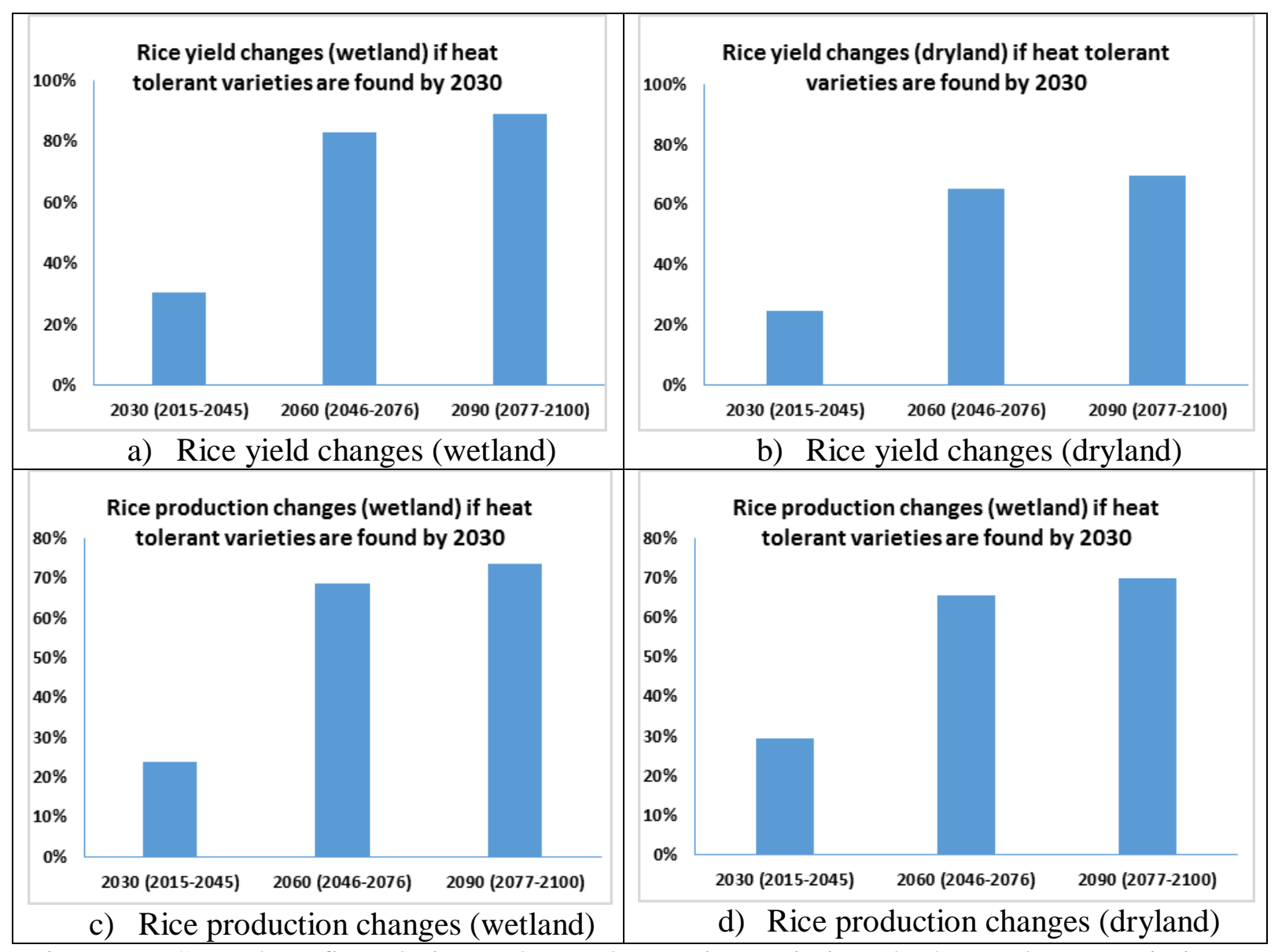

Figure 7.9 Some benefits relating to heat tolerant rice varieties (the heat tolerant varieties found by 2030) - multi year outputs

\subsection{Strategy development}

Table 7.3 depicts possible problems and technical opportunities in rice farming, showing that rice farming will probably face multiple stresses such as droughts, El-Niño and high temperatures. At the same time, there is an increase in rice demand owing to high levels of economic development, leading to a possible rice shortage. An increase in rice demand should be followed by higher yield varieties, and other stresses such as droughts and ElNiño should be followed by SGD varieties. All of these stresses require rice varieties that are resistant to multiple stresses (Gujja \& Thiyagarajan, 2010).

It should be noted that rice SGD varieties are likely to avoid the effects of droughts and ElNiño (Abdullah et al., 2008; Yoshida, 1981). So, rice varieties with two traits, i.e SGD and high yield, are needed to counter multiple stresses in the future, such as dry spells, droughts and growing populations. Incorporating two traits, i.e. SGD and high yield, eliminates rice varieties with a single trait, e.g rice varieties with high yield or rice varieties with SGD. 
Likewise, incorporating two main traits including SGD and high yield is also more feasible than other double traits. Incorporating heat tolerance and high yield will probably not be feasible as these double traits could suffer from droughts and El-Niño. Similarly, incorporating SGD and heat tolerance might be not effective good as these double traits will not include a trait of higher yield - the prefered trait of farmers (Orr, Riches, Mortimer, Harris, \& Mazid, 2008). It should be kept in mind that heat tolerant rice varieties will probably minimise the negative impacts of high temperature but lead to stagnant rice yield without a high yield trait.

Some policies, such as policies of improved rice varieties, can be constructed as alternative strategies (Maani \& Cavana, 2007, p.250). Strategies or combinations of policies should be simulated in assessing the outputs of certain strategies, in order to sustain and/or to increase system performance under different scenarios (e.g different climate projections). In this chapter, three strategies are composed and each strategy is assessed by comparing harvested areas, rice yield and rice production.

The first strategy is called the base case strategy which is simulated in chapter 6 (section 6.7.2). This strategy resembles the base case model with two added structural changes owing to climate factors: the effects of maximum temperature and the negative impacts of minimum temperature. As Indonesia and WNT have already had a higher rice supply than a rice demand since 2008 (Firdaus, Baga, \& Pratiwi, 2008; Prasetyo, 2008) and since 1983 (BPTP NTB, 2013) respectively, the stakeholders of rice supply might feel safe following the basecase strategy. In this strategy, there are no policies for finding improved rice varieties. 


\begin{tabular}{|c|c|c|}
\hline Problems & Technical Opportunities & Descriptions \\
\hline $\begin{array}{l}\text { ENSO is likely the most important } \\
\text { climate variability in the future, eg. } \\
\text { El-Nińo tends to shorten planting } \\
\text { seasons (IPCC, 2013) } \\
\text { Climate change is likely to increase } \\
\text { extremes such as dry spells and heat } \\
\text { waves (IPCC, 2013). }\end{array}$ & $\begin{array}{l}\text { SGD varieties } \\
\text { This trait is important and still a } \\
\text { main concern as El-Nińo in } \\
1965 / 1966 \text { and in 1997/1998 led } \\
\text { the downfall of two Indonesian } \\
\text { presidents, i.e. Sukarno and Suharto } \\
\text { respectively (Kementerian } \\
\text { Pertanian, 2010) }\end{array}$ & $\begin{array}{l}\text { SGD varieties can escape } \\
\text { from droughts, dry spells, } \\
\text { save water and give better } \\
\text { chances for increasing } \\
\text { crop intensity or crop } \\
\text { rotations (Abdullah et al., } \\
\text { 2008; Bouman et al., } \\
\text { 2007; Yoshida, 1981). }\end{array}$ \\
\hline $\begin{array}{l}\text { Growing population and Economic } \\
\text { development } \\
\text { An increase of rice demand due to } \\
\text { growing population and economic } \\
\text { development in developing countries } \\
\text { such as Indonesia (Zeigler, \& } \\
\text { Mohanty, 2010). } \\
\text { Farmers tend to support rice farming } \\
\text { when there are high yield varieties } \\
\text { (Khush, 1987; Orr et al., 2008). }\end{array}$ & $\begin{array}{l}\text { High yield varieties } \\
\text { After the green revolution (1970s- } \\
\text { 1990s), IRRI and the Indonesian } \\
\text { government (Susanto et al., 2003) } \\
\text { have developed higher yield } \\
\text { varieties since the 2000s. } \\
\text { Farmers in developing countries } \\
\text { prefer to sow high yield rice } \\
\text { varieties as they lead to a higher } \\
\text { profit (Khush, 1987; Orr et al., } \\
\text { 2008; Sembiring, 2008; Susanto et } \\
\text { al., 2003). }\end{array}$ & $\begin{array}{l}\text { A higher rice production } \\
\text { is mainly supported by } \\
\text { higher yield varieties } \\
\text { (Khush, 1987; Zeigler, \& } \\
\text { Mohanty, 2010). } \\
\text { IRRI has developed } \\
\text { varieties with multiple } \\
\text { traits including SGD and } \\
\text { high yield since 1970s } \\
\text { (Khush, 1987; IRRI, } \\
\text { 1985). }\end{array}$ \\
\hline $\begin{array}{l}\text { High temperature } \\
\text { High minimum temperature has } \\
\text { already threatened rice yield and in } \\
\text { the future, high maximum } \\
\text { temperature will probably decrease } \\
\text { rice yields. } \\
\text { Distributing N22, the most heat } \\
\text { tolerant rice variety (Ye et al., 2015), } \\
\text { to rice farmers might not be a good } \\
\text { option as N22 has a lower yield ( } \\
\text { tonnes/year*ha), compared to the } \\
\text { most recent rice yield (5 } \\
\text { tonnes/year*ha). This means that } \\
\text { heat tolerant rice varieties, e.g. } \\
\text { N22's yield, should be increased - } \\
\text { i.e. incorporated with a higher yield } \\
\text { trait. }\end{array}$ & $\begin{array}{l}\text { Heat tolerant varieties } \\
\text { As QTL of heat tolerance were } \\
\text { found about a year ago (Ye et al., } \\
\text { 2015), scientists have conducted } \\
\text { research in finding heat tolerant rice } \\
\text { varieties (Magnibas et al., 2014; Ye } \\
\text { et al., 2015) } \\
\text { Although this trait is important, a } \\
\text { combination of a trait of heat } \\
\text { tolerance with a trait of short- } \\
\text { growth duration might not be } \\
\text { feasible as farmers want heat } \\
\text { tolerant varieties with comparable } \\
\text { yields to recent varieties. }\end{array}$ & $\begin{array}{l}\text { This trait is highly } \\
\text { important as climate } \\
\text { change is likely to } \\
\text { increase temperature } \\
\text { (Kondamudi et al., 2014). } \\
\text { Another combination, } \\
\text { heat tolerance and high } \\
\text { yield, is not feasible as } \\
\text { this combination will } \\
\text { suffer from climate } \\
\text { extremes. } \\
\text { Heat tolerance should be } \\
\text { combined with the other } \\
\text { traits i.e short-growth } \\
\text { duration and high yield. }\end{array}$ \\
\hline
\end{tabular}

Table 7.3 Problems and technical opportunities in rice farming

The second strategy is called the non-heat tolerant technological progress. The second strategy resembles the base case strategy with two added policies: SGD varieties and higher rice yield varieties. This strategy resembles the period 1976-1995 - the Green Revolution 
during which improved varieties including rice varieties with shorter growth duration and rice varieties with higher yields increased Indonesian rice production by about $4 \%$ per year (Abdullah et al., 2008; Sembiring, 2008; Susanto et al., 2003). The second strategy holds that rice production can be bettered by increasing cropping intensity, protecting rice from El-Niño and sowing higher yield rice varieties. The government of Indonesia has conducted research to find improved rice varieties with high yields and SGD (Abdullah et al., 2008; Sembiring, 2008; Susanto et al., 2003).

The third strategy is similar to the second strategy with one added policy: technological progress in finding heat tolerant rice varieties. The main objective of the third strategy is to minimise the negative impacts of climate change by finding heat tolerant rice varieties. This strategy anticipates a situation when climate change cannot easily be mitigated, leading to a significant increase in minimum temperature and maximum temperature. The third strategy is supported by some studies (Ainsworth, 2008; Usui, Sakai, Tokida, Nakamura, Nakagawa \& Hasegawa, 2014; Zhang et al., 2013b) suggesting that heat tolerant rice varieties are key to sustaining and increasing rice production under a changing climate. Another study (Ainsworth, 2008) also suggests that heat tolerant rice varieties should be developed first before realising the positive impacts of elevated $\mathrm{CO}_{2}$ on rice yields. Simplified details of all strategies are depicted in table 7.4. 


\begin{tabular}{|c|c|c|c|}
\hline Policies & $\begin{array}{l}\text { The base case strategy } \\
\text { (the first strategy) }\end{array}$ & $\begin{array}{l}\text { The second strategy } \\
\text { (The non heat tolerant } \\
\text { strategy) }\end{array}$ & $\begin{array}{l}\text { The third strategy } \\
\text { (The heat tolerant } \\
\text { strategy) }\end{array}$ \\
\hline $\begin{array}{lcr}\text { Research } & \text { of } & \text { rice } \\
\text { varieties with } & \text { shorter } \\
\text { growth duration } & \end{array}$ & - & $\mathrm{x}$ & $\mathrm{x}$ \\
\hline $\begin{array}{l}\text { Technological progress } \\
\text { of higher yield }\end{array}$ & - & $\mathrm{X}$ & $\mathrm{x}$ \\
\hline $\begin{array}{l}\text { Research on finding heat } \\
\text { tolerant rice varieties }\end{array}$ & - & - & $\mathrm{X}$ \\
\hline Descriptions & $\begin{array}{l}\text { This resembles the } \\
\text { period prior to 1970s } \\
\text { and the period 1996- } \\
2011 \text { when an increase } \\
\text { in rice production only } \\
\text { depended on area } \\
\text { expansion (this strategy } \\
\text { is simulated in section } \\
6.7 .2 \text { ) }\end{array}$ & $\begin{array}{l}\text { The second strategy } \\
\text { This resembles the period } \\
\text { 1970s-1995 when rice } \\
\text { breeding was higly } \\
\text { intensified owing to high } \\
\text { rice demand. } \\
\text { This strategy assumes that } \\
\text { rice varieties have two } \\
\text { main traits including high } \\
\text { yield and short growth } \\
\text { duration. }\end{array}$ & $\begin{array}{l}\text { The third strategy } \\
\text { This strategy similar } \\
\text { to the second strategy, } \\
\text { however, rice varieties } \\
\text { have three traits } \\
\text { including heat } \\
\text { tolerance, high yield } \\
\text { and short growth } \\
\text { duration. } \\
\text { This aims to face an } \\
\text { increase in } \\
\text { temperature owing to } \\
\text { climate change. }\end{array}$ \\
\hline
\end{tabular}

Table 7.4 A summary of three strategies

\subsubsection{The second strategy: non-heat tolerant rice strategy}

It is possible for scientists to find better rice varieties that have two important features including a short growth duration and a higher yield (Khush, 1987; IRRI, 1985; Sembiring, 2008; Susanto et al., 2003). IR64, one of the most popular rice varieties in history, has two significant features: a shorter growth duration and a higher yield compared to its predecessors such as IR8 and IR36 (Khush, 1987; IRRI, 1985).

The objective of short growth duration varieties is to increase farmer cropping intensities especially during El-Niño, while the objective of higher yield varieties is to increase rice yield. SGD varieties also can help farmers to protect their crops from climate extremes such as droughts, heat waves and dry spells.

The second strategy will probably increase rice yield and rice production in wetland and dryland farming (figures 7.10a-7.10b). Greater rice production is also supported by a higher cropping intensity (the grey line) and larger harvested areas (the green line) as shown in figures 7.10c-7.10d for wetland and dryland farming respectively. 


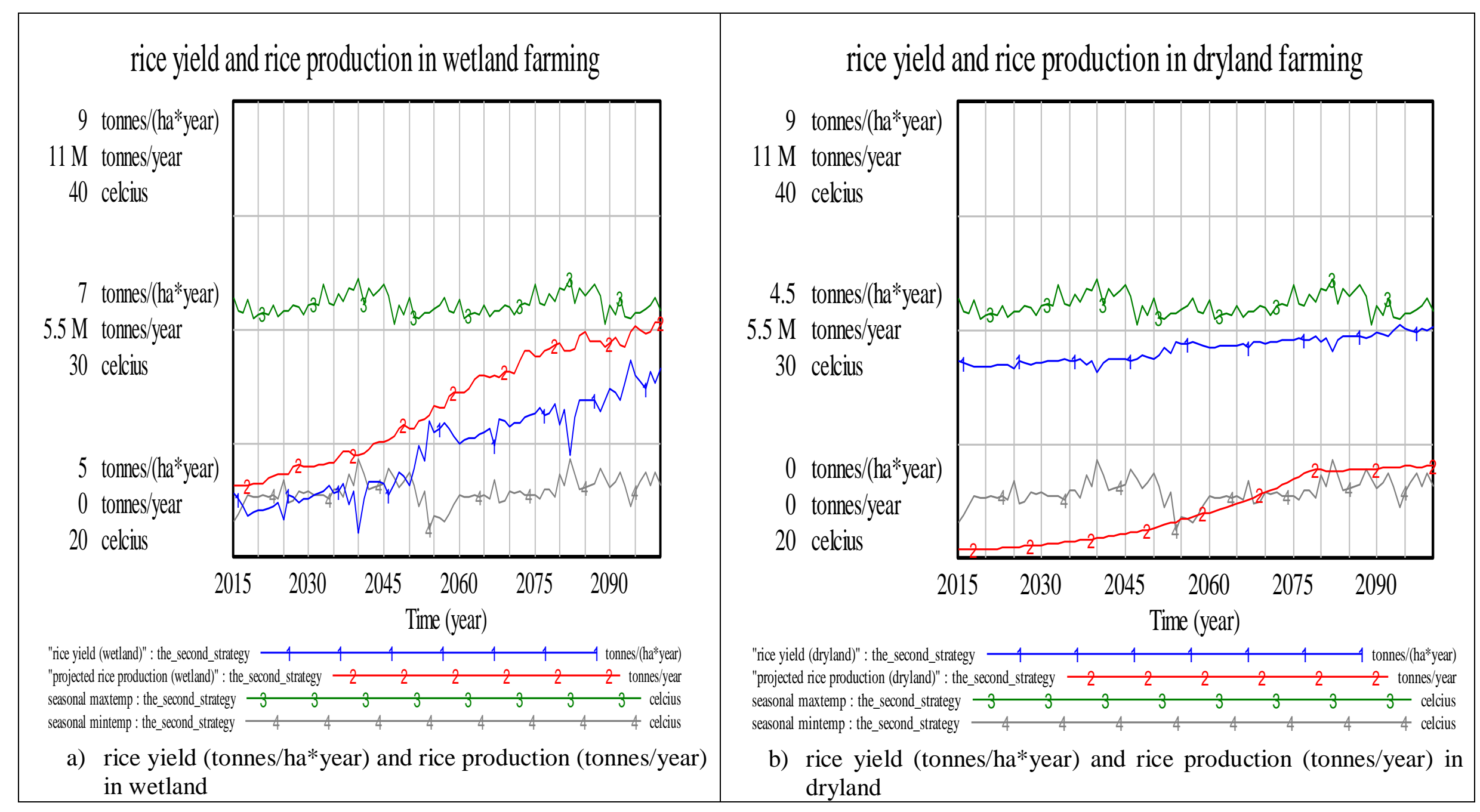




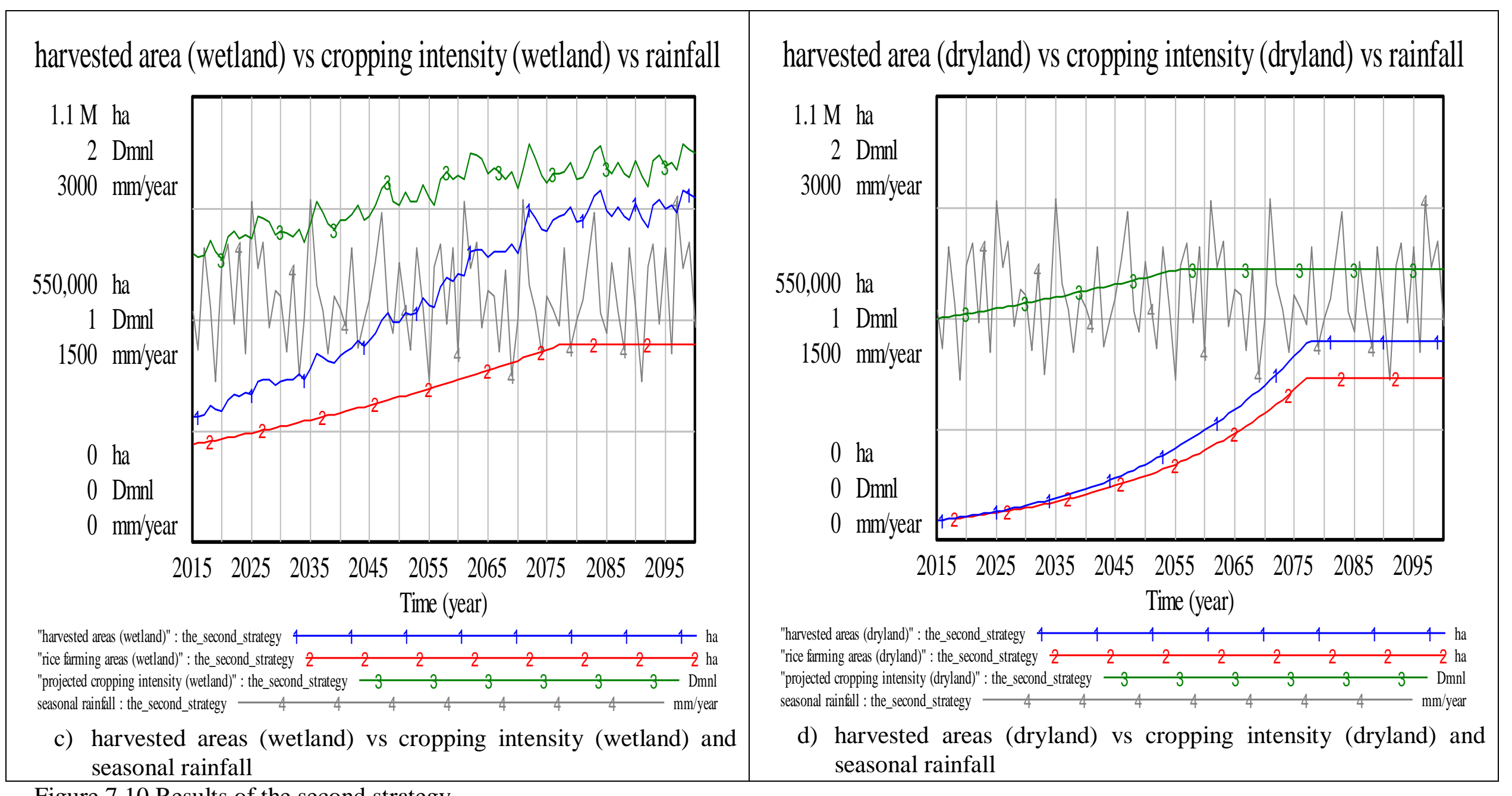

Figure 7.10 Results of the second strategy 


\subsubsection{The third strategy: heat tolerant rice varieties}

This strategy combines three possible traits in rice varieties including short growth duration, high yield and heat tolerant rice varieties. As explained in section 7.2.3, this study assumes that heat tolerant rice varieties will probably be found by 2030 , as one study (Zeigler \& Mohanty, 2010) suggests a 15-year delay between agricultural research spending and its impact on rice yield. This strategy is also feasible as G.K. Khush (personal communication, October 18, 2016) suggests that it is possible to develop rice varieties with three traits including short-growth duration, high yield and heat tolerance.

Figure 7.11 depicts simulation results of the third strategy through rice yield and rice production by 2030 (2015-2045), 2060 (2046-2076) and 2090 (2077-2100) respectively. As expected, rice yield and rice production (figures 7.11a $-7.11 \mathrm{~b}$; figure 7.11e-7.11f; figure 7.11i-7.11j) will probably rise significantly over time compared to those in the base case strategy and to those in the second strategy. While harvested areas (figures 7.11c 7.11d; figure 7.11g-7.11h; figure 7.11k-7.11l) are similar to those in other strategies. 


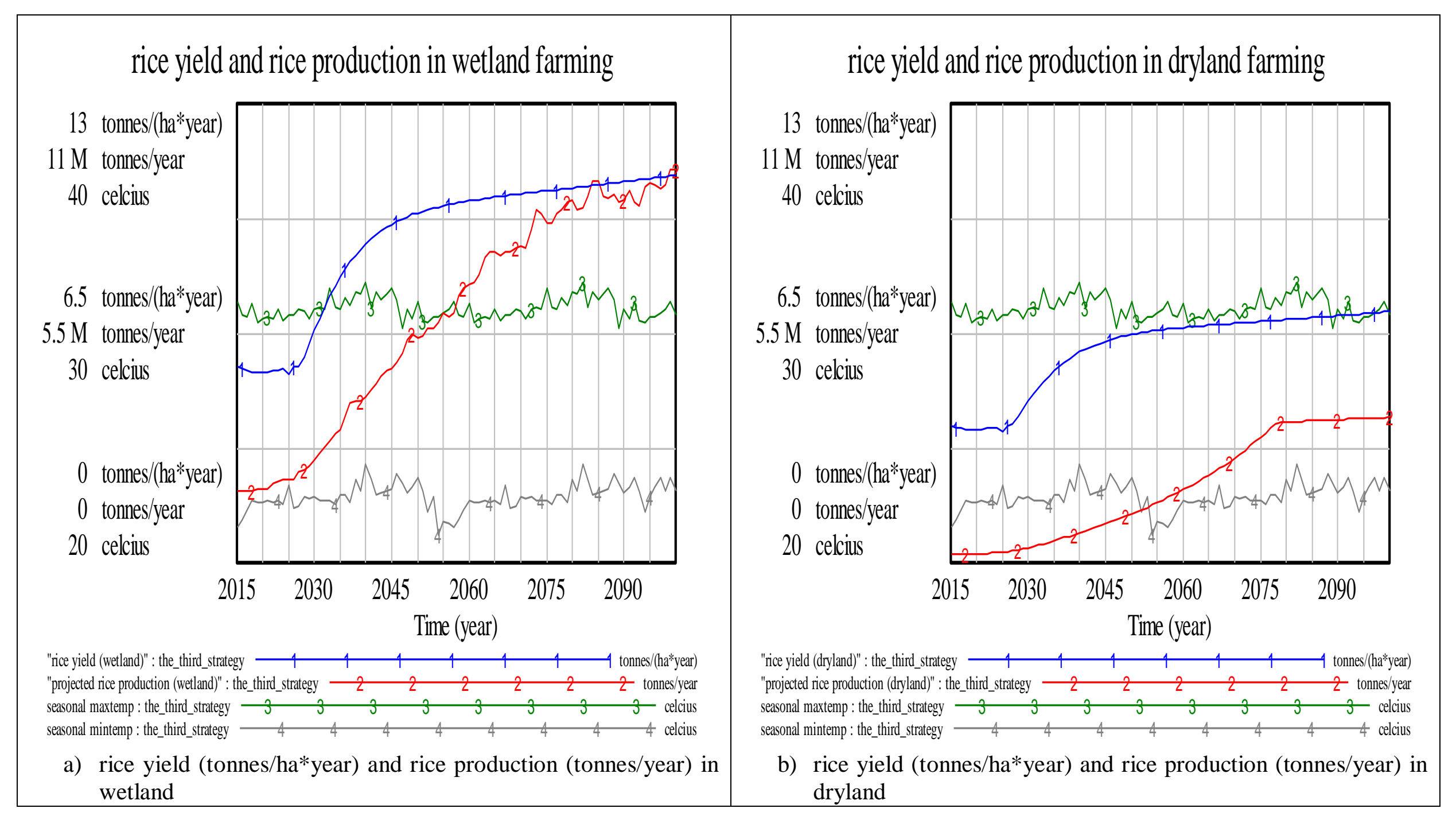




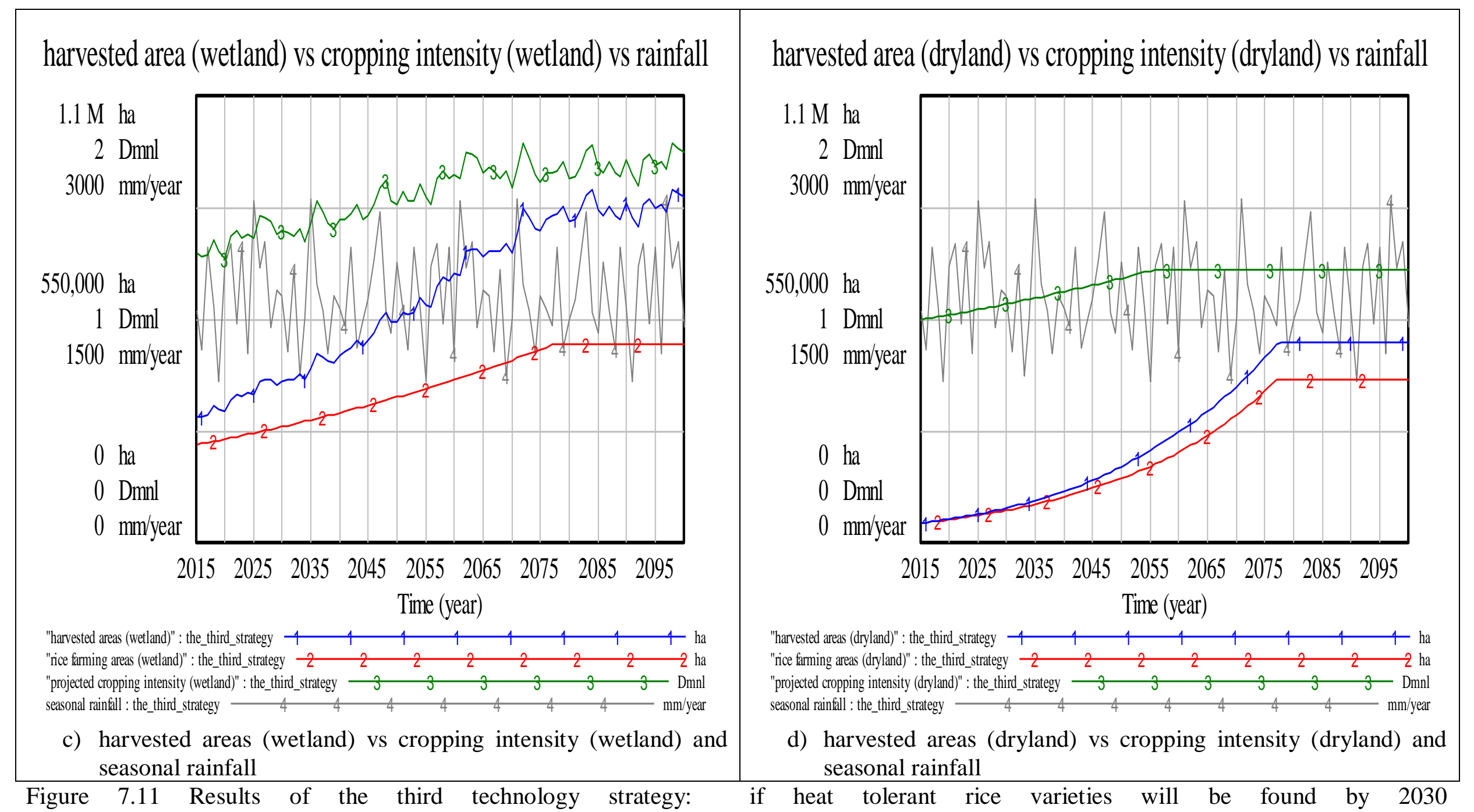




\subsection{Scenario analysis}

Since the objective of this study is to examine the impacts of climate change on the rice farming system of the rice supply chain, this research will evaluate strategies explained in the previous sections under different climate projections. These climate projections are described in section 6.7.2.

\subsubsection{The second strategy: the projected results}

As discussed in section 7.3, the second strategy focuses on finding rice varieties with two important technological features including short-growth duration and high yields. This strategy results in a higher yield for wetland and dryland rice. Compared to those in the basecase scenario, this strategy leads to higher rice yields in all types of rice farming for each RCP scenario over time except for RCP6.0 and RCP8.5 scenarios (figure 7.12a and figure 7.12b). For instance the RCP4.5 scenario projects a wetland rice yield increase of about 1\% (1\%-3\%) and 13\% (1\%-21\%), by 2030 (2015-2045) and by 2090 (2077-2100), respectively.

Rice production in all types of rice farming is likely to increase over time for every RCP scenario (figure 7.12c and figure 7.12d), except for the RCP8.5 scenario. In the RCP4.5 scenario, the second strategy will probably increase rice production by 2090 (2077-2100) about $53 \%(36 \%-63 \%)$ and $41 \%(27 \%-51 \%)$ in wetland and dryland respectively, compared to rice production in the base case scenario (figure 7.12c- figure 7.12d).

Because the second strategy encourages research on finding rice varieties with shorter growth duration, this strategy projects larger harvested areas for all rice farming. In principle, the shorter growth duration leads to larger harvested areas as seen figure 7.12e (wetland harvested areas) and figure 7.12f (dryland harvested areas). Wetland harvested areas will probably increase with RCP2.6, i.e the highest mitigated scenario, compared to RCP8.5, the least mitigated scenario, as RCP8.5 projects a higher rainfall than the other RCP scenarios. Dryland harvested areas will probably increase over time, however such areas will probably level off between 2060 (2046-2076) and 2090 (2077-2100).

Dryland farmers tend to sow their rice only during the first cycle (September-December) to pre-empt insufficient rainfall in subsequent cycles, leading to similar changes of harvested 


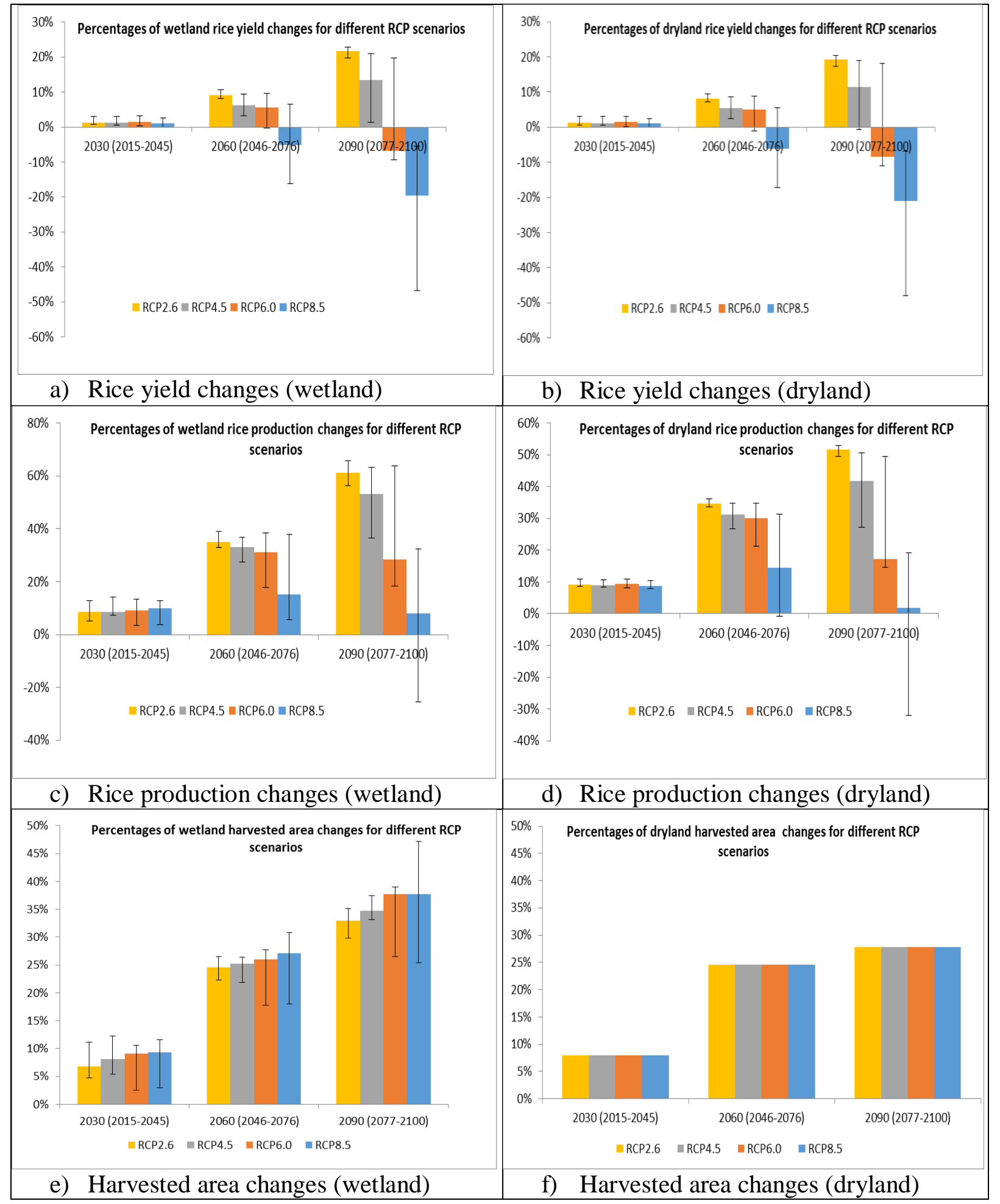

Figure 7.12 Simulation results based on the second strategy. Compared to those in the basecase scenario. Vertical lines are error bars $\left(5^{\text {th }}\right.$ and $95^{\text {th }}$ percentiles - climate projections). It should be noted that dryland harvested areas are not influenced by climate, hence no available error bars for dryland harvested areas. 
areas (as seen in figure 7.12f) for every period. The patterns of harvested areas in wetland and dryland farming in the third strategy will be similar to those in this strategy. The outputs of the Vensim $($ simulation for the second strategy can be seen appendix J.

\subsubsection{The third strategy: the projected results}

This strategy aims to seek benefit from heat tolerant varieties, i.e. rice varieties that can grow well under high minimum temperature and high maximum temperature. The third strategy results in a rapid increase of rice yield and rice production under all RCP scenarios.

Heat tolerant rice varieties are varieties that can grow very well under high temperature (i.e high minimum temperature and high maximum temperature). As such, if heat tolerant rice varieties are found in 2030, rice is projected to grow very well under high temperature for every RCP scenario, leading to similar rice yield changes in each period (as shown in figures $7.13 \mathrm{a}-7.13 \mathrm{~b})$.

Assuming that heat tolerant rice varieties are found in 2030, rice yield and rice production in all rice farming is likely to be higher by about $30 \%$ (i.e $2 \%$ a year) and about $45 \%$ (39\%$47 \%$ ) (i.e $4 \%$ a year) by 2030 (2015-2045) than those in the basecase strategy under all RCP scenarios (figure 7.13a-figure 7.13d). It should be noted that all predicted increases in rice yield for the third strategy are not equipped with error bars as they are relatively small (see figures 7.13). The third strategy leads to smaller error bars of rice yield since heat tolerant varieties are not influenced the rises and variability of temperature.

For harvested area changes in wetland and dryland farming, the third strategy leads to outputs similar to those of the second strategy. The outputs of Vensim@ simulation for the third strategy can be seen appendix J. 


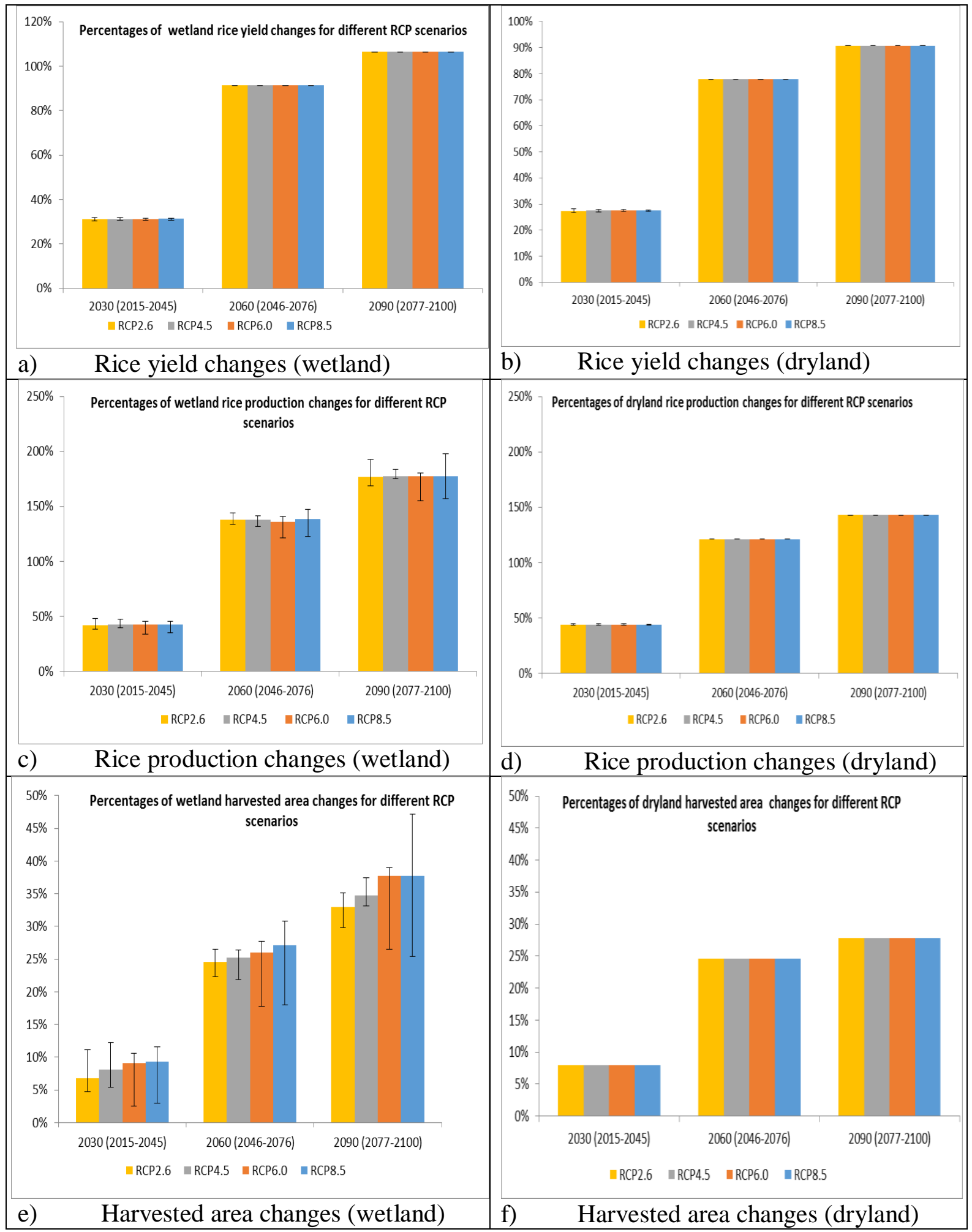

Figure 7.13 Simulation results based on the third technology strategy (heat tolerant varieties found in 2030). Compared to those in the basecase scenario. Vertical lines are error bars $\left(5^{\text {th }}\right.$ and $95^{\text {th }}$ percentiles - climate projections). It should be noted that dryland harvested areas are not influenced by climate, hence no available error bars for dryland harvested areas. 


\subsection{A comparison between the three strategies and the observed period}

Figures 7.14 - 7.15 compare outputs for the observed period (1976-2011) and each strategy for wetland and dryland rice respectively (RCP2.6 vs RCP8.5 scenario). WNT as a region has been self-sufficient in rice since 1983 (BPTP NTB, 2013) and since then has been one of the national hosts for rice production (Lantarsih et al., 2011). This study displays the observed period outputs as the benchmark of each strategy output.

In general, the RCP8.5 scenario projects larger reductions of rice yield and rice production compared to those in the RCP2.6 scenario. For instance, RCP8.5 projects negative growth of rice yield in the first and second strategy for wetland rice (figure 7.14b) while the RCP2.6 scenario projects positive growths of rice yield in the first and second strategy for wetland rice (figure 7.14a). For harvested areas, RCP8.5 scenario projects larger harvested areas than those under RCP2.6 scenario.

Although the second strategy will probably result in a higher rice yield and a higher rice production than those in the first strategy, both strategy outputs are relatively lower than those in the observed period in both RCP scenarios, i.e the RCP2.6 and RCP8.5 scenarios. For instance, wetland rice production will probably increase by about $2 \%$ and $1 \%$ by 2090 (2077-2100) under the second and the first strategy respectively, which are relatively lower than those in the observed period (1976-2011). 


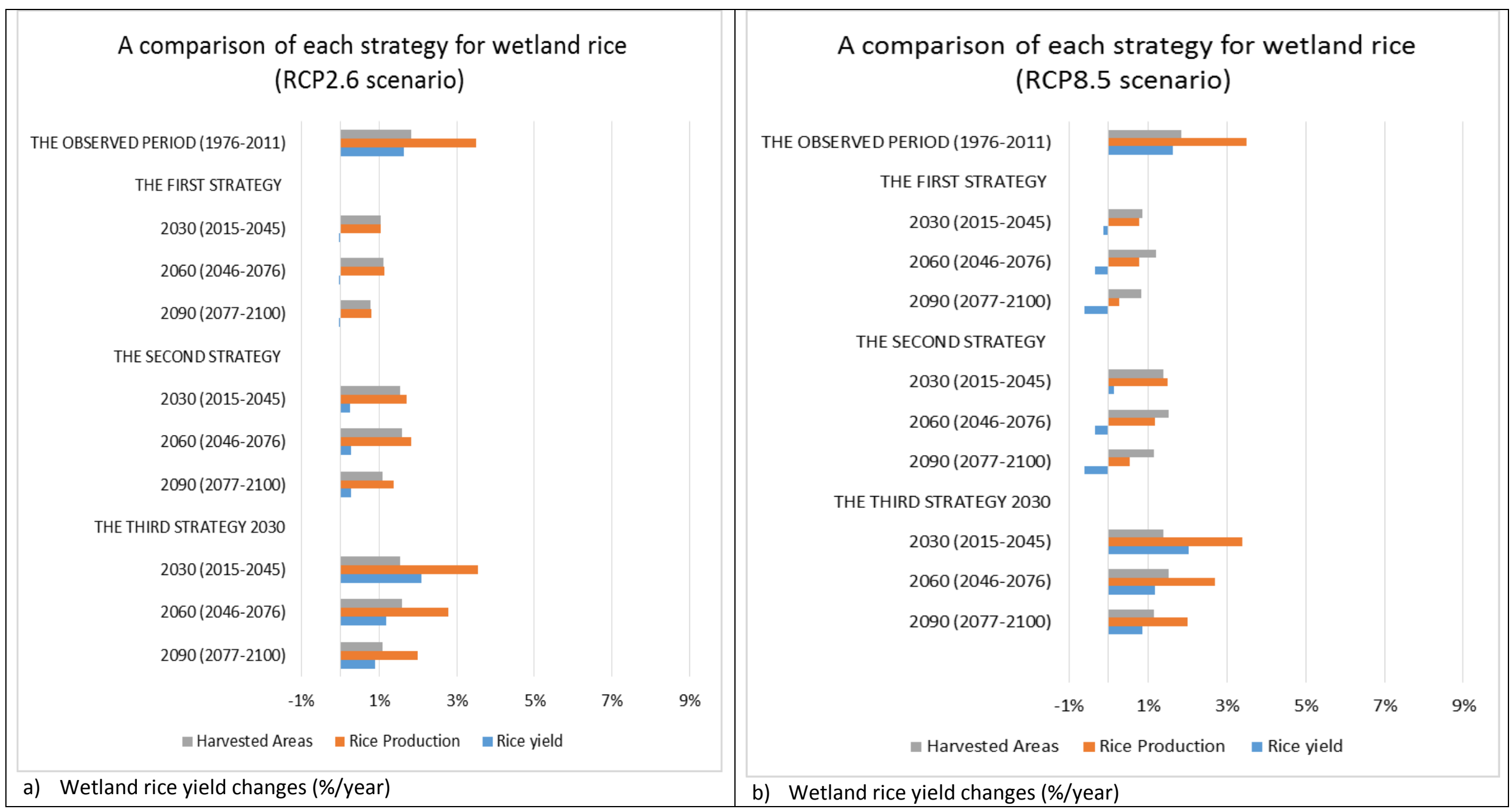

a) Wetland rice yield changes (\%/year)

b) Wetland rice yield changes (\%/year)

Figure 7.14 A comparison of strategies' results and the observed period for wetland rice under RCP2.6 and RCP8.5 scenarios. 


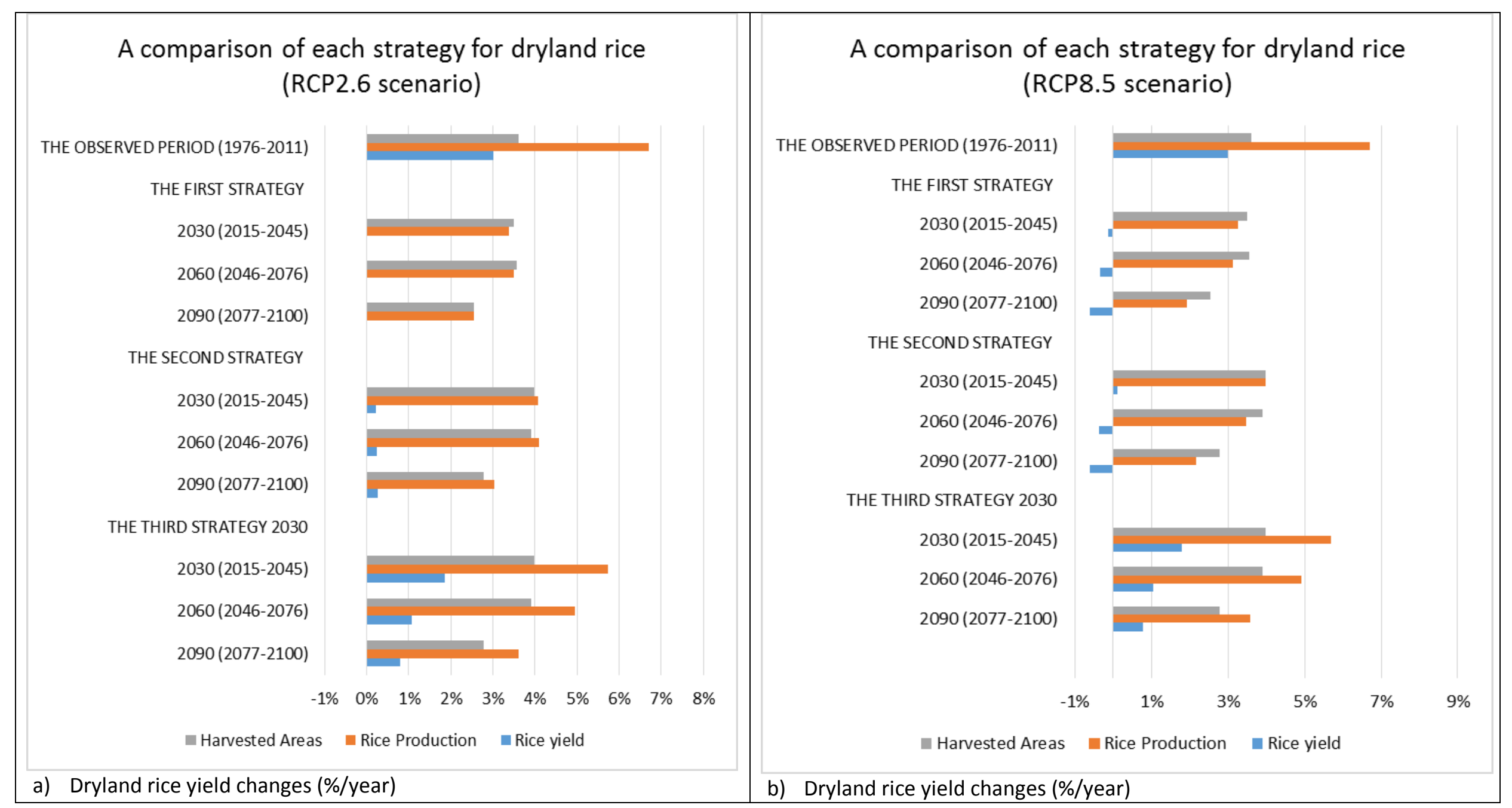

Figure 7.15 A comparison of strategies' results and the observed period for dryland rice under RCP2.6 and RCP8.5 scenarios 
Likewise, RCP8.5 scenario (i.e. the least mitigated scenario) projects declining rice yields under the first and second strategy, however, rice production will probably increase owing to larger harvested areas. However, an increase in rice production in the first strategy and the second strategy is projected to be lower than that in the observed period.

The third strategy will probably produce relatively similar increases in rice production, compared to those in the observed period (1976-2011). Assuming there is no change in rice consumption per capita and that population growth by 2090 (2077-2100) will be relatively similar to the observed period (1976-2011), the third strategy will probably sustain the status of WNT as a self-sufficient region in rice and one of the national hosts for rice production under RCP8.5 scenario. Likewise, another study (GRiSP, 2013) suggests that annual growth of rice yield of about $1 \%^{52}$ is needed to balance rice supply and rice demand beyond 2020, meaning that the third strategy is likely to balance rice demand and rice supply in the future.

\subsection{Summary}

This chapter has assessed the benefits of three policy options for increasing rice production under a changing climate. A policy experiment of rice varieties with higher yields (section 7.2.2) tends to increase rice yields but offers a lower rice production compared to that of short growth duration (section 7.2.1). However it appears that a policy of rice varieties with shorter growth duration would lead to a higher rice production due to a higher cropping intensity (i.e higher crop rotations).

This chapter also demonstrated that the policy experiment of heat tolerant rice varieties (section 7.2.3), compared to other policy options, leads to a higher yield. Likewise, this policy also leads to a higher rice production if heat tolerant rice varieties are found by 2030 .

As climate change leads to frequent climate extremes and high temperatures, developing rice varieties with multiple benefits such as varieties with a high yield and SGD is very

\footnotetext{
${ }^{52}$ Existing studies such as Maclean, Dawe, Hardy \& Hettel (2002) and GRiSP (2013) suggest that the growth of rice yield should be higher than population growth to balance rice demand and rice supply. GRiSP (2013) also states that Indonesia's population growth will be less than 1\%/year beyond 2015 .
} 
useful. Owing to this, strategies combining policies are tested under different climate projections.

Section 7.5 described and compared outputs of each strategy in minimising the negative impacts of climate change on rice supply. The second strategy leads to a higher yield and a higher rice production by 2090 (2077-2100), compared to those in the first strategy (section 6.7.3) under RCP 2.6 (the highest mitigated scenario) and RCP8.5 (the least mitigated scenario). However, the second strategy will probably lead to lower rice production compared to those in the observed period under the RCP2.6 and RCP8.5 scenarios.

The best strategy for minimising the negative impacts of climate change is to combine three policy options, including short-growth duration, high yield and heat tolerant varieties: in other words, this study's third strategy. The third strategy results in an increase in rice yield and an increase in rice production growth under a changing climate, e.g. RCP8.5 scenario by 2090 (2077-2100).

If the third strategy is conducted, the RCP8.5 scenario projects that farmers will probably experience a higher rice yield and a higher rice production, compared to those in other strategies. The third strategy will also probably sustain the WNT's status as a selfsufficient region in rice and one of the national hosts for rice production under a changing climate. 
this page intentionally left blank 


\section{CHAPTER 8 \\ CONCLUSIONS}

Rice is the most popular staple food in Asia and covers about $90 \%$ of total farming areas in Asia (GRIsP, 2013). Rice is also an important source of employment and economy in the region (Gmamanickam, 2009; GRIsP, 2013). Owing to economic development and growing population, rice demand will increase significantly over the next 40 years (GRIsP, 2013; Zeigler, \& Mohanty, 2010). This means that understanding the impacts of climate change on rice production is important, especially for developing countries as they have limited capacity to tackle the negative impacts of climate change (Chijioke, Haile \& Waschkeit, 2011; FAO, 2003; GRIsP, 2013, IFRRI, 2009).

As the world continues to warm, rice growing areas around the world will contend with the impacts of climate change. In particular, Asian rice production may be seriously affected as the minimum temperature has already reached its rice temperature threshold of $21^{\circ} \mathrm{C}$ (Peng et al., 2004), and recent maximum temperature is relatively close to its maximum temperature threshold of about $35^{\circ} \mathrm{C}$ (Devkota, 2011). Owing to this, the negative effects of climate change on rice production (such as the negative impacts of high temperature) should be studied in order to find policy options under a changing climate.

Rice production will probably be more vulnerable in future as climate change is not only associated with higher temperatures but also with climate extremes such as dry spells, heat waves, and prolonged droughts or wet days (IPCC, 2013). Likewise, ENSO, which will continue to be a dominant climate variable in the future (IPCC, 2013), will probably continue to influence the rice production.

Sustaining and increasing rice production under a changing climate relies on the results of climate change impact studies. This research helps stakeholders find appropriate options for sustaining rice production under a changing climate. Most existing studies 
have focused on the impacts of climate change on rice yield, and have overlooked the impacts of climate change on rice production and harvested areas.

Most previous studies eg. Müller et al. (2015), Deryng et al. (2016) and Deryng (2014) also fail to include analysis of rice research policies such as short-growth duration varieties, high yield varieties and heat tolerant varieties. Likewise, those studies did not analyse combined policies under a changing climate, such as short-growth duration of high yield varieties - i.e the second strategy (section 7.4 and 7.5).

In order to fill this research gap, this study investigated the impacts of climate change on rice production in West Nusa Tenggara, Indonesia. The study considered the expanding of harvested areas and assessed the impacts of climate change on rice yield, rice production and harvested areas by 2090 (2077-2100). It also investigated possible options for minimising the impacts of climate change on rice production and supply uncertainties.

By combining statistical analysis and the SD modelling, this study focused on the research question: How will climate change and climate variability affect rice production in WNT, Indonesia? and two additional research questions: 1) What are the most significant supply uncertainties associated with a changing climate? and 2) What are possible solutions to reduce impacts of climate change on rice production?

In answering these research questions, this chapter explains the benefits of combination of statistical analysis and the SD modelling used in this study. Following this, section 8.2 explains three possible impacts of climate change on rice yield, rice production and harvested areas by 2090 (2077-2100). Afterwards, section 8.3 explains the most significant rice supply uncertainty under a climate change. Policy options for minimising the impacts of climate change on rice production are described in section 8.4. Finally, theoretical and practical contributions are explained, followed by limitations of the study and possible future research. 


\subsection{Combination of statistical analysis and the SD modelling}

Statistical analysis provides some useful findings for assessing the impacts of climate change in the future. Most importantly, statistical analysis provided this study with quantitative models for estimating the impacts of climate change on rice yield in wetland and dryland farming. Likewise, statistical models described in chapter 5 demonstrate that during the observed period (1976-2011), the roles of technological progress in supporting rice yield are statistically significant (section 5.3.3). Statistical models also explained that the impacts of climate, in particular the negative impacts of high minimum temperature on rice yield will probably be more pronounced than the impacts of seed on dryland rice yield or than the impacts of labour on wetland rice yield (section 5.4.1).

During the observed period (1976-2011), maximum temperature and seasonal rainfall has had an insignificant impact on rice yield. The highest maximum temperature in the observed period (1976-2011) was about $32^{\circ} \mathrm{C}$ which is lower than $35^{\circ} \mathrm{C}$, a rice threshold for maximum temperature (Welch et al., 2010). Likewise, as wetland farming is surrounded by irrigation facilities, the impacts of seasonal rainfall on rice yields are not statistically significant (Wang et al., 2012).

For dryland farming, rainfall tends not to affect yield of dryland rice as monthly rainfall during growing seasons mostly was above 100 mm/month (BMKG NTB, 1976-2012). This finding corroborates another existing study (Yunizar, 2004) which explains that dryland farming is successful when monthly rainfall is about $100 \mathrm{~mm} / \mathrm{month}$ and this also is underpinned by another study (Wirajaswadi, 2004) suggesting that a higher rainfall than $100 \mathrm{~mm} /$ month has an insignificant impact on dryland rice.

Statistical models, however, should be augmented by the SD approach (Sommer, 1984a; 1984b) when estimating the negative impacts of climate change on rice production, given that statistical models cannot capture the impacts of maximum temperature on rice yields and cannot capture the negative impacts of minimum temperature if it far exceeds historical minimum temperature (Lobell \& Burke, 2010). 
Statistical models cannot capture the negative impacts of maximum temperature because the highest maximum temperature in the observed period (1976-2011) was about $32^{\circ} \mathrm{C}$ which is lower than $35^{\circ} \mathrm{C}$, a rice threshold for maximum temperature (Welch et al., 2010). Statistical models should be replaced if projected temperature is higher by about $1^{0} \mathrm{C}$ than the highest observed temperature (Lobell \& Burke, 2010). Because the highest observed minimum temperature (1976-2011) was about $23.7^{\circ} \mathrm{C}$ and the highest projected minimum temperature by 2090 (2077-2100) is about $27^{\circ} \mathrm{C}$, the SD model follows Zhang et al. (2013) in estimating the impacts of minimum temperature on rice yield by 2090 (2077-2100).

Chapters 6 and 7 show that the SD approach offers benefits for assessing the impacts of climate change on rice production. Firstly, the SD approach can be used to estimate the impacts of high maximum temperature and the impacts of high minimum temperature on rice yield by 2090 (2077-2100).

Secondly, SD can capture non-linear relationships that might occur in climate change impact studies. For example, the SD model can capture non-linear impacts of the August SOI on the timing of monsoon onset. Figure 6.8 describes the non-linear relationship between August SOI and the timing of monsoon onset. Moreover, figure 6.16 shows that a delayed monsoon onset can decrease rice production through decreased harvested areas.

Thirdly, a SD model can simulate the integrated impacts of climate change on rice production, including the simultaneous impacts of climate change on rice yield, rice production and harvested areas. This is very important as studies using crop models usually simplify or make questionable assumptions. For example, existing studies such as Deryng et al. (2016) and Wang (2014), assess the impacts of climate change with an assumption of fixed harvested areas. Also, SD can capture the impacts of climate change by considering the dynamics of harvested areas. Section 6.7.2, for instance, explains the impacts of climate change on rice yield, rice production and harvested areas simultaneously. 
Fourthly, SD modelling can simulate the benefits of different rice breeding policies. Chapter 7 demonstrates the benefits of each policy, such as short-growth duration varieties and higher yield varieties (section 7.21-7.2.3). Section 7.2 explains that heat tolerant policies offer a higher yield and higher rice production than short-growth duration and high yield policies. Chapter 7 also describes the benefits of each strategy under a changing climate (section 7.3.1-7.3.2). Likewise, section 7.4 and 7.5 compare outputs under given strategies.

This study explains important points regarding the combining of statistical analysis and the SD approach. The first point is that the SD model incorporates the statistical models of rice yield to drive other outputs including rice production and harvested areas. For example, when projected minimum temperature of different RCP scenarios is put into statistical models, they only estimate projected rice yield, while the SD approach provides dynamics outputs of rice production and harvested areas.

The second point is that the SD approach should be used when statistical analysis fails to find significant correlations between important independent variables and dependent variables or when projected independent variables or future inputs are unobservable in the observed period (Sommer, 1984a; 1984b). For instance, the SD approach embeds the impacts of maximum temperature based on existing studies (section 6.7) as statistical analysis does not find a significant correlation between maximum temperature and rice yields. Another fact of note is that the SD approach uses findings from Zhang et al. (2013) in which projected minimum temperature is far higher than the highest observed minimum temperature.

The third point is that the combination of statistical analysis and the SD approach leads to more effective policy implications. As explained earlier in this section, the SD approach can provide multiple dynamic outputs such as harvested areas and rice production at any given time. The combination also leads to simulations of different mixed policies such as short-growth duration of high yield varieties, i.e the second strategy and the third strategy (section 7.4-7.5). 


\subsection{The impacts of climate change on the rice production}

Chapters 6 and 7 show three possible impacts of climate change on rice production under a changing climate in West Nusa Tenggara. The first is the negative impacts of climate change on rice yield. By 2030 (2015-2045) and 2090 (2077-2100), RCP4.5 scenario projects that rice yield loss in wetland farming will be about 3\% (1\%-4\%) $)^{53}$ by 2030 (2015-2045) and 6\% (3\%-8\%) by 2090 (2077-2100). For the same periods, RCP4.5 projects that dryland rice loss will be about $2 \%(1 \%-4 \%)$ and $4 \%(2 \%-8 \%)$. As shown in figure 6.28a-6.28b, the RCP8.5 scenario (the least mitigated scenario) projects that rice yield in wetland and dryland will probably lose about 15\%-20\% from 2030 (2015-2045) to 2090 (2077-2100), compared to those in the basecase scenario.

The negative impacts of climate change on rice yield are relatively similar to the negative impacts of climate change on rice production. The RCP4.5 scenario projects that, by 2030 (2015-2045) and by 2090 (2077-2100), wetland rice production loss will probably be about $2 \%(3 \%$ to $+3 \%)$ and $2 \%(0 \%-6 \%)$ respectively. Dryland rice production will probably be lower by about 3\% (1\%-3\%) and 3\% (2\%-8\%) by $2030(2015-2045)$ and by 2090 (2077-2100) respectively under the RCP4.5 scenario. The least mitigated scenario (i.e RCP8.5 scenario) projects that rice production in wetland and dryland will probably be lower by about $20 \%(3 \%-45 \%)$ by $2090(2077-2100)$ as shown in figure $6.28 \mathrm{c}-6.28 \mathrm{~d}$.

By contrast, climate change leads to an increase in harvested areas. RCP6.0 scenario and RCP8.5 scenario project that wetland harvested areas will probably increase about 3\%$10 \%$ from 2030 (2015-2045) to 2090 (2077-2100). All descriptions in this section can also be seen in section 6.7.3.

Figure 8.1 describes the impacts of climate change on total rice production, rice yield and harvested areas compared to those in the basecase scenario. In the context of total rice production, this study arrives at relatively similar results to those described in previous paragraphs of this section. As expected, RCP4.5 projects that total rice production will

\footnotetext{
${ }^{53}$ The bracket includes $5^{\text {th }}$ and $95^{\text {th }}$ percentile climate predictions. This is applied for all brackets in this chapter
} 


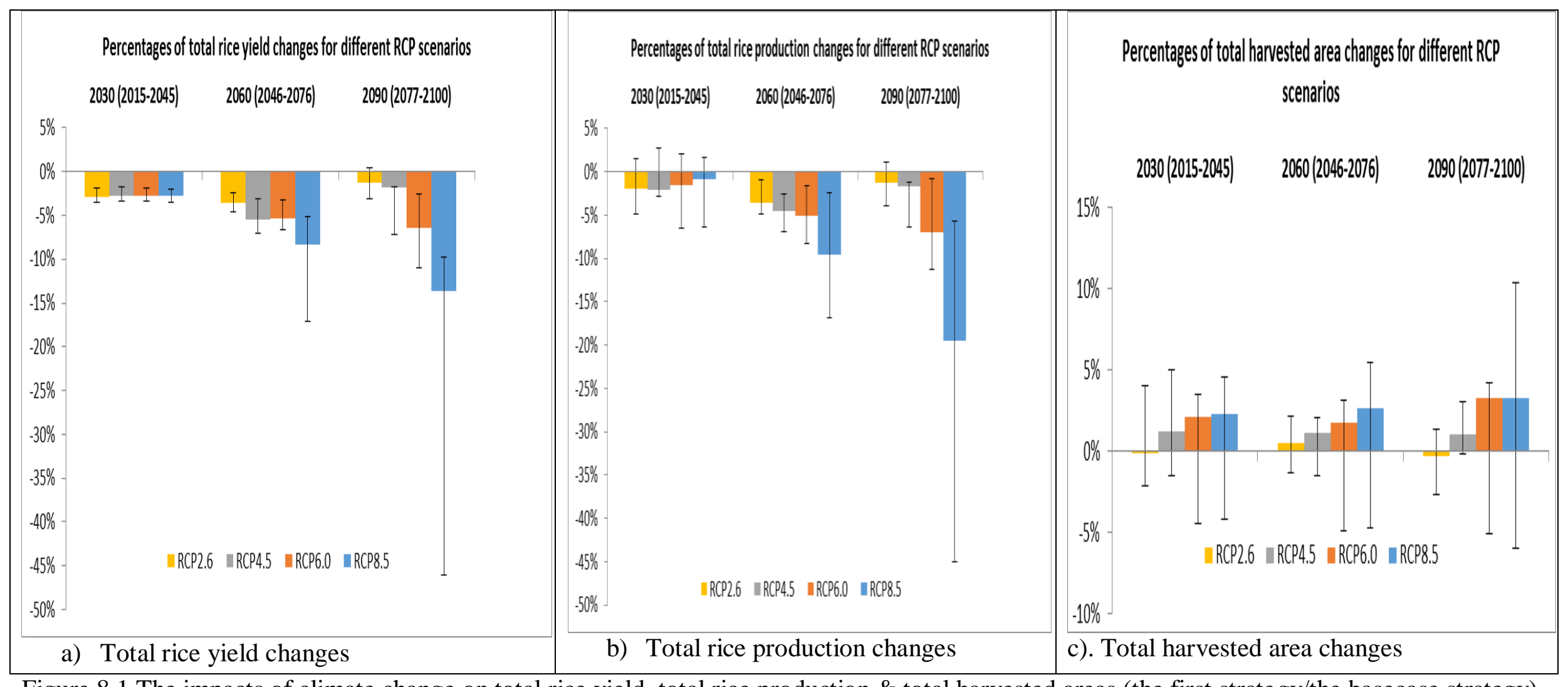

Figure 8.1 The impacts of climate change on total rice yield, total rice production \& total harvested areas (the first strategy/the basecase strategy) Note: vertical lines are error bars based on $5^{\text {th }}$ and $95^{\text {th }}$ percentile of climate projections 
probably be lower by about 2\% (1\%-6\%) by 2090 (2077-2100) under the first strategy (i.e the basecase strategy), owing to a projected loss of total rice yield of about $2 \%$ (2\%$7 \%$ ) by 2090 (2077-2100). On the other hand, RCP4.5 projects an increase in total harvested areas of about $1 \%(0 \%-2 \%)$ by 2090 (2077-2100), compared to that of the basecase scenario.

\subsection{The impacts of climate change on the rice supply uncertainties}

This section describes the impacts of climate change on inherent uncertainties in the rice supply chain. The first uncertainty is the impact of climate change on rice production, the second is the impact on rice yieldm, and the last is the impact on delayed planting seasons. All these impacts are categorised as inherent uncertainties in supply side (Vorst, Beulens, Wit, \& Beek, 1998) as shown in table 8.2. It should be noted that supply uncertainty is a situation when policy makers or decision makers are not certain about the amount of supply or when supply will be delivered.

\begin{tabular}{|c|c|c|}
\hline Production Uncertainty & Quantity & Time \\
\hline The supply Side & rice supply; rice & earlier or delayed planting \\
& yield & seasons \\
\hline
\end{tabular}

Table 8.1 Inherent rice supply uncertainties

Based on the negative impacts of climate change in section 6.7.3 (also in section 8.2), this study concludes that the ranking of the impacts of climate change from the most significant to the least significant is its impact on rice yield, rice production and harvested areas by 2090 (2077-2100). It seems that climate change mainly tends to increase supply uncertainty. It also should be noted that delayed planting seasons also lead to smaller harvested areas, leading to a lower rice production.

\subsection{Strategy analysis}

Figure 8.2 depicts a comparison of total rice yield, total rice production and total harvested areas in WNT for each strategy and the observed period (1976-2011) under the RCP2.6 and RCP8.5 scenarios respectively. Assuming no adaptation (i.e the basecase strategy), WNT might not hold the status of a self-sufficient region in rice and a rice supplier (for its neighbouring regions) as projected total rice yield, projected total 


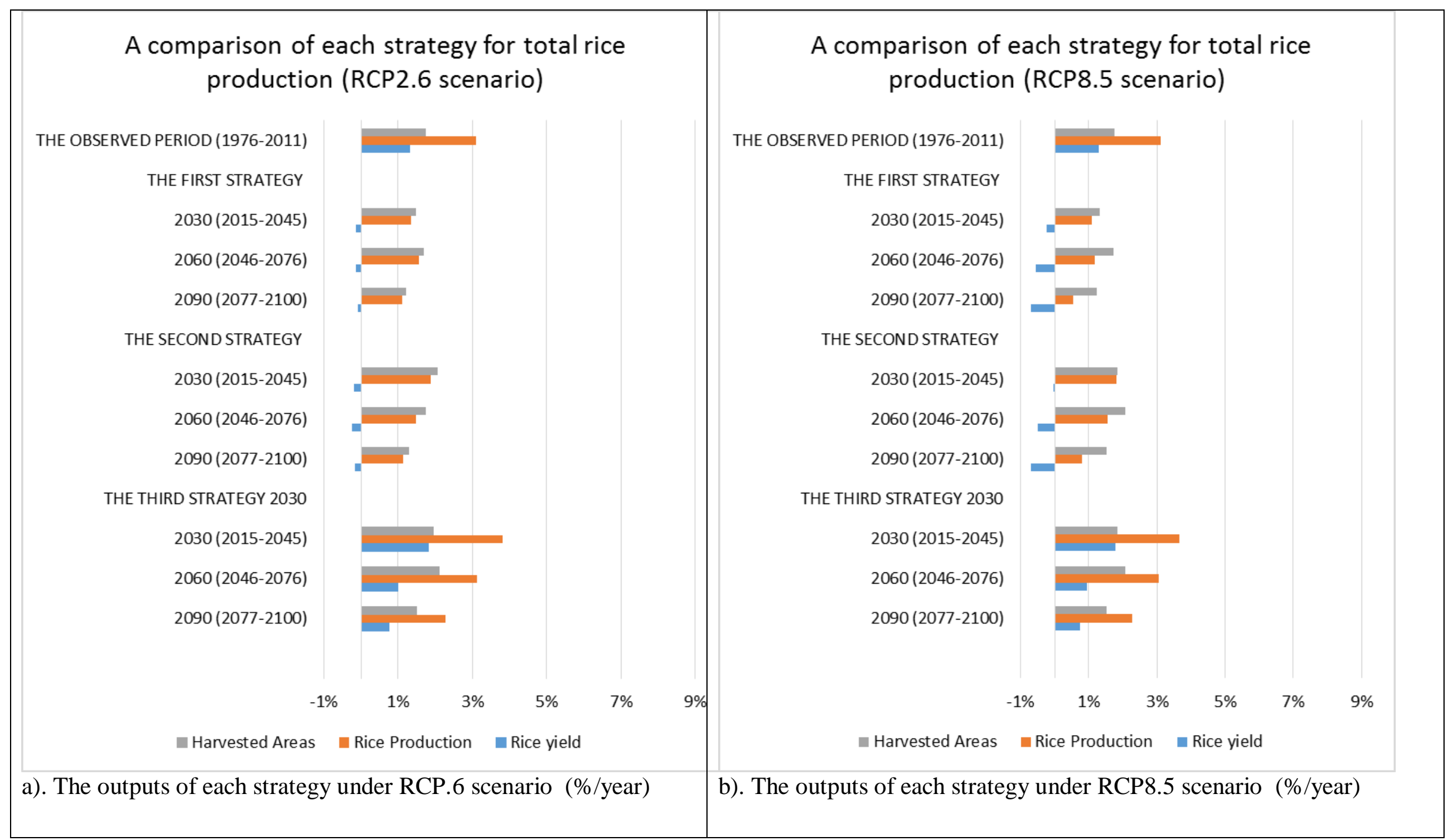

Figure 8.2 A comparison of total rice yield, total rice production and total harvested areas (RCP2.6 vs RCP8.5) 
harvested areas and projected total rice production by 2060 (2046-2076) and by 2090 (20772100) will probably be lower than those in the observed data (1976-2011).

Since the two first strategies will probably experience lower growth of total rice production under a changing climate, the first and the second strategy will probably lead to a rice shortage, assuming no changes in rice consumption per capita or in population growth compared to the observed period (1976-2011).If rice scientists cannot find heat tolerant rice varieties by 2030, the government might import rice to balance total rice production and total rice demand under the RCP2.6 scenario. The rice import might be smaller than that under RCP8.5 scenario.

Since the second strategy leads to an increase in total rice yield under the RCP2.6 scenario, the second strategy can save government funding on farmer subsidies (Wahyuni \& Indraningsih, 2016). It should be noted that most rice farmers are small-scale farmers, i.e poor farmers (BPS, 2015), so they depend significantly on the government subsidy.

The third strategy leads to the highest outputs compared to other strategies. This strategy can sustain total rice yield and total rice production under a changing climate by 2090 (20772100), compared to those in the observed period (1976-2011). This is also supported by another study (GRiSP, 2013) suggesting that annual growth in rice yield of about $1 \%$ is needed to balance rice supply and rice demand beyond 2020 .

In addition to the third strategy, combining different traits of rice varieties such as shortgrowth duration, high yielding and heat tolerance can help farmers to reduce the negative impacts of climate change. For instance, rice varieties that have multiple traits such as shortgrowth duration and high yield might save themselves from multiple stresses such as droughts and high temperature respectively. Another possible benefit of the third strategy is that it may be able to decrease the government subsidy for rice farmers due to high rice yields.

Table 8.2 describes the highest rice yield in wetland and dryland for the given strategies. As seen in table 8.2 , the second strategy will probably result in higher yields compared to those 
in the first strategy, but lower than those in the third strategy. It should be noted that the highest rice yields are those under the RCP2.6 scenario.

\begin{tabular}{|c|c|c|c|}
\hline Strategies & $\begin{array}{c}2030 \\
(2015-2045)\end{array}$ & $\begin{array}{c}2060 \\
(2046-2076)\end{array}$ & $\begin{array}{c}2090 \\
(2077-2100)\end{array}$ \\
\hline $\begin{array}{l}\text { The basecase strategy } \\
\text { This resembles the period prior to } 1970 \text { s } \\
\text { and the period 1996- } 2011 \text { when an } \\
\text { increase of rice production only depended } \\
\text { on area expansion (this strategy is } \\
\text { simulated in section 6.7.2). }\end{array}$ & $5.18 / 3.64$ & $5.15 / 3.62$ & $5.15 / 3.62$ \\
\hline $\begin{array}{l}\text { The second strategy } \\
\text { This resembles the period 1970s-1995 } \\
\text { when rice breeding was higly intensified } \\
\text { owing to high rice demand (this strategy } \\
\text { is simulated in section 7.4). } \\
\text { This strategy assumes that rice varieties } \\
\text { have two main traits including high yield } \\
\text { and short-growth duration. }\end{array}$ & $5.39 / 3.77$ & $5.84 / 4.05$ & $6.34 / 4.35$ \\
\hline $\begin{array}{l}\text { The third strategy } \\
\text { This strategy similar to the second } \\
\text { strategy, however, rice varieties have } \\
\text { three traits including heat tolerance, high } \\
\text { yield and short-growth duration. } \\
\text { This aims to face an increase in } \\
\text { temperature owing to climate change. }\end{array}$ & $6.95 / 4.73$ & $10.21 / 6.64$ & $10.77 / 6.98$ \\
\hline
\end{tabular}

Table 8.2 The highest rice yield for each strategy in each period (wetland/dryland)

A useful indicator used to measure the possible highest rice yield is agronomic yield potential or research yields (Papademetriou et al., 2000). Yield potential is the highest yield under a controlled environment, i.e a controlled climate and controlled crop management (Papademetriou et al., 2000). Under a controlled environment, Doberman (2004) and Horie et al. (1994) suggest that rice yield in the tropics can increase by up to 13 tonnes/year*ha and 14 tonnes/year*ha respectively. As the third strategy suggests that rice yield can be increased by about 11 tonnes/year*ha by 2090 (2077-2100) (as shown in figure 7.14a$7.14 \mathrm{~b}$ ), i.e lower than rice yield potential, the third strategy is a reliable strategy for minimising the impacts of climate change on rice production by 2090 (2077-2100) (Gurdev S. Khush, personnel communication, October $\left.29^{\text {th }}, 2016\right)$. 
The gap between actual yield and yield potential is due to biophysical constraints such as pest and disease attacks and physical constraints such as prolonged droughts and temperature stress (Papademetriou et al., 2000). In the third strategy, new rice varieties resistant to environmental stresses such as prolonged droughts (minimised by short-growth duration varieties), pest/disease attacks, toxic soil (minimised by high yield varieties) and high temperature (hindered by heat tolerant varieties) are developed, narrowing the gap between recent rice yield and its yield potential. In other words, developing rice varieties with three traits including short-growth duration, high yield and heat tolerance up to 11 tonnes/ha*year by 2090 (2077-2100) is a reasonable strategy (Gurdev S. Khush, personnel communication, October $29^{\text {th }}$, 2016).

\subsection{Theoretical contributions}

There are many studies which have assessed the impacts of climate change and climate variability on Indonesian rice production (e.g Naylor et al. (2007) and Naylor \& Mastrandea (2009)). However, those studies did not investigate the impacts of temperature and rainfall change on Indonesian rice production. This study contributes to a better understanding of the impacts of climate change and climate variability on Indonesian rice production.

In terms of statistical analysis, this study also contributes by introducing dummy variables in assessing the impacts of climate change on rice yield. This study uses dummy variables in estimating structural breaks on rice yield. Cereals such as rice and wheat usually experience structural changes as cereal yields have been influenced by government policies and technology adoptions between the 1960s-2000s (Cassman, Dobermann, Walters, \& Yang, 2003). Although existing studies, e.g Lobell et al. (2011), have applied statistical models in assessing the impacts of climate change, they did not use coefficients representing structural changes in cereals.

There are existing studies that explain the negative impacts of high minimum temperature on rice yield (Peng et al., 2004; Welch et al., 2010; Zhang et al., 2013a) and the negative impacts of high maximum temperature on rice yield (Hatfield \& Krueger, 2015; Kim, 1996; Luo, 2011). Other studies describe the impacts of production factors on rice yield, for example, the significant impacts of labour on wetland rice yield (Kasryno et al., 2004) and the significant impacts of seed on dryland rice yield (BPTP, 2011; Kasryno et al., 2004; 
Wirajaswadi, 2004). This contribution of this research is to convert those existing studies into a causal system for analysing the impacts of climate change on rice production, rice yield and harvested areas.

This causal system consists of some relevant factors that influence rice yield, harvested areas, and rice production. The causal system can be divided into three main parts: rice yield (figures 6.5a-6.5b); rice harvested areas (figures 6.6a-6.6b) and rice production (figures 6.7a-6.7b). The first part explains the impacts of known factors such as the impacts of minimum temperature and technological progress on rice yield. The second part includes important factors such as rice farming areas and cropping intensity which interact with each other to estimate harvested areas. The third part of the causal system, i.e rice production, involves August SOI and growth duration of rice varieties which are used to measure rice production. In the context of policy scenarios, the causal system offers another important contribution. That is, this study complements the causal system with three policies including the short-growth duration variety policy, the high yield variety policy, and the heat tolerant variety policy as described in chapter 7 .

As explained in chapter 2, a number of studies use the SD approach to assess the impacts of climate change on crop production (Kopainsky et al., 2013) and on livestock (Adl \& Parvizian, 2009). However, this study goes further by focusing on understanding the impacts of climate change on rice yield and on rice production. In turn, the causal system contributes to a growing literature on the use of the SD approach for assessing the impacts of climate change on rice production.

Statistical models and crop models are regular methods used in assessing the impacts of climate change on crop yield (Lobell \& Burke, 2010). Using statistical models, a number of studies (Naylor et al., 2001; 2002; Falcon et al., 2004) analysed the impacts of ENSO on Indonesian rice production in Java and Bali. Other existing studies e.g Lobell et al., 2011 focused on the impacts of climate change on rice yield. Another study (Naylor et al., 2007) focused on the impacts of ENSO (i.e the timing of monsoon onset on rice production).

The combination of statistical analysis and the SD approach used in this study simultaneously investigates the impacts of climate change on rice yield, rice production and 
harvested areas. This means that this study provides a more holistic view of the impacts of climate change compared with the above cited-studies.

\subsection{Practical contributions}

This research makes contributions to policy and practice in WNT, especially in assessing the impacts of climate change on rice production. Through statistical analysis, this study confirms that the inputs of labour and seed in rice farming areas is already optimal (section $5.4 .1)$.

Statistical analysis also shows that wetland rice experienced a structural change in 1996 which was caused by decreased rice research funding (Zeigler \& Mohanty, 2010). This should warn policy makers to increase funding for the research of rice breeding under a changing climate. For dryland rice, a structural change tells policy makers that P2BN (the National Program for Rice Production) has been effective in increasing dryland rice yield since 2008 .

This study has focused on three impacted factors under a changing climate, namely rice yield, rice production and rice-harvested areas. This study also emphasises the need to conduct the research of the impacts of climate change on three important issues including, crop yield, crop production and harvested areas. As seen in section 6.7.2, section 7.4, and section 7.5 , climate change will probably not only influence rice yield but also the total size of harvested areas.

This study also informs policy makers that farming extension (i.e area expansion) will probably not be effective in minimising the impacts of climate change on rice production. Rather, farming intensification (i.e developing more resilient-climate rice varieties) will probably be the more effective option in tackling the negative impacts of climate change on rice production.

Two strategies - the business as usual scenario and the short-growth duration of high yield varieties (i.e the second strategy) - will not be sufficient for sustaining rice production under the expected changing climate scenarios considered by this thesis. In turn, this study informs policy makers that improved rice varieties should have three traits: SGD, heat tolerance, and 
high yield in order to minimise the impacts of climate change on rice production by 2090 (2077-2100). This study also concludes that sustaining and/or increasing rice production by 2090 (2077-2100) is possible as increasing rice yield up to potential yields of 11 tonnes/ha*year by 2090 (2077-2100) is plausible as described in section 8.3.

\subsubsection{Creating system innovation to support rice breeding research}

Agriculture is considered to be an industry in need of systemic innovation (de Bruijn, van der Voort, Dicke, de Jong \& Veeneman, 2004). In most cases, the business as usual scenario is not sufficient to solve current problems. A successful system innovation should be supported by three entities: system science, system government and system market (de Bruijn et al., 2004). System science can support the system innovation with scientifically viable knowledge, while system government can provide some suitable policies in supporting the system innovation. System market, on the other hand, can support system innovation through funding availability.

A successful system innovation can be initiated by at least two entities: either system market and system government or system science and system government (de Bruijn et al., 2004). Afterwards, the other system can join the system innovation (de Bruijn et al., 2004). The successful system innovation is also initiated under an emergent situation (de Bruijn et al., 2004).

An example of this is the Green revolution of the 1970s-1990s. The Green revolution was ignited by a possible food shortage due to a rising population: in other words, an emergent situation (Khush, 1987; 2005; Estudillo \& Otsuka, 2013). The Green revolution was supported by chemical corporations in developing modern rice varieties (Shiva, 1988; 1991). These modern rice varieties increased rice production rapidly around the world and including Indonesia, leading to a higher rice production compared to rice demand during the period (Khush, 1987; 2005; Estudillo \& Otsuka, 2013).

The Green revolution was initiated by two systems: system market (chemical corporations) and system science (rice scientists and research institutions such as IRRI). Afterwards, system governments around the world supported the Green revolution. For the first time, 
system market (chemical corporations) and system science (rice scientists) worked together to find improved rice varieties, i.e higher yield varieties. Later, governments such as the Indonesian government supported the Green revolution owing to a higher rice demand.

In more recent times, supporting conditions for increasing the funding of rice breeding research (as a system innovation) have been identified. Possible climate change threats such as rice yield loss and rice production loss might lead to an emergent situation such as a rice shortage. Likewise, there are a lot of people around the world facing a possible rice shortage under a changing climate, leading to research collaborations around the world.

Successful system innovations are usually started by two systems such as system market and rice scientists or system government and rice scientists. A recent study (Ye et al., 2015) in developing heat tolerant varieties has been supported by a corporation: Microsoft inc. through The Bill and Melinda Gates foundation. Current rice breeding technology has a real potential to succed as research on the breeding of heat tolerant varieties has been supported by system scientists in IRRI and system markets like Microsoft.

In the context of system innovation, a practical contribution of this study is to inform policy makers that there is an emergent situation; that is that rice production will probably be lower than rice demand under a changing climate. In other words, if rice breeding research for developing rice varieties is not supported, a rice shortage will probably occur under a changing climate.

\subsubsection{Managerial implications in the global and the local contexts for the agrifood supply chain}

Since the rice supply highly depend on climate fluctuation, the supply chain managers should encourage the application of planting calendar. The planting season calendar will help farmers to prevent from unfortunate climate condition owing to El-Niño Southern Oscillation (ENSO). The calendar provides information about the beginning of planting seasons which is updated regularly (Badan Penelitian dan Pengembangan Pertanian, 2013; Iakovou, Bochtis, Vlachos, \& Aidonis, 2016). 
Since rice yield is projected to experience the worst impacts of climate change, rice supply chain managers should encourage rice-breeding research in developing heat tolerance rice varieties. This also is supported by section 8.6.1 as follows: "In the context of system innovation, a practical contribution of this study is to inform policy makers that there is an emergent situation; that is that rice production will probably be lower than rice demand under a changing climate". In other words, if rice breeding research for developing rice varieties is not supported, a rice shortage will probably occur under a changing climate". This should encourage supply chain managers to support funding research in developing more resilient varieties.

Because the climate change is projected to negatively influence rice yield significantly, supply chain managers should be aware the implications of buying more land (farming extension or area expansion) to sustain rice supply as extended farming areas are not a properly long-term option under a changing climate (Lobell \& Burke, 2010) but developing more climate-resilient varieties (Lobell \& Burke, 2010).

The modelers of the real world usually face constraints such as budget and time (Rahmandad $\&$ Sterman, 2008). This study shows that the combination of statistics and system dynamics approach can analyse the impacts of climate change with limited data compared to crop models. Rice supply chain managers should use the combination of system dynamics and statistics in understanding the impacts of climate on their supply chain to save time and funding. As the application of system dynamics may provide multiple outputs, rice supply chain managers can use the SD approach to analyse different impacts of climate change throughout their supply chain.

It should be noted that as main crops including rice, corn and wheat are vulnerable to climate change (Lobell \& Burke, 2010; Lobell et al., 2011; Lobell et al., 2008; Lobell \& Asner, 2013). Managerial implications explained in this section are also beneficial for the global agrifood supply chain, especially maize, rice and wheat. 


\subsubsection{Some learning lessons for the global and the local contexts}

There are some learning lessons can be taken from this study in the global and local context of the rice supply chain or the agrifood supply chain. This sections begins with a comparison between approaches used in the agrifood or rice supply chain compared with the approach used in this study. How the approach used in this study helps the rice supply managers in understanding the impacts of climate change are explained prior to policy change impacts.

\section{- A comparison of existing approaches and the combination of statistics and the SD approach}

There are some approaches used in analysing the agrifood supply chain. These approaches are qualitative, quantitative and simulation (Aslam, \& Ng; 2015; Campuzano \& Mula 2011; Ghadge, Dani, Chester, \& Kalawsky, 2013). Quantitative approaches might use various mathematical models (Aslam, \& Ng; 2015; Ghadge et al., 2013). Qualitative models, at one hand, are usually collecting respondent opinions through surveys or interviews (Thongrattana, 2010; Ortiz-Monasterio \& Lobell, 2005).

Both approaches are useful approaches in analysing the agrifood supply chain. For example, after collecting respondent questioners, some studies such as Thongrattana (2012) and (Thongrattana, Jie, \& Perera, 2009) explain some important uncertainties in rice supply chain. Another instance, using quantitative approaches, some existing studies (Dabbene, Gay, \& Sacco, 2008; Hasan, 2010) analyse the agrifood supply chain and provide some suggestion to decrease supply chain uncertainty in the agrifood supply chain. Although both approaches are useful in analysing the agrifood supply chain, especially the supply chain uncertainty in the agrifood supply chain, both approaches should be used with further notices as explained in next paragraphs.

Qualitative approaches such as interviews and questionnaires are useful to understand respondents' perspectives, for instance, on climate change impact studies (Lobell \& Burke, 2010; Thongrattana, Jie, \& Perera, 2009). However, qualitative models may lead to biased results as what perceived by respondents may not represent the main issues. For instance, although farmers in Mexico agreed that there were temperature shifts, surveys show that Mexican farmers did not realise that temperature shifts were a main cause of declined yield (Ortiz-Monasterio \& Lobell, 2005). This means that qualitative approaches are not sufficient 
to analyse and develop proper policies in tackling the negative impacts of climate change on crop supply as outputs of qualitative approaches may be cognitive biases (Lobell \& Burke, 2010).

Based on methodical steps and robust assessment, quantitative approaches can quantify the effects of input on intended output based on observed system or observed data. But, quantitative approaches may simplify the real world (Ghadge et al., 2013; Hong 2005; Sterman, 2000). The real world is also too complex to be converted to mathematical formulations as the real world may involve feedback process, delay and dynamic of system (Sterman, 2000).Hence, quantitative approaches are incapable of incorporating the dynamic behavior and complexities of systems or processes such as supply chains (Campuzano, \& Mula 2011; Ghadge et al., 2013; Hong 2005; Sterman, 2000).

- How the combination of statistics and SD approach helps the managers to understand the impacts and assess possible options under a changing climate in the local and global level

The combination of statistics and SD approach is a promising method to analyse the supply chain uncertainty (Ghadge et al., 2013; Sterman, 2000). As shown in this study, statistics can be used to conduct supply chain uncertainty assessment based on observed data and the SD approach can be applied to conduct forward analysis of the supply chain uncertainty (Ghadge et al., 2013; PricewaterhouseCoopers, 2008). The SD approach also help policy makers to recognise complex interaction factors and to assess different policies or strategies in observed systems such as the supply chain under different possible scenarios / futures (Aslam, \& Ng; 2015; Turner, Menendez, Gates, Tedeschi, \& Atzori, 2016; Sterman, 2000).

The benefits of the combination of statistics and the SD approach such as statistical analysis of the supply chain uncertainty and assessment of different policies in tackling the supply chain uncertainty can be applied in either in the local level or the global level as explained in following paragraphs.

Moreover, rice farming across the world is categorised to two categorises: wetland (irrigated) and dryland (unirrigated) rice (GRiSP, 2013; Welch et al., 2010; Jagadish et al., 2010). So, the approach used in this study, the combination of statistics and system dynamics modelling, can be used to assess the impacts of climate change on rice supply 
across the world as this study assessed the impacts of climate change two categories of rice farming: wetland and dryland rice. Especially, the impacts of climate change on the farming field of the rice supply chain (the second phase of the rice supply chain based on Hasan's study (2010)).

Maximum temperature and minimum temperature in most Asian countries is relatively close to the threshold of maximum temperature $\left(35^{\circ} \mathrm{C}\right.$ ) (Devkota, 2011, Dietz \& Bidwell, 2011; IPCC, 2013; Welch et al., 2010) and has exceeded the threshold of minimum temperature $\left(22^{0} \mathrm{C}\right)$, (Peng et al., 2004; Welch et al., 2010).

This means that statistical analysis in this study can be applied to estimate the impacts of climate change on Asian rice production i.e. the global rice supply. Furthermore, the SD approach can be applied to assess possible solutions under a changing climate relaxing an assumption of constant harvested areas.

\section{- The impacts of policy changes on the global agrifood supply chain}

Since most important crops including maize, wheat and rice will probably experience yield decreases under a changing climate (Lobell \& Burke, 2010; Lobell et al., 2011; Lobell et al., 2008; Lobell \& Asner, 2013), developing more resilient-climate crop varieties should be a main focus of the global agrifood supply chain (Lobell \& Burke, 2010).

Several research institutions have joined together to start in finding options of sustainable rice supply under a changing climate. This partnership is called the Global Rice Science Partnership (GRiSP) which is the global partnership involving a lot of entities such as rice scientists and national research institutes across the world (GRiSP, 2013). For wheat and maize (or corn), the global partnership information in developing more climate resilient varieties is available in http://www.cimmyt.org/.

The policy changes i.e. developing more climate-resilient varieties explained in this study may advise companies to develop private research and development (R\&D) institutions (Pingali, 2012; Dani 2015). For instance, Monsanto (www.monsanto.com) develops its private $R \& D$ institution to sustain its agricultural supplies through collecting and developing 
high quality genes. Another possible impact is agricultural companies may collaborate with research institutions to develop more climate-resilient varieties (Pingali, 2012).

One long-term option to tackle the negative impacts of climate change is the mitigation of climate change (Lobell \& Burke, 2010). This study shows that higher temperature leads to worse impacts of climate change, so mitigation of climate change may decrease the negative impacts of climate change. Because agriculture activity emits greenhouse gases such as methane (IPCC, 2013; GRiSP, 2013), the agrifood supply chain management introduces the concept of the sustainable food supply chain (Dani, 2015; Iakovou et al., 2016). The sustainable food supply chain tends to decrease greenhouse emission owing to less input and less waste, leading to less greenhouse emission throughout the agrifood supply chain (Dani, 2015; Iakovou et al., 2016).

\subsection{Adaptation by changing cropping pattern}

One possible way to make up any shortfall in food calories/production may be to consider different cereal crops and cropping ptterns. Maize is one such cereal crop (Roberts \& Schlenker, 2009), however this study's findings suggest this may not be feasible for the following reasons.

Throughout Indonesia and WNT, rice is planted between October and June (a higher temperature period) while maize is planted between July-September (a lower temperature period). In general, maize has a lower temperature threshold $\left(29^{\circ} \mathrm{C}\right.$ according to Robert \& Schlenker, 2009; $32^{0} \mathrm{C}$ according to Deryng, 2014) than rice $\left(35^{\circ} \mathrm{C}\right)$. Sowing more maize during October-June would therefore probably not be feasible, given that maize yields will probably be relatively lower.

\subsection{Limitations}

Although this study leads to some important contributions, it has many limitations that are explained in this section. This section also explains limitations of statistical models and climate projections. The limitation of the effects of other climate factors on rice.

Although this study suggests developing short-growth duration varieties to escape climate extremes such as dry spells, heat waves and prolonged droughts, this study does not consider the effects of climate extremes on rice yield. 
The impacts of other climate factors such as humidity and wind spped might be important (Jagadish et al., 2010). For instance, in high midday temperatures, rice can grow well under low humidity (Jagadish et al., 2010). In Australia, rice can grow well when maximum temperature is about $40^{\circ} \mathrm{C}$, owing to high wind speed (Matsui, Kobayashi, Yoshimoto, \& Hasegawa, 2007).

However, the effects of humidity and wind on rice yield are variable and are limited in some regions (de Datta, 1981; Jagadish et al., 2010). In this study, the possible impacts of wind and humidity are not considered as average wind speed in WNT is low ( $2 \mathrm{~m} / \mathrm{second}$; D. Kirono, personal communication, May $\left.24^{\text {th }}, 2017\right)^{54}$ and relative humidity is high and relatively unvarying $(81 \pm 3 \%) \%$ (BPS NTB, 2010; BPS NTB, 2011; BPS NTB, 2012; BPS NTB, 2013; D. Kirono, personal communication, May $\left.24^{\text {th }}, 2017\right)^{55}$.

Statistical models used in this study are based on the observed data and thus the results of statistical models assume that the relationships in the past also apply to the future. Crop management might be changed in the future so the response of the crop to climate may also change.

Climate models and their projections may improve in the future (Lobell \& Burke, 2010). However, uncertainty in climate projections may still exist. Uncertain climate projections stem from climate scenarios and model uncertainty. Although we are free to choose climate scenarios, scenarios may not reflect climate projections owing to uncertainty in emissions. Model uncertainty is caused by our incomplete understanding of the climate system (Lobell \& Burke, 2010), leading to inappropriate transformation of the climate system into numerical climate models (Lobell \& Burke, 2010).

\subsubsection{Comparing outputs of six chosen climate models and those of IPCC ensemble}

For mean temperature, average change under RCP8.5 scenario by 2100 (2081-2100) is about $+4 \pm 1^{\circ} \mathrm{C}$ (IPCC, 2013) while climate models used in this study project mean temperature rises about $+4 \pm 1^{\circ} \mathrm{C}$ for the same period and scenario, leading to a similar projection. It

\footnotetext{
54 This wind speed is relatively lower than wind speed explained in Matsui et al. (2007) which is about $4 \mathrm{~m} / \mathrm{second}$. That study (Matsui et al., 2007) suggests wind speed $\leq 3 \mathrm{~m} /$ second tends not to affect rice yield.

${ }^{55}$ In high humidity about $80 \%$, the negative effects of temperature on rice yield explained in this study are relatively similar to those explained in existing studies (De Abeysiriwardena, Maruyama, \& Ohba, 2002; Weerakoon, Maruyama, \& Ohba 2008).
} 
seems that the impacts of climate change on rice yield explained in this study is relatively similar to those under the IPCC's ensemble by 2100 (2081-2100) under RCP8.5 scenario.

Furthermore, based on chosen climate models used in this study, projected average precipitation by 2100 (2077-2100) is $1800 \pm 90 \mathrm{~mm} /$ year while projected precipitation based the IPCC's ensemble is $1700 \pm 85 \mathrm{~mm} /$ year for the same period and RCP scenario. Hence, projected wetland harvested areas explained in this study is is relatively similar to those under the IPCC's wider ensemble.

\subsection{Future research}

This study could be extended to consider the impacts of climate change on rice quality. Several studies (Counce et al., 2005; Lanning et al., 2011; Lanning et al., 2012; Lyman, Jagadish, Nalley, Dixon, \& Siebenmorgen, 2013) explain that high minimum temperature tends to negatively affect rice grain qualities such as high chalkiness (leading to low milling ratio) and low nutrient quality, i.e a lower protein content. Chalkiness is an important physical quality of rice (Lyman et al., 2013) and nutrient quality is important since rice is a main source of energy and protein (Pemerintah Nusa Tenggara Barat, 2011). Those studies suggest further research on understanding the negative impacts of climate change on rice qualities.

WNT farmers rely heavily on the sun to dry the harvested paddy prior to threshing. Extreme precipitation and high precipitation might influence rice drying days. Longer rice drying days owing to extreme and high precipitation can increase rice moisture level. High moisture level leads to a lower milling ratio (Listyawati, 2007). In turn, further study is needed to understand the impacts of climate change on the rice drying process since this study does not consider the effects of precipitation on rice drying days.

Higher carbon dioxide levels are associated with climate change. The elevated $\mathrm{CO}_{2}$ tends to increase photosynthesis rates (Ainsworth, 2008; Kim et al., 2011; Lee, Park, Jang, \& You, 2015; Lobell \& Burke, 2010), lessening the stomatal conductance and leading to a higher crop biomass or crop carbon gain (Ainsworth, 2008; Kim et al., 2011; Lee et al., 2015; Lobell \& Burke, 2010).

However, a number of studies confirm that the beneficial effects of elevated $\mathrm{CO}_{2}$ is negated by the negative impacts of high temperature, especially if recent temperature is relatively 
close to, or higher than optimal temperature (Ainsworth, 2008; Cai et al., 2016; Kim et al., 2011; Lee et al., 2015). Another study (Ainsworth, 2008) suggests that the positive impacts of $\mathrm{CO}_{2}$ can be negated by the negative impacts of ozone, as a higher $\mathrm{CO}_{2}$ concentration is accompanied by a higher ozone level. Likewise, Zhang et al (2013) suggest that the positive impacts of elevated $\mathrm{CO}_{2}$ cannot be realised unless heat tolerant rice varieties are readily developed. However Lobell \& Burke (2010) suggest that research on the benefits of the elevated $\mathrm{CO}_{2}$ should be sought in order to increase crop yield under a changing climate.

Another possible course for further study is to seek the benefit of no-tillage in reducing greenhouse emissions, given that another study (Rochecouste, Dargusch, Cameron, \& Smith, 2015) suggests that no-tillage and retaining crop stubbles can reduce the greenhouse emission and increase soil moisture and hinder weed growth.

The impacts of climate change can be seen throughout the rice supply chain. A number of studies (Counce et al., 2005; Lanning, Siebenmorgen, Counce, Ambardekar, \& Mauromoustakos, 2011; Lanning, Siebenmorgen, Ambardekar, Counce, \& Bryant, 2012) explain that high minimum temperature tends to negatively affect rice grain qualities such as high chalkiness (leading to low milling ratio) and low nutrient quality. Furthermore, the rice drying stage is an important activity after harvesting seasons (Listyawati, 2007; Hasbullah \& Dewi, 2011; Swastika, 2012). If extreme precipitation occurs during harvesting seasons when farmers dry their rice, rice drying days will be longer, leading to higher moisture and a lower milling ratio (Listyawati, 2007). All of those studies suggest analysing the impacts of climate change on the rice supply chain.

Last but not the least, the impacts of climate change on the economic system should be conducted further, as rice production will probably decrease under a changing climate. In developing countries, rice farming contributes significantly to employment and GDP. 


\section{REFERENCES}

Abdullah, A., Tjokrowidjojo, S., \& Sularjo (2008). Perkembangan dan Propsek perakitan padi tipe baru di Indonesia. Jurnal Litbang Pertanian, 27(1), 1.

Abeysiriwardena, Maruyama, \& Ohba (2002). Influence of temperature and relative humidity on grain sterility in rice.

Ackerman, F., \& Stanton, E. A. (2012). Climate impacts on agriculture: A challenge to complacency. A working paper. Tufts University.

Adams, R. M., Hurd, B. H., Lenhart, S., \& Leary, N. (1998). Effects of global climate change on agriculture: An interpretative review. Climate Research, 11(1), 19-30.

Adl, A., \& Parvizian, J. (2009). Drought and Production Capacity of Meat; A System Dynamics Approach. Proceedings of the 27th International Conference of the System Dynamics Society. Retrieved on December 5th, 2013 from http://www.systemdynamics.org/conferences/2009/proceed/papers/P1355.pdf.

Agrawala, S., Carraro, M., Kingsmill, N., Lanzi, E., Mullan, M., \& Prudent-Richard, G. (2011). Private sector engagement in adaptation to climate change. OECD Environment Working Paper.

Agunbiade, A., \& Adeboye, O. (2012). Estimation under Heteroscedasticity: A Comparative Approach Using Cross-Sectional Data. Mathematical Theory and Modeling, 2(11), 1-8.

Ahmad, P., Wani, M. R., Azooz, M. M., \& Tran, L. S. P. (Eds.). (2014).Improvement of Crops in the Era of Climatic Changes (Vol. 1). Springer.

Ainsworth, E. A. (2008). Rice production in a changing climate: a meta-analysis of responses to elevated carbon dioxide and elevated ozone concentration.Global Change Biology, 14(7), 1642-1650.

Al-Amin, A. Q., Walter, L., Trinxeria, J. M., Jaafar, A. H.,\& Ghani, Z. A.(2011). Assessing the impacts of climate change in the malaysian agriculture sector and its influences in investment decision. Middle East Journal of Scientific Research, 7(2), 225-234.

Aldrian, E. (2002). Spatial patterns of ENSO impact on Indonesia rainfall. Jurnal Sains \& Teknologi Modifikasi Cuaca, 3 (1), 5-15.

Aldrian, E. (2012). Peluang dan tantangan berbasis riset kebencanaan akibat perubahan iklim di Indonesia. Jakarta, Indonesia: BMKG

Ambarinanti, M. (2007). Analisis faktor-faktor yang mempengaruhi produksi dan ekspor beras Indonesia. Unpublished dissertation. Institut Pertanian Bogor, Indonesia. 
Annamalai, H., Hamilton, K., \& Sperber, K. R. (2007).The South Asian summer monsoon and its relationship with ENSO in the IPCC AR4 simulations. Journal of Climate, 20(6), 1071-1092.

Anderson, K.(2013). Agricultural price distortions: trends and volatility, past, and prospective. Agricultural Economics,00, 1-9.

Aramyan, L. H., Lansink, A. G. O., Van der Vorst, J. G., \& Van Kooten, O. (2007). Performance measurement in agri-food supply chains: A case study. Supply Chain Management: An International Journal, 12(4), 304-315.

Asnawi, R. (2016). Perubahan Iklim Dan Kedaulatan Pangan Di Indonesia. Tinjauan Produksi Dan Kemiskinan. Sosio Informa,1(3).

Aslam, T., \& Ng, A. H. (2015, December). Strategy evaluation using system dynamics and multi-objective optimization for an internal supply chain. In Winter Simulation Conference (WSC), 2015 (pp. 2033-2044). IEEE.

Astuti, E. P. (2008). Analisis Preferensi dan Kepuasan Konsumen terhadap Beras Di Kecamatan Mulyorejo Surabaya Jawa Timur. Unpublished undergraduate thesis, Institut Pertanian Bogor, Bogor, Indonesia.

Attri, S. D., \& Rathore, L. S. (2003). Simulation of impact of projected climate change on wheat in India. International journal of climatology, 23(6), 693-705.

Axelsson, T. (2010). Agricultural transformation in Java-legacies of the past challenges for the future. In The 6th Euroseas Conference. In Hillbom, E., \& Svensson, P. (2013). Agricultural transformation in a global history perspective (Vol. 63). Routledge.

Ayyangar, L. (2007). Skewness, Multicollinearity, Heteroskedasticity-You Name It, Cost Data Have It! Solutions to Violations of Assumptions of Ordinary Least Squares Regression Models Using SAS®.

Balai Wilayah Sungai I NTB. (2012). Data dan informasi pengelolaan sumber daya air. Kementerian Pekerjaan Umum, Direktorat Jenderal Sumber Daya Air, Balai Wilayah Sungai I NTB.

Badan Penelitian dan Pengembangan Pertanian. (2011). Inovasi tepat guna dalam mendukung pertanian daerah. Agro Inovasi, 3402, 1-10.

Badan Penelitian dan Pengembangan Pertanian. (2013). Politik Pembangunan Pertanian Menghadapi Perubahan Iklim. Jakarta, Indonesia.: Kementerian Pertanian Republik Indonesia. 
Badan Penelitian dan Pengembangan Pertanian. (2005). Rencana aksi pemantapan ketahanan pangan 2005-2010. Jakarta, Indonesia.: Kementerian Pertanian Republik Indonesia.

Balai Wilayah Sungai I NTB. (2012). Data dan Informasi pengelolaan sumber daya air Kementerian PU, Direktorat Jenderal Sumber Daya Air, Balai Wilayah Sungai I NTB

Bappenas. (2010). Indonesia climate change sectoral roadmap - ICCSR. Kelautan dan Perikanan. Bappenas. Jakarta, Indonesia.

Bassi, A. M., Herren, H. R., Tan, Z., \& Saslow, B. (2010). Assessing future prospects of the agriculture sector using an integrated approach.

Behdani, B.(2012). Evaluation of paradigms for modeling supply chains as complex sociotechnical systems. Evaluation of paradigms for modeling supply chains as complex sociotechnical systems. In Simulation Conference (WSC), Proceedings of the 2012 Winter (pp. 115). IEEE.

Berry, S., \& Schlenker, W. (2011). Technical Report for the ICCT: Empirical Evidence on Crop Yield Elasticities. International Council on Clean Transportation. http://www. theicctorg/sites/default/files/publications/berry_schlenker_cropyieldelasticities_sep2011. $p d f$.

Bita, C., \& Gerats, T. (2013). Plant tolerance to high temperature in a changing environment: scientific fundamentals and production of heat stress-tolerant crops. Frontiers in Plant Science, 4, 273.

BMKG. (2012). Buku Informasi Perubahan Iklim Dan Kualitas Udara Di Indonesia. Jakarta, Indonesia: BMKG.

BMKG NTB. (1971-2011). Data of temperature and rainfall in West Nusa Tenggara between 1971-2011. Badan Meteorologi, Klimatologi dan Geofisika Propinsi Nusa Tenggara Barat.

Bocchiola, D. (2015). Impact of potential climate change on crop yield and water footprint of rice in the Po valley of Italy. Agricultural Systems, 139, 223-237.

Boer, R. and A. Faqih. (2004). Current and Future Rainfall Variability in Indonesia. In An Integrated Assessment of Climate Change Impacts, Adaptation and Vulnerability in Watershed Areas and Communities in Southeast Asia. Report from AIACC Project No. AS21 (Annex C, 95-126). International START Secretariat, Washington, District of Columbia.

Borshchev, A., \& Filippov, A. (2004). From system dynamics and discrete event to practical agent based modeling: Reasons, techniques, tools. Proceedings of the 22nd International Conference of the System Dynamics Society (pp. 25-29). 
BPTP NTB. (2013). Informasi Teknologi Pertanian. Volume II tahun 2013

BPS NTB. (1976-2011). Struktur ongkos usaha tani padi dan palawija. Mataram: BPS Propinsi Nusa Tenggara Barat.

BPS NTB. (2010). Nusa Tenggara Barat dalam angka 2010. Mataram, Indonesia: BPS NTB.

BPS NTB.(2011). Nusa Tenggara Barat dalam angka 2011. Mataram: BPS Propinsi Nusa Tenggara Barat.

BPS NTB.(2012). Nusa Tenggara Barat dalam angka 2012. Mataram: BPS Propinsi Nusa Tenggara Barat.

BPS NTB.(2013). Nusa Tenggara Barat dalam angka 2012. Mataram: BPS Propinsi Nusa Tenggara Barat.

BPS NTB. (2000-2012). Statistik Harga Produsen Gabah Provinsi Nusa Tenggara Barat. Mataram: BPS Propinsi Nusa Tenggara Barat

BPS (2015) Analisis kebijakan pertanian Indonesia: Implementasi dan dampak terhadap kesejahteraan petani dari perspektif sensus pertanian 2013. Jakarta : BPS Pusat Republik Indonesia.

Brennan J.P. and Malabayabas A. (2011). International Rice Research Institute's contribution to rice varietal yield improvement in South-East Asia. ACIAR Impact Assessment Series Report No. 74. Australian Centre for International Agricultural Research: Canberra

Brooks, C. (2009). Introductory econometrics for finance. International edition. New York: Cambridge University Press

Brown, M. B., \& Forsythe, A. B. (1974). Robust tests for the equality of variances. Journal of the American Statistical Association, 69(346), 364-367.

Campuzano, F., \& Mula, J. (2011). Supply chain simulation: A system dynamics approach for improving performance. Springer Science \& Business Media.

Case, M., Ardiansyah, F., \& Spector, E. (2007). Climate change in Indonesia: implications for humans and nature. Climate change in Indonesia: implications for humans and nature. A working paper: WWF.

Cassman, K. G., Dobermann, A., Walters, D. T., \& Yang, H. (2003). Meeting cereal demand while protecting natural resources and improving environmental quality. Annual Review of Environment and Resources, 28(1), 315-358. 
Chijioke, O. B., Haile, M., \& Waschkeit, C. (2011). Implication of climate change on crop yield and food assessibility in Sub-Saharan Africa. Interdisciplinary term papers. Center for Development Research. University of Bonn.

Chou, J., Dong, W., \& Feng, G. (2010). Application of an economy-climate model to assess the impact of climate change. Advances in Atmospheric Sciences, 27(4), 957-965. doi:10.1007/s00376-009-8166-8.

Counce, P. A., Bryant, R. J., Bergman, C. J., Bautista, R. C., Wang, Y. J., Siebenmorgen, T. J., \& Meullenet, J. F. (2005). Rice milling quality, grain dimensions, and starch branching as affected by high night temperatures. Cereal Chemistry, 82(6), 645-648.

Dabbene, F., Gay, P., \& Sacco, N. (2008). Optimisation of fresh-food supply chains in uncertain environments, Part I: Background and methodology. Biosystems Engineering, 99(3), 348-359.

Dani, S. (2015). Food supply chain management and logistics: From farm to fork. Kogan Page Publishers.

Davis, T. (1993).Effective supply chain management. Sloan Management Review, 34, 3546.Retrieved March 15, 2012 from http://sloanreview.mit.edu/summer/summer-1993.

Daulay, S.B. (2005). Pengeringan padi: Metode dan peralatan. Jurusan Teknologi Pertanian, Fakultas Pertanian, Universitas Sumatera Utara, Indonesia.

de Bruijn, H., van der Voort, H., Dicke, W., de Jong, M., \& Veeneman, W. (2004). Creating system innovation: How large scale transitions emerge. CRC Press.

De Datta, S.K. 1981. Principles and practices of rice production. Wiley-Interscience Publications. New York, U.S.A.

Deng, X., Huang, J., Qiao, F., Naylor, R. L., Falcon, W. F., Burke, M., Rozelle, S., Battisti, D. S.(2010). Impacts of El Niño-Southern Oscillation events on China's rice production. Journal of Geographcial Sciences, 20, 3-16.

Deryng, D. (2014). Climate change and global crop yield: impacts, uncertainties and adaptation (Doctoral dissertation, University of East Anglia).

Deryng, D., Elliott, J., Folberth, C., Müller, C., Pugh, T. A., Boote, K. J. ... \& Khabarov, N. (2016). Regional disparities in the beneficial effects of rising $\mathrm{CO}_{2}$ concentrations on crop water productivity. Nature Climate Change, 6(8), 786-790. 
Deryng, D., W.J. Sacks, C.C. Barford, and N. Ramankutty. (2011) Simulating the effects of climate and agricultural management practices on global crop yield. Global Biogeochemical Cycles, 25, GB2006, Doi: 10.1029/2009GB003765

De Salvo, M., Begalli, D., \& Signorello, G. (2013). Measuring the effect of climate change on agriculture: A literature review of analytical models. Journal of Development and Agricultural, 5(12), 499-509.

De Salvo, M., Begalli, D., \& Signorello, G. (2014). The Ricardian analysis twenty years after the original model: Evolution, unresolved issues and empirical problems. Journal of Development and Agricultural, 6(3), 124-131.

Devkota, K. P. (2011). Resource utilization and sustainability of conservation-based ricewheat cropping systems in Central Asia. Unpublished dissertation. Rheinischen FriedrichWilhelms-Universität. Bonn, Germany.

Dietz, T., \& Bidwell, D. (Eds.). (2011). Climate Change in the Great Lakes Region: Navigating an Uncertain Future. MSU Press.

Dinas Pertanian Nusa Tenggara Barat. (2006). Laporan Tahunan 2006. Mataram, Indonesia: Dinas Pertanian Nusa Tenggara Barat.

Dinas Pertanian Nusa Tenggara Barat. (2012). Data luas padi di Nusa Tenggara Barat. Mataram, Indonesia: Dinas Pertanian Nusa Tenggara Barat.

Doane, D. P., \& Seward, L. E. (2011). Measuring skewness: a forgotten statistic. Journal of Statistics Education, 19(2), 1-18.

Dobermann, A., \& Fairhurst, T. (2000). Rice: nutrient disorders \& nutrient management (Vol. 1). International Rice Research Institute.

Dreyer, B., \& Grønhaug, K. (2012). Coping with unpredictable supply: the role of flexibility and adaptation. European Journal of Marketing, 46(10), 1268-1282.

Dudley, R. (2012). Might Continued Emphasis on Maize at the Expense of More Drought Tolerant Crops Endanger Food Security in the Horn of Africa?. In In $30^{\text {th }}$ International Conference of the System Dynamics Society.

Dueri, S., Calanca, P. L., \& Fuhrer, J. (2007). Climate change affects farm nitrogen loss-A Swiss case study with a dynamic farm model. Agricultural Systems, 93(1), 191-214.

Duvick, D. N. (2001). Systemwide Review of Plant Breeding Methodologies in the CGIAR. 
Eastham, J., Sharples, L., \& Ball, S. (Eds.). (2007). Food supply chain management. Taylor $\&$ Francis.

Effendi, B. S. (2009). Strategi pengendalian hama terpadu tanaman padi dalam perspektif praktek pertanian yang baik (Good Agricultural Practices).Jurnal Pengembangan Inovasi Pertanian, 2(1).

Elliott, J., Müller, C., Deryng, D., Chryssanthacopoulos, J., Boote, K. J., Büchner, M., ... \& Izaurralde, R. C. (2015). The global gridded crop model intercomparison: data and modeling protocols for phase 1 (v1. 0).Geoscientific Model Development, 8(2), 261-277.

Evans, M. K. (2002). Practical business forecasting. John Wiley \& Sons.

Fagi, A. M., B. Abdullah dan S. Kartaatmaja. (2001). Peranan padi Indonesia dalam pengembangan padi unggul. In Prosiding Budidaya Padi. Pusat Penelitian dan Pengembangan Tanaman Pangan. Bogor.

Falcon, W. P., Naylor, R.L., Smith, W. L., \& Burke, M. (2004).Using climate models to improve Indonesian food security.Bulletin of Indonesian Economic Studies, 40(3), 355-377.

Faulkner, H. W., \& Faulkner, B. (2003). Progressing tourism research (Vol. 9). Channel View Publications.

Fearne, Andrew and Duffy, Rachel and Hughes, David (2001) Concepts of Collaboration: Supply Chain Management in a Global Food Industry. In: Sharples, Liz and Ball, Stephen and Eastham, Jane F., eds. (2001). Food and Drink Supply Chain Management Issues for the Hospitality and Retail Sectors. Butterworth-Heinemann, pp. 55-89.

Feng, S., Oppenheimer, M., \& Schlenker, W. (2013). Weather Anomalies, Crop Yields, and Migration in the US Corn Belt. Working Paper.

Forrester, J. W. (1961). Industrial dynamics. Cambridge, MA: M.I.T. Press.

Forrester, J.W. \& Senge.P.M. (1980). Tests for building confidence in system dynamics models. Management Sciences, 14 (1980), 209-228.

Fiddaman, T. (1997). Feedback complexity in integrated climate-economy model. Unpublished dissertation, Massachusetts Institute of Technology, MA, USA.

Falcon, W. P., Naylor, R. L., Smith, W. L., Burke, M. B., \& McCullough, E. B. (2004). Using climate models to improve Indonesian food security. Bulletin of Indonesian Economic Studies, 40(3), 355-377. 
Franck, T. R. (2009). Coastal communities and climate change: A dynamic model of risk perception, storms, and adaptation (Doctoral dissertation, Massachusetts Institute of Technology).

Ghadge, A., Dani, S., Chester, M., \& Kalawsky, R. (2013). A systems approach for modelling supply chain risks. Supply Chain Management: An International Journal, 18(5), 523-538.

Gesch, R. W., Vu, J. C., Allen, L. H., \& Boote, K. J. (2001). Photosynthetic responses of rice and soybean to elevated $\mathrm{CO}_{2}$ and temperature. Recent research developments in plant physiology, 125-137.

Gnanamanickam, S. S. (2009). Rice and its importance to human life. In Biological Control of Rice Diseases (pp. 1-11). Springer Netherlands. http://www.springerlieenk.com/index/XQ344493155V0305.pdf

Gomez, S. Q., \& Iglesias, A. (2005). Crop production functions for analysis of global change impacts in Spain. In 2005 International Congress, August 23-27, 2005, Copenhagen, Denmark (No. 24565). European Association of Agricultural Economists.

Gourdji, S. M., Sibley, A. M., \& Lobell, D. B. (2013). Global crop exposure to critical high temperatures in the reproductive period: historical trends and future projections. Environmental Research Letters, 8(2), 024041.

Greene, W. H. (2003). Econometric analysis. Pearson Education India.

Green, M., \& Weatherhead, E. K. (2014). Coping with climate change uncertainty for adaptation planning: An improved criterion for decision making under uncertainty using UKCP09. Climate Risk Management, 1, 63-75.

GRiSP (Global Rice Science Partnership). (2013). Rice almanac, 4th edition. Los Baños (Philippines): International Rice Research Institute. 283 p.

Guisan, A., Edwards, T. C., \& Hastie, T. (2002). Generalized linear and generalized additive models in studies of species distributions: setting the scene. Ecological modelling, 157(2), 89-100.

Gujarati, D. N. (2004). Basic econometrics. New York: McGraw-Hill

Gujja, B., \& Thiyagarajan, T. M. (2010). Producing more with less: exploring farm-based approaches to improve productivity and providing options to farmers in adapting to climate change In Wassmann (2010). Advanced technologies of rice production for coping with climate change: 'no regret' options for adaptation and mitigation and their potential uptake. Proceedings of the Workshop Advanced Technologies of Rice Production for Coping with Climate Change: 'No Regret' Options for Adaptation and Mitigation and their Potential Uptake held on 23-25 June 2010 in Los Baños, Philippines. IRRI Limited Proceedings No. 16. Los Baños (Philippines): International Rice Research Institute. 81 p. 
Hadi, P. U., \& Susilowati, S. H. (2011). Prospek masalah dan strategi pemenuhan kebutuhan pangan pokok. In Seminar Nasional Era Baru Pembangunan Pertanian: Strategi Mengatasi Masalah Pangan, Bio-Energi dan Perubahan Iklim. Bogor (Vol. 25).

Haefele.S.M., Ismail.A.M., Johnson.D.E., Vera Cruz.C., \& Samson.B.(2010). Crop and natural resource management for climate-ready rice in favourable environments: coping with adverse conditions and creating opportunities. In R. Wassmann (Ed.), Advanced technologies of rice production for coping with climate change: 'no regret' options for adaptation and mitigation and their potential uptake (pp. 8-18). Los Banos, Philippines: IRRI.

Haghighi, M. M. (2009). Combination of Econometric Methods and System Dynamics Approach to Improve the Iranian Agricultural Policies. In $27^{\text {th }}$ International Conference of the System Dynamics Society.

Haifa Group. (n.d). Nutritional recommendations for rice. Haifa Group. Retrieved on September 9, 2013 from http://www.haifa-group.com/files/Guides/Rice.pdf.

Hamprecht, J., Corsten, D., Noll, M., \& Meier, E. (2005). Controlling the sustainability of food supply chains. Supply Chain Management: An International Journal, 10(1), 7-10.

Hartmann, D. L. (1994). Global Physical Climatology (Vol. 56). Academic Press.

Hasan, A. H. R. (2010). Measuring climate change risk on supply chain of rice in Bangladesh. In Sustainability in Food and Water (pp. 327-334). Springer Netherlands.

Haris, S. (2009). The impact of rice trade liberalization on farmers and food security: the case of Indonesia (Doctoral dissertation, Simon Fraser University).

Hasbullah, R., \& Dewi, A. R. (2011) Konfigurasi mesin penggilingan padi untuk menekan susut dan meningkatkan rendemen. In Prosiding Seminar Nasional Perteta, 125-133.

Hatfield, J. L., \& Prueger, J. H. (2015). Temperature extremes: Effect on plant growth and development. Weather and Climate Extremes, WACED1400046.

Haverkort, A. J., \& Verhagen, A. (2008). Climate change and its repercussions for the potato supply chain. Potato Research, 51(3-4), 223.

Hauke, J. E., Wicharn, D. W., \& Reitch, A. Y. (2001). Business Forecasting. New Jersey, NJ: Practises-Hall Inc. 
Hawkins, E., T.M. Osborne, C.K. Hoa, and A.C. Challinor. (2012): Calibration and bias correction of climate projections for crop modelling: An idealised case study over Europe. Agricultural and Forest Meteorology, 170, 19-31.

Hay, L. E., Wilby, R. L., \& Leavesley, G. H. (2000). A comparison of delta change and downscaled GCM scenarios for three mounfainous basins in the United States.

Hessie, R. (2009). Analisis Produksi dan Konsumsi Beras Dalam Negeri serta Implikasinya terhadap Swasembada Beras di Indonesia. Unpublished doctoral's thesis, Institut Pertanian Bogor, Bogor, Indonesia.

Hillel, D., \& Rosenzweig, C. (2011). Handbook of climate change and agroecosystems. Imperial College Press, London, pp 109129Boote KJ, Ibrahim AMH, Lafitte R, McCulley R, Messina C, Murray SC, Specht JE, Taylor S, Westgate ME.

Ho, C., Tai, Y., \& Chi, Y. (2005). A structural approach to measuring uncertainty in supply chains. International Journal of Electronic Commerce, 9(3), 91-114.

Hossain, M. (1988). Nature and impact of the green revolution in Bangladesh. Research Report 67. International Food Research Institute

Hong, L.J. (2005). Discrete Optimization Via Simulation Using Coordinate Search. In Proceedings of the 2005 Winter Simulation Conference, Edited by M. E. Kuhl, N. M. Steiger, F. B. Armstrong, and J. A. Joines. 803 -810, Piscataway, New Jersey: IEEE.

Horie, T., M. Onishi, J.F. Angus, L.G. Lewin, and T. Matano, 1994. Physiological characteristics of high yielding rice inferred from cross-location experiments. In Proceedings of International Conference on Temperate Rice- achievements and potential, Yanco, Australia, 21-24 February 1994, vol. II: 635-650

Horowitz, J. L. (2009). Semiparametric and nonparametric methods in econometrics. New York: Springer.

Hossain, M. (1988). Nature and impact of the green revolution in Bangladesh. Research Report 67. International Food Research Institute

Hu. W., Hu. B., \& Han. B. (2009). Genome-wide survey and expression of profiling heat shock proteins and heat shock factors revealed overlapped and stress specific response under abiotic stresses in rice. Plant Science (583-590).

Huang, P. (1985). The peasant economy and social change in North China. Stanford University Press. 
Huerta, J., Esquivel-Longoria, M., Arellano-Lara, F., Dominguez-Ruiz, S., \& RosalesFlores, F. (2011). A system dynamics approach to examine climate change impacts: The case of the state of Guanajuato, México. Proceedings of the 29th International Conference of the System Dynamics Society. Retrieved on March 21, 2013 from http://www.systemdynamics.org/conferences/2011/proceed/papers/P1104.pdf.

Hull, B. Z. (2005). Are supply (driven) chains forgotten?. The International Journal of Logistics Management, 16(2), 218-236.

Iakovou, E., Bochtis, D., Vlachos, D., \& Aidonis, D. (2016). Supply Chain Management for Sustainable Food Networks. John Wiley \& Sons.

Ibáñez, J., Martínez-Valderrama, J., Taguas, E. V., \& Gómez, J. A. (2014). Long-term implications of water erosion in olive-growing areas in southern Spain arising from a modelbased integrated assessment at hillside scale. Agricultural Systems, 127, 70-80.

IPCC. (2007). Climate Change 2007: The Physical Science Basis. Contribution of Working Group I to the Fourth Assessment Report of the Intergovernmental Panel on Climate Change [Solomon, S., D. Qin, M. Manning, Z. Chen, M. Marquis, K.B. Averyt, M. Tignor and H.L. Miller (eds.)]. Cambridge University Press, Cambridge, United Kingdom and New York, NY, USA, 996 pp.

IPCC.(2012).Managing the risks of extreme events and disasters to advance climate change adaptation. A Special Report of Working Groups I and II of the Intergovernmental Panel on Climate Change [Field, C.B., V. Barros, T.F. Stocker, D. Qin, D.J. Dokken, K.L. Ebi, M.D. Mastrandrea, K.J. Mach, G.-K. Plattner, S.K. Allen, M. Tignor, and P.M. Midgley (eds.)]. Cambridge University Press, Cambridge, UK, and New York, NY, USA, 582 pp.

IPCC.(2013). Climate change 2013: The physical science basis. contribution of working group I to the fifth assessment report of the intergovernmental panel on climate change [Stocker, T.F., D. Qin, G.-K. Plattner, M. Tignor, S.K. Allen, J. Boschung, A. Nauels, Y. Xia, V. Bex and P.M. Midgley (eds.)]. Cambridge University Press, Cambridge, United Kingdom and New York, NY, USA.

Iglesias, A., Garrote, L., Quiroga, S., \& Moneo, M. (2009). Impacts of climate change in Agriculture in Europe. PESETA-Agriculture study. JRC Scientific and Technical Reports, EUR, 24107. Retrieved on March 21, 2013 from http://www.eurosfaire.prd.fr/7pc/doc/1260198300_climate_change_agriculture_jrc55386.pd $\mathrm{f}$

Irianto \& Suciantini. (2006). Anomali iklim: Faktor penyebab, karakteristik dan antisipasinya. Iptek Tanaman Pangan, 2, 101-201.

IRRI. (1980). Standart Evaluation System for Rice.Internasional Rice testing program. IRRI. Philippines. 
IRRI. (1980). Standart Evaluation System for Rice.Internasional Rice testing program. . Los Banos, Philippines: IRRI.

IRRI. (1985). International Rice Research: 25 Years of Partnership. Los Banos, Philippines: IRRI.

International Rice Research Institute (IRRI). (2015). Rice Today. Vol. 14 (1). http://books.irri.org/RT14_1_content.pdf

Iswari, K. (2013). Kesiapan teknologi panen dan pascapanen padi dalam menekan kehilangan hasil dan meningkatkan mutu beras. Jurnal Penelitian dan Pengembangan Pertanian, 31(2). Retrieved on March 21, 2013 from http://pustaka.litbang.deptan.go.id/publikasi/p3312123.pdf.

Jagadish, S.V.K., Sumfleth, K., Howell, G., Redona, R., Wassmann, R., \& Heuer, S. (2010).Temperature effects on rice: significance and possible adaptation.In R. Wassmann (Ed.), Advanced technologies of rice production for coping with climate change: 'no regret' options for adaptation and mitigation and their potential uptake (pp. 19-25). Los Banos, Philippines: IRRI.

Jaiwal, P. K., Singh, R. P., \& Dhankher, O. P. (Eds.). (2015). Genetic Manipulation in Plants for Mitigation of Climate Change. Springer.

Jamal, E., Ariningsih, E., Hendiarto, Noekman, K.M., \& Askin, A (2007). Beras dan jebakan kepentingan jangka pendek. Analisa Kebijakan Pertanian. 3(5). 224-240.

Jena K., Hardy B (eds). (2012). Advances in temperate rice research. Los Baños (Philippines): International Rice Research Institute. 105 p.

Junninen, H., Niska, H., Tuppurainen, K., Ruuskanen, J., \& Kolehmainen, M. (2004). Methods for imputation of missing values in air quality data sets.Atmospheric Environment, 38(18), 2895-2907.

Karim, M. R., Ishikawa, M., Ikeda, M., \& Islam, M. T. (2012). Climate change model predicts $33 \%$ rice yield decrease in 2100 in Bangladesh. Agronomy for sustainable development, 32(4), 821-830.

Kartaatmadja, S., Pane, H., Wirajaswadi, L., Sembiring, H., Simatupang, S., Bachrein, S., \& Fagi, A. M. (2004). Optimizing the use of natural resources and increasing rice yield. In Proceedings of the 4th ISCO Conference, Brisbane, Australia. Paper (Vol. 758).

Kasryno, F., Pasandaran, E., \& Fagi, A. M. (2004). Ekonomi padi dan beras Indonesia. Badan Penelitian dan Pengembangan Pertanian, Departemen Pertanian.

Kementerian Pertanian (2010). Satu Dasawarsa Ketahanan Pangan. Badan Ketahanan Pangan. Kementerian Pertanian Republik Indonesia. 
Khairunniza-Bejo, S., Mustaffha, S., \& Ismail, W. I. W. (2014). Application of Artificial Neural Network in Predicting Crop Yield: A Review. Journal of Food Science and Engineering, 4(1), 1.

Kim, H. Y. (1996). Effects of elevated $\mathrm{CO}_{2}$ concentration and high temperature on growth and yield of rice. I. The effect on development, dry matter production and some growth characteristics. Jpn. J. Crop Sci., 65, 634-643.

Klink, K., Wiersma, J. J., Crawford, C. J., \& Stuthman, D. D. (2014). Impacts of temperature and precipitation variability in the Northern Plains of the United States and Canada on the productivity of spring barley and oat. International Journal of Climatology, 34(8), 2805-2818.

Koca, D., \& Sverdrup, H.(2012). Use of causal loop and system analysis to explore alternative climate change adaptation strategies in Seyhan River Basin, Turkey. Proceedings of the 30th International Conference of the System Dynamics Society. Retrieved on March 21, 2013 from http://www.systemdynamics.org/conferences/2012/proceed/papers/P1191.pdf.

Khush, G. S. (1987). Rice breeding: past, present and future. Journal of Genetics, 66(3), 195-216.

Khush, G. S. (2001). Green revolution: the way forward. Nature Reviews Genetics, 2(10), 815-822.

Klink, K., Wiersma, J. J., Crawford, C. J., \& Stuthman, D. D. (2014). Impacts of temperature and precipitation variability in the Northern Plains of the United States and Canada on the productivity of spring barley and oat. International Journal of Climatology, 34(8), 2805-2818.

Kondamudi, R., Swamy, K. N., Chakravarthy, D. V. N., Vishnuprasanth, V., Rao, Y. V., Rao, P. R., Sarla, N., Subrahmanyam, D., \& Voleti, S. R. (2012). Heat Stress in RicePhysiological Mechanisms and Adaptation Strategies. In Crop Stress and its Management: Perspectives and Strategies (pp. 193-224). Springer Netherlands.

Kopainsky, B., Züllich, G., \& Blanco, S. M. (2013). Adaptation to climate change in sub Saharan Africa. Proceedings of the 31th International Conference of the System Dynamics Society. Retrieved on February 21, 2014 from http://www.systemdynamics.org/conferences/2013/proceed/papers/P1312.pdf.

Krishna Kumar, K., Rupa Kumar, K., Ashrit, R. G., Deshpande, N. R., \& Hansen, J. W. (2004). Climate impacts on Indian agriculture. International Journal of Climatology, 24(11), 1375-1393. 
Kvam, P. H., \& Vidakovic, B. (2007). Nonparametric statistics with applications to science and engineering (Vol. 653). John Wiley \& Sons.

Kumar, S., \& Nigmatullin, A. (2011). A system dynamics analysis of food supply chains case study with non-perishable products. Simulation Modelling Practice and Theory, 19(10), 2151-2168.

Lanning, S. B., Siebenmorgen, T. J., Counce, P. A., Ambardekar, A. A., \& Mauromoustakos, A. (2011). Extreme nighttime air temperatures in 2010 impact rice chalkiness and milling quality. Field Crops Research, 124(1), 132-136.

Lanning, S. B., Siebenmorgen, T. J., Ambardekar, A. A., Counce, P. A., \& Bryant, R. J. (2012). Effects of nighttime air temperature during kernel development of field-grown rice on physicochemical and functional properties.Cereal Chemistry, 89(3), 168-175.

Lantarsih, R., Widodo, S., Darwanto, D. H., Lestari, S. B., \& Paramita, S. (2011). Sistem ketahanan pangan nasional: Kontribusi ketersediaan dan konsumsi energi serta optimalisasi distribusi beras. Jurnal Analisis Kebijakan Pertanian, 9 (1). 33-51

Las, I., Abdullah, B., \& Darajat, A. A. (2003). Padi tipe baru dan padi hibrida mendukung ketahanan pangan. Tabloid Sinar Tani.

Lee, J., Gryze, S., \& Six, J. (2011). Effect of climate change on field crop production in $\begin{array}{llll}\text { california's central } \quad \text { valley. Climatic } & \text { Change,109(1), }\end{array}$ doi:http://dx.doi.org/10.1605/01.301-0018831195.2012

Lee, J., Nadolnyak, D., \& Hartarska, V. (2012, February). Impact of Climate Change on Agricultural Production in Asian Countries: Evidence from Panel Study. In presentation at the Southern Agricultural Economics Association Annual Meeting, Birmingham, AL.

Lenderink, G., Buishand, A., \& Deursen, W. V. (2007). Estimates of future discharges of the river Rhine using two scenario methodologies: direct versus delta approach. Hydrology and Earth System Sciences, 11(3), 1145-1159

Levene, H. (1960). Contributions to probability and statistics. Essays in honor of Harold Hotelling, 278-292.

Li, F. J., Dong, S. C., \& Li, F. (2012). A system dynamics model for analyzing the ecoagriculture system with policy recommendations. Ecological Modelling,227, 34-45.

Li, T., \& Wassmann, R. (2011). Modeling approaches for assessing adaptation strategies in rice germplasm development to cope with climate change.CEEDIN, 55.

Listyawati. (2007). Kajian susut pasca panen dan pengaruh kadar air gabah terhadap mutu beras giling varietas Ciherang. Unpublished undergraduate thesis, Institut Pertanian Bogor, Bogor, Indonesia. 
Lobell, D. (2010). Crop responses to climate: time-series models. In Lobell \& Burke. (Eds.). (2010). Climate change and food security: Adapting agriculture to a warmer world (Vol. 37). Springer.

Lobell, D. B., \& Asner, G. P. (2003). Climate and management contributions to recent trends in US agricultural yields. Science, 299(5609), 1032-1032.

Lobell, D. B., \& Burke, M. B. (2008). Why are agricultural impacts of climate change so uncertain? The importance of temperature relative to precipitation. Environmental Research Letters, 3(3), 034007.

Lobell, D., \& Burke, M. (2010). Climate change and food security: Adapting agriculture to a warmer world (Vol. 37). Springer Science \& Business Media.

Lobell, D.B., Burke, M.B., Tebaldi, C., Mastrandrea, M.D., Falcon, W.P., \& Naylor, R. L. (2008). Prioritizing climate change adaptation needs for food security in 2030. Science, 319 (5863), 607-610. doi: 10.1126/science.1152339.

Lobell, D. B., \& Field, C. B. (2007). Global scale climate-crop yield relationships and the impacts of recent warming. Environmental Research Letters, 2(1), 014002

Lobell, D. B., \& Field, C. B. (2008). Estimation of the carbon dioxide $\left(\mathrm{CO}_{2}\right)$ fertilization effect using growth rate anomalies of CO2 and crop yields since 1961. Global Change Biology, 14(1), 39-45.

Lobell, D. B., Field, C. B., Cahill, K. N., \& Bonfils, C. (2006). Impacts of future climate change on california perennial crop yields: Model projections with climate and crop uncertainties. Agricultural and Forest Meteorology, 141(2), 208-218. doi:10.1016/j.agrformet.2006.10.006

Lobell, D. B., \& Gourdji, S. M. (2012). The influence of climate change on global crop productivity. Plant Physiology, 160(4), 1686-1697.

Lobell, D. B., Ortiz-Monasterio, J. I., Asner, G. P., Naylor, R. L., \& Falcon, W. P. (2005). Combining field surveys, remote sensing, and regression trees to understand yield variations in an irrigated wheat landscape. Agronomy Journal,97(1), 241-249.

Lobell, D. B., Schlenker, W., \& Costa-Roberts, J. (2011). Climate trends and global crop production since 1980. Science, 333(6042), 616-620.

Lobell, D. B., \& Tebaldi, C. (2014). Getting caught with our plants down: the risks of a global crop yield slowdown from climate trends in the next two decades. Environmental Research Letters, 9(7), 074003. 
Lokollo, E. (2007). Bantuan domestik (domestic support): Salah satu pilar utama perundingan pertanian pada WTO. Badan Penelitian dan Pengembangan Kementerian Pertanian Republik Indonesia.

Long, S. P., Ainsworth, E. A., Leakey, A. D., Nösberger, J., \& Ort, D. R. (2006). Food for thought: lower-than-expected crop yield stimulation with rising $\mathrm{CO} 2$ concentrations. Science, 312(5782), 1918-1921.

Lorenz, T. M., \& Bassi, A. M. (2005). Comprehensibility as a discrimination criteria for agent-based modelling and system dynamics: An empirical approach. Proceedings of the 23rd International Conference of the System Dynamics Society.

Luo, Q. (2011). Temperature thresholds and crop production: a review. Climatic Change, 109(3-4), 583-598.

Lyman, N. B., Jagadish, K. S., Nalley, L. L., Dixon, B. L., \& Siebenmorgen, T. (2013). Neglecting rice milling yield and quality underestimates economic losses from hightemperature stress. PloS one, 8(8), e72157.

Maani. K. \& Cavana.R.Y. (2007). Systems thinking system dynamics: Managing change and complexity. Auckland, New Zealand: Pearson Education New Zealand

Maclean, J. L., Dawe, D. C., Hardy, B., \& Hettel, G. P. (2002). Rice almanac, 3rd edn. International Rice Research Institute.

Makino, A., Harada, M., Kaneko, K., Mae, T., Shimada, T., \& Yamamoto, N. (2000). Whole-plant growth and $\mathrm{N}$ allocation in transgenic rice plants with decreased content of ribulose-1, 5-bisphosphate carboxylase under different $\mathrm{CO} 2$ partial pressures. Functional Plant Biology, 27(1), 1-12.

Mandal, S. (2012). Supply chain performance: Review of empirical literature. Romanian Review of Social Sciences, 3, 24-34.

Mangrauthia, S. K., Revathi, P., Agarwal, S., Singh, A. K., \& Bhadana, V. P. (2014). Breeding and Transgenic Approaches for Development of Abiotic Stress Tolerance in Rice. In Improvement of Crops in the Era of Climatic Changes (pp. 153-190). Springer New York.

Manigbas, N. L., Lambio, L. A. F., Luvina, B., \& Cardenas, C. C. (2014). Germplasm innovation of heat tolerance in rice for irrigated lowland conditions in the Philippines. Rice Science, 21(3), 162-169. http://dx.doi.org/10.1016/S1672-6308(13)60180-8

Mardiyanto, S., Supriatna, Y., \& Agustin, N. K. (2005). Dinamika pola pemasaran gabah dan beras di Indonesia. In Forum Penelitian Agro Ekonomi Pusat Analisis Sosial Ekonomi dan Kebijakan Pertanian. Bogor, Indonesia. 
Mariyono, J. (2009). Technological and institutional changes in the Indonesian rice sector: from intensification to sustainable revitalization. Asian Journal of Agriculture and Development, 6(2), 125-144.

Matsui T, Kobayashi K, Yoshimoto M, Hasegawa T. 2007. Stability of rice pollination in the field under hot and dry conditions in the Riverina region of New South Wales, Australia. Plant Prod. Sci. 10:57-63.

Matthews, R. B., Kropff, M. J., Horie, T., \& Bachelet, D. (1997). Simulating the impact of climate change on rice production in Asia and evaluating options for adaptation. Agricultural systems, 54(3), 399-425.

Maulana, M. (2004). Peranan Luas Lahan, Intensitas pertanaman dan produktivitas sebagai sumber pertumbuhan Padi Sawah di Indonesia 1980-2001. Jurnal Agro Ekonomi, 22(1).

Maulana, M. (2012). Prospek implementasi kebijakan Harga Pembelian Pemerintah (HPP) multikualitas gabah dan beras di Indonesia. Pusat Sosial Ekonomi dan Kebijakan Pertanian.

Maulana, M., \& Rachman, B. (2010). Harga Pembelian Pemerintah (HPP) Gabah-Beras tahun 2010: Efektivitas dan implikasinya terhadap kualitas dan pengadaan Bulog.

Meadows, D. H. (1980). The unavoidable a priori. Elements of the system dynamics method, 23-57.

Meadows, D., Randers, J., \& Meadows, D. (2004). Limits to growth: The 30-year update. Chelsea Green Publishing.

Merriam, S. B. (1998). Qualitative research and case study applications in education. San Francisco, California: Jossey-Bass

Mew TW, Brar DS, Peng S, Dawe D, Hardy B, editors. (2003). Rice science: innovations and impact for livelihood. Proceedings of the International Rice Research Conference, 16-19 September 2002, Beijing, China. Beijing (China): International Rice Research Institute, Chinese Academy of Engineering, and Chinese Academy of Agricultural Sciences. 1,022 p.

Miller, C., \& Newell, B. (2013). Framing integrated research to address a dynamically complex issue: The red headed cockchafer challenge. Agricultural Systems, 117, 13-18.

Modin-Edman, A. K., Öborn, I., \& Sverdrup, H. (2007). FARMFLOW-A dynamic model for phosphorus mass flow, simulating conventional and organic management of a Swedish dairy farm. Agricultural Systems, 94(2), 431-444.

Mohammed \& Tarpley (2009). Impacts high night temperature on respiration, membrane stability, antioxidant capacity and yields of rice plants. Crop Science, 49(1), 313-322. 
Mohanty S, Wassmann R, Nelson A, Moya P, and Jagadish SVK. (2013). Rice and climate change: significance for food security and vulnerability. IRRI Discussion Paper Series No. 49. Los Baños (Philippines): International Rice Research Institute. 14 p.

Motulsky, H., \& Christopoulos, A. (2004). Fitting models to biological data using linear and nonlinear regression: a practical guide to curve fitting. Oxford University Press.

Muhammadi, M., Aminullah, E., \& Soesilo, B. (2001). Analisis sistem dinamis lingkungan hidup, sosial, ekonomi, manajemen. Universitas Muhammadiyah Jakarta (UMJ) Press:

Moron, V., Boyard-Micheau, J., Camberlin, P., Hernandez, V., Leclerc, C., Mwongera, C., Philippon, N., Fossa Riglos, F., \& Sultan, B. (2015). Ethnographic context and spatial coherence of climate indicators for farming communities-A multi-regional comparative assessment. Climate Risk Management, 8, 28-46.

Mottaleb, K. A., Gumma, M. K., Mishra, A. K., \& Mohanty, S. (2015). Quantifying production losses due to drought and submergence of rainfed rice at the household level using remotely sensed MODIS data. Agricultural Systems, 137, 227-235.

Martinez-Moyano, I. J. (2012). Documentation for model transparency.System Dynamics Review, 28(2), 199-208.

Müller, C., Elliott, J., Chryssanthacopoulos, J., Deryng, D., Folberth, C., Pugh, T. A., \& Schmid, E. (2015). Implications of climate mitigation for future agricultural production. Environmental Research Letters, 10(12), 125004.

Mulyantara, L.T., \& Hendriadi, A.(2004). Analisis rasional penggunaan energi pada budidaya padi di kabupaten Karawang Jawa Barat. In Prosiding Seminar Nasional Mekanisasi Pertanian (pp. 203-212).

Nahas, A.C., Maslakah, F.A., \& Setiawan, B. (2009). Pengukuran konsentrasi gas rumah kaca di bukit Kototabang tahun 2009. Buletin Data Tahun 2009 SPAG Bukit Kototabang, 114.

Nahas, A.C. (2010). Proyeksi perubahan temperatur berdasarkan kecenderungan konsentrasi karbon dioksida di Bukit Kototabang. Buletin Meteorologi, Klimatologi, Kualitas Udara, Geofisika, dan Lingkungan, 1(1), 9-16.

Nakicenovic, N., \& Swart, R. (2000). Special report on emissions scenarios.Special Report on Emissions Scenarios, Edited by Nebojsa Nakicenovic and Robert Swart, pp. 612. ISBN 0521804930. Cambridge, UK: Cambridge University Press, July 2000., 1.

Naylor, R. L., Falcon, W., Wada, N., \& Rochberg, D.(2001). Using El Niño-Southern Oscillation climate data to rice production in Indonesia.Climatic Change, 50(3), 255-265. 
Naylor, R. L., Falcon, W., Wada, N., \& Rochberg, D. (2002). Using El Niño-Southern Oscillation climate data to improve food policy planning in Indonesia. Bulletin of Indonesian Economic Studies, Taylor and Francis Journals, 38(1), 75-91.

Naylor, R. L., Battisti, D.S., Vimont, D. J., Falcon, W. F., \& Burke, M.B. (2007). Assessing risks of climate variability and climate change for Indonesian rice agriculture. In Proceedings of The National Academy of Sciences - PNAS , 104(19), 7752-7757.

Naylor, R. L., \& Mastrandrea, M. D. (2009). Coping with Climate Risks in Indonesian Rice Agriculture: A Policy Perspective. In In J.A. Filar \& A. Haurie (Eds.), Uncertainty and Environmental Decision Making A Handbook of Research and Best Practice (pp. 127-153). New York: Springer.

Nazam, M. (2011). Penyusunan model untuk penetapan luas lahan optimum usaha tani padi sawah pada wilayah beriklim kering mendukung kemandirian pangan berkelanjutan. Unpublished dissertation, Institut Pertanian Bogor, Bogor, Indonesia.

Nguyen, N., Wegener, M., Russell, I., Cameron, D., Coventry, D., \& Cooper, I. (2005). Risk management strategies by Australian farmers. In The 15th International Farm Management Conference (Vol. 2, pp. 94-103). International Farm Management Association.

Nhemachena, C. (2009). Agriculture and future climate dynamics in Africa :Impacts and adaptation options. Unpublished dissertation, University of Pretoria, Pretoria, South Africa.

Nhamo, N., Rodenburg, J., Zenna, N., Makombe, G., \& Luzi-Kihupi, A. (2014). Narrowing the rice yield gap in East and Southern Africa: Using and adapting existing technologies. Agricultural Systems, 131, 45-55.

Noor, N. M., Al Bakri Abdullah, M. M., Yahaya, A. S., \& Ramli, N. A. (2015). Comparison of Linear Interpolation Method and Mean Method to Replace the Missing Values in Environmental Data Set. In Materials Science Forum (Vol. 803, pp. 278-281). Trans Tech Publications.

Nurhasanah \& Sunaryo, W.(2015). Keragaman genetik padi lokal Kalimantan Timur. Prosiding Nasional Masyarakat Biodiversity Indonesia. Volume 1 No. 7. 1553-1558.

O'Keeffe, M. (1998). Establishing supply chain partnerships: lessons from Australian agribusiness. Supply Chain Management: An International Journal, 3(1), 5-9.

Oliva, R., \& Sterman, J. D. (2010). Death spirals and virtuous cycles. In Handbook of Service Science (pp. 321-358). Springer US. 
Ortiz, A., Sarriegi, J. M., \& Santos, J. (2006).Applying modelling paradigms to analyse organisational problems. Proceedings of the 24th International Conference of the System Dynamics Society.

Ossimitz, G.,Mrotzek, M. (2008). The basics of system dynamics : discrete vs . continuous modelling of time. Proceedings of the 26th International Conference of the System Dynamics Society.

Ottesen, G. G., \& Grønhaug, K. (2002). Market orientation and uncertain supply in upstream markets: an exploratory study. European Journal of Purchasing \& Supply Management, 8(4), 209-219.

Palazzoli, I., Maskey, S., Uhlenbrook, S., Nana, E., \& Bocchiola, D. (2015). Impact of prospective climate change on water resources and crop yields in the Indrawati basin, Nepal. Agricultural Systems, 133, 143-157.

Papademetriou, M. K., Dent, F. J., \& Herath, E. M. (Eds.). (2000). Bridging the rice yield gap in the Asia-Pacific Region. FAO Regional Office for Asia and the Pacific.

Pappis, C.P.(2011). Climate change, supply chain management and enterprise adaptation: implications of global warming to economy. Hershey, Pennsylvania: IGI Global.

Patil, P., Shrotri, A. P., \& Dandekar, A.R. (2012). Management of uncertainty in supply chain. International Journal of Emerging Technology and Advanced Engineering,2(5), 303308

Patil, P., Shrotri, A. P., \& Dandekar, A.R. (2012). Management of uncertainty in supply chain. International Journal of Emerging Technology and Advanced Engineering,2(5), 303308.

Peiris, T. S. G., Hansen, J. W., \& Zubair, L. (2008). Use of seasonal climate information to predict coconut production in Sri Lanka. International Journal of Climatology, 28(1), 103110.

Pemerintah Nusa Tenggara Barat.(2010). Peta ketahanan dan kerentanan pangan provinsi Nusa Tenggara Barat. Mataram, Nusa Tenggara Barat: Pemerintah Nusa Tenggara Barat

Pemerintah Nusa Tenggara Barat. (2011). Strategi dan rencana aksi ketahanan pangan menghadapi perubahan iklim provinsi Nusa Tenggara Barat tahun 2011-2015. Mataram, Indonesia: Pemerintah Nusa Tenggara Barat.

Peng, S., Huang, J., Sheehy, J. E., Laza, R. C., Visperas, R. M., Zhong, X., \& Cassman, K. G. (2004). Rice yields decline with higher night temperature from global 
warming. Proceedings of the National Academy of Sciences of the United States of America, 101(27), 9971-9975

Pingali, P. L. (2012). Green revolution: impacts, limits, and the path ahead. Proceedings of the National Academy of Sciences, 109(31), 12302-12308.

Pingali P, Hossain M, editors. (1998). Impact of rice research. Proceedings of the International Conference on the Impact of Rice Research, 3-5 Jun 1996, Bangkok, Thailand. Thailand Development Research Institute, Bangkok, Thailand, and International Rice Research Institute, P.O. Box 933, Manila, Philippines. 428 p.

Porter, J. R., \& Semenov, M. A. (2005). Crop responses to climatic variation. Philosophical Transactions of the Royal Society B: Biological Sciences,360(1463), 2021-2035.

Prasad, P. V. V., Boote, K. J., Allen, L. H., Sheehy, J. E., \& Thomas, J. M. G. (2006). Species, ecotype and cultivar differences in spikelet fertility and harvest index of rice in response to high temperature stress. Field crops research, 95(2), 398-411.

Prasekti, Y. H. (2015). Analisa Ekonomi Usaha Penangkar Benih Padi Ciherang (di Kelurahan Tamanan Kec. Tulungagung Kab. Tulungagung). Jurnal Agribisnis, 11(13), 1-11.

Prasetyo, E. (2009). Pengaruh konsentrasi dan frekuensi aplikasi formulasi Pseudomonas fluorescens terhadap intensitas penyakit, pertumbuhan dan produksi padi sawah [Oryza sativa L.]. Undergraduate thesis. Institut Pertanian Bogor, Bogor, Indonesia.

PricewaterhouseCoopers (2008), "A practical guide to risk assessment", available at: http://www.pwc.com/en_us/us/issues/enterprise-riskmanagement/ assets/risk_assessment_guide.pdf (accessed 08 April 2017).

Purwadaria (1995). Problem and priorities in of grain drying in Indonesia in Champ, B. R., Highley, E., \& Johnson, G. I. (1996). Grain drying in Asia. ACIAR proceedings (Vol. 71, p. 410pp).

Pusat Sosial Ekonomi dan Kebijakan Pertanian.(2010). Kajian penurunan kualitas gabahberas di luar kualitas di provinsi Jawa Tengah. A working paper. Jakarta, Indonesia.

Pusat Studi Kebijakan dan Dinamika Sistem.Centre for Policy Studies and System Dynamics (CPSSD), Universitas Muhammadiyah Jakarta (UMJ).

Puslitbang Tanaman Pangan. (2010). Padi untuk ketahanan pangan. Jakarta: Puslitbang Tanaman Pangan

Quiroga, S., \& Iglesias, A. (2009). A comparison of the climate risks of cereal, citrus, grapevine and olive production in Spain. Agricultural Systems, 101(1), 91-100. http://dx.doi.org/10.1016/j.agsy.2009.03.006 
Racine, J., Su, L., \& Ullah, A. (2014). The Oxford Handbook of Applied Nonparametric and Semiparametric Econometrics and Statistics. Oxford University Press.

Radzicki, M., \& Taylor, R. (2008). Origin of System Dynamics: Jay, W.Forrester and the History of System Dynamics. US Department of Energy's Introduction to System Dynamics. Available online: http://www. systemdynamics. org/DL-IntroSysDyn/start. htm (accessed on 22 August 2016).

Raharjo, B., Hadiyanti, D., \& Kodir, K. A. (2012). Kajian kehilangan hasil pada pengeringan dan penggilingan padi di lahan pasang surut Sumatera Selatan. Jurnal Lahan Suboptimal, 1(1).

Rahmandad, H. (2004). Heterogeneity and network structure in the dynamics of contagion: comparing agent-based and differential equation models. In Proceedings of the 22nd International Conference of the System Dynamics Society.

Rahmandad, H., \& Sterman, J. (2008). Heterogeneity and network structure in the dynamics of diffusion: comparing agent-based and differential equation models. Management Science, 54(5), 998-1014.

Ramirez-Rodrigues, M. A., Asseng, S., Fraisse, C., Stefanova, L., \& Eisenkolbi, A. (2014). Tailoring wheat management to ENSO phases for increased wheat production in Paraguay. Climate Risk Management, 3, 24-38.

Randall, D.A., R.A. Wood, S. Bony, R. Colman, T. Fichefet, J. Fyfe, V. Kattsov, A. Pitman, J. Shukla, J. Srinivasan, R.J. Stouffer, A. Sumi and K.E. Taylor, 2007: Cilmate Models and Their Evaluation. In: Climate Change 2007: The Physical Science Basis. Contribution of Working Group I to the Fourth Assessment Report of the Intergovernmental Panel on Climate Change [Solomon, S., D. Qin, M. Manning, Z. Chen, M. Marquis, K.B. Averyt, M.Tignor and H.L. Miller (eds.)]. Cambridge University Press, Cambridge, United Kingdom and New York, NY, USA.

Rasmussen, L. V., Rasmussen, K., Reenberg, A., \& Proud, S. (2012). A system dynamics approach to land use changes in agro-pastoral systems on the desert margins of Sahel. Agricultural Systems, 107, 56-64.

Rasul, G., Chaudhry, Q. Z., Mahmood, A., \& Hyder, K. W. (2011). Effect of temperature rise on crop growth and productivity. Pak. J. Meteorol, 8, 53-62.

Raymundo, R., Kleinwechter, U., \& Asseng, S. (2014). Virtual potato crop modeling: A comparison of genetic coefficients of the DSSAT-SUBSTOR potato model with breeding goals for developing countries.

Reardon, T. (2015). The hidden middle: the quiet revolution in the midstream of agrifood value chains in developing countries. Oxford Review of Economic Policy, 31(1), 45-63. 
Reardon, T., Zilberman, D. (2017). Climate smart food supply chains in developing countries in an era of rapid dual change in agrifood systems and the climate. In: Zilberman, D., McCarthy, N., Lipper, L., Asfaw, S., Branca, G. (Eds.), Climate Smart Agriculture: Building Resilience to Climate Change. FAO, Rome

Riahi, K., Rao, S., Krey, V., Cho, C., Chirkov, V., Fischer, G., Kindermann, G., Nakicenovic, N., \& Rafaj, P. (2011). RCP 8.5-A scenario of comparatively high greenhouse gas emissions. Climatic Change, 109(1-2), 33-57.

Richardson, G. P. (2011). Reflections on the foundations of system dynamics. System Dynamics Review, 27(3), 219-243. doi:10.1002/sdr.462

Richter, G. M., \& Semenov, M. A. (2005). Modelling impacts of climate change on wheat yields in England and Wales: assessing drought risks. Agricultural Systems, 84(1), 77-97.

Rochecouste, J. F., Dargusch, P., Cameron, D., \& Smith, C. (2015). An analysis of the socio-economic factors influencing the adoption of conservation agriculture as a climate change mitigation activity in Australian dryland grain production. Agricultural Systems, 135, 20-30.

Roeder, M. (2010). Adaptation of the food supply chain to climate change. Sustainable consumption institute of University of Manchester.

Rosenzweig, C., Elliott, J., \& Deryng, D. (2013). Assessing agricultural risks of climate change in the 21 st century in a global gridded crop model intercomparison. PNAS, 111(9), 16.

Rosenzweig, C., \& Parry, M. L. (1994). Potential impact of climate change on world food supply. Nature, 367(6459), 133-138.

Rosenzweig, C., Phillips, J., Goldberg, R., Carroll, J., \& Hodges, T. (1996). Potential impacts of climate change on citrus and potato production in the US.Agricultural Systems, 52(4), 455-479.

Rothman, P. (Ed.). (2012). Nonlinear time series analysis of economic and financial data (Vol. 1). Springer Science \& Business Media.

Rötter, R. P., Carter, T. R., Olesen, J. E., \& Porter, J. R. (2011).Crop-climate models need an overhaul. Nature Climate Change, 1(4), 175-177.doi: 10.1038/nclimate1152.

Roudier, P., Muller, B., d'Aquino, P., Roncoli, C., Soumaré, M. A., Batté, L., \& Sultan, B. (2014). The role of climate forecasts in smallholder agriculture: Lessons from participatory research in two communities in Senegal. Climate Risk Management, 2, 42-55. 
Rusastra, I. W., Rachman, B., \& Sumedi, T. S. (2004). Struktur Pasar dan Pemasaran Gabah Beras dan Komoditas Kompetitor Utama. Pusat Penelitian dan Pengembangan Sosial Ekonomi Pertanian. Departemen Pertanian Republik Indonesia.

Sacks, W. J., D. Deryng, J. A. Foley, and N. Ramankutty (2010), Crop planting dates: An analysis of global patterns, Global Ecol. Biogeogr., 19(5), 607-620.

Saeed, K. (1992). Slicing a complex problem for system dynamics modeling. System Dynamics review, 8(3), 251-261. doi:10.1002/sdr.4260080305

Sarker, Md., A., Rashid. (2012). Impacts of climate change on rice production and farmers' adaptation in Bangladesh (Doctoral dissertation, University of Southern Queensland).

Sarker, M. A. R., Alam, K., \& Gow, J. (2012). Exploring the relationship between climate change and rice yield in Bangladesh: An analysis of time series data. Agricultural Systems, 112, 11-16.

Schieritz, N., \& Milling, P. M. (2003). Modeling the forest or modeling the trees: A comparison of system dynamics and agent-based simulation. InProceedings of the 21st International Conference of the System Dynamics Society (pp. 20-24).

Schlenker, W., \& Lobell, D. B. (2010). Robust negative impacts of climate change on African agriculture. Environmental Research Letters, 5(1), 014010.

Schlenker, W., \& Roberts, M. J. (2009). Nonlinear temperature effects indicate severe damages to US crop yields under climate change. Proceedings of the National Academy of Sciences, 106 (37), 15594-15598.

Schlenker, W., \& Roberts, M. J. (2008). Estimating the impact of climate change on crop yields: The importance of nonlinear temperature effects (No. w13799). National Bureau of Economic Research.

Schlesinger, M. E., Kheshgi, H. S., Smith, J., Francisco, C., Reilly, J. M., Wilson, T., \& Kolstad, C. (Eds.). (2007). Human-induced climate change: an interdisciplinary assessment. Cambridge University Press.

Schroth, G., Laderach, P., Dempewolf, J., Philpott, S., Haggar, J., Eakin, H., ... \& Eitzinger, A. (2009). Towards a climate change adaptation strategy for coffee communities and ecosystems in the Sierra Madre de Chiapas, Mexico. Mitigation and Adaptation Strategies for Global Change, 14(7), 605-625. 
Schultz, A., Wieland, R., \& Lutze, G. (2000). Neural networks in agroecological modelling-stylish application or helpful tool? Computers and Electronics in Agriculture, 29(1), 73-97.

Sehgal, V. (2010). Supply chain as strategic asset: The key to reaching business goals (Vol. 22). John Wiley \& Sons.

Sembiring H. (2010). Deksripsi Varietas Padi. Jakarta: Balitang Departemen Pertanian Republik Indonesia

Sembiring, H. (2008). Kebijakan penelitian dan rangkuman hasilpenelitian BB Padi dalam mendukung peningkatan produksi beras nasional. In Prosiding Seminar Apresiasi Hasil Penelitian Padi Menunjang P2BN, Buku (Vol. 1).

Sengar, K., \& Sengar, R. S. (2015). Climate change effect on crop productivity. Boca Raton, FL: CRC Press.

Setyawan, B.H. \& Doddy, F.(2011). Pengaruh penyimpanan terhadap kualitas beras : Perubahan sifat fisik selama penyimpanan. Technical Report. Diponegoro University.

Shahbazbegian, M., \& Bagheri, A. (2010). Rethinking assessment of drought impacts: a systemic approach towards sustainability. Sustainability Science,5(2), 223-236.

Sharma, A. K. (2005). Text book of correlations and regression. Discovery Publishing House.

Shi, W., Tao, F., \& Zhang, Z. (2013). A review on statistical models for identifying climate contributions to crop yields. Journal of Geographical Sciences, 23(3), 567-576.

Shiva, V. (1988). Staying alive: Women, ecology, and survival in India. New Delhi: Kali for Women.

Shiva, V. (1991). The violence of the green revolution. Third World Agriculture, Ecology and Politics. Londres \& Nueva York: Zed Books Ltd,20.

Sidik, M. (2007). Prospek perberasan dan ketahanan pangan Asia Timur. In Prosiding Lokakarya Nasional Peningkatan Daya Saing Beras Melalui Perbaikan Kualitas, 33-54.

Sitaresmi, T., Wening, R. H., Rakhmi, A. T., Yunani, N., \& Susanto, U. (2015). Pemanfaatan plasma nutfah padi varietas lokal dalam perakitan varietas unggul. Buletin Iptek Tanaman Pangan, 8(1).

Sommer, M. (1984a). On the applicability of econometric methods to system dynamics models. Dynamica, 10, 91-102. 
Sommer, M. (1984b). The econometric challenge to system dynamics and vice versa: Some future perspectives. Technological Forecasting and Social Change, 25(3), 263-280.

Soussana, J. F., Graux, A. I., \& Tubiello, F. N. (2010). Improving the use of modelling for projections of climate change impacts on crops and pastures. Journal of experimental botany, 61(8), 2217-2228.

Sperber, K. R., Annamalai, H., Kang, I.S., Kitoh, A., Moise, A., Turner, A., \& Wang, B. (2012). The Asian summer monsoon: an intercomparison of CMIP5 vs CMIP3 simulations of the late 20th century. Climate Dynamics. Doi: 10.1007/s00382-012-1607-6

Stephens, E. C., Nicholson, C. F., Brown, D. R., Parsons, D., Barrett, C. B., Lehmann, J \& Riha, S. J. (2012). Modeling the impact of natural resource-based poverty traps on food security in Kenya: The Crops, Livestock and Soils in Smallholder Economic Systems (CLASSES) model. Food Security, 4(3), 423-439.

Sterman, J.D. (2000). Business dynamics: Systems thinking and modeling for a complex world. Boston, MA:Irwin McGraw Hill.

Sterman, J. D. (2002). All models are wrong: Reflections on becoming a systems scientist. System Dynamics Review, 18(4), 501-531. doi:10.1002/sdr.261.

Sterman, J. D., Fiddaman, T., Franck, T., Jones, A., McCauley, S., Rice, P., Sawin. E, \& Siegel, L. (2013). Management flight simulators to support climate negotiations. Environmental Modelling and Software (44), 122-135. doi:10.1016/j.envsoft.2012.06.004.

Stock, J. R. (2004). The US food supply chain. Food supply chain management, 14, 211221.

Studenmund, A, H. Using Econometrics: A Practical Guide (5 ed). Boston: AddisonWesley, 2005.

Subantoro, R., Wahyuningsih, S., \& Prabowo, R. (2008). Pemuliaan tanaman padi (Oryza sativa L.) varietas lokal menjadi varietas lokal yang ungguL. MEDIAGRO, 4(2).

Subash, N., \& Gangwar, B. (2014). Statistical analysis of Indian rainfall and rice yield anomalies over the last decades. International Journal of Climatology, 34(7), 2378-2392.

Suheiti, K.(2007). Alat dan mesin pertanian tepat guna untuk tanaman padi dalam mendukung program peningkatan produksi beras nasional. A working paper. Balai Pengkajian Teknologi Pertanian Jambi: Jambi, Indonesia. 
Sumarno, Wargiono, J., Kartasasminata, U. G., Hasanuddin, A., Soejitno, \& Ismail, I.G. (2008). Anomali iklim 2006/2007 dan saran kebijakan teknis pencapaian target produksi padi. Iptek Tanaman Pangan, 3 (1), 69-97.

Suprihatno, B., \& Darajat, A. A. (2008). Kemajuan dan ketersediaan varietas unggul padi. Padi inovasi teknologi dan ketahanan pangan. Balai Besar Penelitian Tanaman Padi. Badan Penelitian dan Pengembangan Pertanian, Sukamandi.

Suprihatno, B., Samaullah, Y. \& Sri, B.(2008). Inovasi teknologi galur harapan padi sawah toleran kekeringan. Sinar Tani. Juli 2008.

Suprihatno, B., Poniman (2007). keragaan galur padi sawah generasi menengah pada kondisi kekeringan. Balai Besar Penelitian Tanaman Padi. Badan Penelitian dan Pengembangan Pertanian, Sukamandi.

Supriyanto, B. (2012). Penentuan Musim Tanam dan Waktu Tanam Padi Sawah Berdasarkan Akumulasi Curah Hujan Sepuluh Hari Hitung Maju dan Mundur di Kelurahan Lempake Kota Samarinda. ZIRAA'AH MAJALAH ILMIAH PERTANIAN, 35(3), 182-189.

Susanto, U., Daradjat, A. A., \& Suprihatno, B. (2003). Perkembangan pemuliaan padi sawah di Indonesia. Jurnal Litbang Pertanian, 22(3), 125-131.

Sutrisno.(2004). RPC sebagai suatu alternatif peningkatan mutu dan nilai tambah beras. Lokakarya Nasional Upaya Peningkatan Nilai Tambah Pengolahan Padi, 168-186.

Sussman, F. G., \& Freed, J. R. (2008). Adapting to climate change: A business approach. Arlington, VA: The Pew Center on Global Climate Change.

Swastika, D. S.K. (2012). The role of postharvesting handling on rice quality in Indonesia. Forum Penelitian Agro Ekonomi, 30 (1), 1-11.

Tao, F., \& Zhang, Z.(2010). Adaptation of maize production to climate change in North China Plain: Quantify the relative contributions of adaptation options. European Journal of Agronomy, 33(2): 103-116.

Mohammed, A. R., \& Tarpley, L. (2010). Effects of high night temperature and spikelet position on yield-related parameters of rice (Oryza sativa L.) plants. European journal of agronomy, 33(2), 117-123.

Taylor, K. E., R. J. Stouffer, and G. A. Meehl, 2011: An overview of CMIP5 and the experiment design. Bull. Amer. Meteor. Soc., 93, doi: 10.1175/bams-d-11-00094.1, 485-498.

Tebaldi, C., and D. B. Lobell (2008), Towards probabilistic projections of climate change impacts on global crop yields. Geophysical Research Letters, 35, L08705, doi:10.1029/2008GL033423. 
The Indonesian Ministry of Agriculture. (2005). Padi gogo dan pola pengembangannya. Badan Penelitian dan Pengembangan Pertanian.

The Indian Ministry of Science \& Technology and The Indian Ministry of Environment \& Forest. (2011). Biology of Oryza Sativa. India: Ministry of Science \& Technology and Ministry of Environment \& Forest.

The Indonesian Ministry of Environment. (2010). Indonesia climate change sectoral roadmap - ICCSR. Marine and fishery sector report. The Indonesian Ministry of Environment. Jakarta, Indonesia.

The Indonesian Ministry of Environment. (2010). Kajian resiko dan adaptasi terhadap perubahan iklim di pulau lombok nusa tenggara barat. Ministry of Environment: Jakarta. The book is organized by the Ministry of Environment in collaborationwith the Deutsche Gesellschaft für Technische Zussamenarbeit - GTZ within the framework of Policy Advice Programme for Environmental Protection and Climate Change (PAKLIM).

The Indonesian Ministry of National Development Planning. (2013). National Action Plan for Climate Change Adaptation (RAN-API). Synthesis report. Jakarta, Indonesia.

Thomson, A. M., Calvin, K. V., Smith, S. J., Kyle, G. P., Volke, A., Patel, P. \& Edmonds, J. A. (2011). RCP4. 5: a pathway for stabilization of radiative forcing by 2100. Climatic Change, 109(1-2), 77-94.

Thongrattana, P. T. (2012). An analysis of the uncertainty factors affecting the sustainable supply of rice production in Thailand. Unpublished dissertation, University of Wollongong, Sydney, Australia.

Thongrattana, P., \& Jie, F.(2010). Identifying sources of perceived environmental uncertainty along Thai rice supply chain. Operations \& Supply Chain Management, 3 (3), 117-133.

Thongrattana, P., Jie, F., \& Perera, N. (2009). Understanding the impact of environmental uncertainty on efficiency performance indicator of Thai rice millers. Proceedings of the Australian and New Zealand Marketing Academy Conference (pp. 1-8). Melbourne, Australia: Australian and New Zealand Marketing Academy

Thorpe, J., \& Fennell, S. (2012). Climate Change Risks and Supply Chain Responsibility: How should companies respond when extreme weather affects small-scale producers in their supply chain?. Oxfam Policy and Practice: Private Sector, 9(1), 39-62.

Toha, H, M. (2012). Pengembangan padi gogo mengatasi rawan pangan wilayah marginal. In Badan Penelitian dan Pengembangan Pertanian Prospek pertanian lahan kering dalam 
mendukung ketahanan pangan (144-163). Jakarta: Badan Penelitian dan Pengembangan Pertanian (Balitbangtan)

Toriman, M. E., Er, A. C., Lee, Q. Y., Mastura, S. A., Jali, F. M., Mokhtar, M.,Elfithri, R., Gasim, M.B., Yusop, Z., Aziz, N. A., Ahmah, H. \& Jusoh, H. (2013). Paddy production and climate change variation in Selangor, Malaysia. Asian Social Science, 9(14), 55-62.

Turner, B. L., Menendez, H. M., Gates, R., Tedeschi, L. O., \& Atzori, A. S. (2016). System Dynamics Modeling for Agricultural and Natural Resource Management Issues: Review of Some Past Cases and Forecasting Future Roles. Resources, 5(4), 40.

Van Alfen, N. K. (2014). Encyclopedia of agriculture and food systems. Elsevier.

Van der Vorst, J. G., \& Beulens, A.J.M. (2002). Identifying sources of uncertainty to generate supply chain redesign strategies. International Journal of Physical Distribution and Logistics Management, 32(6), 409-430.

Vorst, J. G. A. J., Beulens, A. J., Wit, W. D., \& Beek, P. V. (1998). Supply chain management in food chains: Improving performance by reducing uncertainty. International Transactions in Operational Research, 5(6), 487-499.

Van der Vorst, J. G., Da Silva, C. A., \& Trienekens, J. H. (2007). Agro-industrial supply chain management: Concepts and application. Rome, Italy: FAO.

van Roosmalen, L., Sonnenborg, T. O., Jensen, K. H., \& Christensen, J. H. (2011). Comparison of hydrological simulations of climate change using perturbation of observations and distribution-based scaling. Vadose Zone Journal, 10(1), 136-150.

van Vuuren, D., J. Edmonds, M. Kainuma, K. Riahi, A. Thomson, K. Hibbard, G. Hurtt, T. Kram, V. Krey, J.-F. Lamarque, T. Masui, M. Meinshausen, N. Nakicenovic, S. Smith, and S. Rose. (2011). The representative concentration pathways: an overview. Climatic Change, 109, doi: 10.1007/s10584-011-0148-z, 5-31.

Verdouw, C. N. (2010). Business process modelling in demand-driven agri-food supply chains: a reference framework. Unpublished dissertation, Wageningen University, Wageningen, Netherland.

Vergara, B. S., Tanaka, A., Lilis, R., \& Puranabhavung, S. (1966). Relationship between duration growth and grain yield of rice plants. Soil Science and Plant Nutrition, 12(1), 3139.

Verón, S. R., de Abelleyra, D., \& Lobell, D. B. (2015) Impacts of precipitation and temperature on crop yields in the Pampas. Climatic Change, 130(2), 235-245. 
Villano, R., \& Fleming, E. (2004). Analysis of technical efficiency in a rainfed lowland rice environment in Central Luzon Philippines using a stochastic frontier production function with a heteroskedastic error structure. Working paper series in Agricultural and Resource Economics (No. 2004-15).

Vogelvang, B. (2005). Econometrics: theory and applications with Eviews. Pearson Education.

Upton, M. (1987). African farm management. Cambridge University Press.

Upton, M. (1996). The economics of tropical farming systems. Cambridge University Press

Wahyudi, B.I., Rial, A., \& Shiddiq, M. (2012). Deskripsi varietas padi. Jakarta: Badan Tenaga Atom.

Wahyuni, S., \& Indraningsih, K. S. (2016, August). Dinamika program dan kebijakan peningkatan produksi padi. In Forum Penelitian Agro Ekonomi(Vol. 21, No. 2, pp. 143156).

Wahyunindyawati. (2012). Pengaruh faktor-faktor produksi terhadap keuntungan usahatani padi. Seminas Competitive Advantage II. Vol 1 No. 2 tahun 2012.

Wang, J. H., Chang, H. H., Lu, C. F., Chang, L. F., \& Tan, C. H. (2012). How important are climate characteristics to the estimation of rice production function?. African Journal of Agricultural Research, 7(35), 4867-4875.

Wang, M. (2014). Integrated Model Development for the Assessment of Food Security in China Related to Climate Change and Adaptation (Doctoral dissertation, University of East Anglia).

Wasserman, L. (2006). All of nonparametric statistics. Springer Science \& Business Media.

Wassmann, R., Jagadish, S. V. K., Heuer, S., Ismail, A., Redona, E., Serraj, R., Singh, R. K., Howell,G., Pathak, H., \& Sumfleth, K. (2009). Climate change affecting rice production: The physiological and agronomic basis for possible adaptation strategies. Advances in Agronomy, 101, 59-122.

Welch, J. R., Vincent, J. R., Auffhammer, M., Moya, P. F., Dobermann, A., \& Dawe, D. (2010). Rice yields in tropical/subtropical Asia exhibit large but opposing sensitivities to minimum and maximum temperatures. Proceedings of the National Academy of Sciences, 107(33), 14562-14567.

Weerakoon, W. M. W., Maruyama, A., \& Ohba, K. (2008). Impact of Humidity on Temperature-Induced Grain Sterility in Rice (Oryza sativa L). Journal of Agronomy and Crop Science, 194(2), 135-140. 
Wibig, J., Maraun, D., Benestad, R., Kjellström, E., Lorenz, P., \& Christensen, O. B. (2015). Projected Change-Models and Methodology. InSecond Assessment of Climate Change for the Baltic Sea Basin (pp. 189-215). Springer International Publishing.

Williams, J. (2012). Competition and efficiency in international food supply chains: Improving food security. Routledge.

Wirajaswadi, L. (2004). Padi gogorancah tanpa olah tanah prospeknya dalam meningkatkan pendapatan petani sawah tadah hujan. Seminar Nasional Pemberdayaan Petani Miskin di Lahan Marginal melalui Inovasi Teknologi Tepat Guna.

Xiong W, Lin E, Ju H., Xu.,Y. (2007). Climate change and critical thresholds in China's food security. Climatic Change, 81(2): 205-221.

Xiao, R., Cai, Z., \& Zhang, X. (2012). A production optimization model of supply-driven chain with quality uncertainty. Journal of Systems Science and Systems Engineering, 21(2), 144-160.

Yaffee, R. A., \& McGee, M. (2000). An introduction to time series analysis and forecasting: with applications of SAS® and SPSS®. Academic Press.

Yasin, I., Mansur M., Idris, H., \& Suriadi, A.(2004). Pemanfaatan indeks osilasi selatan (IOS) untuk mendukung model pertanian strategicdi lahan tadah hujan pulau Lombok. (2004). Jurnal Agrometerologi,18(2), 24-36.

Ye, C., Tenorio, F. A., Argayoso, M. A., Laza, M. A., Koh, H.-J., Redoña, E. D., Gregorio, G. B. (2015). Identifying and confirming quantitative trait loci associated with heat tolerance at flowering stage in different rice populations.BMC Genetics, 16, 41. http://doi.org/10.1186/s12863-015-0199-7

Yegbemey, R. N., Kabir, H., Awoye, O. H., Yabi, J. A., \& Paraïso, A. A. (2014). Managing the agricultural calendar as coping mechanism to climate variability: A case study of maize farming in northern Benin, West Africa.Climate Risk Management, 3, 13-23.

Yoshida (1978). Tropical rice and climate. 1978's Intenational Rice Research Conference. Los Banos, Philippines.

Yoshida, S. (1981). Fundamentals of rice crop science. Los Banos, Philippines : IRRI Yule, G. U. and Kendall, M. G. (1950), An Introduction to the Theory of Statistics, 3rd edition, Harper Publishing Company, 162-163.

Yulia, R \& Casper, A. (2011). Pengaruh penyimpanan terhadap kualitas beras : Perubahan sifat kimia selama penyimpanan. Technical Report. Diponegoro University. 
Yunizar. (2014). Kajian teknologi hemat air pada padi gogo pada lahan kering masam dalam mengantisipasi perubahan iklim di propinsi Riau. Prosiding Seminar Nasional Lahan Suboptimal 2014, Palembang 26-27 September 2014. http://purplso.unsri.ac.id/userfiles/128_yun-red(3).pdf

Zeigler, R. S., \& Mohanty, S. (2010). Support for international agricultural research: current status and future challenges. New biotechnology, 27(5), 565-572.

Zhang, T., Zhu, J., \& Yang, X.(2008). Non-stationary thermal time accumulation reduces the predictability of climate change effects on agriculture.Agricultural and Forest Meteorology, 148(10): 1412-1418.

Zhang, T., Zhu, J., \& Wassmann, R. (2010). Responses of rice yields to recent climate change in China: An empirical assessment based on long-term observations at different spatial scales (1981-2005). Agricultural and Forest Meteorology, 150(7/8): 1128-1137

Zhang, T., Zhu, J., \& Wassmann, R. (2010). Responses of rice yields to recent climate change in China: An empirical assessment based on long-term observations at different spatial scales (1981-2005). Agricultural and Forest Meteorology, 150(7/8): 1128-1137

Zhang, Y., Tang, Q., Peng, S., Zou, Y., Chen, S., Shi, W., Qin, J., \& Laza, M. R. C. (2013). Effects of high night temperature on yield and agronomic traits of irrigated rice under field chamber system condition. Australian Journal of Crop Science, 7(1), 7.

Zhao, X., \& Fitzgerald, M. (2013). Climate change: Implications for the yield of edible rice. PloS one, 8(6), e66218.

Ziska, L. H., \& Bunce, J. A. (2007). Predicting the impact of changing $\mathrm{CO}_{2}$ on crop yields: some thoughts on food. New Phytologist, 175(4), 607-618.

Ziska, L. H., \& Manalo, P. A. (1996). Increasing night temperature can reduce seed set and potential yield of tropical rice. Functional Plant Biology, 23(6), 791-794.

Zolvinski S. 2008. Listening to farmers: qualitative impact assessments in unfavorable rice environments. IRRI Technical Bulletin No. 12. Los Baños (Philippines): International Rice Research Institute. 47 p.

Zulmi, R., \& Arianti, F. (2011). Pengaruh luas lahan, tenaga kerja, penggunaan benih dan pupuk terhadap produksi padi di Jawa Tengah tahun 1994-2008 (Undergraduate thesis, Universitas Diponegoro). 


\section{Appendix A. The kinds of structural break (Chapter 5)}

There are two types structural break: a structural break due to the change of trend and the change of level (intercept).

a) a structural break due to the change of trend

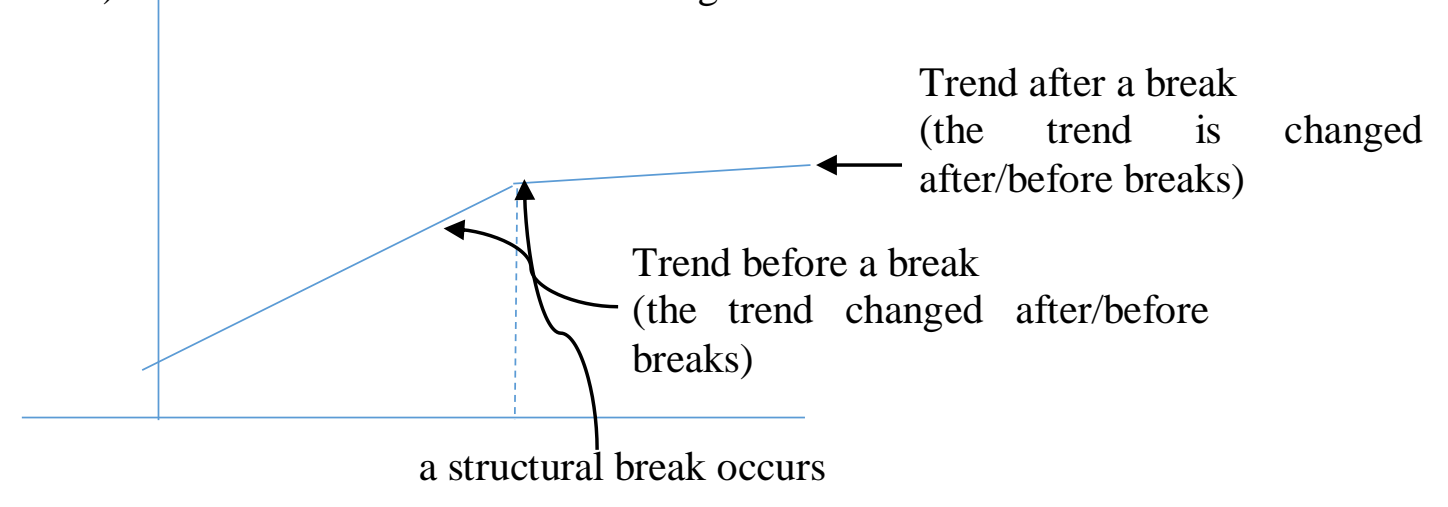

Table A1. a structural break due to the change of trend

This structural break occurs due to a change of trend. For example, yield of wetland farming increased about $4 \%$ a year (1976-1995) and then a structural break occurred in 1996 so that the yield between 1995 and 2011 increased less than $1 \%$ a year.

b) a structural break due to the change of level (intercept)

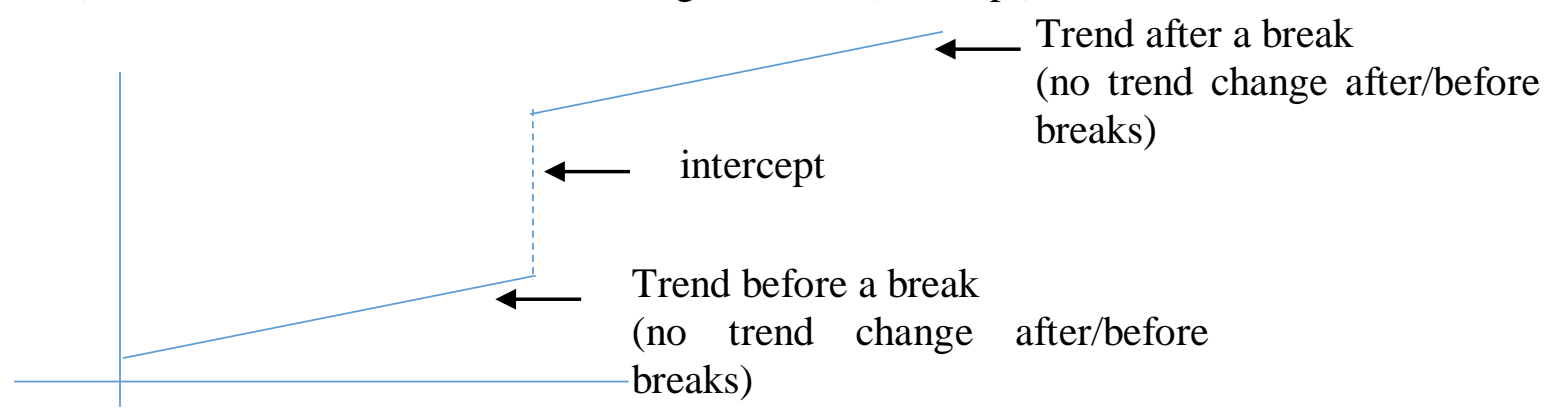

Table A2. A structural break due to the change of intercept or level

This structural break occurs owing to a change of level or intercept. For example, yield of dryland farming since 2008 experienced a rapid increase due to the introduction of new varieties in 2008 under the national rice program. Before 2008 dryland farmers planted unsuitable rice varieties and then since 2008, dryland farmers have planted more suitable rice varieties. 
this page intentionally left blank 


\section{Appendix B. Correlation analysis after first differencing (Chapter 5)}

Both tables in this appendix depict correlation analysis based on the first differential in dryland and wetland farming respectively. For dryland rice yield and wetland rice yield, minimum temperature has a significant correlation. In wetland farming, labour almost has a significant correlation with rice yield $(\mathrm{p}=.1)$.

\begin{tabular}{|l|c|c|}
\hline \multicolumn{1}{|c|}{ Variables } & r (correlation) & p-values \\
\hline Seasonal Minimum Temperature & $\mathrm{r}=-.31$ & $\mathrm{p}>.1$ \\
\hline Seasonal Maximum Temperature & $\mathrm{r}=-.21$ & $\mathrm{p}<.1$ \\
\hline Seasonal Rainfall & $\mathrm{r}=8 \mathrm{e}-3$ & $\mathrm{p}>.1$ \\
\hline Capital & $\mathrm{r}=-.02$ & $\mathrm{p}>.1$ \\
\hline Labour & $\mathrm{r}=-.03$ & $\mathrm{p}>.1$ \\
\hline Seed & $\mathrm{r}=.17$ & $\mathrm{p}>.1$ \\
\hline Fertiliser & $\mathrm{r}=-.08$ & $\mathrm{p}>.1$ \\
\hline Pesticide & $\mathrm{r}=-.03$ & $\mathrm{p}>.1$ \\
\hline
\end{tabular}

Table C1. Correlation analysis based on the first differential in dryland farming

\begin{tabular}{|l|c|c|}
\hline \multicolumn{1}{|c|}{ Variables } & r (correlation) & p-values \\
\hline Seasonal Minimum Temperature & $\mathbf{r}=-.35$ & $\mathbf{p}<. \mathbf{0 5}$ \\
\hline Seasonal Maximum Temperature & $\mathrm{r}=-.23$ & $\mathrm{p}>.1$ \\
\hline Seasonal Rainfall & $\mathrm{r}=.09$ & $\mathrm{p}>.1$ \\
\hline Capital & $\mathrm{r}=-.11$ & $\mathrm{p}>.1$ \\
\hline Labour & $\mathbf{r}=. \mathbf{2 8}$ & $\mathbf{p}=. \mathbf{1}$ \\
\hline Seed & $\mathrm{r}=.17$ & $\mathrm{r}>.1$ \\
\hline Fertiliser & $\mathrm{r}=.02$ & $\mathrm{p}>.1$ \\
\hline Pesticide & $\mathrm{r}=-.14$ & $\mathrm{p}>.1$ \\
\hline
\end{tabular}

Table C2. Correlation analysis based on the first differential in wetland farming 
this page intentionally left blank 


\section{Appendix C. The Historical System Dynamics Model (Chapter 6)}

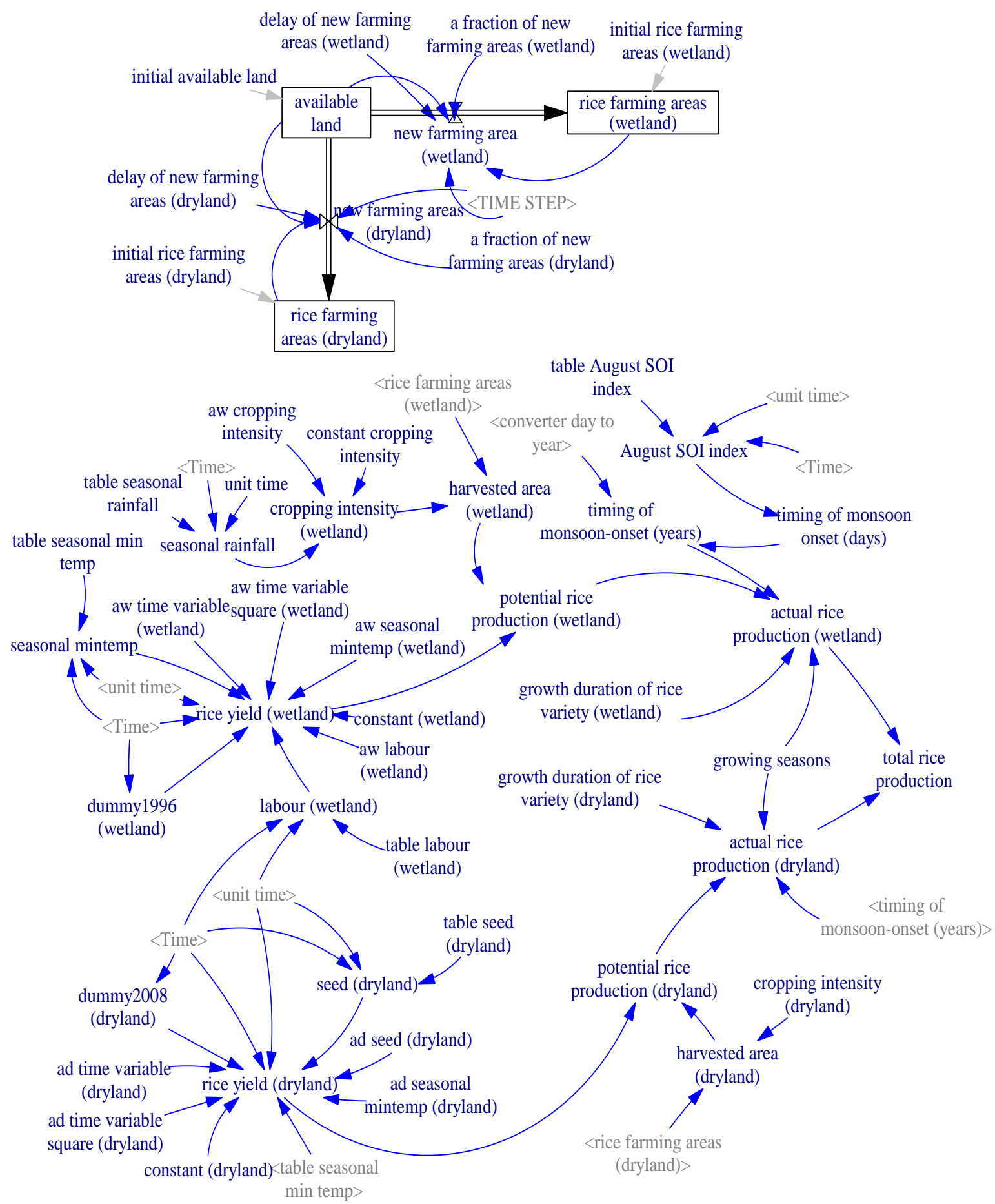

Figure C1. A complete of the SD historical model (the model used to reproduce observed system) 
this page intentionally left blank 
Appendix D. System Dynamics Model Documentation (SD Historical Model - Chapter 6)

Documentation of HISTORICAL_SD_MODEL

Model Assessment Results

\begin{tabular}{|l|c|}
\hline \multicolumn{1}{|c|}{ Model Information } & Number \\
\hline Total Number of Variables & 58 \\
\hline \begin{tabular}{l|c|} 
Total Number of State Variables \\
(Level+Smooth+Delay Variables)
\end{tabular} & $5(8.6 \%)$ \\
\hline $\begin{array}{l}\text { Total Number of Stocks (Stocks in } \\
\text { Level+Smooth+Delay Variables) } \dagger\end{array}$ & $9(15.5 \%)$ \\
\hline Time Unit & year \\
\hline Initial Time & 1976 \\
\hline Final Time & 2014 \\
\hline Reported Time Interval & 1 \\
\hline Time Step & 0.0078125 \\
\hline \hline Model Is Fully Formulated & Yes \\
\hline
\end{tabular}




\begin{tabular}{|c|c|c|c|}
\hline Module & Group & Type & Variable Name and Description \\
\hline Default & $\begin{array}{l}\text { HISTORI } \\
\text { CAL SD } \\
\text { MODEL } \\
\text { (Default) }\end{array}$ & $\begin{array}{l}1 \\
C \\
\text { Vab }\end{array}$ & $\begin{array}{l}\text { "a fraction of new farming areas (dryland)" (1/year) } \\
=0.0355 \\
\text { Description: This is annual growth (fraction) of new dryland farming based on observed data between } 1976 \text { and } 2011 . \\
\text { Present in } 1 \text { view: } \\
\text { View } 1 \\
\text { Used by: } \\
\text { "new farming areas (dryland)" - This is an increase in dryland farming area a year. }\end{array}$ \\
\hline Default & $\begin{array}{l}\text { HISTORI } \\
\text { CAL SD } \\
\text { MODEL } \\
\text { (Default) }\end{array}$ & $\begin{array}{l}\# 2 \\
C \\
\text { VAB }\end{array}$ & $\begin{array}{l}\text { "a fraction of new farming areas (wetland)" (1/year) } \\
=0.0115 \\
\text { Description: This is annual growth (fraction) of new wetland farming based on observed data between } 1976 \text { and } 2011 . \\
\text { Present in } 1 \text { view: } \\
\text { View } 1 \\
\text { Used by: } \\
\text { "new farming area (wetland)" - This is an increase in wetland farming area a year. }\end{array}$ \\
\hline Default & $\begin{array}{l}\text { HISTORI } \\
\text { CAL SD } \\
\text { MODEL } \\
\text { (Default) }\end{array}$ & $\begin{array}{l}\# 3 \\
D E\end{array}$ & $\begin{array}{l}\text { "actual rice production (dryland)" (tonnes/year) } \\
=\text { DELAY3(STEP("potential rice production (dryland)","timing of monsoon-onset (years)"), "duration growth of rice variety (dryland)"* } * \text { growing seasons) } \\
\text { Description: this is actual rice production in dryland farming between September year t and August year } t+1 . \\
\text { Present in } 1 \text { view: } \\
\text { - View } 1 \\
\text { Used by: } \\
\quad \text { total rice production - a sum of rice production in wetland and dryland areas }\end{array}$ \\
\hline Default & $\begin{array}{l}\text { HISTORI } \\
\text { CAL SD } \\
\text { MODEL } \\
\text { (Default) }\end{array}$ & $\begin{array}{l}\# 4 \\
\mathrm{DE}\end{array}$ & $\begin{array}{l}\text { "actual rice production (wetland)" (tonnes/year) } \\
\text { = DELAY3( STEP("potential rice production (wetland)","timing of monsoon-onset (years)"), "duration growth of rice variety (wetland)"*growing } \\
\text { seasons) } \\
\text { Description: this is actual rice production in wetland farming between September year t and August year t+1. } \\
\text { Present in } 1 \text { view: } \\
\text { View } 1 \\
\text { Used by: } \\
\text { total rice production - a sum of rice production in wetland and dryland areas }\end{array}$ \\
\hline Default & $\begin{array}{l}\text { HISTORI } \\
\text { CAL SD } \\
\text { MODEL } \\
\text { (Default) }\end{array}$ & $\begin{array}{l}\# 5 \\
C \\
\text { VAB }\end{array}$ & $\begin{array}{l}\text { "ad seasonal mintemp (dryland)" (tonnes/ha/year/celcius) } \\
=-0.120636 \\
\text { Description: this is a coefficient of minimum temperature to measure dryland rice yield } \\
\text { Present in } 1 \text { view: } \\
\text { - View } 1 \\
\text { Used by: } \\
\text { "rice yield (dryland)" - this represents dryland rice yield between between September } \mathrm{t} \text { and August year } \mathrm{t}+1 \text {. }\end{array}$ \\
\hline
\end{tabular}




\begin{tabular}{|c|c|c|c|}
\hline Default & $\begin{array}{l}\text { HISTORI } \\
\text { CAL SD } \\
\text { MODEL } \\
\text { (Default) }\end{array}$ & $\begin{array}{l}\# 6 \\
\text { C } \\
\text { VAB }\end{array}$ & $\begin{array}{l}\text { "ad seed (dryland)" (tonnes/ha/year/(IDR/year)) } \\
=0.01843 \\
\text { Description: This is a coefficient of seed to measure dryland rice yield } \\
\text { Present in } 1 \text { view: } \\
\bullet \quad \text { View } 1 \\
\text { Used by: } \\
\qquad \quad \text { "rice yield (dryland)" - this represents dryland rice yield between between September t and August year t+1. }\end{array}$ \\
\hline Default & $\begin{array}{l}\text { HISTORI } \\
\text { CAL SD } \\
\text { MODEL } \\
\text { (Default) }\end{array}$ & $\begin{array}{l}\# 7 \\
\text { C } \\
\text { VAB }\end{array}$ & $\begin{array}{l}\text { "ad time variable (dryland)" (tonnes/ha/year) } \\
=0.062616 \\
\text { Description: this is a coefficient of linear time variable of dryland rice. This represent the effects of technological progress on dryland rice yield. } \\
\text { Present in } 1 \text { view: } \\
\text { Uiew } 1 \\
\text { Used by: } \\
\quad \text { "rice yield (dryland)" - this represents dryland rice yield between between September } \mathrm{t} \text { and August year } \mathrm{t}+1 \text {. }\end{array}$ \\
\hline Default & $\begin{array}{l}\text { HISTORI } \\
\text { CAL SD } \\
\text { MODEL } \\
\text { (Default) }\end{array}$ & $\begin{array}{l}\# 8 \\
C \\
\text { VAB }\end{array}$ & $\begin{array}{l}\text { "ad time variable square (dryland)" (tonnes/ha/year) } \\
=-0.000566 \\
\text { Description: this is a coefficient of squared time variable of dryland rice. This represent the effects of technological progress on dryland rice yield. } \\
\text { Present in } 1 \text { view: } \\
\text { • } \\
\text { Used by: } \\
\text { - } \quad \text { "rice yield (dryland)" - this represents dryland rice yield between between September } \mathrm{t} \text { and August year } \mathrm{t}+1 .\end{array}$ \\
\hline Default & $\begin{array}{l}\text { HISTORI } \\
\text { CAL SD } \\
\text { MODEL } \\
\text { (Default) }\end{array}$ & $\begin{array}{l}\# 9 \\
A \\
\text { VAB }\end{array}$ & $\begin{array}{l}\text { August SOI index (Dmnl) } \\
=\text { table August SOI index(Time/unit time) } \\
\text { Description: August SOI index based on observed data between } 1976 \text { and } 2011 . \\
\text { Present in } 1 \text { view: } \\
\text { Used by: } \\
\text { View } 1 \\
\text { dimension }\end{array}$ \\
\hline Default & $\begin{array}{l}\text { HISTORI } \\
\text { CAL SD } \\
\text { MODEL } \\
\text { (Default) }\end{array}$ & 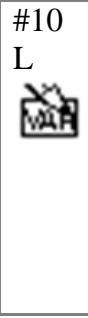 & $\begin{array}{l}\text { available land (ha) } \\
=\int-" \text { new farming area (wetland)"-"new farming areas (dryland)" } d t+[\text { initial available land }] \\
\text { Description: Available land is potential land to be converted into wetland and dryland farming. This land is reserved to increase areas of wetland and } \\
\text { dryland farming. } \\
\text { Present in } 1 \text { view: } \\
\text { View } 1 \\
\text { Used by: } \\
\quad \text { "new farming area (wetland)" - This is an increase in wetland farming area a year. }\end{array}$ \\
\hline
\end{tabular}




\begin{tabular}{|c|c|c|c|}
\hline & & & - $\quad$ "new farming areas (dryland)" - This is an increase in dryland farming area a year. \\
\hline Default & $\begin{array}{l}\text { HISTORI } \\
\text { CAL SD } \\
\text { MODEL } \\
\text { (Default) }\end{array}$ & $\begin{array}{l}\# 11 \\
C \\
\text { VAB }\end{array}$ & $\begin{array}{l}\text { aw cropping intensity }(\mathrm{year} / \mathrm{mm}) \\
=0.000233 \\
\text { Description: This is a coefficient of an equation in estimating the effect of seasonal rainfall on cropping intensity of wetland farming } \\
\text { Present in } 1 \text { view: } \\
\text { - } \\
\text { Used by: } \\
\text { - }\end{array}$ \\
\hline Default & $\begin{array}{l}\text { HISTORI } \\
\text { CAL SD } \\
\text { MODEL } \\
\text { (Default) }\end{array}$ & $\begin{array}{l}\# 12 \\
C \\
\text { VAB }\end{array}$ & $\begin{array}{l}\text { "aw labour (wetland)" (tonnes/ha/year/(IDR/year)) } \\
=0.003383 \\
\text { Description: This is a coefficient of used labour in wetland farming } \\
\text { Present in } 1 \text { view: } \\
\text { - } \quad \text { View } 1 \\
\text { Used by: } \\
\text { "rice yield (wetland)" - this represents wetland rice yield between between September } t \text { and August year } \mathrm{t}+1 \text {. }\end{array}$ \\
\hline Default & $\begin{array}{l}\text { HISTORI } \\
\text { CAL SD } \\
\text { MODEL } \\
\text { (Default) }\end{array}$ & $\begin{array}{l}\# 13 \\
C \\
\text { VAB }\end{array}$ & $\begin{array}{l}\text { "aw seasonal mintemp (wetland)" (tonnes/ha/year/celcius) } \\
=-0.196844 \\
\text { Description: This is a coefficient of minimum temperature for wetland farming } \\
\text { Present in } 1 \text { view: } \\
\text { View } 1 \\
\text { Used by: } \\
\quad \text { "rice yield (wetland)" - this represents wetland rice yield between between September } \mathrm{t} \text { and August year } \mathrm{t}+1 \text {. }\end{array}$ \\
\hline Default & $\begin{array}{l}\text { HISTORI } \\
\text { CAL SD } \\
\text { MODEL } \\
\text { (Default) }\end{array}$ & $\begin{array}{l}\# 14 \\
C \\
\text { VAB }\end{array}$ & $\begin{array}{l}\text { "aw time variable (wetland)" (tonnes/ha/year) } \\
=0.181188 \\
\text { Description: This is a coefficient of linear time variable of wetland rice. This represent the effects of technological progress on wetland rice yield. } \\
\text { Present in } 1 \text { view: } \\
\text { Used by: } \\
\quad \text { View } 1 \\
\quad \text { "rice yield (wetland)" - this represents wetland rice yield between between September t and August year } \mathrm{t}+1 \text {. }\end{array}$ \\
\hline Default & $\begin{array}{l}\text { HISTORI } \\
\text { CAL SD } \\
\text { MODEL } \\
\text { (Default) }\end{array}$ & $\begin{array}{l}\# 15 \\
C \\
\text { VAB }\end{array}$ & $\begin{array}{l}\text { "aw time variable square (wetland)" (tonnes/ha/year) } \\
=-0.004098 \\
\text { Description: This is a coefficient of squared time variable of wetland rice. This represent the effects of technological progress on wetland rice yield. } \\
\text { Present in } 1 \text { view: } \\
\text { - View } 1 \\
\text { Used by: } \\
\text { "rice yield (wetland)" - this represents wetland rice yield between between September } \mathrm{t} \text { and August year } \mathrm{t}+1 \text {. }\end{array}$ \\
\hline Default & HISTORI & $\# 16$ & "constant (dryland)" (tonnes/ha/year) \\
\hline
\end{tabular}




\begin{tabular}{|c|c|c|c|}
\hline & $\begin{array}{l}\text { CAL SD } \\
\text { MODEL } \\
\text { (Default) }\end{array}$ & $\begin{array}{l}\mathrm{C} \\
\text { WAB }\end{array}$ & $\begin{array}{l}=3.71407 \\
\text { Description: this is a constant of a statistical model in measuring dryland rice yield } \\
\text { Present in } 1 \text { view: } \\
\text { - } \\
\text { Used by: } \\
\text { - } \quad \text { "riew } 1 \\
\quad \text { rice yield (dryland)" - this represents dryland rice yield between between September } t \text { and August year } \mathrm{t}+1 \text {. }\end{array}$ \\
\hline Default & $\begin{array}{l}\text { HISTORI } \\
\text { CAL SD } \\
\text { MODEL } \\
\text { (Default) }\end{array}$ & $\begin{array}{l}\# 17 \\
\text { C } \\
\text { VAB }\end{array}$ & $\begin{array}{l}\text { "constant (wetland)" (tonnes/ha/year) } \\
=6.73 \\
\text { Description: this is a constant of a statistical model in measuring wetland rice yield } \\
\text { Present in } 1 \text { view: } \\
\bullet \quad \text { View } 1 \\
\text { Used by: } \\
\text { - } \quad \text { rice yield (wetland)" - this represents wetland rice yield between between September t and August year } \mathrm{t}+1 \text {. }\end{array}$ \\
\hline Default & $\begin{array}{l}\text { HISTORI } \\
\text { CAL SD } \\
\text { MODEL } \\
\text { (Default) }\end{array}$ & $\begin{array}{l}\# 18 \\
C \\
\text { VAB }\end{array}$ & $\begin{array}{l}\text { constant cropping intensity (Dmnl) } \\
=0.935 \\
\text { Description: This is a constant of an equation in estimating the effect of seasonal rainfall on cropping intensity of wetland farming } \\
\text { Present in } 1 \text { view: } \\
\text { View } 1 \\
\text { Used by: } \\
\text { "cropping intensity (wetland)" - this is a cropping intensity in wetland farming based on the period 1976-2011. }\end{array}$ \\
\hline Default & $\begin{array}{l}\text { HISTORI } \\
\text { CAL SD } \\
\text { MODEL } \\
\text { (Default) }\end{array}$ & $\begin{array}{l}\# 19 \\
C \\
\text { VAB }\end{array}$ & $\begin{array}{l}\text { converter day to year (day/year) } \\
=365 \\
\text { Description: this is a variable which is used to convert a day dimension to be a year dimension } \\
\text { Present in } 1 \text { view: } \\
\text { Used by: } \\
\text { View } 1 \\
\text { dimension. }\end{array}$ \\
\hline Default & $\begin{array}{l}\text { HISTORI } \\
\text { CAL SD } \\
\text { MODEL } \\
\text { (Default) }\end{array}$ & $\begin{array}{l}\# 20 \\
C \\
\text { WAB }\end{array}$ & $\begin{array}{l}\text { "cropping intensity (dryland)" (Dmnl) } \\
=1 \\
\text { Description: This is a division between harvested dryland areas and dryland rice areas. Based observed data 1976-2011, the cropping intensity of } \\
\text { dryland farming is } 1 \text { or 100\%. } \\
\text { Present in 1 view: } \\
\text { View } 1 \\
\text { Used by: } \\
\text { "harvested area (dryland)" - This is a total harvested area in dryland farming between September year t and August year } \mathrm{t}+1 .\end{array}$ \\
\hline Default & HISTORI & $\# 21$ & "cropping intensity (wetland)" (Dmnl) \\
\hline
\end{tabular}




\begin{tabular}{|c|c|c|c|}
\hline & $\begin{array}{l}\text { CAL SD } \\
\text { MODEL } \\
\text { (Default) }\end{array}$ & $\begin{array}{l}\text { A } \\
\text { Wab }\end{array}$ & $\begin{array}{l}=(\text { seasonal rainfall } * \text { aw cropping intensity }+ \text { constant cropping intensity }) \\
\text { Description: } \text { this is a cropping intensity in wetland farming based on the period 1976-2011. } \\
\text { Present in } 1 \text { view: } \\
\text { View } 1 \\
\text { Used by: } \\
\text { - } \quad \text { "harvested area (wetland)" - this is total harvested area in wetland farming between September year t and August year } t+1\end{array}$ \\
\hline Default & $\begin{array}{l}\text { HISTORI } \\
\text { CAL SD } \\
\text { MODEL } \\
\text { (Default) }\end{array}$ & $\begin{array}{l}\# 22 \\
C \\
\text { VAB }\end{array}$ & $\begin{array}{l}\text { "delay of new farming areas (dryland)" (year) } \\
=1 \\
\text { Description: The needed time for opening new dryland farming. In general, the government prepares programs to open new farming area } 1 \text { year prior to } \\
\text { the intended year. } \\
\text { Present in } 1 \text { view: } \\
\text { View } 1 \\
\text { Used by: } \\
\text { - } \quad \text { new farming areas (dryland)" - This is an increase in dryland farming area a year. }\end{array}$ \\
\hline Default & $\begin{array}{l}\text { HISTORI } \\
\text { CAL SD } \\
\text { MODEL } \\
\text { (Default) }\end{array}$ & $\begin{array}{l}\# 23 \\
C \\
\text { VAB }\end{array}$ & $\begin{array}{l}\text { "delay of new farming areas (wetland)" (year) } \\
=1 \\
\text { Description: The needed time for opening new wetland farming. In general, the government prepares programs to open new farming area } 1 \text { year prior to } \\
\text { the intended year. } \\
\text { Present in 1 view: } \\
\text { View } 1 \\
\text { Used by: } \\
\text { "new farming area (wetland)" - This is an increase in wetland farming area a year. }\end{array}$ \\
\hline Default & $\begin{array}{l}\text { HISTORI } \\
\text { CAL SD } \\
\text { MODEL } \\
\text { (Default) }\end{array}$ & $\begin{array}{l}\# 24 \\
A \\
\text { VAB }\end{array}$ & $\begin{array}{l}\text { "dummy1996 (wetland)" (tonnes/ha/year) } \\
\text { = IF THEN ELSE(Time<1996, 0, 1) } \\
\text { Description: this is a dummy variable representing a structural break of wetland farming in } 1996 \\
\text { Present in } 1 \text { view: } \\
\text { - View } 1 \\
\text { Used by: } \\
\text { - } \quad \text { "rice yield (wetland)" - this represents wetland rice yield between between September t and August year } \mathrm{t}+1 \text {. }\end{array}$ \\
\hline Default & $\begin{array}{l}\text { HISTORI } \\
\text { CAL SD } \\
\text { MODEL } \\
\text { (Default) }\end{array}$ & $\begin{array}{l}\# 25 \\
A \\
\text { VAB }\end{array}$ & $\begin{array}{l}\text { "dummy2008 (dryland)" (tonnes/ha/year) } \\
=\text { IF THEN ELSE(Time>=2008, } 0.860216,0) \\
\text { Description: this is a dummy variable representing a structural break of dryland farming in } 2008 \\
\text { Present in } 1 \text { view: } \\
\text { • View } 1 \\
\text { Used by: } \\
\text { - } \quad \text { "rice yield (dryland)" - this represents dryland rice yield between between September } t \text { and August year } \mathrm{t}+1 .\end{array}$ \\
\hline Default & HISTORI & \#26 & "duration growth of rice variety (dryland)" (year) \\
\hline
\end{tabular}




\begin{tabular}{|c|c|c|c|}
\hline & $\begin{array}{l}\text { CAL SD } \\
\text { MODEL } \\
\text { (Default) }\end{array}$ & & $\begin{array}{l}=110 / 365 \\
\text { Description: the duration growth of dryland rice variety. The duration growth of rice variety is about } 120 \text { days which is converted into (110/365) years. } \\
\text { Present in } 1 \text { view: } \\
\text { - } \\
\text { Used by: } \\
\text { - }\end{array}$ \\
\hline Default & $\begin{array}{l}\text { HISTORI } \\
\text { CAL SD } \\
\text { MODEL } \\
\text { (Default) }\end{array}$ & $\begin{array}{l}\# 27 \\
A \\
\text { VAB }\end{array}$ & $\begin{array}{l}\text { "duration growth of rice variety (wetland)" (year) } \\
=115 / 365 \\
\text { Description: the duration growth of wetland rice variety. The duration growth of rice variety is about } 120 \text { days which is converted into (115/365) years. } \\
\text { Present in } 1 \text { view: } \\
\text { - } \\
\text { Used by: } \\
\text { "actual rice production (wetland)" - this is actual rice production in wetland farming between September year } \mathrm{t} \text { and August year } \mathrm{t}+1 \text {. }\end{array}$ \\
\hline Default & $\begin{array}{l}\text { HISTORI } \\
\text { CAL SD } \\
\text { MODEL } \\
\text { (Default) }\end{array}$ & $\begin{array}{l}\# 29 \\
C \\
\text { VAB }\end{array}$ & 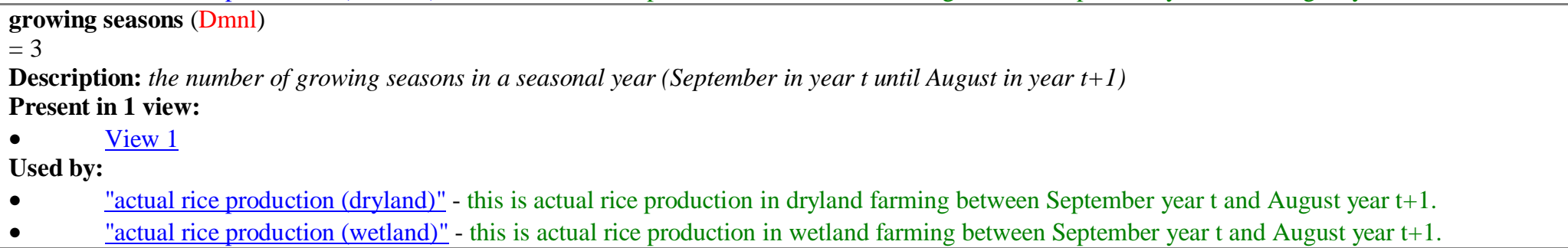 \\
\hline Default & $\begin{array}{l}\text { HISTORI } \\
\text { CAL SD } \\
\text { MODEL } \\
\text { (Default) }\end{array}$ & $\begin{array}{l}\# 30 \\
A \\
\text { VAB }\end{array}$ & $\begin{array}{l}\text { "harvested area (dryland)" (ha) } \\
=\text { "rice farming areas (dryland)" } * \text { "cropping intensity (dryland)" } \\
\text { Description: This is a total harvested area in dryland farming between September year t and August year } t+1 \text {. } \\
\text { Present in } 1 \text { view: } \\
\text { View } 1 \\
\text { Used by: } \\
\text { case the timing of monsoon onset is not delayed or nor earlier. }\end{array}$ \\
\hline Default & $\begin{array}{l}\text { HISTORI } \\
\text { CAL SD } \\
\text { MODEL } \\
\text { (Default) }\end{array}$ & $\begin{array}{l}\# 31 \\
A \\
\text { VAB }\end{array}$ & $\begin{array}{l}\text { "harvested area (wetland)" (ha) } \\
=\text { "cropping intensity (wetland)"*"rice farming areas (wetland)" } \\
\text { Description: this is total harvested area in wetland farming between September year t and August year } t+1 \\
\text { Present in } 1 \text { view: } \\
\text { Used by: } \\
\text { " } \\
\text { case the timing of monsoon onset is not delayed or nor earlier. }\end{array}$ \\
\hline
\end{tabular}




\begin{tabular}{|c|c|c|c|}
\hline Default & $\begin{array}{l}\text { HISTORI } \\
\text { CAL SD } \\
\text { MODEL } \\
\text { (Default) }\end{array}$ & $\begin{array}{l}\# 32 \\
\text { LI,C } \\
\text { VAB }\end{array}$ & $\begin{array}{l}\text { initial available land (ha) } \\
\text { = } 843000 \\
\text { Description: total potential land to be converted into wetland and dryland farming. This land is secured by the law. } \\
\text { Present in } 1 \text { view: } \\
\text { Used by: } \\
\text { - } \\
\text { wetland and dryland farming. . }\end{array}$ \\
\hline Default & $\begin{array}{l}\text { HISTORI } \\
\text { CAL SD } \\
\text { MODEL } \\
\text { (Default) }\end{array}$ & $\begin{array}{l}\# 33 \\
C \\
\text { VAB }\end{array}$ & $\begin{array}{l}\text { "initial rice farming areas (dryland)" (ha) } \\
=14274 \\
\text { Description: initial rice dryland areas } \\
\text { Present in } 1 \text { view: } \\
\text { View } 1 \\
\text { Used by: } \\
\quad \text { "rice farming areas (dryland)" - rice farming area is total physical land of wetland farming. }\end{array}$ \\
\hline Default & $\begin{array}{l}\text { HISTORI } \\
\text { CAL SD } \\
\text { MODEL } \\
\text { (Default) }\end{array}$ & $\begin{array}{l}\# 34 \\
C \\
\text { VAB }\end{array}$ & $\begin{array}{l}\text { "initial rice farming areas (wetland)" (ha) } \\
=157530 \\
\text { Description: initial rice wetland areas } \\
\text { Present in } 1 \text { view: } \\
\text { View } 1 \\
\text { Used by: } \\
\text { "rice farming areas (wetland)" - rice farming area is total physical land of wetland farming. }\end{array}$ \\
\hline Default & Control & $\begin{array}{l}\# 35 \\
\text { C } \\
\text { WAB }\end{array}$ & $\begin{array}{l}\text { INITIAL TIME (year) } \\
=1976 \\
\text { Description: The initial time for the simulation. } \\
\text { Present in } 1 \text { view: } \\
\text { Uiew } 1 \\
\text { Used by: } \\
\text { Time - Internally defined simulation time. }\end{array}$ \\
\hline Default & $\begin{array}{l}\text { HISTORI } \\
\text { CAL SD } \\
\text { MODEL } \\
\text { (Default) }\end{array}$ & $\begin{array}{l}\# 36 \\
A \\
\text { VAB }\end{array}$ & $\begin{array}{l}\text { "labour (wetland)" (IDR/year) } \\
=\text { "table labour (wetland)" (Time/unit time) } \\
\text { Description: the amount of labour at any given year during simulation } \\
\text { Present in } 1 \text { view: } \\
\text { View } 1 \\
\text { Used by: } \\
\text { - }\end{array}$ \\
\hline Default & HISTORI & $\# 37$ & "new farming area (wetland)" (ha/year) \\
\hline
\end{tabular}




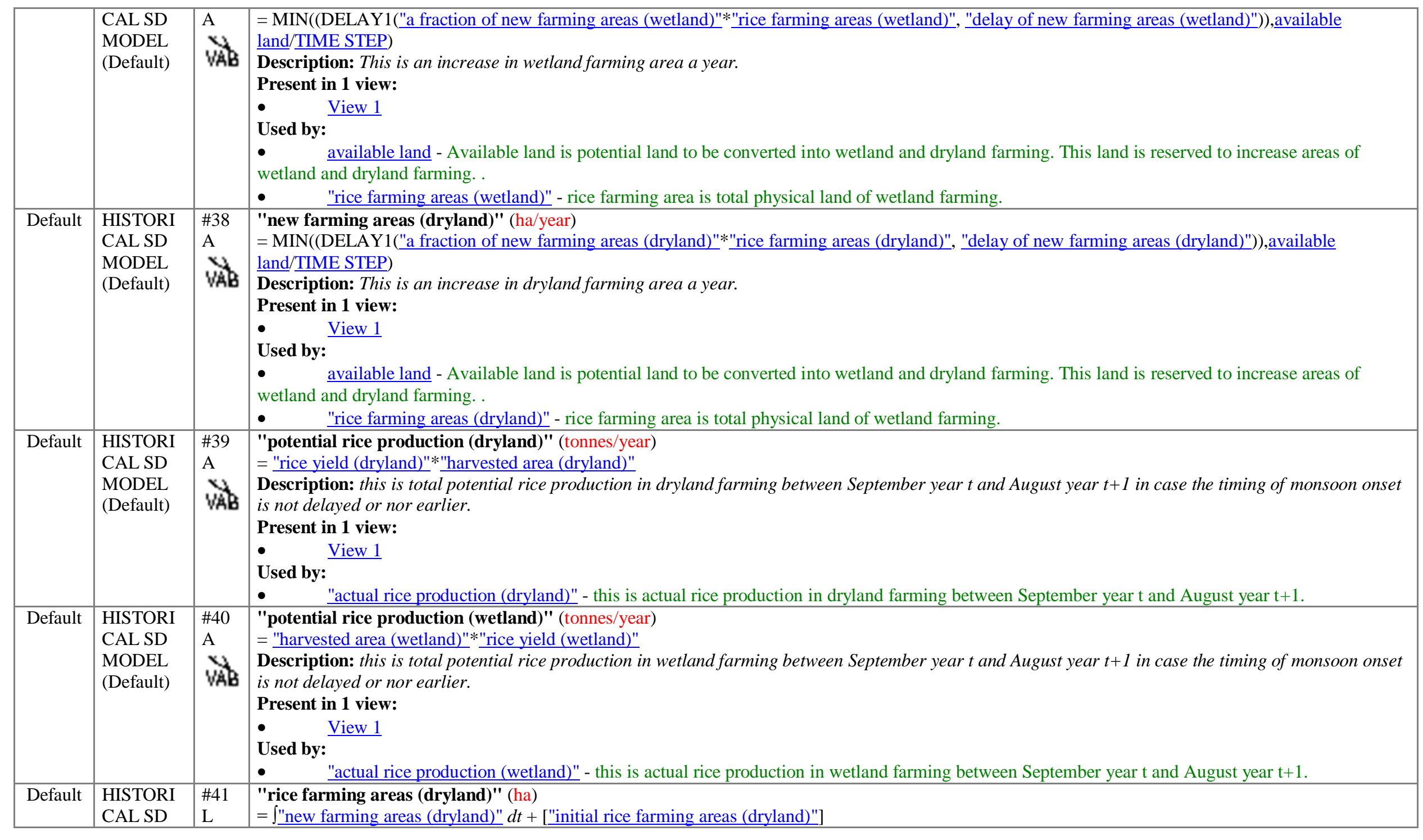




\begin{tabular}{|c|c|c|c|}
\hline & $\begin{array}{l}\text { MODEL } \\
\text { (Default) }\end{array}$ & 峈 & $\begin{array}{l}\text { Description: rice farming area is total physical land of wetland farming. } \\
\text { Present in } 1 \text { view: } \\
\text { View } 1 \\
\text { Used by: } \\
\text { - } \quad \text { "harvested area (dryland)" - This is a total harvested area in dryland farming between September year } \mathrm{t} \text { and August year } \mathrm{t}+1 \text {. } \\
\text { "new farming areas (dryland)" - This is an increase in dryland farming area a year. }\end{array}$ \\
\hline Default & $\begin{array}{l}\text { HISTORI } \\
\text { CAL SD } \\
\text { MODEL } \\
\text { (Default) }\end{array}$ & 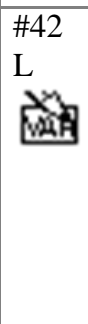 & $\begin{array}{l}\text { "rice farming areas (wetland)" (ha) } \\
=\int " \text { new farming area (wetland)" } d t+[\text { "initial rice farming areas (wetland)"] } \\
\text { Description: } \text { rice farming area is total physical land of wetland farming. } \\
\text { Present in } 1 \text { view: } \\
\text { View } 1 \\
\text { Used by: } \\
\text { " } \\
\text { "harvested area (wetland)" - this is total harvested area in wetland farming between September year t and August year } \mathrm{t}+1\end{array}$ \\
\hline Default & $\begin{array}{l}\text { HISTORI } \\
\text { CAL SD } \\
\text { MODEL } \\
\text { (Default) }\end{array}$ & $\begin{array}{l}\# 43 \\
\text { A } \\
\text { VAB }\end{array}$ & 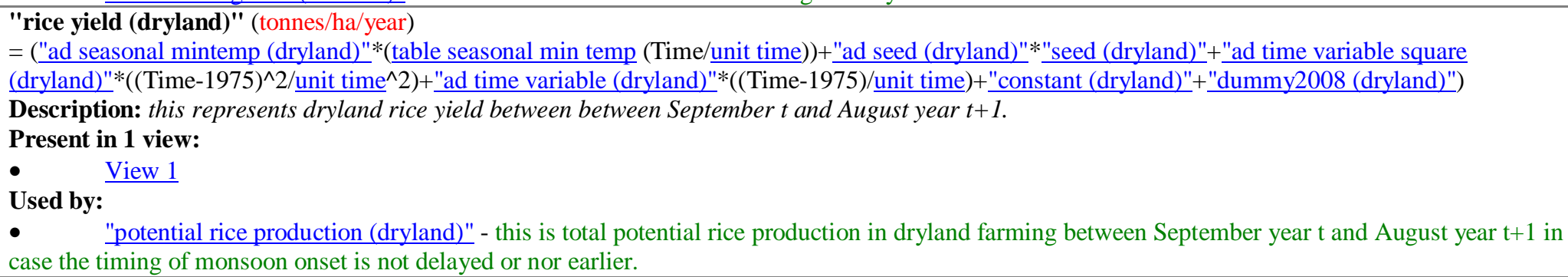 \\
\hline Default & $\begin{array}{l}\text { HISTORI } \\
\text { CAL SD } \\
\text { MODEL } \\
\text { (Default) }\end{array}$ & $\begin{array}{l}\# 44 \\
A \\
\text { VAB }\end{array}$ & 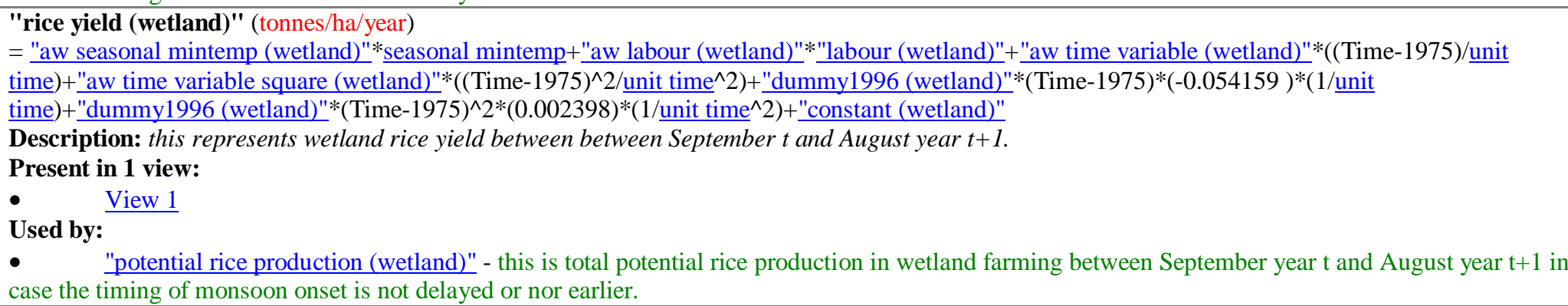 \\
\hline Default & $\begin{array}{l}\text { HISTORI } \\
\text { CAL SD } \\
\text { MODEL } \\
\text { (Default) }\end{array}$ & $\begin{array}{l}\# 46 \\
A \\
\text { VAB }\end{array}$ & $\begin{array}{l}\text { seasonal mintemp (celcius) } \\
=\text { table seasonal min temp (Time/unit time) } \\
\text { Description: seasonal minimum temperature at any given year. } \\
\text { Present in } 1 \text { view: }\end{array}$ \\
\hline
\end{tabular}




\begin{tabular}{|c|c|c|c|}
\hline & & & $\begin{array}{l}\bullet \quad \underline{\text { View } 1} \\
\text { Used by: } \\
\text { "rice yield (wetland)" - this represents wetland rice yield between between September } t \text { and August year } t+1 .\end{array}$ \\
\hline Default & $\begin{array}{l}\text { HISTORI } \\
\text { CAL SD } \\
\text { MODEL } \\
\text { (Default) }\end{array}$ & $\begin{array}{l}\# 47 \\
\text { A } \\
\text { VAB }\end{array}$ & $\begin{array}{l}\text { seasonal rainfall (mm/year) } \\
\text { = table seasonal rainfall (Time/unit time) } \\
\text { Description: Seasonal rainfall based on climate model projections or the base case scenario. } \\
\text { Present in } 1 \text { view: } \\
\text { Used by: } \\
\quad \text { "cropping intensity (wetland)" - this is a cropping intensity in wetland farming based on the period 1976-2011. } \\
\text { - }\end{array}$ \\
\hline Default & $\begin{array}{l}\text { HISTORI } \\
\text { CAL SD } \\
\text { MODEL } \\
\text { (Default) }\end{array}$ & $\begin{array}{l}\# 48 \\
\text { A } \\
\text { VAB }\end{array}$ & $\begin{array}{l}\text { "seed (dryland)" (IDR/year) } \\
=\text { "table seed (dryland)" (Time/unit time) } \\
\text { Description: the amount of seed at any given year in during simulation } \\
\text { Present in } 1 \text { view: } \\
\text { View } 1 \\
\text { Used by: } \\
\quad \text { "rice yield (dryland)" - this represents dryland rice yield between between September } \mathrm{t} \text { and August year } \mathrm{t}+1 \text {. }\end{array}$ \\
\hline Default & $\begin{array}{l}\text { HISTORI } \\
\text { CAL SD } \\
\text { MODEL } \\
\text { (Default) }\end{array}$ & $\begin{array}{l}\# 49 \\
\mathrm{~L} \\
\frac{\mathrm{v}}{\mathrm{x}}\end{array}$ & $\begin{array}{l}\text { table August SOI index }(\mathrm{Dmnl}) \\
=[(1976,-23.6)-(2011,18.8)],(1976,-12.1),(1977,-12.1),(1978,1.4),(1979,-5),(1980,1.4),(1981,5.9),(1982,-23.6),(1983,0.1),(1984,2.7),(1985,8.5),(1986,- \\
7.6),(1987,-14),(1988,14.9),(1989,-6.3),(1990,-5),(1991,-7.6),(1992,1.4),(1993,-14),(1994,-17.2),(1995,0.8),(1996,4.6),(1997,- \\
19.8),(1998,9.8),(1999,2.1),(2000,5.3),(2001,-8.9),(2002,-14.6),(2003,-1.8),(2004,-7.6),(2005,-6.9),(2006,-15.9),(2007,2.7),(2008,9.1),(2009,- \\
\text { 5),(2010,18.8),(2011,2.1) } \\
\text { Description: this is a lookup table of August SOI for a given year during simulation. } \\
\text { This Lookup Table is used as a Data Repository. } \\
\text { Present in 1 view: } \\
\quad \text { View 1 } \\
\text { Used by: } \\
\quad \text { August SOI index - August SOI index based on observed data between } 1976 \text { and } 2011 .\end{array}$ \\
\hline
\end{tabular}




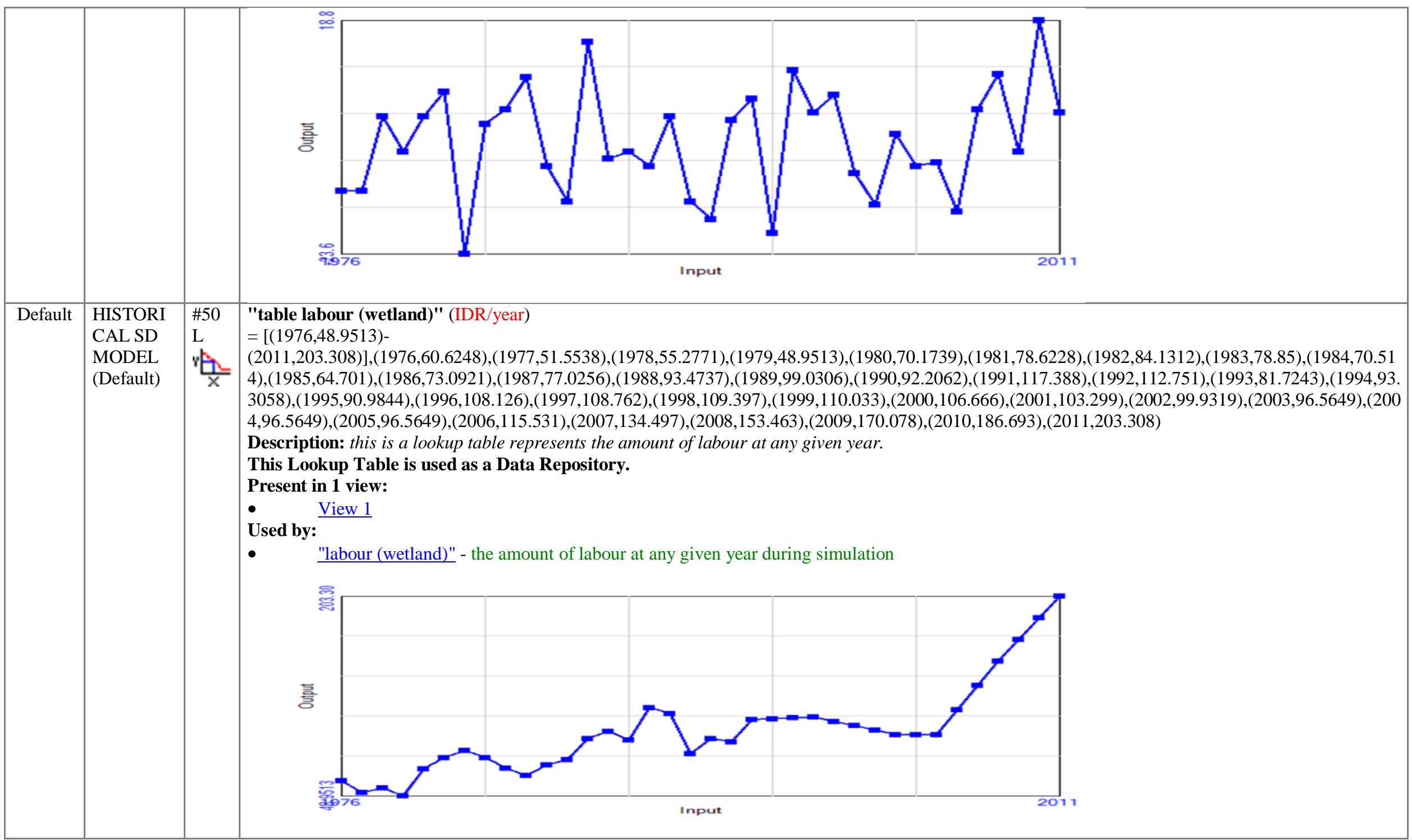




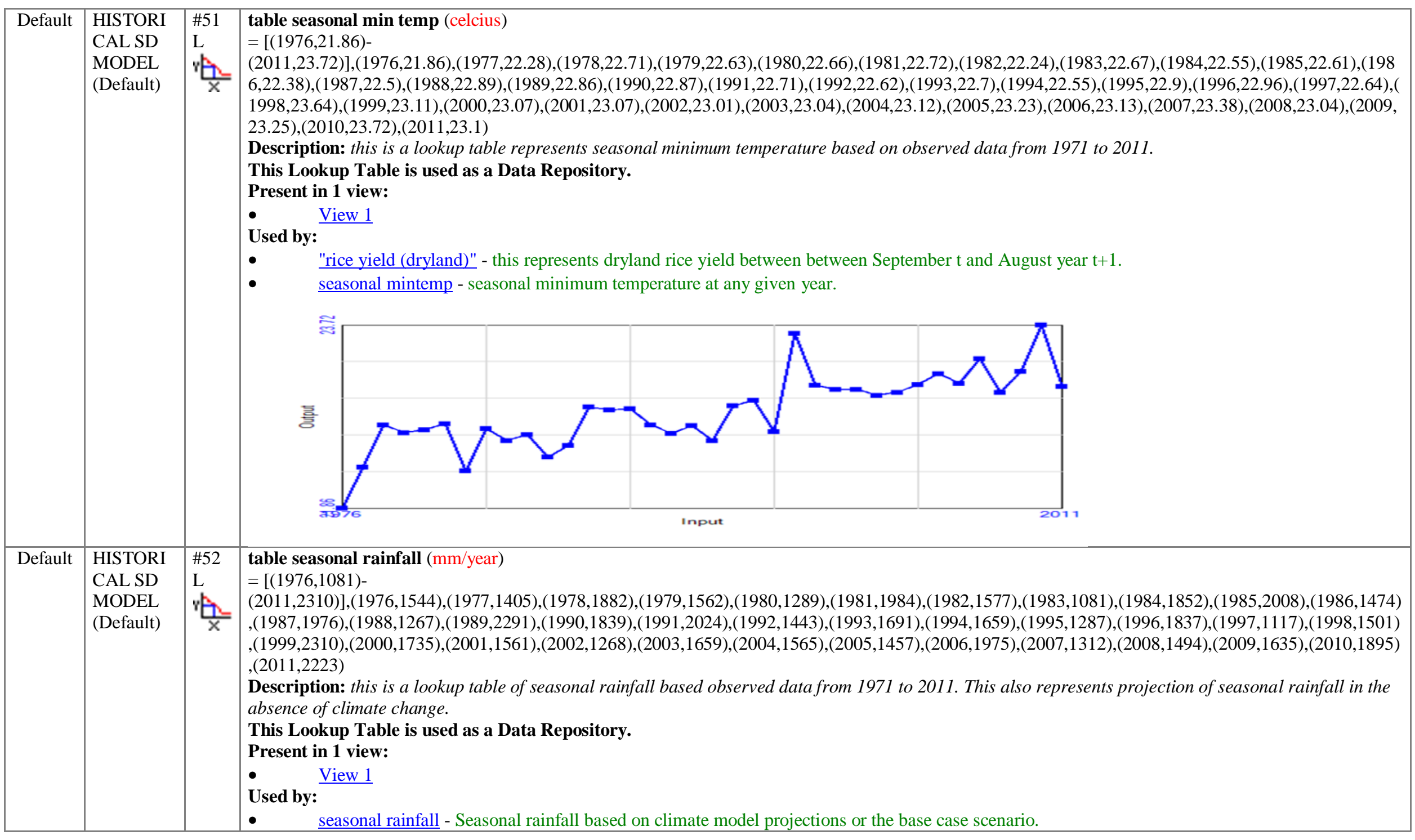




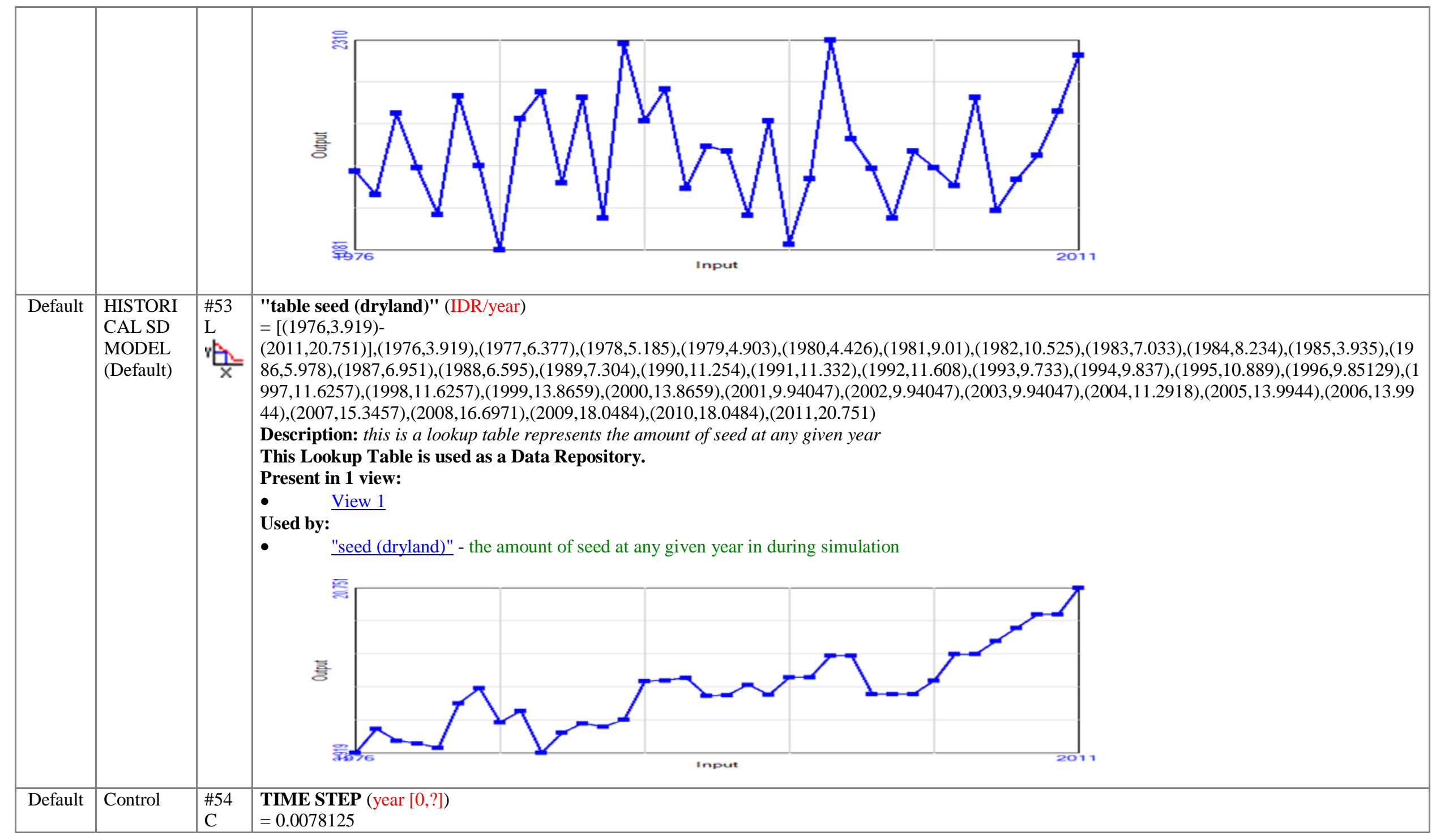




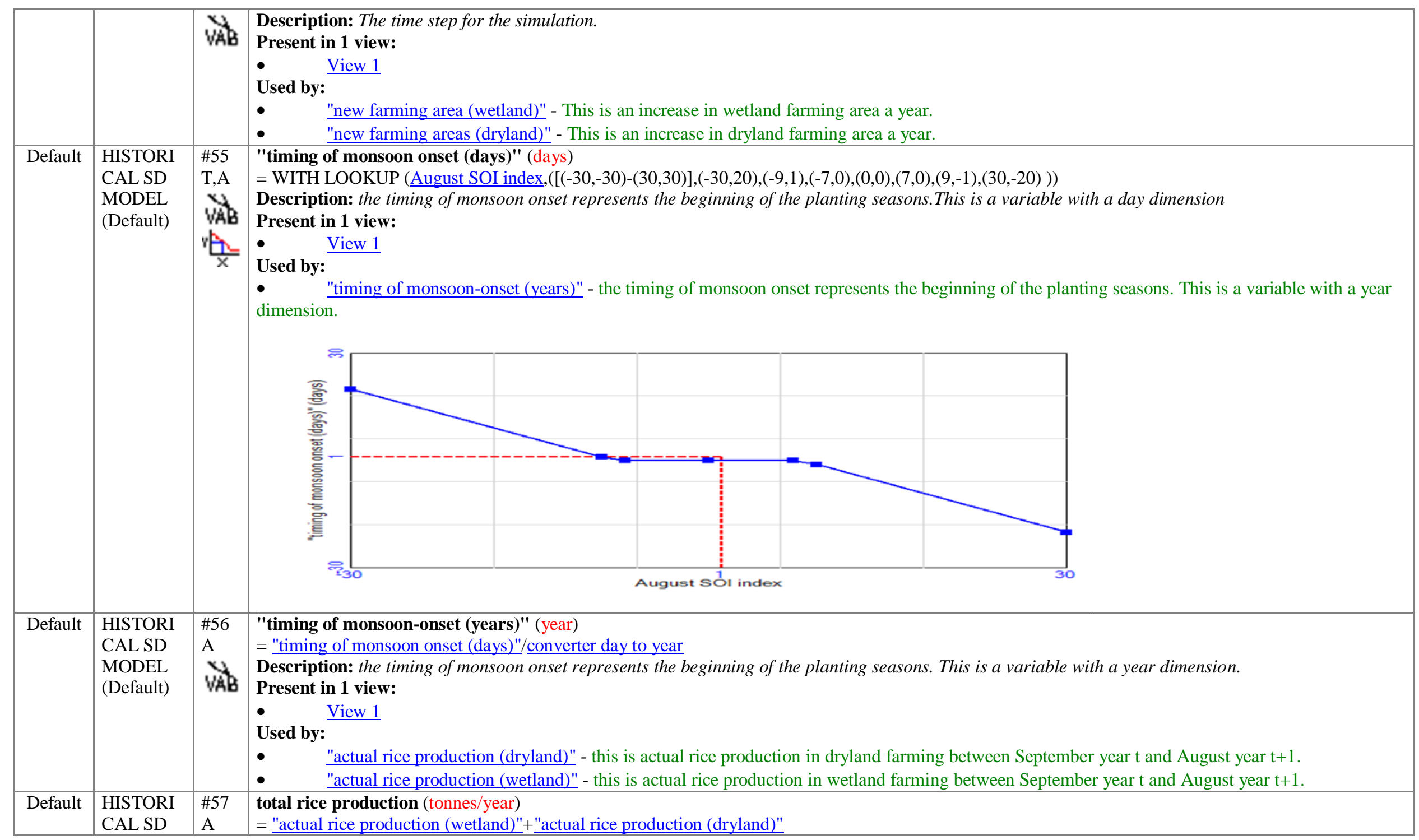




\begin{tabular}{|c|c|c|c|}
\hline & $\begin{array}{l}\text { MODEL } \\
\text { (Default) }\end{array}$ & WAB & $\begin{array}{l}\text { Description: a sum of rice production in wetland and dryland areas } \\
\text { Present in } 1 \text { view: } \\
\text { - }\end{array}$ \\
\hline Default & $\begin{array}{l}\text { HISTORI } \\
\text { CAL SD } \\
\text { MODEL } \\
\text { (Default) }\end{array}$ & $\begin{array}{l}\# 58 \\
C \\
\text { WAB }\end{array}$ & 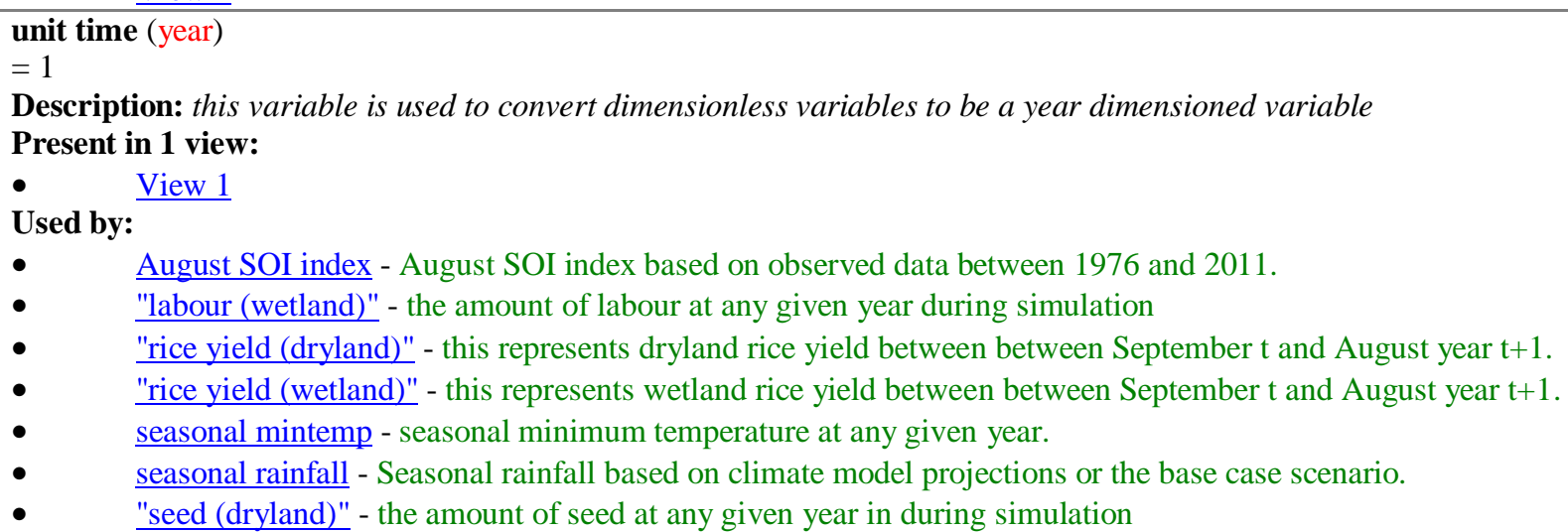 \\
\hline Module & Group & Type & Variable Name and Description \\
\hline
\end{tabular}

Decision and Information Sciences Division Argonne National Laboratory 


\section{Appendix E. The Basecase Model (Chapter 6)}

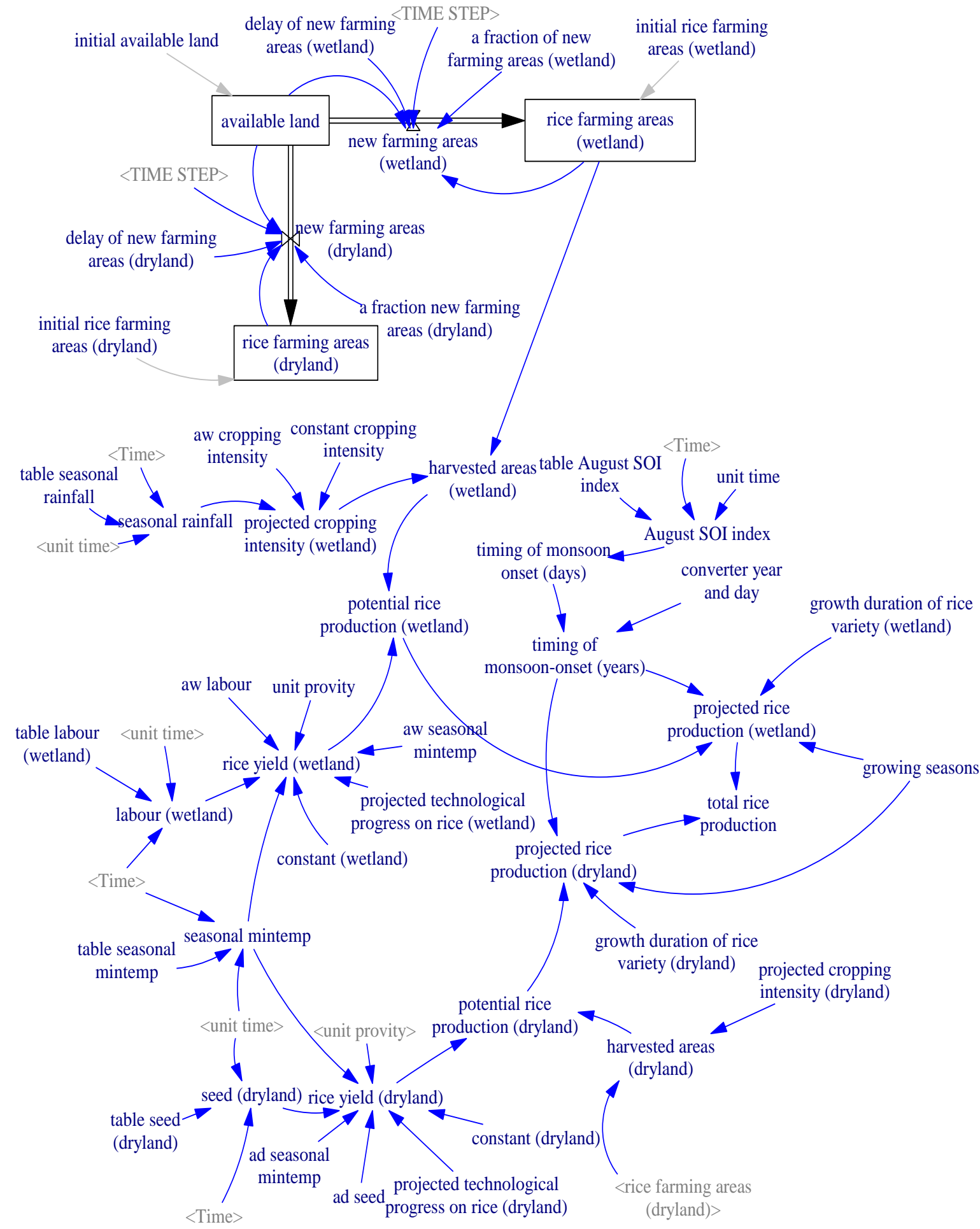

Figure E1. A complete of the basecase SD model 
this page intentionally left blank 


\section{Appendix F. The Basecase Model Documentation}

Documentation of SD BASECASE MODEL

\begin{tabular}{|l|c|}
\hline \multicolumn{1}{|c|}{ Model Information } & Number \\
\hline Total Number of Variables & 55 \\
\hline \begin{tabular}{l|c|} 
Total Number of State Variables \\
(Level+Smooth+Delay Variables)
\end{tabular} & $5(9.1 \%)$ \\
\hline $\begin{array}{l}\text { Total Number of Stocks (Stocks in } \\
\text { Level+Smooth+Delay Variables) } \dagger\end{array}$ & $9(16.4 \%)$ \\
\hline Time Unit & year \\
\hline Initial Time & 2015 \\
\hline Final Time & 2100 \\
\hline Reported Time Interval & 1 \\
\hline Time Step & 0.0078125 \\
\hline Model Is Fully Formulated & Yes \\
\hline
\end{tabular}




\begin{tabular}{|c|c|c|c|}
\hline Module & Group & Type & Variable Name and Description \\
\hline Default & $\begin{array}{c}\text { SD } \\
\text { BASECASE } \\
\text { MODEL } \\
\text { (Default) }\end{array}$ & $\begin{array}{c}\# 1 \\
C \\
\text { WAB }\end{array}$ & $\begin{array}{l}\text { "a fraction new farming areas (dryland)" (1/year) } \\
=0 \\
\text { Description: This is annual growth (fraction) of new dryland farming based on observed data between } 1976 \text { and } 2011 . \\
\text { Present in } 1 \text { view: } \\
\qquad \quad \text { View } 1 \\
\text { Used by: } \\
\quad \bullet \quad \text { "new farming areas (dryland)" - This is an increase in dryland farming area a year. }\end{array}$ \\
\hline Default & $\begin{array}{c}\text { SD } \\
\text { BASECASE } \\
\text { MODEL } \\
\text { (Default) }\end{array}$ & $\begin{array}{c}\# 2 \\
C \\
W A B\end{array}$ & $\begin{array}{l}\text { "a fraction of new farming areas (wetland)" (1/year) } \\
=0 \\
\text { Description: This is annual growth (fraction) of new wetland farming based on observed data between } 1976 \text { and } 2011 . \\
\text { Present in } 1 \text { view: } \\
\qquad \quad \text { View } 1 \\
\text { Used by: } \\
\quad \text { "new farming areas (dryland)." - This is a change in wetland farming areas a year. }\end{array}$ \\
\hline Default & $\begin{array}{c}\text { SD } \\
\text { BASECASE } \\
\text { MODEL } \\
\text { (Default) }\end{array}$ & $\begin{array}{l}\text { \#3 } \\
\text { DE }\end{array}$ & $\begin{array}{l}\text { "actual rice production (dryland)" (tonnes/year) } \\
=\text { DELAY3(STEP("potential rice production (dryland)","timing of monsoon-onset (years)"),"duration growth of rice variety (dryland)"* growing } \\
\text { seasons) } \\
\text { Description: this is total actual rice production in dryland farming between September year t and August year } t+1 \\
\text { Present in } 1 \text { view: } \\
\quad \bullet \quad \text { View } 1 \\
\text { Used by: } \\
\quad \text { total rice production - a sum of rice production in wetland and dryland areas }\end{array}$ \\
\hline Default & $\begin{array}{c}\text { SD } \\
\text { BASECASE } \\
\text { MODEL } \\
\text { (Default) }\end{array}$ & $\begin{array}{l}\text { \#4 } \\
\text { DE }\end{array}$ & $\begin{array}{l}\text { "actual rice production (wetland)" (tonnes/year) } \\
=\text { DELAY3(STEP("potential rice production (wetland)","timing of monsoon-onset (years)"),"duration growth of rice variety (wetland)"* growing } \\
\text { seasons) } \\
\text { Description: this is total actual rice production in wetland farming between September year t and August year } t+1 \text {. } \\
\text { Present in } 1 \text { view: } \\
\quad \text { View } 1 \\
\text { Used by: } \\
\quad \text { total rice production - a sum of rice production in wetland and dryland areas }\end{array}$ \\
\hline Default & $\begin{array}{c}\text { SD } \\
\text { BASECASE } \\
\text { MODEL } \\
\text { (Default) }\end{array}$ & $\begin{array}{c}\# 5 \\
C \\
\text { Wab }\end{array}$ & $\begin{array}{l}\text { "ad seasonal mintemp (dryland)" ((tonnes/ha/year)/celcius) } \\
=-0.121 \\
\text { Description: this a coefficient of minimum temperature to measure rice yield (dryland). } \\
\text { Present in } 1 \text { view: }\end{array}$ \\
\hline
\end{tabular}




\begin{tabular}{|c|c|c|c|}
\hline & & & 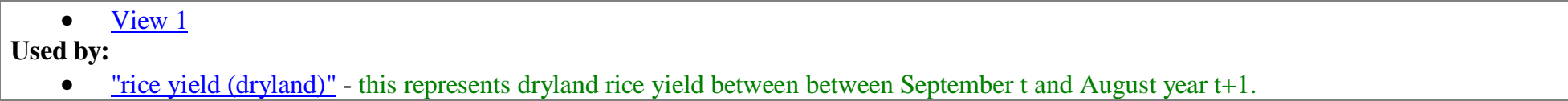 \\
\hline Default & $\begin{array}{l}\text { SD } \\
\text { BASECASE } \\
\text { MODEL } \\
\text { (Default) }\end{array}$ & $\begin{array}{c}\# 6 \\
\mathrm{C} \\
\mathrm{VAB}\end{array}$ & $\begin{array}{l}\text { "ad seed (dryland)" (tonnes/ha/year/(IDR/year)) } \\
=0.0184 \\
\text { Description: this is a coefficient of seed to measure dryland rice yield } \\
\text { Present in } 1 \text { view: } \\
\qquad \quad \text { View } 1 \\
\text { Used by: } \\
\quad \text { "rice yield (dryland)" - this represents dryland rice yield between between September } t \text { and August year } \mathrm{t}+1 \text {. }\end{array}$ \\
\hline Default & $\begin{array}{l}\text { SD } \\
\text { BASECASE } \\
\text { MODEL } \\
\text { (Default) }\end{array}$ & $\begin{array}{c}\# 7 \\
\text { A } \\
\text { Wab }\end{array}$ & $\begin{array}{l}\text { August SOI index (Dmnl) } \\
=\text { IF THEN ELSE( table August SOI index (Time/unit time) }=-20 \text {, table August SOI index (Time/unit time), -20) } \\
\text { Description: August SOI index based on observed data between } 1976 \text { and } 2011 \\
\text { Present in } 1 \text { view: } \\
\text { Used by: } \\
\quad-\quad \frac{\text { View } 1}{\text { seasons. This is a variable with a day dimension. }}\end{array}$ \\
\hline Default & $\begin{array}{l}\text { SD } \\
\text { BASECASE } \\
\text { MODEL } \\
\text { (Default) }\end{array}$ & $\begin{array}{c}\# 8 \\
\mathrm{~L}\end{array}$ & $\begin{array}{l}\text { available land (ha) } \\
=\int-" n e w \text { farming areas (dryland)."-"new farming areas (dryland)" } d t+[\text { initial available land }] \\
\text { Description: Available land is potential land to be converted into wetland and dryland farming. This land is reserved to increase areas of wetland } \\
\text { and dryland farming. } \\
\text { Present in } 1 \text { view: } \\
\text { - View } 1 \\
\text { Used by: } \\
\qquad \text { "new farming areas (dryland)" - This is an increase in dryland farming area a year. } \\
\quad \text { "new farming areas (dryland)." - This is a change in wetland farming areas a year. }\end{array}$ \\
\hline Default & $\begin{array}{c}\text { SD } \\
\text { BASECASE } \\
\text { MODEL } \\
\text { (Default) }\end{array}$ & $\begin{array}{c}\# 9 \\
C \\
\text { VAB }\end{array}$ & $\begin{array}{l}\text { aw cropping intensity }(\mathrm{year} / \mathrm{mm}) \\
=0.00023 \\
\text { Description: This is a coefficient of an equation in estimating the effect of seasonal rainfall on cropping intensity of wetland farming } \\
\text { Present in } 1 \text { view: } \\
\quad \bullet \quad \text { View } 1 \\
\text { Used by: } \\
\quad \text { "cropping intensity (wetland)" - this is cropping intensity in wetland farming based on the period 1976-2011 }\end{array}$ \\
\hline
\end{tabular}




\begin{tabular}{|c|c|c|c|}
\hline Default & $\begin{array}{c}\text { SD } \\
\text { BASECASE } \\
\text { MODEL } \\
\text { (Default) }\end{array}$ & $\begin{array}{c}\# 10 \\
\mathrm{C} \\
\mathrm{VAB}\end{array}$ & $\begin{array}{l}\text { "aw labour (wetland)" (tonnes/ha/year/(IDR/year)) } \\
=0.0033 \\
\text { Description: This is a coefficient of used labour in wetland farming } \\
\text { Present in } 1 \text { view: } \\
\qquad \quad \text { View } 1 \\
\text { Used by: } \\
\quad \text { "rice yield (wetland)" - this represents wetland rice yield between between September } \mathrm{t} \text { and August year } \mathrm{t}+1 .\end{array}$ \\
\hline Default & $\begin{array}{c}\text { SD } \\
\text { BASECASE } \\
\text { MODEL } \\
\text { (Default) }\end{array}$ & $\begin{array}{c}\# 11 \\
C \\
\text { VAB }\end{array}$ & $\begin{array}{l}\text { "aw seasonal mintemp (wetland)" (tonnes/ha/year/celcius) } \\
=-0.197 \\
\text { Description: This is a coefficient of minimum temperature for wetland farming } \\
\text { Present in } 1 \text { view: } \\
\quad \bullet \quad \text { View } 1 \\
\text { Used by: } \\
\quad \text { "rice yield (wetland)" - this represents wetland rice yield between between September } t \text { and August year } t+1 \text {. }\end{array}$ \\
\hline Default & $\begin{array}{c}\text { SD } \\
\text { BASECASE } \\
\text { MODEL } \\
\text { (Default) }\end{array}$ & $\begin{array}{c}\# 12 \\
C \\
\text { Wab }\end{array}$ & $\begin{array}{l}\text { "constant (dryland)" (tonnes/ha/year) } \\
=4.56 \\
\text { Description: this is a constant of a statistical model in measuring dryland rice yield } \\
\text { Present in } 1 \text { view: } \\
\qquad \quad \text { View } 1 \\
\text { Used by: } \\
\quad \text { "rice yield (dryland)" - this represents dryland rice yield between between September } \mathrm{t} \text { and August year } \mathrm{t}+1 \text {. }\end{array}$ \\
\hline Default & $\begin{array}{c}\text { SD } \\
\text { BASECASE } \\
\text { MODEL } \\
\text { (Default) }\end{array}$ & $\begin{array}{c}\# 13 \\
C \\
\text { Wab }\end{array}$ & $\begin{array}{l}\text { "constant (wetland)" (tonnes/ha/year) } \\
=6.73 \\
\text { Description: this is a constant of a statistical model in measuring wetland rice yield } \\
\text { Present in } 1 \text { view: } \\
\quad \bullet \quad \text { View } 1 \\
\text { Used by: } \\
\quad \text { "rice yield (wetland)" - this represents wetland rice yield between between September } t \text { and August year } \mathrm{t}+1 \text {. }\end{array}$ \\
\hline Default & $\begin{array}{c}\text { SD } \\
\text { BASECASE } \\
\text { MODEL } \\
\text { (Default) }\end{array}$ & $\begin{array}{c}\# 14 \\
\mathrm{C} \\
\mathrm{WAB}\end{array}$ & $\begin{array}{l}\text { constant cropping intensity (Dmnl) } \\
=0.935 \\
\text { Description: This is a constantof an equation in estimating the effect of seasonal rainfall on cropping intensity of wetland farming } \\
\text { Present in } 1 \text { view: } \\
\quad \text { View } 1 \\
\text { Used by: } \\
\quad \text { "cropping intensity (wetland)" - this is cropping intensity in wetland farming based on the period 1976-2011 }\end{array}$ \\
\hline
\end{tabular}




\begin{tabular}{|c|c|c|c|}
\hline Default & $\begin{array}{c}\text { SD } \\
\text { BASECASE } \\
\text { MODEL } \\
\text { (Default) }\end{array}$ & $\begin{array}{c}\# 15 \\
\mathrm{C} \\
\mathrm{WAB}\end{array}$ & $\begin{array}{l}\text { converter year and day (days/year) } \\
=365 \\
\text { Description: this variable is used to convert a day dimension to be a year dimension } \\
\text { Present in } 1 \text { view: } \\
\text { Used by: } \\
\quad \text { View } 1 \\
\quad \text { "timing of monsoon-onset (years)" - the timing of monsoon onset represents the beginning of the planting seasons. This is a variable with } \\
\text { a year dimension. }\end{array}$ \\
\hline Default & $\begin{array}{c}\text { SD } \\
\text { BASECASE } \\
\text { MODEL } \\
\text { (Default) }\end{array}$ & $\begin{array}{c}\# 16 \\
\mathrm{C} \\
\mathrm{WAB}\end{array}$ & $\begin{array}{l}\text { "cropping intensity (dryland)" (Dmnl) } \\
=1 \\
\text { Description: This is a division between harvested dryland areas and dryland rice areas. Based observed data 1976-2011, the cropping intensity of } \\
\text { dryland farming is } 1 \text { or 100\%. } \\
\text { Present in } 1 \text { view: } \\
\text { - View } 1 \\
\text { Used by: } \\
\quad \text { "harvested areas (dryland)" - This is a total harvested area in dryland farming between September year t and August year t+1. }\end{array}$ \\
\hline Default & $\begin{array}{c}\text { SD } \\
\text { BASECASE } \\
\text { MODEL } \\
\text { (Default) }\end{array}$ & $\begin{array}{c}\# 17 \\
A \\
\text { VAB }\end{array}$ & $\begin{array}{l}\text { "cropping intensity (wetland)" (Dmnl) } \\
=\text { (seasonal rainfall*aw cropping intensity+constant cropping intensity) } \\
\text { Description: this is cropping intensity in wetland farming based on the period 1976-2011 } \\
\text { Present in } 1 \text { view: } \\
\quad \bullet \quad \text { View } 1 \\
\text { Used by: } \\
\quad \text { - "harvested areas (wetland)" - this is total harvested area in wetland farming between September year } t \text { and August year } \mathrm{t}+1 \text {. }\end{array}$ \\
\hline Default & $\begin{array}{c}\text { SD } \\
\text { BASECASE } \\
\text { MODEL } \\
\text { (Default) }\end{array}$ & $\begin{array}{c}\# 18 \\
\mathrm{C} \\
\mathrm{W}\end{array}$ & $\begin{array}{l}\text { "delay of new farming areas (dryland)" (year) } \\
=1 \\
\text { Description: The needed time for opening new dryland farming. In general, the government prepares programs to open new farming area } 1 \text { year } \\
\text { prior to the intended year. } \\
\text { Present in } 1 \text { view: } \\
\qquad \text { View } 1 \\
\text { Used by: } \\
\quad \text { "new farming areas (dryland)" - This is an increase in dryland farming area a year. }\end{array}$ \\
\hline Default & $\begin{array}{c}\text { SD } \\
\text { BASECASE } \\
\text { MODEL } \\
\text { (Default) }\end{array}$ & $\begin{array}{c}\# 19 \\
\mathrm{C} \\
\mathrm{VAB}\end{array}$ & $\begin{array}{l}\text { "delay of new farming areas (wetland)" (year) } \\
=1 \\
\text { Description: The needed time for opening new wetland farming. In general, the government prepares programs to open new farming area } 1 \text { year } \\
\text { prior to the intended year. }\end{array}$ \\
\hline
\end{tabular}




\begin{tabular}{|c|c|c|c|}
\hline & & & $\begin{array}{l}\text { Present in } 1 \text { view: } \\
\qquad \text { View } 1 \\
\text { Used by: } \\
\bullet \quad \text { "new farming areas (dryland)." - This is a change in wetland farming areas a year. }\end{array}$ \\
\hline Default & $\begin{array}{l}\text { SD } \\
\text { BASECASE } \\
\text { MODEL } \\
\text { (Default) }\end{array}$ & $\begin{array}{l}\# 20 \\
\text { A } \\
\text { WAB }\end{array}$ & $\begin{array}{l}\text { "duration growth of rice variety (dryland)" (year) } \\
=110 / 365 \\
\text { Description: the duration growth of dryland rice variety. The duration growth of rice variety is about } 110 \text { days which is converted into (110/365) } \\
\text { years. } \\
\text { Present in } 1 \text { view: } \\
\text { Used by: } \\
\quad \bullet \quad \text { "actual rice production (dryland)" - this is total actual rice production in dryland farming between September year } \mathrm{t} \text { and August year } \mathrm{t}+1\end{array}$ \\
\hline Default & $\begin{array}{l}\text { SD } \\
\text { BASECASE } \\
\text { MODEL } \\
\text { (Default) }\end{array}$ & $\begin{array}{l}\# 21 \\
\text { A } \\
\text { VAB }\end{array}$ & $\begin{array}{l}\text { "duration growth of rice variety (wetland)" (year) } \\
=115 / 365 \\
\text { Description: the duration growth of wetland rice variety. The duration growth of rice variety is about } 115 \text { days which is converted into (115/365) } \\
\text { years. } \\
\text { Present in } 1 \text { view: } \\
\quad \text { View } 1 \\
\text { Used by: } \\
\quad \text { "actual rice production (wetland)" - this is total actual rice production in wetland farming between September year } t \text { and August year } \mathrm{t}+1 .\end{array}$ \\
\hline Default & $\begin{array}{l}\text { SD } \\
\text { BASECASE } \\
\text { MODEL } \\
\text { (Default) }\end{array}$ & $\begin{array}{c}\text { C23 } \\
\mathrm{C} \\
\mathrm{VAB}\end{array}$ & $\begin{array}{l}\text { growing seasons (Dmnl) } \\
=3 \\
\text { Description: the number of growing seasons in a seasonal year (September in year t until August in year } t+1 \text { ) } \\
\text { Present in } 1 \text { view: } \\
\text { Used by: } \\
\quad \text { View } 1 \\
\quad \text { "actual rice production (dryland)" - this is total actual rice production in dryland farming between September year } t \text { and August year } t+1 \\
\text { "actual rice production (wetland)" - this is total actual rice production in wetland farming between September year } t \text { and August year } t+1 \text {. }\end{array}$ \\
\hline Default & $\begin{array}{l}\text { SD } \\
\text { BASECASE } \\
\text { MODEL } \\
\text { (Default) }\end{array}$ & $\begin{array}{c}\# 24 \\
\mathrm{~A} \\
\text { WAB }\end{array}$ & $\begin{array}{l}\text { "harvested areas (dryland)" (ha) } \\
=\text { "rice farming areas (dryland)"*"cropping intensity (dryland)" } \\
\text { Description: This is a total harvested area in dryland farming between September year t and August year } t+1 \text {. } \\
\text { Present in } 1 \text { view: } \\
\quad \bullet \quad \text { View } 1 \\
\text { Used by: } \\
\quad \text { "potential rice production (dryland)" - this is total potential rice production in dryland farming between September year } t \text { and August year }\end{array}$ \\
\hline
\end{tabular}




\begin{tabular}{|c|c|c|c|}
\hline & & & t+1 in case the timing of monsoon onset is not delayed or nor earlier. \\
\hline Default & $\begin{array}{c}\text { SD } \\
\text { BASECASE } \\
\text { MODEL } \\
\text { (Default) }\end{array}$ & $\begin{array}{c}\# 25 \\
A \\
\text { VAB }\end{array}$ & $\begin{array}{l}\text { "harvested areas (wetland)" (ha) } \\
=\text { "cropping intensity (wetland)"*"rice farming areas (wetland)" } \\
\text { Description: this is total harvested area in wetland farming between September year t and August year } t+1 \text {. } \\
\text { Present in } 1 \text { view: } \\
\qquad \text { View } 1 \\
\text { Used by: } \\
\quad \text { "potential rice production (wetland)" - this is total potential rice production in wetland farming between September year } t \text { and August } \\
\quad \text { year } \mathrm{t}+1 \text { in case the timing of monsoon onset is not delayed or nor earlier. }\end{array}$ \\
\hline Default & $\begin{array}{c}\text { SD } \\
\text { BASECASE } \\
\text { MODEL } \\
\text { (Default) }\end{array}$ & $\begin{array}{l}\# 26 \\
\mathrm{LI}, \mathrm{C} \\
\mathrm{WAB}\end{array}$ & $\begin{array}{l}\text { initial available land (ha) } \\
=719751 \\
\text { Description: total potential land to be converted into wetland and dryland farming. This land is secured by the law. } \\
\text { Source: Source of Data } \\
\text { Present in } 1 \text { view: } \\
\qquad \quad \text { View } 1 \\
\text { Used by: } \\
\quad \text { available land - Available land is potential land to be converted into wetland and dryland farming. This land is reserved to increase areas } \\
\quad \text { of wetland and dryland farming. }\end{array}$ \\
\hline Default & $\begin{array}{c}\text { SD } \\
\text { BASECASE } \\
\text { MODEL } \\
\text { (Default) }\end{array}$ & $\begin{array}{c}\# 27 \\
\mathrm{C} \\
\mathrm{WAB}\end{array}$ & $\begin{array}{l}\text { "initial rice farming areas (dryland)" (ha) } \\
=47496.2 \\
\text { Description: initial rice dryland areas. } \\
\text { Source: Source of Data } \\
\text { Present in } 1 \text { view: } \\
\quad \text { View } 1 \\
\text { Used by: } \\
\quad \text { "rice farming areas (dryland)" - rice farming area is total physical land of wetland farming. }\end{array}$ \\
\hline Default & $\begin{array}{c}\text { SD } \\
\text { BASECASE } \\
\text { MODEL } \\
\text { (Default) }\end{array}$ & $\begin{array}{c}\# 28 \\
\mathrm{C} \\
\mathrm{VAB}\end{array}$ & $\begin{array}{l}\text { "initial rice farming areas (wetland)" (ha) } \\
=240180 \\
\text { Description: initial rice wetland areas. } \\
\text { Source: Source of Data } \\
\text { Present in } 1 \text { view: } \\
\quad \text { View } 1 \\
\text { Used by: } \\
\quad \text { "rice farming areas (wetland)" - rice farming area is total physical land of wetland farming. }\end{array}$ \\
\hline
\end{tabular}




\begin{tabular}{|c|c|c|c|}
\hline Default & $\begin{array}{c}\text { SD } \\
\text { BASECASE } \\
\text { MODEL } \\
\text { (Default) }\end{array}$ & $\begin{array}{c}\# 30 \\
A \\
\mathrm{VAB}\end{array}$ & $\begin{array}{l}\text { "labour (wetland)" (IDR/year) } \\
=\text { "table labour (wetland)"(Time/unit time) } \\
\text { Description: the the amount of labour at any given year during simulation } \\
\text { Present in } 1 \text { view: } \\
\text { • View } 1 \\
\text { Used by: } \\
\quad \text { "rice yield (wetland)" - this represents wetland rice yield between between September } \mathrm{t} \text { and August year } \mathrm{t}+1 .\end{array}$ \\
\hline Default & $\begin{array}{c}\text { SD } \\
\text { BASECASE } \\
\text { MODEL } \\
\text { (Default) }\end{array}$ & $\begin{array}{c}\# 31 \\
A \\
\text { VAB }\end{array}$ & $\begin{array}{l}\text { "new farming areas (dryland)" (ha/year) } \\
=\text { MIN((DELAY1("a fraction new farming areas (dryland)"* rice farming areas (dryland)","delay of new farming areas (dryland)")), available } \\
\text { land/TIME STEP) } \\
\text { Description: This is an increase in dryland farming area a year. } \\
\text { Present in } 1 \text { view: } \\
\text { - View } 1 \\
\text { Used by: } \\
\text { - available land - Available land is potential land to be converted into wetland and dryland farming. This land is reserved to increase areas } \\
\quad \text { of wetland and dryland farming. }\end{array}$ \\
\hline Default & $\begin{array}{c}\text { SD } \\
\text { BASECASE } \\
\text { MODEL } \\
\text { (Default) }\end{array}$ & $\begin{array}{c}\# 32 \\
A \\
\text { VAB }\end{array}$ & $\begin{array}{l}\text { "new farming areas (dryland)." (ha/year) } \\
=\text { MIN((DELAY1("a fraction of new farming areas (wetland)"*"rice farming areas (wetland)", "delay of new farming areas (wetland)")), available } \\
\text { land/TIME STEP) } \\
\text { Description: This is a change in wetland farming areas a year. } \\
\text { Present in } 1 \text { view: } \\
\text { • View } 1 \\
\text { Used by: } \\
\text { - } \quad \text { available land - Available land is potential land to be converted into wetland and dryland farming. This land is reserved to increase areas } \\
\quad \text { of wetland and dryland farming. } \\
\text { "rice farming areas (wetland)" - rice farming area is total physical land of wetland farming. }\end{array}$ \\
\hline Default & $\begin{array}{c}\text { SD } \\
\text { BASECASE } \\
\text { MODEL } \\
\text { (Default) }\end{array}$ & $\begin{array}{c}\# 33 \\
A \\
\text { Wab }\end{array}$ & $\begin{array}{l}\text { "potential rice production (dryland)" (tonnes/year) } \\
=\text { "rice yield (dryland)"*"harvested areas (dryland)" } \\
\text { Description: this is total potential rice production in dryland farming between September year t and August year } t+1 \text { in case the timing of } \\
\text { monsoon onset is not delayed or nor earlier. } \\
\text { Present in } 1 \text { view: } \\
\quad \bullet \quad \text { View } 1 \\
\text { Used by: } \\
\quad \text { "actual rice production (dryland)" - this is total actual rice production in dryland farming between September year } t \text { and August year } t+1\end{array}$ \\
\hline
\end{tabular}




\begin{tabular}{|c|c|c|c|}
\hline Default & $\begin{array}{c}\text { SD } \\
\text { BASECASE } \\
\text { MODEL } \\
\text { (Default) }\end{array}$ & $\begin{array}{c}\# 34 \\
A \\
\text { VAB }\end{array}$ & $\begin{array}{l}\text { "potential rice production (wetland)" (tonnes/year) } \\
=\text { "harvested areas (wetland)"*"rice yield (wetland)" } \\
\text { Description: this is total potential rice production in wetland farming between September year t and August year } t+1 \text { in case the timing of } \\
\text { monsoon onset is not delayed or nor earlier. } \\
\text { Present in } 1 \text { view: } \\
\text { Used by: } \\
\quad \text { View } 1 \\
\text { "actual rice production (wetland)" - this is total actual rice production in wetland farming between September year } t \text { and August year } t+1 .\end{array}$ \\
\hline Default & $\begin{array}{c}\text { SD } \\
\text { BASECASE } \\
\text { MODEL } \\
\text { (Default) }\end{array}$ & $\begin{array}{c}\# 35 \\
\mathrm{~L} \\
\text { 出为 }\end{array}$ & $\begin{array}{l}\text { "rice farming areas (dryland)" (ha) } \\
=\int \text { "new farming areas (dryland)" } d t+[\text { "initial rice farming areas (dryland)"] } \\
\text { Description: rice farming area is total physical land of wetland farming. } \\
\text { Present in } 1 \text { view: } \\
\text { Used by: } \\
\quad \text { View } 1 \\
\quad \text { "harvested areas (dryland)" - This is a total harvested area in dryland farming between September year t and August year } \mathrm{t}+1 . \\
\text { "new farming areas (dryland)" - This is an increase in dryland farming area a year. }\end{array}$ \\
\hline Default & $\begin{array}{c}\text { SD } \\
\text { BASECASE } \\
\text { MODEL } \\
\text { (Default) }\end{array}$ & $\begin{array}{c}\# 36 \\
\mathrm{~L} \\
\text { 崩 }\end{array}$ & $\begin{array}{l}\text { "rice farming areas (wetland)" (ha) } \\
=\int " \text { new farming areas (dryland)." } d t+[\text { "initial rice farming areas (wetland)"] } \\
\text { Description: rice farming area is total physical land of wetland farming. } \\
\text { Present in } 1 \text { view: } \\
\text { Used by: } \\
\quad \text { View } 1 \\
\quad \text { "harvested areas (wetland)" - this is total harvested area in wetland farming between September year } t \text { and August year } t+1 .\end{array}$ \\
\hline Default & $\begin{array}{c}\text { SD } \\
\text { BASECASE } \\
\text { MODEL } \\
\text { (Default) }\end{array}$ & $\begin{array}{c}\# 37 \\
\text { A } \\
\text { WAB }\end{array}$ & 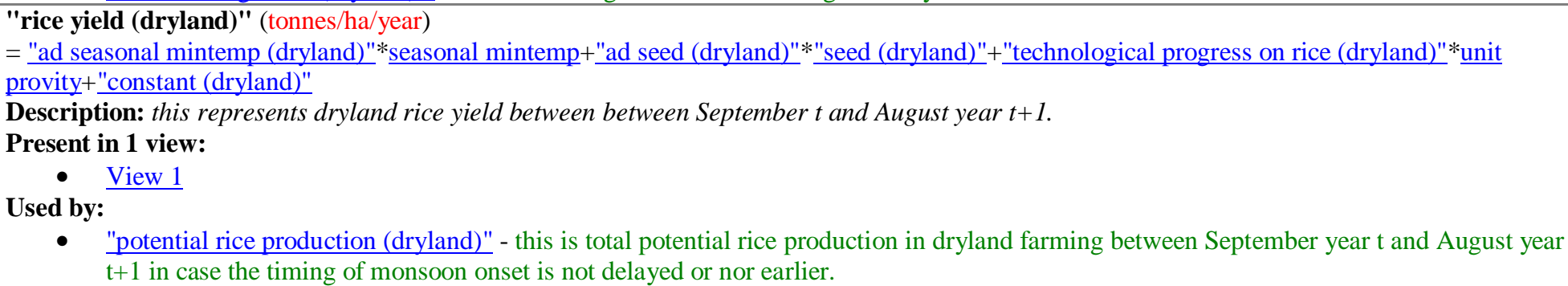 \\
\hline Default & $\begin{array}{c}\text { SD } \\
\text { BASECASE }\end{array}$ & \#38 & $\begin{array}{l}\text { "rice yield (wetland)" (tonnes/ha/year) } \\
=((\text { "aw labour (wetland)"*"labour (wetland)")+("aw seasonal mintemp (wetland)"* seasonal mintemp)+("technological progress on rice }\end{array}$ \\
\hline
\end{tabular}




\begin{tabular}{|c|c|c|c|}
\hline & $\begin{array}{l}\text { MODEL } \\
\text { (Default) }\end{array}$ & WAB & $\begin{array}{l}\text { (wetland)"*unit provity })+(" \text { constant (wetland)")) } \\
\text { Description: this represents wetland rice yield between between September } t \text { and August year } t+1 . \\
\text { Present in } 1 \text { view: } \\
\text { - View } 1 \\
\text { Used by: } \\
\quad \text { "potential rice production (wetland)" - this is total potential rice production in wetland farming between September year } t \text { and August } \\
\quad \text { year } t+1 \text { in case the timing of monsoon onset is not delayed or nor earlier. }\end{array}$ \\
\hline Default & $\begin{array}{c}\text { SD } \\
\text { BASECASE } \\
\text { MODEL } \\
\text { (Default) }\end{array}$ & $\begin{array}{c}\# 40 \\
\text { A } \\
\text { WAB }\end{array}$ & $\begin{array}{l}\text { seasonal mintemp (celcius) } \\
=\text { table seasonal mintemp(Time/unit time) } \\
\text { Description: seasonal minimum temperature based on climate model projections or the base case scenario. } \\
\text { Present in } 1 \text { view: } \\
\text { - View } 1 \\
\text { Used by: } \\
\quad \text { - } \quad \text { "rice yield (dryland)" - this represents dryland rice yield between between September } \mathrm{t} \text { and August year } \mathrm{t}+1 \text {. } \\
\quad \text { "riceld (wetland)" - this represents wetland rice yield between between September } \mathrm{t} \text { and August year } \mathrm{t}+1 \text {. }\end{array}$ \\
\hline Default & $\begin{array}{c}\text { SD } \\
\text { BASECASE } \\
\text { MODEL } \\
\text { (Default) }\end{array}$ & $\begin{array}{c}\# 41 \\
\text { A } \\
\text { VAB }\end{array}$ & $\begin{array}{l}\text { seasonal rainfall (mm/year) } \\
=\text { table seasonal rainfall(Time/unit time) } \\
\text { Description: Seasonal rainfall based on climate model projections or the base case scenario. } \\
\text { Present in } 1 \text { view: } \\
\quad \text { View } 1 \\
\text { Used by: } \\
\quad \text { "cropping intensity (wetland)" - this is cropping intensity in wetland farming based on the period 1976-2011 }\end{array}$ \\
\hline Default & $\begin{array}{c}\text { SD } \\
\text { BASECASE } \\
\text { MODEL } \\
\text { (Default) }\end{array}$ & $\begin{array}{c}\# 42 \\
A \\
\text { VAB }\end{array}$ & $\begin{array}{l}\text { "seed (dryland)" ((IDR/year)) } \\
=\text { "table seed (dryland)"(Time/unit time) } \\
\text { Description: the amount of seed in dryland farming at any given year during simulation } \\
\text { Present in } \mathbf{1} \text { view: } \\
\quad \bullet \quad \text { View } 1 \\
\text { Used by: } \\
\quad \bullet \quad \text { "rice yield (dryland)" - this represents dryland rice yield between between September } \mathrm{t} \text { and August year } \mathrm{t}+1 \text {. }\end{array}$ \\
\hline Default & $\begin{array}{c}\text { SD } \\
\text { BASECASE } \\
\text { MODEL } \\
\text { (Default) }\end{array}$ & $\begin{array}{c}\# 43 \\
L \\
\frac{A_{L}}{x}\end{array}$ & $\begin{array}{l}\text { table August SOI index }(\mathrm{Dmnl}) \\
=[(2015,-35)-(2100,35)],(2015,-5),(2016,1.4),(2017,5.9),(2018,-23.6),(2019,0.1),(2020,2.7),(2021,8.5),(2022,-7.6),(2023,-14),(2024,14.9),(2025,- \\
6.3),(2026,-5),(2027,-7.6),(2028,1.4),(2029,-14),(2030,-17.2),(2031,0.799999),(2032,4.6),(2033,-19.8),(2034,9.8),(2035,2.1),(2036,5.3),(2037,- \\
8.9),(2038,-14.6),(2039,-1.8),(2040,-7.6),(2041,-6.9),(2042,-15.9),(2043,2.7),(2044,9.1),(2045,-5),(2046,18.8),(2047,2.1),(2048,-12.1),(2049,- \\
12.1),(2050,1.4),(2051,-5),(2052,1.4),(2053,5.9),(2054,-23.6),(2055,0.1),(2056,2.7),(2057,8.5),(2058,-7.6),(2059,-14),(2060,14.9),(2061,- \\
6.3),(2062,-5),(2063,-7.6),(2064,1.4),(2065,-14),(2066,-17.2),(2067,0.799999),(2068,4.6),(2069,-19.8),(2070,9.8),(2071,2.1),(2072,5.3),(2073,-\end{array}$ \\
\hline
\end{tabular}




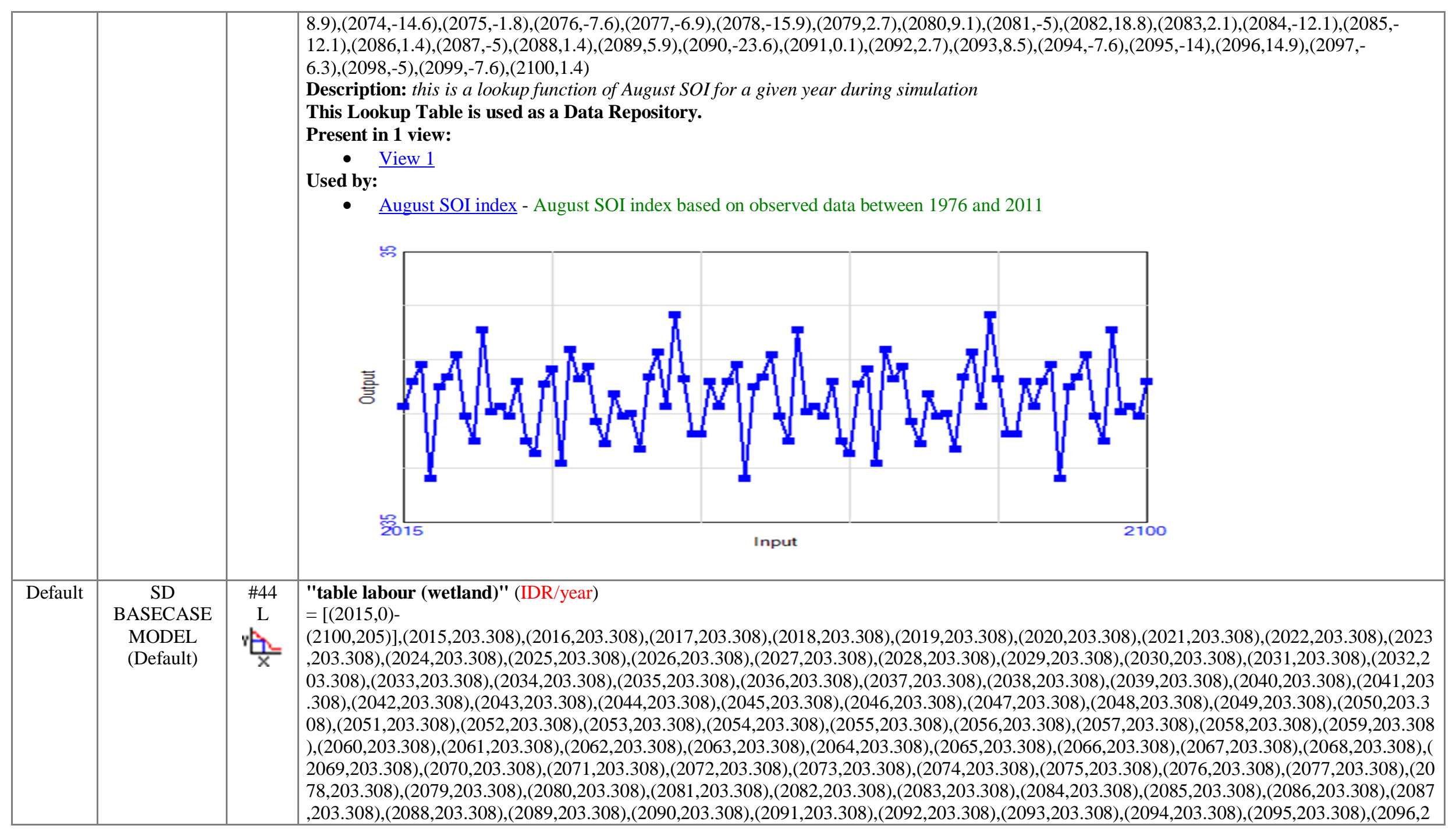




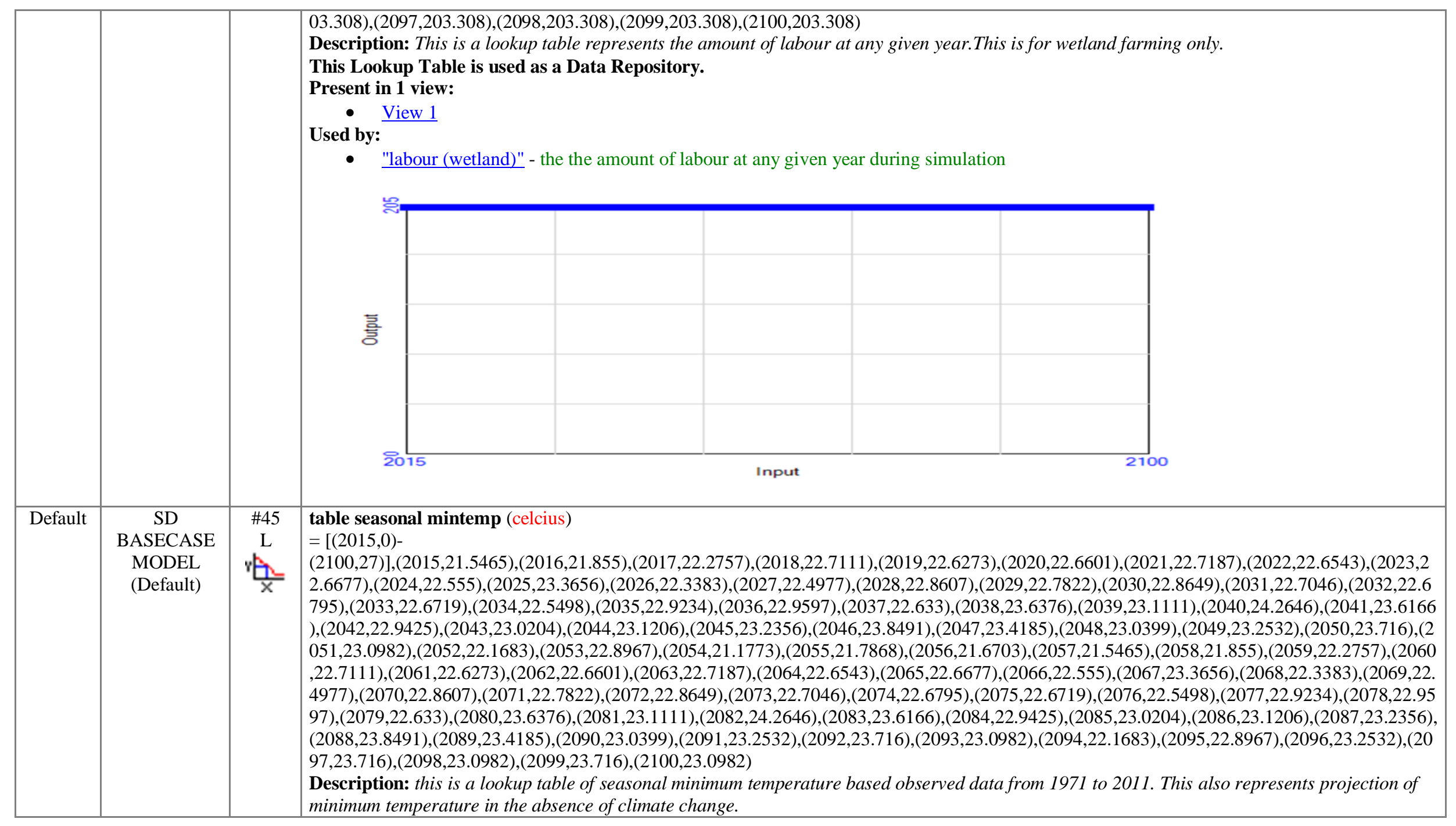




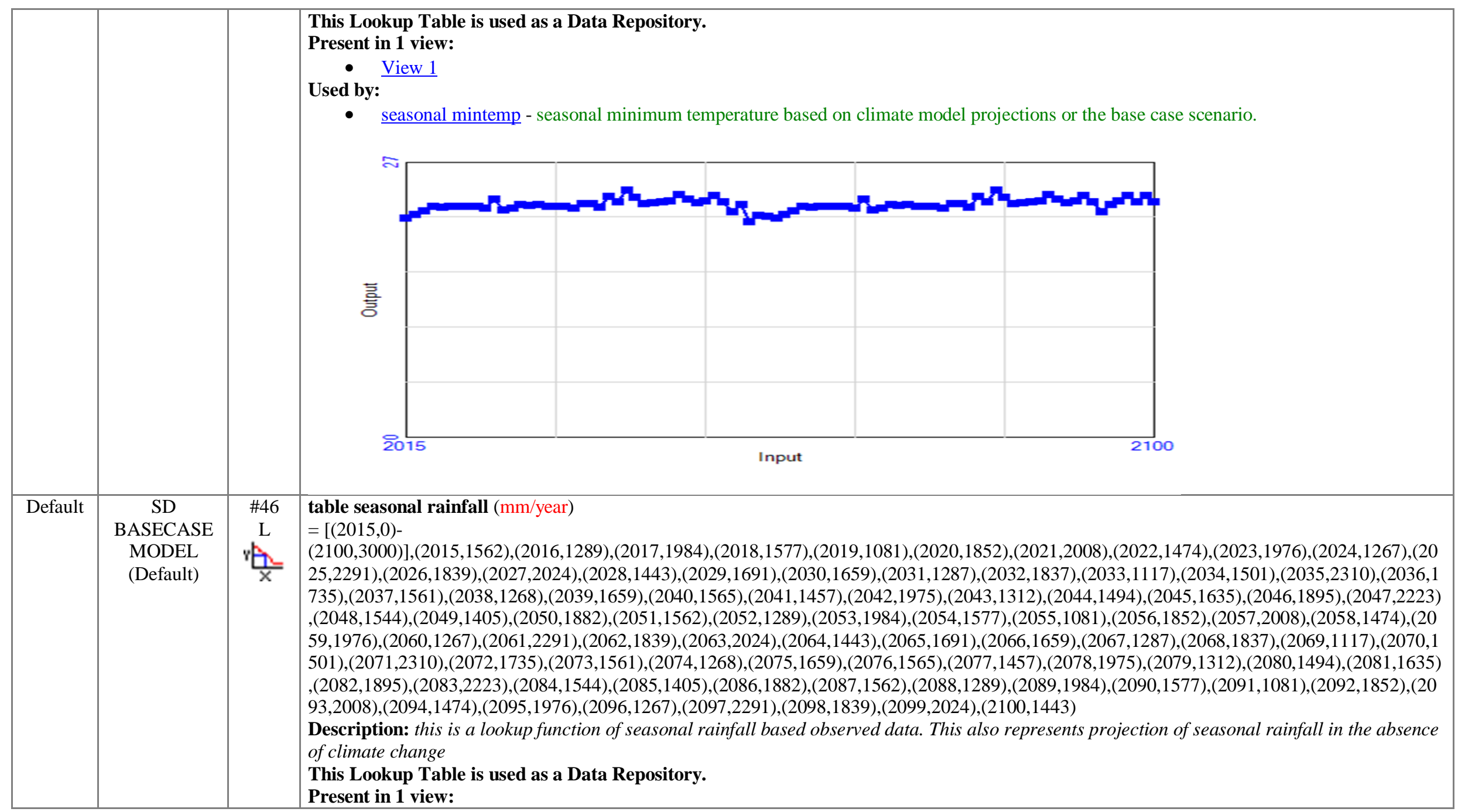




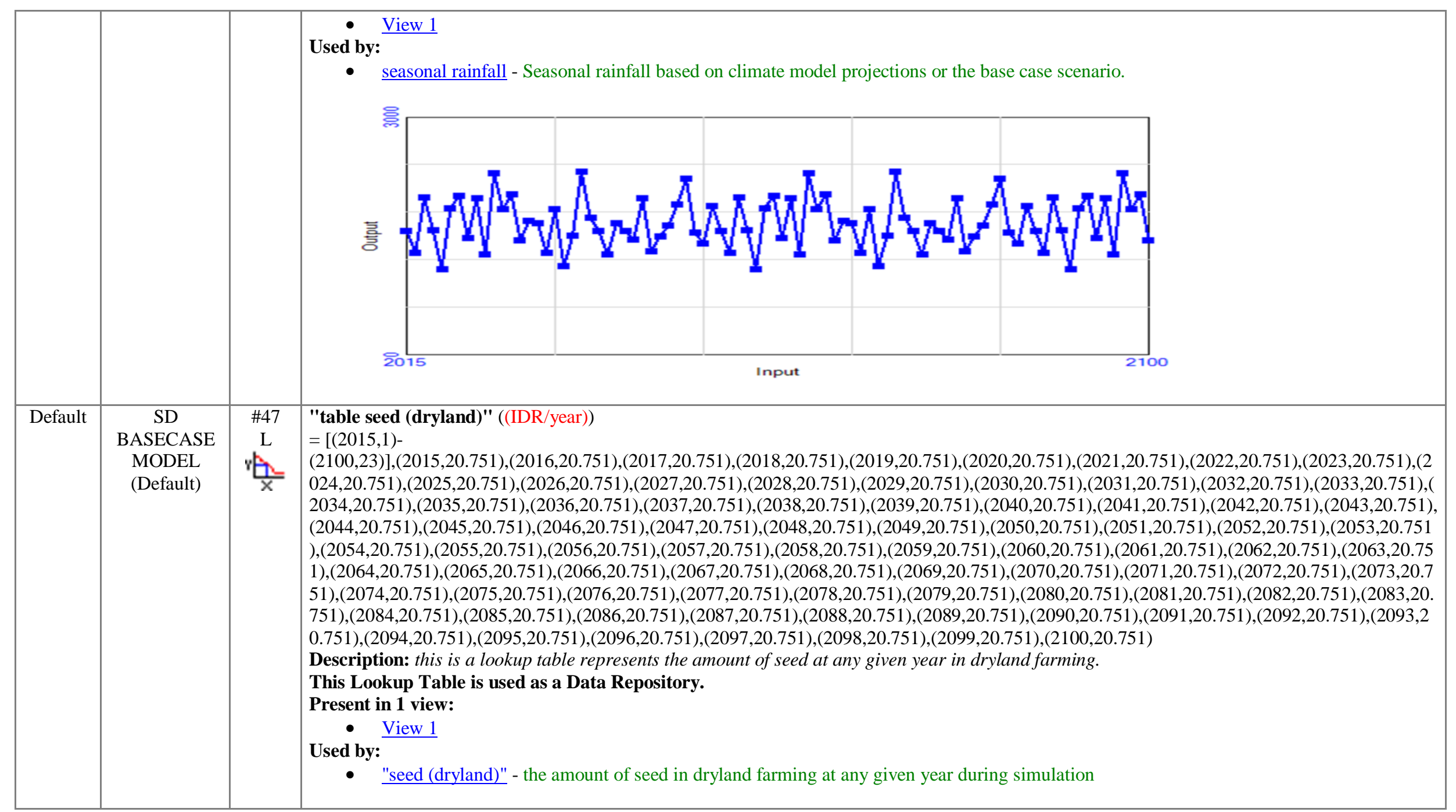




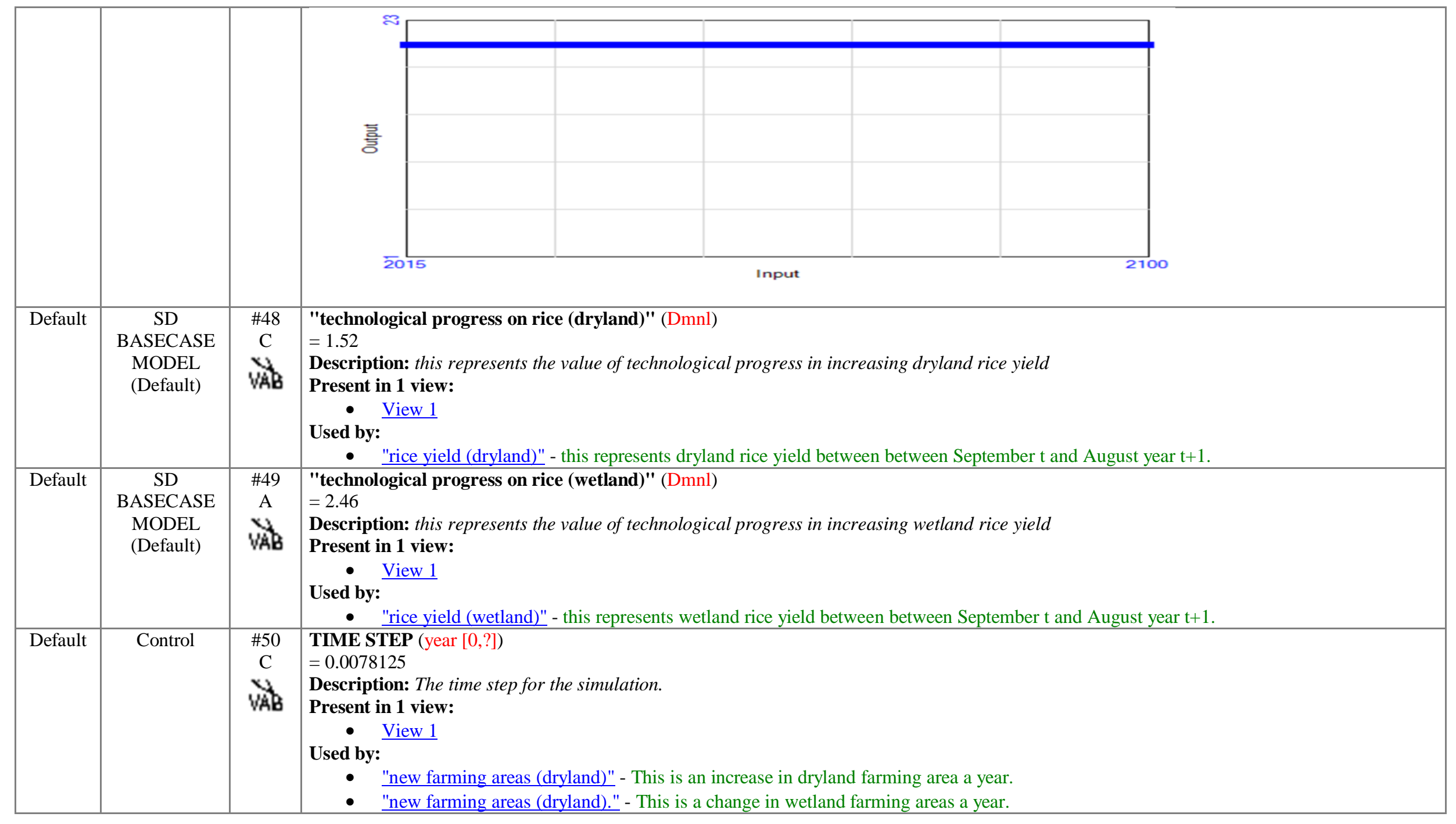




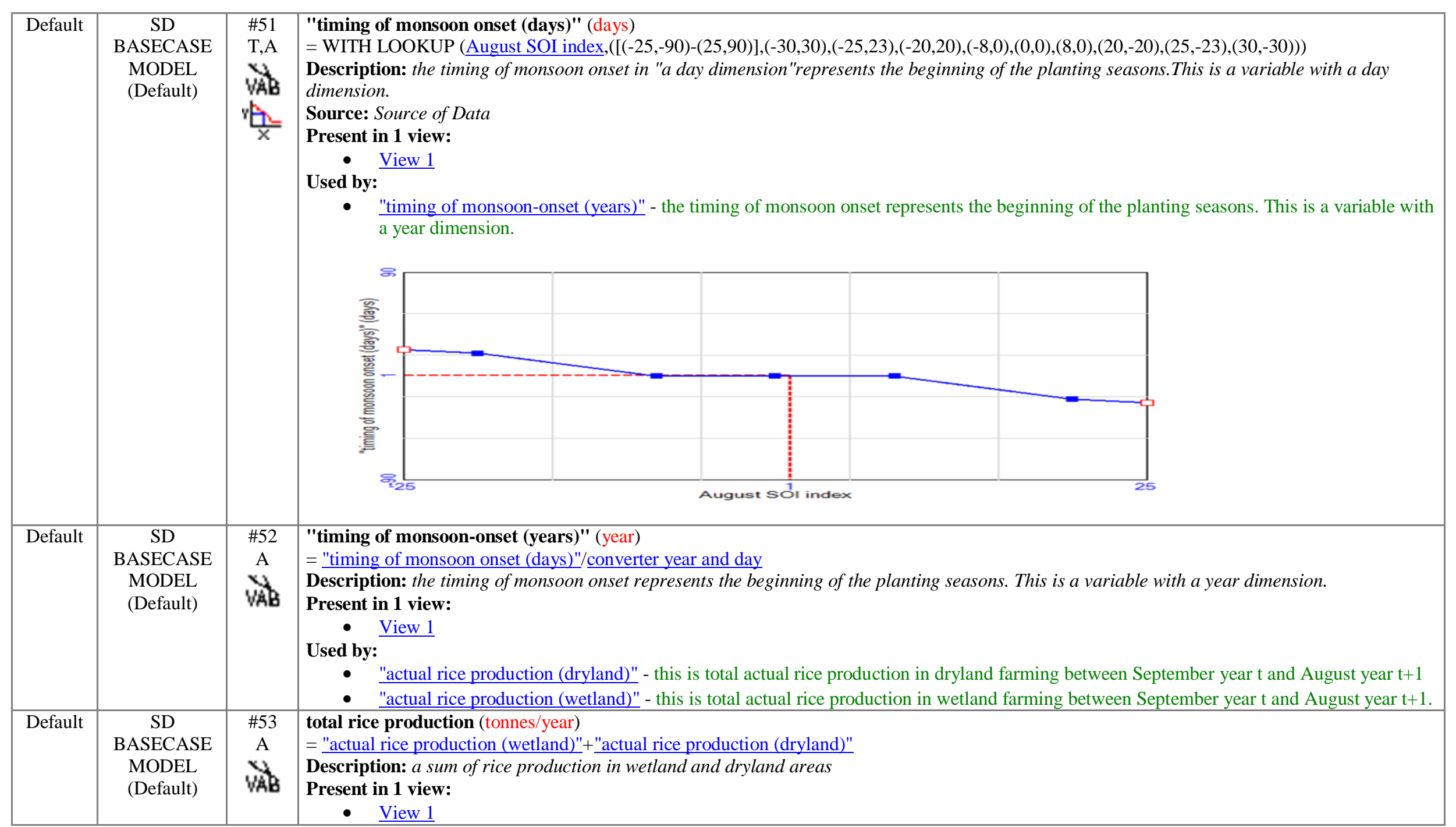




\begin{tabular}{|c|c|c|c|}
\hline Default & $\begin{array}{c}\text { SD } \\
\text { BASECASE } \\
\text { MODEL } \\
\text { (Default) }\end{array}$ & $\begin{array}{c}\# 54 \\
\mathrm{C} \\
\mathrm{VAB}\end{array}$ & $\begin{array}{l}\text { unit provity (tonnes/ha/year) } \\
=1 \\
\text { Description: this variable is used to convert dimensionless variables to be variable with a tonnes/ha/year dimension } \\
\text { Present in } 1 \text { view: } \\
\text { - View } 1 \\
\text { Used by: } \\
\quad \text { "rice yield (dryland)" - this represents dryland rice yield between between September } \mathrm{t} \text { and August year } \mathrm{t}+1 \text {. } \\
\quad \text { "rice yield (wetland)" - this represents wetland rice yield between between September } \mathrm{t} \text { and August year } \mathrm{t}+1 \text {. }\end{array}$ \\
\hline Default & $\begin{array}{c}\text { SD } \\
\text { BASECASE } \\
\text { MODEL } \\
\text { (Default) }\end{array}$ & $\begin{array}{c}\# 55 \\
\mathrm{C} \\
\mathrm{WAB}\end{array}$ & $\begin{array}{l}\text { unit time (year) } \\
=1 \\
\text { Description: this is a variable is used to convert dimensionless variables to be a year dimensioned variable } \\
\text { Present in } 1 \text { view: } \\
\text { Used by: } \\
\text { - } \text { - Aiew } 1 \\
\text { - llabour (wetland)" - the the amount of labour at any given year during simulation } \\
\text { - } \text { seasonal mintemp - seasonal minimum temperature based on climate model projections or the base case scenario. } \\
\text { - } \text { "seasonal rainfall - Seasonal rainfall based on climate model projections or the base case scenario. }\end{array}$ \\
\hline Module & Group & Type & Variable Name and Description \\
\hline
\end{tabular}

Decision and Information Sciences Division Argonne National Laboratory 
this page intentionally left blank 


\section{Appendix G. The Basecase Strategy Model (Chapter 6)}

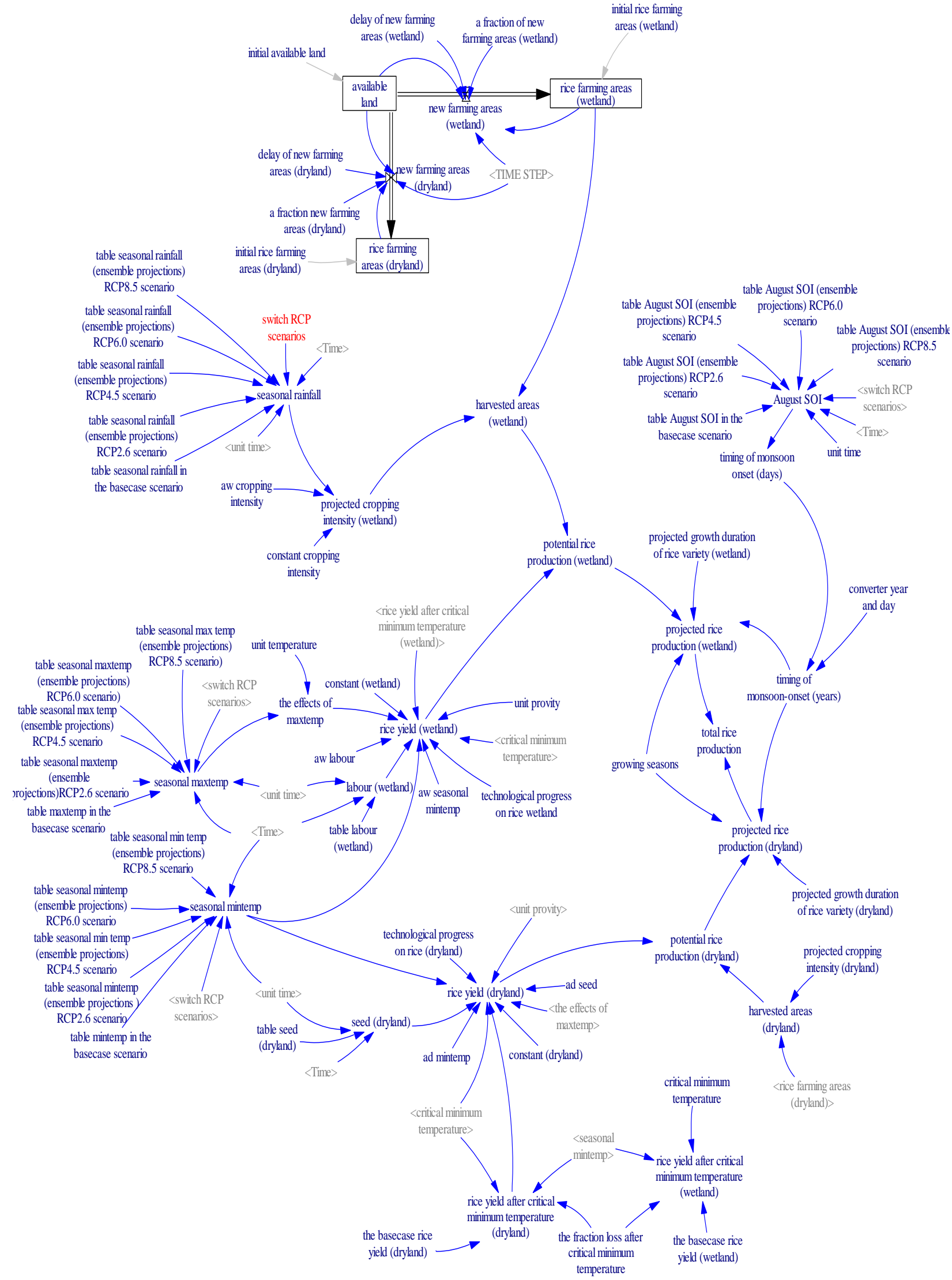

Figure G1. The system dynamics model (SD model) for the basecase / the first strategy 
this page intentionally left blank 
Appendix H. The Basecase Strategy Model Documentation (Chapter 6) Documentation of THE BASECASE STRATEGY

Model Assessment Results

\begin{tabular}{|l|c|}
\hline \multicolumn{1}{|c|}{ Model Information } & Number \\
\hline Total Number of Variables & 84 \\
\hline \begin{tabular}{l|c|} 
Total Number of State Variables \\
(Level+Smooth+Delay Variables)
\end{tabular} & $5(6 \%)$ \\
\hline $\begin{array}{l}\text { Total Number of Stocks (Stocks in } \\
\text { Level+Smooth+Delay Variables) } \dagger\end{array}$ & $9(10.7 \%)$ \\
\hline \hline Time Unit & year \\
\hline Initial Time & 2015 \\
\hline Final Time & 2100 \\
\hline Reported Time Interval & 1 \\
\hline Time Step & 0.0078125 \\
\hline Model Is Fully Formulated & Yes \\
\hline
\end{tabular}




\begin{tabular}{|c|c|c|c|}
\hline Module & Group & Type & Variable Name and Description \\
\hline$\overline{\text { Default }}$ & $\begin{array}{l}\text { THE } \\
\text { BASECASE } \\
\text { STRATEG } \\
\text { Y } \\
\text { (Default) }\end{array}$ & & $\begin{array}{l}\text { "a fraction new farming areas (dryland)" (1/year) } \\
=0.0355 \\
\text { Description: This is annual growth (fraction) of new dryland farming a year based on observed data between } 1976 \text { and } 2011 . \\
\text { Present in } 1 \text { view: } \\
\text { Used by: } \\
\text { "new farming areas (dryland)" - This is an increase in dryland farming area a year.Used by -- farming areas (dryland) which represents } \\
\text { total physical rice farming areas (dryland) }\end{array}$ \\
\hline Default & $\begin{array}{l}\text { THE } \\
\text { BASECASE } \\
\text { STRATEG } \\
\text { Y } \\
\text { (Default) }\end{array}$ & $\begin{array}{l}\# 2 \\
C \\
W A B\end{array}$ & $\begin{array}{l}\text { "a fraction of new farming areas (wetland)" (1/year) } \\
=0.0115 \\
\text { Description: This is annual growth (fraction) of new wetland farming a year based on observed data between } 1976 \text { and } 2011 . \\
\text { Present in } 1 \text { view: } \\
\text { Used by: } \\
\text { "new } 1 \\
\text { physical rice farming areas (wetland) }\end{array}$ \\
\hline Default & $\begin{array}{l}\text { THE } \\
\text { BASECASE } \\
\text { STRATEG } \\
\text { Y } \\
\text { (Default) }\end{array}$ & $\begin{array}{l}\# 3 \\
C \\
\text { Vab }\end{array}$ & $\begin{array}{l}\text { ad mintemp (tonnes/ha/year/celcius) } \\
=-0.12 \\
\text { Description: this a coefficient of minimum temperature to measure rice yield (dryland). } \\
\text { Present in } 1 \text { view: } \\
\text { Used by: } \\
\quad \text { "riew } 1 \\
\end{array}$ \\
\hline Default & $\begin{array}{l}\text { THE } \\
\text { BASECASE } \\
\text { STRATEG } \\
\text { Y } \\
\text { (Default) }\end{array}$ & $\begin{array}{l}\# 4 \\
C \\
\text { VAB }\end{array}$ & $\begin{array}{l}\text { ad seed (tonnes/ha/year/(IDR/year)) } \\
=0.018 \\
\text { Description: this a coefficient of seed to measure rice productivity (dryland). } \\
\text { Present in } 1 \text { view: } \\
\text { Used by: } \\
\quad \underline{\text { niew } 1} \\
\text { "rice yield (dryland)" - this is total rice yield in dryland farming between between September year t and August year t+1. }\end{array}$ \\
\hline Default & $\begin{array}{l}\text { THE } \\
\text { BASECASE } \\
\text { STRATEG } \\
\text { Y }\end{array}$ & $\begin{array}{l}\# 5 \\
A \\
\text { VAB }\end{array}$ & 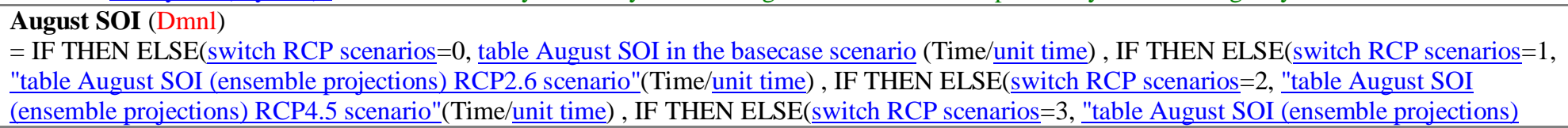 \\
\hline
\end{tabular}




\begin{tabular}{|c|c|c|c|}
\hline & (Default) & & $\begin{array}{l}\text { RCP6.0 scenario"(Time/unit time), "table August SOI (ensemble projections) RCP8.5 scenario"(Time/unit time) )) ) ) } \\
\text { Description: August SOI based on climate model projections or the base case scenario. } \\
\text { Source: Source of Data } \\
\text { Present in } 1 \text { view: } \\
\text { Used by: } \\
\text { "tiew } 1 \\
\text { dimension. }\end{array}$ \\
\hline Default & $\begin{array}{l}\text { THE } \\
\text { BASECASE } \\
\text { STRATEG } \\
\text { Y } \\
\text { (Default) }\end{array}$ & 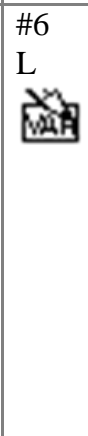 & $\begin{array}{l}\text { available land (ha) } \\
=\int-" \text { new farming areas (wetland)"-"new farming areas (dryland)" } d t+[\underline{\text { initial available land }]} \\
\text { Description: Available land is potential land to be converted into wetland and dryland farming. This land is served to increase areas of wetland } \\
\text { and dryland farming. } \\
\text { Present in } 1 \text { view: } \\
\quad \text { View } 1 \\
\text { Used by: } \\
\text { "new farming areas (dryland)" - This is an increase in dryland farming area a year.Used by -- farming areas (dryland) which represents } \\
\text { total physical rice farming areas (dryland) } \\
\text { "new farming areas (wetland)" - This is a change in wetland farming areas a year.Used by -- farming areas (wetland) which represents total } \\
\text { physical rice farming areas (wetland) }\end{array}$ \\
\hline Default & $\begin{array}{l}\text { THE } \\
\text { BASECASE } \\
\text { STRATEG } \\
\text { Y } \\
\text { (Default) }\end{array}$ & $\begin{array}{l}\# 7 \\
C \\
\text { WAB }\end{array}$ & $\begin{array}{l}\text { aw cropping intensity }(\mathrm{year} / \mathrm{mm}) \\
=0.00023 \\
\text { Description: This is a coefficient of an equation in estimating the effect of seasonal rainfall on cropping intensity of wetland farming } \\
\text { Present in } 1 \text { view: } \\
\text { Used by: } \\
\quad \text { "projected cropping intensity (wetland)" - the expected cropping intensity }\end{array}$ \\
\hline Default & $\begin{array}{l}\text { THE } \\
\text { BASECASE } \\
\text { STRATEG } \\
\text { Y } \\
\text { (Default) }\end{array}$ & $\begin{array}{l}\# 8 \\
\mathrm{C} \\
\mathrm{WAB}\end{array}$ & $\begin{array}{l}\text { aw labour (tonnes/ha/(IDR/year)/year) } \\
=0.003 \\
\text { Description: a coefficient of labour relative for irrigated farming } \\
\text { Present in } 1 \text { view: } \\
\quad \text { View } 1 \\
\text { Used by: } \\
\quad \text { "rice yield (wetland)" - this is total rice yield in wetland farming between between September t and August year t+1. }\end{array}$ \\
\hline Default & $\begin{array}{l}\text { THE } \\
\text { BASECASE }\end{array}$ & $\begin{array}{l}\# 9 \\
\mathrm{C}\end{array}$ & $\begin{array}{l}\text { aw seasonal mintemp (tonnes/ha/celcius/year) } \\
=-0.197\end{array}$ \\
\hline
\end{tabular}




\begin{tabular}{|c|c|c|c|}
\hline & $\begin{array}{l}\text { STRATEG } \\
\text { Y } \\
\text { (Default) }\end{array}$ & VAB & $\begin{array}{l}\text { Description: this a coefficient of minimum temperature to measure rice yield (wetland). } \\
\text { Present in } 1 \text { view: } \\
\text { View } 1 \\
\text { Used by: } \\
\quad \text { "rice yield (wetland)" - this is total rice yield in wetland farming between between September t and August year } \mathrm{t}+1 \text {. }\end{array}$ \\
\hline Default & $\begin{array}{l}\text { THE } \\
\text { BASECASE } \\
\text { STRATEG } \\
\text { Y } \\
\text { (Default) }\end{array}$ & $\begin{array}{l}10 \\
C \\
\text { VAB }\end{array}$ & $\begin{array}{l}\text { "constant (dryland)" (tonnes/ha/year) } \\
=4.56 \\
\text { Description: a constant to measure rice yield in dryland farming. } \\
\text { Present in } 1 \text { view: } \\
\text { Uiew } 1 \\
\quad \text { "rice yield (dryland)" - this is total rice yield in dryland farming between between September year } t \text { and August year } t+1 .\end{array}$ \\
\hline Default & $\begin{array}{l}\text { THE } \\
\text { BASECASE } \\
\text { STRATEG } \\
\text { Y } \\
\text { (Default) }\end{array}$ & $\begin{array}{l}\# 11 \\
C \\
\text { VAB }\end{array}$ & $\begin{array}{l}\text { "constant (wetland)" (tonnes/ha/year) } \\
=6.73 \text { } \\
\text { Description: a constant to measure rice yield in wetland farming. } \\
\text { Present in } 1 \text { view: } \\
\text { Uiew } 1 \\
\quad \text { "rice yield (wetland)" - this is total rice yield in wetland farming between between September t and August year } \mathrm{t}+1 \text {. }\end{array}$ \\
\hline Default & $\begin{array}{l}\text { THE } \\
\text { BASECASE } \\
\text { STRATEG } \\
\text { Y } \\
\text { (Default) }\end{array}$ & $\begin{array}{l}\# 12 \\
C \\
\text { VAB }\end{array}$ & $\begin{array}{l}\text { constant cropping intensity }(\mathrm{Dmnl}) \\
=0.935 \\
\text { Description: This is a constantof an equation in estimating the effect of seasonal rainfall on cropping intensity of wetland farming } \\
\text { Present in } 1 \text { view: } \\
\quad \text { View } 1 \\
\quad \text { Used by: } \\
\quad \text { projected cropping intensity (wetland)" - the expected cropping intensity }\end{array}$ \\
\hline Default & $\begin{array}{l}\text { THE } \\
\text { BASECASE } \\
\text { STRATEG } \\
\text { Y } \\
\text { (Default) }\end{array}$ & $\begin{array}{l}\# 13 \\
\mathrm{C} \\
\mathrm{WAB}\end{array}$ & $\begin{array}{l}\text { converter year and day (days/year) } \\
=365 \\
\text { Description: this variable is used to convert a day dimension to be a year dimension } \\
\text { Present in } 2 \text { views: } \\
\qquad \underline{\text { View } 1} \\
\text { Used by: } \\
\quad \text { View } 2 \\
\text { - } \\
\text { "projected growth duration of rice variety in days (dryland)." }\end{array}$ \\
\hline
\end{tabular}




\begin{tabular}{|c|c|c|c|}
\hline & & & $\begin{array}{l}\text { "timing of monsoon-onset (years)" - the timing of monsoon onset represents the start of the planting seasons. Used by --- actual paddy } \\
\text { oduction which represents the actual paddy production (wetland) in harvesting seasons. }\end{array}$ \\
\hline Default & $\begin{array}{l}\text { THE } \\
\text { BASECASE } \\
\text { STRATEG } \\
\text { Y } \\
\text { (Default) }\end{array}$ & $\begin{array}{l}\# 14 \\
\mathrm{C} \\
\text { VAB }\end{array}$ & $\begin{array}{l}\text { critical minimum temperature (celcius) } \\
=24.7 \\
\text { Description: the maximum minimum temperature when statistical model of rice yield should be replaced by "rice yield after critical minimum } \\
\text { temperature for wetland rice and dryland rice" } \\
\text { Present in } 1 \text { view: } \\
\text { Used by: } \\
\quad \text { "riew } 1 \\
\quad \text { "rice yield (dryland)" - this is total rice yield in dryland farming between between September year } t \text { and August year } \mathrm{t}+1 \text {. } \\
\quad \text { "rice yield after critical minimum temperature (dryland)" - The rice yield after critical minimum temperature (dryland) } \\
\text { "rice yield after critical minimum temperature (wetland)" - The rice yield after critical minimum temperature (wetland) }\end{array}$ \\
\hline Default & $\begin{array}{l}\text { THE } \\
\text { BASECASE } \\
\text { STRATEG } \\
\text { Y } \\
\text { (Default) }\end{array}$ & $\begin{array}{l}\# 15 \\
\mathrm{C} \\
\mathrm{WAB}\end{array}$ & $\begin{array}{l}\text { "delay of new farming areas (dryland)" (year) } \\
=1 \\
\text { Description: The time it takes for opening new wetland farming. In general, the government prepares programs to open new farming area } 1 \text { year } \\
\text { prior to the intended year. } \\
\text { Present in } 1 \text { view: } \\
\text { View } 1 \\
\text { Used by: } \\
\text { "new farming areas (dryland)" - This is an increase in dryland farming area a year.Used by -- farming areas (dryland) which represents } \\
\text { total physical rice farming areas (dryland) }\end{array}$ \\
\hline Default & $\begin{array}{l}\text { THE } \\
\text { BASECASE } \\
\text { STRATEG } \\
\text { Y } \\
\text { (Default) }\end{array}$ & $\begin{array}{l}\# 16 \\
C \\
\text { VAB }\end{array}$ & $\begin{array}{l}\text { "delay of new farming areas (wetland)" (year) } \\
=1 \\
\text { Description: The time it takes for opening new dryland farming. In general, the government prepares programs to open new farming area } 1 \text { year } \\
\text { prior to the intended year. } \\
\text { Present in } 1 \text { view: } \\
\quad \text { View } 1 \\
\text { Used by: } \\
\text { "new farming areas (wetland)" - This is a change in wetland farming areas a year.Used by -- farming areas (wetland) which represents total } \\
\text { physical rice farming areas (wetland) }\end{array}$ \\
\hline Default & $\begin{array}{l}\text { THE } \\
\text { BASECASE } \\
\text { STRATEG } \\
\text { Y }\end{array}$ & $\begin{array}{l}\# 17 \\
A \\
\text { Vab }\end{array}$ & $\begin{array}{l}\text { " growth duration of rice variety (dryland)" (year) } \\
=(110 / 365) \\
\text { Description: The initial growth duration of dryland rice variety. The growth duration of rice variety is about } 110 \text { days which is converted into } \\
\text { (110/365) years. }\end{array}$ \\
\hline
\end{tabular}




\begin{tabular}{|c|c|c|c|}
\hline & (Default) & & $\begin{array}{l}\text { Source: Source of Data } \\
\text { Present in } 2 \text { views: } \\
\qquad \frac{\text { View } 1}{\text { View } 2} \\
\text { Used by: } \\
\qquad \quad \frac{\text { "projected growth duration of rice variety in days (dryland)." }}{\text { "projected rice production (dryland)" - this is total actual rice production in dryland farming between September year } t \text { and August year } t+1}\end{array}$ \\
\hline Default & $\begin{array}{l}\text { THE } \\
\text { BASECASE } \\
\text { STRATEG } \\
\text { Y } \\
\text { (Default) }\end{array}$ & $\begin{array}{l}\# 18 \\
A \\
\text { VAb }\end{array}$ & $\begin{array}{l}\text { "growth duration of rice variety (wetland)" (year) } \\
=(115 / 365) \\
\text { Description: The initial growth duration of wetland rice variety. The growth duration of rice variety is about } 115 \text { days which is converted into } \\
\text { (115/365) years. } \\
\text { Source: Source of Data } \\
\text { Present in } 2 \text { views: } \\
\quad \frac{\text { View } 1}{\text { View } 2} \\
\text { Used by: } \\
\quad \text { "projected growth duration of rice variety in days (wetland)." } \\
\quad \text { "projected rice production (wetland)" - this is total actual rice production in wetland farming between September year } t \text { and August year } \\
\text { t+1. }\end{array}$ \\
\hline Default & $\begin{array}{l}\text { THE } \\
\text { BASECASE } \\
\text { STRATEG } \\
\text { Y } \\
\text { (Default) }\end{array}$ & $\begin{array}{l}\# 20 \\
\mathrm{C} \\
\mathrm{WAB}\end{array}$ & $\begin{array}{l}\text { growing seasons (Dmnl) } \\
=3 \\
\text { Description: the number of growing seasons in a seasonal year (September in year t until August in year } t+1) \text {. } \\
\text { This Lookup Table is used as a Data Repository. } \\
\text { Present in } 1 \text { view: } \\
\text { Used by: } \\
\qquad \quad \text { "projected rice production (dryland)" - this is total actual rice production in dryland farming between September year } t \text { and August year } t+1 \\
\quad \text { "projected rice production (wetland)" - this is total actual rice production in wetland farming between September year } t \text { and August year }\end{array}$ \\
\hline Default & $\begin{array}{l}\text { THE } \\
\text { BASECASE } \\
\text { STRATEG } \\
\text { Y } \\
\text { (Default) }\end{array}$ & $\begin{array}{l}\# 21 \\
A \\
\text { VAB }\end{array}$ & $\begin{array}{l}\text { "harvested areas (dryland)" (ha) } \\
=\text { "rice farming areas (dryland)"*"projected cropping intensity (dryland)" } \\
\text { Description: This is a total harvested area in dryland farming between September year t and August year } t+1 \text {. } \\
\text { Present in } 2 \text { views: } \\
\quad \underline{\text { View } 1} \\
\quad \underline{\text { View } 2}\end{array}$ \\
\hline
\end{tabular}




\begin{tabular}{|c|c|c|c|}
\hline & & & $\begin{array}{l}\text { Used by: } \\
\text { "potential rice production (dryland)" - this is total potential rice production in dryland farming between September year } t \text { and August year }\end{array}$ \\
\hline Default & $\begin{array}{l}\text { THE } \\
\text { BASECASE } \\
\text { STRATEG } \\
\text { Y } \\
\text { (Default) }\end{array}$ & $\begin{array}{l}\# 22 \\
\text { A } \\
\text { WAB }\end{array}$ & $\begin{array}{l}\text { "harvested areas (wetland)" (ha) } \\
=\text { "projected cropping intensity (wetland)" } * \text { "rice farming areas (wetland)" } \\
\text { Description: this is total harvested area in wetland farming between September year t and August year } t+1 \\
\text { Present in } 2 \text { views: } \\
\qquad \frac{\text { View } 1}{\text { View } 2} \\
\text { Used by: } \\
\text { "potential rice production (wetland)" - this is total potential rice production in wetland farming between September year } t \text { and August year }\end{array}$ \\
\hline Default & $\begin{array}{l}\text { THE } \\
\text { BASECASE } \\
\text { STRATEG } \\
\text { Y } \\
\text { (Default) }\end{array}$ & $\begin{array}{l}\# 23 \\
\text { LI,C } \\
\text { WAB }\end{array}$ & $\begin{array}{l}\text { initial available land (ha) } \\
\text { = } 600795 \\
\text { Description: total potential land to be converted into wetland and dryland farming. This land is secured by the law. } \\
\text { Source: Source of Data } \\
\text { Present in } 1 \text { view: } \\
\text { Uiew } 1 \\
\text { Used by: } \\
\text { available land - Available land is potential land to be converted into wetland and dryland farming. This land is served to increase areas of } \\
\text { wetland and dryland farming. }\end{array}$ \\
\hline Default & $\begin{array}{l}\text { THE } \\
\text { BASECASE } \\
\text { STRATEG } \\
\text { Y } \\
\text { (Default) }\end{array}$ & $\begin{array}{l}\# 24 \\
\text { I } \\
\text { VAB }\end{array}$ & $\begin{array}{l}\text { "initial rice farming areas (dryland)" (ha) } \\
\text { = INITIAL(47496.2) } \\
\text { Description: initial rice dryland areas. } \\
\text { Source: Source of Data } \\
\text { Present in } 1 \text { view: } \\
\text { View } 1 \\
\quad \text { Used by: } \\
\text { "rice farming areas (dryland)" - rice farming area is total physical land of dryland farming. }\end{array}$ \\
\hline Default & $\begin{array}{l}\text { THE } \\
\text { BASECASE } \\
\text { STRATEG } \\
\text { Y } \\
\text { (Default) }\end{array}$ & $\begin{array}{l}\# 25 \\
\text { I } \\
\text { VAB }\end{array}$ & $\begin{array}{l}\text { "initial rice farming areas (wetland)" (ha) } \\
=\text { INITIAL(240180) } \\
\text { Description: initial rice wetland areas. } \\
\text { Source: Source of Data } \\
\text { Present in } 1 \text { view: } \\
\quad \text { View } 1\end{array}$ \\
\hline
\end{tabular}




\begin{tabular}{|c|c|c|c|}
\hline & & & $\begin{array}{l}\text { Used by: } \\
\text { "rice farming areas (wetland)" - rice farming area is total physical land of wetland farming. }\end{array}$ \\
\hline Default & $\begin{array}{l}\text { THE } \\
\text { BASECASE } \\
\text { STRATEG } \\
\text { Y } \\
\text { (Default) }\end{array}$ & $\begin{array}{l}\# 27 \\
A \\
W A B\end{array}$ & $\begin{array}{l}\text { "labour (wetland)" (IDR/year) } \\
=\text { "table labour (wetland)"(Time/unit time) } \\
\text { Description: a used labour value for a given year during simulation } \\
\text { Present in } 1 \text { view: } \\
\quad \text { View } 1 \\
\text { Used by: } \\
\quad \text { "rice yield (wetland)" - this is total rice yield in wetland farming between between September t and August year } \mathrm{t}+1 \text {. }\end{array}$ \\
\hline Default & $\begin{array}{l}\text { THE } \\
\text { BASECASE } \\
\text { STRATEG } \\
\text { Y } \\
\text { (Default) }\end{array}$ & $\begin{array}{l}\# 28 \\
A \\
\text { WAB }\end{array}$ & $\begin{array}{l}\text { "new farming areas (dryland)" (ha/year) } \\
=\text { MIN((DELAY1("a fraction new farming areas (dryland)"*"rice farming areas (dryland)","delay of new farming areas (dryland)")), available } \\
\text { land/TIME STEP) } \\
\text { Description: This is an increase in dryland farming area a year.Used by -- farming areas (dryland) which represents total physical rice farming } \\
\text { areas (dryland) } \\
\text { Present in } 1 \text { view: } \\
\quad \text { View } 1 \\
\text { Used by: } \\
\quad \text { available land - Available land is potential land to be converted into wetland and dryland farming. This land is served to increase areas of } \\
\text { wetland and dryland farming. } \\
\quad \text { "rice farming areas (dryland)" - rice farming area is total physical land of dryland farming. }\end{array}$ \\
\hline Default & $\begin{array}{l}\text { THE } \\
\text { BASECASE } \\
\text { STRATEG } \\
\text { Y } \\
\text { (Default) }\end{array}$ & $\begin{array}{l}\# 29 \\
A \\
\text { WAB }\end{array}$ & $\begin{array}{l}\text { "new farming areas (wetland)" (ha/year) } \\
=\text { MIN((DELAY1("a fraction of new farming areas (wetland)"*"rice farming areas (wetland)", "delay of new farming areas (wetland)")), available } \\
\text { land/TIME STEP) } \\
\text { Description: This is a change in wetland farming areas a year.Used by -- farming areas (wetland) which represents total physical rice farming } \\
\text { areas (wetland) } \\
\text { Present in } 1 \text { view: } \\
\quad \text { View } 1 \\
\text { Used by: } \\
\quad \text { available land - Available land is potential land to be converted into wetland and dryland farming. This land is served to increase areas of } \\
\text { wetland and dryland farming. } \\
\quad \text { "rice farming areas (wetland)" - rice farming area is total physical land of wetland farming. }\end{array}$ \\
\hline Default & $\begin{array}{l}\text { THE } \\
\text { BASECASE } \\
\text { STRATEG } \\
\text { Y }\end{array}$ & $\begin{array}{l}\# 30 \\
A \\
\text { VAB }\end{array}$ & $\begin{array}{l}\text { "potential rice production (dryland)" (tonnes/year) } \\
=\text { "rice yield (dryland)"*"harvested areas (dryland)" } \\
\text { Description: } \text { this is total potential rice production in dryland farming between September year t and August year } t+1 \\
\text { Present in } 1 \text { view: }\end{array}$ \\
\hline
\end{tabular}




\begin{tabular}{|c|c|c|c|}
\hline & (Default) & & $\begin{array}{l}\text { Used by: } \\
\text { "projected rice production (dryland)" - this is total actual rice production in dryland farming between September year } t \text { and August year } t+1\end{array}$ \\
\hline Default & $\begin{array}{l}\text { THE } \\
\text { BASECASE } \\
\text { STRATEG } \\
\text { Y } \\
\text { (Default) }\end{array}$ & $\begin{array}{l}\# 31 \\
\text { A } \\
\text { VAB }\end{array}$ & $\begin{array}{l}\text { "potential rice production (wetland)" (tonnes/year) } \\
=\text { "harvested areas (wetland)"*"rice yield (wetland)" } \\
\text { Description: this is total potential rice production in wetland farming between September year t and August year } t+1 . \\
\text { Present in } 1 \text { view: } \\
\text { Used by: } \\
\quad \text { "projected rice production (wetland)" - this is total actual rice production in wetland farming between September year } t \text { and August year } \\
\mathrm{t}+1 . \quad\end{array}$ \\
\hline Default & $\begin{array}{l}\text { THE } \\
\text { BASECASE } \\
\text { STRATEG } \\
\text { Y } \\
\text { (Default) }\end{array}$ & $\begin{array}{l}\# 32 \\
\text { C } \\
\text { WAB }\end{array}$ & $\begin{array}{l}\text { "projected cropping intensity (dryland)" (Dmnl) } \\
=1 \\
\text { Description: The initial cropping intensity of dryland rice } \\
\text { Present in } 1 \text { view: } \\
\text { Used by: } \\
\quad \text { "harvested areas (dryland)" - This is a total harvested area in dryland farming between September year t and August year } \mathrm{t}+1 .\end{array}$ \\
\hline Default & $\begin{array}{l}\text { THE } \\
\text { BASECASE } \\
\text { STRATEG } \\
\text { Y } \\
\text { (Default) }\end{array}$ & $\begin{array}{l}\# 33 \\
\text { A } \\
\text { VAB }\end{array}$ & $\begin{array}{l}\text { "projected cropping intensity (wetland)" (Dmnl) } \\
=\text { (seasonal rainfall*aw cropping intensity+constant cropping intensity ) } \\
\text { Description: the expected cropping intensity } \\
\text { Present in } 1 \text { view: } \\
\text { View } 1 \\
\quad \text { "harved by: } \\
\quad \text { "haresteas (wetland)" - this is total harvested area in wetland farming between September year } t \text { and August year } t+1\end{array}$ \\
\hline Default & $\begin{array}{l}\text { THE } \\
\text { BASECASE } \\
\text { STRATEG } \\
\text { Y } \\
\text { (Default) }\end{array}$ & $\begin{array}{l}\text { \#36 } \\
\text { DE }\end{array}$ & $\begin{array}{l}\text { "projected rice production (dryland)" (tonnes/year) } \\
=\text { DELAY3(STEP("potential rice production (dryland)",timing of monsoon-onset (years)"), growing seasons*" growth duration of rice variety } \\
\text { (dryland)") } \\
\text { Description: this is total actual rice production in dryland farming between September year t and August year } t+1 \\
\text { Present in } 2 \text { views: } \\
\quad \underline{\text { View } 1} \\
\quad \underline{\text { View } 2} \\
\quad \text { Used by: } \\
\quad \text { total rice production - a sum of rice production in wetland and dryland areas }\end{array}$ \\
\hline Default & THE & $\# 37$ & "projected rice production (wetland)" (tonnes/year) \\
\hline
\end{tabular}




\begin{tabular}{|c|c|c|c|}
\hline & $\begin{array}{l}\text { BASECASE } \\
\text { STRATEG } \\
\text { Y } \\
\text { (Default) }\end{array}$ & $\mathrm{DE}$ & $\begin{array}{l}\text { = DELAY3(STEP("potential rice production (wetland)","timing of monsoon-onset (years)"), growing seasons*" growth duration of rice variety } \\
\text { (wetland)") } \\
\text { Description: this is total actual rice production in wetland farming between September year t and August year } t+1 . \\
\text { Present in } 2 \text { views: } \\
\quad \quad \frac{\text { View } 1}{\text { View } 2} \\
\quad \text { Used by: } \\
\quad \text { total rice production - a sum of rice production in wetland and dryland areas }\end{array}$ \\
\hline Default & $\begin{array}{l}\text { THE } \\
\text { BASECASE } \\
\text { STRATEG } \\
\text { Y } \\
\text { (Default) }\end{array}$ & $\begin{array}{l}\# 38 \\
\mathrm{~L} \\
\text { 朔用 }\end{array}$ & $\begin{array}{l}\text { "rice farming areas (dryland)" (ha) } \\
=\int \text { "new farming areas (dryland)" } d t+[\text { [initial rice farming areas (dryland)"] } \\
\text { Description: rice farming area is total physical land of dryland farming. } \\
\text { Present in } 1 \text { view: } \\
\text { Used by: } \\
\quad \frac{\text { View } 1}{\text { "harvested areas (dryland)" - This is a total harvested area in dryland farming between September year t and August year } \mathrm{t}+1 .} \\
\text { total physical rice farming areas (dryland)" - This is an increase in dryland farming area a year.Used by -- farming areas (dryland) which represents }\end{array}$ \\
\hline Default & $\begin{array}{l}\text { THE } \\
\text { BASECASE } \\
\text { STRATEG } \\
\text { Y } \\
\text { (Default) }\end{array}$ & $\begin{array}{l}\# 39 \\
\mathrm{~L} \\
\text { 解 }\end{array}$ & $\begin{array}{l}\text { "rice farming areas (wetland)" (ha) } \\
=\int \text { "new farming areas (wetland)" } d t+[\text { "initial rice farming areas (wetland)"] } \\
\text { Description: rice farming area is total physical land of wetland farming. } \\
\text { Present in } 1 \text { view: } \\
\text { Used by: } \\
\quad \frac{\text { "hiew } 1}{\text { "harvested areas (wetland)" - this is total harvested area in wetland farming between September year } t \text { and August year } t+1} \\
\text { physical rice farming areas (wetland) }\end{array}$ \\
\hline Default & $\begin{array}{l}\text { THE } \\
\text { BASECASE } \\
\text { STRATEG } \\
\text { Y } \\
\text { (Default) }\end{array}$ & $\begin{array}{l}\# 40 \\
A \\
\text { VAB }\end{array}$ & 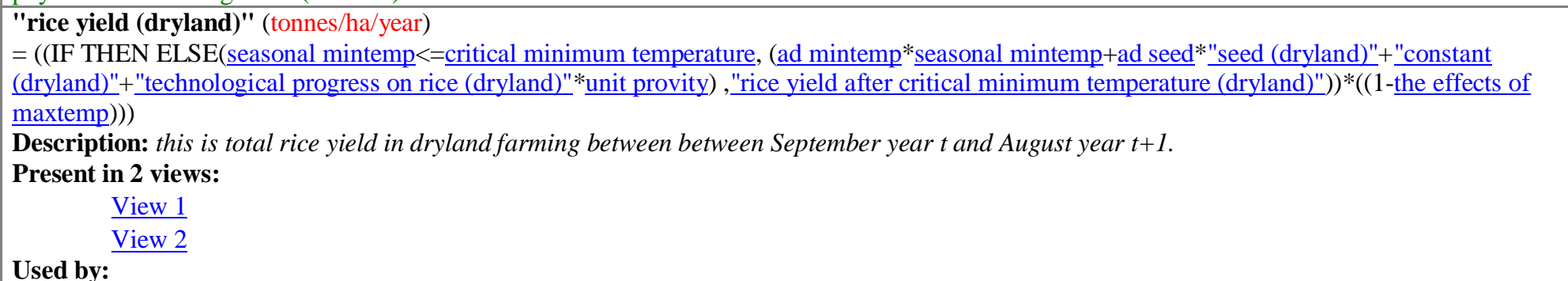 \\
\hline
\end{tabular}




\begin{tabular}{|c|c|c|c|}
\hline & & & t+1 "potential rice production (dryland)" - this is total potential rice production in dryland farming between September year $t$ and August year \\
\hline Default & $\begin{array}{l}\text { THE } \\
\text { BASECASE } \\
\text { STRATEG } \\
\text { Y } \\
\text { (Default) }\end{array}$ & $\begin{array}{l}\# 41 \\
\text { A } \\
\text { WAB }\end{array}$ & 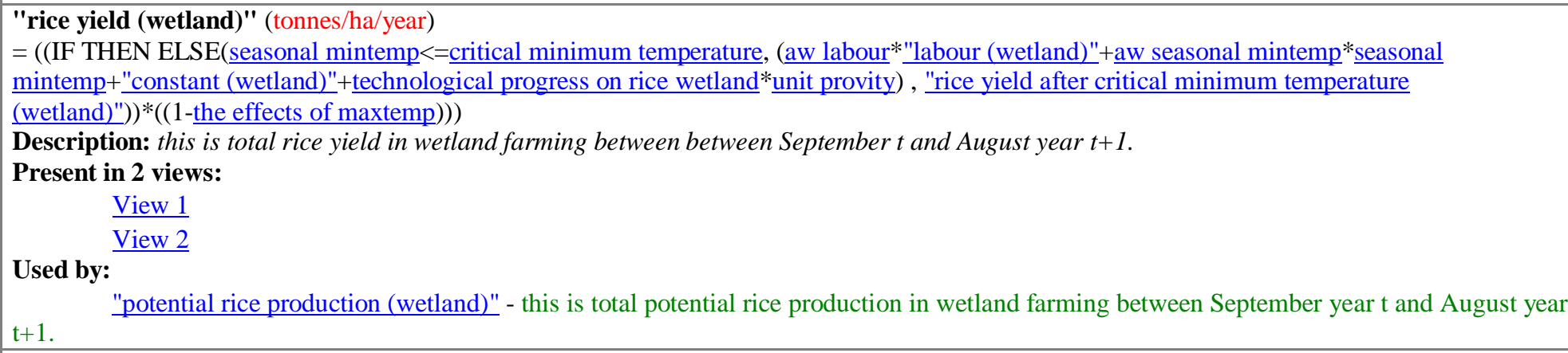 \\
\hline Default & $\begin{array}{l}\text { THE } \\
\text { BASECASE } \\
\text { STRATEG } \\
\text { Y } \\
\text { (Default) }\end{array}$ & $\begin{array}{l}\# 42 \\
A \\
\text { VAB }\end{array}$ & $\begin{array}{l}\text { "rice yield after critical minimum temperature (dryland)" (tonnes/ha/year) } \\
=(\text { "the basecase rice yield (dryland)"+(seasonal mintemp-critical minimum temperature })^{*} \text { the fraction loss after critical minimum temperature } \\
\text { basecase rice yield (dryland)" } \\
\text { Description: The rice yield after critical minimum temperature (dryland) } \\
\text { Present in } 1 \text { view: } \\
\quad \text { View } 1 \\
\quad \text { Used by: } \\
\quad \text { "rice yield (dryland)" - this is total rice yield in dryland farming between between September year } t \text { and August year } t+1 \text {. }\end{array}$ \\
\hline Default & $\begin{array}{l}\text { THE } \\
\text { BASECASE } \\
\text { STRATEG } \\
\text { Y } \\
\text { (Default) }\end{array}$ & $\begin{array}{l}\# 43 \\
\mathrm{~A} \\
\mathrm{~W} \\
\mathrm{VAB}\end{array}$ & $\begin{array}{l}\text { "rice yield after critical minimum temperature (wetland)" (tonnes/year/ha) } \\
=\left(\text { "the basecase rice yield (wetland)"+(seasonal mintemp-critical minimum temperature) }{ }^{*} \text { the fraction loss after critical minimum temperature }\right. \\
\text { basecase rice yield (wetland)" } \\
\text { Description: The rice yield after critical minimum temperature (wetland) } \\
\text { Present in } 1 \text { view: } \\
\text { View } 1 \\
\text { Used by: } \\
\text { "rice yield (wetland)" - this is total rice yield in wetland farming between between September } t \text { and August year } t+1 \text {. }\end{array}$ \\
\hline Default & $\begin{array}{l}\text { THE } \\
\text { BASECASE } \\
\text { STRATEG } \\
\text { Y } \\
\text { (Default) }\end{array}$ & $\begin{array}{l}\# 45 \\
\mathrm{~A} \\
\mathrm{VAB}\end{array}$ & 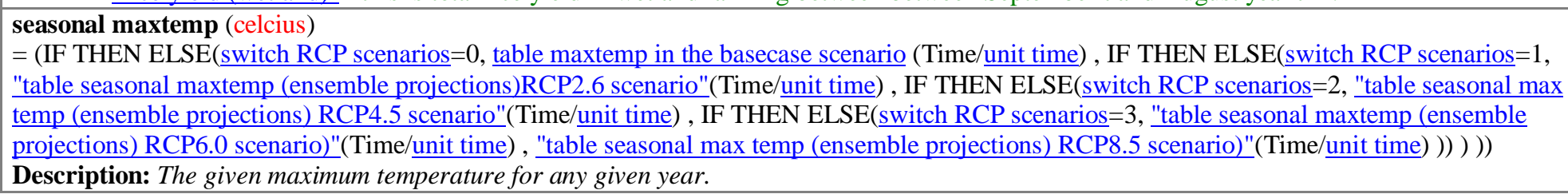 \\
\hline
\end{tabular}




\begin{tabular}{|c|c|c|c|}
\hline & & & $\begin{array}{l}\text { Source: Source of Data } \\
\text { Present in } 1 \text { view: } \\
\text { Used by: } \\
\text { the effects of maxtemp - the effects of maximum temperature on rice yield if rice yield is vulnerable to maximum temperature in } 33 \text { degree } \\
\text { celsius. }\end{array}$ \\
\hline Default & $\begin{array}{l}\text { THE } \\
\text { BASECASE } \\
\text { STRATEG } \\
\text { Y } \\
\text { (Default) }\end{array}$ & $\begin{array}{l}\# 46 \\
\text { A } \\
\text { VAB }\end{array}$ & 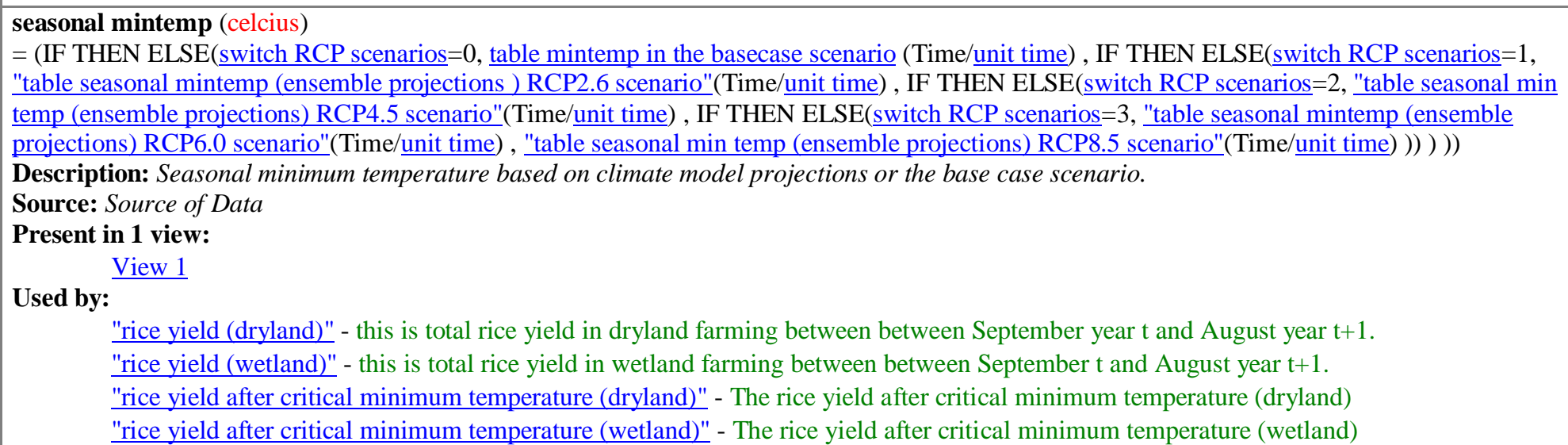 \\
\hline Default & $\begin{array}{l}\text { THE } \\
\text { BASECASE } \\
\text { STRATEG } \\
\text { Y } \\
\text { (Default) }\end{array}$ & $\begin{array}{l}\# 47 \\
\text { A } \\
\text { VAB }\end{array}$ & 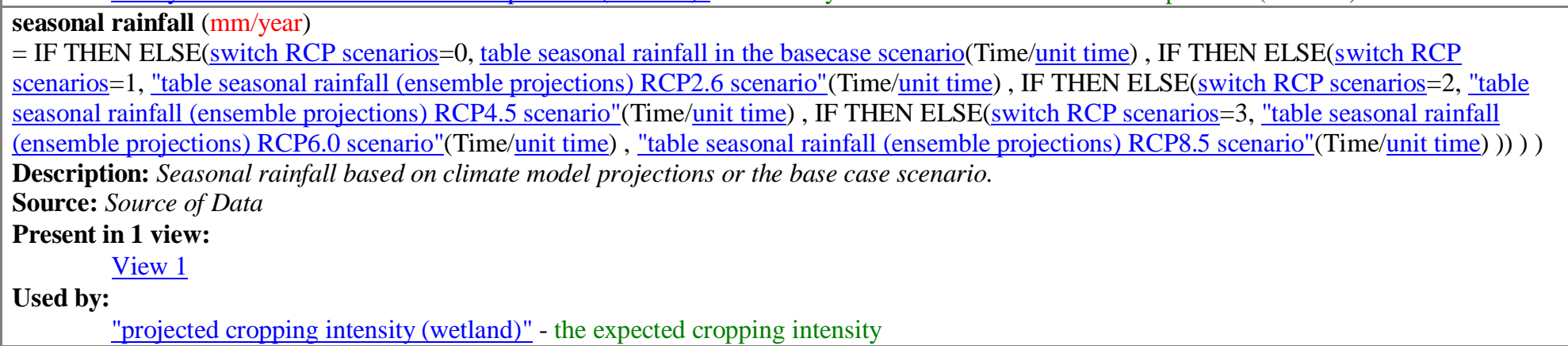 \\
\hline Default & $\begin{array}{l}\text { THE } \\
\text { BASECASE } \\
\text { STRATEG } \\
\text { Y }\end{array}$ & $\begin{array}{l}\# 48 \\
\text { A } \\
\text { VAB }\end{array}$ & $\begin{array}{l}\text { "seed (dryland)" (IDR/year) } \\
=\text { "table seed (dryland)"(Time/unit time) } \\
\text { Description: the used seed in dryland farming for a given year during simulation } \\
\text { Present in } 1 \text { view: }\end{array}$ \\
\hline
\end{tabular}




\begin{tabular}{|c|c|c|c|}
\hline & (Default) & & $\begin{array}{l}\text { Used by: } \\
\text { "rice yield (dryland)" - this is total rice yield in dryland farming between between September year } t \text { and August year } t+1 \text {. }\end{array}$ \\
\hline Default & $\begin{array}{l}\text { THE } \\
\text { BASECASE } \\
\text { STRATEG } \\
\text { Y } \\
\text { (Default) }\end{array}$ & $\begin{array}{l}\# 49 \\
\text { C } \\
\text { VAB }\end{array}$ & $\begin{array}{l}\text { Switch RCP scenarios (Dmnl) } \\
=1 \\
\text { Description: a switch to set a RCP scenario. Set this variable to be } 0,1,2,3,4 \text { for the base case, RCP2.6, RCP4.5, RCP6.0, RCP8.5 scenario } \\
\text { respectively. } \\
\text { Present in } 2 \text { views: } \\
\qquad \frac{\text { View } 1}{\text { View } 2} \\
\text { Used by: } \\
\quad \frac{\text { August SOI - August SOI based on climate model projections or the base case scenario. }}{\text { seasonal maxtemp - The given maximum temperature for any given year. }} \\
\quad \text { seasonal mintemp - Seasonal minimum temperature based on climate model projections or the base case scenario. } \\
\text { seasonal rainfall - Seasonal rainfall based on climate model projections or the base case scenario. }\end{array}$ \\
\hline Default & $\begin{array}{l}\text { THE } \\
\text { BASECASE } \\
\text { STRATEG } \\
\text { Y } \\
\text { (Default) }\end{array}$ & $\begin{array}{l}\# 50 \\
L \\
\frac{L}{x}\end{array}$ & 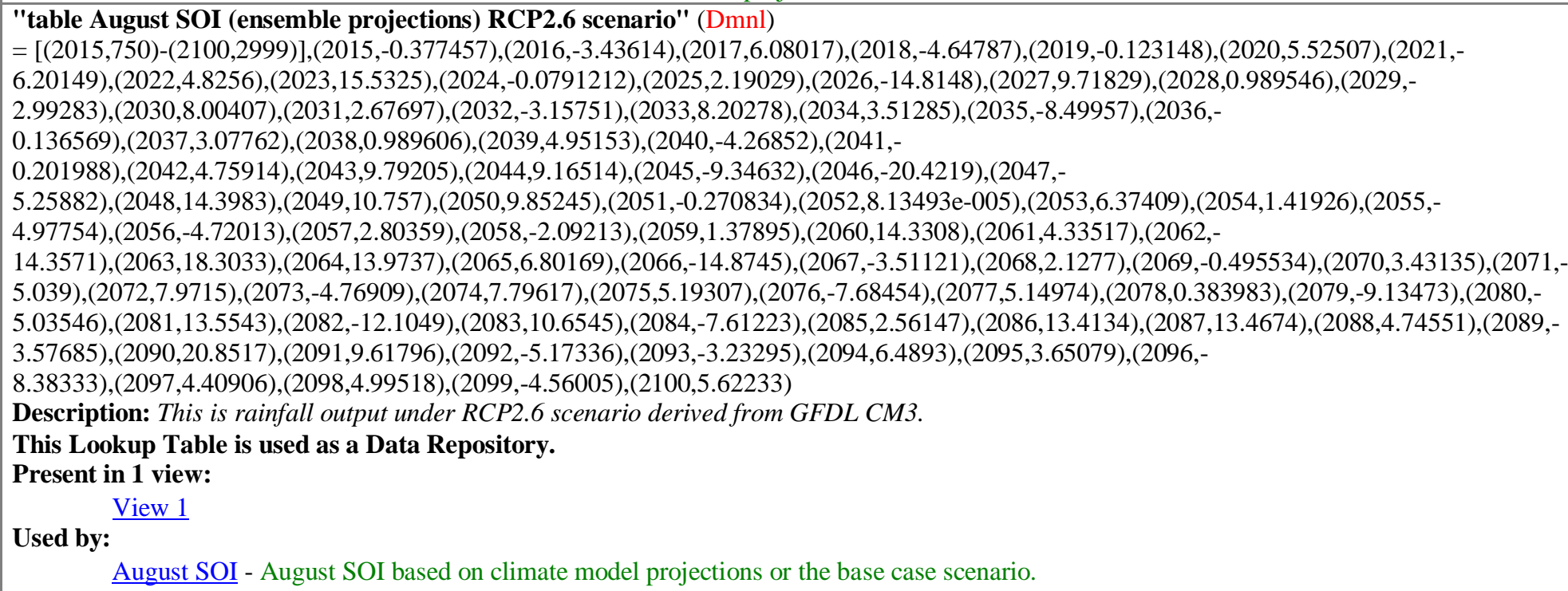 \\
\hline
\end{tabular}




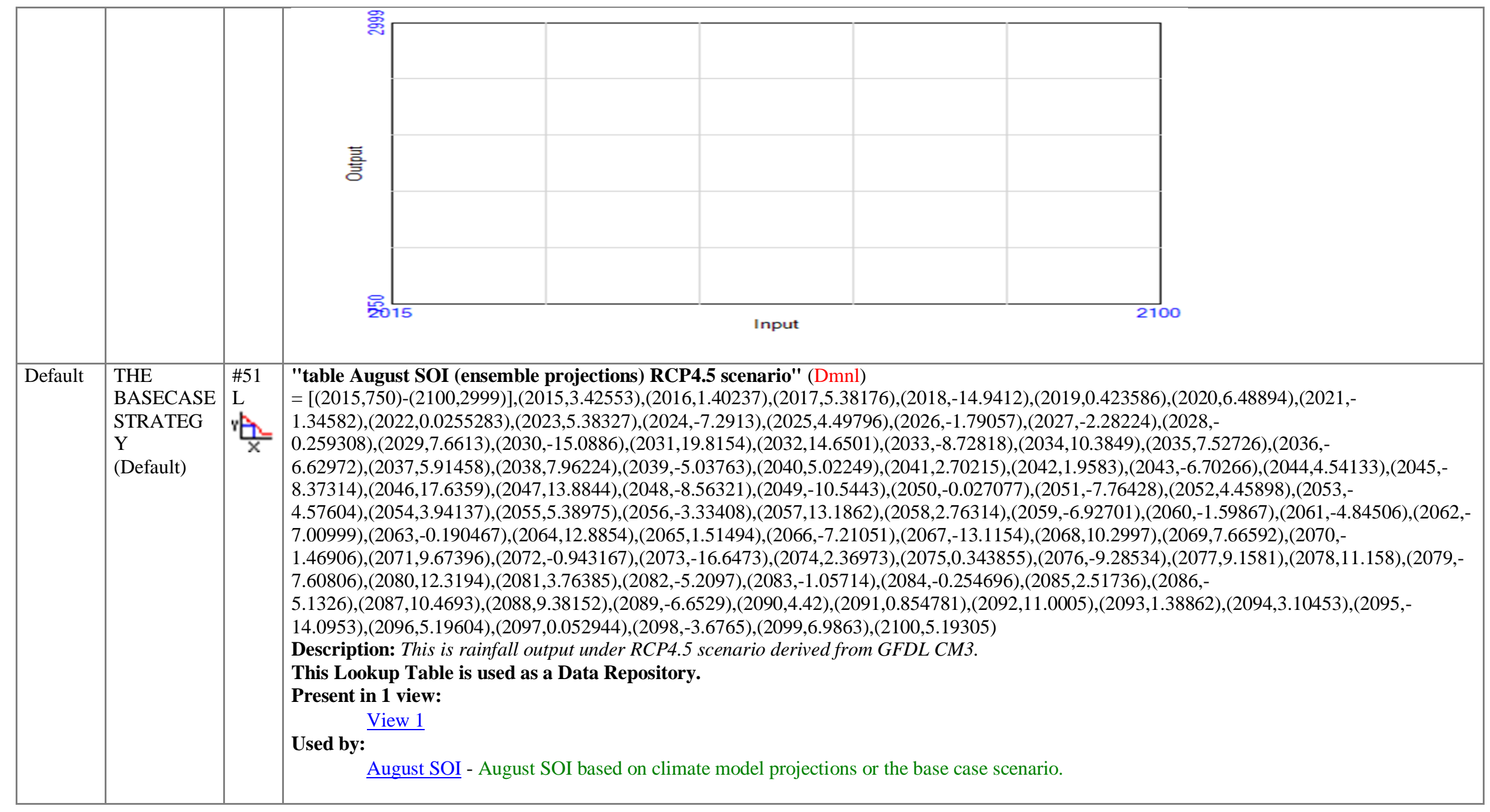




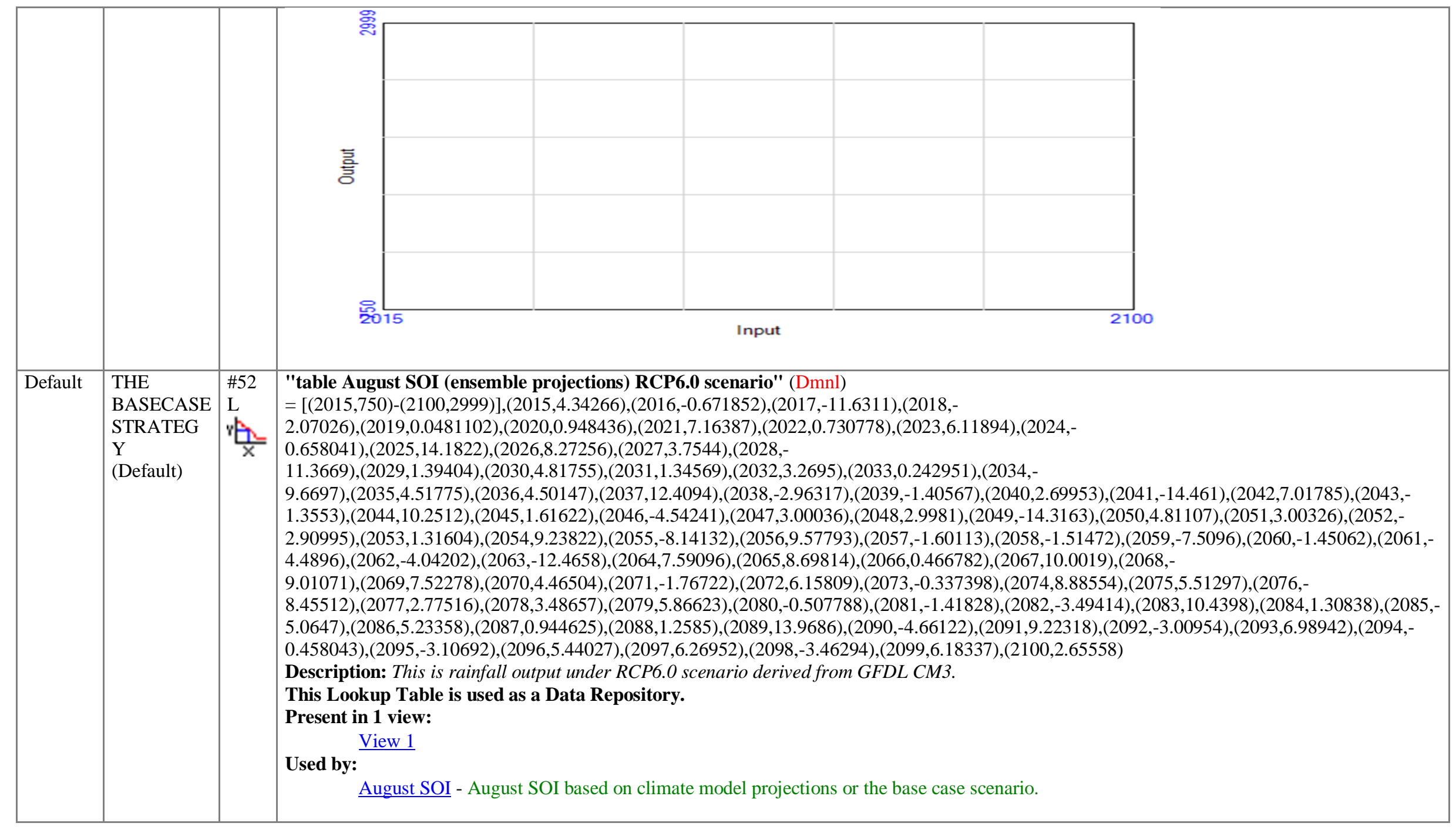




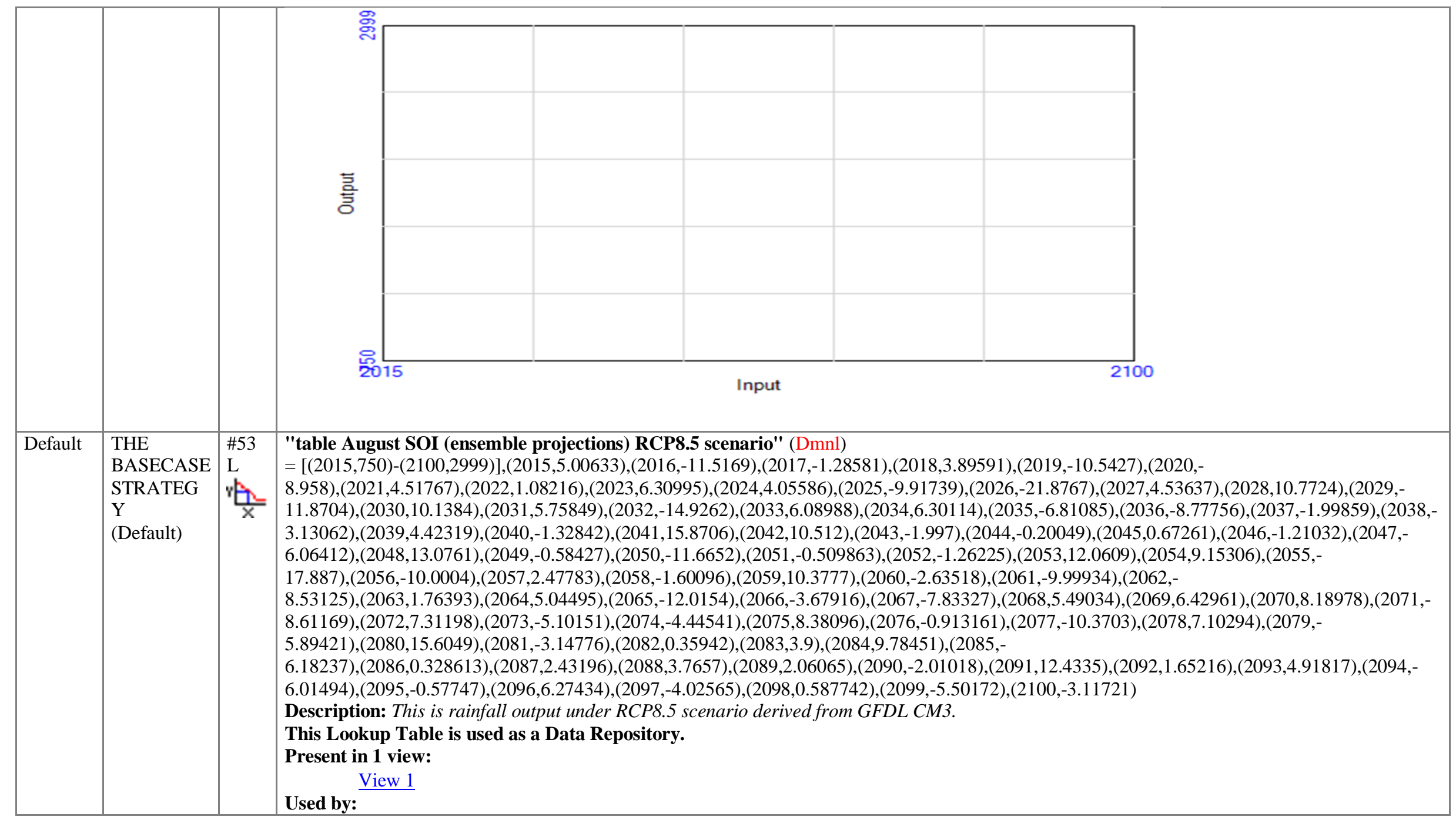




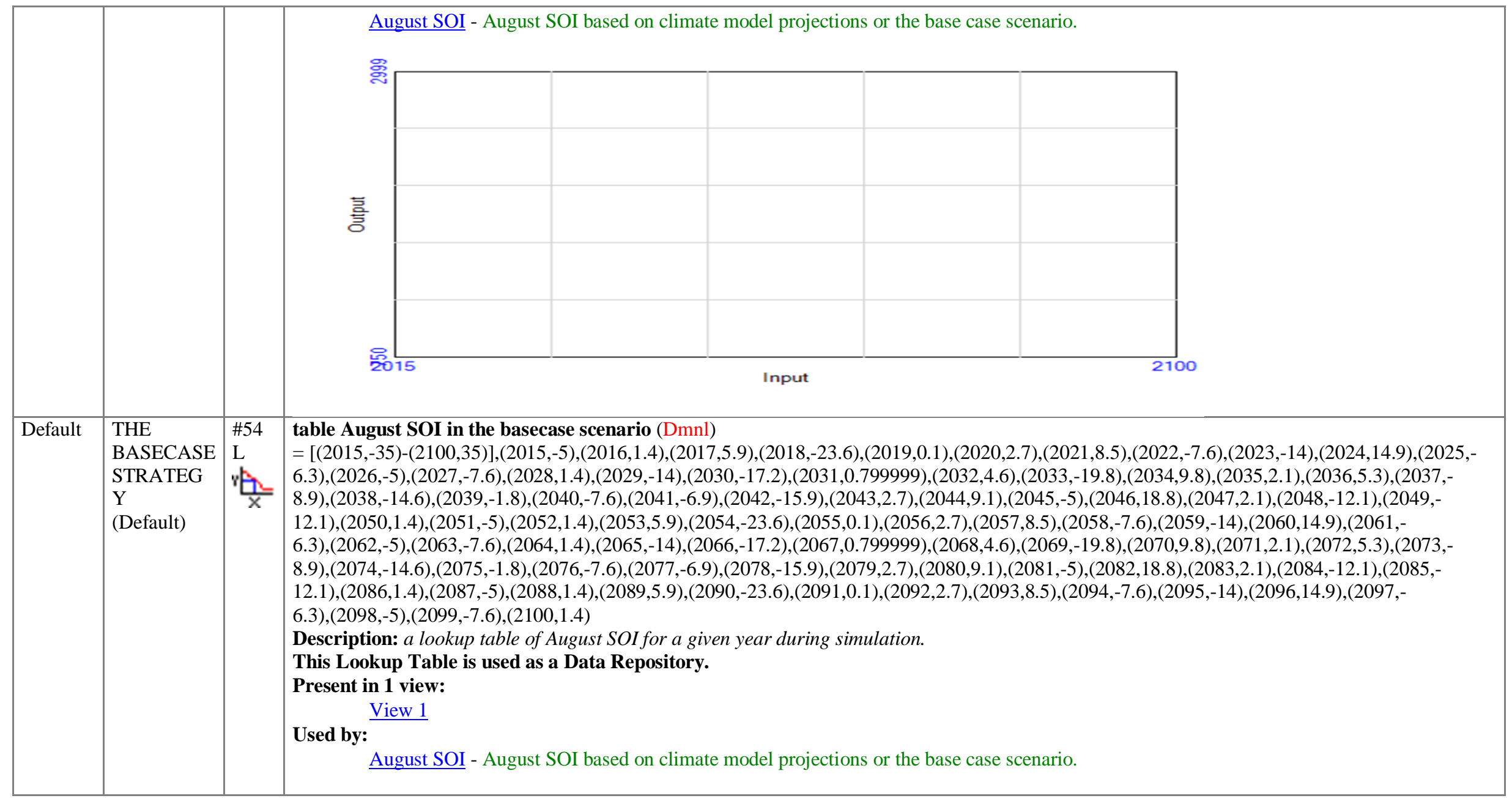




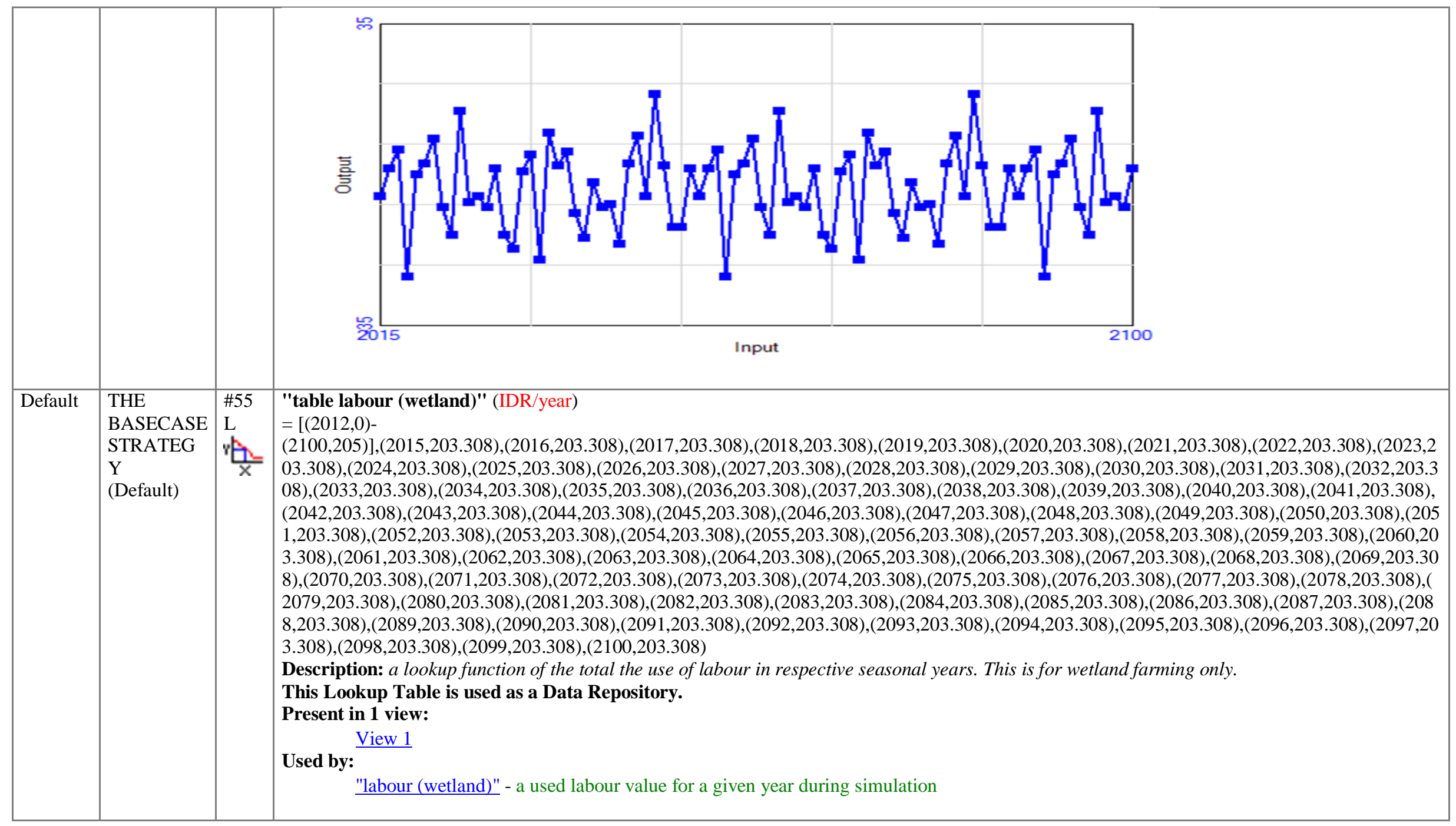




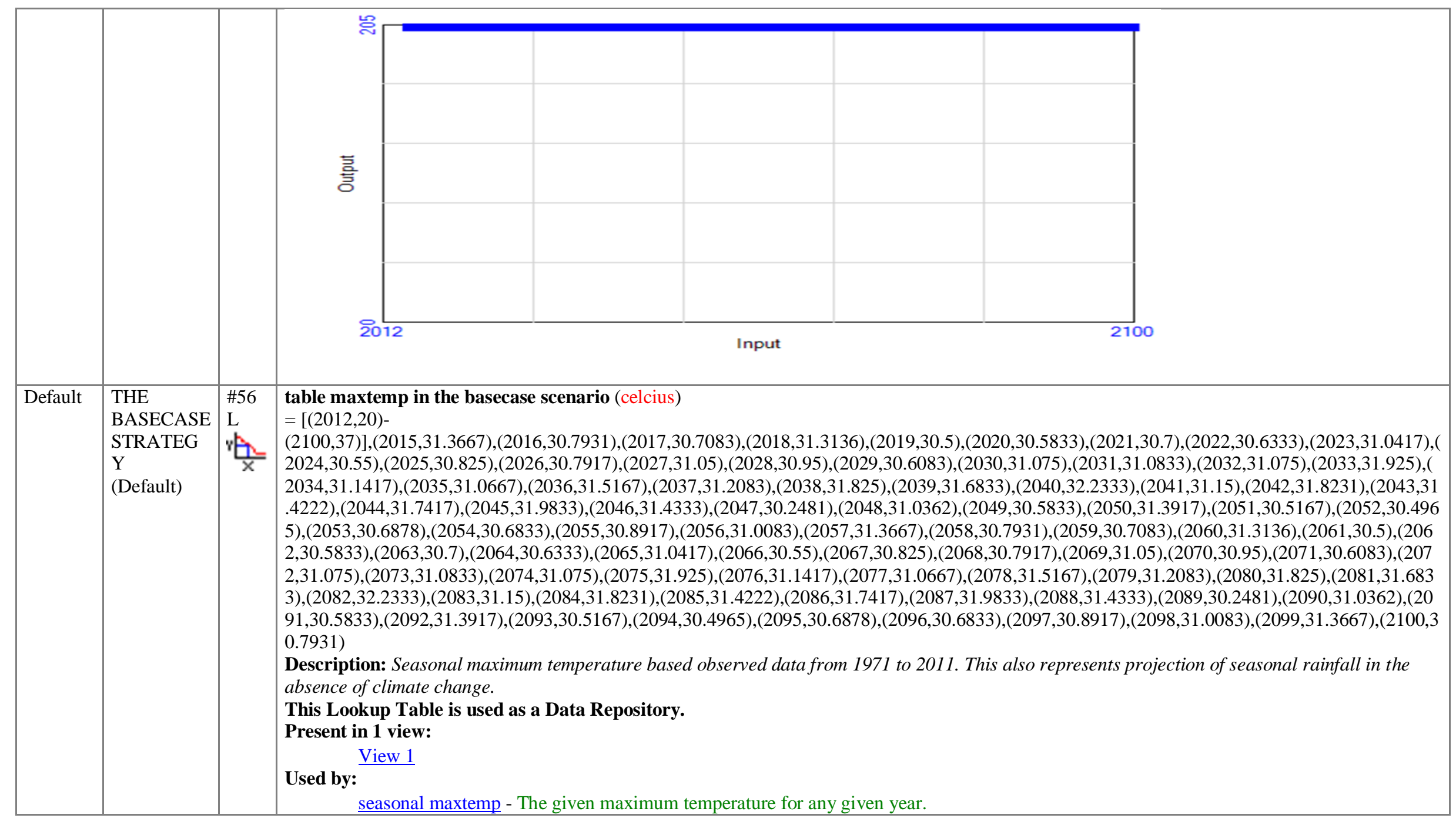




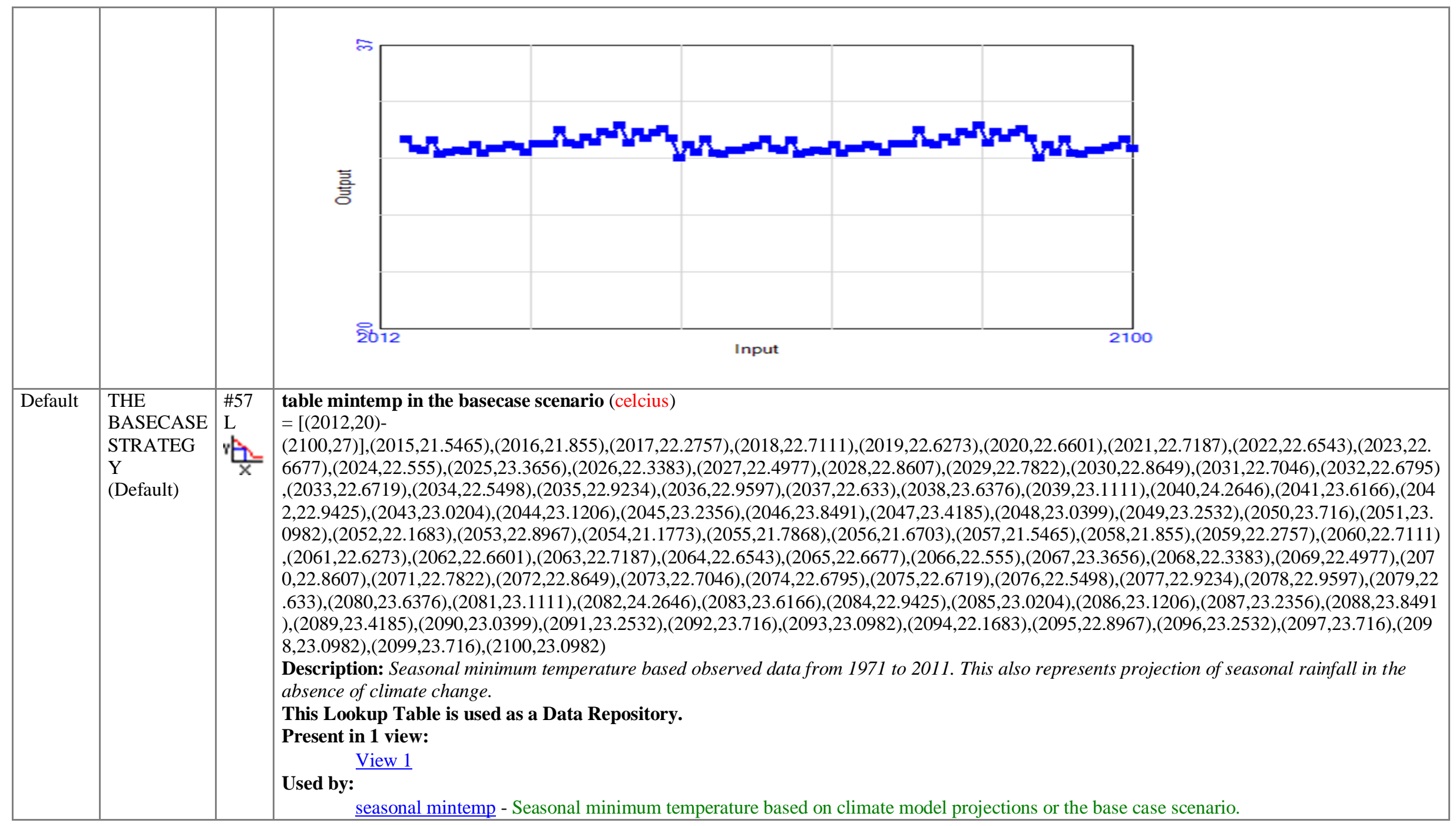




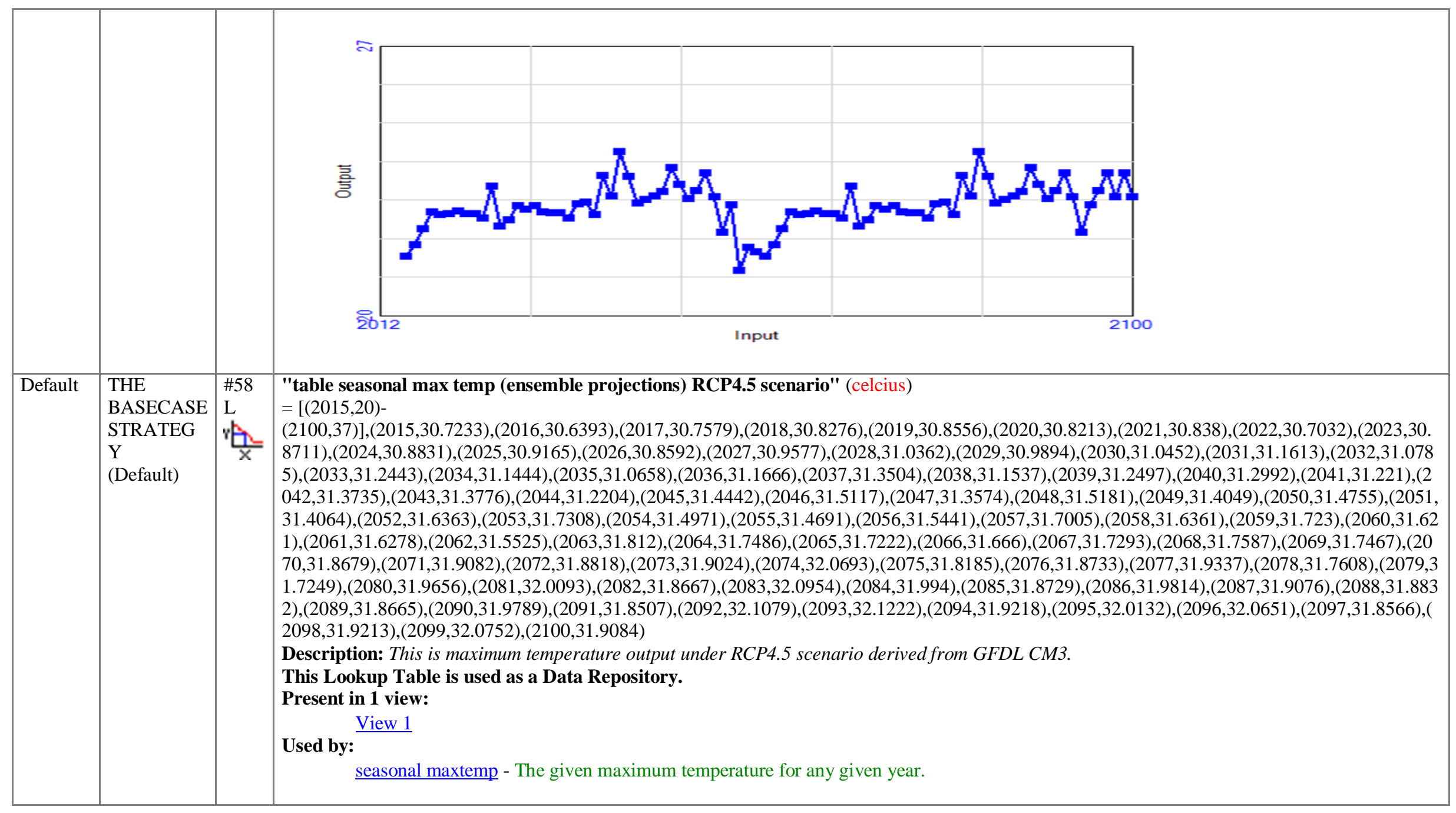




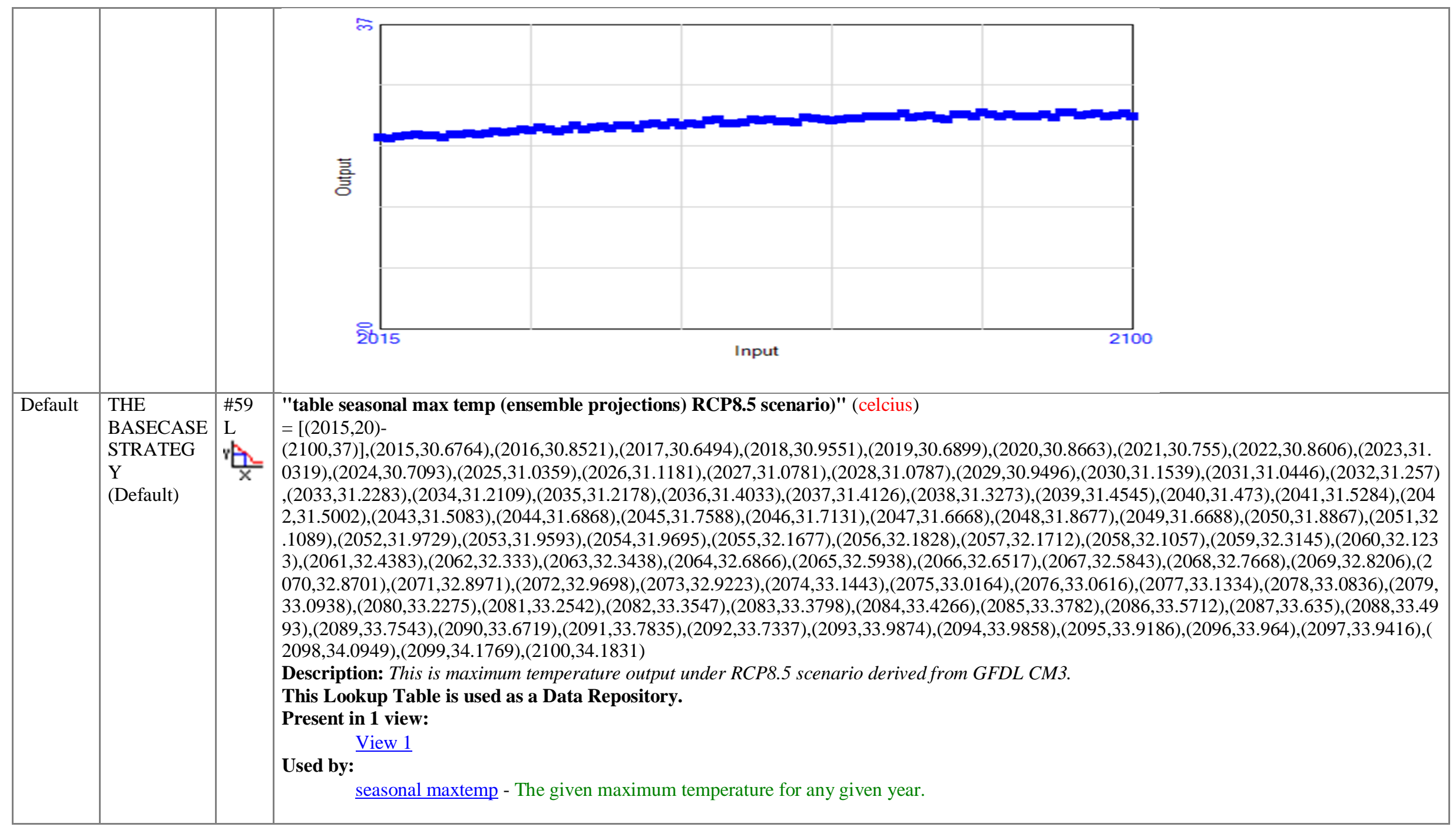




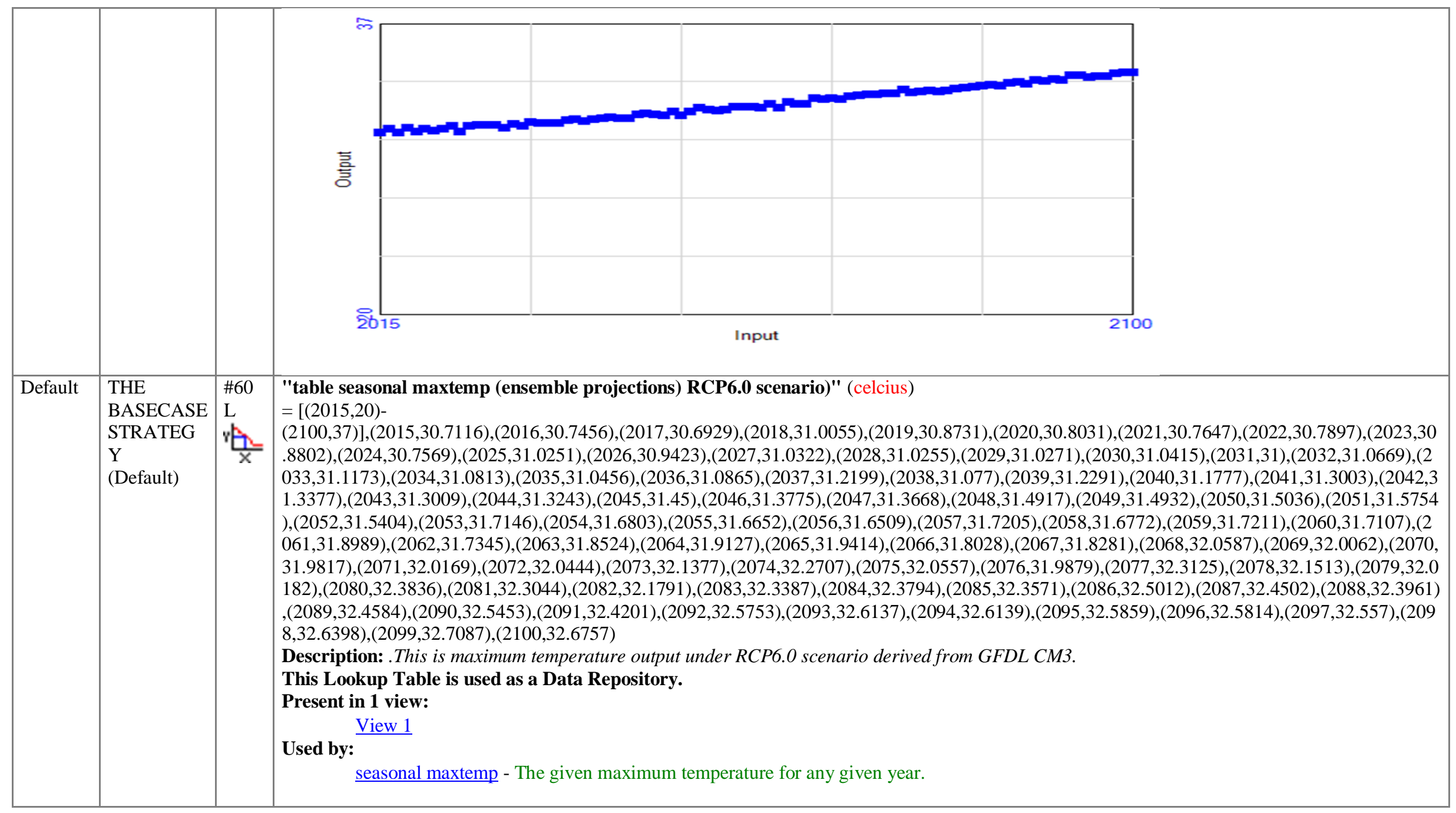




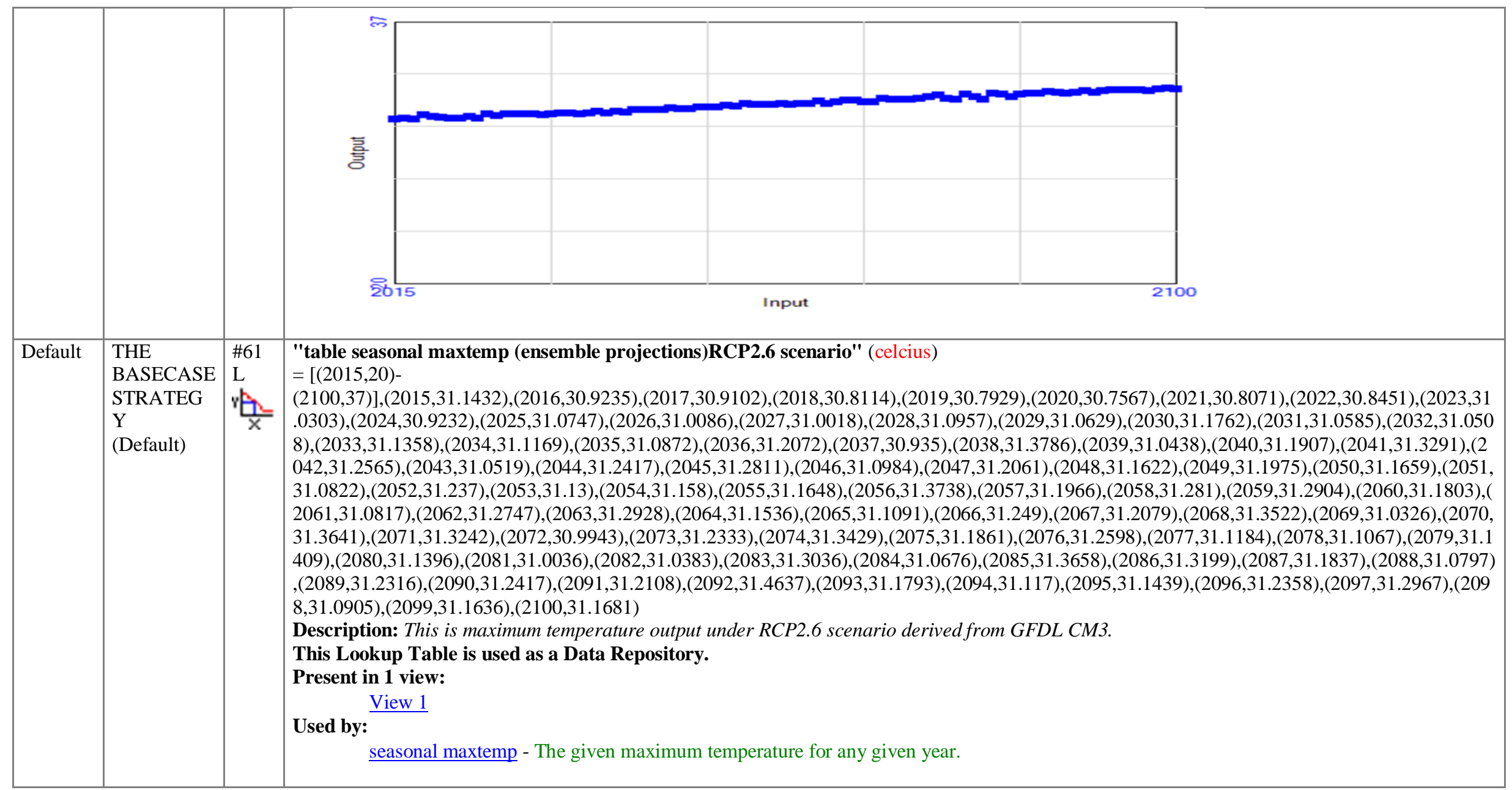




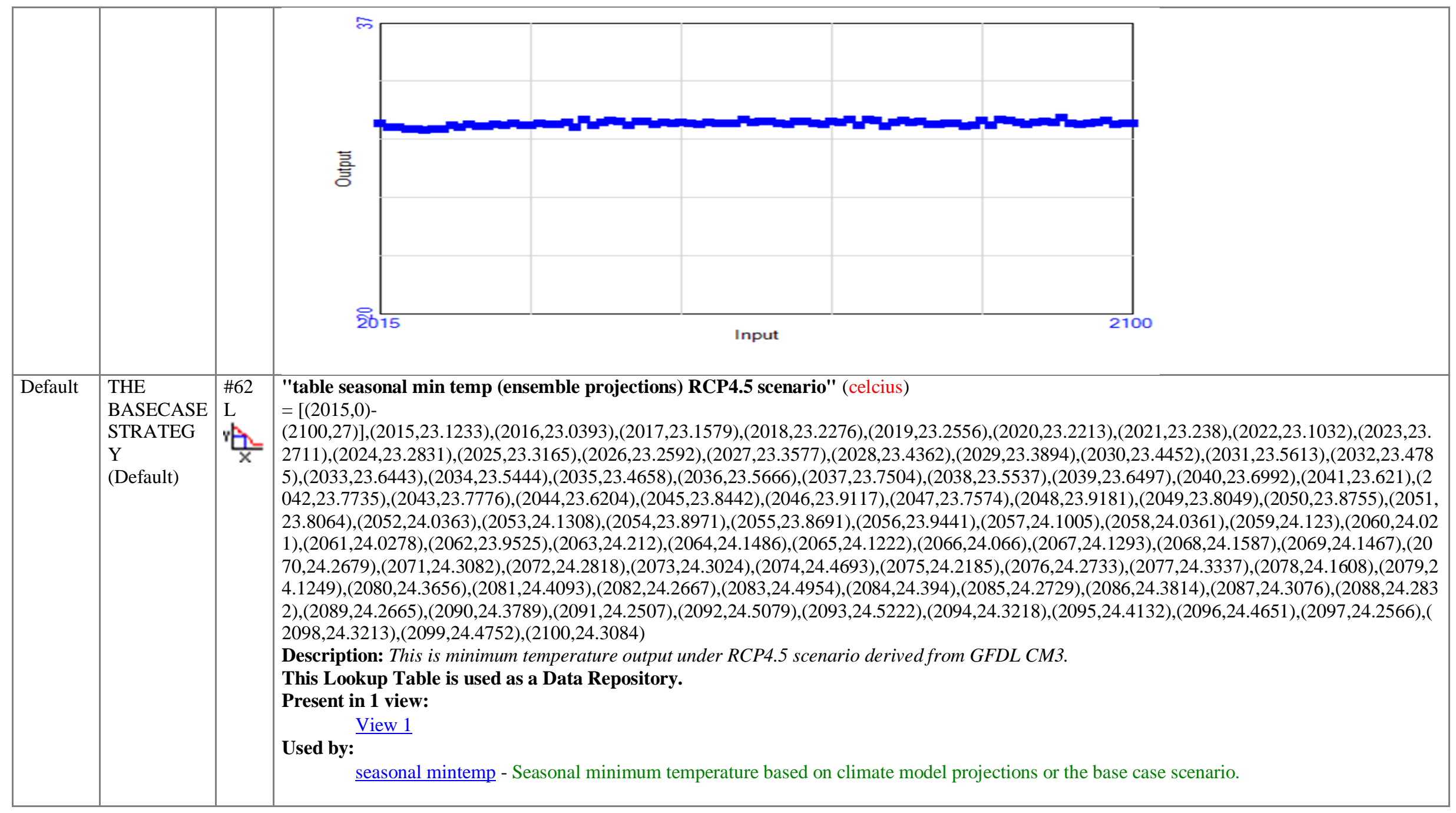




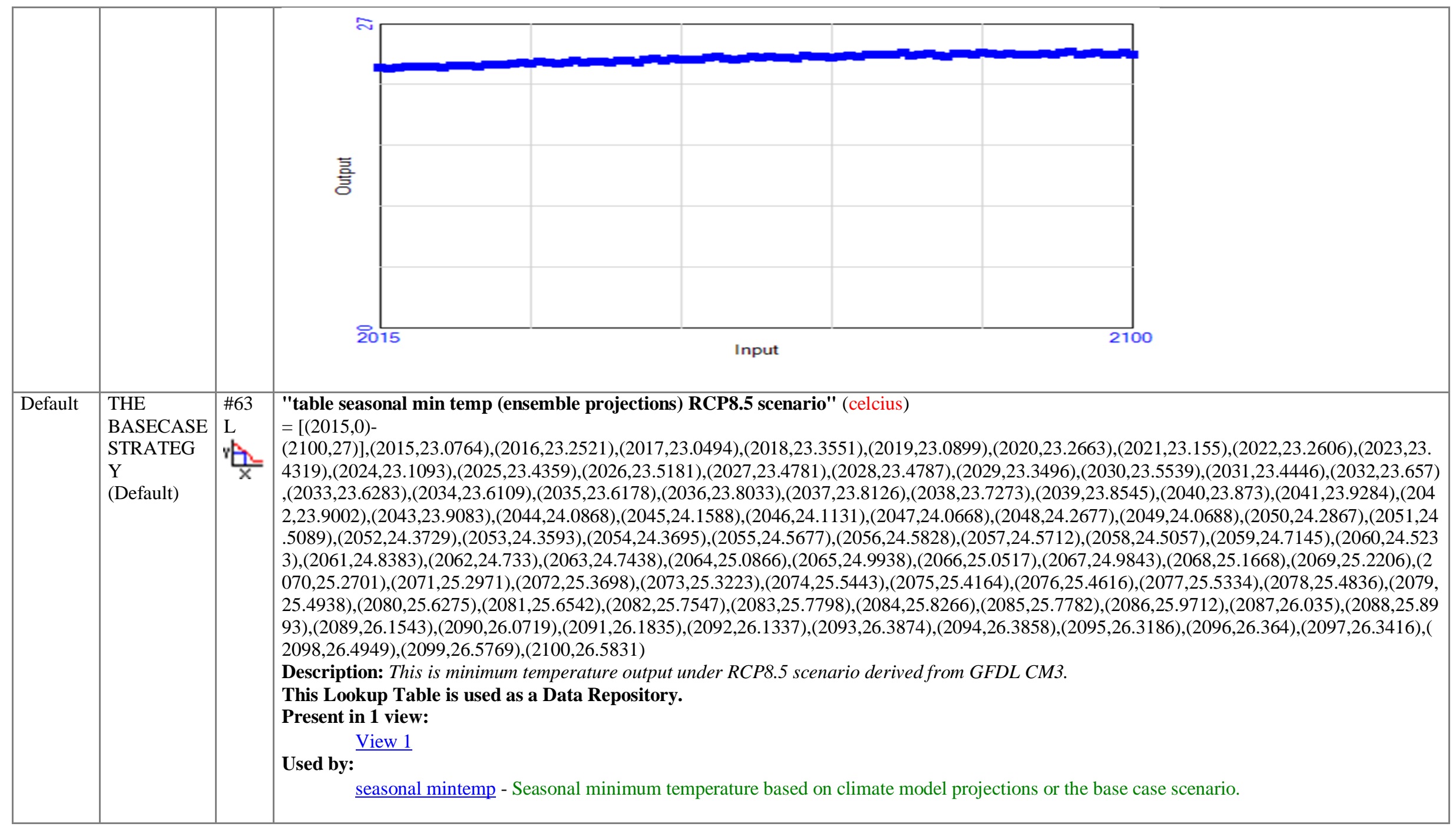




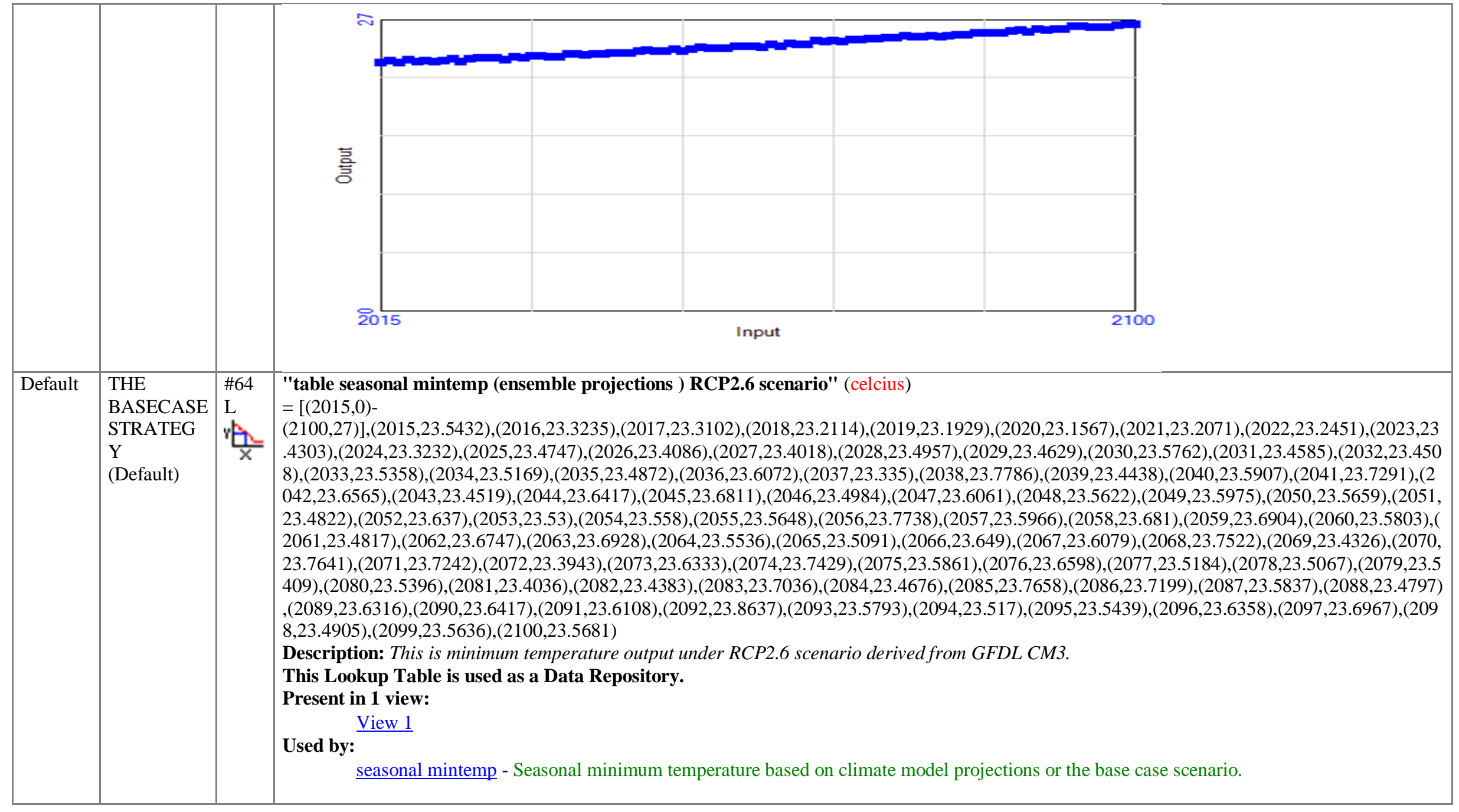




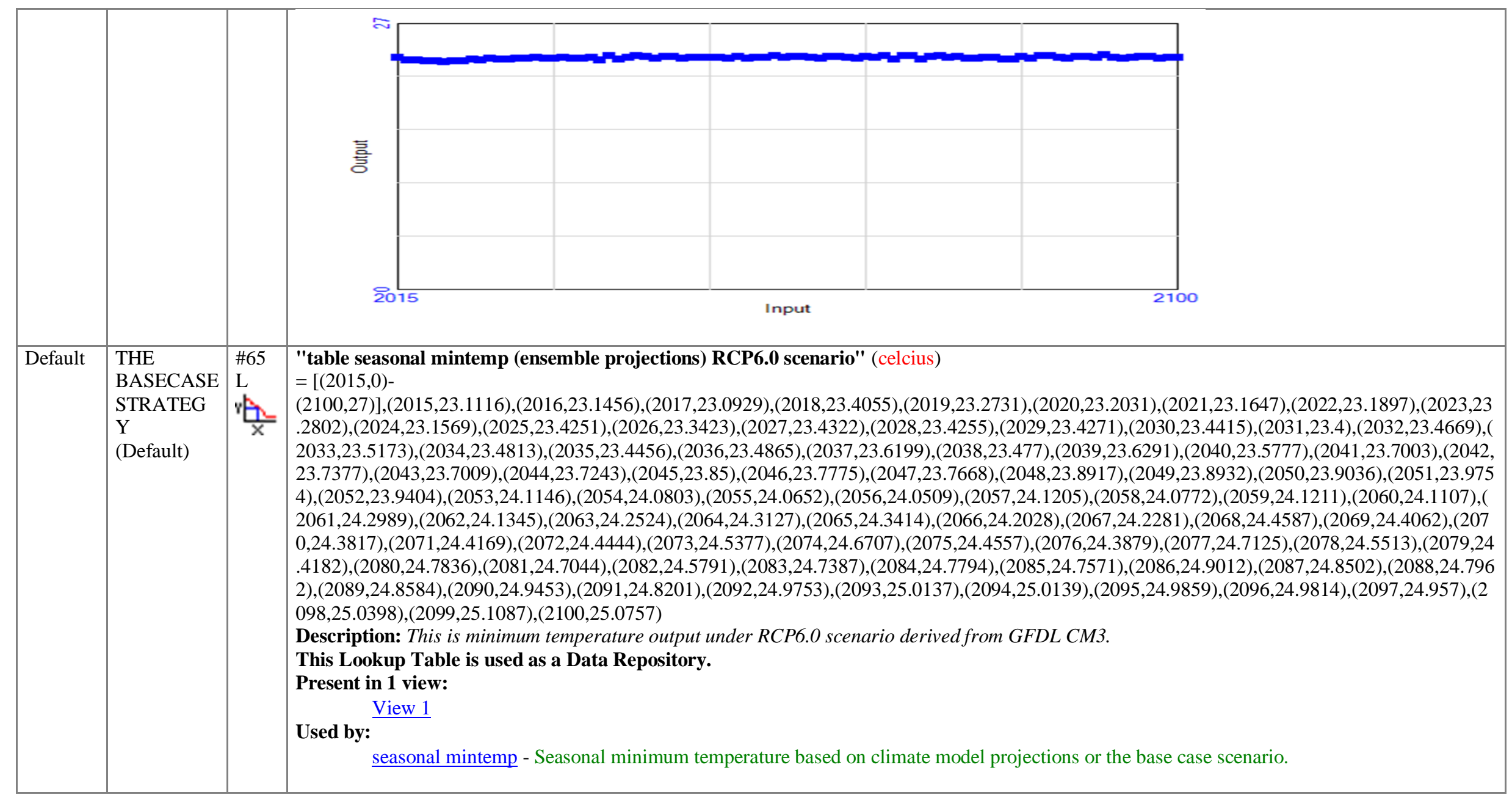




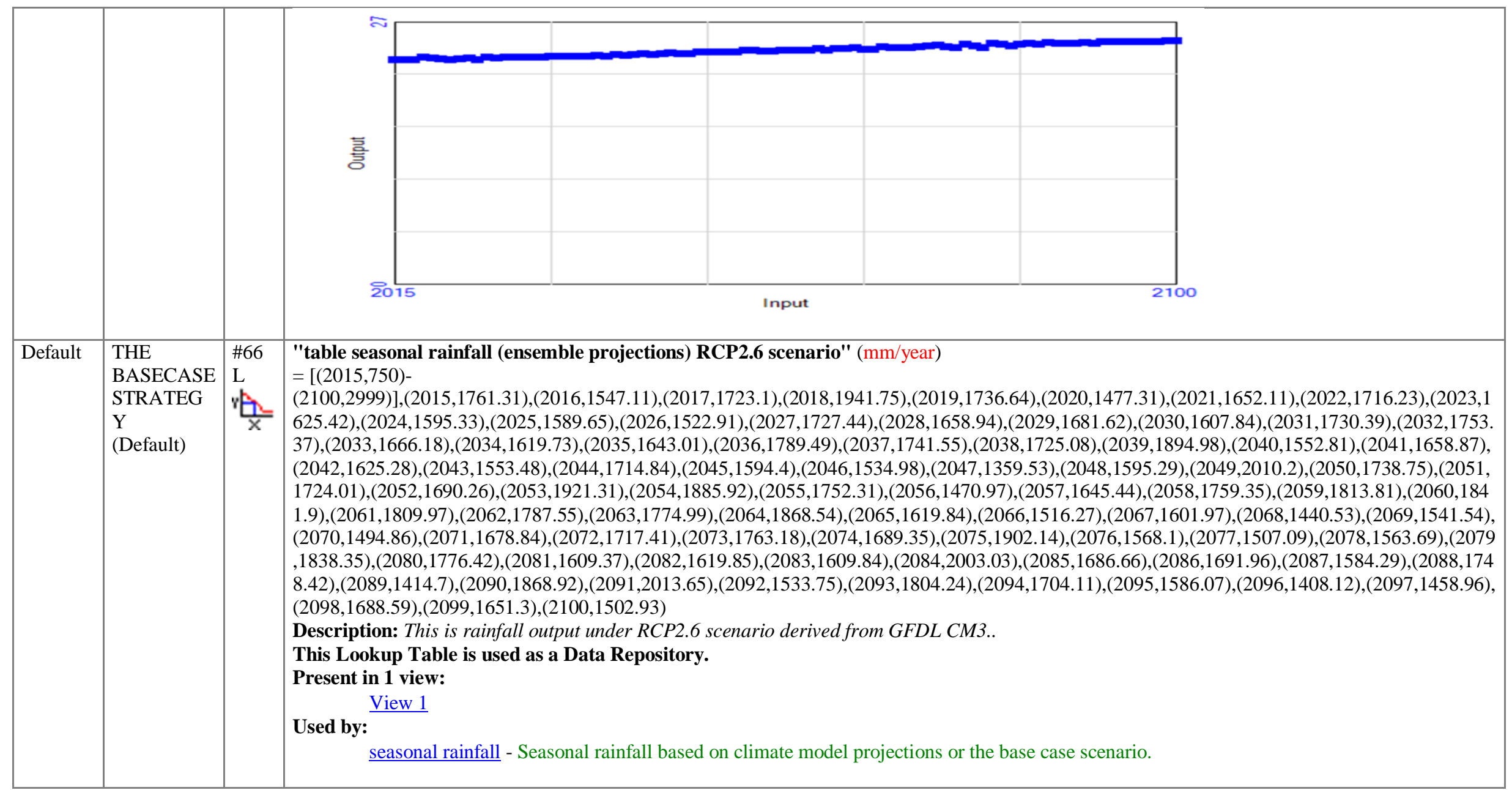




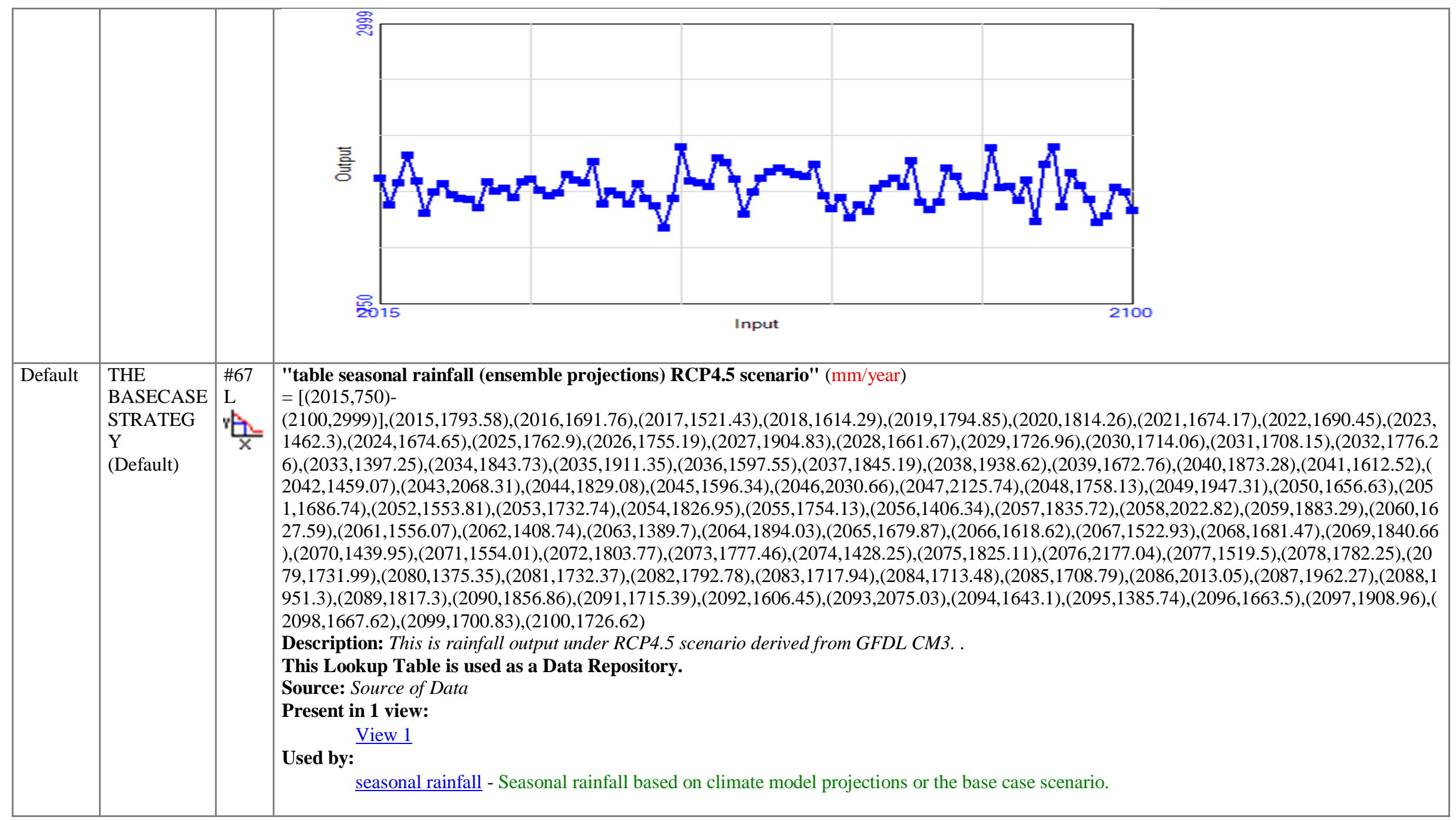




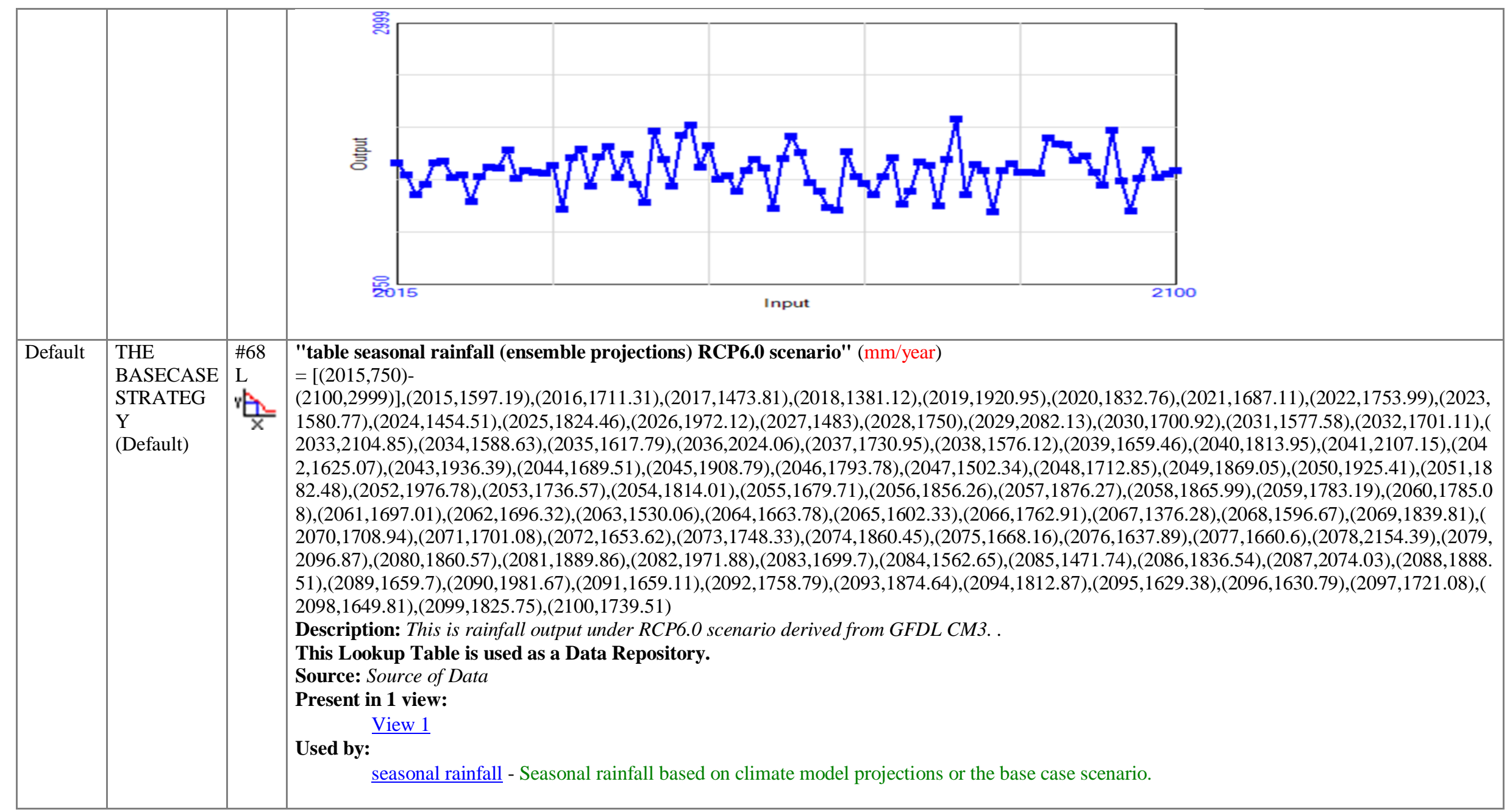




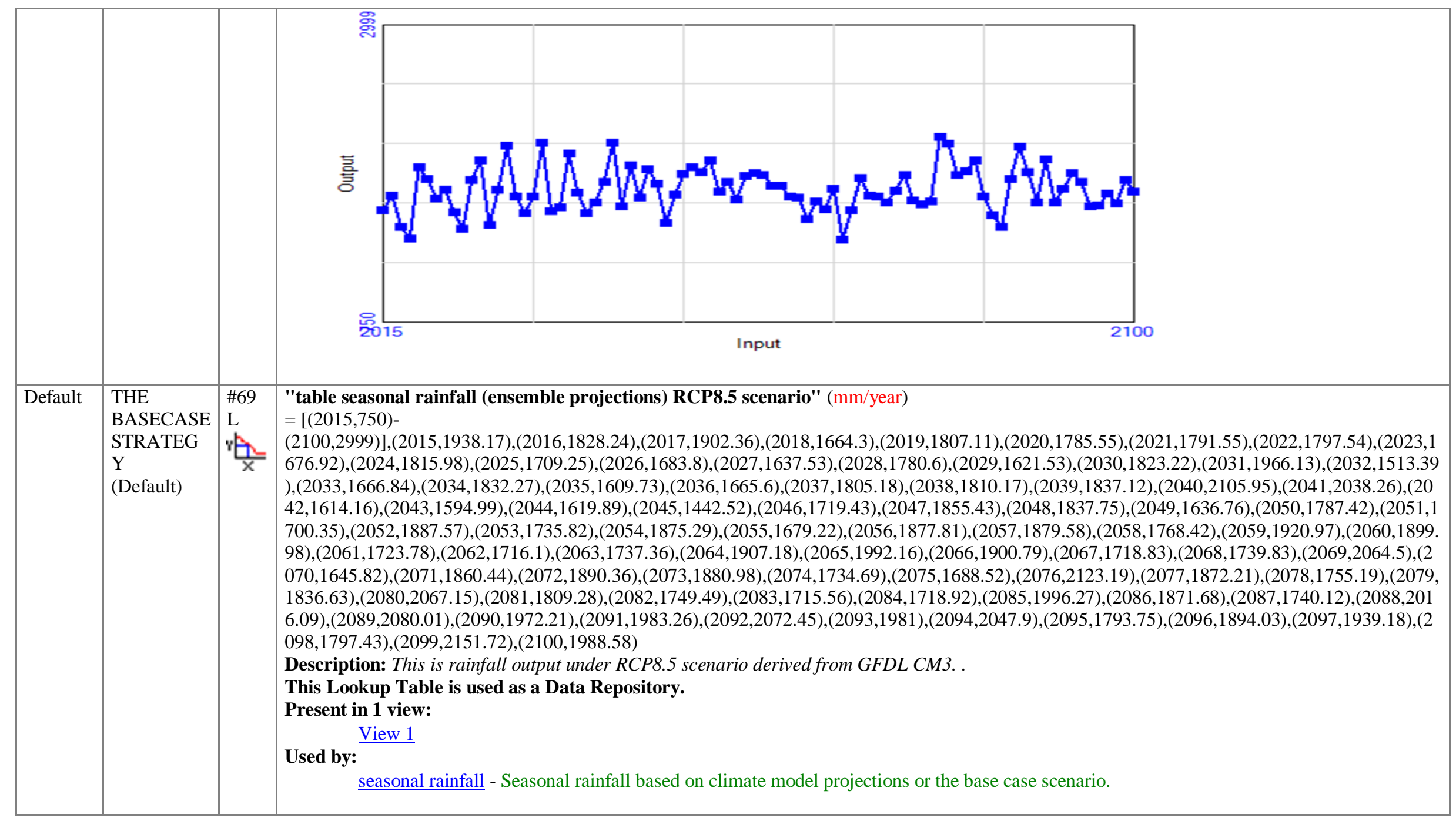




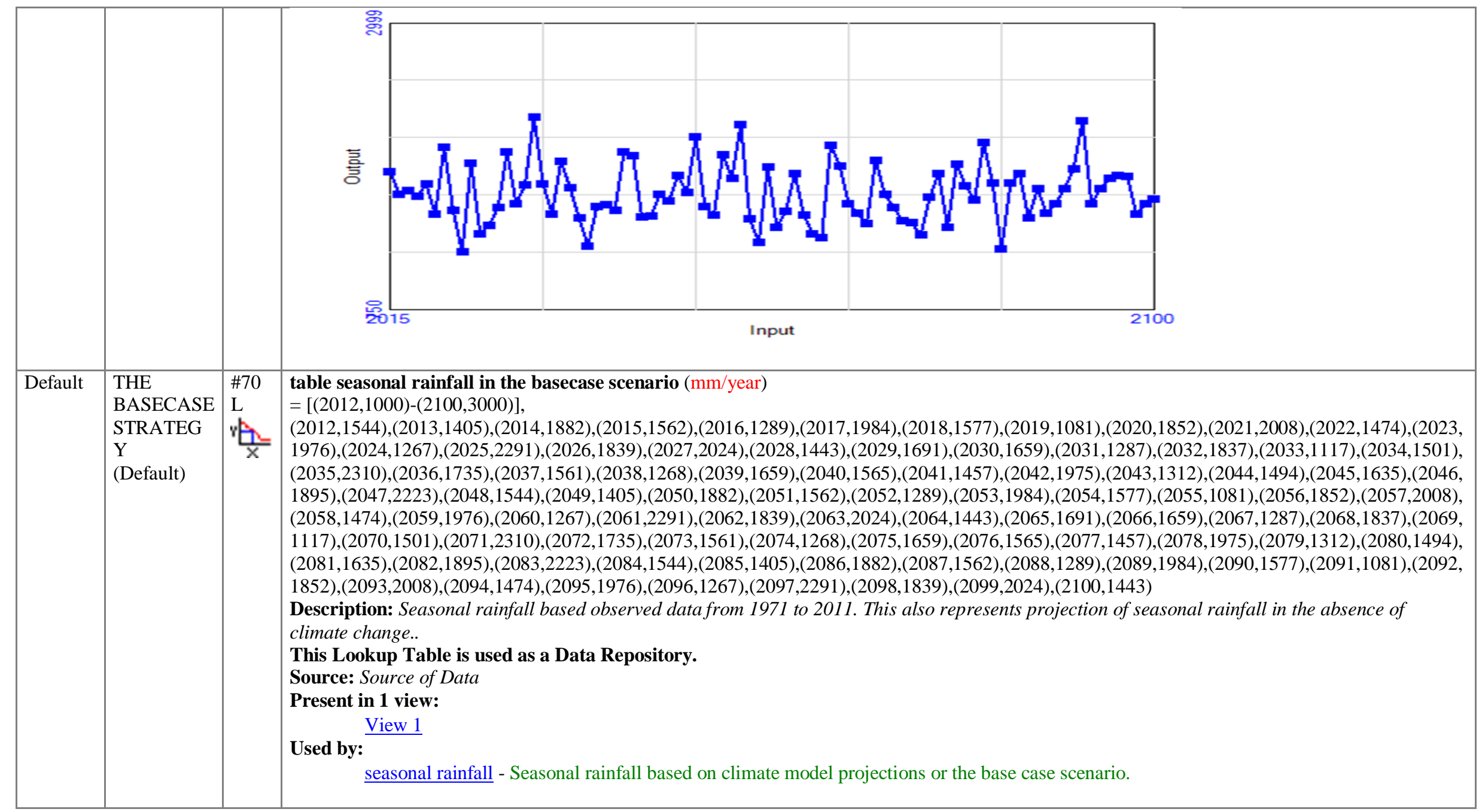




\begin{tabular}{|c|c|c|c|}
\hline & & & 言 \\
\hline Default & $\begin{array}{l}\text { THE } \\
\text { BASECASE } \\
\text { STRATEG } \\
\text { Y } \\
\text { (Default) }\end{array}$ & 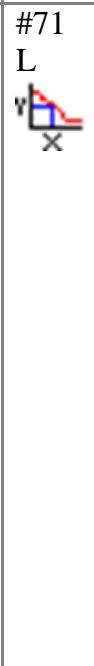 & $\begin{array}{l}\text { "table seed }(\text { dryland }) "(I D R / y e a r) \\
=[(2012,19)- \\
(2100,23)],(2015,20.751),(2016,20.751),(2017,20.751),(2018,20.751),(2019,20.751),(2020,20.751),(2021,20.751),(2022,20.751),(2023,20.751),(202 \\
4,20.751),(2025,20.751),(2026,20.751),(2027,20.751),(2028,20.751),(2029,20.751),(2030,20.751),(2031,20.751),(2032,20.751),(2033,20.751),(203 \\
4,20.751),(2035,20.751),(2036,20.751),(2037,20.751),(2038,20.751),(2039,20.751),(2040,20.751),(2041,20.751),(2042,20.751),(2043,20.751),(204 \\
4,20.751),(2045,20.751),(2046,20.751),(2047,20.751),(2048,20.751),(2049,20.751),(2050,20.751),(2051,20.751),(2052,20.751),(2053,20.751),(205 \\
4,20.751),(2055,20.751),(2056,20.751),(2057,20.751),(2058,20.751),(2059,20.751),(2060,20.751),(2061,20.751),(2062,20.751),(2063,20.751),(206 \\
4,20.751),(2065,20.751),(2066,20.751),(2067,20.751),(2068,20.751),(2069,20.751),(2070,20.751),(2071,20.751),(2072,20.751),(2073,20.751),(207 \\
4,20.751),(2075,20.751),(2076,20.751),(2077,20.751),(2078,20.751),(2079,20.751),(2080,20.751),(2081,20.751),(2082,20.751),(2083,20.751),(208 \\
4,20.751),(2085,20.751),(2086,20.751),(2087,20.751),(2088,20.751),(2089,20.751),(2090,20.751),(2091,20.751),(2092,20.751),(2093,20.751),(209 \\
4,20.751),(2095,20.751),(2096,20.751),(2097,20.751),(2098,20.751),(2099,20.751),(2100,20.751) \\
\text { Description: } \text { a lookup table of used seed in dryland farming. } \\
\text { This Lookup Table is used as a Data Repository. } \\
\text { Present in 1 view: } \\
\quad \text { View } 1 \\
\text { Used by: } \\
\quad \text { "seed (dryland)" - the used seed in dryland farming for a given year during simulation }\end{array}$ \\
\hline
\end{tabular}




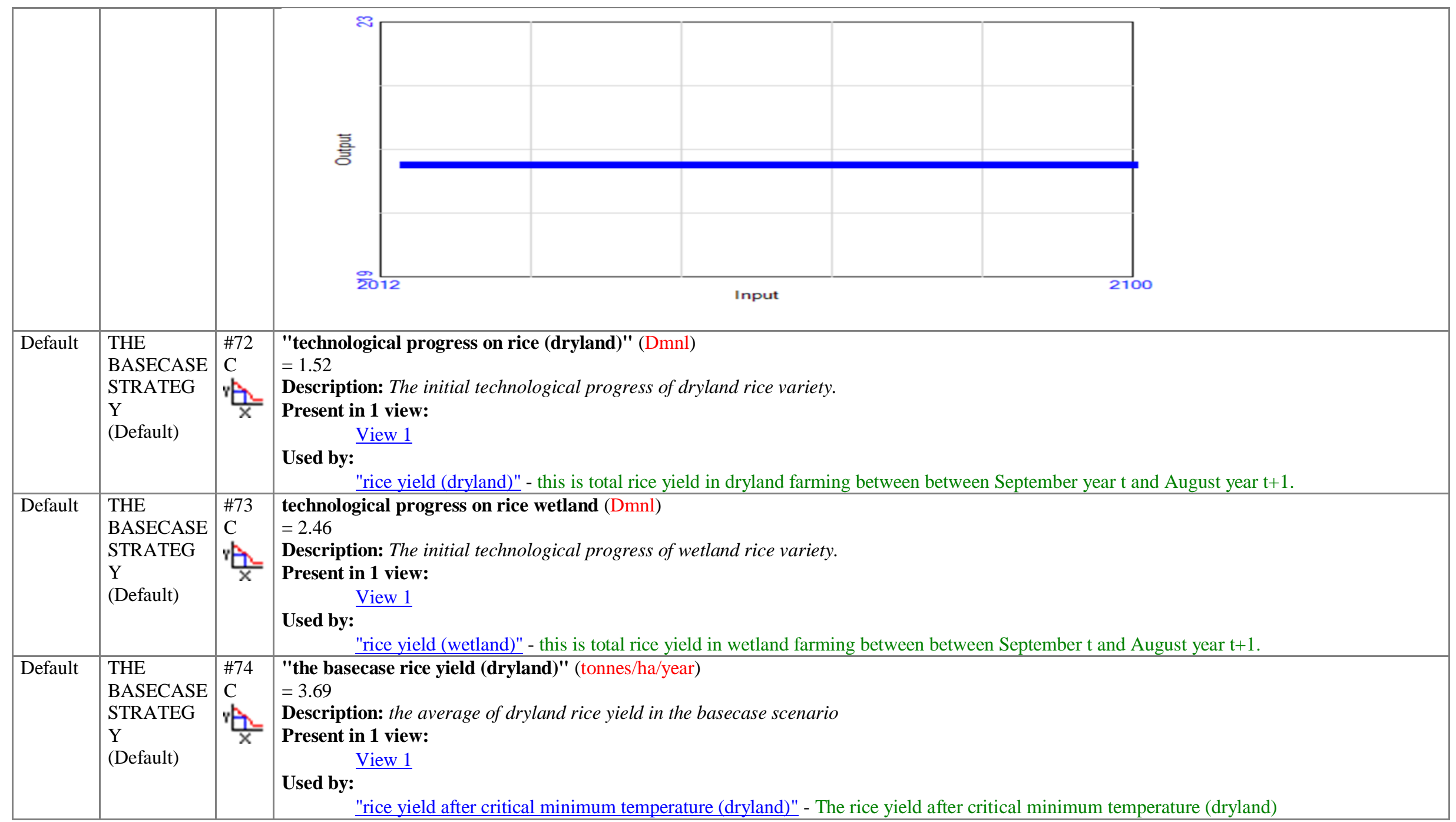




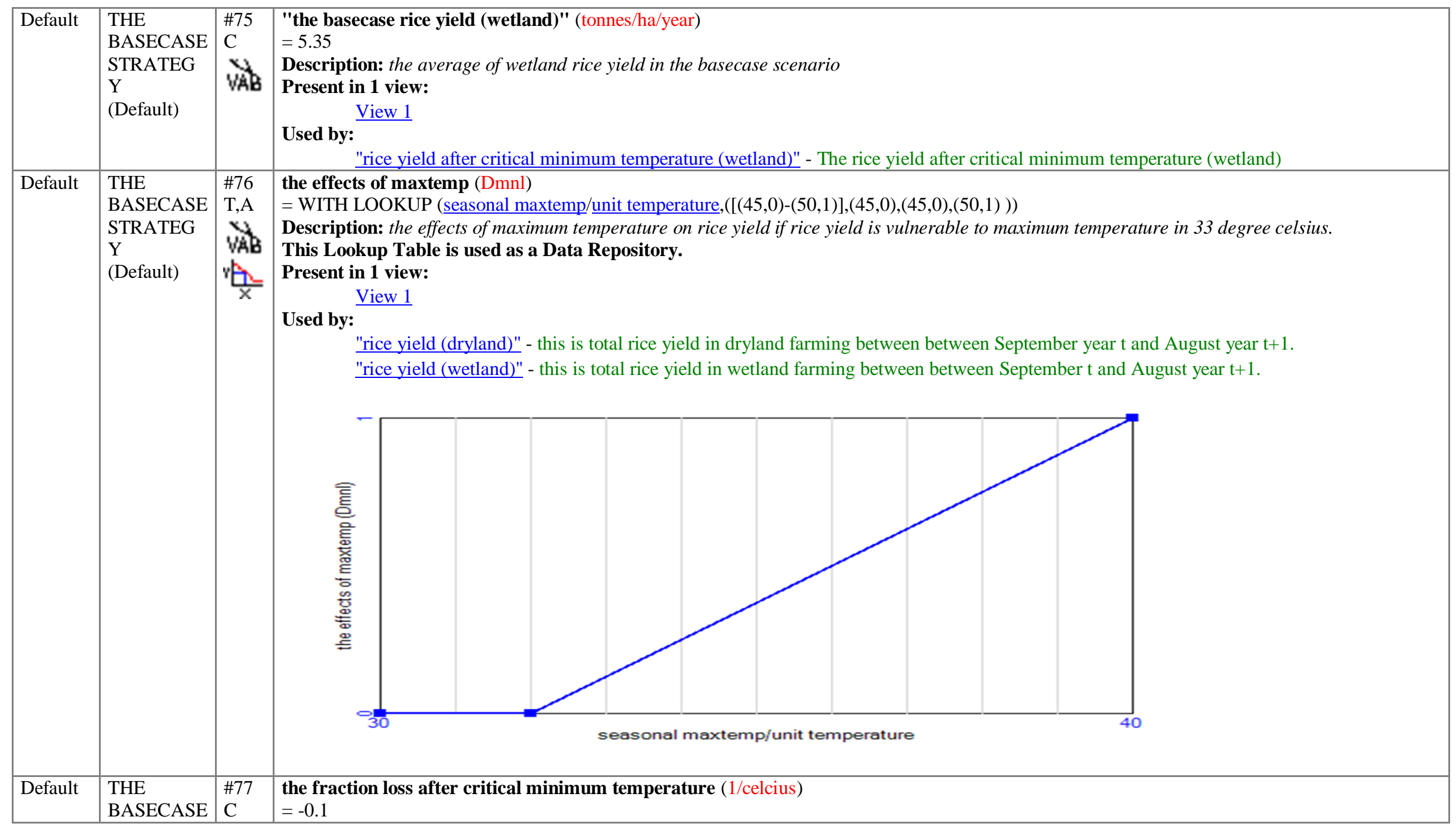




\begin{tabular}{|c|c|c|c|}
\hline & $\begin{array}{l}\text { STRATEG } \\
\text { Y } \\
\text { (Default) }\end{array}$ & VAB & $\begin{array}{l}\text { Description: the loss fraction of rice yield when minimum temperature exceeds critical minimum temperature } \\
\text { Present in } 1 \text { view: } \\
\text { View } 1 \\
\text { Used by: } \\
\text { "rice yield after critical minimum temperature (dryland)" - The rice yield after critical minimum temperature (dryland) } \\
\text { "rice yield after critical minimum temperature (wetland)" - The rice yield after critical minimum temperature (wetland) }\end{array}$ \\
\hline Default & Control & & $\begin{array}{l}\text { TIME STEP (year }[0, ?]) \\
=0.0078125 \\
\text { Description: The time step for the simulation. } \\
\text { Present in } 1 \text { view: } \\
\text { View } 1 \\
\text { Used by: } \\
\text { "new farming areas (dryland)" - This is an increase in dryland farming area a year.Used by -- farming areas (dryland) which represents } \\
\text { total physical rice farming areas (dryland) } \\
\text { physical rice farming areas (wetland) }\end{array}$ \\
\hline Default & $\begin{array}{l}\text { THE } \\
\text { BASECASE } \\
\text { STRATEG } \\
\text { Y } \\
\text { (Default) }\end{array}$ & $\begin{array}{l}\# 79 \\
\text { T,A } \\
\text { Wab } \\
\frac{1}{X}=\end{array}$ & $\begin{array}{l}\text { "timing of monsoon onset (days)" (days) } \\
=\text { WITH LOOKUP (August SOI, }([(-25,-90)-(25,90)],(-30,30),(-25,23),(-20,20),(-8,0),(0,0),(8,0),(20,-20),(25,-23),(30,-30))) \\
\text { Description: the timing of monsoon onset represents the beginning of the planting seasons. This a variable with a day dimension. } \\
\text { Source: Source of Data } \\
\text { Present in } 1 \text { view: } \\
\text { View } 1 \\
\text { Used by: } \\
\text { production which represents the actual paddy production (wetland) in harvesting seasons. }\end{array}$ \\
\hline
\end{tabular}




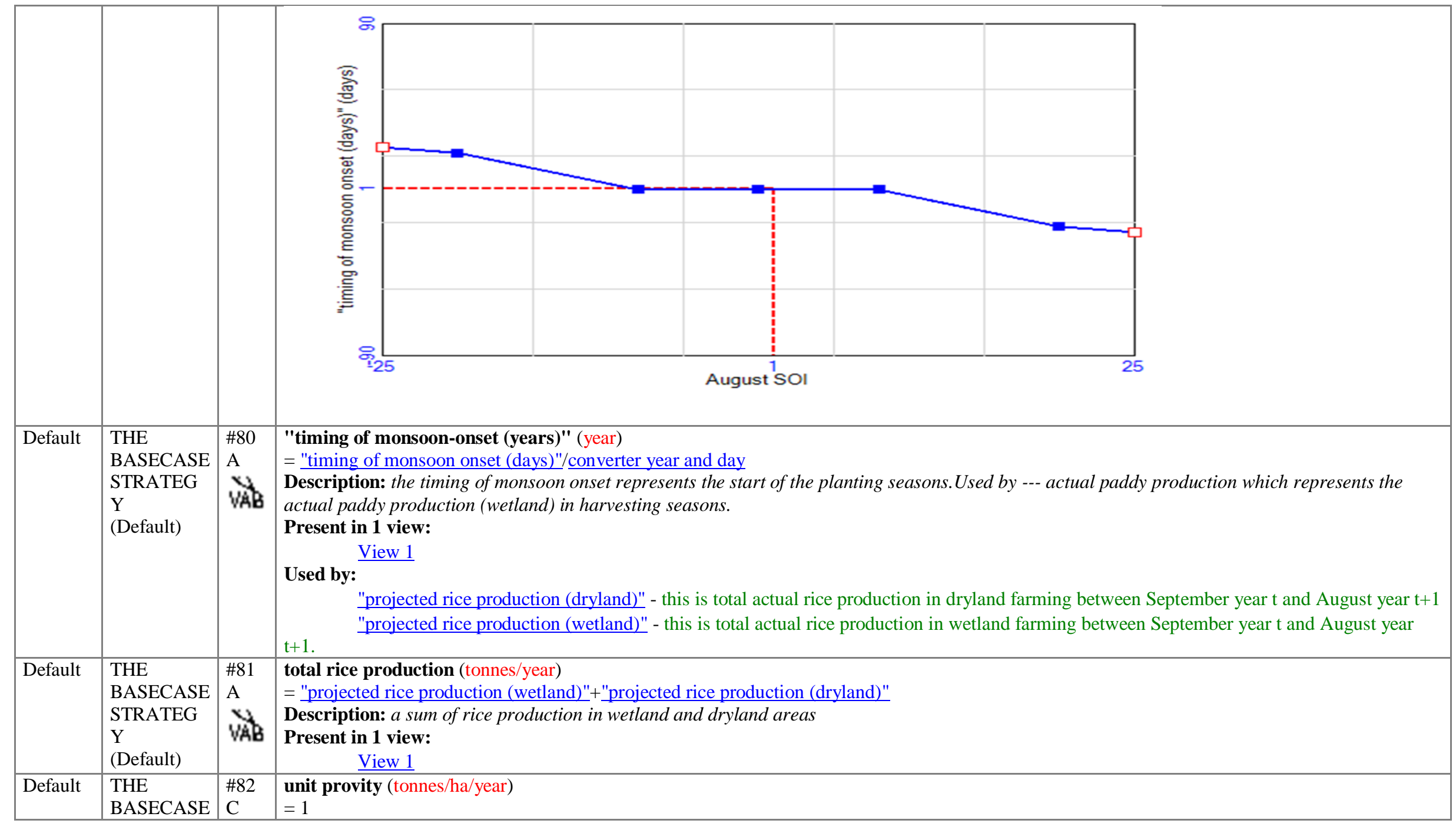




\begin{tabular}{|c|c|c|c|}
\hline & $\begin{array}{l}\text { STRATEG } \\
\text { Y } \\
\text { (Default) }\end{array}$ & VAB & $\begin{array}{l}\text { Description: this variable is used to convert dimensionless variables to be variable with a tonnes/ha/year dimension } \\
\text { Present in } 1 \text { view: } \\
\text { Used by: } \\
\text { "riew } 1 \\
\quad \text { "rice yield (dryland)" - this is total rice yield in dryland farming between between September year t and August year } t+1 \text {. } \\
\text { Unis is total rice yield in wetland farming between between September t and August year } t+1 \text {. }\end{array}$ \\
\hline Default & $\begin{array}{l}\text { THE } \\
\text { BASECASE } \\
\text { STRATEG } \\
\text { Y } \\
\text { (Default) }\end{array}$ & $\begin{array}{l}\# 83 \\
\mathrm{C} \\
\mathrm{WAB}\end{array}$ & $\begin{array}{l}\text { unit temperature (celcius) } \\
=1 \\
\text { Description: } \text { a unit of temperature to set maximum temperature to be dimensionless after a lookup function } \\
\text { Present in } 1 \text { view: } \\
\quad \text { View } 1 \\
\text { Used by: } \\
\text { the effects of maxtemp - the effects of maximum temperature on rice yield if rice yield is vulnerable to maximum temperature in } 33 \text { degree } \\
\text { celsius. }\end{array}$ \\
\hline Default & $\begin{array}{l}\text { THE } \\
\text { BASECASE } \\
\text { STRATEG } \\
\text { Y } \\
\text { (Default) }\end{array}$ & $\begin{array}{l}\# 84 \\
\mathrm{C} \\
\mathrm{WAB}\end{array}$ & 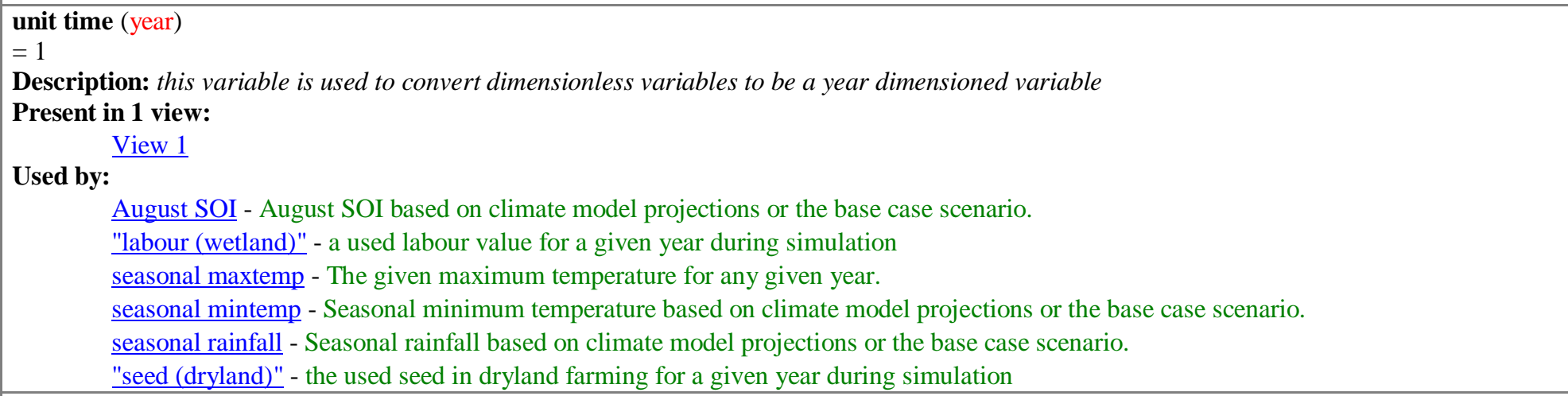 \\
\hline$\underline{\text { Module }}$ & $\underline{\text { Group }}$ & $\underline{\text { Type }}$ & $\underline{\text { Variable Name and Description }}$ \\
\hline
\end{tabular}

Decision and Information Sciences Division Argonne National Laboratory 
this page intentionally left blank 


\title{
Appendix I. The SD Models With Policy Scenarios (Chapter 7)
}

\author{
FARMING AREA AND \\ AVAILABLE LAND
}

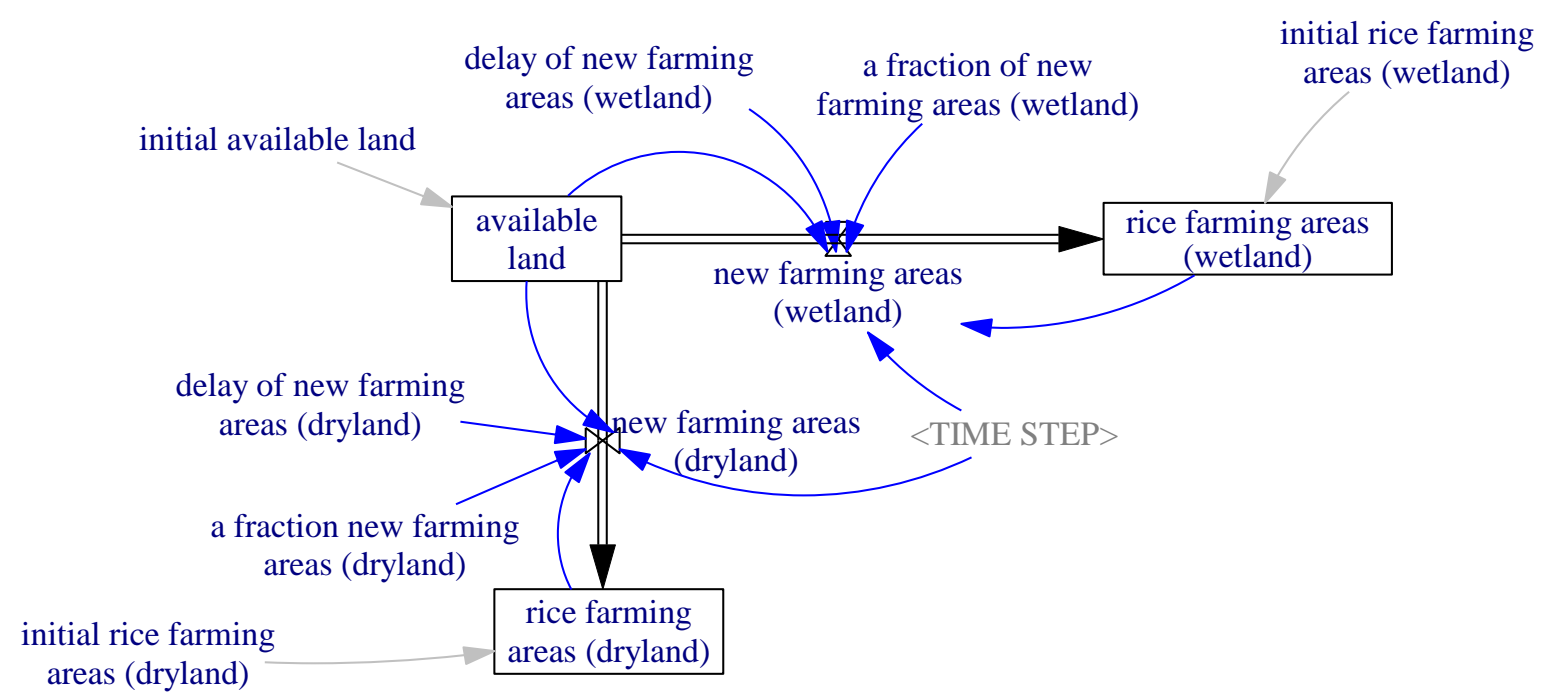

Figure I1. A part of SD model explaining the farming area and available land

\section{CROPPING INTENSITY AND HARVESTED AREA (WETLAND)}

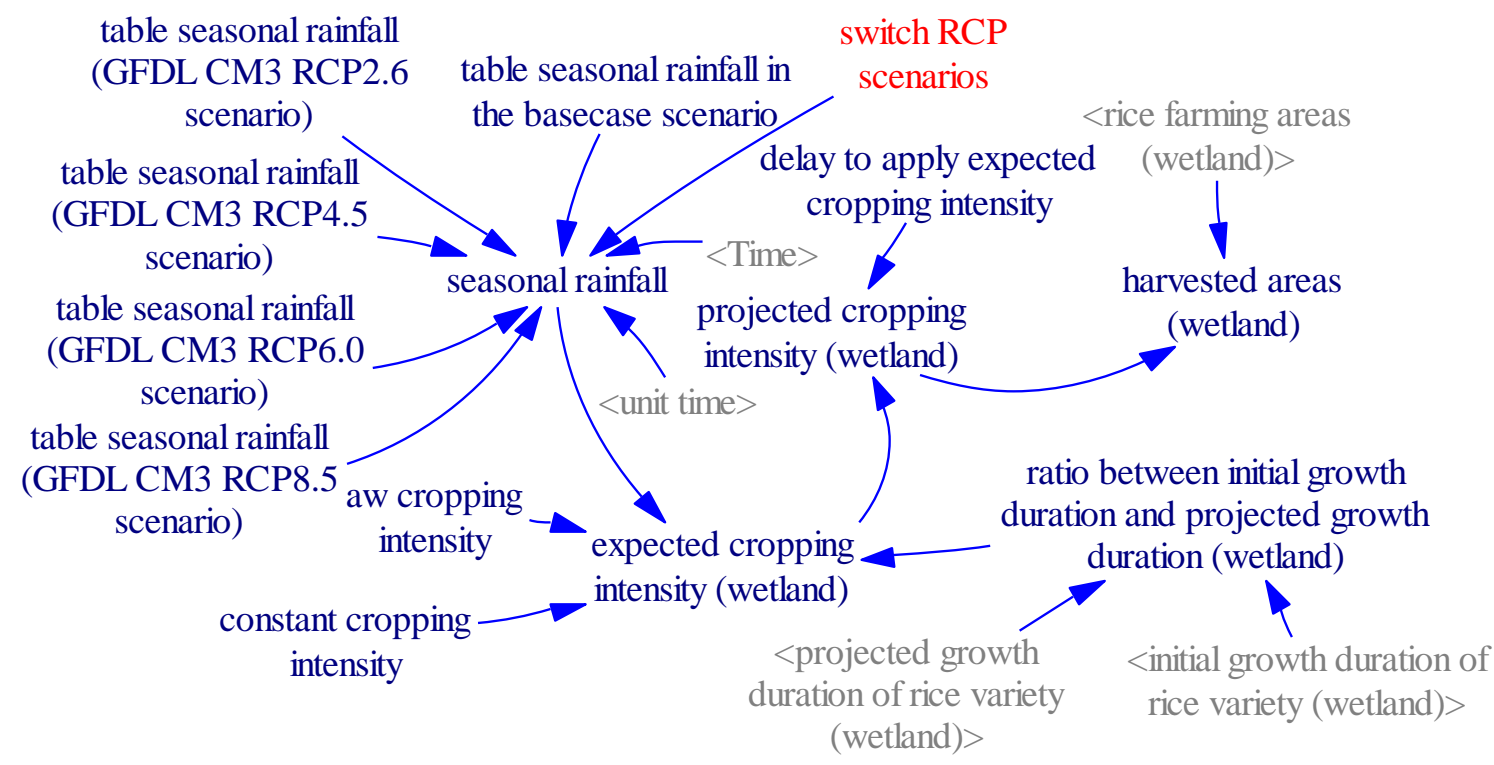

Figure I2. A part of SD model explaining the cropping intensity and harvested area (wetland farming). In this figure, "rice farming areas (wetland)" is from figure I1 and "projected duration growth of rice variety (wetland)" and "initial duration growth of rice variety (wetland)" are from figure I4. 


\section{CROPPING INTENSITY AND HARVESTED AREA (DRYLAND)}

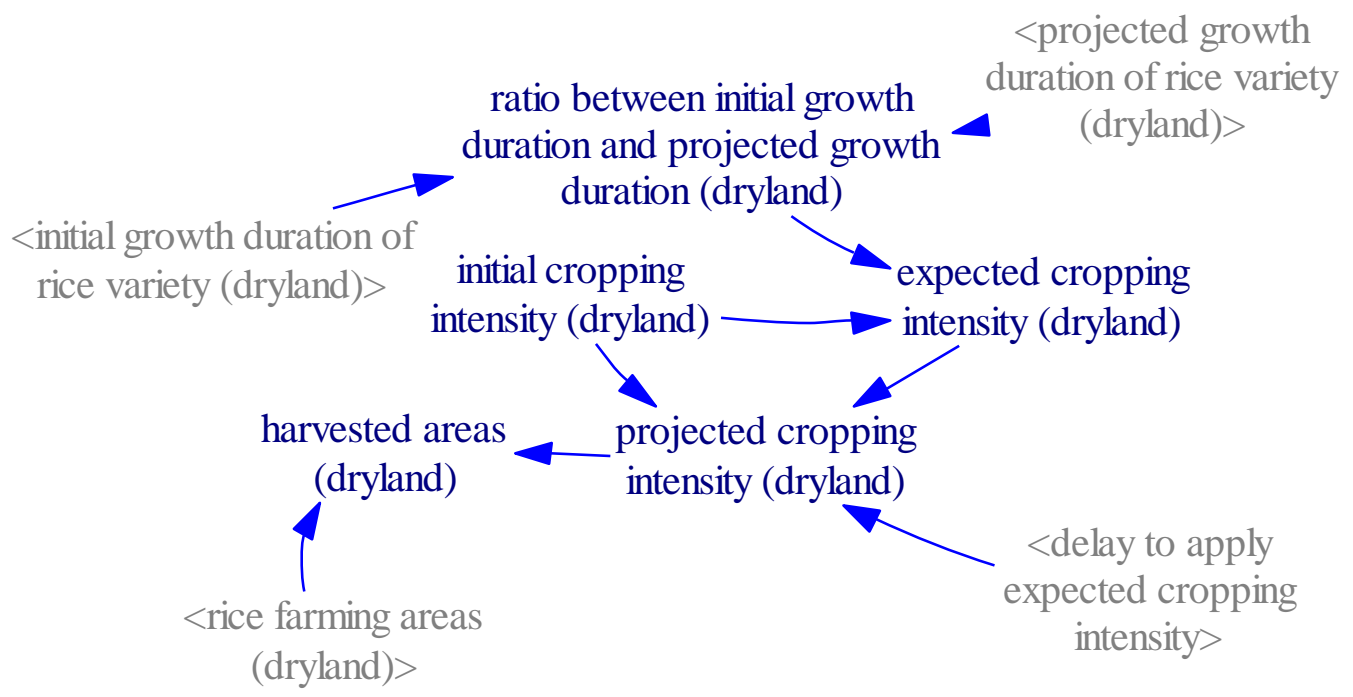

Figure I3. A part of SD model explaining the cropping intensity and harvested area (dryland farming). In this figure, "rice farming areas (dryland)" is from figure I1 and "projected duration growth of rice variety (dryland)" and "initial duration growth of rice variety (dryland)" are from figure I4. 


\section{RICE PRODUCTION AND DURATION GROWTH (WETLAND-DRYLAND)}

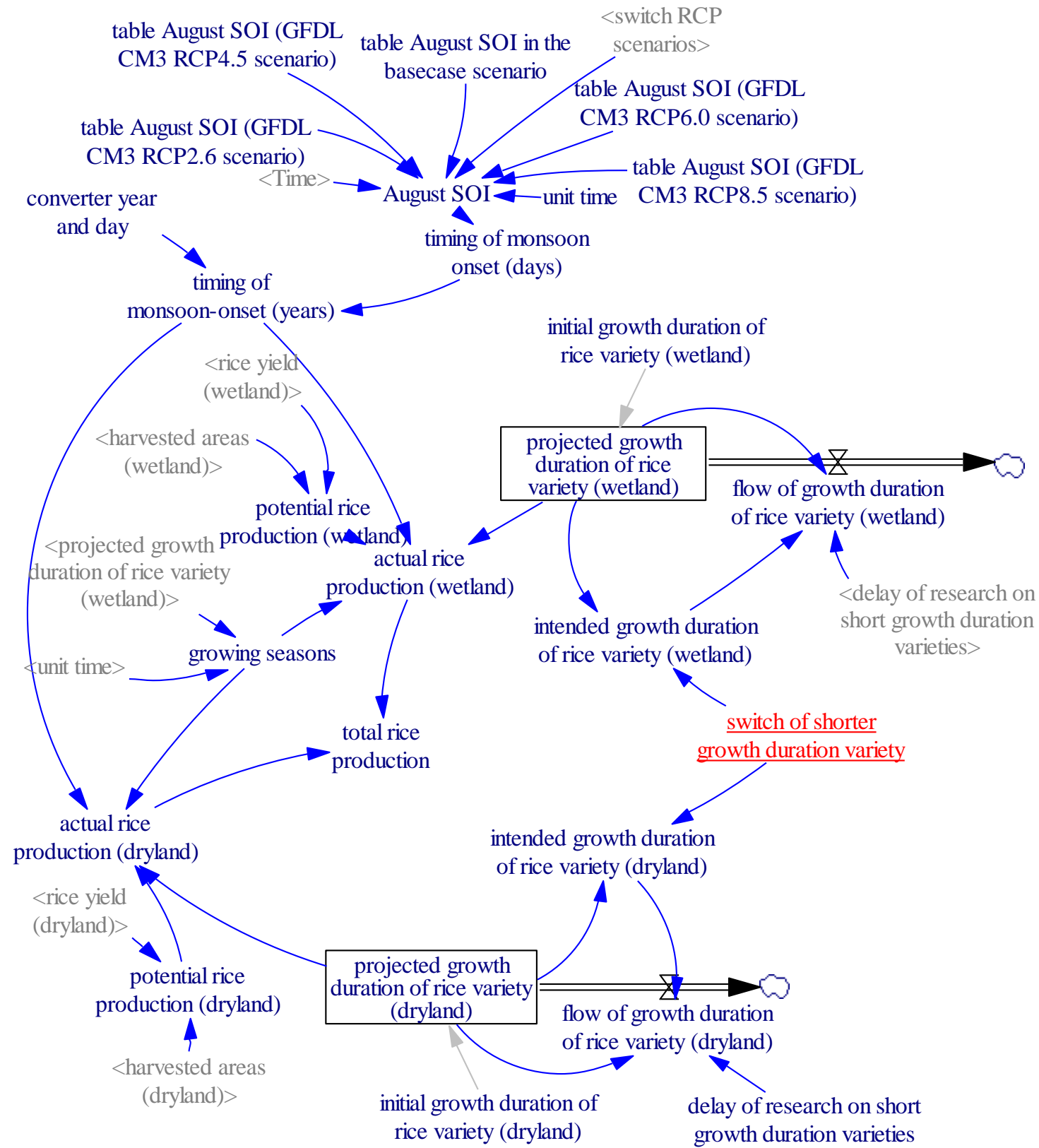

Figure I4. A part of SD model explaining rice production and duration growth of rice variety (wetland-dryland). In this figure, "rice yield (wetland)" and "rice yield (dryland)" are from figure I5. This figure also inserts "harvested areas (wetland)" and "harvested areas (dryland)" are from figure I2 and figure I3 respectively. 


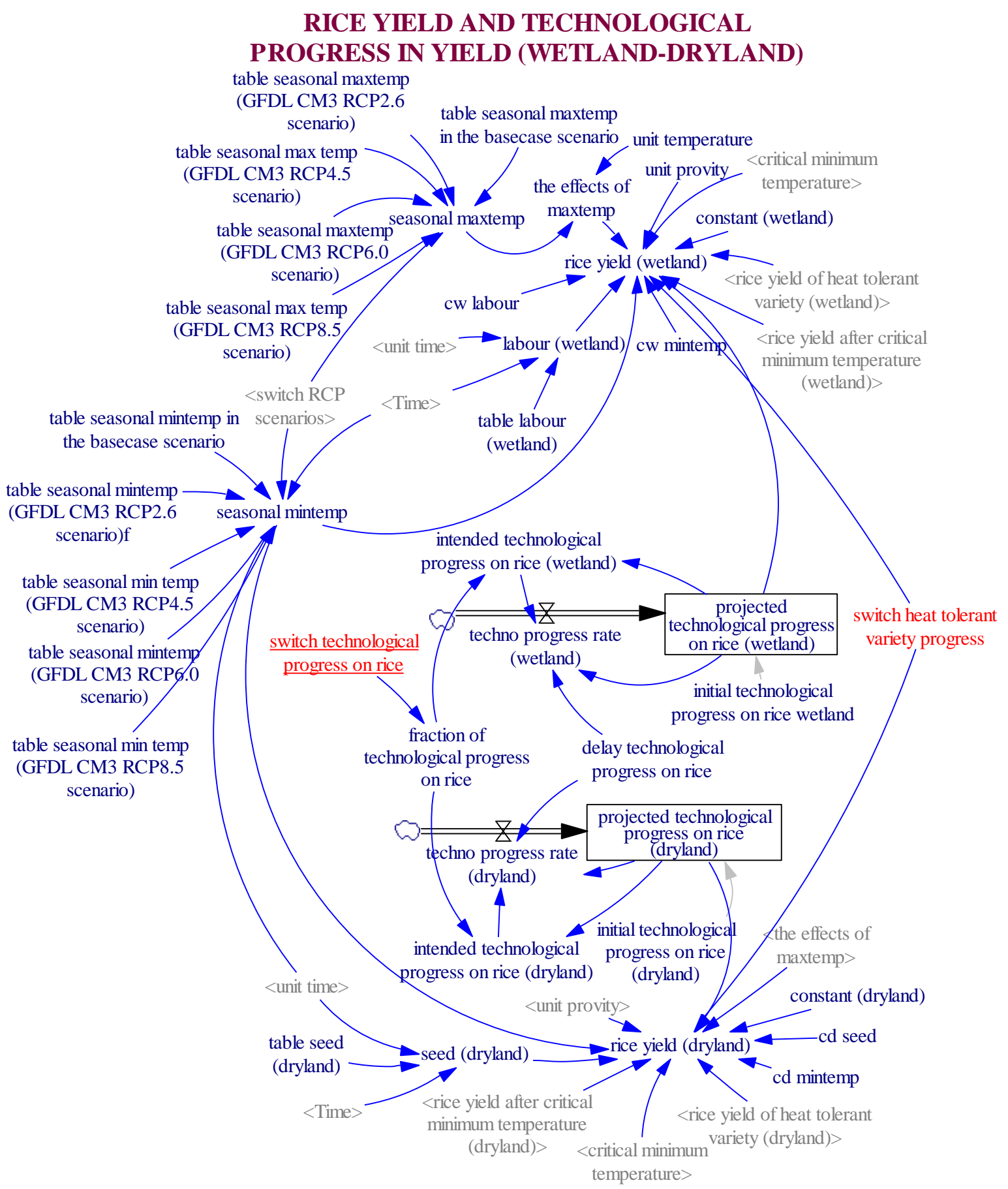

Figure I5. A part of SD model explaining rice yield and technological progress in rice yield (wetland - dryland). In this figure, "critical minimum temperature" is from figure I6. This figure also inserts "rice yield after critical minimum temperature (wetland)" and "rice yield after critical minimum temperature (dryland)" are from figure I6. The other inserted variables are "rice yield of heat tolerant variety (wetland)" and "rice yield of heat tolerant variety (dryland)" from figure I7. 


\section{THE IMPACTS OF MIN TEMP \\ AFTER CRITICAL MIN TEMP \\ (WETLAND-DRYLAND)}

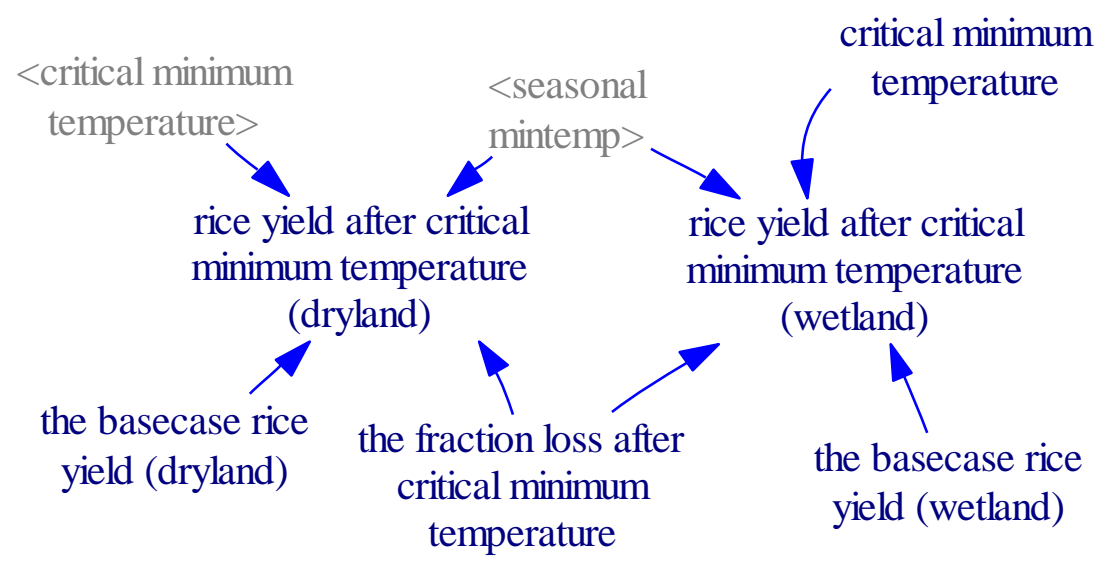

Figure I6. A part of SD model explaining the impacts of minimum temperature on rice yield after projected minimum temperature is higher than critical minimum temperature.

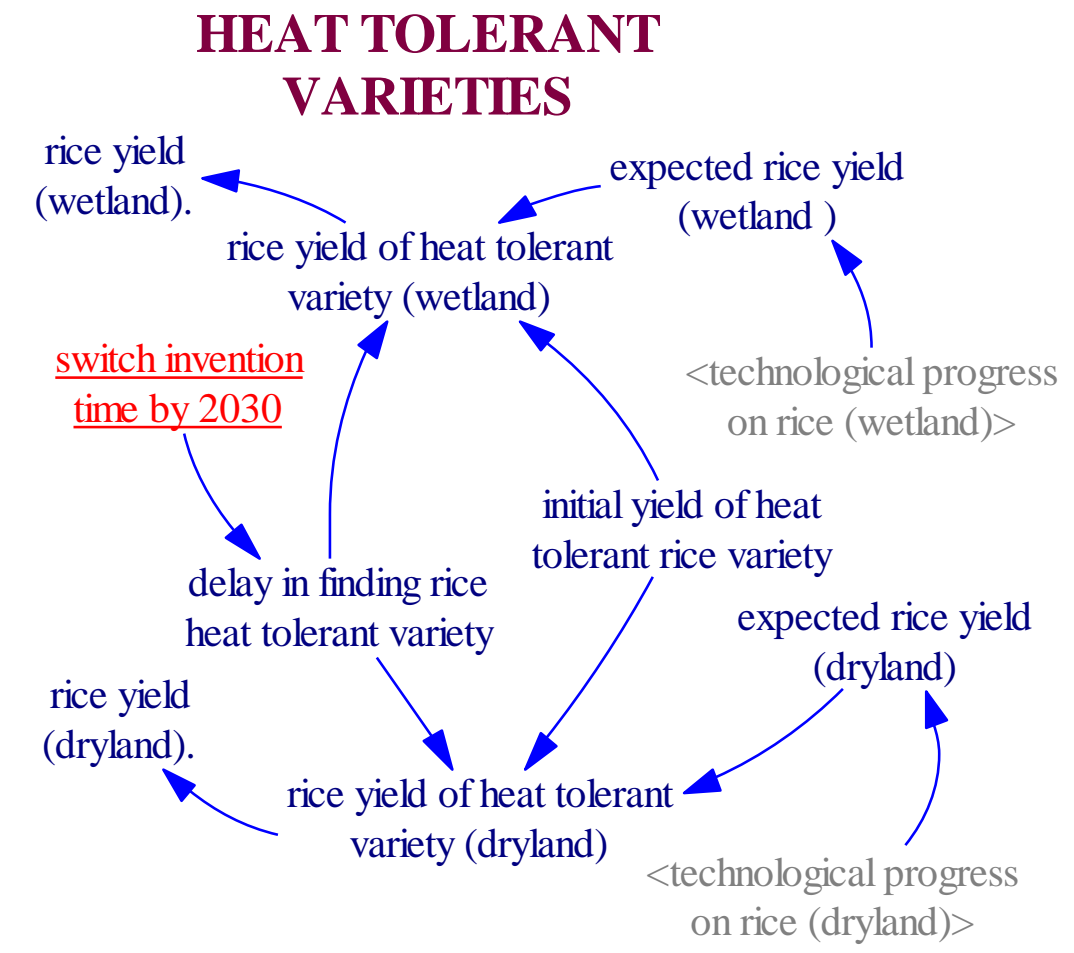

Figure I7. A part of SD model explaining projected rice yield of heat tolerant rice variety in wetland and dryland farming. 
this page intentionally left blank 


\title{
Appendix J. Vensim Simulation Outputs (Chapter 7)
}

\section{J1. THE SECOND STRATEGY}

\section{I.Simulation run under RCP8.5 scenario}

\section{rice yield and rice production in wetland farming}

\author{
13 tonnes/(ha*year) \\ $11 \mathrm{M}$ tonnes/year \\ 40 celcius
}

6.5 tonnes/(ha*year)

$5.5 \mathrm{M}$ tonnes/year

30 celcius

0 tonnes/(ha*year)

0 tonnes/year

20 celcius

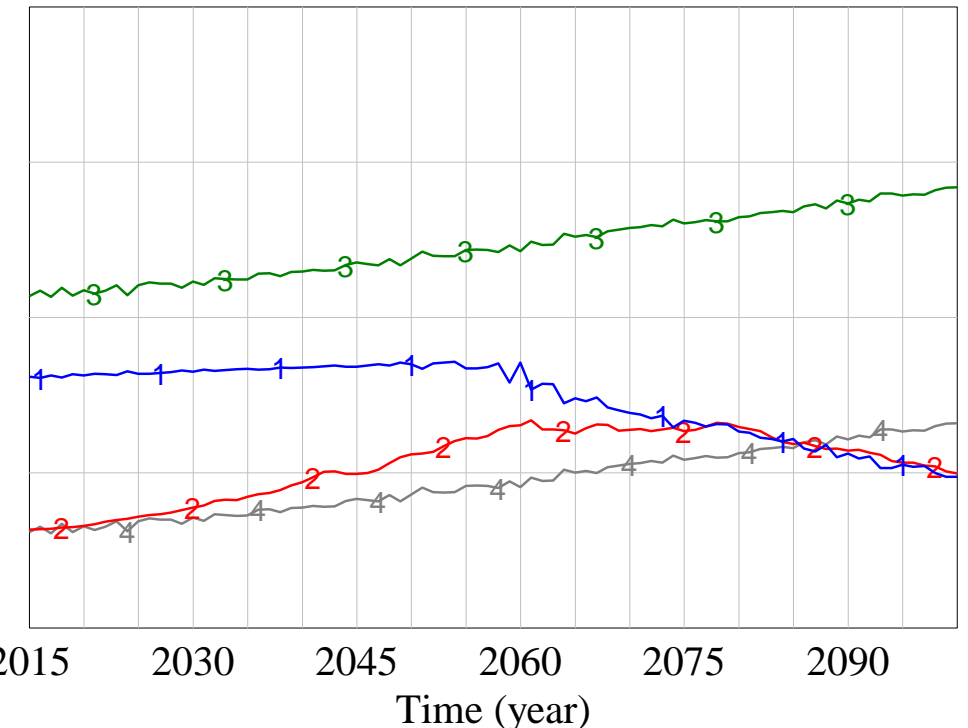

"rice yield (wetland)" : the_second_strategy_RCP8.5_scenario 1 11 1 1 1 1 tonnes/(ha*year) "projected rice production (wetland)" : the_second_strategy_RCP8.5_scenario $\begin{gathered}2 \\ 2\end{gathered}$ seasonal maxtemp : the_second_strategy_RCP8.5_scenario $3 \begin{array}{lllll}3 & 3 & 3 & 3 & 3\end{array}$

Figure J1. Rice yield and rice production in wetland under RCP8.5 scenario

\section{rice yield and rice production in dryland farming}

13 tonnes/(ha*year)

$11 \mathrm{M}$ tonnes/year

40 celcius

6.5 tonnes/(ha*year)

$5.5 \mathrm{M}$ tonnes/year

30 celcius

0 tonnes/(ha*year)

0 tonnes/year

20 celcius

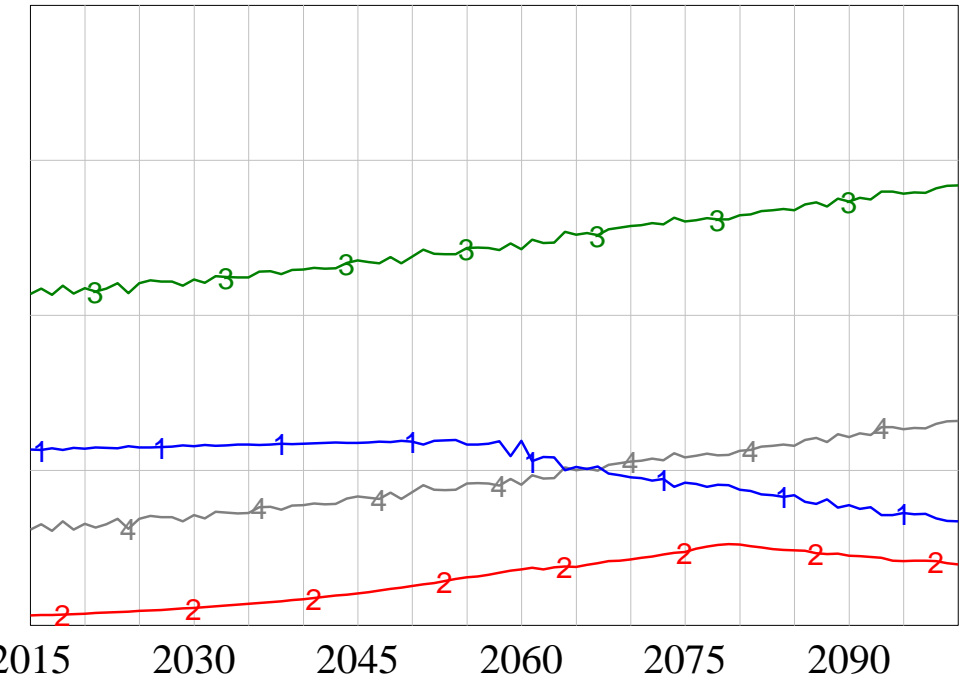

Time (year) "rice yield (dryland)" : the_second_strategy_RCP8.5_scenario 1 1
"projected rice production (dryland)" : the_second_strategy_RCP8.5_scenario seasonal maxtemp : the_second_strategy_RCP8.5_scenario seasonal mintemp : the_second_strategy_RCP8.5_scenario

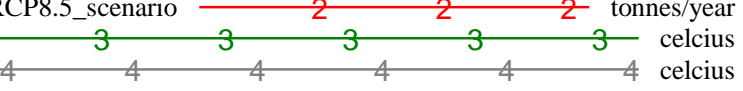

Figure J2. Rice yield and rice production in dryland under RCP8.5 scenario 
harvested area (wetland) vs cropping intensity (wetland) vs rainfall

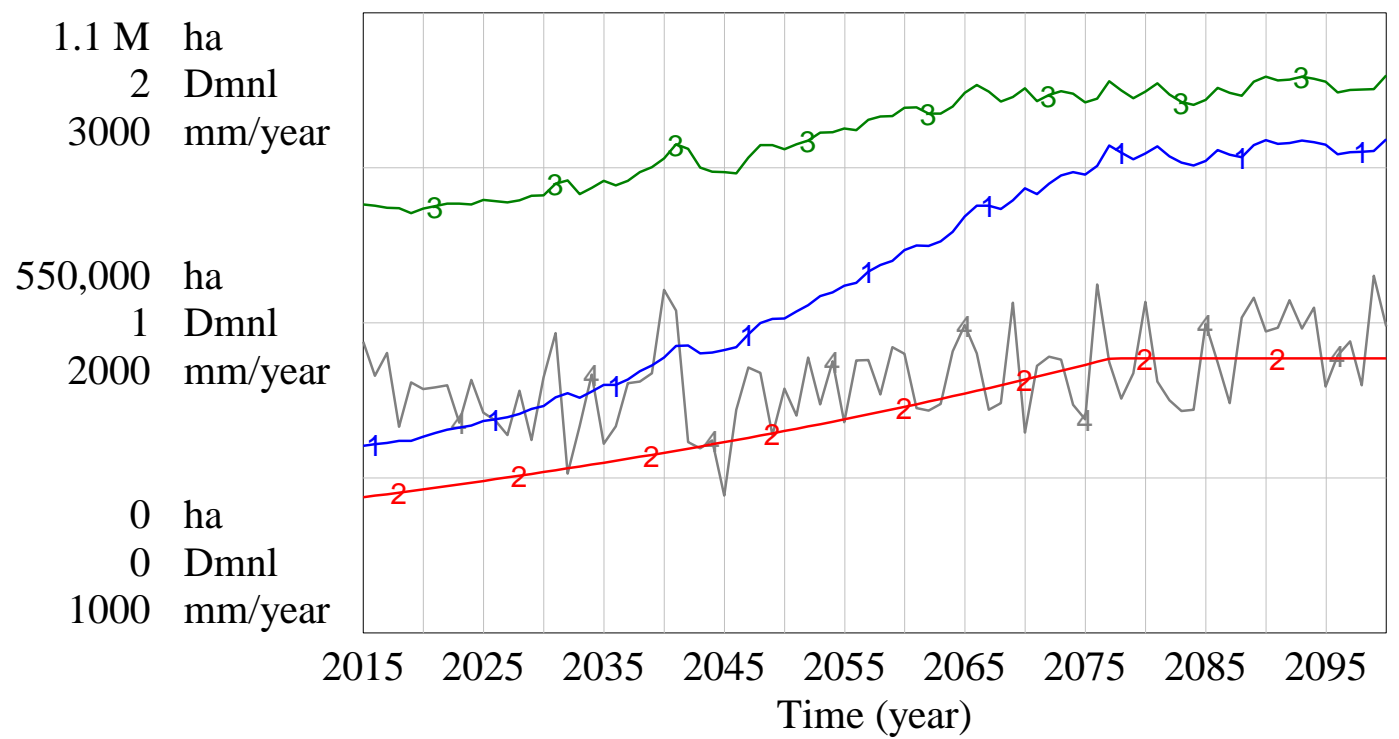

"harvested areas (wetland)" : the_second_strategy_RCP8.5_scenario
"rice farming areas (wetland)" : the_second_strategy_RCP8.5_scenario
"projected cropping intensity (wetland)" : the_second_strategy_RCP8.5_scenario \begin{tabular}{l} 
"projected cropping intensity (wetland)" : the_second_strategy_RCP8.5_scenario \\
\cline { 3 - 4 } seasonal rainfall : the_second_strategy_RCP8.5_scenario
\end{tabular}

Figure J3. Harvested areas and cropping intensity in wetland under RCP8.5 scenario

harvested area (dryland) vs cropping intensity (dryland) vs rainfall

$\begin{array}{rl}1.1 \mathrm{M} & \text { ha } \\ 2 & \text { Dmnl } \\ 3000 & \mathrm{~mm} / \text { year } \\ & \\ 550,000 & \text { ha } \\ 1 & \text { Dmnl } \\ 2000 & \mathrm{~mm} / \text { year } \\ & \\ 0 & \text { ha } \\ 0 & \text { Dmnl } \\ 1000 & \mathrm{~mm} / \text { year }\end{array}$

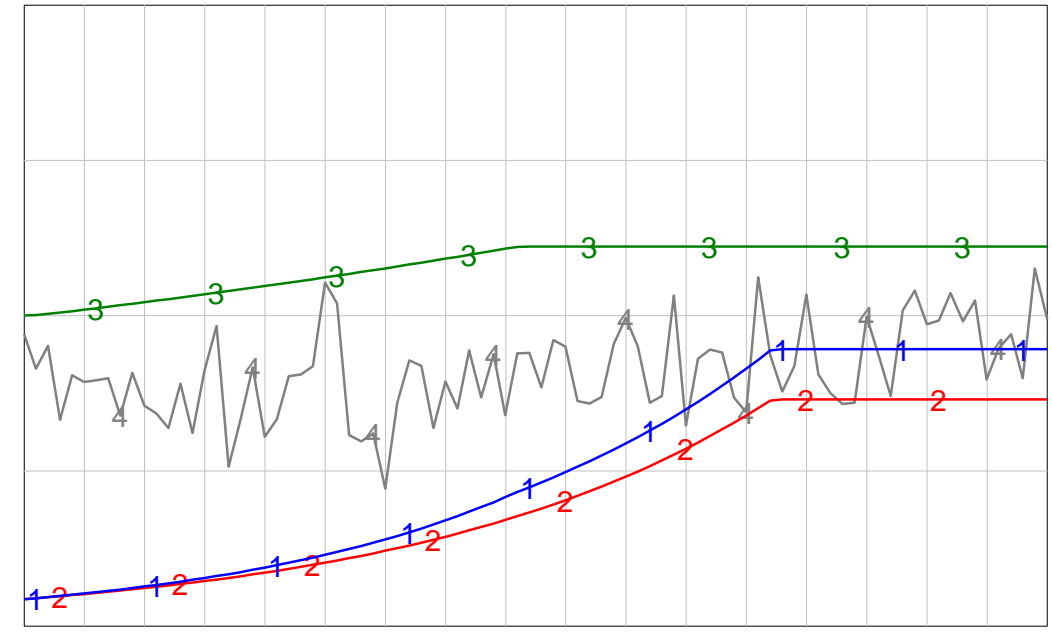

$\begin{array}{lllllllll}2015 & 2025 & 2035 & 2045 & 2055 & 2065 & 2075 & 2085 & 2095\end{array}$

Time (year)

"harvested areas (dryland)" : the_second_strategy_RCP8.5_scenario 11 1 1 1 1 ha

"rice farming areas (dryland)" : the_second_strategy_RCP8.5_scenario $2 \begin{gathered}2 \\ 2\end{gathered} 2$ ha

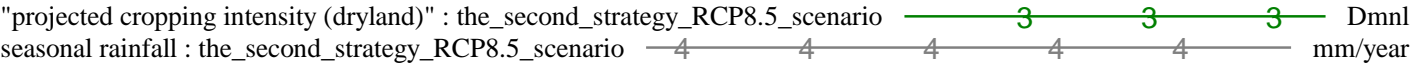

Figure J4. Harvested areas and cropping intensity in dryland under RCP8.5 scenario 


\title{
I.Simulation run under RCP2.6 scenario
}

\section{rice yield and rice production in wetland farming}

\author{
13 tonnes/(ha*year) \\ $11 \mathrm{M}$ tonnes/year \\ 40 celcius
}

6.5 tonnes/(ha*year)

$5.5 \mathrm{M}$ tonnes/year

30 celcius

0 tonnes/(ha*year)

0 tonnes/year

20 celcius

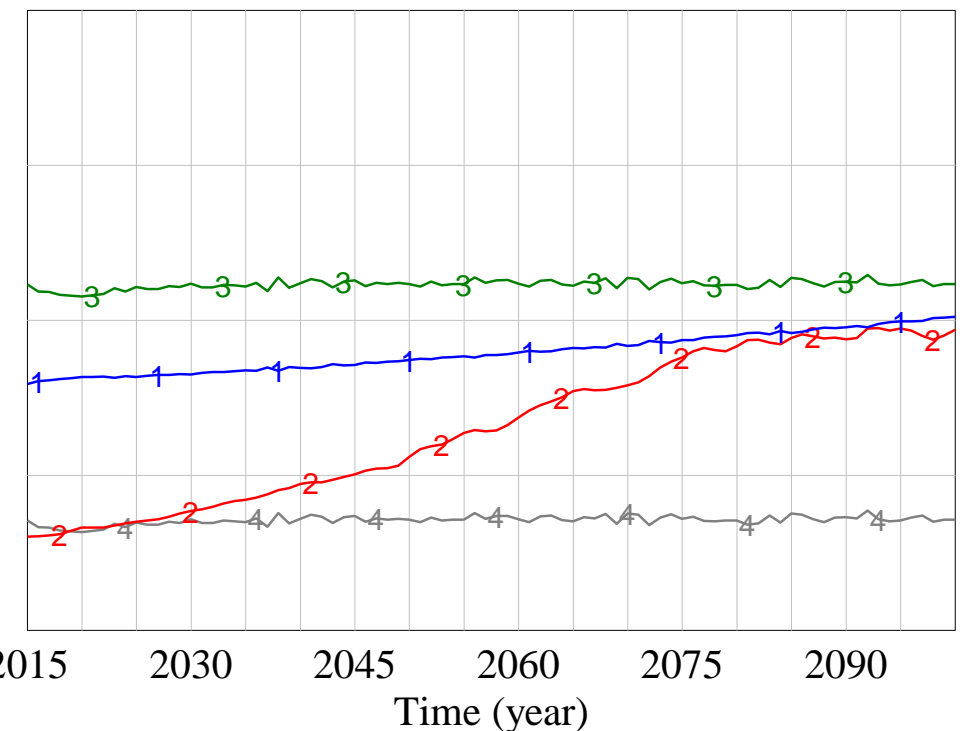

"rice yield (wetland)" : the_second_strategy_RCP2.6_scenario 1 _ 11 1 1 tonnes/(ha*year) "projected rice production (wetland)" : the_second_strategy_RCP2.6_scenario $\quad 2 \quad 2 \quad 2 \quad$ tonnes/year seasonal maxtemp : the_second_strategy_RCP2.6_scenario
seasonal mintemp : the_second_strategy_RCP2.6_scenario 4

Figure J5. Rice yield and rice production in wetland under RCP2.6 scenario

\section{rice yield and rice production in dryland farming}

$\begin{aligned} 13 & \text { tonnes/(ha*year) } \\ 11 \mathrm{M} & \text { tonnes/year } \\ 40 & \text { celcius }\end{aligned}$

6.5 tonnes/(ha*year)

$5.5 \mathrm{M}$ tonnes/year

30 celcius

0 tonnes/(ha*year)

0 tonnes/year

20 celcius

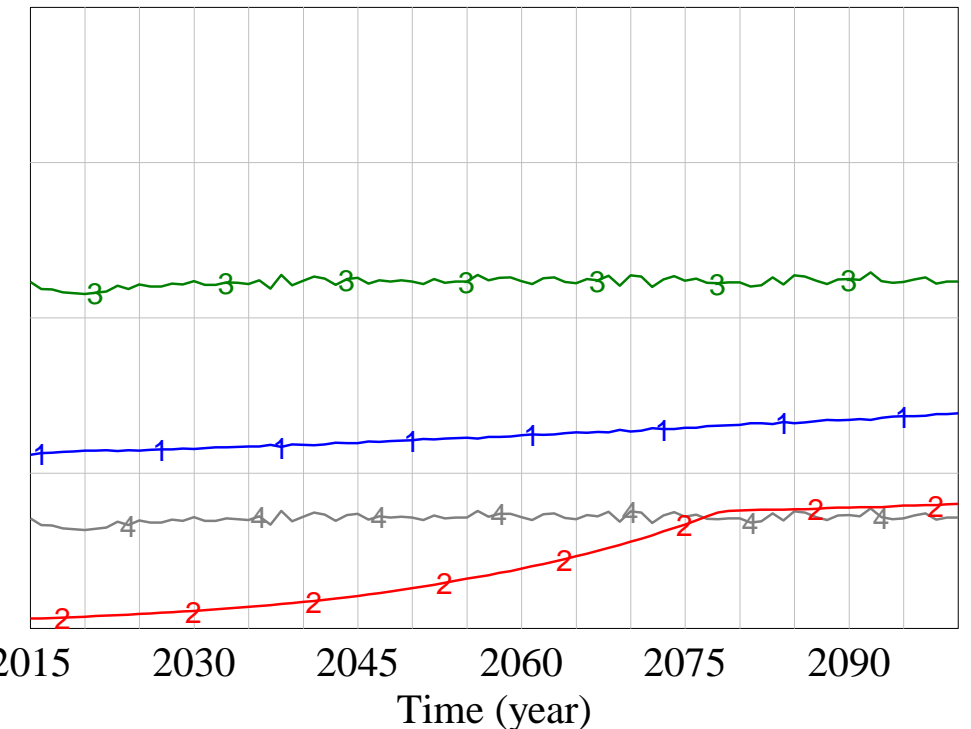

"rice yield (dryland)" : the_second_strategy_RCP2.6_scenario 1 111 1 1 tonnes/(ha*year) "projected rice production (dryland)" : the_second_strategy_RCP2.6_scenario $\quad 2 \quad 2$ tonnes/year seasonal maxtemp : the_second_strategy_RCP2.6_scenario $3 \begin{array}{llllll}3 & 3 & 3 & 3 & & 3\end{array}$ seasonal mintemp : the_second_strategy_RCP2.6_scenario

Figure J6. Rice yield and rice production in dryland under RCP2.6 scenario 
harvested area (wetland) vs cropping intensity (wetland) vs rainfall

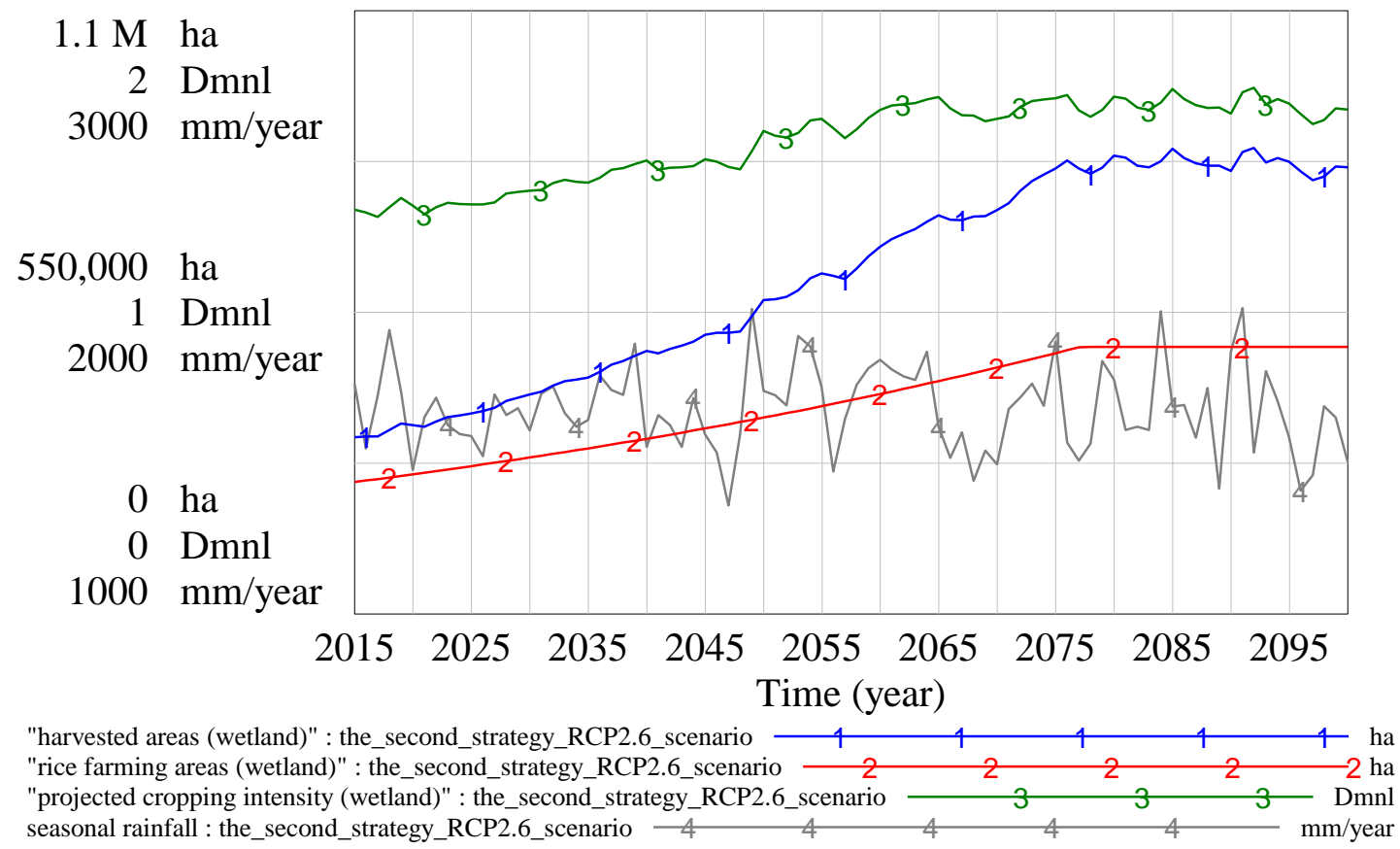

Figure J7. Harvested areas and cropping intensity in wetland under RCP2.6 scenario

harvested area (dryland) vs cropping intensity (dryland) vs rainfall

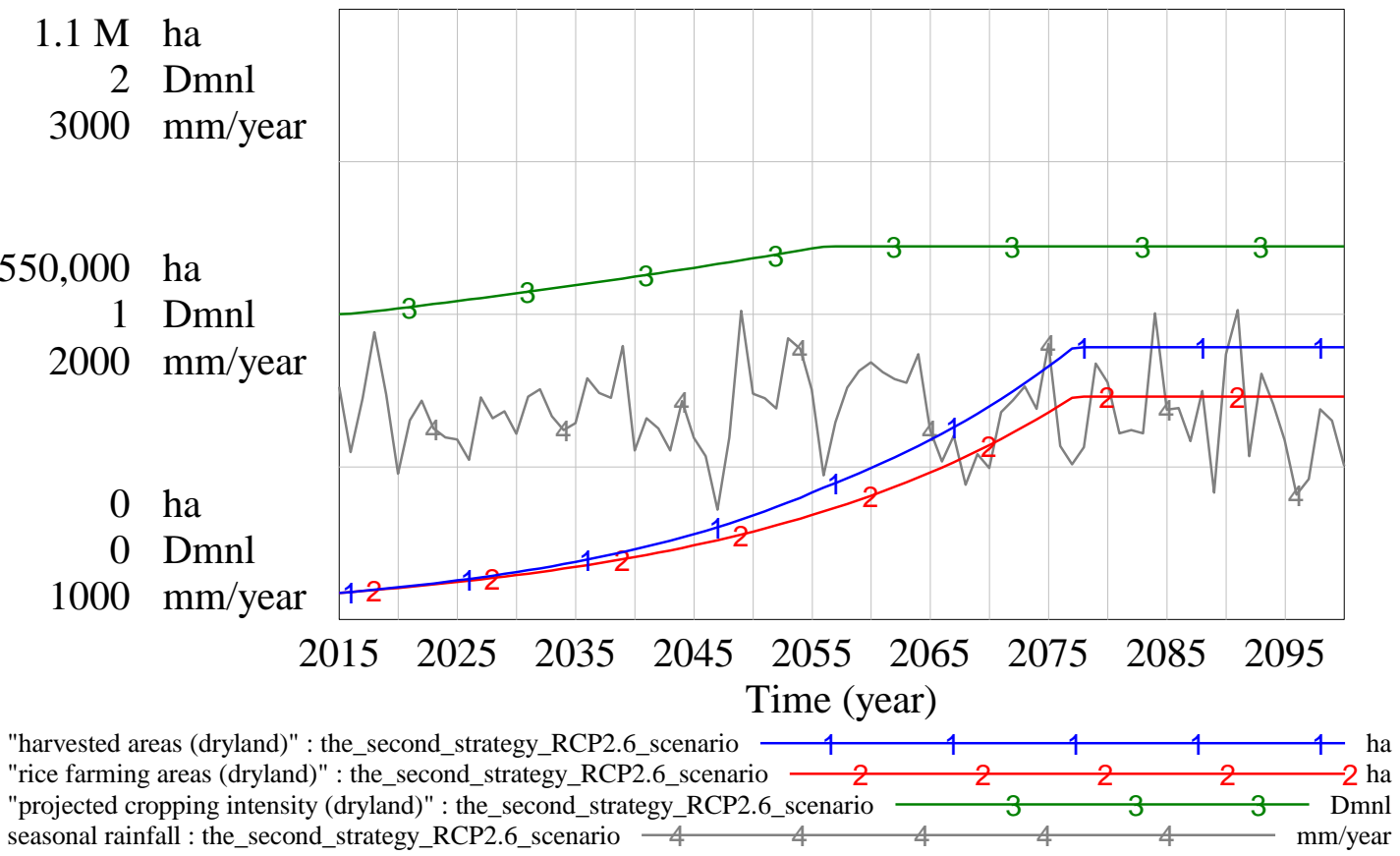

Figure J8. Harvested areas and cropping intensity in wetland under RCP2.6 scenario 


\section{I2. THE THIRD STRATEGY}

II. Simulation run under RCP8.5 scenario

\section{rice yield and rice production in wetland farming}

\section{3 tonnes/(ha*year)}

$11 \mathrm{M}$ tonnes/year

40 celcius

6.5 tonnes/(ha*year)

$5.5 \mathrm{M}$ tonnes/year

30 celcius

0 tonnes/(ha*year)

0 tonnes/year

20 celcius

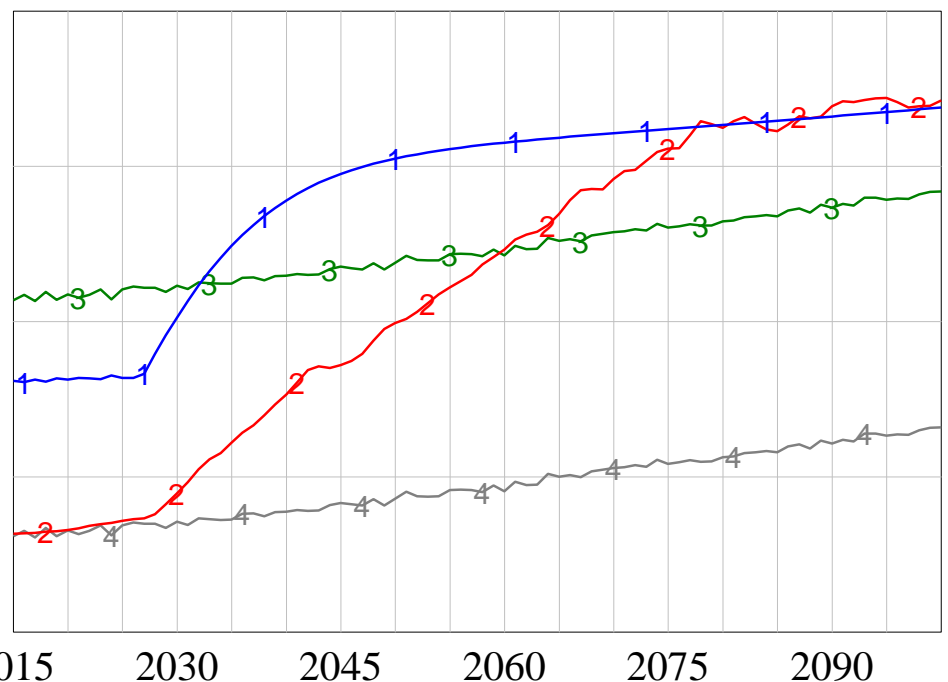

$$
\begin{array}{rrr}
2015 & 2030 \quad 2045 & 2060 \\
& \text { Time (year) }
\end{array}
$$

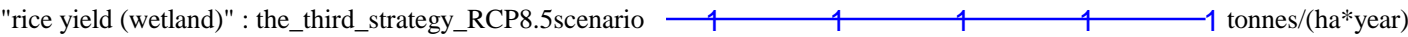
"projected rice production (wetland)" : the_third_strategy_RCP8.5scenario $\begin{array}{llllll}2 & 2 & 2 & 2 & 2\end{array}$

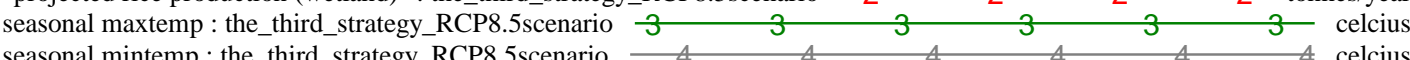

Figure J9. Rice yield and rice production in wetland under RCP8.5 scenario

\section{rice yield and rice production in dryland farming}

$\begin{aligned} 13 & \text { tonnes/(ha*year) } \\ 11 \mathrm{M} & \text { tonnes/year } \\ 40 & \text { celcius }\end{aligned}$

6.5 tonnes/(ha*year)

$5.5 \mathrm{M}$ tonnes/year

30 celcius

0 tonnes/(ha*year)

0 tonnes/year

20 celcius

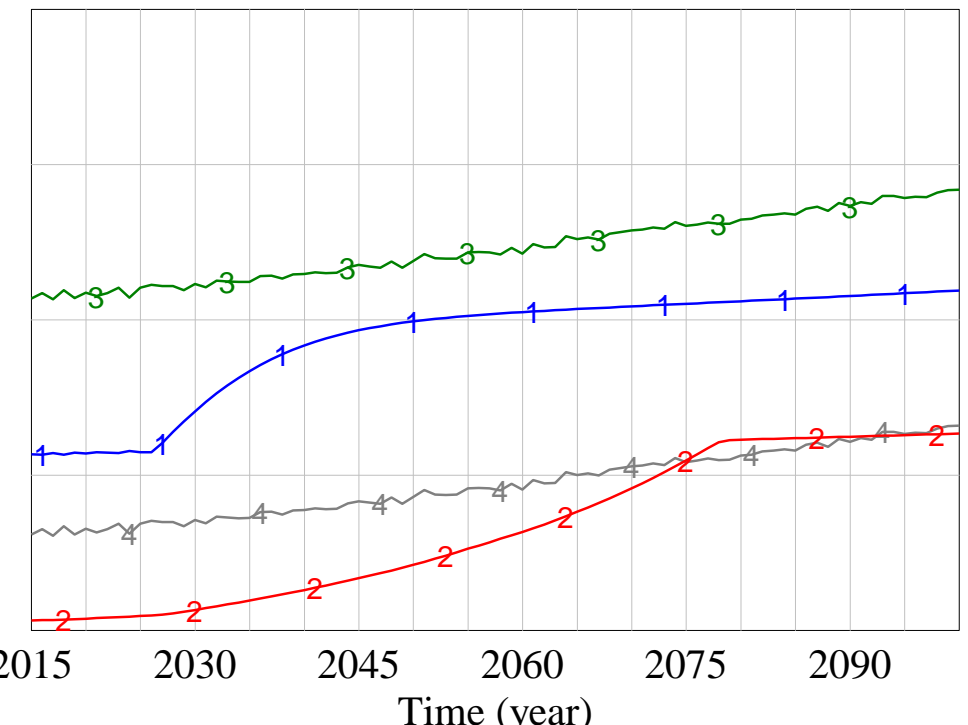

"rice yield (dryland)" : the_third_strategy_RCP8.5scenario $\quad \begin{array}{lllll}1 & 1 & 1 & 1 & 1\end{array}$ "projected rice production (dryland)" : the_third_strategy_RCP8.5scenario $\begin{array}{lllll}2 & 2 & 2 & 2 & \text { tonnes/year }\end{array}$ seasonal maxtemp : the_third_strategy_RCP8.5scenario $3 \quad 3 \quad 3 \quad 3-3$ celcius seasonal mintemp : the_third_strategy_RCP8.5scenario $\quad 4 \quad 4 \quad 4 \quad 4 \quad 4 \quad 4 \quad 4 \quad 4 \quad 4$ celcius

Figure J10. Rice yield and rice production in dryland under RCP8.5 scenario 
harvested area (wetland) vs cropping intensity (wetland) vs rainfall

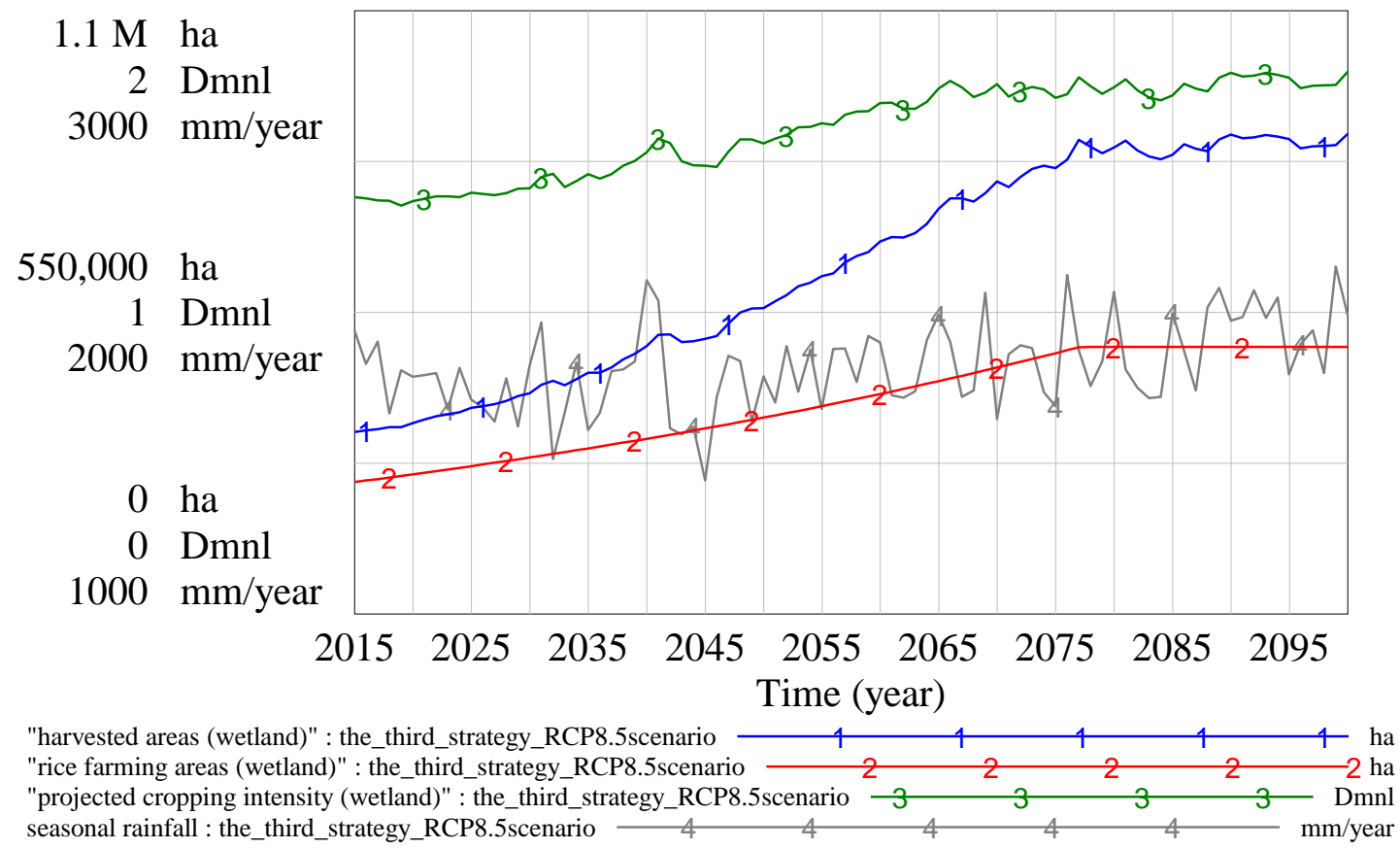

Figure J11. Harvested areas and cropping intensity in wetland under RCP8.5 scenario

harvested area (dryland) vs cropping intensity (dryland) vs rainfall

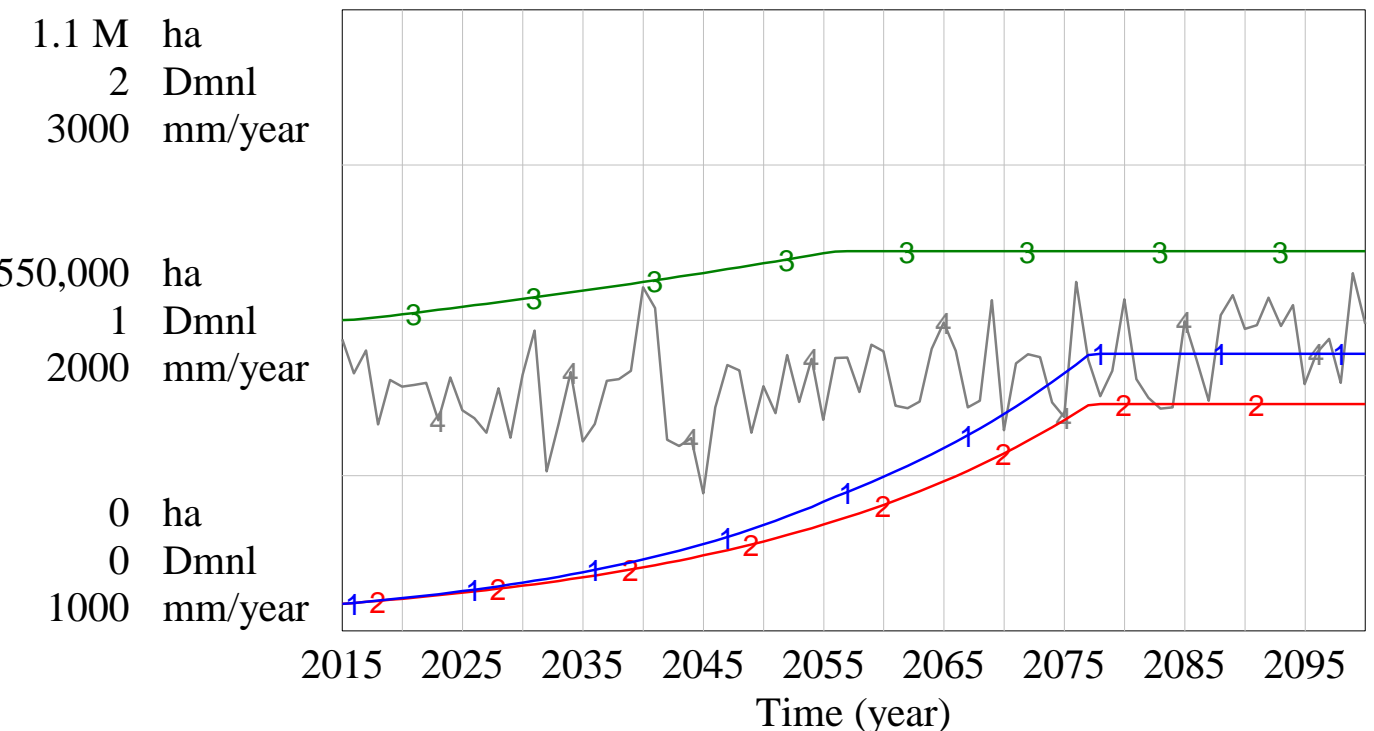

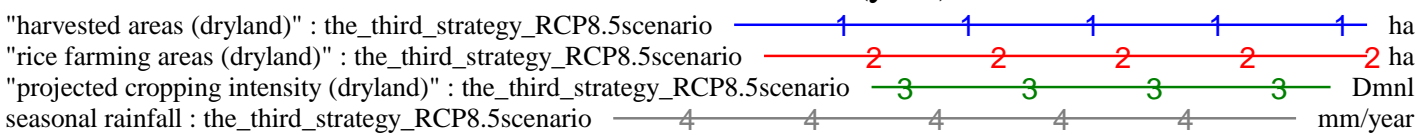

Figure J12. Harvested areas and cropping intensity in dryland under RCP8.5 scenario 
III. Simulation run under RCP2.6 scenario

\title{
rice yield and rice production in wetland farming
}

\author{
13 tonnes/(ha*year) \\ $11 \mathrm{M}$ tonnes/year \\ 40 celcius
}

6.5 tonnes/(ha*year)

$5.5 \mathrm{M}$ tonnes/year

30 celcius

0 tonnes/(ha*year)

0 tonnes/year

20 celcius

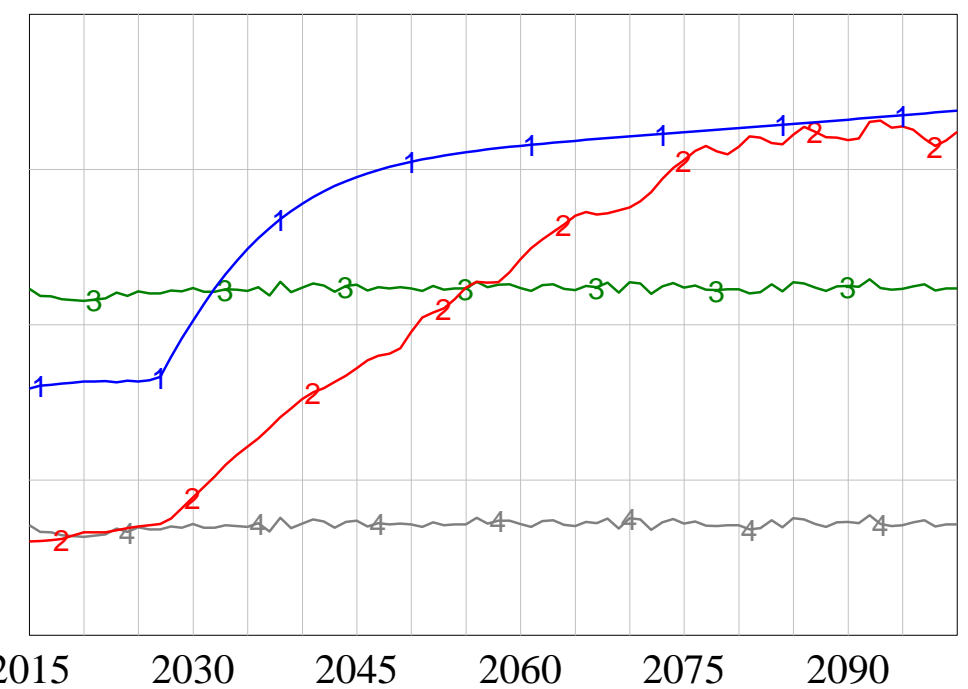

Time (year)

"rice yield (wetland)" : the_third_strategy_RCP2.6scenario 1101 1 1 1 1 tonnes/(ha*year) "projected rice production (wetland)" : the_third_strategy_RCP2.6scenario $\begin{array}{llllll}2 & 2 & 2 & 2 & \text { tonnes/year }\end{array}$

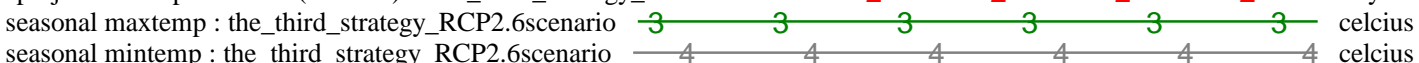

Figure J13. Rice yield and rice production in wetland under RCP2.6 scenario

\section{rice yield and rice production in dryland farming}

13 tonnes/(ha*year)

$11 \mathrm{M}$ tonnes/year

40 celcius

6.5 tonnes/(ha*year)

$5.5 \mathrm{M}$ tonnes/year

30 celcius

0 tonnes/(ha*year)

0 tonnes/year

20 celcius

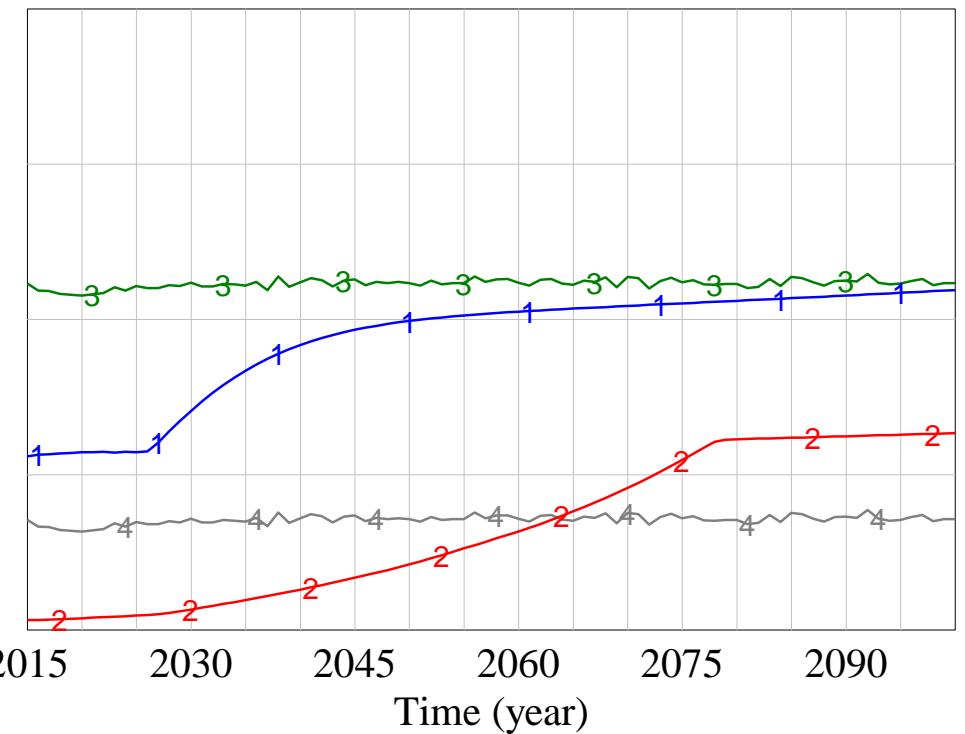

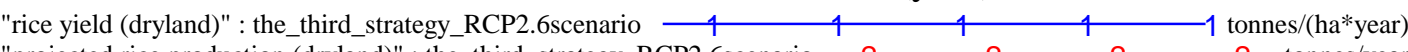

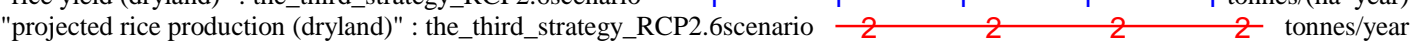
seasonal maxtemp : the_third_strategy_RCP2.6scenario
seasonal mintemp : the third_strategy_RCP2.6scenario

Figure J14. Rice yield and rice production in dryland under RCP2.6 scenario 
harvested area (wetland) vs cropping intensity (wetland) vs rainfall

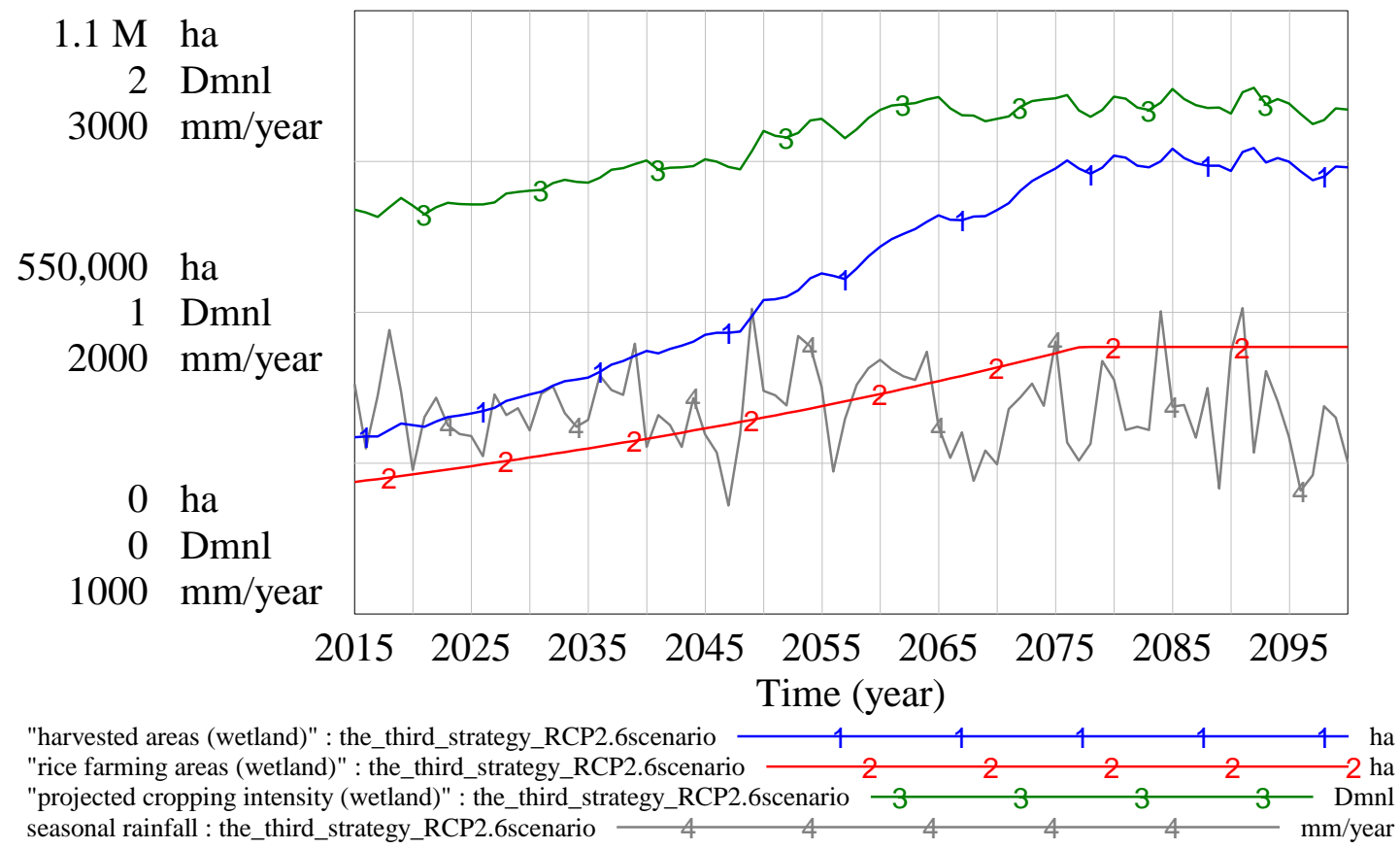

Figure J15. Harvested areas and cropping intensity in wetland RCP2.6 scenario

harvested area (dryland) vs cropping intensity (dryland) vs rainfall

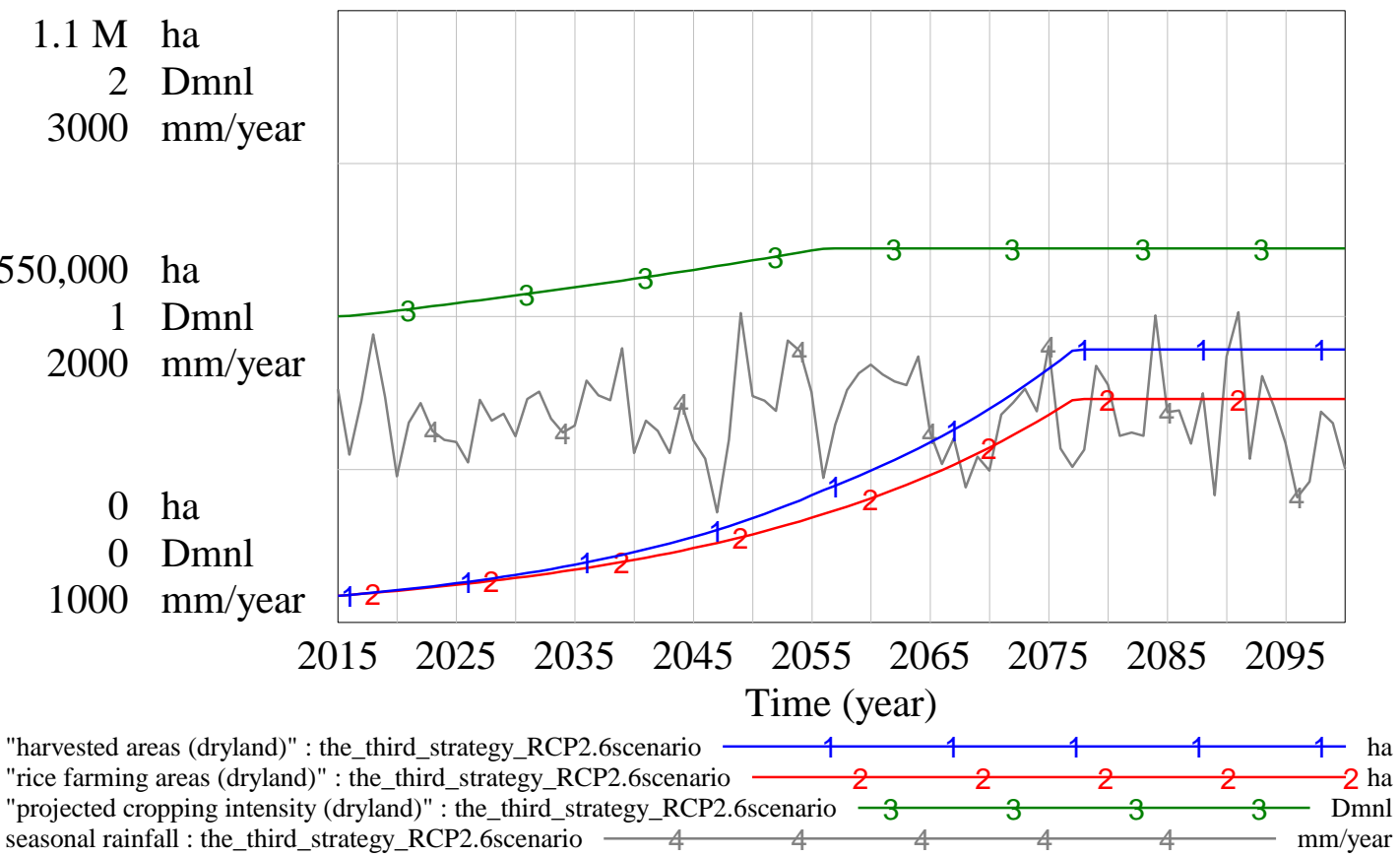

Figure J16. Harvested areas and cropping intensity in dryland RCP2.6 scenario 


\section{Appendix K. Vensim Model Documentation (Chapter 7) \\ Documentation of THE SD MODEL WITH POLICY SCENARIOS Model Assessment Results}

\begin{tabular}{|l|c|}
\hline \multicolumn{1}{|c|}{ Model Information } & Number \\
\hline Total Number of Variables & 115 \\
\hline Total Number of State Variables & 13 \\
(Level+Smooth+Delay Variables) & $(11.3 \%)$ \\
\hline $\begin{array}{l}\text { Total Number of Stocks (Stocks in } \\
\text { Level+Smooth+Delay Variables) } \uparrow\end{array}$ & $\begin{array}{c} \\
\dagger\end{array}$ \\
\hline Total Number of Macros & 0 \\
\hline Time Unit & year \\
\hline Initial Time & 2015 \\
\hline Final Time & 2100 \\
\hline Reported Time Interval & 1 \\
\hline Time Step & 0.0078125 \\
\hline Model Is Fully Formulated & Yes \\
\hline
\end{tabular}




\begin{tabular}{|c|c|c|c|}
\hline Module & Group & Type & Variable Name and Description \\
\hline Default & $\begin{array}{l}\text { THE SD } \\
\text { POLICY } \\
\text { SCENA } \\
\text { RIO } \\
\text { MODEL } \\
\text { (Default) }\end{array}$ & $\begin{array}{c}\# 1 \\
C \\
\mathrm{WAB}\end{array}$ & $\begin{array}{l}\text { "a fraction new farming areas (dryland)" (1/year) } \\
=0.0355 \\
\text { Description: This is annual growth (fraction) of new dryland farming a year based on observed data between } 1976 \text { and } 2011 . \\
\text { Present in } 1 \text { view: } \\
\text { - } \\
\text { Used by: } \\
\text { - } \\
\text { physical rice farming areas (dryland) }\end{array}$ \\
\hline Default & $\begin{array}{c}\text { THE SD } \\
\text { POLICY } \\
\text { SCENA } \\
\text { RIO } \\
\text { MODEL } \\
\text { (Default) }\end{array}$ & $\begin{array}{c}\# 2 \\
\mathrm{C} \\
\mathrm{WAB}\end{array}$ & $\begin{array}{l}\text { "a fraction of new farming areas (wetland)" (1/year) } \\
\text { = } 0.0115 \\
\text { Description: This is annual growth (fraction) of new wetland farming a year based on observed data between } 1976 \text { and } 2011 . \\
\text { Present in } 1 \text { view: } \\
\text { - } \\
\text { Used by: } \\
\text { • } \\
\text { physical rice farming areas (wetland) }\end{array}$ \\
\hline Default & $\begin{array}{c}\text { THE SD } \\
\text { POLICY } \\
\text { SCENA } \\
\text { RIO } \\
\text { MODEL } \\
\text { (Default) }\end{array}$ & $\begin{array}{c}\# 3 \\
\mathrm{C} \\
\mathrm{WAB}\end{array}$ & $\begin{array}{l}\text { ad mintemp (tonnes/ha/year/celcius) } \\
=-0.12 \\
\text { Description: this a coefficient of minimum temperature to measure rice yield (dryland). } \\
\text { Present in } \mathbf{1} \text { view: } \\
\text { - } \\
\text { Used by: } \\
\text { View } 1 \\
\quad \text { "rice yield (dryland)" - this is total rice yield in dryland farming between between September year t and August year } \mathrm{t}+1 \text {. }\end{array}$ \\
\hline Default & $\begin{array}{c}\text { THE SD } \\
\text { POLICY } \\
\text { SCENA } \\
\text { RIO } \\
\text { MODEL } \\
\text { (Default) }\end{array}$ & $\begin{array}{c}\# 4 \\
\mathrm{C} \\
\mathrm{XAB}\end{array}$ & $\begin{array}{l}\text { ad seed (tonnes/ha/year/(IDR/year)) } \\
=0.018 \\
\text { Description: this a coefficient of seed to measure rice productivity (dryland). } \\
\text { Present in } 1 \text { view: } \\
\text { Used by: } \\
\text { View } 1 \\
\text { "rice yield (dryland)" - this is total rice yield in dryland farming between between September year t and August year } \mathrm{t}+1 \text {. }\end{array}$ \\
\hline Default & $\begin{array}{l}\text { THE SD } \\
\text { POLICY } \\
\text { SCENA } \\
\text { RIO } \\
\text { MODEL } \\
\text { (Default) }\end{array}$ & $\begin{array}{c}\# 5 \\
\mathrm{~A} \\
\mathrm{VAB}\end{array}$ & 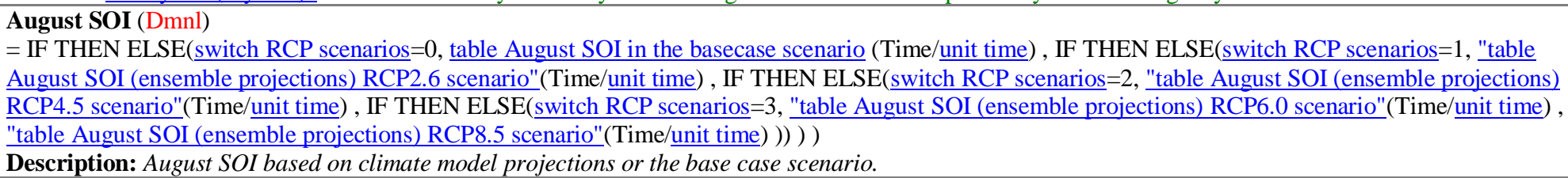 \\
\hline
\end{tabular}




\begin{tabular}{|c|c|c|c|}
\hline & & & $\begin{array}{l}\text { Source: Source of Data } \\
\text { Present in } 1 \text { view: } \\
\bullet \\
\text { Used by: } \\
\bullet \\
\text { dimension. }\end{array}$ \\
\hline Default & $\begin{array}{l}\text { THE SD } \\
\text { POLICY } \\
\text { SCENA } \\
\text { RIO } \\
\text { MODEL } \\
\text { (Default) }\end{array}$ & $\begin{array}{c}\# 6 \\
\mathrm{~L} \\
\mathrm{M} \\
\mathrm{M}\end{array}$ & $\begin{array}{l}\text { available land (ha) } \\
=\int-\text {-new farming areas (wetland)"-"new farming areas (dryland)" } d t+[\text { [initial available land }] \\
\text { Description: Available land is potential land to be converted into wetland and dryland farming. This land is served to increase areas of wetland and } \\
\text { dryland farming. . } \\
\text { Present in } 1 \text { view: } \\
\text { - } \\
\text { Used by: } \\
\text { - } \\
\text { physical rice farming areas } 1 \\
\bullet \\
\text { physical rice farming areas (wetland) }\end{array}$ \\
\hline Default & $\begin{array}{l}\text { THE SD } \\
\text { POLICY } \\
\text { SCENA } \\
\text { RIO } \\
\text { MODEL } \\
\text { (Default) }\end{array}$ & $\begin{array}{c}\# 7 \\
\mathrm{C} \\
\mathrm{VAB}\end{array}$ & $\begin{array}{l}\text { aw cropping intensity }(\mathrm{year} / \mathrm{mm}) \\
=0.00023 \\
\text { Description: This is a coefficient of an equation in estimating the effect of seasonal rainfall on cropping intensity of wetland farming } \\
\text { Present in } 1 \text { view: } \\
\text { • } \\
\text { Used by: } \\
\text { - } \quad \text { "expected cropping intensity (wetland)" - the expected cropping intensity }\end{array}$ \\
\hline Default & $\begin{array}{l}\text { THE SD } \\
\text { POLICY } \\
\text { SCENA } \\
\text { RIO } \\
\text { MODEL } \\
\text { (Default) }\end{array}$ & $\begin{array}{c}\# 8 \\
\mathrm{C} \\
\mathrm{W} \\
\mathrm{W}\end{array}$ & $\begin{array}{l}\text { aw labour (tonnes/ha/(IDR/year)/year) } \\
=0.003 \\
\text { Description: } \text { a coefficient of labour relative for irrigated farming } \\
\text { Present in } 1 \text { view: } \\
\text { • } \\
\text { Used by: } \quad \text { View } 1 \\
\text { - } \quad \text { "rice yield (wetland)" - this is total rice yield in wetland farming between between September } \mathrm{t} \text { and August year } \mathrm{t}+1 \text {. }\end{array}$ \\
\hline Default & $\begin{array}{l}\text { THE SD } \\
\text { POLICY } \\
\text { SCENA } \\
\text { RIO } \\
\text { MODEL } \\
\text { (Default) }\end{array}$ & $\begin{array}{c}\# 9 \\
\mathrm{C} \\
\mathrm{VAB}\end{array}$ & $\begin{array}{l}\text { aw seasonal mintemp (tonnes/ha/celcius/year) } \\
=-0.197 \\
\text { Description: this a coefficient of minimum temperature to measure rice yield (wetland). } \\
\text { Present in } 1 \text { view: } \\
\text { - } \\
\text { Used by: }\end{array}$ \\
\hline
\end{tabular}




\begin{tabular}{|c|c|c|c|}
\hline & & & • $\quad$ "rice yield (wetland)" - this is total rice yield in wetland farming between between September $\mathrm{t}$ and August year $\mathrm{t}+1$. \\
\hline Default & $\begin{array}{l}\text { THE SD } \\
\text { POLICY } \\
\text { SCENA } \\
\text { RIO } \\
\text { MODEL } \\
\text { (Default) }\end{array}$ & $\begin{array}{c}\# 10 \\
C \\
\text { WAB }\end{array}$ & $\begin{array}{l}\text { "constant (dryland)" (tonnes/ha/year) } \\
=4.56 \\
\text { Description: } \text { a constant to measure rice yield in dryland farming. } \\
\text { Present in } 1 \text { view: } \\
\text { Used by: } \\
\text { - }\end{array}$ \\
\hline Default & $\begin{array}{l}\text { THE SD } \\
\text { POLICY } \\
\text { SCENA } \\
\text { RIO } \\
\text { MODEL } \\
\text { (Default) }\end{array}$ & $\begin{array}{c}\# 11 \\
C \\
\text { WAB }\end{array}$ & $\begin{array}{l}\text { "constant (wetland)" (tonnes/ha/year) } \\
=6.73 \\
\text { Description: } \text { a constant to measure rice yield in wetland farming. } \\
\text { Present in } 1 \text { view: } \\
\text { Used by: } \\
\text { View } 1 \\
\text { "rice yield (wetland)" - this is total rice yield in wetland farming between between September t and August year } \mathrm{t}+1 \text {. }\end{array}$ \\
\hline Default & $\begin{array}{l}\text { THE SD } \\
\text { POLICY } \\
\text { SCENA } \\
\text { RIO } \\
\text { MODEL } \\
\text { (Default) }\end{array}$ & $\begin{array}{c}\# 12 \\
C \\
\text { WAB }\end{array}$ & $\begin{array}{l}\text { constant cropping intensity (Dmnl) } \\
=0.935 \\
\text { Description: This is a constantof an equation in estimating the effect of seasonal rainfall on cropping intensity of wetland farming } \\
\text { Present in } 1 \text { view: } \\
\text { Used by: } \\
\text { View } 1 \\
\text { "expected cropping intensity (wetland)" - the expected cropping intensity }\end{array}$ \\
\hline Default & $\begin{array}{l}\text { THE SD } \\
\text { POLICY } \\
\text { SCENA } \\
\text { RIO } \\
\text { MODEL } \\
\text { (Default) }\end{array}$ & $\begin{array}{c}\# 13 \\
C \\
\text { WAB }\end{array}$ & $\begin{array}{l}\text { converter year and day (days/year) } \\
=365 \\
\text { Description: this variable is used to convert a day dimension to be a year dimension } \\
\text { Present in } 2 \text { views: } \\
\quad \text { View } 1 \\
\text { Used by: } \\
\text { - } \\
\text { "prew } 2 \\
\text { "thich represents the actual paddy production (wetland) in harvesting seasons. }\end{array}$ \\
\hline Default & $\begin{array}{l}\text { THE SD } \\
\text { POLICY } \\
\text { SCENA }\end{array}$ & $\begin{array}{c}\# 14 \\
\text { C }\end{array}$ & $\begin{array}{l}\text { critical minimum temperature (celcius) } \\
=24.7 \\
\text { Description: the maximum minimum temperature when statistical model of rice yield should be replaced by "rice yield after critical minimum temperature }\end{array}$ \\
\hline
\end{tabular}




\begin{tabular}{|c|c|c|c|}
\hline & $\begin{array}{c}\text { RIO } \\
\text { MODEL } \\
\text { (Default) }\end{array}$ & WAB & $\begin{array}{l}\text { for wetland rice and dryland rice" } \\
\text { Present in } \mathbf{1} \text { view: } \\
\text { - } \\
\text { Used by: } \\
\text { - } \\
\text { - } \\
\text { - } \\
\text { - } \\
\text { "riew } 1 \\
\text { "rice yield (dryland)" - thield (wetland)" - this is total rice yield in wetland farming between between September t and August year } t+1 . \\
\text { "rice yield after critical minimum temperature (dryland)" - The rice yield after critical minimum temperature (dryland) }\end{array}$ \\
\hline Default & $\begin{array}{c}\text { THE SD } \\
\text { POLICY } \\
\text { SCENA } \\
\text { RIO } \\
\text { MODEL } \\
\text { (Default) }\end{array}$ & $\begin{array}{l}\# 15 \\
\text { T,A } \\
\text { WAB } \\
\frac{X}{X}\end{array}$ & $\begin{array}{l}\text { delay in finding rice heat tolerant variety }(\text { year) } \\
=\text { WITH LOOKUP (switch invention time by } 2030,([(1,0)-(4,80)],(1,15),(2,30),(2,30),(3,75),(3,75))) \\
\text { Description: a delay in finding heat tolerant rice variety. } \\
\text { This Lookup Table is used as a Data Repository. } \\
\text { Present in } 1 \text { view: } \\
\text { - } \\
\text { Used by: } \\
\text { View } 1 \\
\text { "rice yield of heat tolerant variety (dryland)" - the yield of heat tolerant rice variety in dryland farming if heat tolerant rice varieties are found in } \\
\text { - } \quad \text { "rice yield of heat tolerant variety (wetland)" - the yield of heat tolerant rice variety in wetland farming if heat tolerant rice varieties are found in } \\
2030 \quad\end{array}$ \\
\hline
\end{tabular}




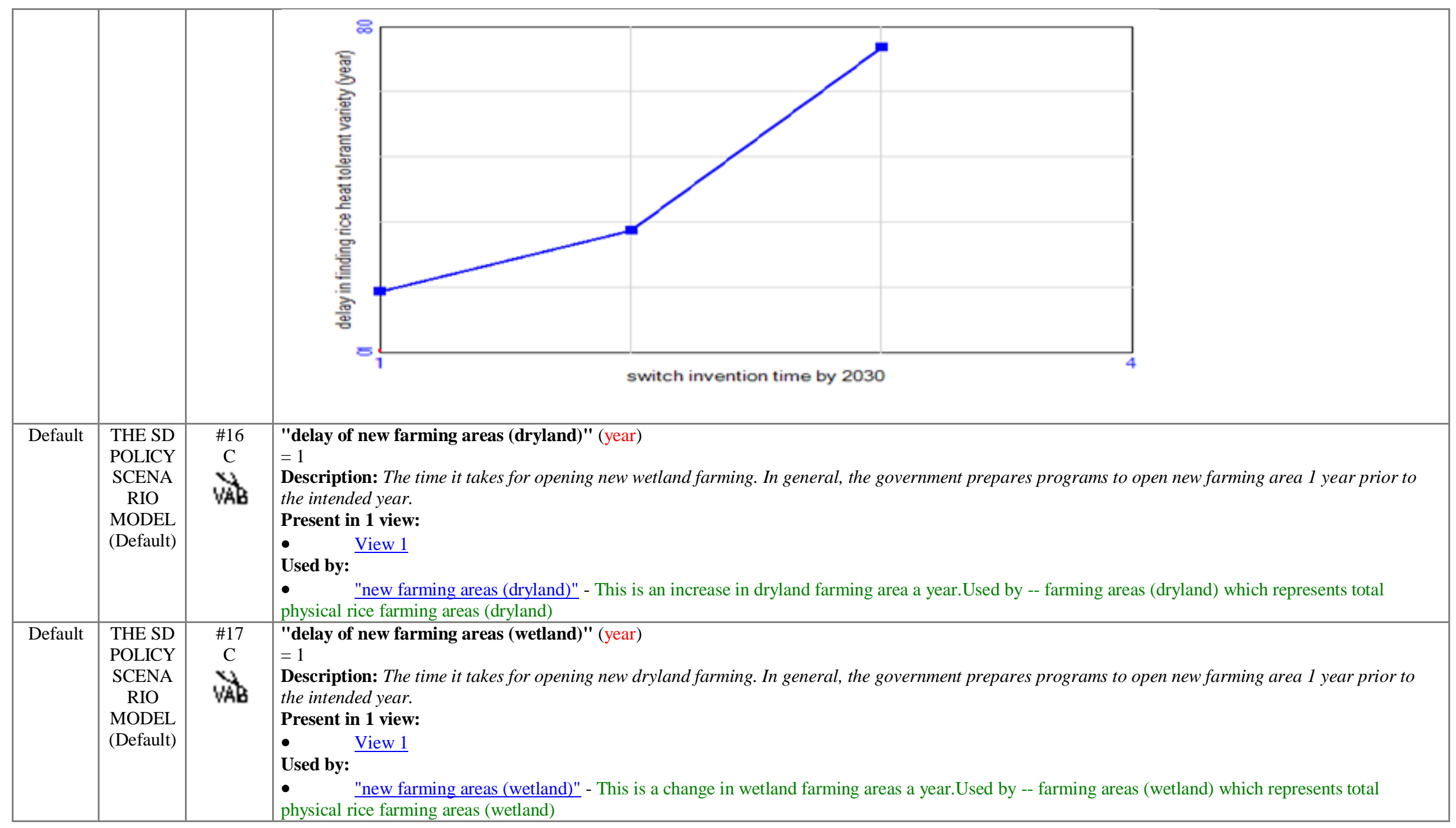




\begin{tabular}{|c|c|c|c|}
\hline Default & $\begin{array}{l}\text { THE SD } \\
\text { POLICY } \\
\text { SCENA } \\
\text { RIO } \\
\text { MODEL } \\
\text { (Default) }\end{array}$ & $\begin{array}{c}\# 18 \\
\mathrm{C} \\
\mathrm{W} \\
\mathrm{W}\end{array}$ & $\begin{array}{l}\text { delay of research on short growth duration varieties (year) } \\
=10 \\
\text { Description: a delay in finding rice variety with the indended growth duration } \\
\text { Present in } 1 \text { view: } \\
\text { - } \\
\text { Used by: } \\
\text { - } \\
\text { - }\end{array}$ \\
\hline Default & $\begin{array}{c}\text { THE SD } \\
\text { POLICY } \\
\text { SCENA } \\
\text { RIO } \\
\text { MODEL } \\
\text { (Default) }\end{array}$ & $\begin{array}{c}\# 19 \\
\mathrm{C} \\
\mathrm{WAB}\end{array}$ & $\begin{array}{l}\text { delay technological progress on rice (year) } \\
=7.5 \\
\text { Description: a delay in finding rice variety with the a higher technological progress } \\
\text { Present in } \mathbf{1} \text { view: } \\
\text { - } \\
\text { Used by: } \\
\text { - } \\
\text { - } \\
\quad \text { "techno progress rate (dryland)" - a change of technological progress of dryland rice variety } \\
\end{array}$ \\
\hline Default & $\begin{array}{c}\text { THE SD } \\
\text { POLICY } \\
\text { SCENA } \\
\text { RIO } \\
\text { MODEL } \\
\text { (Default) }\end{array}$ & $\begin{array}{c}\# 20 \\
\mathrm{C} \\
\mathrm{W} \\
\mathrm{WAB}\end{array}$ & $\begin{array}{l}\text { delay to apply expected cropping intensity (year) } \\
=1 \\
\text { Description: a delay in applying the expected cropping intensity } \\
\text { Present in } 1 \text { view: } \\
\text { - } \\
\text { Used by: } \\
\text { - } \quad \text { "projected cropping intensity (dryland)" - The actual cropping intensity of dryland rice } \\
\text { "projected cropping intensity (wetland)" - The actual cropping intensity of wetland rice }\end{array}$ \\
\hline Default & $\begin{array}{c}\text { THE SD } \\
\text { POLICY } \\
\text { SCENA } \\
\text { RIO } \\
\text { MODEL } \\
\text { (Default) }\end{array}$ & $\begin{array}{c}\# 21 \\
\mathrm{~A} \\
\mathrm{WAB}\end{array}$ & $\begin{array}{l}\text { "expected cropping intensity (dryland)" (Dmnl) } \\
=\text { "ratio between initial growth duration and actual growth duration (dryland)"*"initial cropping intensity (dryland)" } \\
\text { Description: The expected cropping intensity of dryland rice } \\
\text { Present in } 1 \text { view: } \\
\text { - View } 1 \\
\text { Used by: } \\
\quad \text { "projected cropping intensity (dryland)" - The actual cropping intensity of dryland rice }\end{array}$ \\
\hline Default & $\begin{array}{c}\text { THE SD } \\
\text { POLICY } \\
\text { SCENA } \\
\text { RIO } \\
\text { MODEL }\end{array}$ & $\begin{array}{c}\# 22 \\
\mathrm{~A} \\
\mathrm{VAB}\end{array}$ & $\begin{array}{l}\text { "expected cropping intensity (wetland)" (Dmnl) } \\
=(\text { (seasonal rainfall**aw cropping intensity+constant cropping intensity }) * " \text { ratio between initial growth duration and actual growth duration (wetland)" } \\
\text { Description: the expected cropping intensity } \\
\text { Present in } 1 \text { view: } \\
\quad \text { View } 1\end{array}$ \\
\hline
\end{tabular}




\begin{tabular}{|c|c|c|c|}
\hline & (Default) & & $\begin{array}{l}\text { Used by: } \\
\text { - } \quad \text { "projected cropping intensity (wetland)" - The actual cropping intensity of wetland rice }\end{array}$ \\
\hline Default & $\begin{array}{c}\text { THE SD } \\
\text { POLICY } \\
\text { SCENA } \\
\text { RIO } \\
\text { MODEL } \\
\text { (Default) }\end{array}$ & $\begin{array}{c}\# 23 \\
\mathrm{~A} \\
\mathrm{VAB}\end{array}$ & $\begin{array}{l}\text { "expected rice yield (dryland)" (tonnes/ha/year) } \\
=4.9+" \text { projected technological progress on rice (dryland)"* unit provity } \\
\text { Description: the expected rice yield in wetland farming. } \\
\text { Present in } \mathbf{1} \text { view: } \\
\bullet \quad \text { View } 1 \\
\text { Used by: } \\
\text { • } \\
2030 \quad \text { rice yield of heat tolerant variety (dryland)" - the yield of heat tolerant rice variety in dryland farming if heat tolerant rice varieties are found in }\end{array}$ \\
\hline Default & $\begin{array}{c}\text { THE SD } \\
\text { POLICY } \\
\text { SCENA } \\
\text { RIO } \\
\text { MODEL } \\
\text { (Default) }\end{array}$ & $\begin{array}{c}\# 24 \\
\mathrm{~A} \\
\mathrm{WAB}\end{array}$ & $\begin{array}{l}\text { "expected rice yield (wetland )" (tonnes/ha/year) } \\
=7.4+" \text { projected technological progress on rice (wetland)"*unit provity } \\
\text { Description: the expected rice yield in wetland farming. } \\
\text { Present in } \mathbf{1} \text { view: } \\
\bullet \quad \text { View } 1 \\
\text { Used by: } \\
\bullet \quad \text { "rice yield of heat tolerant variety (wetland)" - the yield of heat tolerant rice variety in wetland farming if heat tolerant rice varieties are found in } \\
2030 \quad \text { ing }\end{array}$ \\
\hline Default & $\begin{array}{c}\text { THE SD } \\
\text { POLICY } \\
\text { SCENA } \\
\text { RIO } \\
\text { MODEL } \\
\text { (Default) }\end{array}$ & $\begin{array}{c}\# 26 \\
A \\
\text { VAB }\end{array}$ & $\begin{array}{l}\text { "flow of growth duration of rice variety (dryland)" (Dmnl) } \\
=\text { IF THEN ELSE("projected growth duration of rice variety (dryland)" } \angle=(90 / 365), 0,(\text { "projected growth duration of rice variety (dryland)"-"intended } \\
\text { growth duration of rice variety (dryland)")/delay of research on short growth duration varieties) } \\
\text { Description: the change of the growth duration of rice variety (dryland) } \\
\text { Present in 1 view: } \\
\text { - } \\
\text { Used by: } \\
\text { - }\end{array}$ \\
\hline Default & $\begin{array}{c}\text { THE SD } \\
\text { POLICY } \\
\text { SCENA } \\
\text { RIO } \\
\text { MODEL } \\
\text { (Default) }\end{array}$ & $\begin{array}{c}\# 27 \\
\mathrm{~A} \\
\mathrm{VAB}\end{array}$ & $\begin{array}{l}\text { "flow of growth duration of rice variety (wetland)" (Dmnl) } \\
=\text { IF THEN ELSE("projected growth duration of rice variety (wetland)" }<=(90 / 365), 0,(\text { projected growth duration of rice variety (wetland)"-"intended } \\
\text { growth duration of rice variety (wetland)")/delay of research on short growth duration varieties) } \\
\text { Description: the change of the growth duration of rice variety (wetland) } \\
\text { Present in } 1 \text { view: } \\
\text { Used by: } \\
\text { View } 1 \\
\quad \text { "projected growth duration of rice variety (wetland)" - The actual growth duration of wetland rice variety. }\end{array}$ \\
\hline Default & $\begin{array}{l}\text { THE SD } \\
\text { POLICY } \\
\text { SCENA }\end{array}$ & $\begin{array}{c}\# 28 \\
\mathrm{~A}\end{array}$ & $\begin{array}{l}\text { fraction of technological progress on rice (Dmnl) } \\
=\text { IF THEN ELSE(switch technological progress on rice }=0,0,0.04) \\
\text { Description: } \text { a growth fraction of technological progress. }\end{array}$ \\
\hline
\end{tabular}




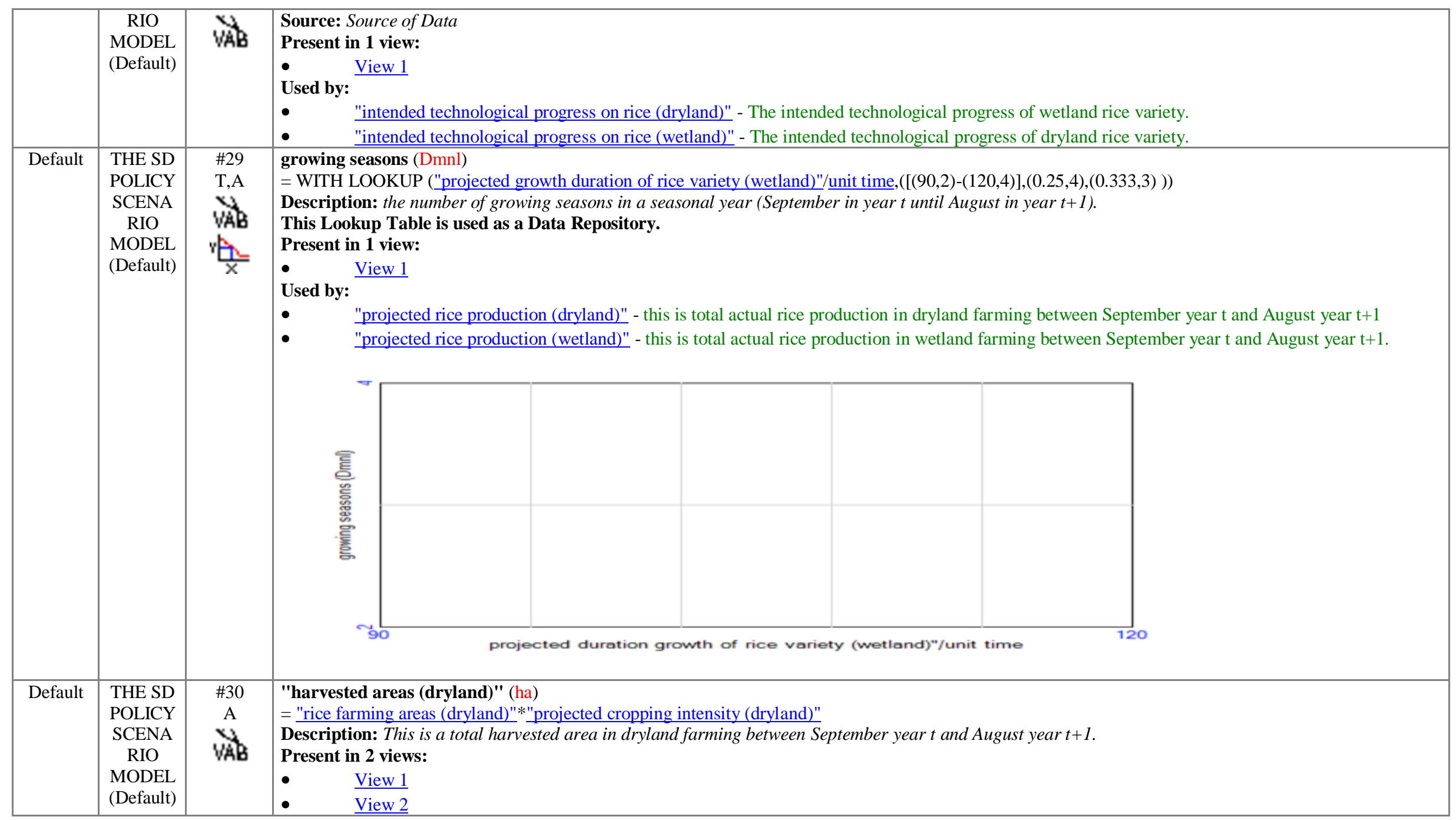




\begin{tabular}{|c|c|c|c|}
\hline & & & $\begin{array}{l}\text { Used by: } \\
\text { - } \quad \text { "potential rice production (dryland)" - this is total potential rice production in dryland farming between September year } t \text { and August year } t+1\end{array}$ \\
\hline Default & $\begin{array}{c}\text { THE SD } \\
\text { POLICY } \\
\text { SCENA } \\
\text { RIO } \\
\text { MODEL } \\
\text { (Default) }\end{array}$ & $\begin{array}{c}\# 31 \\
\mathrm{~A} \\
\mathrm{WAB}\end{array}$ & $\begin{array}{l}\text { "harvested areas (wetland)" (ha) } \\
=\text { "projected cropping intensity (wetland)"*"rice farming areas (wetland)" } \\
\text { Description: this is total harvested area in wetland farming between September year t and August year } t+1 \\
\text { Present in } 2 \text { views: } \\
\qquad \quad \underline{\text { View } 1} \\
\text { View } 2 \\
\text { Used by: } \\
\text { - }\end{array}$ \\
\hline Default & $\begin{array}{l}\text { THE SD } \\
\text { POLICY } \\
\text { SCENA } \\
\text { RIO } \\
\text { MODEL } \\
\text { (Default) }\end{array}$ & $\begin{array}{l}\# 32 \\
\text { LI,C } \\
\text { WAB }\end{array}$ & $\begin{array}{l}\text { initial available land (ha) } \\
\text { = } 600795 \\
\text { Description: total potential land to be converted into wetland and dryland farming. This land is secured by the law. } \\
\text { Source: Source of Data } \\
\text { Present in } \mathbf{1} \text { view: } \\
\text { - } \\
\text { Used by: } \\
\text { - } \quad \text { available land - Available land is potential land to be converted into wetland and dryland farming. This land is served to increase areas of wetland } \\
\text { and dryland farming. . }\end{array}$ \\
\hline Default & $\begin{array}{c}\text { THE SD } \\
\text { POLICY } \\
\text { SCENA } \\
\text { RIO } \\
\text { MODEL } \\
\text { (Default) }\end{array}$ & $\begin{array}{c}\# 33 \\
\mathrm{C} \\
\mathrm{WAB}\end{array}$ & $\begin{array}{l}\text { "initial cropping intensity (dryland)" (Dmnl) } \\
=1 \\
\text { Description: The initial cropping intensity of dryland rice } \\
\text { Present in } 1 \text { view: } \\
\text { - } \\
\text { Used by: } \\
\text { - } \\
\text { - } \\
\quad \text { "expected cropping intensity (dryland)" - The expected cropping intensity of dryland rice } \\
\text { "proping intensity (dryland)" - The actual cropping intensity of dryland rice }\end{array}$ \\
\hline Default & $\begin{array}{l}\text { THE SD } \\
\text { POLICY } \\
\text { SCENA } \\
\text { RIO } \\
\text { MODEL } \\
\text { (Default) }\end{array}$ & $\begin{array}{c}\# 34 \\
\mathrm{~A} \\
\mathrm{WAB}\end{array}$ & $\begin{array}{l}\text { "initial growth duration of rice variety (dryland)" (year) } \\
\text { =(110/365) } \\
\text { Description: The initial growth duration of dryland rice variety. The growth duration of rice variety is about } 110 \text { days which is converted into (110/365) } \\
\text { years. } \\
\text { Source: Source of Data } \\
\text { Present in } 1 \text { view: } \\
\text { • View } 1 \\
\text { Used by: } \\
\text { "projected growth duration of rice variety (dryland)" - The actual growth duration of dryland rice variety. }\end{array}$ \\
\hline
\end{tabular}




\begin{tabular}{|c|c|c|c|}
\hline & & & $\begin{array}{l}\text { - } \\
\text { dryland rice variety }\end{array}$ \\
\hline Default & $\begin{array}{c}\text { THE SD } \\
\text { POLICY } \\
\text { SCENA } \\
\text { RIO } \\
\text { MODEL } \\
\text { (Default) }\end{array}$ & $\begin{array}{c}\# 35 \\
\mathrm{~A} \\
\mathrm{VAB}\end{array}$ & $\begin{array}{l}\text { "initial growth duration of rice variety (wetland)" (year) } \\
=(115 / 365) \\
\text { Description: The initial growth duration of wetland rice variety. The growth duration of rice variety is about } 115 \text { days which is converted into (115/365) } \\
\text { years. } \\
\text { Source: Source of Data } \\
\text { Present in } 1 \text { view: } \\
\text { - View } 1 \\
\text { Used by: } \\
\text { "projected growth duration of rice variety (wetland)" - The actual growth duration of wetland rice variety. } \\
\text { - } \quad \text { "ratio between initial growth duration and actual growth duration (wetland)" - the ratio between the initial and the actual growth duration of } \\
\text { wetland rice variety }\end{array}$ \\
\hline Default & $\begin{array}{c}\text { THE SD } \\
\text { POLICY } \\
\text { SCENA } \\
\text { RIO } \\
\text { MODEL } \\
\text { (Default) }\end{array}$ & $\begin{array}{c}\# 36 \\
I \\
\text { WAB }\end{array}$ & $\begin{array}{l}\text { "initial rice farming areas (dryland)" (ha) } \\
\text { = INITIAL(47496.2) } \\
\text { Description: initial rice dryland areas. } \\
\text { Source: Source of Data } \\
\text { Present in } 1 \text { view: } \\
\text { Uiew } 1 \\
\text { Used by: } \\
\text { - }\end{array}$ \\
\hline Default & $\begin{array}{c}\text { THE SD } \\
\text { POLICY } \\
\text { SCENA } \\
\text { RIO } \\
\text { MODEL } \\
\text { (Default) }\end{array}$ & $\begin{array}{c}\# 37 \\
\text { I } \\
\text { WAB }\end{array}$ & $\begin{array}{l}\text { "initial rice farming areas (wetland)" (ha) } \\
\text { = INITIAL(240180) } \\
\text { Description: initial rice wetland areas. } \\
\text { Source: Source of Data } \\
\text { Present in } 1 \text { view: } \\
\text { View } 1 \\
\text { Used by: } \\
\text { "rice farming areas (wetland)" - rice farming area is total physical land of wetland farming. The initial value in } 2011 \text { is about } 240,000 \text { ha. }\end{array}$ \\
\hline Default & $\begin{array}{c}\text { THE SD } \\
\text { POLICY } \\
\text { SCENA } \\
\text { RIO } \\
\text { MODEL } \\
\text { (Default) }\end{array}$ & $\begin{array}{c}\# 38 \\
\mathrm{C} \\
\mathrm{VAB}\end{array}$ & $\begin{array}{l}\text { "initial technological progress on rice (dryland)" (Dmnl) } \\
=1.52 \\
\text { Description: The initial technological progress of dryland rice variety. } \\
\text { Present in } 1 \text { view: } \\
\bullet \quad \text { View } 1 \\
\text { Used by: } \\
\text { "projected technological progress on rice (dryland)" - The actual technological progress of dryland rice variety. }\end{array}$ \\
\hline Default & THE SD & \#39 & initial technological progress on rice wetland (Dmnl) \\
\hline
\end{tabular}




\begin{tabular}{|c|c|c|c|}
\hline & $\begin{array}{l}\text { POLICY } \\
\text { SCENA } \\
\text { RIO } \\
\text { MODEL } \\
\text { (Default) }\end{array}$ & $\begin{array}{l}\text { LI,C } \\
\text { WAB }\end{array}$ & $\begin{array}{l}=2.46 \\
\text { Description: The initial technological progress of wetland rice variety. } \\
\text { Present in } \mathbf{1} \text { view: } \\
\text { - } \\
\text { Used by: } \\
\text { - }\end{array}$ \\
\hline Default & $\begin{array}{l}\text { THE SD } \\
\text { POLICY } \\
\text { SCENA } \\
\text { RIO } \\
\text { MODEL } \\
\text { (Default) }\end{array}$ & $\begin{array}{c}\# 41 \\
\mathrm{C} \\
\mathrm{WAB}\end{array}$ & $\begin{array}{l}\text { initial yield of heat tolerant rice variety (tonnes/ha/year) } \\
\text { = } 2 \\
\text { Description: the initial rice yield in wetland and dryland farming. It is assumed that yield of heat tolerant rice variety (wetland and dryland) is same. } \\
\text { Present in } 1 \text { view: } \\
\text { - } \\
\text { Used by: } \\
\text { View } 1 \\
\text { "rice yield of heat tolerant variety (dryland)" - the yield of heat tolerant rice variety in dryland farming if heat tolerant rice varieties are found in } \\
\text { - } \\
2030 \quad \text { "rice yield of heat tolerant variety (wetland)" - the yield of heat tolerant rice variety in wetland farming if heat tolerant rice varieties are found in }\end{array}$ \\
\hline Default & $\begin{array}{l}\text { THE SD } \\
\text { POLICY } \\
\text { SCENA } \\
\text { RIO } \\
\text { MODEL } \\
\text { (Default) }\end{array}$ & $\begin{array}{c}\# 42 \\
\mathrm{~A} \\
\mathrm{VAB}\end{array}$ & $\begin{array}{l}\text { "intended growth duration of rice variety (dryland)" (year) } \\
=\text { "projected growth duration of rice variety (dryland)"-IF THEN ELSE(switch of shorter growth duration variety=0, 0, (5/365) ) } \\
\text { Description: The intended growth duration of dryland rice variety. } \\
\text { Source: Source of Data } \\
\text { Present in } 1 \text { view: } \\
\text { View } 1 \\
\text { Used by: } \\
\quad \text { "flow of growth duration of rice variety (dryland)" - the change of the growth duration of rice variety (dryland) }\end{array}$ \\
\hline Default & $\begin{array}{l}\text { THE SD } \\
\text { POLICY } \\
\text { SCENA } \\
\text { RIO } \\
\text { MODEL } \\
\text { (Default) }\end{array}$ & $\begin{array}{c}\# 43 \\
\mathrm{~A} \\
\mathrm{WAB}\end{array}$ & $\begin{array}{l}\text { "intended growth duration of rice variety (wetland)" (year) } \\
\text { = "projected growth duration of rice variety (wetland)"-IF THEN ELSE( switch of shorter growth duration variety=0,0, } 0,3 / 365) \text { ) } \\
\text { Description: The intended growth duration of wetland rice variety. } \\
\text { Source: Source of Data } \\
\text { Present in } 1 \text { view: } \\
\text { View } 1 \\
\text { Used by: } \\
\text { "flow of growth duration of rice variety (wetland)" - the change of the growth duration of rice variety (wetland) }\end{array}$ \\
\hline Default & $\begin{array}{l}\text { THE SD } \\
\text { POLICY } \\
\text { SCENA } \\
\text { RIO } \\
\text { MODEL }\end{array}$ & $\begin{array}{c}\# 44 \\
\mathrm{~A} \\
\mathrm{VAB}\end{array}$ & $\begin{array}{l}\text { "intended technological progress on rice (dryland)" (Dmnl) } \\
=\text { "projected technological progress on rice (dryland)"* }(1+\text { fraction of technological progress on rice }) \\
\text { Description: The intended technological progress of wetland rice variety. } \\
\text { Present in } 1 \text { view: } \\
\quad \text { View } 1\end{array}$ \\
\hline
\end{tabular}




\begin{tabular}{|c|c|c|c|}
\hline & (Default) & & $\begin{array}{l}\text { Used by: } \\
\text { - } \quad \text { "techno progress rate (dryland)" - a change of technological progress of dryland rice variety }\end{array}$ \\
\hline Default & $\begin{array}{c}\text { THE SD } \\
\text { POLICY } \\
\text { SCENA } \\
\text { RIO } \\
\text { MODEL } \\
\text { (Default) }\end{array}$ & $\begin{array}{c}\# 45 \\
\mathrm{~A} \\
\mathrm{VAB}\end{array}$ & $\begin{array}{l}\text { "intended technological progress on rice (wetland)" (Dmnl) } \\
=\text { "projected technological progress on rice (wetland)"*(1+fraction of technological progress on rice) } \\
\text { Description: The intended technological progress of dryland rice variety. } \\
\text { Present in } 1 \text { view: } \\
\text { - View } 1 \\
\text { Used by: } \\
\text { - }\end{array}$ \\
\hline Default & $\begin{array}{c}\text { THE SD } \\
\text { POLICY } \\
\text { SCENA } \\
\text { RIO } \\
\text { MODEL } \\
\text { (Default) }\end{array}$ & $\begin{array}{c}\# 46 \\
\mathrm{~A} \\
\mathrm{WAB}\end{array}$ & $\begin{array}{l}\text { "labour (wetland)" (IDR/year) } \\
=\text { "table labour (wetland)"(Time/unit time) } \\
\text { Description: a used labour value for a given year during simulation } \\
\text { Present in } 1 \text { view: } \\
\text { • View } 1 \\
\text { Used by: } \\
\text { - } \quad \text { rice yield (wetland)" - this is total rice yield in wetland farming between between September } t \text { and August year } t+1 .\end{array}$ \\
\hline Default & $\begin{array}{c}\text { THE SD } \\
\text { POLICY } \\
\text { SCENA } \\
\text { RIO } \\
\text { MODEL } \\
\text { (Default) }\end{array}$ & $\begin{array}{c}\# 47 \\
\mathrm{~A} \\
\mathrm{WAB}\end{array}$ & $\begin{array}{l}\text { "new farming areas (dryland)" (ha/year) } \\
=\text { MIN((DELAY1("a fraction new farming areas (dryland)"*"rice farming areas (dryland)","delay of new farming areas (dryland)")), available land/TIME } \\
\text { STEP) } \\
\text { Description: This is an increase in dryland farming area a year.Used by -- farming areas (dryland) which represents total physical rice farming areas } \\
\text { (dryland) } \\
\text { Present in } 1 \text { view: } \\
\text { - View } 1 \\
\text { Used by: } \\
\text { a available land - Available land is potential land to be converted into wetland and dryland farming. This land is served to increase areas of wetland } \\
\text { and dryland farming. . } \\
\text { - } \quad \text { "rice farming areas (dryland)" - rice farming area is total physical land of wetland farming. The initial value in } 2011 \text { is about } 47,496 \text { ha. }\end{array}$ \\
\hline Default & $\begin{array}{c}\text { THE SD } \\
\text { POLICY } \\
\text { SCENA } \\
\text { RIO } \\
\text { MODEL } \\
\text { (Default) }\end{array}$ & $\begin{array}{c}\# 48 \\
\mathrm{~A} \\
\mathrm{VAB}\end{array}$ & $\begin{array}{l}\text { "new farming areas (wetland)" (ha/year) } \\
\text { = MIN((DELAY1("a fraction of new farming areas (wetland)"*"rice farming areas (wetland)", "delay of new farming areas (wetland)")), available } \\
\text { land/TIME STEP) } \\
\text { Description: This is a change in wetland farming areas a year. Used by -- farming areas (wetland) which represents total physical rice farming areas } \\
\text { (wetland) } \\
\text { Present in } 1 \text { view: } \\
\text { View } 1 \\
\text { Used by: } \\
\text { and dryland farming. . }\end{array}$ \\
\hline
\end{tabular}




\begin{tabular}{|c|c|c|c|}
\hline & & & - $\quad$ "rice farming areas (wetland)" - rice farming area is total physical land of wetland farming. The initial value in 2011 is about 240,000 ha. \\
\hline Default & $\begin{array}{c}\text { THE SD } \\
\text { POLICY } \\
\text { SCENA } \\
\text { RIO } \\
\text { MODEL } \\
\text { (Default) }\end{array}$ & $\begin{array}{c}\# 49 \\
\mathrm{~A} \\
\mathrm{~V} \\
\mathrm{~V} \text { B }\end{array}$ & $\begin{array}{l}\text { "potential rice production (dryland)" (tonnes/year) } \\
=\text { "rice yield (dryland)"*"harvested areas (dryland)" } \\
\text { Description: this is total potential rice production in dryland farming between September year t and August year } t+1 \\
\text { Present in } 1 \text { view: } \\
\text { • } \\
\text { Used by: } \\
\text { - } \quad \text { "projected rice production (dryland)" - this is total actual rice production in dryland farming between September year } \mathrm{t} \text { and August year } \mathrm{t}+1\end{array}$ \\
\hline Default & $\begin{array}{c}\text { THE SD } \\
\text { POLICY } \\
\text { SCENA } \\
\text { RIO } \\
\text { MODEL } \\
\text { (Default) }\end{array}$ & $\begin{array}{c}\# 50 \\
A \\
\text { VAB }\end{array}$ & $\begin{array}{l}\text { "potential rice production (wetland)" (tonnes/year) } \\
=\text { "harvested areas (wetland)"*"rice yield (wetland)" } \\
\text { Description: this is total potential rice production in wetland farming between September year t and August year } t+1 . \\
\text { Present in } \mathbf{1} \text { view: } \\
\bullet \quad \text { View } 1 \\
\text { Used by: } \\
\text { - } \quad \text { "projected rice production (wetland)" - this is total actual rice production in wetland farming between September year } \mathrm{t} \text { and August year } \mathrm{t}+1 \text {. }\end{array}$ \\
\hline Default & $\begin{array}{c}\text { THE SD } \\
\text { POLICY } \\
\text { SCENA } \\
\text { RIO } \\
\text { MODEL } \\
\text { (Default) }\end{array}$ & $\begin{array}{c}\# 51 \\
\text { DE }\end{array}$ & $\begin{array}{l}\text { "projected cropping intensity (dryland)" (Dmnl) } \\
=\text { DELAY3I("expected cropping intensity (dryland)", delay to apply expected cropping intensity,"initial cropping intensity (dryland)") } \\
\text { Description: The actual cropping intensity of dryland rice } \\
\text { Present in } 2 \text { views: } \\
\text { - } \\
\qquad \quad \underline{\text { View } 1} \\
\text { Used by: } \\
\text { - } \\
\text { "harvested areas (dryland)" - This is a total harvested area in dryland farming between September year } t \text { and August year } t+1 .\end{array}$ \\
\hline Default & $\begin{array}{l}\text { THE SD } \\
\text { POLICY } \\
\text { SCENA } \\
\text { RIO } \\
\text { MODEL } \\
\text { (Default) }\end{array}$ & $\begin{array}{l}\# 52 \\
\text { DE }\end{array}$ & $\begin{array}{l}\text { "projected cropping intensity (wetland)" (Dmnl) } \\
\text { = DELAY3("expected cropping intensity (wetland)", delay to apply expected cropping intensity) } \\
\text { Description: The actual cropping intensity of wetland rice } \\
\text { Present in } 1 \text { view: } \\
\text { - } \\
\text { Used by: } \\
\text { - } \quad \text { "harvested areas (wetland)" - this is total harvested area in wetland farming between September year } \mathrm{t} \text { and August year } \mathrm{t}+1\end{array}$ \\
\hline Default & $\begin{array}{c}\text { THE SD } \\
\text { POLICY } \\
\text { SCENA } \\
\text { RIO } \\
\text { MODEL } \\
\text { (Default) }\end{array}$ & $\begin{array}{c}\# 53 \\
\mathrm{~L} \\
\text { 解 }\end{array}$ & $\begin{array}{l}\text { "projected growth duration of rice variety (dryland)" (year) } \\
=\int-" \text { flow of growth duration of rice variety (dryland)" } d t+[\text { [initial growth duration of rice variety (dryland)"] } \\
\text { Description: The actual growth duration of dryland rice variety. } \\
\text { Present in } 2 \text { views: } \\
\qquad \quad \underline{\text { View } 1} \\
\quad \text { View } 2\end{array}$ \\
\hline
\end{tabular}




\begin{tabular}{|c|c|c|c|}
\hline & & & $\begin{array}{l}\text { Used by: } \\
\text { - } \\
\text { - } \quad \frac{\text { "flow of growth duration of rice variety (dryland)" - the change of the growth duration of rice variety (dryland) }}{\text { "intended growth duration of rice variety (dryland)" - The intended growth duration of dryland rice variety. }} \\
\text { - } \quad \frac{\text { "projected growth duration of rice variety in days (dryland)." }}{\text { "ratio between initial growth duration and actual growth duration (dryland)" - the ratio between the initial and the actual growth duration of }} \\
\text { dryland rice variety }\end{array}$ \\
\hline Default & $\begin{array}{c}\text { THE SD } \\
\text { POLICY } \\
\text { SCENA } \\
\text { RIO } \\
\text { MODEL } \\
\text { (Default) }\end{array}$ & $\begin{array}{c}\# 55 \\
\mathrm{~L} \\
\text { 崩 }\end{array}$ & 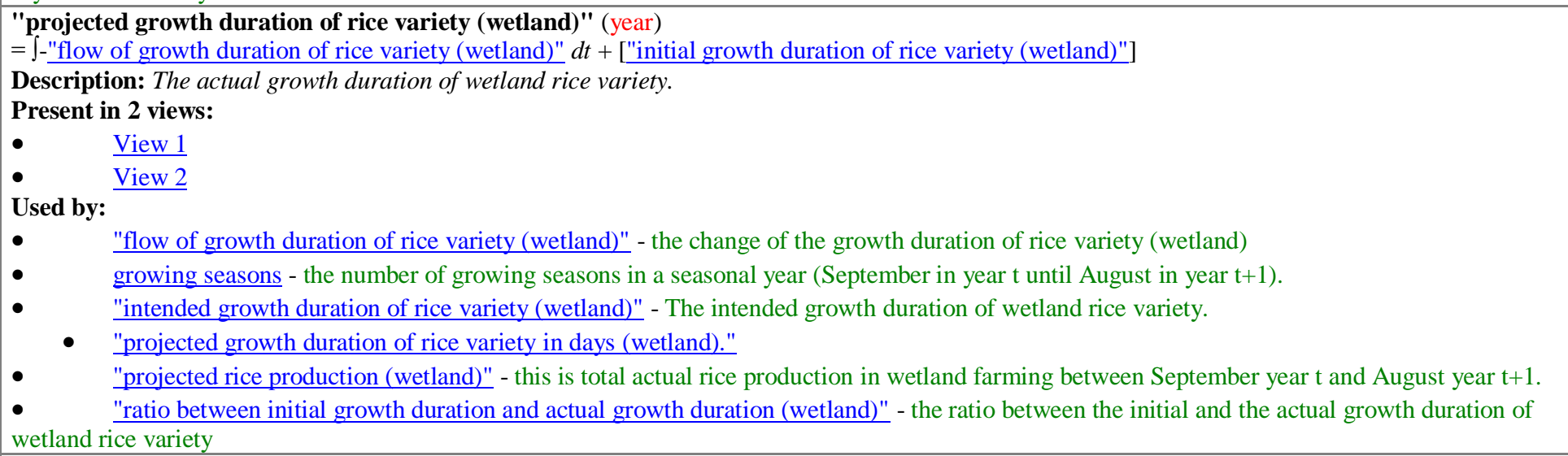 \\
\hline Default & $\begin{array}{c}\text { THE SD } \\
\text { POLICY } \\
\text { SCENA } \\
\text { RIO } \\
\text { MODEL } \\
\text { (Default) }\end{array}$ & $\begin{array}{l}\# 57 \\
\text { DE }\end{array}$ & $\begin{array}{l}\text { "projected rice production (dryland)" (tonnes/year) } \\
=\text { DELAY3(STEP("potential rice production (dryland)","timing of monsoon-onset (years)"), growing seasons * "projected growth duration of rice variety } \\
\text { (dryland)") } \\
\text { Description: this is total actual rice production in dryland farming between September year t and August year } t+1 \\
\text { Present in } 2 \text { views: } \\
\qquad \quad \underline{\text { View } 1} \\
\text { View } 2 \\
\text { Used by: } \\
\quad \text { total rice production - a sum of rice production in wetland and dryland areas }\end{array}$ \\
\hline Default & $\begin{array}{c}\text { THE SD } \\
\text { POLICY } \\
\text { SCENA } \\
\text { RIO } \\
\text { MODEL } \\
\text { (Default) }\end{array}$ & $\begin{array}{l}\# 58 \\
\text { DE }\end{array}$ & $\begin{array}{l}\text { "projected rice production (wetland)" (tonnes/year) } \\
=\text { DELAY3(STEP("potential rice production (wetland)","timing of monsoon-onset (years)"), growing seasons*"projected growth duration of rice variety } \\
\text { (wetland)") } \\
\text { Description: this is total actual rice production in wetland farming between September year t and August year } t+1 . \\
\text { Present in } 2 \text { views: } \\
\quad \text { View } 1\end{array}$ \\
\hline
\end{tabular}




\begin{tabular}{|c|c|c|c|}
\hline & & & $\begin{array}{l}- \text { Used by: } \\
\text { - } \quad \text { total rice production }- \text { a sum of rice production in wetland and dryland areas }\end{array}$ \\
\hline Default & $\begin{array}{l}\text { THE SD } \\
\text { POLICY } \\
\text { SCENA } \\
\text { RIO } \\
\text { MODEL } \\
\text { (Default) }\end{array}$ & 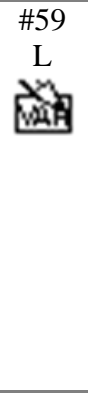 & 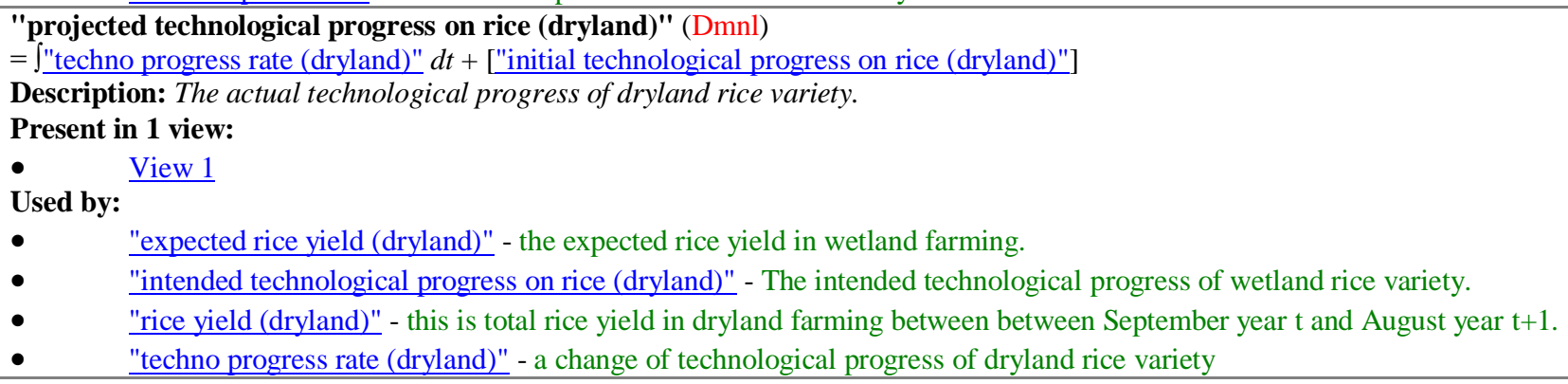 \\
\hline Default & $\begin{array}{l}\text { THE SD } \\
\text { POLICY } \\
\text { SCENA } \\
\text { RIO } \\
\text { MODEL } \\
\text { (Default) }\end{array}$ & $\begin{array}{l}\text { \#60 } \\
\mathrm{L} \\
\mathrm{M}\end{array}$ & 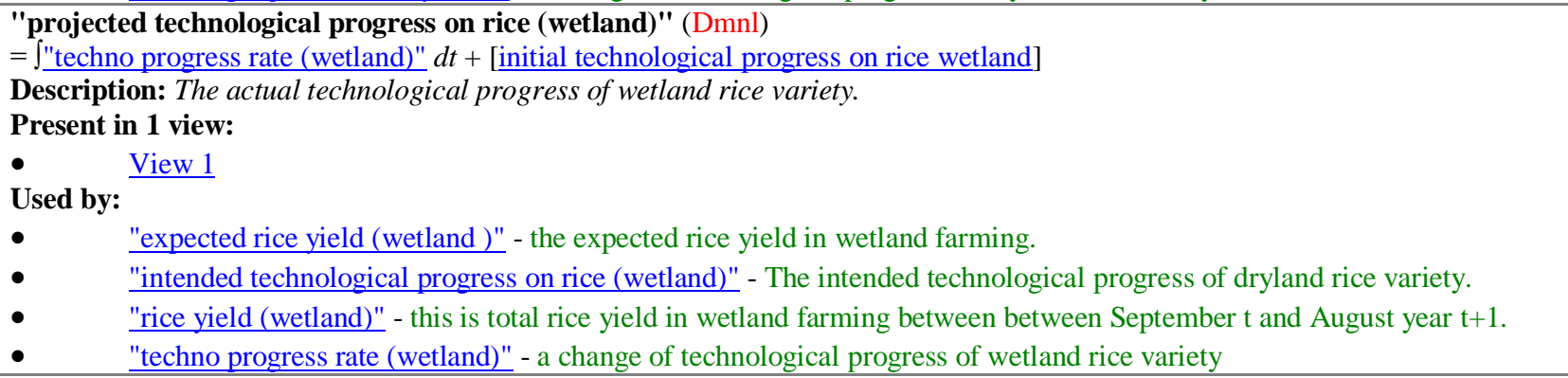 \\
\hline Default & $\begin{array}{l}\text { THE SD } \\
\text { POLICY } \\
\text { SCENA } \\
\text { RIO } \\
\text { MODEL } \\
\text { (Default) }\end{array}$ & $\begin{array}{c}\# 61 \\
\text { A } \\
\text { Varb }\end{array}$ & $\begin{array}{l}\text { "ratio between initial growth duration and actual growth duration (dryland)" (Dmnl) } \\
=\text { "initial growth duration of rice variety (dryland)"/"projected growth duration of rice variety (dryland)" } \\
\text { Description: the ratio between the initial and the actual growth duration of dryland rice variety } \\
\text { Present in } \mathbf{1} \text { view: } \\
\bullet \quad \text { View } 1 \\
\text { Used by: } \\
\text { - } \quad \text { "expected cropping intensity (dryland)" - The expected cropping intensity of dryland rice }\end{array}$ \\
\hline Default & $\begin{array}{l}\text { THE SD } \\
\text { POLICY } \\
\text { SCENA } \\
\text { RIO } \\
\text { MODEL } \\
\text { (Default) }\end{array}$ & $\begin{array}{c}\# 62 \\
A \\
\text { Wab }\end{array}$ & $\begin{array}{l}\text { "ratio between initial growth duration and actual growth duration (wetland)" (Dmnl) } \\
=\text { "initial growth duration of rice variety (wetland)"/"projected growth duration of rice variety (wetland)" } \\
\text { Description: the ratio between the initial and the actual growth duration of wetland rice variety } \\
\text { Present in } 1 \text { view: } \\
\text { - } \\
\text { Used by: }\end{array}$ \\
\hline
\end{tabular}




\begin{tabular}{|c|c|c|c|}
\hline & & & - $\quad$ "expected cropping intensity (wetland)" - the expected cropping intensity \\
\hline Default & $\begin{array}{c}\text { THE SD } \\
\text { POLICY } \\
\text { SCENA } \\
\text { RIO } \\
\text { MODEL } \\
\text { (Default) }\end{array}$ & $\begin{array}{c}\# 63 \\
\mathrm{~L} \\
\mathrm{~m} \\
\mathrm{M}\end{array}$ & $\begin{array}{l}\text { "rice farming areas (dryland)" (ha) } \\
=\int " \text { new farming areas (dryland)" } d t+[\text { [initial rice farming areas (dryland)"] } \\
\text { Description: rice farming area is total physical land of wetland farming.The initial value in } 2011 \text { is about 47,496 ha. } \\
\text { Present in } 1 \text { view: } \\
\text { - } \\
\text { Used by: } \\
\text { View } 1 \\
\text { - } \\
\text { physical rice farming areas (dryland) }\end{array}$ \\
\hline Default & $\begin{array}{l}\text { THE SD } \\
\text { POLICY } \\
\text { SCENA } \\
\text { RIO } \\
\text { MODEL } \\
\text { (Default) }\end{array}$ & $\begin{array}{c}\# 64 \\
\mathrm{~L} \\
\text { 出为 }\end{array}$ & $\begin{array}{l}\text { "rice farming areas (wetland)" (ha) } \\
=\int " \text { new farming areas (wetland)" } d t+[\text { "initial rice farming areas (wetland)"] } \\
\text { Description: rice farming area is total physical land of wetland farming.The initial value in } 2011 \text { is about 240,000 ha. } \\
\text { Present in } 1 \text { view: } \\
\text { - } \\
\text { Used by: } \\
\text { View } 1 \\
\text { - } \\
\text { physical rice farming areas (wetland) }\end{array}$ \\
\hline Default & $\begin{array}{c}\text { THE SD } \\
\text { POLICY } \\
\text { SCENA } \\
\text { RIO } \\
\text { MODEL } \\
\text { (Default) }\end{array}$ & $\begin{array}{c}\# 65 \\
A \\
\times A B\end{array}$ & 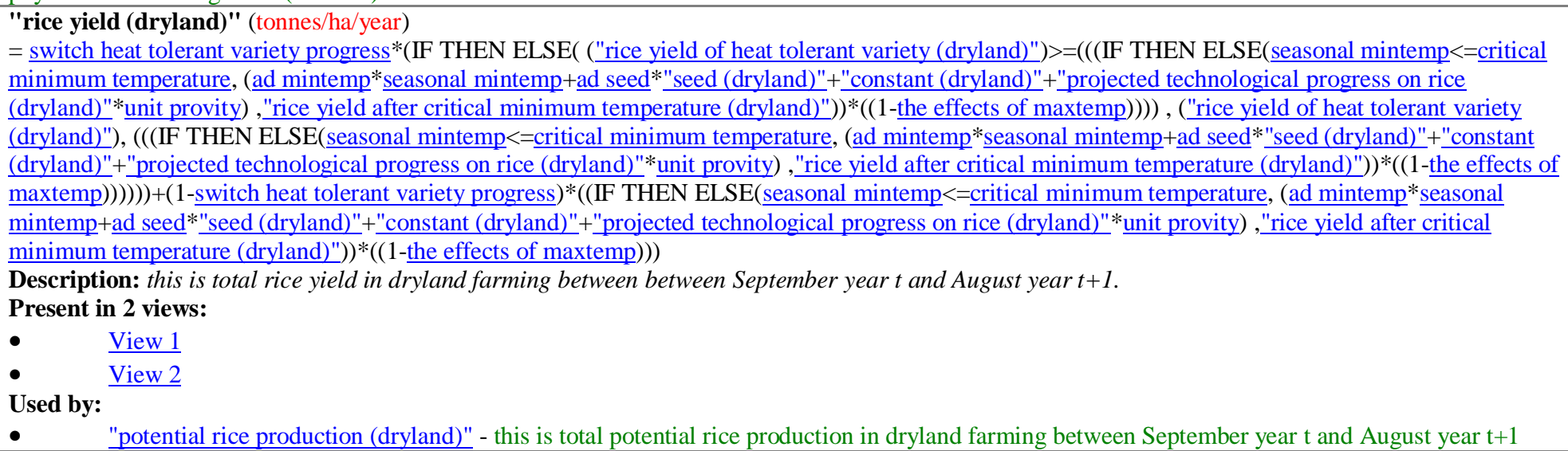 \\
\hline Default & $\begin{array}{l}\text { THE SD } \\
\text { POLICY } \\
\text { SCENA }\end{array}$ & $\begin{array}{c}\# 66 \\
\text { A }\end{array}$ & $\begin{array}{l}\text { "rice yield (wetland)" (tonnes/ha/year) } \\
=\text { switch heat tolerant variety progress* (IF THEN ELSE( ("rice yield of heat tolerant variety (wetland)")>=(((IF THEN ELSE(seasonal mintemp }<=\text { critical } \\
\text { minimum temperature, (aw labour*"labour (wetland)"+aw seasonal mintemp*seasonal mintemp+"constant (wetland)"+"projected technological progress on }\end{array}$ \\
\hline
\end{tabular}




\begin{tabular}{|c|c|c|c|}
\hline & $\begin{array}{c}\text { RIO } \\
\text { MODEL } \\
\text { (Default) }\end{array}$ & WAB & 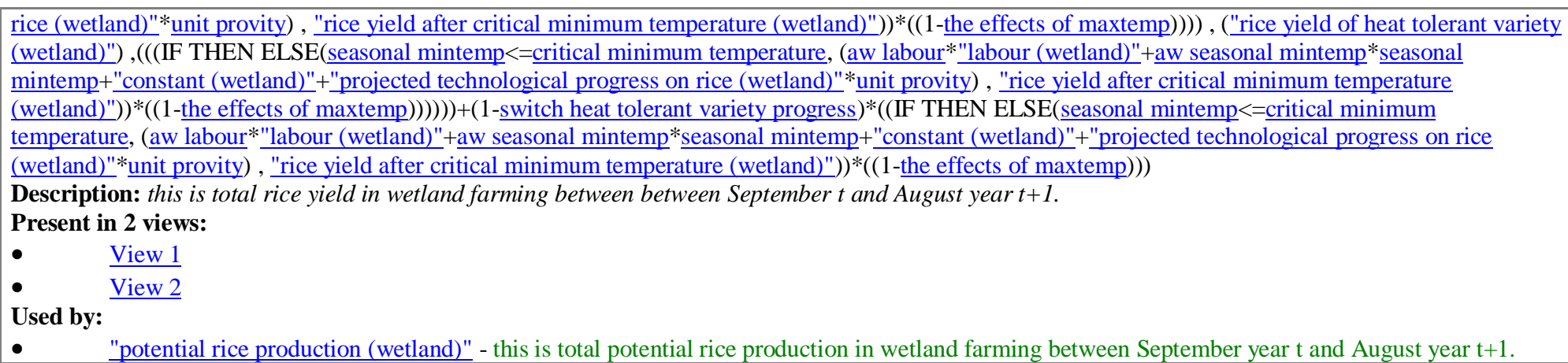 \\
\hline Default & $\begin{array}{c}\text { THE SD } \\
\text { POLICY } \\
\text { SCENA } \\
\text { RIO } \\
\text { MODEL } \\
\text { (Default) }\end{array}$ & $\begin{array}{c}\# 67 \\
A \\
\times A B\end{array}$ & 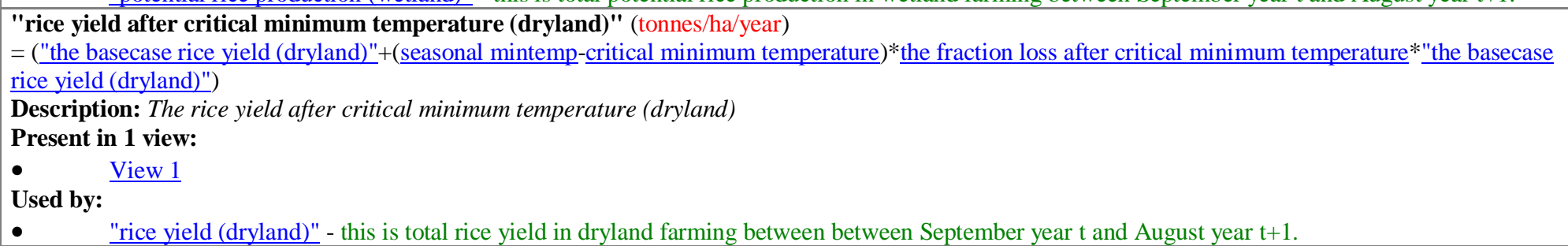 \\
\hline Default & $\begin{array}{c}\text { THE SD } \\
\text { POLICY } \\
\text { SCENA } \\
\text { RIO } \\
\text { MODEL } \\
\text { (Default) }\end{array}$ & $\begin{array}{c}\# 68 \\
\mathrm{~A} \\
\mathrm{WAB}\end{array}$ & $\begin{array}{l}\text { "rice yield after critical minimum temperature (wetland)" (tonnes/year/ha) } \\
=(\text { "the basecase rice yield (wetland)" }+ \text { (seasonal mintemp-critical minimum temperature })^{*} \text { the fraction loss after critical minimum temperature } * \text { "the basecase } \\
\text { rice yield (wetland)") } \\
\text { Description: The rice yield after critical minimum temperature (wetland) } \\
\text { Present in 1 view: } \\
\text { - View } 1 \\
\text { Used by: } \\
\text { - }\end{array}$ \\
\hline Default & $\begin{array}{c}\text { THE SD } \\
\text { POLICY } \\
\text { SCENA } \\
\text { RIO } \\
\text { MODEL } \\
\text { (Default) }\end{array}$ & $\begin{array}{l}\# 69 \\
\mathrm{DE}\end{array}$ & $\begin{array}{l}\text { "rice yield of heat tolerant variety (dryland)" (tonnes/ha/year) } \\
\text { = DELAY3I("expected rice yield (dryland)", delay in finding rice heat tolerant variety, initial yield of heat tolerant rice variety) } \\
\text { Description: the yield of heat tolerant rice variety in dryland farming if heat tolerant rice varieties are found in } 2030 \\
\text { Present in } 1 \text { view: } \\
\text { • } \\
\text { Used by: } \\
\text { - } \quad \text { "rice yield (dryland)" - this is total rice yield in dryland farming between between September year t and August year } t+1 .\end{array}$ \\
\hline Default & $\begin{array}{l}\text { THE SD } \\
\text { POLICY }\end{array}$ & $\begin{array}{l}\# 70 \\
\mathrm{DE}\end{array}$ & $\begin{array}{l}\text { t tolerant variety (wetland)" (tonnes/ha/year) } \\
\text { ected rice yield (wetland )", delay in finding rice heat tolerant variety, initial yield of heat tolerant rice variety) }\end{array}$ \\
\hline
\end{tabular}




\begin{tabular}{|c|c|c|c|}
\hline & $\begin{array}{c}\text { SCENA } \\
\text { RIO } \\
\text { MODEL } \\
\text { (Default) }\end{array}$ & & $\begin{array}{l}\text { Description: the yield of heat tolerant rice variety in wetland farming if heat tolerant rice varieties are found in } 2030 \\
\text { Present in } 1 \text { view: } \\
\text { - } \\
\text { Used by: } \\
\text { - }\end{array}$ \\
\hline Default & $\begin{array}{l}\text { THE SD } \\
\text { POLICY } \\
\text { SCENA } \\
\text { RIO } \\
\text { MODEL } \\
\text { (Default) }\end{array}$ & $\begin{array}{c}\# 72 \\
A \\
\text { VAB }\end{array}$ & 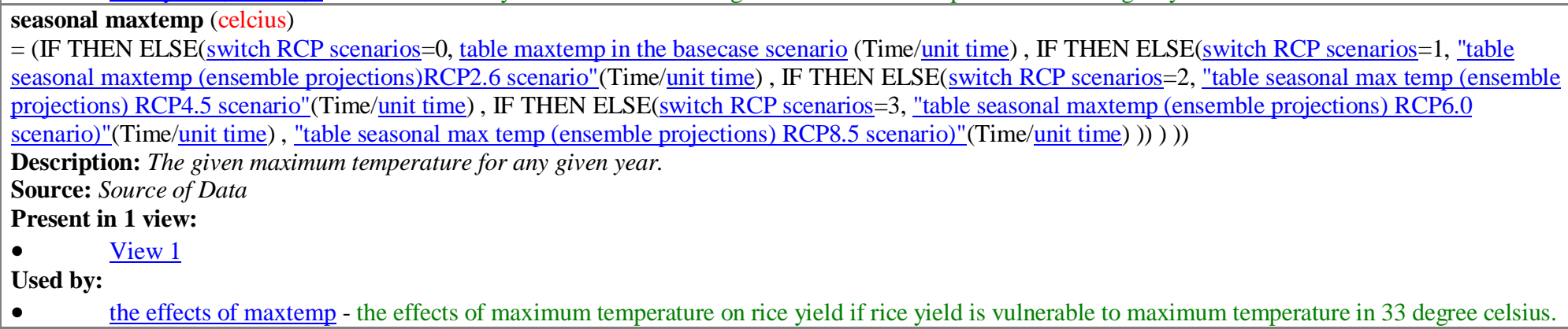 \\
\hline Default & $\begin{array}{l}\text { THE SD } \\
\text { POLICY } \\
\text { SCENA } \\
\text { RIO } \\
\text { MODEL } \\
\text { (Default) }\end{array}$ & $\begin{array}{c}\# 73 \\
A \\
\text { VAB }\end{array}$ & 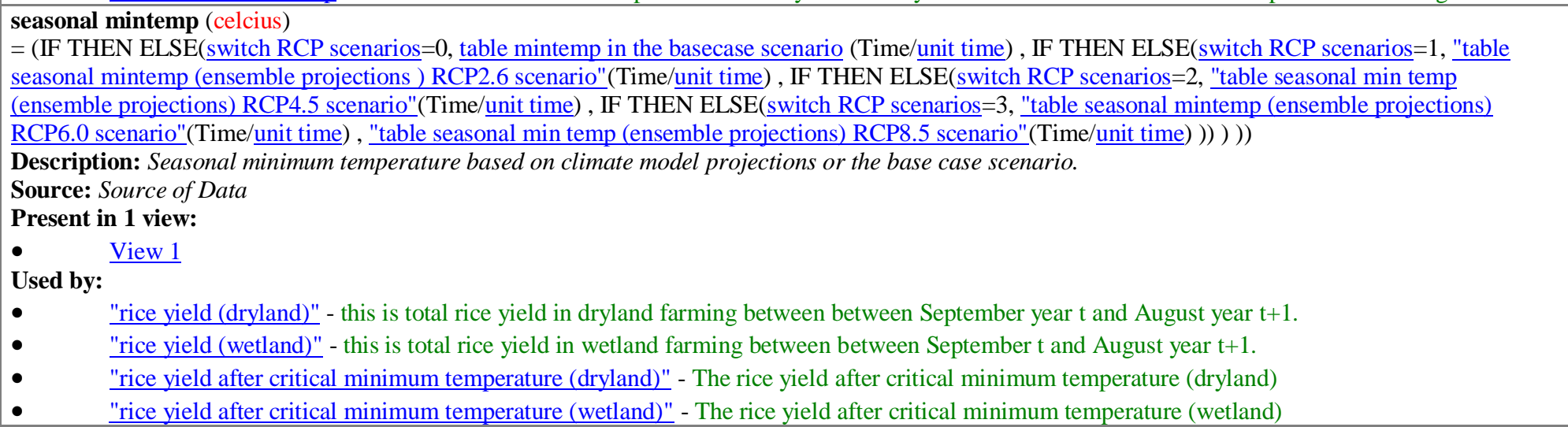 \\
\hline Default & $\begin{array}{l}\text { THE SD } \\
\text { POLICY } \\
\text { SCENA } \\
\text { RIO } \\
\text { MODEL } \\
\text { (Default) }\end{array}$ & $\begin{array}{c}\# 74 \\
A \\
\text { VAB }\end{array}$ & 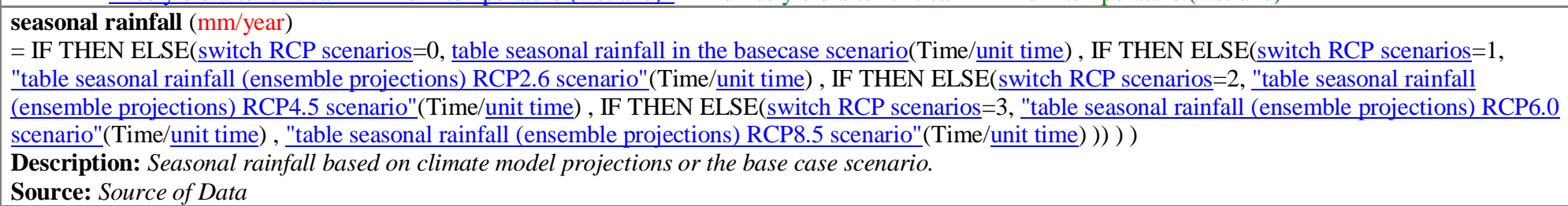 \\
\hline
\end{tabular}




\begin{tabular}{|c|c|c|c|}
\hline & & & $\begin{array}{l}\text { Present in } 1 \text { view: } \\
\text { View } 1 \\
\text { Used by: } \\
\text { "expected cropping intensity (wetland)" - the expected cropping intensity }\end{array}$ \\
\hline Default & $\begin{array}{c}\text { THE SD } \\
\text { POLICY } \\
\text { SCENA } \\
\text { RIO } \\
\text { MODEL } \\
\text { (Default) }\end{array}$ & $\begin{array}{c}\# 75 \\
\text { A } \\
\text { Wab }\end{array}$ & $\begin{array}{l}\text { "seed (dryland)" (IDR/year) } \\
=\text { "table seed (dryland)"(Time/unit time) } \\
\text { Description: the used seed in dryland farming for a given year during simulation } \\
\text { Present in } \mathbf{1} \text { view: } \\
\bullet \quad \text { View } 1 \\
\text { Used by: } \\
\text { "rice yield (dryland)" - this is total rice yield in dryland farming between between September year } t \text { and August year } t+1 \text {. }\end{array}$ \\
\hline Default & $\begin{array}{c}\text { THE SD } \\
\text { POLICY } \\
\text { SCENA } \\
\text { RIO } \\
\text { MODEL } \\
\text { (Default) }\end{array}$ & $\begin{array}{l}\# 76 \\
\mathrm{C} \\
\mathrm{Nab}\end{array}$ & 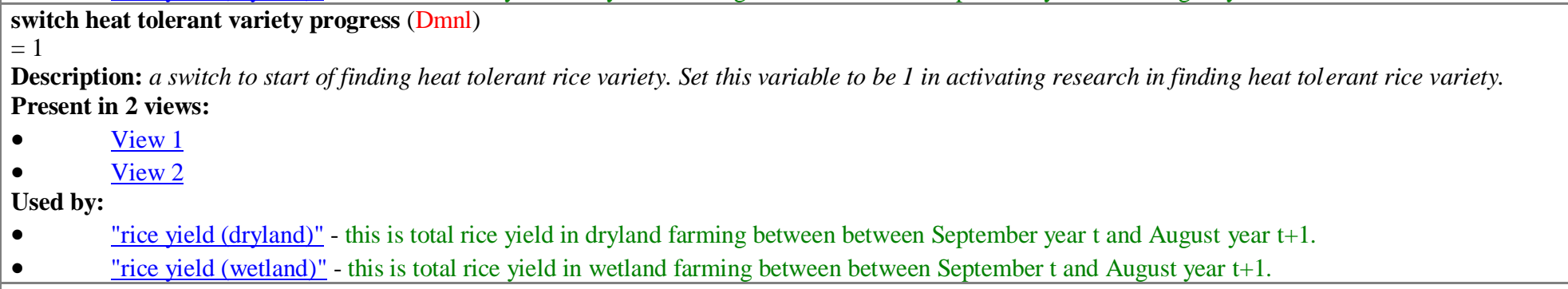 \\
\hline Default & $\begin{array}{l}\text { THE SD } \\
\text { POLICY } \\
\text { SCENA } \\
\text { RIO } \\
\text { MODEL } \\
\text { (Default) }\end{array}$ & $\begin{array}{c}\# 77 \\
\mathrm{C} \\
\text { VAB }\end{array}$ & $\begin{array}{l}\text { Switch invention time by } 2030 \text { (Dmnl) } \\
=1 \\
\text { Description: a switch to set the time of finding heat tolerant rice variety. Set this variable to be } 1 \text {, assuming heat tolerant rice variety will be found in } 2030 . \\
\text { Present in } \mathbf{2} \text { views: } \\
\qquad \frac{\text { View } 1}{\text { View } 2} \\
\text { Used by: } \\
\text { - }\end{array}$ \\
\hline Default & $\begin{array}{c}\text { THE SD } \\
\text { POLICY } \\
\text { SCENA } \\
\text { RIO } \\
\text { MODEL } \\
\text { (Default) }\end{array}$ & $\begin{array}{l}\# 78 \\
\mathrm{C} \\
\mathrm{WAB}\end{array}$ & $\begin{array}{l}\text { switch of shorter growth duration variety }(\mathrm{Dmnl}) \\
=0 \\
\text { Description: } \text { a switch to start of finding shorter growth duration of rice variety. Set this variable to be } 1 \text { start research in finding shorter growth duration } \\
\text { varieties. } \\
\text { Present in } 2 \text { views: } \\
\qquad \quad \underline{\text { View } 1} \\
\text { Used by: }\end{array}$ \\
\hline
\end{tabular}




\begin{tabular}{|c|c|c|c|}
\hline & & & $\begin{array}{l}\text { - } \\
\text { - }\end{array}$ \\
\hline Default & $\begin{array}{c}\text { THE SD } \\
\text { POLICY } \\
\text { SCENA } \\
\text { RIO } \\
\text { MODEL } \\
\text { (Default) }\end{array}$ & $\begin{array}{c}\# 79 \\
\mathrm{C} \\
\mathrm{WAB}\end{array}$ & $\begin{array}{l}\text { Switch RCP scenarios (Dmnl) } \\
=0 \\
\text { Description: } \text { a switch to set a RCP scenario. Set this variable to be } 0,1,2,3,4 \text { for the base case, RCP2.6, RCP4.5, RCP6.0, RCP8.5 scenario respectively. } \\
\text { Present in } 2 \text { views: } \\
\text { - } \\
\text { - } \quad \frac{\text { View } 1}{\text { View } 2} \\
\text { Used by: } \\
\text { - } \\
\text { August SOI - August SOI based on climate model projections or the base case scenario. } \\
\text { - } \quad \text { seasonal maxtemp - The given maximum temperature for any given year. } \\
\text { - }\end{array}$ \\
\hline Default & $\begin{array}{c}\text { THE SD } \\
\text { POLICY } \\
\text { SCENA } \\
\text { RIO } \\
\text { MODEL } \\
\text { (Default) }\end{array}$ & $\begin{array}{c}\# 80 \\
\mathrm{C} \\
\mathrm{VAB}\end{array}$ & $\begin{array}{l}\text { switch technological progress on rice (Dmnl) } \\
=0 \\
\text { Description: } \text { a switch to start of finding a higher yield rice variety. Set this variable to be } 1 \text { start research in increasing technological progress. } \\
\text { Present in } 2 \text { views: } \\
\qquad \quad \underline{\text { View } 1} \\
\text { View } 2 \\
\text { Used by: } \\
\text { fraction of technological progress on rice - a growth fraction of technological progress. }\end{array}$ \\
\hline Default & $\begin{array}{c}\text { THE SD } \\
\text { POLICY } \\
\text { SCENA } \\
\text { RIO } \\
\text { MODEL } \\
\text { (Default) }\end{array}$ & $\begin{array}{c}\# 81 \\
L \\
\mathrm{H}_{\mathrm{X}}\end{array}$ & $\begin{array}{l}\text { "table August SOI }(\text { ensemble projections) RCP2.6 scenario" }(\text { Dmnl }) \\
=[(2015,750)-(2100,2999)],(2015,-0.377457),(2016,-3.43614),(2017,6.08017),(2018,-4.64787),(2019,-0.123148),(2020,5.52507),(2021,- \\
6.20149),(2022,4.8256),(2023,15.5325),(2024,-0.0791212),(2025,2.19029),(2026,-14.8148),(2027,9.71829),(2028,0.989546),(2029,- \\
2.99283),(2030,8.00407),(2031,2.67697),(2032,-3.15751),(2033,8.20278),(2034,3.51285),(2035,-8.49957),(2036,- \\
0.136569),(2037,3.07762),(2038,0.989606),(2039,4.95153),(2040,-4.26852),(2041,-0.201988),(2042,4.75914),(2043,9.79205),(2044,9.16514),(2045,- \\
9.34632),(2046,-20.4219),(2047,-5.25882),(2048,14.3983),(2049,10.757),(2050,9.85245),(2051,-0.270834),(2052,8.13493 \mathrm{e}- \\
005),(2053,6.37409),(2054,1.41926),(2055,-4.97754),(2056,-4.72013),(2057,2.80359),(2058,- \\
2.09213),(2059,1.37895),(2060,14.3308),(2061,4.33517),(2062,-14.3571),(2063,18.3033),(2064,13.9737),(2065,6.80169),(2066,-14.8745),(2067,- \\
3.51121),(2068,2.1277),(2069,-0.495534),(2070,3.43135),(2071,-5.039),(2072,7.9715),(2073,-4.76909),(2074,7.79617),(2075,5.19307),(2076,- \\
7.68454),(2077,5.14974),(2078,0.383983),(2079,-9.13473),(2080,-5.03546),(2081,13.5543),(2082,-12.1049),(2083,10.6545),(2084,- \\
7.61223),(2085,2.56147),(2086,13.4134),(2087,13.4674),(2088,4.74551),(2089,-3.57685),(2090,20.8517),(2091,9.61796),(2092,-5.17336),(2093,- \\
3.23295),(2094,6.4893),(2095,3.65079),(2096,-8.38333),(2097,4.40906),(2098,4.99518),(2099,-4.56005),(2100,5.62233) \\
\text { Description: This is rainfall output under RCP2.6 scenario derived from GFDL CM3. } \\
\text { This Lookup Table is used as a Data Repository. } \\
\text { Present in 1 view: }\end{array}$ \\
\hline
\end{tabular}




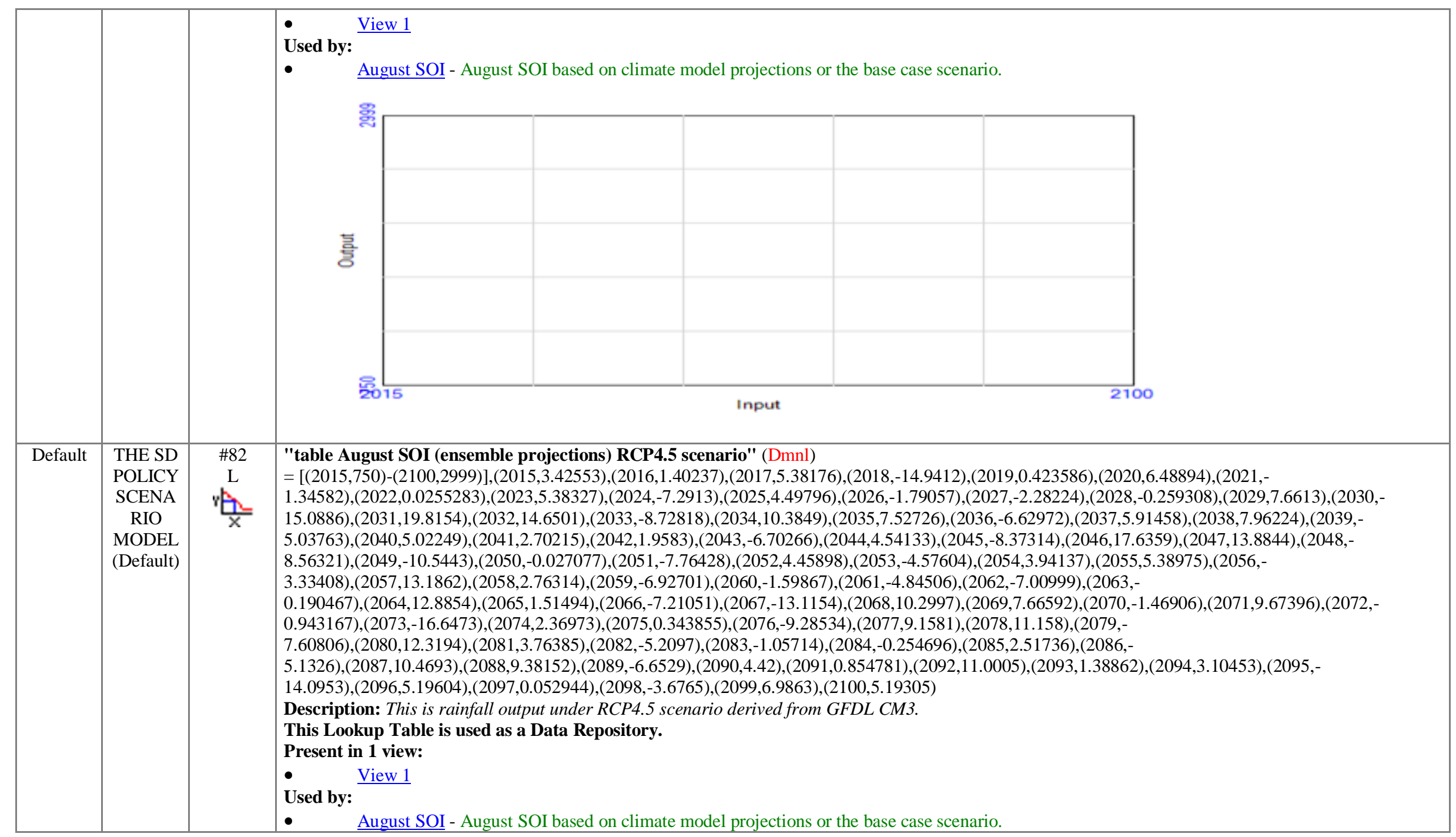




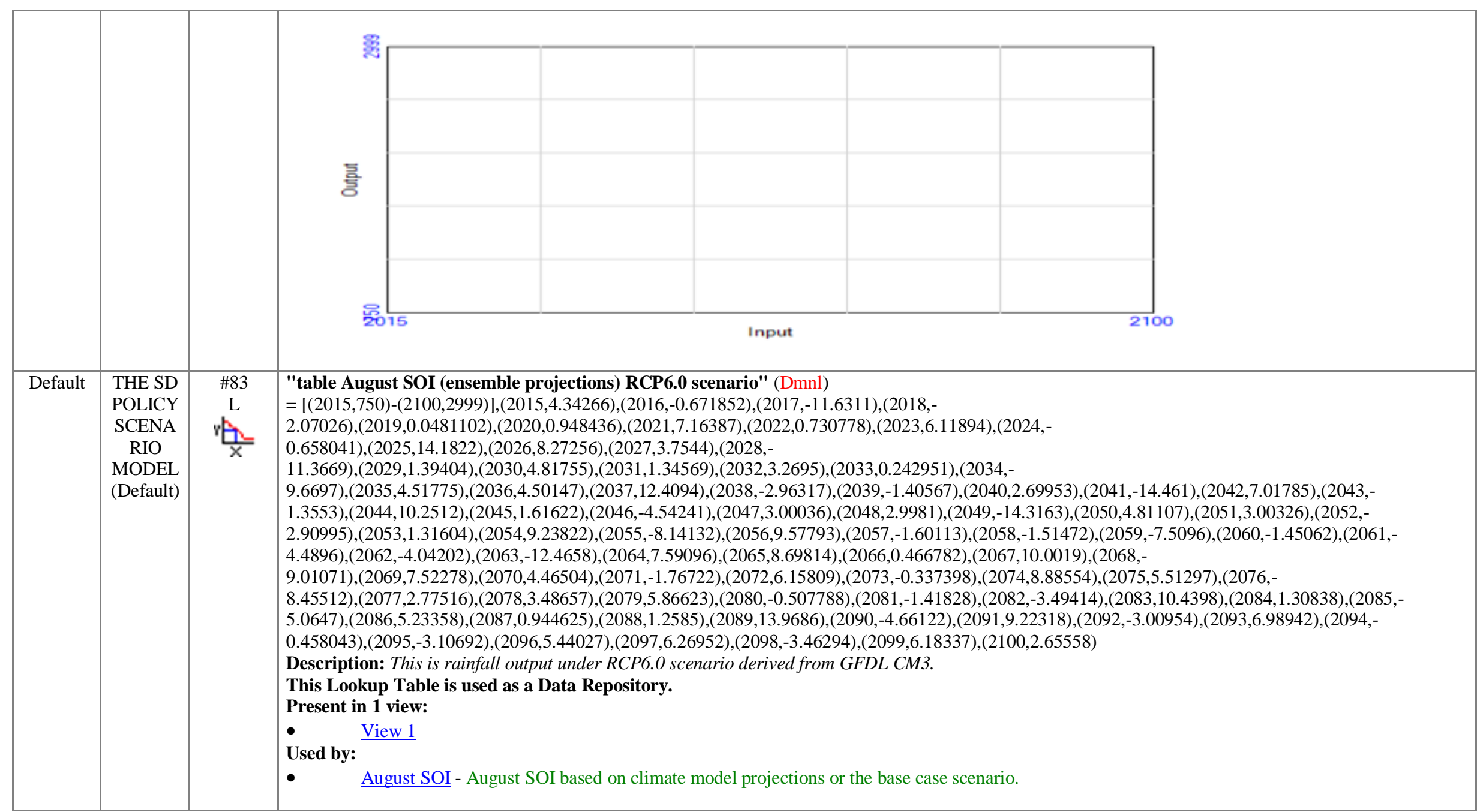




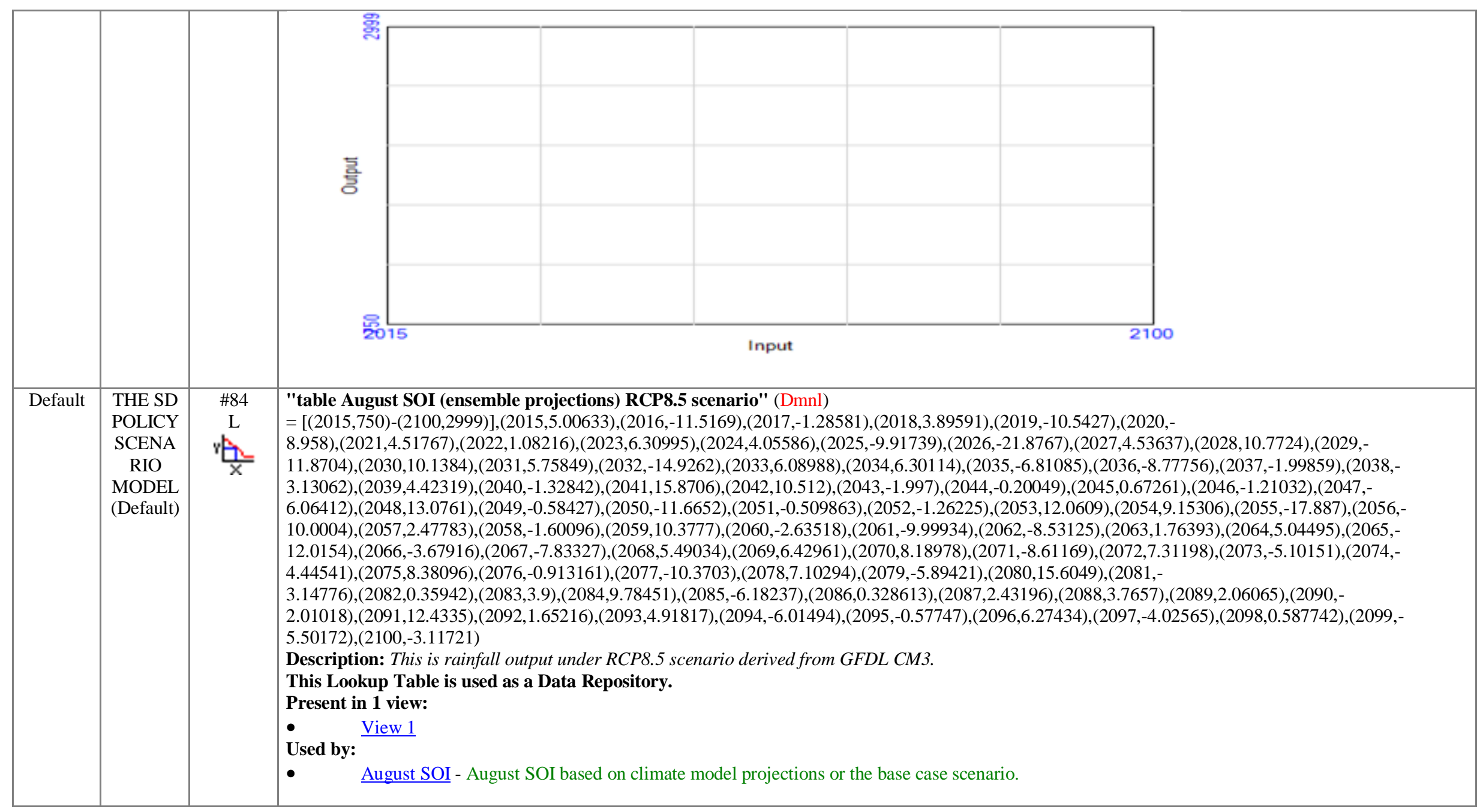




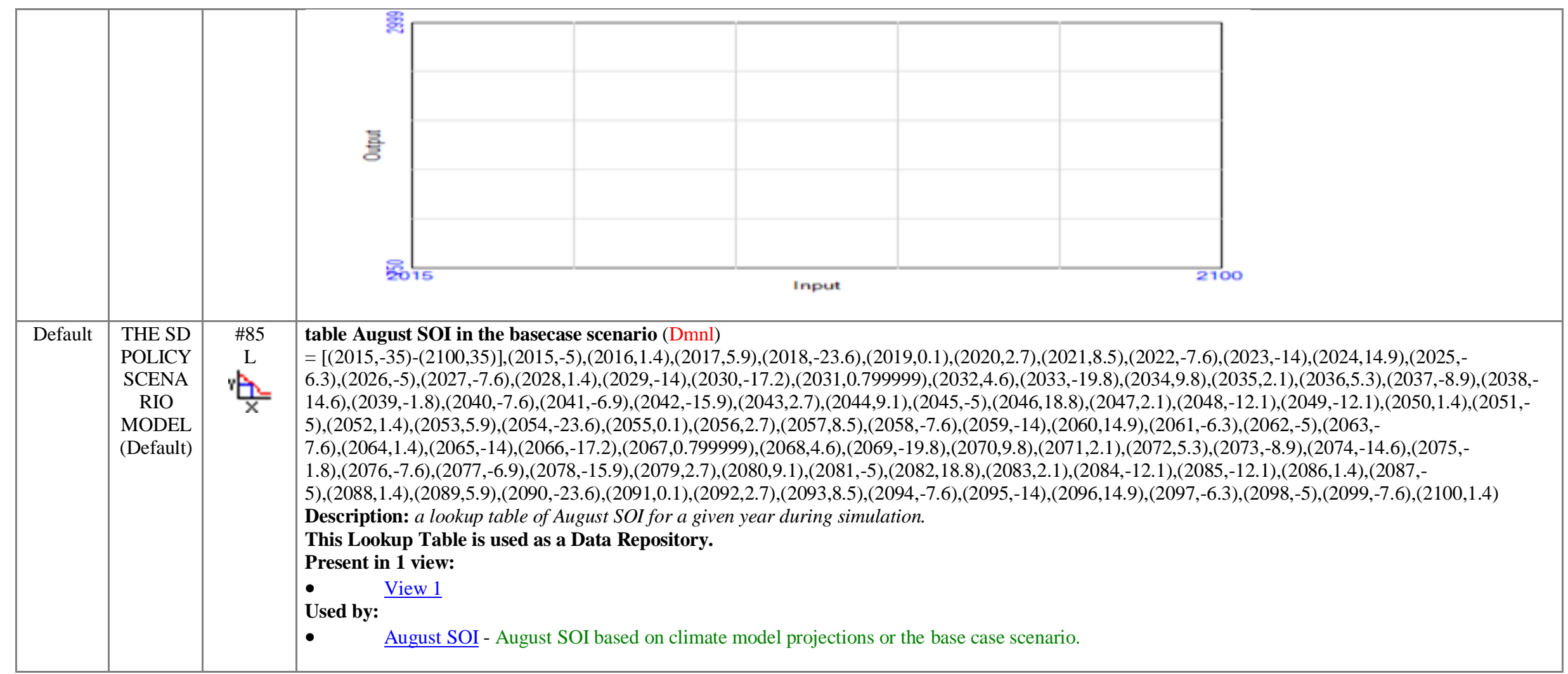




\begin{tabular}{|c|c|c|c|}
\hline & & & 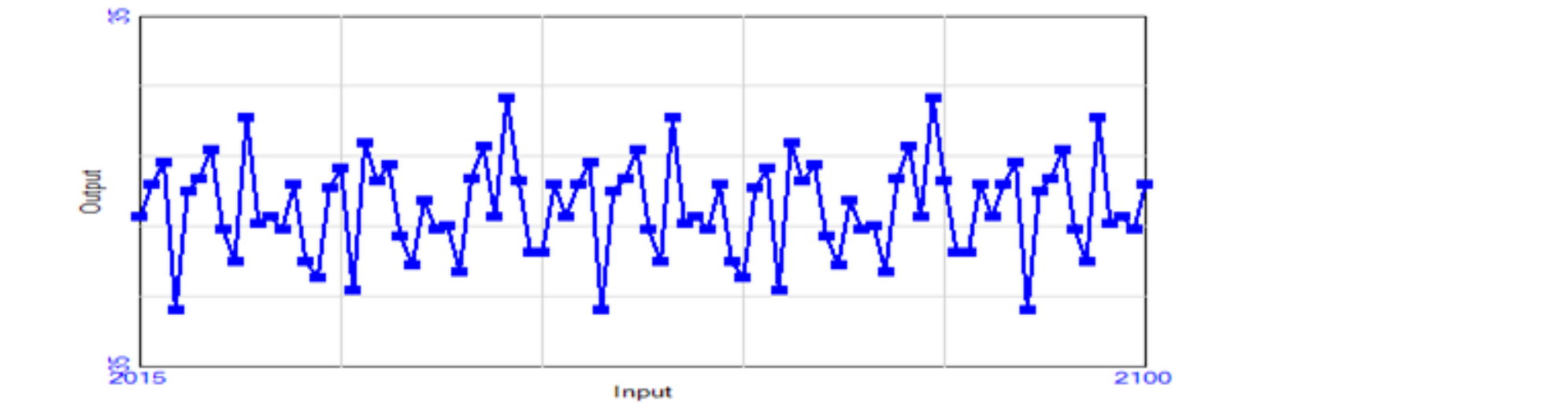 \\
\hline Default & $\begin{array}{l}\text { THE SD } \\
\text { POLICY } \\
\text { SCENA } \\
\text { RIO } \\
\text { MODEL } \\
\text { (Default) }\end{array}$ & $\begin{array}{c}\# 86 \\
\mathrm{~L} \\
\frac{\mathrm{X}}{\mathrm{X}}\end{array}$ & 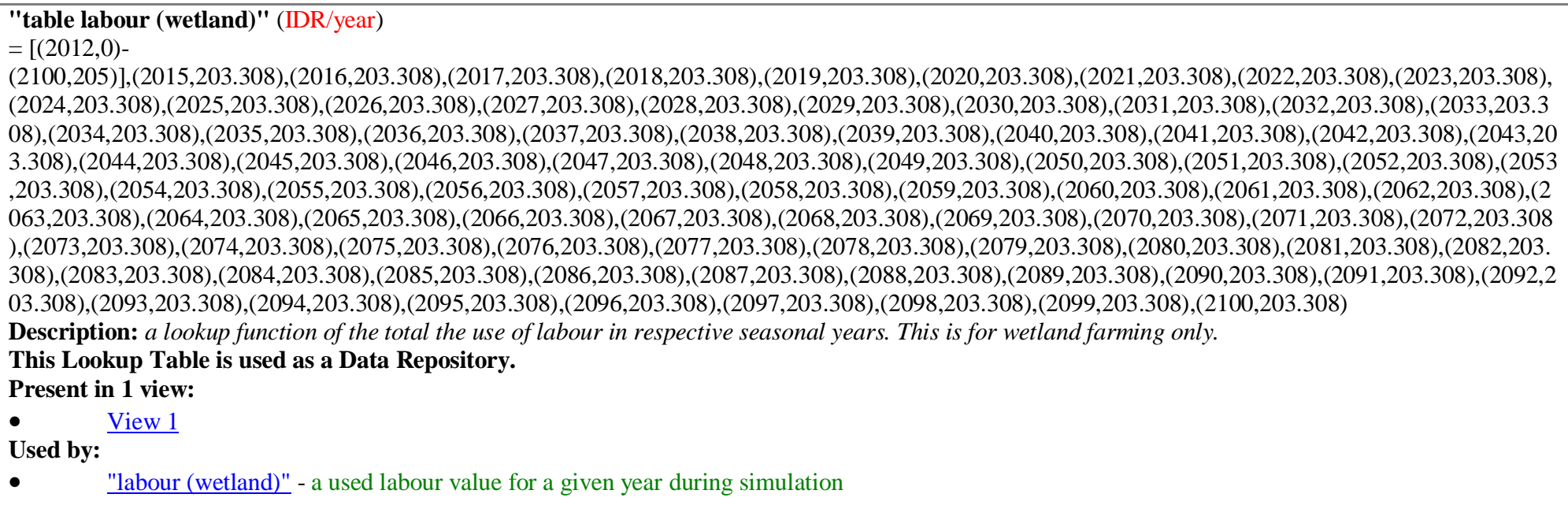 \\
\hline
\end{tabular}




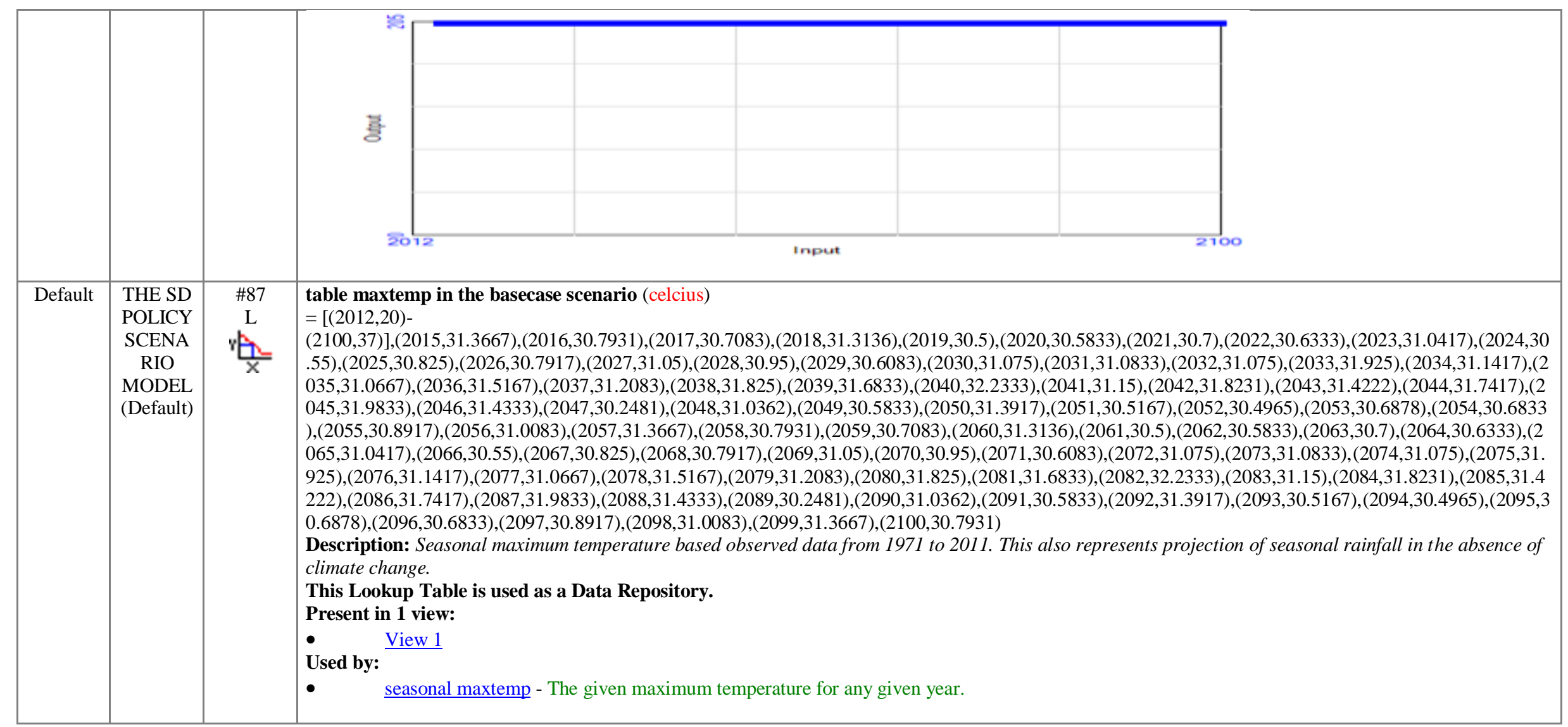




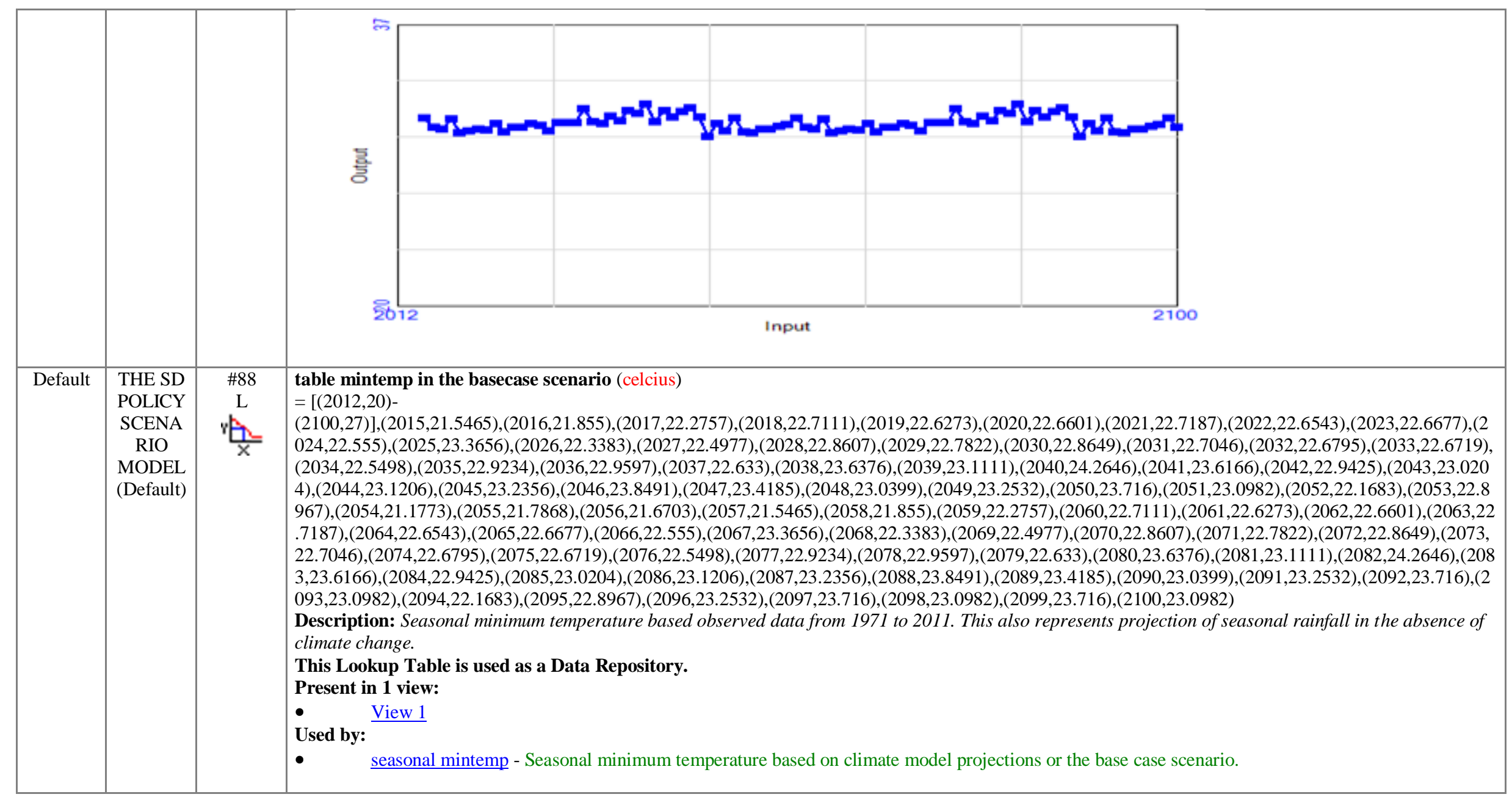




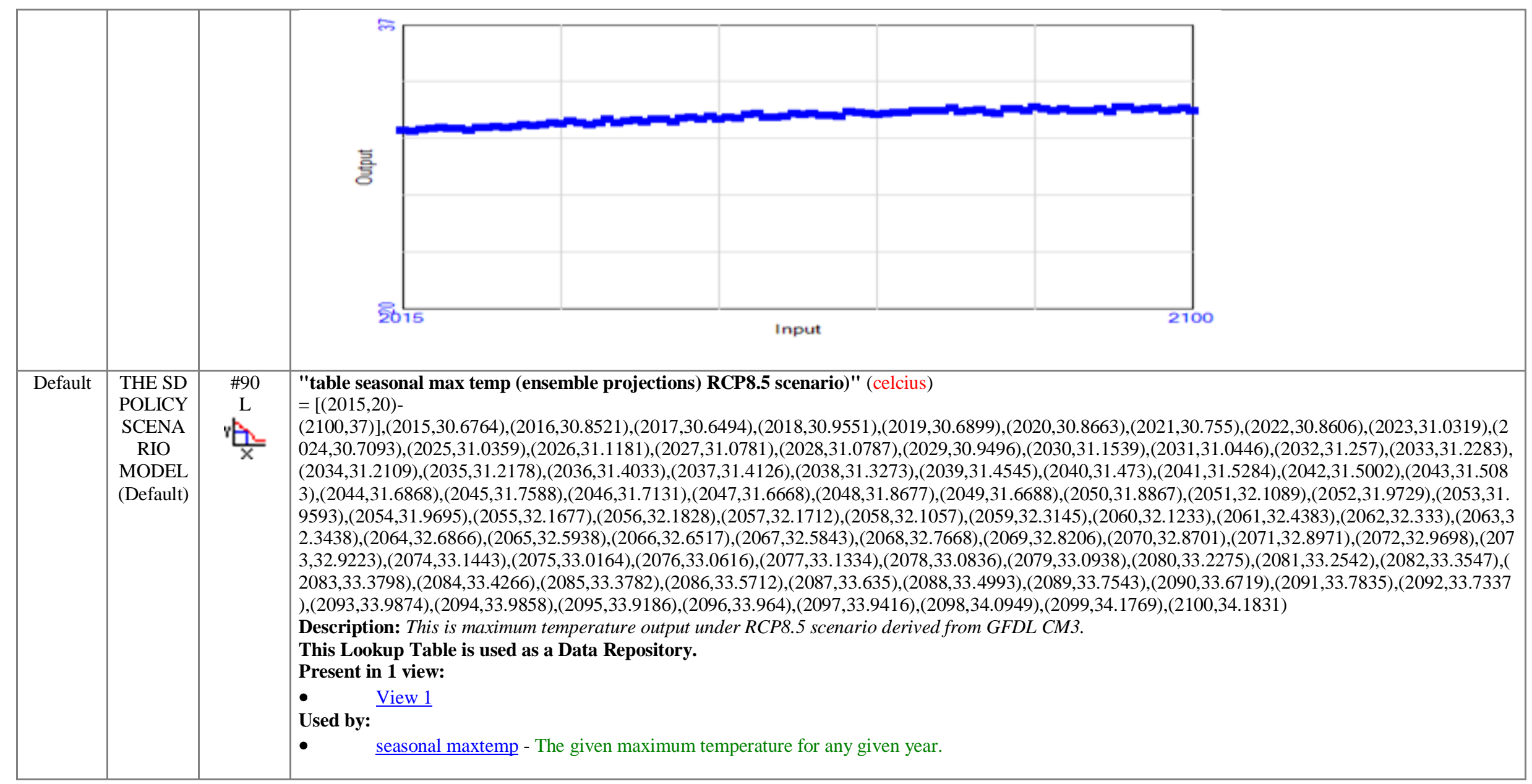




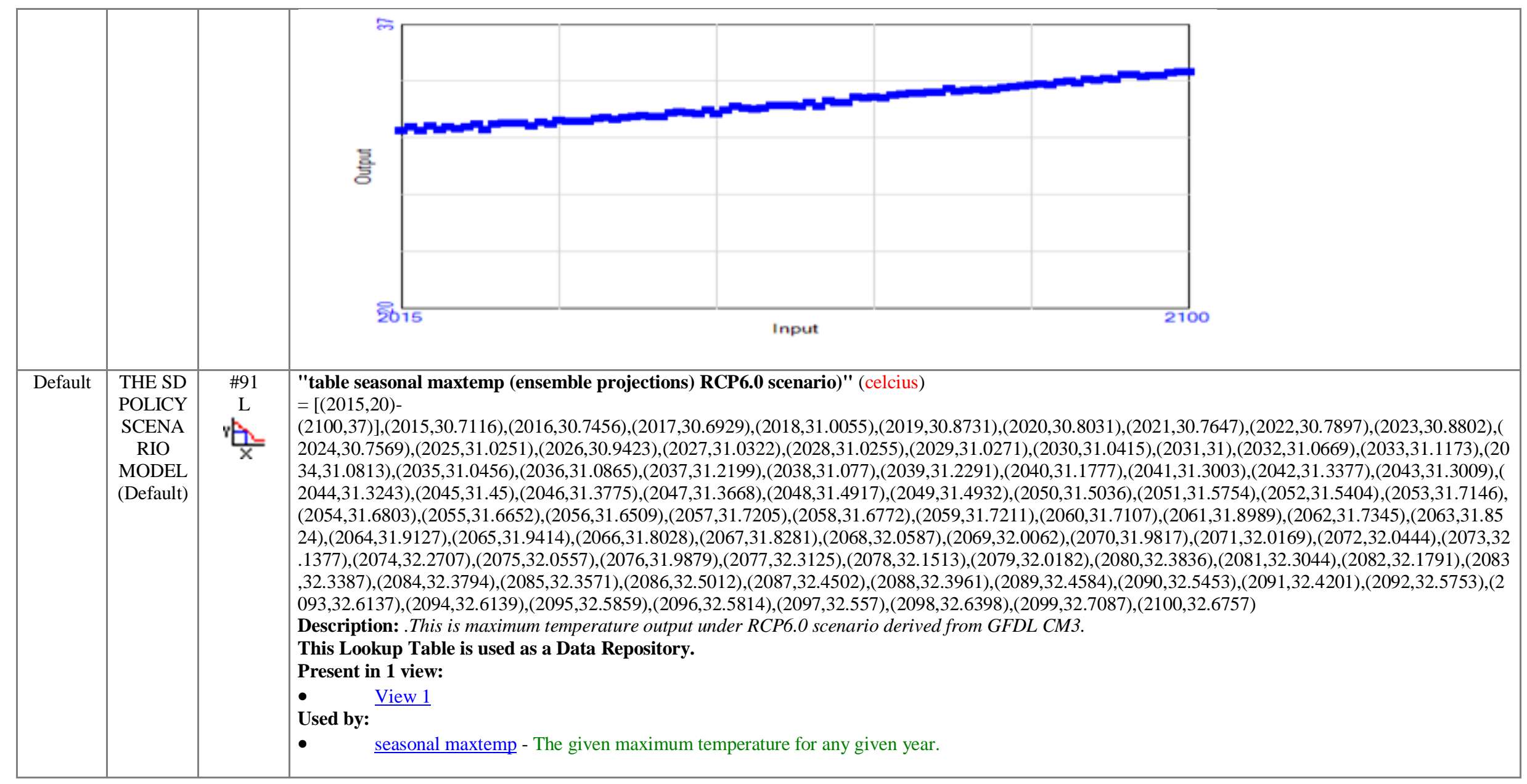




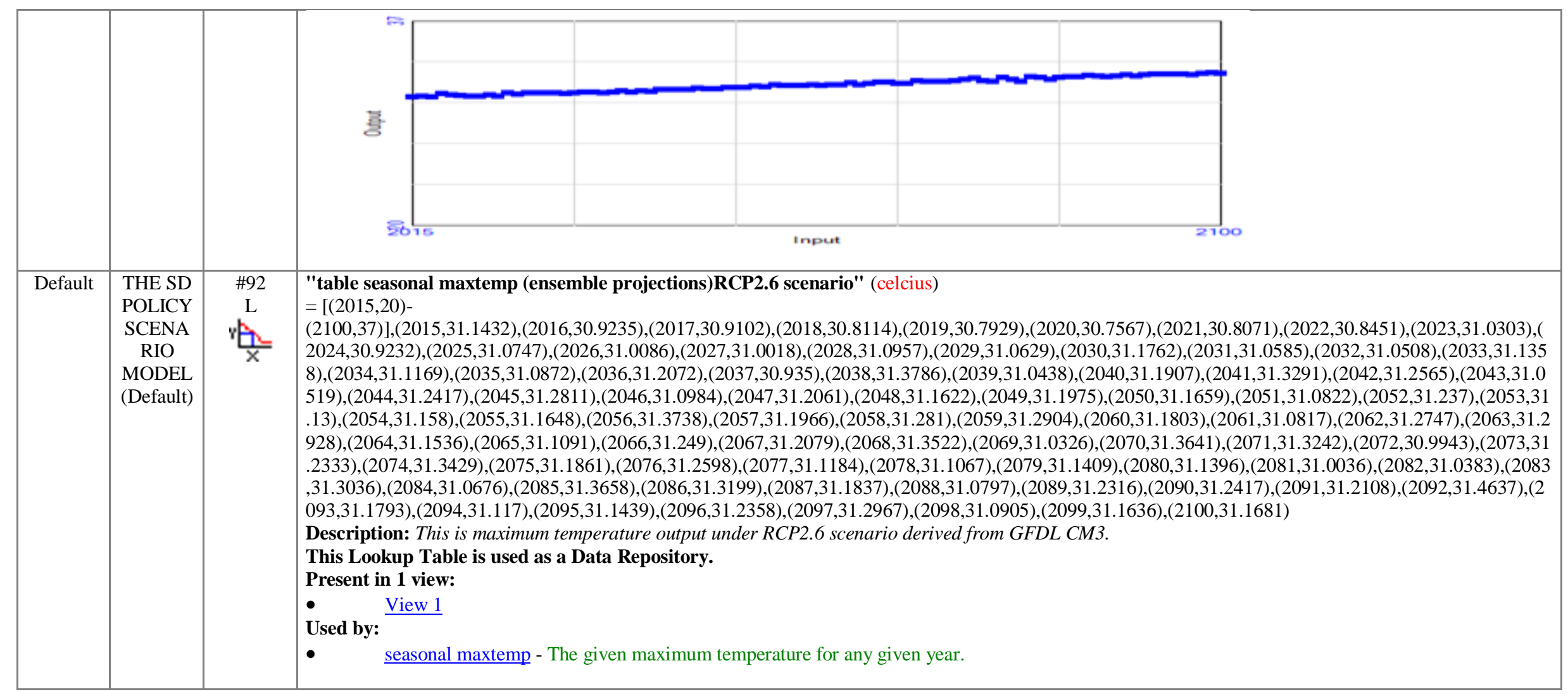




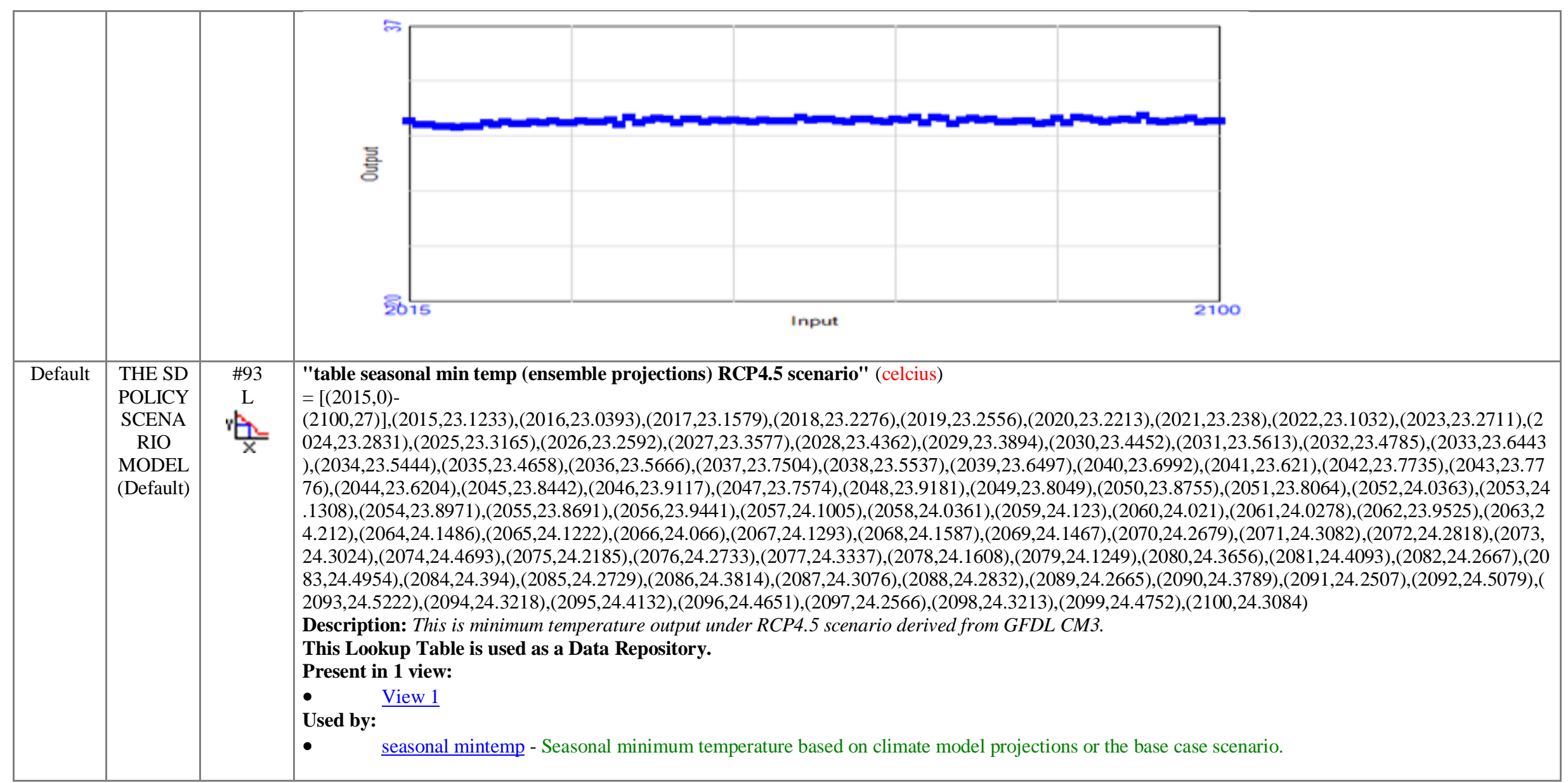




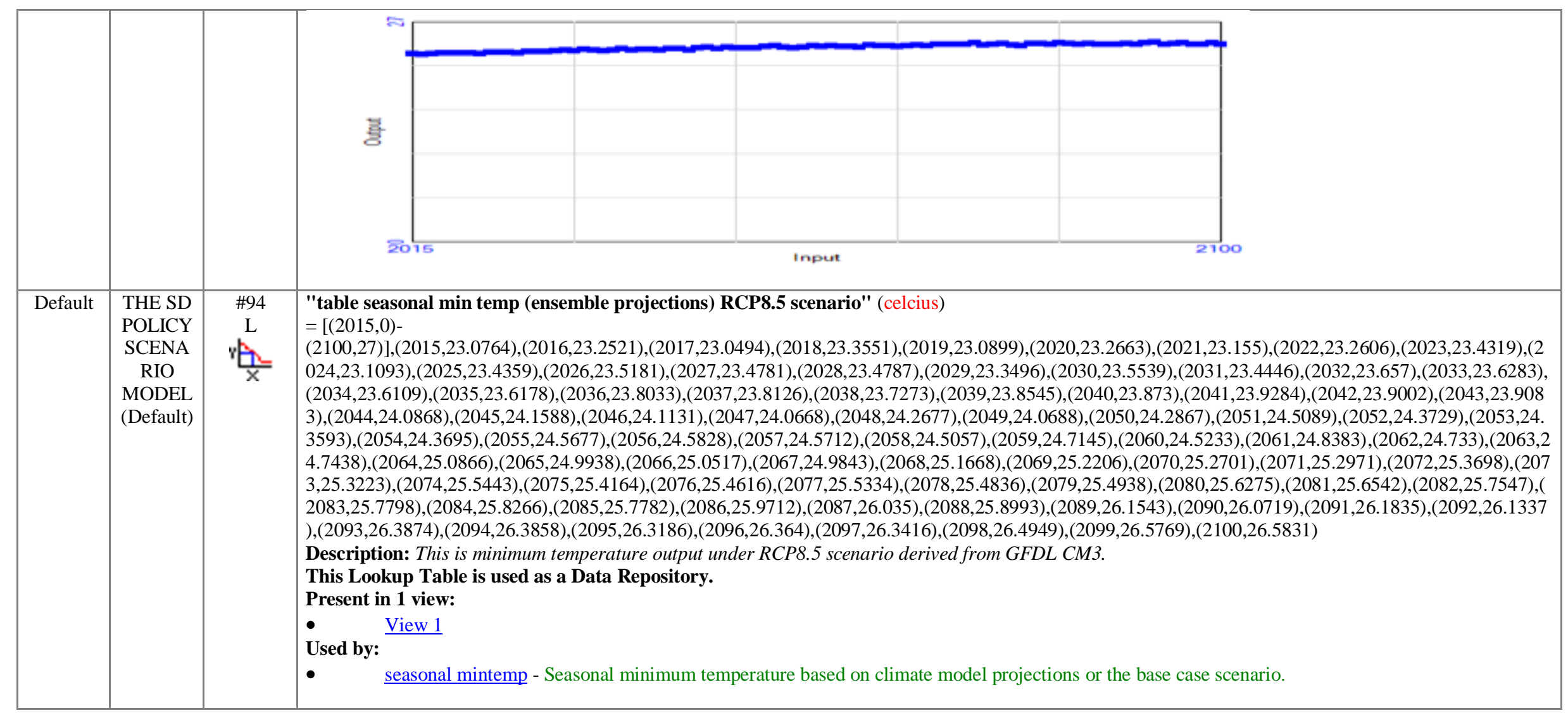




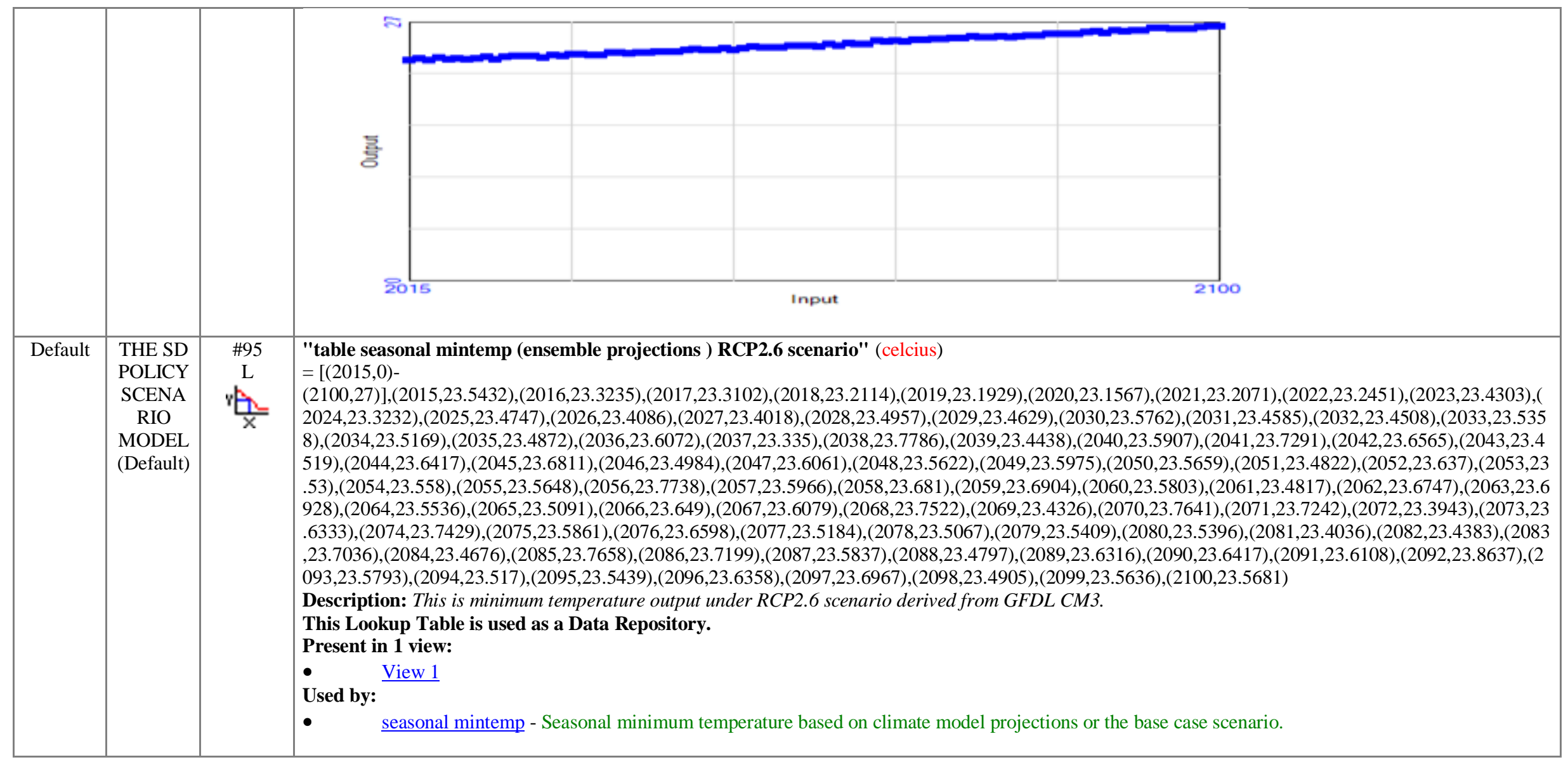




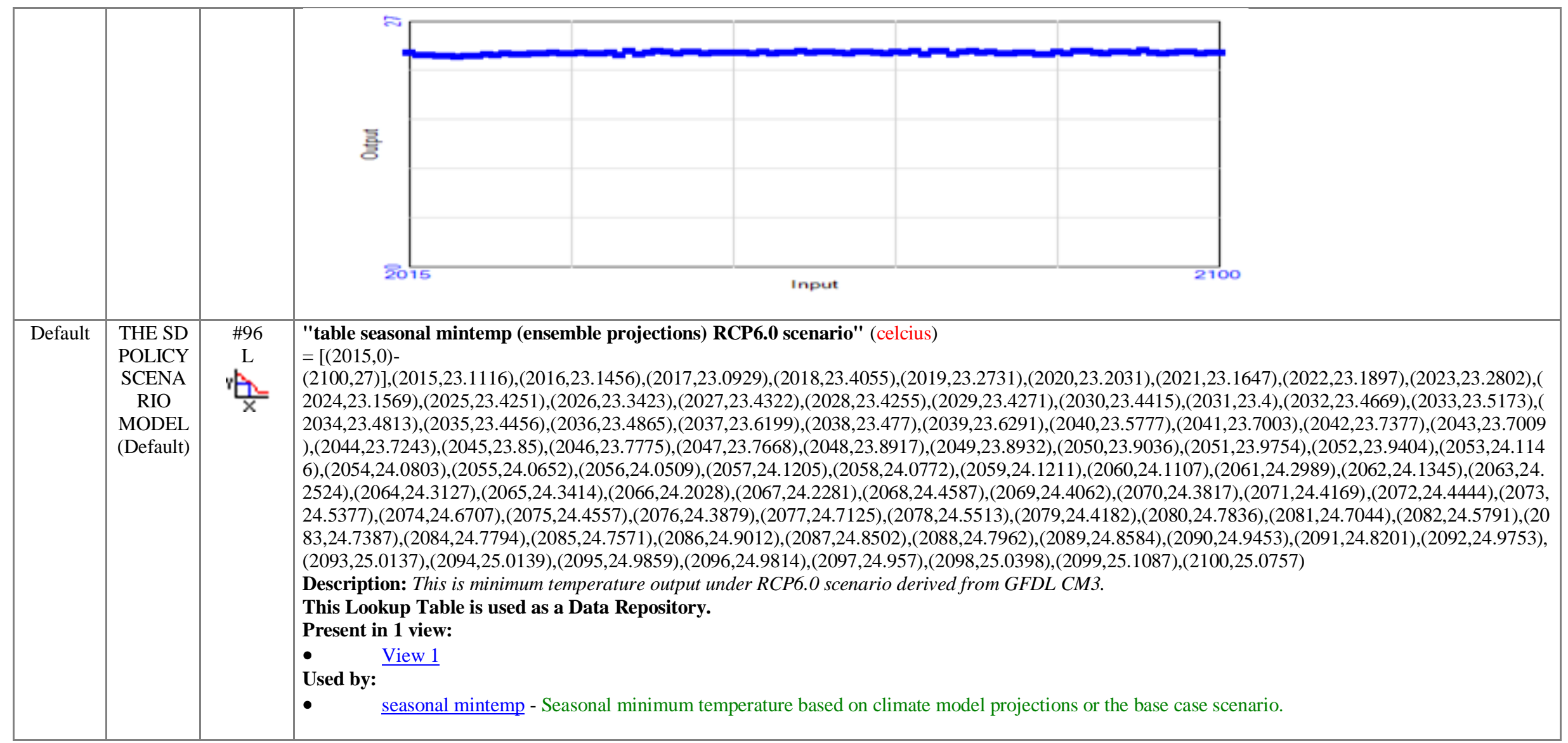




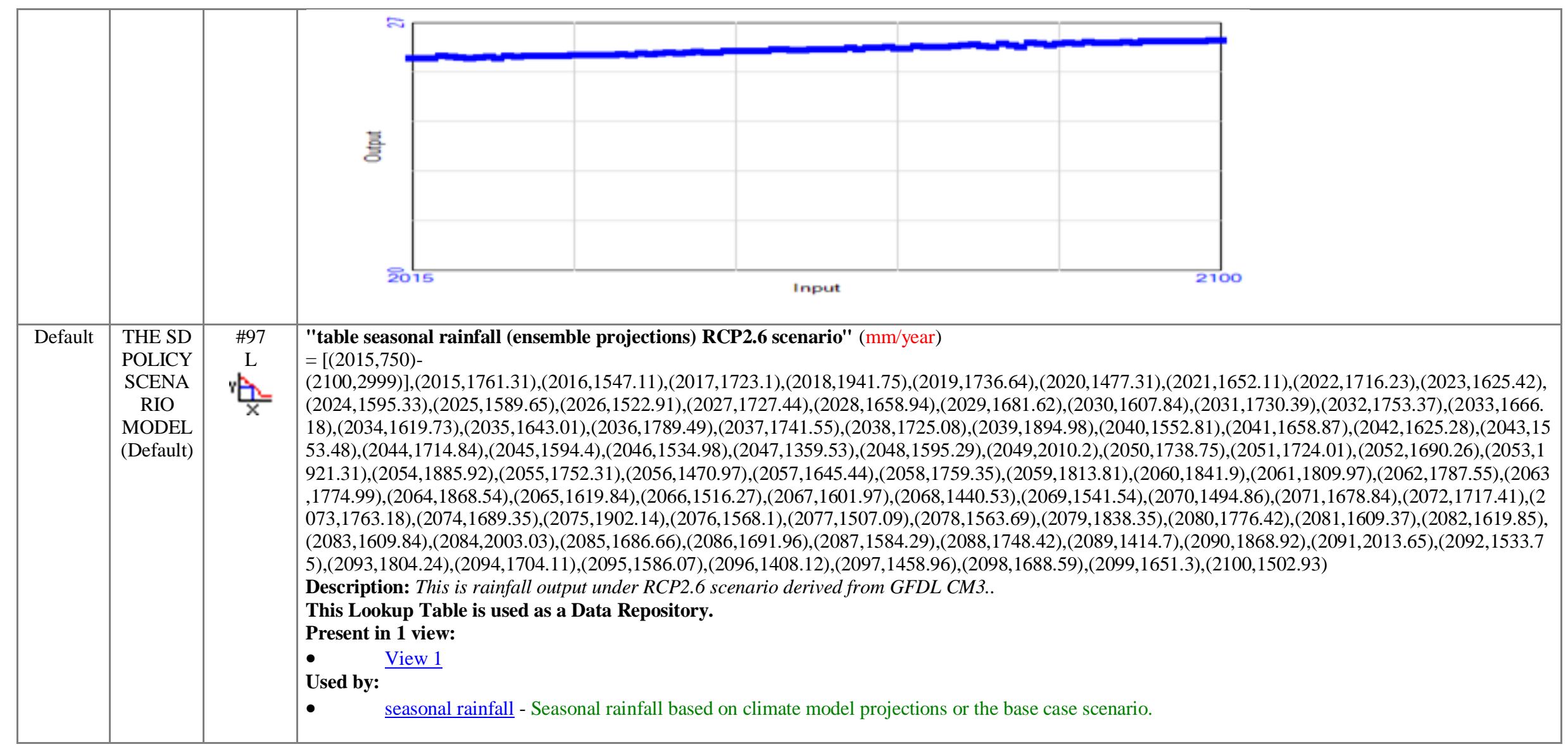




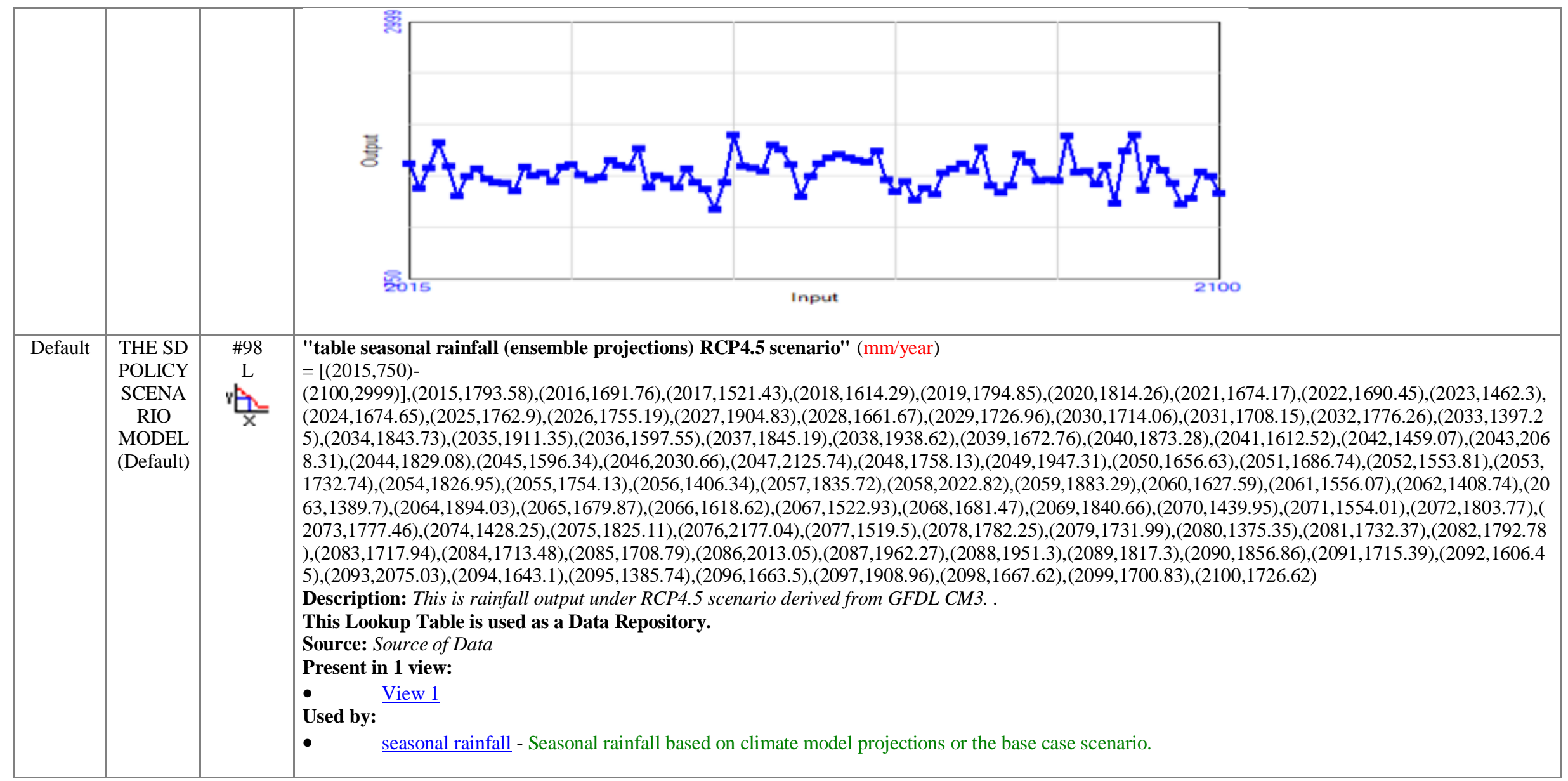




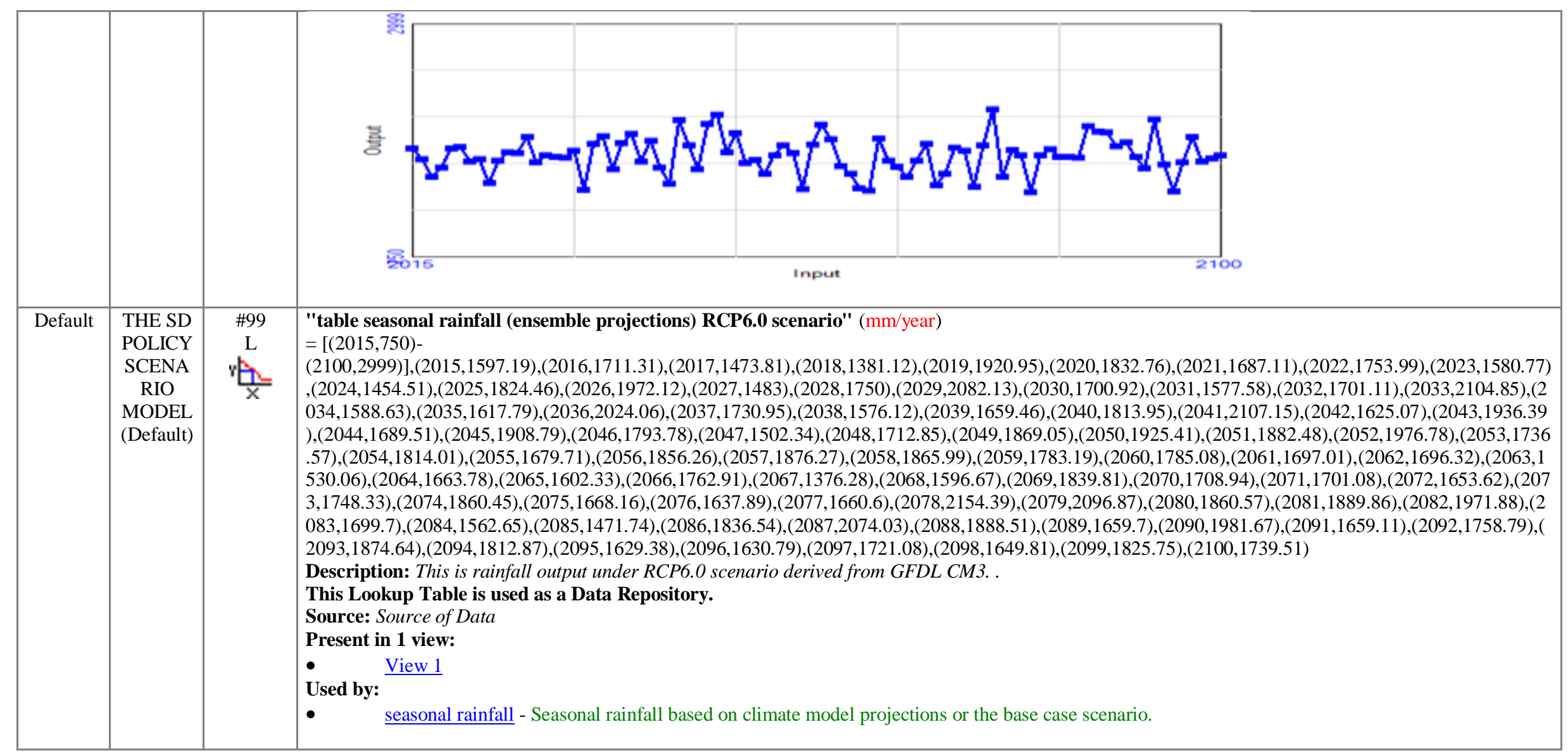




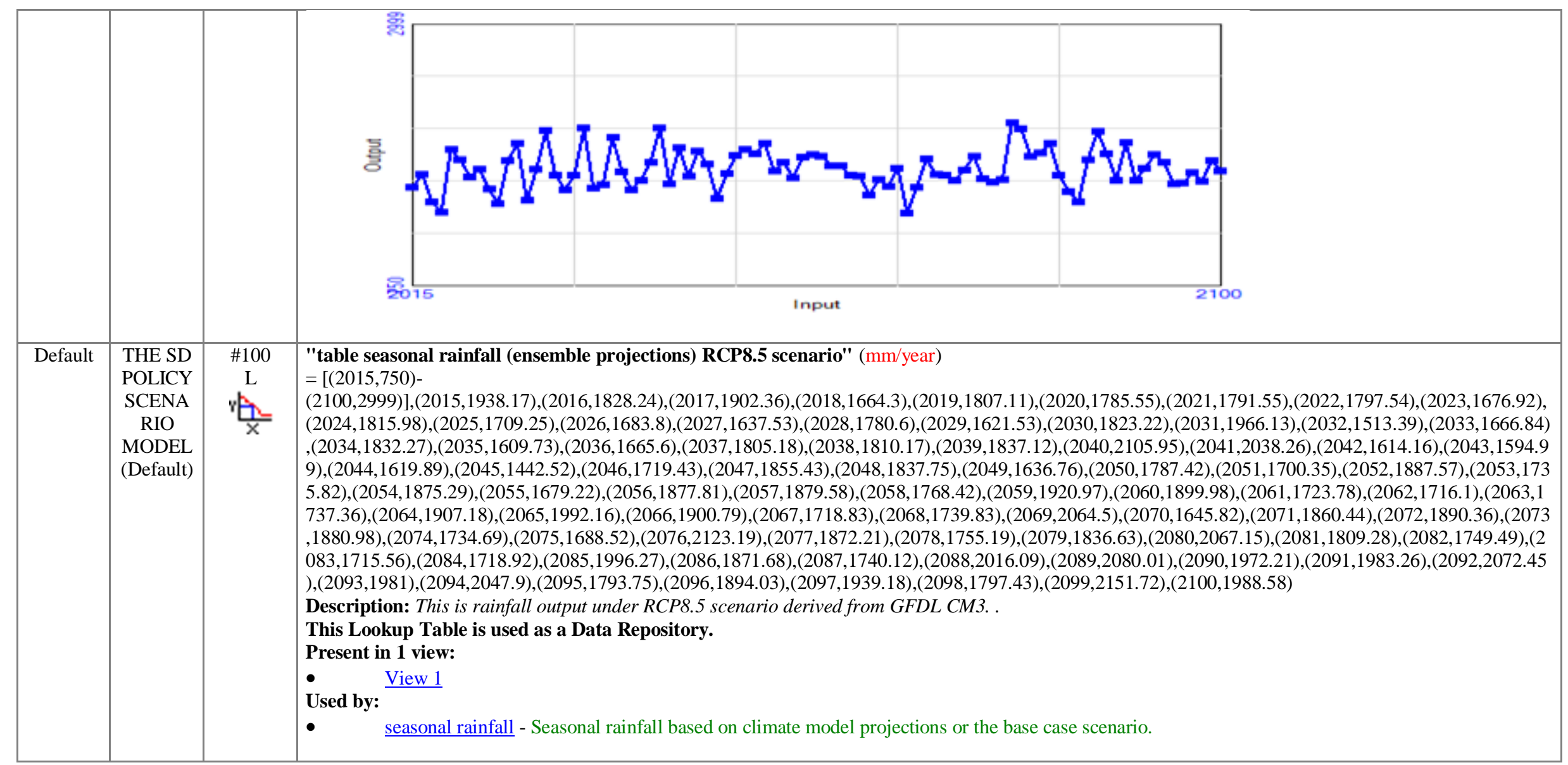




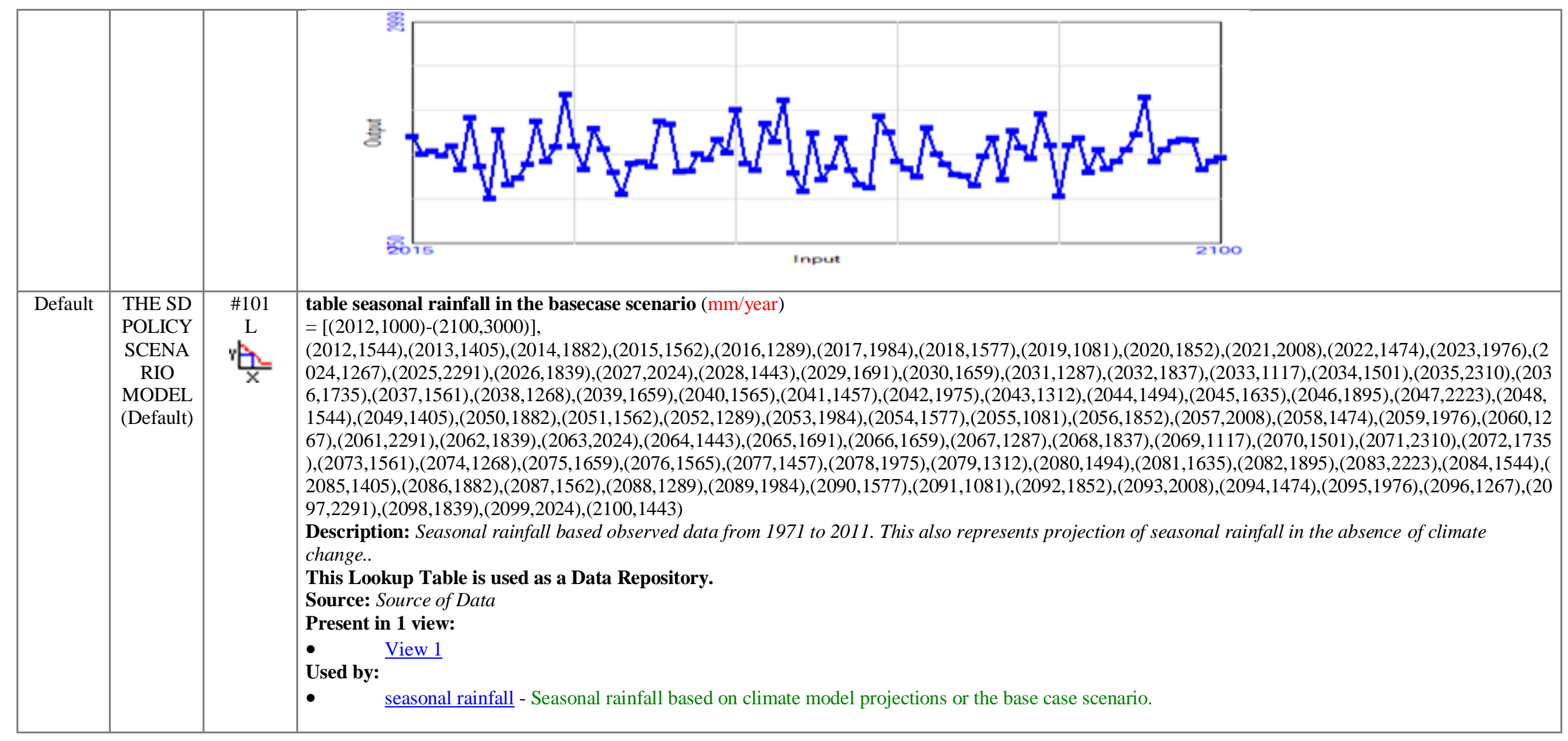




\begin{tabular}{|c|c|c|c|}
\hline & & & 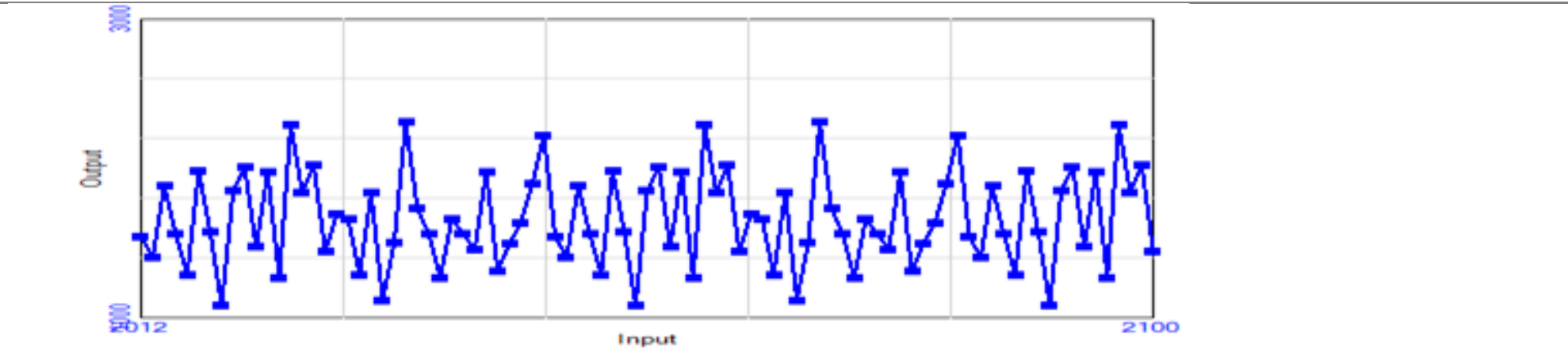 \\
\hline Default & $\begin{array}{l}\text { THE SD } \\
\text { POLICY } \\
\text { SCENA } \\
\text { RIO } \\
\text { MODEL } \\
\text { (Default) }\end{array}$ & $\begin{array}{c}\# 102 \\
\mathrm{~L} \\
\frac{\mathrm{x}}{\mathrm{X}}\end{array}$ & $\begin{array}{l}\text { "table seed (dryland)" (IDR/year) } \\
=[(2012,19)- \\
(2100,23)],(2015,20.751),(2016,20.751),(2017,20.751),(2018,20.751),(2019,20.751),(2020,20.751),(2021,20.751),(2022,20.751),(2023,20.751),(2024,20.75 \\
1),(2025,20.751),(2026,20.751),(2027,20.751),(2028,20.751),(2029,20.751),(2030,20.751),(2031,20.751),(2032,20.751),(2033,20.751),(2034,20.751),(2035, \\
20.751),(2036,20.751),(2037,20.751),(2038,20.751),(2039,20.751),(2040,20.751),(2041,20.751),(2042,20.751),(2043,20.751),(2044,20.751),(2045,20.751),( \\
2046,20.751),(2047,20.751),(2048,20.751),(2049,20.751),(2050,20.751),(2051,20.751),(2052,20.751),(2053,20.751),(2054,20.751),(2055,20.751),(2056,20 . \\
751),(2057,20.751),(2058,20.751),(2059,20.751),(2060,20.751),(2061,20.751),(2062,20.751),(2063,20.751),(2064,20.751),(2065,20.751),(2066,20.751),(20 \\
67,20.751),(2068,20.751),(2069,20.751),(2070,20.751),(2071,20.751),(2072,20.751),(2073,20.751),(2074,20.751),(2075,20.751),(2076,20.751),(2077,20.75 \\
1),(2078,20.751),(2079,20.751),(2080,20.751),(2081,20.751),(2082,20.751),(2083,20.751),(2084,20.751),(2085,20.751),(2086,20.751),(2087,20.751),(2088, \\
20.751),(2089,20.751),(2090,20.751),(2091,20.751),(2092,20.751),(2093,20.751),(2094,20.751),(2095,20.751),(2096,20.751),(2097,20.751),(2098,20.751),( \\
2099,20.751),(2100,20.751) \\
\text { Description: } \text { a lookup table of used seed in dryland farming. } \\
\text { This Lookup Table is used as a Data Repository. } \\
\text { Present in 1 view: } \\
\text { • View 1 } \\
\text { Used by: } \\
\text { • }\end{array}$ \\
\hline
\end{tabular}




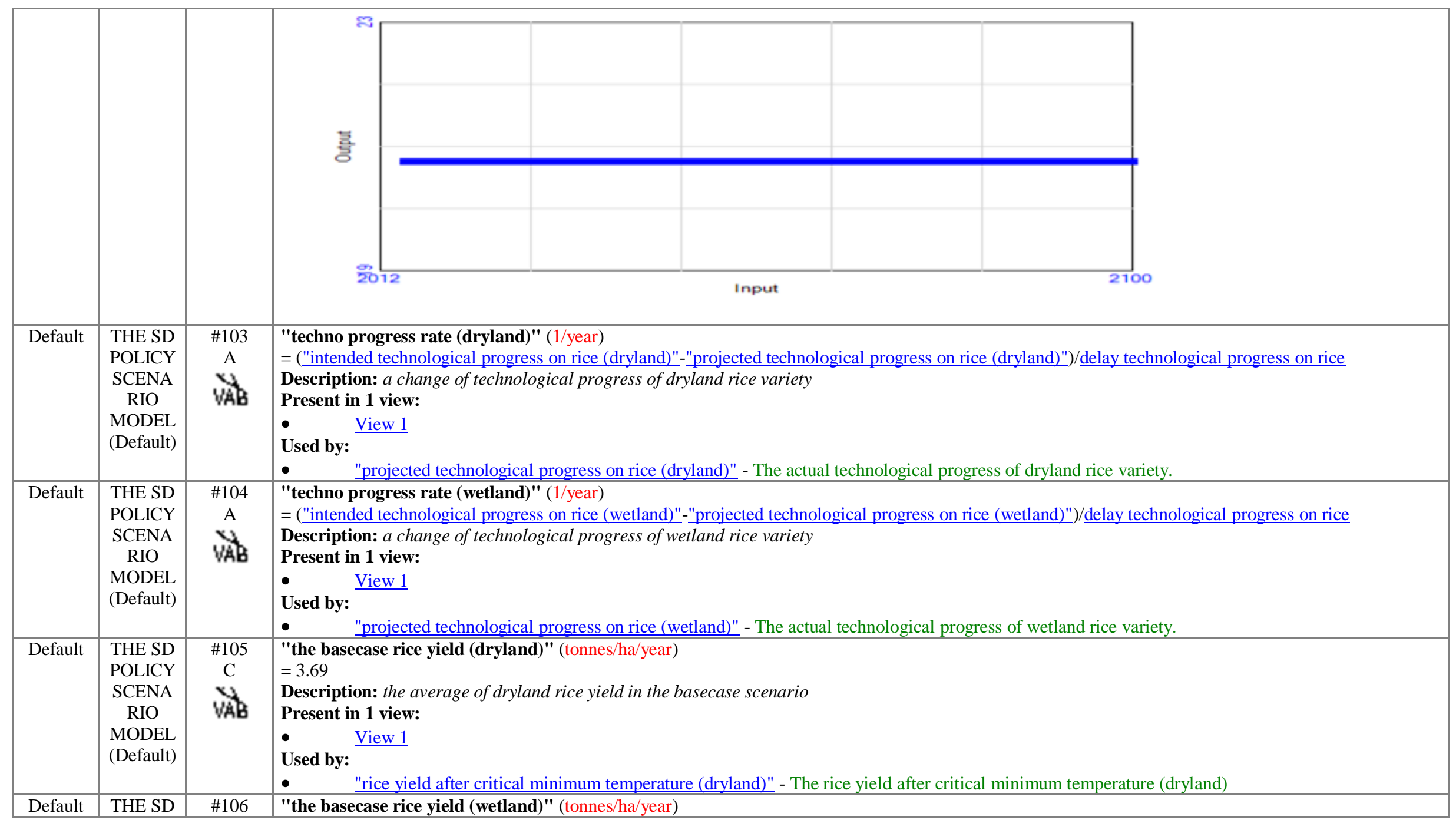




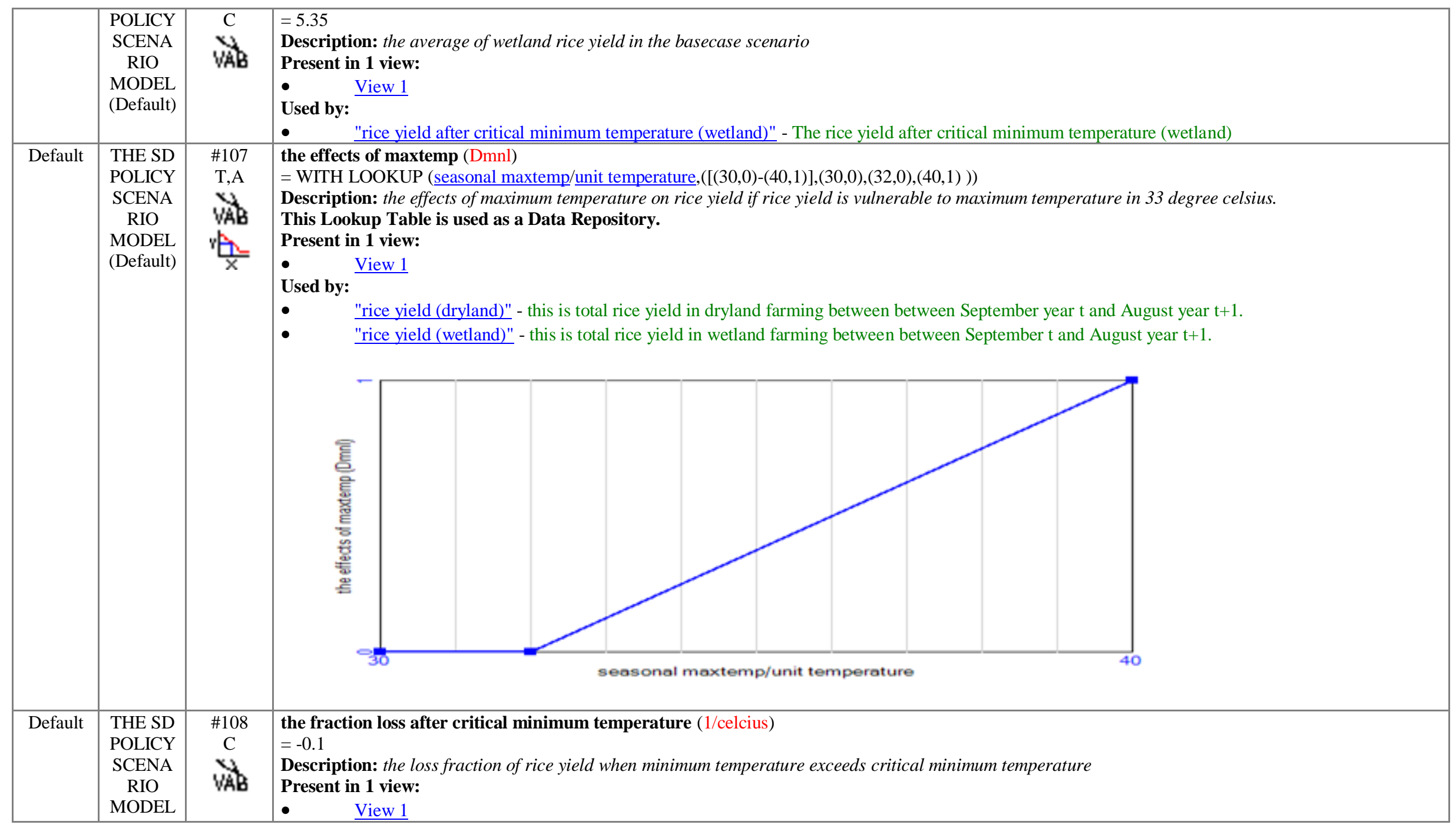




\begin{tabular}{|c|c|c|c|}
\hline & (Default) & & $\begin{array}{l}\text { Used by: } \\
\text { - } \quad \text { "rice yield after critical minimum temperature (dryland)" - The rice yield after critical minimum temperature (dryland) } \\
\text { - } \quad \text { "rice yield after critical minimum temperature (wetland)" - The rice yield after critical minimum temperature (wetland) }\end{array}$ \\
\hline Default & Control & $\begin{array}{l}\# 109 \\
\mathrm{C} \\
\mathrm{VAB}\end{array}$ & $\begin{array}{l}\text { TIME STEP (year }[0, ?]) \\
=0.0078125 \\
\text { Description: The time step for the simulation. } \\
\text { Present in } 1 \text { view: } \\
\text { U } \\
\text { Used by: } \\
\text { View } 1 \\
\text { physical rice farming areas (dryland) } \\
\text { p } \\
\text { physical rice farming areas (wetland) }\end{array}$ \\
\hline Default & $\begin{array}{c}\text { THE SD } \\
\text { POLICY } \\
\text { SCENA } \\
\text { RIO } \\
\text { MODEL } \\
\text { (Default) }\end{array}$ & $\begin{array}{l}\# 110 \\
T, A \\
\text { WAB } \\
\frac{X}{x}\end{array}$ & $\begin{array}{l}\text { "timing of monsoon onset (days)" (days) } \\
=\text { WITH LOOKUP (August SOI, }[(-25,-90)-(25,90)],(-30,30),(-25,23),(-20,20),(-8,0),(0,0),(8,0),(20,-20),(25,-23),(30,-30))) \\
\text { Description: the timing of monsoon onset represents the beginning of the planting seasons. This a variable with a day dimension. } \\
\text { Source: Source of Data } \\
\text { Present in } 1 \text { view: } \\
\text { - View } 1 \\
\text { Used by: } \\
\text { "timing of monsoon-onset (years)" - the timing of monsoon onset represents the start of the planting seasons. Used by --- actual paddy production } \\
\text { which represents the actual paddy production (wetland) in harvesting seasons. }\end{array}$ \\
\hline
\end{tabular}




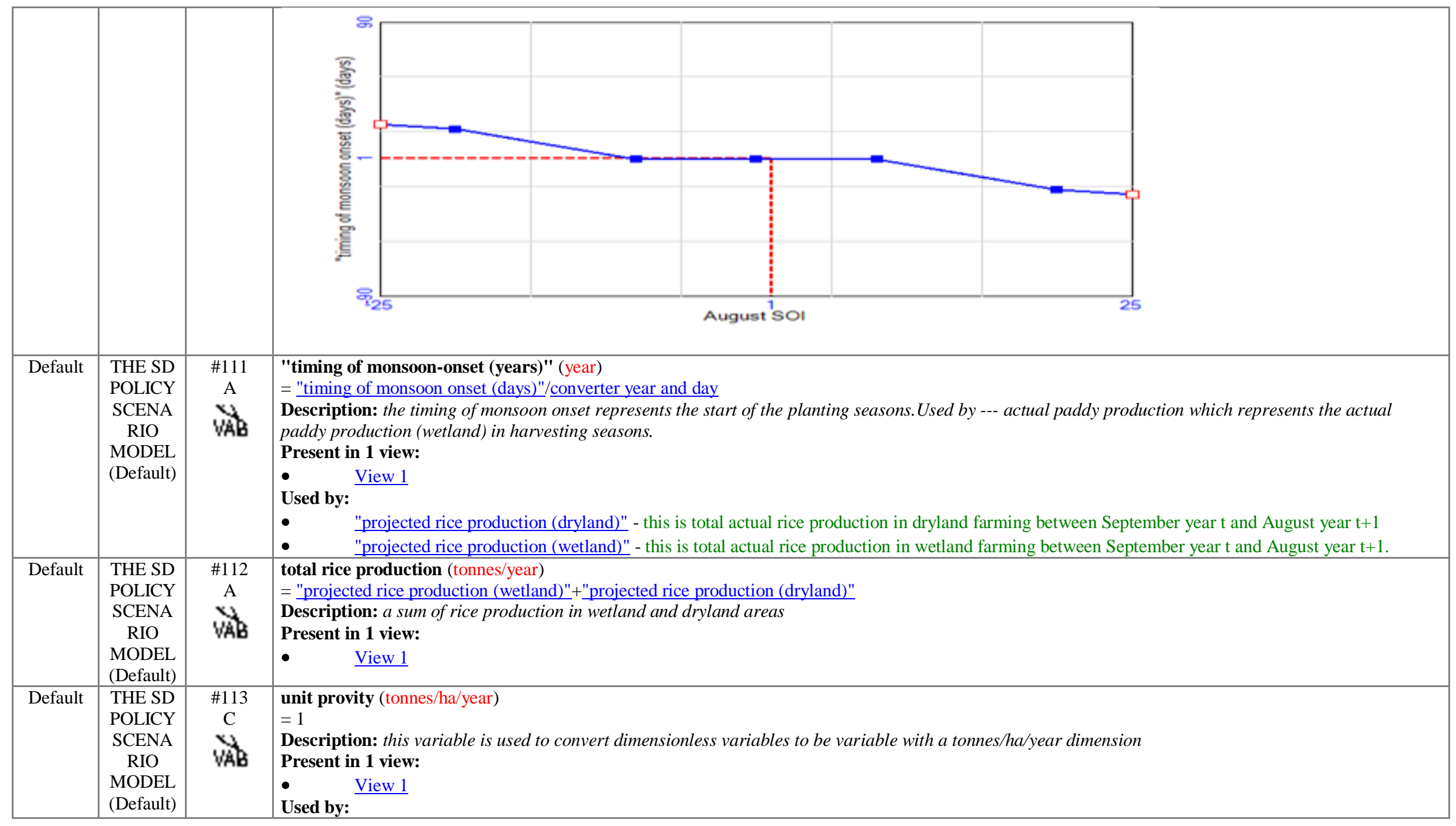




\begin{tabular}{|c|c|c|c|}
\hline & & & $\begin{array}{l}\text { - } \\
\text { - } \\
\text { - } \\
\text { "expected rice yield (dryland)" - the expected rice yield in wetland farming. } \\
\text { "rice yield (dryland)" - this is total rice yield in dryland farming between between September year } t \text { and August year } t+1 \text {. } \\
\text { "rice yield (wetland)" - this is total rice yield in wetland farming between between September } t \text { and August year } t+1 \text {. }\end{array}$ \\
\hline Default & $\begin{array}{l}\text { THE SD } \\
\text { POLICY } \\
\text { SCENA } \\
\text { RIO } \\
\text { MODEL } \\
\text { (Default) }\end{array}$ & $\begin{array}{l}\# 114 \\
\mathrm{C} \\
\mathrm{VAB}\end{array}$ & $\begin{array}{l}\text { unit temperature (celcius) } \\
=1 \\
\text { Description: a unit of temperature to set maximum temperature to be dimensionless after a lookup function } \\
\text { Present in } 1 \text { view: } \\
\text { Used by: } \\
\text { View } 1 \\
\text { the effects of maxtemp - the effects of maximum temperature on rice yield if rice yield is vulnerable to maximum temperature in } 33 \text { degree celsius. }\end{array}$ \\
\hline Default & $\begin{array}{l}\text { THE SD } \\
\text { POLICY } \\
\text { SCENA } \\
\text { RIO } \\
\text { MODEL } \\
\text { (Default) }\end{array}$ & $\begin{array}{l}\text { C115 } \\
\text { CAB }\end{array}$ & 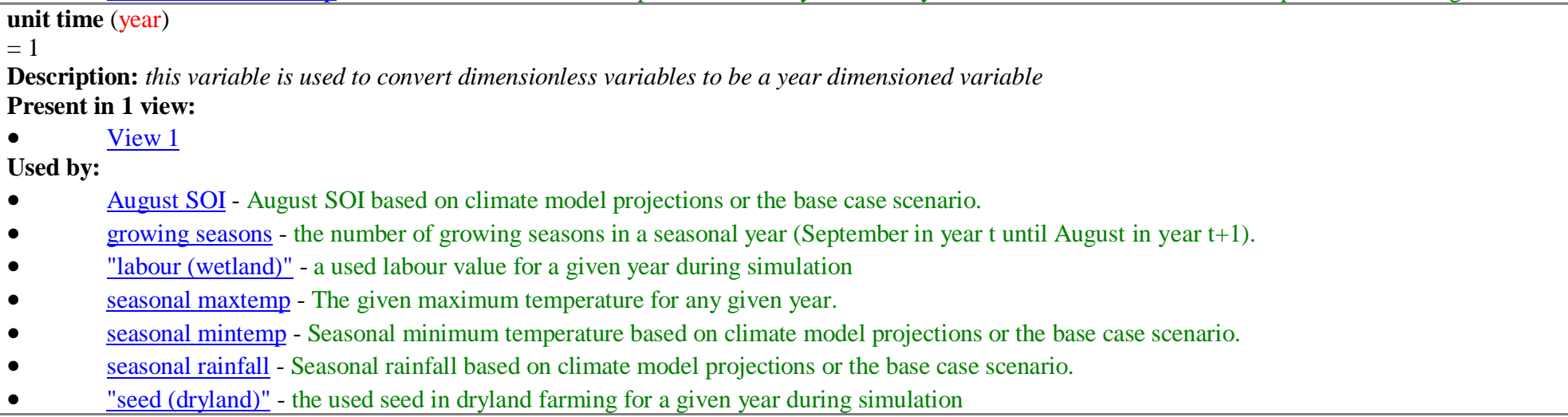 \\
\hline Module & Group & Type & Variable Name and Description \\
\hline
\end{tabular}

SDM-Doc Tool Decision and Information Sciences Division Argonne National Laboratory 